UNIVERSIDADE DE SÃO PAULO

FACULDADE DE FILOSOFIA, LETRAS E CIÊNCIAS HUMANAS

DEPARTAMENTO DE SOCIOLOGIA

PROGRAMA DE PÓS-GRADUAÇÃO EM SOCIOLOGIA

\title{
LUCAS RODRIGUES AZAMBUJA
}

O Cálculo Econômico de Valor das Firmas no Mercado de Trabalho: estudos de caso no setor de tecnologias da informação. 


\section{UNIVERSIDADE DE SÃO PAULO \\ FACULDADE DE FILOSOFIA, LETRAS E CIÊNCIAS HUMANAS \\ DEPARTAMENTO DE SOCIOLOGIA PROGRAMA DE PÓS-GRADUAÇÃO EM SOCIOLOGIA}

\section{O Cálculo Econômico de Valor das Firmas no Mercado de Trabalho: estudos de caso no setor de tecnologias da informação.}

Tese apresentada ao programa de Pós-Graduação de Sociologia do Departamento de Sociologia da Faculdade de Filosofia, Letras e Ciências Humanas da Universidade de São Paulo, para a obtenção do título de Doutor em Sociologia.

Orientadora: Prof. ${ }^{\text {a }}$ Dr. ${ }^{a}$ Nadya Araujo Guimarães

\section{EXEMPLAR REVISADO}

"De acordo" do orientador

Orientadora: Prof. ${ }^{a}$ Dr. ${ }^{a}$ Nadya Araujo Guimarães

Assinatura: 
À minha avó Laurabela Cardoso de Area Leão e à minha tia Sonia Maria de Area Leão Pereira, falecidas ao longo dessa trajetória. À memória daquele que mais do que um amigo foi meu segundo pai, Luiz Germano Seifritz. 


\section{AGREDECIMENTOS}

Agradeço às seguintes pessoas e organizações:

Professora Dr. ${ }^{a}$ Nadya Araujo Guimarães pelo valioso processo de orientação ao longo do doutorado. Processo esse que incluiu a ajuda e paciência para comigo, mesmo em decisões fora da alçada da tese, por exemplo, o objetivo de buscar após este doutorado a carreira diplomática e, em 2011, de voltar para Porto Alegre. Devo ainda agradecer a atenção dispensada para me integrar na sua equipe de pesquisa, formada por seus alunos e orientandos. Sem dúvida através desses anos, essa relação de orientação constituiu uma enorme contribuição para minha formação intelectual e para uma ética de trabalho.

Aos participantes das Oficinas de Sociologia Econômica e do Trabalho (OSET) que prestaram enorme contribuição para realização e aprimoramento das ideias constantes nesta tese. Críticas de ótimos níveis sempre estiveram presentes quando era minha vez de ser sabatinado neste maravilhoso momento em que, por "culpa" da Professora Nadya, eram reunidos o mais livre e desafiador debate acadêmico com a confraternização e camaradagem. Agradeço a todos de coração por "tolerarem" e até "incentivado" o tom "lucasiano" das minhas críticas e sugestões sobre seus trabalhos. Agradeço, então, aos colegas André Nahoum, Gustavo Taniguti, Ian Prates, Jaime Santos Júnior, Laura Chartain, Murillo Marschner Alves de Brito e Rogério Barbosa. Aos que não somente contribuíram durantes os encontros da OSET como, também, no Seminário Redes e Trabalho, realizado no Centro de Estudos da Metrópole: Ana Carolina Andrada, Ivo Torres Costa, João Santoro, Jonas Bicev, Monise Picanço e Priscila Vieira.

Serei eternamente grato pelo apoio e carinho de minha mãe, Regina Lúcia Area Leão Rodrigues. Ao meu pai, Harvey De Valentin Azambuja, pelos exageros gastronômicos e por ter me incutido o hábito da leitura. À minha irmã, Mariana Rodrigues Azambuja. Ao carinho da minha madrinha, Ana Patrícia Vieira Seifritz e de sua mãe, Ana Emy Vieira Seifritz (não esqueci que estou devendo todos aqueles litros de leite que tomei quando era criança!) e de seu irmão e meu padrinho Carlos Cézar Vieira Seifritz (policial íntegro e churrasqueiro de mão cheia!).

Aos antigos colegas de mestrado na Universidade Federal do Rio Grande do Sul (UFRGS), Daniel Gustavo Mocelin e Leandro Raizer. Também minha orientadora na 
graduação e mestrado, Professora Dr. ${ }^{a}$ Cinara Rosenfield, pela inspiração cujo trabalho ao seu lado foi lapidar para que eu tenha chegado até aqui. Por fim, à Professora Dr. ${ }^{\text {a }}$ Sonia M. K. Guimarães por ter me apresentado à Professora Nadya, pelo aceite de participar da banca examinadora desta tese e pelo continuo contato, iniciado quando fui seu aluno no mestrado, que contribuiu de maneira decisiva para minha formação.

Aos amigos de longa data, ainda dos tempos do colégio, e "confrades ogros", especialmente Pedro Vargas Fernandes e Emilio Oliveira, que ajudaram com os contatos para pesquisa de campo.

Agradeço a disponibilidade por participarem da qualificação de doutorado e, agora, na banca examinadora da tese, os Professores Dr. André Portela Souza e Dr. Ricardo Abramovay.

Também agradeço à Professora Dr. ${ }^{a}$ Flávia Consoni. Por seus valiosos comentários da versão inicial de um dos capítulos da tese, durante um dos encontros da OSET, e por ter aceitado participar da banca examinadora desta tese.

Gostaria de agradecer aos profissionais e empresas de tecnologias da informação na qual foram realizados os estudos de caso. Sem eles esta pesquisa não teria sido possível.

Por fim, agradeço ao Conselho Nacional de Desenvolvimento Científico e Tecnológico (CNPq) pelo subsídio financeiro através da bolsa de doutorado. O apoio financeiro do Centro de Estudos da Metrópole. O apoio recebido pelo Ministério do Trabalho e do Emprego na disponibilização da consulta da base RAIS. E ao apoio recebido do Programa de Pós-Graduação em Sociologia da Universidade de São Paulo. 
De modo que o livro fica assim com todas as vantagens do método, sem a rigidez do método. Na verdade, era tempo. Que isto de método, sendo, como é, uma coisa indispensável, todavia é melhor tê-lo sem gravata nem suspensórios, mas um pouco à fresca e à solta, como quem não se lhe dá da vizinha fronteira, nem do inspetor de quarteirão.

\section{MACHADO DE ASSIS}

Individual valuation is the keystone of economic theory. For, fundamentally, economics does not deal with things or material objects. Economics analyzes the logical attributes and consequence of the existence of individual valuations. "Things" enter into the picture, of course, since there can be no valuation without things to be valued. But the essence and the drive force of human action, and therefore of the human market economy, are the valuations of individuals. Action is the result of choice among alternatives, and choice reflects values, that is, individual preferences among these alternatives. 


\section{RESUMO}

Nas últimas décadas, cientistas sociais vêm defendendo a ideia de estarmos presenciando o início de uma nova etapa do desenvolvimento histórico do capitalismo, a chamada nova economia. Entre outros aspectos, aponta-se para mudanças profundas no âmbito das organizações e do trabalho, que foram provocadas pelo impacto do surgimento e difusão das tecnologias da informação. Nesse sentido, esta tese escolhe por contribuir em torno do conhecimento sobre a nova economia a partir de um interesse analítico bem delimitado, a saber, compreender o cálculo econômico de valor realizado por firmas de tecnologia da informação, quando estas comparecem no mercado de trabalho. Tal interesse analítico se operacionaliza através de três perguntas de pesquisa: Quais são e como as condições engendradas por redes sociotécnicas das firmas de tecnologias da informação estruturam as suas capacidades de cálculo econômico de valor? Quais valores econômicos e economicamente relevantes, essas firmas lançam mão para definir o valor e, por conseguinte, a sua demanda no mercado de trabalho? E quais procedimentos e práticas elas adotam para classificar e julgar a oferta de trabalho e planejar a realização de sua demanda diante dessa oferta? Visando responder essas três perguntas, procedeu-se à realização de quatro estudos de casos em empresas de diferentes segmentos de atividade econômica das tecnologias da informação. Os quatro casos estão localizados no município de Porto Alegre (RS) ou na sua região metropolitana. Com base na análise dos dados coletados nesses estudos, a tese encerra refletindo sobre o valor do trabalho como mercadoria no contexto da nova economia e também sobre o desenvolvimento de uma abordagem de sociologia econômica voltada para o comportamento da firma no mercado de trabalho e a sua capacidade de cálculo econômico de valor.

Palavras-chave: nova economia, demanda de trabalho, mercado de trabalho, firmas, redes sociotécnicas. 


\begin{abstract}
In the last decades, an increasing number of social scientists have defended the idea that we are witnessing the beginning of a new stage of the historical development of capitalism, the so-called new economy. Among other aspects it has been recognizing profound changes within organizations and the labor world that are related by the impact of the emergence and diffusion of information technologies. The present thesis chooses to contribute in the comprehension of the new economy trough a well-defined analytical interest, namely, understand the economic calculation of values that are realized by information technologies firms in the labor market. This analytical interest is reflected through three research questions: Which are and how the conditions articulated by socio-technical networks of firms, structure their abilities to economic calculation of values? What economic and economic relevant values these firms resort to set the value and therefore their demand in the labor market? And what procedures and practices these firms adopt to classify and judge the supply of labor and plan the realization of their demand? In order to answer these three questions, we carried out four case studies with companies from different segments of economic activities in information technologies. All of these cases are located at city of Porto Alegre (RS) or at the metropolitan area. Based on the analysis of data collected in these four case studies, the thesis closes with a reflection on the value of labor as a commodity in the context of the new economy and also discussing the development of an economic sociology approach about firms' behavior in the labor market.
\end{abstract}

Key-words: new economy, labor demand, labor market, firms, socio-technical networks. 


\section{LISTA DE SIGLAS}

ADSL - Asymmetric Digital Subscriber Line

BNDES - Banco Nacional de Desenvolvimento

BR - Brasil

CBO - Classificação Brasileira de Ocupações

CLT - Consolidação das Leis do Trabalho

CNAE - Classificação Nacional de Atividades Econômicas

DP - Departamento de Pessoal

EUA - Estados Unidos da América

FINEP - Financiadora de Estudos e Pesquisas

IBGE - Instituto Brasileiro de Geografia e Estatística

ITI-BR - Indústria de Tecnologias da Informação - Brasil

ITI-RS - Indústria de Tecnologias da Informação - Rio Grande do Sul

MTE - Ministério do Trabalho e Emprego

NSE - Nova Sociologia Econômica

OCDE - Organização para a Cooperação e Desenvolvimento Econômico

PE - Personnel Economics

P\&D - Pesquisa e Desenvolvimento

PJI - Pessoa Jurídica Individual

PMT - Produtividade Marginal do Trabalho

PPA - Professional Profile Assessment

PUC - Pontifícia Universidade Católica

RAIS - Registro Anual de Informações Sociais

RH - Recursos Humanos

RMPA - Região Metropolitana de Porto Alegre

RS - Rio Grande do Sul

STI-BR - Serviços de Tecnologias da Informação - Brasil

STI-RS - Serviços de Tecnologias da Informação - Rio Grande do Sul

TPM - Teoria da Produtividade Marginal

TI - Tecnologias da Informação

TICs - Tecnologias da Informação e Comunicação

UERGS - Universidade Estadual do Rio Grande do Sul 
UFRGS - Universidade Federal do Rio Grande do Sul UNISINOS - Universidade do Vale do Rio dos Sinos USP - Universidade de São Paulo 


\section{LISTA DE GRÁFICOS}

Gráfico 1 - \% de Estabelecimentos RAIS Negativa - Brasil 96

Gráfico 2 - Taxa de Crescimento Anual do No. de Estabelecimentos - Brasil.. 97

Gráfico 3 - Taxa de Crescimento Anual dos Vínculos de Trabalho por Segmentos de TI e Grandes Setores - Brasil

Gráfico 4 - Distribuição de Estabelecimentos por Faixas de Vínculos de Trabalho - Brasil, 2010 100

Gráfico 5 - Distribuição de Vínculos de Trabalho por Tamanho de Estabelecimentos - Brasil, 2010

Gráfico 6 - Distribuição dos Vínculos por Faixa de Tempo em Meses - Brasil, 2010

Gráfico 7 - Valor Nominal Médio de Salários - Brasil 103

Gráfico 8 - \% de Vínculos por Faixa Etária - Brasil, 2010. 105

Gráfico 9 - \% de Vínculos por Escolaridade - Brasil, 2010 106

Gráfico 10 - Valor Médio do Salário Nominal para Trabalhadores com Curso Superior Completo - Brasil 108

Gráfico 11 - Valor Médio do Salário Nominal para Trabalhadores com Ensino Médio Completo - Brasil 108

Gráfico 12 - \% de Vínculos de Trabalho por Tamanho de Estabelecimentos - BR e RS, 2010 .

Gráfico 13 - \% de Vínculos por Faixa de Tempo em Meses - BR e RS, 2010112 Gráfico 14 - Taxa (\%) de Crescimento Anual do No. de Estabelecimentos - BR e RS

Gráfico 15 - Taxa (\%) de Crescimento Anual do No. de Vínculos de Trabalho Demandados nos Segmentos de TI - BR e RS

Gráfico 16 - Valor Nominal Médio de Salários - BR e RS 
Gráfico 18 - \% de Vínculos por Escolaridade- BR e RS, 2010

Gráfico 19 - Valor Médio do Salário Nominal para Trabalhadores com Curso

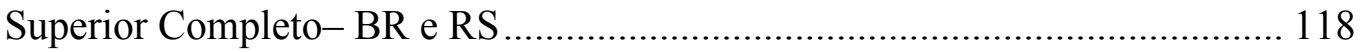




\section{LISTA DE TABELAS}

Tabela 1 - Setor de TICs segundo CNAE 2.0 ….......................................... 86

Tabela 2 - Setor de Tecnologia da Informação e Comunicação ........................ 92

Tabela 3 - Serviços de Tecnologia da Informação............................................. 93

Tabela 4 - Indústria de Tecnologia da Informação ............................................ 94

Tabela 5 - Participação dos Estabelecimentos de TI nos Grandes Setores - Brasil

Tabela 6 - Participação do No. de Vínculos de Trabalho por Estabelecimentos de TI nos Grandes Setores - Brasil....................................................................... 98

Tabela 7 - Média de Tempo em Meses dos Vínculos de Trabalho - Brasil..... 102

Tabela 8 - Participação (\%) de Vínculos Não Desligados - Brasil ................. 103

Tabela 9 - Participação (\%) Feminina nos Vínculos de Trabalho Demandados Brasil 104

Tabela 10 - \% de Vínculos de Trabalho Demandados com Curso Superior Completo - Brasil. 107

Tabela 11 - \% de Vínculos de Trabalho Demandados com Ensino Médio Completo - Brasil. 107

Tabela 12 - Participação do No. Estabelecimentos de TI do RS no Setor de TI Brasileiro.

Tabela 13 - Participação do No. de Vínculos de Trabalho Demandados em Estabelecimentos de TI do RS no Setor de TI Brasileiro 110

Tabela 14 - Média do No. de Vínculos Ativos por Estabelecimentos de TI - BR e RS.

Tabela 15 - Média em Meses de Tempo dos Vínculos de Trabalho - BR e RS

Tabela 16 - \% Anual de Vínculos Não Desligados - BR e RS

Tabela 17 - Participação Feminina nos Vínculos de Trabalho- BR e RS 
Tabela 18 - Média de Idade em Anos - BR e RS

Tabela 19 - \% de Vínculos de Trabalho com Curso Superior Completo - BR e RS 118

Tabela 20 - No. de Entrevistados e de Entrevistas por Estudos de Caso 124

Tabela 21 - Aproximação dos Casos em Relação às Características Organizacionais Típicas da Nova Economia....

Tabela 22 - Agentes humanos e dispositivos de cálculo na rede sociotécnica da EC1 149

Tabela 23 - Agentes humanos e dispositivos de cálculo na rede sociotécnica da EC2 162

Tabela 24 - Agentes humanos e dispositivos de cálculo na rede sociotécnica da EC3 174

Tabela 25 - Agentes humanos e dispositivos de cálculo na rede sociotécnica da $\mathrm{EC} 4$ 184

Tabela 26 - Valores Econômicos Calculados pela EC1 1.................................. 206

Tabela 27 - Valores Econômicos Calculados pela EC2 _................................. 216

Tabela 28 - Valores Econômicos Calculados pela EC3 ................................. 227

Tabela 29 - Valores Econômicos Calculados pela EC4 .................................. 237

Tabela 30 - Valores Econômicos e Economicamente Relevantes Calculados pelas Empresas de TI 244

Tabela 31 - Rede Sociotécnica e Operações de Cálculo de Valor da EC1 ...... 250

Tabela 32 - Rede Sociotécnica e Operações de Cálculo de Valor da EC2 ...... 260

Tabela 33 - Rede Sociotécnica e Operações de Cálculo de Valor da EC3 ...... 268

Tabela 34 - Rede Sociotécnica e Operações de Cálculo de Valor da EC4 ...... 276

Tabela 35 - Agentes humanos e dispositivos de cálculo nas redes sociotécnicas das empresas estudadas. 295 


\section{SUMÁRIO}

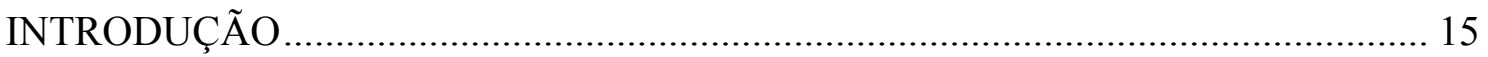

1. O CÁlCULO ECONÔMICO ENTRE A SOCIOLOGIA E A ECONOMIA ............ 27

1.1. O mercado de trabalho entre a sociologia e a economia.................................. 29

1.2. O comportamento da firma no mercado de trabalho, segundo a visão econômica ortodoxa

1.3. O cálculo econômico entre a atomização e a rede social.................................... 39

2. MODELO SOCIOLÓGICO DE ANÁLISE DO CÁLCULO ECONÔMICO............ 47

2.1. Valores na economia e o trabalho como mercadoria ......................................... 47

2.2. A perspectiva de redes sociais para uma abordagem do cálculo econômico....... 57

2.3. A rede sociotécnica e a capacidade de agência calculadora das firmas............... 67

3. NOVA ECONOMIA E TECNOLOGIAS DA INFORMAÇÃO ............................... 75

3.1. Transformações econômicas recentes e o protagonismo das tecnologias da

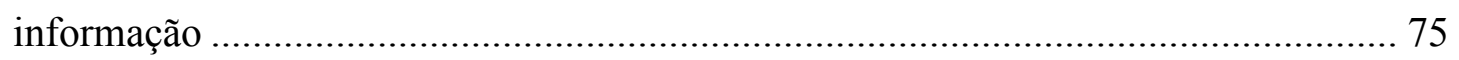

3.2. Firmas de tecnologias da informação: uma definição e os seus papéis no mercado de trabalho 85

3.3. Contextualização e caracterização das firmas e da demanda de trabalho de tecnologia da informação - Brasil e Rio Grande do Sul............................................. 91

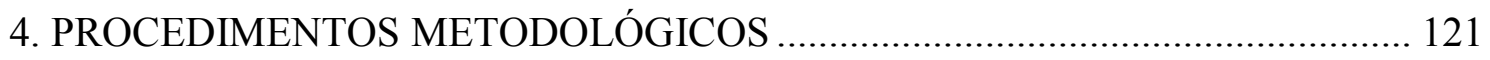

4.1. Procedimentos e técnicas de coleta e análise de dados................................... 121

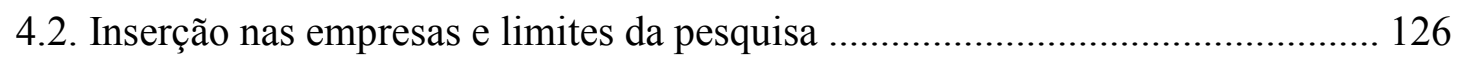

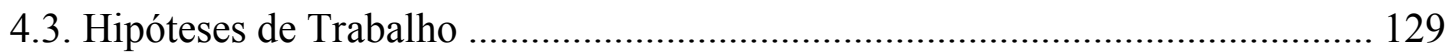

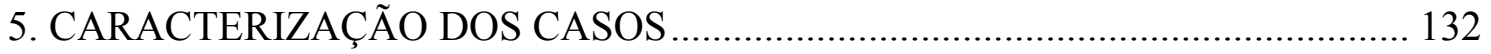

5.1. Estudo de Caso 1: uma indústria de TI ........................................................... 133

5.2. Estudo de Caso 2: uma empresa de software por encomenda e customizável .. 137

5.3. Estudo de Caso 3: uma empresa de software customizável............................. 141 
5.4. Estudo de Caso 4: uma empresa de consultoria e desenvolvimento de software sob encomenda

6. AS REDES SOCIOTECNICAS DAS FIRMAS 148

6.1. Estudo de Caso 1: uma rede sociotécnica em transição e instável 148

6.2. Estudo de Caso 2: uma rede sociotécnica compartimentada e rotinizada 162

6.3. Estudo de Caso 3: uma rede sociotécnica em formação e estável 174

6.4. Estudo de Caso 4: uma rede sociotécnica complexa e adensada 184

7. OS VALORES NA DEMANDA DA FIRMA NO MERCADO DE TRABALHO 205

7.1. Estudo de Caso 1: "tradicionais" valores econômicos. 206

7.2. Estudo de Caso 2: valores econômicos estruturados da nova economia 216

7.3. Estudo de Caso 3: valores econômicos em formação da nova economia 227

7.4. Estudo de Caso 4: valores econômicos e economicamente relevantes 236

8. A CAPACIDADE DE CÁLCULO DE VALOR DAS FIRMAS ... 246

8.1. Estudo de Caso 1: o cálculo de valor mais longe da nova economia 250

8.2. Estudo de Caso 2: o cálculo de valor estruturado da nova economia................. 260

8.3. Estudo de Caso 3: o cálculo de valor em formação da nova economia.............. 268

8.4. Estudo de Caso 4: o cálculo de valor adensado da nova economia ................... 275

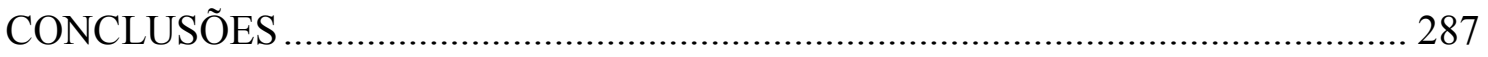

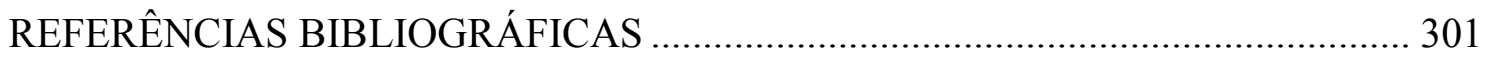

ANEXO 


\section{INTRODUÇÃO}

Nas últimas décadas, uma quantidade crescente de autores das Ciências Sociais vem analisando uma série de transformações no campo da economia e do trabalho. É cada vez mais consensual entre esses autores, a ideia de estarmos presenciando o início de uma nova etapa do desenvolvimento histórico do capitalismo. Nesse sentido, argumenta-se, de diferentes maneiras, em favor do surgimento de um novo paradigma de produção e desenvolvimento, isto é, de uma nova economia. Essa última, então, recebeu diversos nomes, por exemplo, sociedade pós-industrial (BELL, 1973), capitalismo informacional (CASTELLS, 2007), capitalismo cognitivo (COCCO; GALVÃO; SILVA, 2003), pós-fordismo (HARVEY, 1996); pós-modernidade ${ }^{1}$ (JAMESON, 1985); economia do conhecimento (POWELL; SNELLMAN, 2004) e sociedade da informação (MASUDA, 1982). Cada qual dessas perspectivas tem registrado, de uma maneira ou de outra, a perda da centralidade no desenvolvimento econômico da grande indústria voltada para o consumo de massa; a revolução tecnológica em torno do surgimento e difusão das tecnologias da informação; alterações nos modelos de gestão e da produção das empresas, afastando-se do chamado paradigma "taylorista-fordista"; transformações nas condições e nas relações de trabalho e de emprego, marcadas pela tendência à flexibilização ou à precarização, dependendo da corrente de interpretação que se considere.

Se estamos presenciando um contexto de profundas transformações econômicas, tal como sugere a literatura mencionada acima, e sendo o mercado elemento essencial e característico da economia capitalista, torna-se importante analisar os processos que dizem respeito ao seu funcionamento e, deste modo, identificar tendências e lógicas de funcionamento da nova economia. Em outros termos, "[w] hether one talks about the new economy, the information economy, the knowledge economy or [...] the service economy, one is expressing the possibility of a profound transformation of the rules by which markets function [...]" (CALLON, MÉADEL; REBEHARISOA, 2002, p. 196).

\footnotetext{
${ }^{1}$ Em contraposição, Giddens (1991) não vê nas transformações contemporâneas uma nova etapa de desenvolvimento social e econômico, mas uma continuidade na evolução da sociedade moderna, ou seja, é menos o surgimento de uma nova etapa e mais a realização da continuidade de uma lógica de desenvolvimento histórico. Kumar (1997) também advoga que as transformações recentes não deram início a uma nova etapa histórica, mas que estamos presenciado a "radicalização da modernidade".

${ }^{2}$ Para uma breve definição do paradigma de produção taylorista-fordista, ver Pereira e Oliveira (2001).
} 
Mercados são espaços nos quais indivíduos e organizações - ora na posição de ofertantes, ora na de demandantes - transacionam bens e serviços, frequentemente através do uso de moeda. Logo, para que essas transações ocorram, é preciso que os agentes econômicos definam quais, como e o quanto valorizam bens e serviços. Em outros termos, "[f]or products to be sold in markets, customers must value them and assess their value in relation to other products. Firms must produce products and position them in the market where customers will consider them valuable" (ASPERS; BECKERT, 2011, p. 3). De maneira simples, as transações de mercado ocorrem quando os agentes são capazes de responder à pergunta: quanto vale isso? Portanto, a definição e o funcionamento dos mercados estão intrinsecamente conectados ao processo de atribuição de valor, ou seja, mercados são interações sociais em condições de competição, nas quais indivíduos e firmas atribuem valor e preço a produtos, para, então, adquirir direitos de propriedade sobre bens e serviços em troca de dinheiro (ASPERS, 2011; BECKERT, 2009; FLIGSTEIN, 2001).

Portanto, a existência dos mercados é indissociável ao processo de atribuição de valor a bens e serviços; logo, é pertinente o exame empírico desse processo em contextos mercadológicos centrais e peculiares à nova economia. Assim, com esta pesquisa pretendemos somarmo-nos aos que refletem sobre como agentes calculam o valor de bens e serviços na nova economia.

Adotamos nesta pesquisa a perspectiva de que o valor de um bem ou serviço é determinado pelo processo subjetivo de avaliação realizado por indivíduos e firmas em condições de competição no mercado. Entretanto, não partilhamos a perspectiva da chamada teoria econômica neoclássica que considera as preferências de indivíduos e firmas como exógenas (VARIAN, 2006, p. 1-143), ou seja, a economia neoclássica adota o pressuposto que os agentes econômicos adentram no mercado com preferências fixas e estáveis. Portanto, essa perspectiva não oferece uma explicação para o nosso interesse de pesquisa, a saber, compreender a formação do modo como os agentes avaliam e valorizam um bem ou serviço. Para a perspectiva econômica ortodoxa ou neoclássica, os agentes entram no mercado com esse processo já definido, isto é, suas preferências já estão formadas e são estáticas, apenas respondendo às variações nos preços relativos das mercadorias ${ }^{3}$.

${ }^{3}$ É preciso mencionar que a teoria econômica contemporânea cada vez mais vem se interessando pela questão da formação das preferências dos agentes (FEHR; HOFF, 2011) e como elas são afetadas por variáveis extraeconômicas (AKERLOF; KRANTON, 2000). 
Entretanto, mesmo no contexto de mercado, não devemos reduzir à formação dos preços a resposta à pergunta que nos importa - a saber, como os agentes calculam o valor de bens e serviços? Ou seja, os agentes econômicos precisam considerar, além do preço, quais produtos têm valor para eles e o que eles precisam saber acerca dos produtos, ou seja, quais informações precisam obter sobre um produto para calcular seu valor. Em outros termos, o agente consumidor toma decisões também a partir de considerações sobre a qualidade do produto e o classifica em relação a outras mercadorias consideradas do mesmo gênero ou equivalentes.

Ademais, o valor no mercado não é somente valor monetário (preço). Como nos mostra Patrick Aspers e Jens Beckert (ASPERS, 2011; BECKERT, 2009; ASPERS; BECKERT, 2011), o processo de avaliação no mercado pode ser estar assentado em valores de ordem política, estética, cultural e/ou moral. Esses valores não-econômicos podem inclusive estabelecer aquilo que é socialmente aceitável ser transacionado no mercado, por exemplo, o caso da constituição do mercado de seguro de vida, analisado por Viviana Zelizer (1978), que mostra como as empresas tiveram que lidar com valores religiosos e morais a respeito do caráter sagrado de questões relacionadas à vida e à morte, onde considerações financeiras eram tidas como algo que profanava e vulgarizava essas questões. Podemos ainda citar o estudo de Peter Gourevitch (2011) que mostra como valores éticos e morais estruturam o funcionamento e a precificação em mercados de consumo de produtos tidos como "social ou ambientalmente responsáveis". Claramente inspirados em Max Weber, Aspers e Beckert (2011) definem que quando valores advindos de fora da esfera econômica passam a estruturar a constituição e/ou funcionamento de mercados, eles tornam-se "valores economicamente relevantes".

Além disso, o valor econômico possui diferentes parâmetros através dos quais um bem se torna economicamente valioso para um indivíduo ou firma. Assim sendo, os valores econômicos podem ser divididos entre aqueles que são formados por atributos físicos e materiais dos bens e serviços ofertados nos mercados e os que são fundamentados em critérios simbólicos ou imateriais que o consumo ou a posse do bem ou serviço expressariam (ASPERS, 2011; ASPERS; BECKERT, 2011; BECKER, 2009).

Com base nessas perspectivas, entendemos nesta tese que o ato de avaliação (que pode estar assentado em diferentes valores econômicos ou economicamente relevantes) de bens e serviços é uma capacidade dos agentes que a exercitam 
permanentemente quando comparecem nos mercados. Mas, como se exercita tal capacidade? O que exatamente o agente realiza nesse processo? Em uma palavra, ele calcula.

Se a perspectiva de Aspers e Beckert nos permitiu melhor abordar a questão dos valores; a noção de "cálculo econômico", tal como é formulada por Michel Callon, nos será de grande valia. O autor define "cálculo econômico" como uma capacidade de agência que se exerce por meio de três operações: 1) a de listar possíveis cenários sobre a realidade (sendo cada cenário composto por uma lista de atores e produtos e uma distribuição dos últimos entre os primeiros); 2) a de hierarquizar esses possíveis cenários (o que evidencia o objeto da preferência dos agentes, e lhes confere conteúdo); 3) a de identificar e descrever as ações necessárias para a produção de cada um dos cenários possíveis (CALLON, 1998, 2004; CALLON; MUNIESA, 2005). Denominamos estas três operações como, respectivamente, classificar, julgar e planejar.

Portanto, o cálculo econômico é a forma que assumem os processos de avaliação ${ }^{4}$ em contextos de mercado, ou seja, por meio de operações de classificar, julgar e planejar. Essas, por sua vez, se escudam, assentando-se, nos diferentes tipos de valores a que aludimos acima, tanto os econômicos como os economicamente relevantes; eles dotam de sentido cada uma das três operações que conformam o cálculo econômico. Assim sendo, poderíamos dizer que as variações nas modalidades de cálculo econômico no mercado refletem as variações nas combinações de valores postas em prática pelos agentes.

Se o cálculo econômico é "o quê" o agente faz no mercado e a atribuição de valor estabelece "com o quê" ele o faz, como todo esse processo se torna possível? Quais são as suas condições de possibilidade?

Apresentou-se, até aqui, que os processos de avaliação e o de cálculo econômico são subjetivamente determinados. Entretanto, convém desde logo resalvar, que reconhecer a determinação subjetiva que opera nesse processo não pode levar a concluir que a atribuição de valores e o cálculo sejam possíveis em razão de uma capacidade cognitiva natural de um agente individual e socialmente atomizado. Através da perspectiva de análise de redes da Nova Sociologia Econômica (GRANOVETTER,

\footnotetext{
${ }^{4}$ Callon estabelece também essa relação de identidade, mas denomina o processo de avaliação de qualifying (CALLON, MÉADEL; RABEHARISOA, 2002, p. 202-7).
} 
1985, 2005; MIZRUCHI, 2009) e da teoria do ator-rede (CALLON, 1998, 2004; LATOUR, 1999, 2006; LAW, 1999) podemos dizer que essa é uma capacidade de agência socialmente construída e, assim, recusar toda e qualquer naturalização dos processos subjetivos de cálculo e de definição de valor, reivindicando o seu caráter socialmente construído. Como se verá adiante, capacidades de agência como as do cálculo econômico de valor, são resultado de possibilidades engendradas por redes de relações sociais e sociotécnicas, isto é, são resultado de relações entre humanos e nãohumanos (como, por exemplo, os artefatos tecnológicos, os conhecimentos científicos e os instrumentos e protocolos técnicos). Utilizaremos, doravante, a categoria "redes sociotécnicas" para referir àquelas mesoestruturas que criam as condições de possibilidade para o cálculo de valor. Assim faremos por reconhecer que, o conceito de redes tal como formulado por Michel Callon tem a virtude de contemplar tanto relações sociais entre pessoas (foco da análise de redes consagrado pela Nova Sociologia Econômica) como as relações entre pessoas e agentes não-humanos.

Chegando a este ponto, podemos resumir o quadro teórico e analítico adotado por esta pesquisa em quatro proposições principais:

1) o funcionamento dos mercados é indissociável do modo como os agentes conferem valor a bens e serviços;

2) os agentes organizam suas preferências tanto com base em valores econômicos (das mais diferentes modalidades), como em valores nãoeconômicos, mas que são economicamente relevantes;

3) a sistemática de avaliação de bens e serviços se sustenta em três operações que conformam o cálculo econômico, as de classificar, julgar e planejar;

4) o cálculo econômico de valor é uma capacidade subjetiva que, como tal, se constitui numa capacidade de agência; mas sua possibilidade está condicionada pelas chances engendradas por meio de redes sociotécnicas.

Anteriormente mencionamos que o interesse analítico desta pesquisa consiste nos processos de avaliação de bens e serviços na nova economia. Portanto, com base nessa sumária exposição do marco teórico de interpretação, podemos compreender que, tal interesse de pesquisa se faz por meio do exame da relação entre três elementos: os tipos de valores utilizados pelos agentes, as suas operações de cálculo e as redes sociotécnicas nas quais esses agentes estão imersos. 
Todavia, essas definições analíticas são ainda insuficientes em razão de deixar a formulação do problema desta pesquisa em termos demasiadamente genéricos. Isso porque ficam sem respostas algumas perguntas importantes, quais sejam: Quando aludimos à necessidade de compreender como os agentes avaliam bens e serviços, a quais bens ou a quais serviços estamos nos referindo? Que tipos de agentes econômicos interessam, as firmas ou os consumidores? Agentes econômicos atuando em que tipos de mercados? O que é mesmo a nova economia? Vale dizer, quais segmentos de atividade melhor a representam? Em suma, há que seguir além na busca por precisar os termos e fixar o escopo da questão analítica que moverá este estudo.

A maior parte da literatura que se debruça sobre os processos recentes de mudança econômica tem destacado o rompimento com o modelo de organização da economia centrado na lógica taylorista-fordista da indústria de produção de massa, com suas sólidas hierarquias organizacionais, elevada centralização, alto grau de especialização das tarefas no processo produtivo e com suas rígidas relações de trabalho e de emprego. Conquanto preocupada em não recair no determinismo tecnológico, essa literatura não resiste em atribuir às tecnologias da informação um protagonismo no encaminhamento e lógica dessas transformações econômicas recentes, que estariam rompendo com o paradigma anterior.

Dentre outros, o trabalho de Manuel Castells (2007) se destaca ao defender que, no que ele chama de "capitalismo informacional", o desenvolvimento e funcionamento da economia passam a estar centrados na capacidade de geração de novas tecnologias que atuem na produção, processamento e circulação do conhecimento e informação; diferente do capitalismo industrial movido pelos investimentos em fontes de energias e pelo incremento no uso de capital físico no processo produtivo. Por isso mesmo, ressalta Castells, se antes o conhecimento só tinha valor por sua aplicação em tecnologias que maximizassem a produtividade, no capitalismo informacional, ele importa por sua capacidade de desenvolver tecnologias propulsoras da produção e processamento da (própria) informação e conhecimento, daí a centralidade e protagonismo das tecnologias da informação.

Todavia, essa perspectiva não confere atenção principal às dinâmicas internas dos mercados. Quiçá, por isso mesmo, pudéssemos novamente recorrer ao repertório analítico de Michel Callon, em seu esforço por oferecer uma perspectiva de análise sobre a nova economia centrada na compreensão do funcionamento dos mercados (CALLON, 2007; CALLON; MÉADEL; RABEHARISOA, 2002). Vejamos. 
Através da noção de "economia de qualidades", Callon define a nova economia em termos de um contexto no qual a organização e o funcionamento dos mercados dependem de relações sociotécnicas crescentemente complexas e que reúnem maior variabilidade de agentes para interagirem no processo de (re)qualificação de produtos, ou seja, no processo de definição e cálculo do valor dos bens e serviços ofertados. Assim pensando, atribui um caráter central e peculiar às tecnologias da informação na economia de qualidades, uma vez que sua função seria justamente a de coordenar as relações sociotécnicas requeridas pelos processos de (re)qualificação de produtos.

A perspectiva de Callon sobre a nova economia é, portanto, centrada na compreensão do funcionamento dos mercados, destacando a crescente complexidade de relações sociotécnicas nos processos que definem o valor de bens e serviços neles ofertados. Por isso mesmo, torna-se de importância estratégica para as empresas, analisarem e saberem mobilizar as relações sociotécnicas crescentemente complexas, pois assim definem adequadamente o valor de seu produto no mercado e, por conseguinte, concretizam a sua oferta, isto é, "conquistam" o consumidor. Desse modo, Callon coloca no centro da sua concepção sobre a nova economia - ou sobre a economia de qualidades, como prefere - o processo de cálculo e definição de valor, e nele destaca o papel das tecnologias da informação.

Ora, este é exatamente o ponto que se propõe investigar nesta tese e a pista analítica aberta por Callon será central nesse sentido. Isso porque esta pesquisa além de estabelecer o valor estratégico da mobilização de redes sociotécnicas na definição do valor do de produtos, também empreende o esforço de investigar como os mecanismos de cálculo e os de estabelecimento de valor se manifestam igualmente quando empresas chegam ao mercado de trabalho na condição de compradoras do insumo que lhes será fundamental, o trabalho. Em outros termos, se para as firmas como ofertantes é fundamental saberem lidar com relações sociotécnicas crescentemente complexas para definir e calcular o valor do seu produto; compreende-se que os processos de cálculo, informados por valores e assentados em redes sociotécnicas, são igualmente importantes quando as empresas produtoras daquelas tecnologias vitais nas economias de qualidade lançam-se em busca dos trabalhadores que precisam contratar para a produção de tais produtos, de tão elevado valor estratégico.

Nesse sentido, o foco no comportamento e transações travadas pelos agentes no mercado de trabalho, não pode ignorar as óbvias transformações que ocorreram nos processos produtivos e nas relações de trabalho. Em especial a Sociologia do Trabalho 
tem se dedicado à tarefa de registrar e compreender mudanças como a flexibilização e/ou precarização das relações de trabalho (CARNOY; CASTELLS; BENNER, 1997; DRUCK; FRANCO, 2007; KALLEBERG, 2009; NORONHA, 2003; SILVA, 2009), os processos de reestruturação das empresas (BUDROS, 2002; GUIMARÃES, 2004; KATZ, 1997; RAMALHO; SANTANA, 2006); novos regimes de disciplina e controle da força-de-trabalho (ALVES, 2009; KOVÁCS, 2002; ROSENFIELD; ALVES, 2011), a perda ou reconfiguração do poder dos sindicatos (COSTA, 2005; LARAGEIRA, 2003) e os efeitos na conduta dos agentes correlatos à experiência do desemprego de longa duração (GUIMARÃES, 2009b). A Sociologia do Trabalho tem procurado compreender esses e outros temas de pesquisa, em conexão com as transformações nos modelos de organização produtiva que caracterizam a nova economia e com as mudanças nas instituições e regulações estatais que afetam as relações laborais. Entretanto, ao contrário desta pesquisa, as análises de Sociologia do Trabalho quando consideram a firma, não focalizam o seu comportamento no mercado de trabalho, mas as transformações que ocorrem nos seus modelos de gestão e nas relações e condições de trabalho. Por outro lado, quando essa área do conhecimento sociológico dedica atenção ao mercado de trabalho, ela o faz, principalmente, com vista à experiência do trabalhador nas relações que tem lugar nesse mercado ou, então, compreendendo mudanças estruturais em aspectos do funcionamento dos mercados de trabalho, por exemplo, desigualdades salariais, tempo de desemprego, discriminação, etc. Portanto, não é que a Sociologia do Trabalho ignore completamente a firma e o mercado de trabalho, mas sim não realiza um esforço analítico específico para compreender o comportamento da empresa nesse mercado.

Em contrapartida, a Nova Sociologia Econômica (NSE) mais frequentemente assume o enfoque de compreender o comportamento dos agentes econômicos, entre eles a firma, nos processos internos ao funcionamento dos mercados, inclusive o de trabalho. Cabe destacar que, em 1974, o estudo seminal dessa corrente abordava o mercado de trabalho ao analisar a influência das redes de relações sociais na procura e obtenção de um emprego (Granovetter, 1994). Desde então, a grande maioria das pesquisas de sociologia econômica sobre o mercado de trabalho tem enfocado o lado da oferta desse mercado, isto é, o comportamento e os resultados econômicos obtidos pelos trabalhadores e profissionais ${ }^{5}$. Outro aspecto do mercado de trabalho que tem recebido

\footnotetext{
${ }^{5}$ Para um resumo da literatura de sociologia econômica sobre análise de redes e mercados de trabalho, ver (GRANOVETTER, 1988; STEINER, 2006, p. 65-71).
} 
crescente atenção na NSE, mas que se relaciona mais diretamente com o lado da demanda, é o papel dos chamados intermediários na formação das ofertas ocupacionais, isto é, agências de emprego e firmas de recrutamento e seleção e sites de vagas de emprego na Internet (AUTOR, 2001; BICEV, 2010; GUIMARÃES, 2009a; NAKAMURA et. al., 2009; STEVENSON, 2009; VIEIRA, 2009). Mesmo assim, podemos afirmar que, no caso do mercado de trabalho, estudos de sociologia econômica que abordam especificamente o comportamento da firma são escassos e, por isso, foi escolhido esse enfoque pouco explorado.

Por fim, a Economia em seus modelos analíticos sobre o funcionamento e resultados econômicos do mercado de trabalho leva em consideração, como será tratado adiante, o comportamento da firma. Entretanto, pouca ou nenhuma atenção é dada ao nosso interesse analítico, as condições (extraeconômicas) de possibilidade e formação das modalidades de cálculo econômico de valor que as firmas executam no mercado de trabalho. Todavia, a economia do trabalho tem pontos relevantes sobre o comportamento das firmas no mercado de trabalho que precisam ser considerados por uma abordagem sociológica como a adotada nesta tese. Ademais, será evidenciado que a economia do trabalho tem desenvolvido pesquisas interessantes sobre a influência das redes de relações sociais no funcionamento do mercado de trabalho (CALVÓARMENGOL, 2006; IOANNIDES; LOURY, 2004).

Portanto, através da literatura sociológica identificamos uma série de transformações no seio das empresas no contexto da nova economia e também vislumbramos a influência de variáveis extraeconômicas no comportamento dos agentes e no funcionamento do mercado de trabalho. Assim, o estudo que aqui se apresenta encontra sua razão de ser analítica e sua novidade interpretativa no esforço por trazer para o centro da análise de maneira a bem compreender o cálculo econômico de valor realizado por firmas de tecnologia da informação quando estas comparecem no mercado de trabalho.

Por meio dele trataremos de responder às seguintes questões:

$>$ Quais são e como as condições engendradas pelas redes sociotécnicas das firmas de tecnologias da informação estruturam as suas capacidades de cálculo econômico de valor?

$>$ Quais valores econômicos e economicamente relevantes, as firmas de tecnologias da informação lançam mão para definir o valor e, por conseguinte, a sua demanda no mercado de trabalho? 
Quais modalidades de cálculo de valor, isto é, quais procedimentos e práticas essas firmas adotam para classificar e julgar a oferta de trabalho e planejar a realização de sua demanda diante dessa oferta?

Acreditamos que só respondendo a essas perguntas é que estaremos analiticamente capacitados a bem refletir sobre o valor do trabalho como mercadoria no contexto da nova economia e, também, contribuir para o desenvolvimento de uma abordagem de sociologia econômica voltada para o comportamento da firma no mercado de trabalho.

Os resultados deste esforço se organizam, nesta tese, num conjunto de nove capítulos. O primeiro é intitulado "O Cálculo Econômico entre a Sociologia e a Economia" e é composto por três seções. Na primeira seção, vamos tratar das principais diferenças teóricas entre a abordagem econômica neoclássica e a de sociologia econômica no que diz respeito em compreender o mercado de trabalho. Na segunda seção, uma vez que essa tese se situa no campo da sociologia econômica, trata-se de resumir a perspectiva econômica neoclássica sobre a firma no mercado de trabalho para bem esclarecer a especificidade da abordagem sociológica. Por fim, a última seção do primeiro capítulo traz a já tradicional crítica teórica sobre se pensar o comportamento dos agentes nos mercados como socialmente atomizados. Apontaremos para a crescente tendência de redefinição da diferença entre a teoria econômica e a sociológica nesse aspecto. Portanto, o objetivo geral do capítulo 1 é situar esta pesquisa em amplas questões teórico-metodológicas entre Sociologia e Economia, quando se trata de compreender o comportamento dos agentes nos contextos de mercados, especialmente o de trabalho.

Composto por três seções, o capítulo 2 chama-se "Modelo Sociológico de Análise do Cálculo Econômico". Nesse capítulo esclarecemos melhor os termos que configuram o quadro analítico desta tese. Na primeira seção, com base especialmente em Patrick Aspers e Jens Beckert, vamos discorrer sobre a noção de processo de definição de valor nos mercados e, em seguida, abordaremos essa questão a partir de aspectos que configuram o trabalho como uma mercadoria de tipo peculiar. A segunda e terceira seções são, respectivamente, sobre a ideia de redes sociais e a de redes sociotécnicas como condições de possibilidade para capacidades de agência, tais como o cálculo econômico de valor. Na seção dois vamos expor como as pesquisas da NSE sobre o papel das redes sociais no funcionamento dos mercados de trabalho, fornecem a uma primeira pista interpretativa para pensá-las como mesoestruturas que articulam 
condições para os agentes exercerem certas capacidades nas relações e escolhas que têm lugar no mercado de trabalho. Por fim, com base na perspectiva calloniana, iremos discorrer sobre a noção de cálculo econômico, de redes sociotécnicas e o modo como essa abordagem teórica foi adaptada para o caso da firma no mercado de trabalho.

"Nova Economia e Tecnologias da Informação" é o título do terceiro capítulo. $\mathrm{Na}$ primeira seção, articulando seletivamente algumas correntes de interpretação da nova economia, vamos destacar determinadas mudanças recentes na economia e no mundo do trabalho, consideradas relevantes para esta pesquisa no sentido de bem compreender o contexto em que se move a sua unidade de análise, a firma no mercado de trabalho. Também demonstraremos como, de uma maneira ou de outra, essas correntes atribuem um papel de destaque para as tecnologias da informação nesse cenário de transformações. Na segunda seção, discutiremos como se pode definir o que são as firmas de tecnologias da informação e as possíveis posições que elas ocupam no mercado de trabalho. Na última seção deste terceiro capítulo, para melhor contextualizar os estudos de caso realizados na tese, vamos tratar de caracterizar o mercado de trabalho e as firmas de tecnologias da informação através de dados secundários do Ministério do Trabalho e Emprego, tanto paro o Brasil como para o Rio Grande do Sul.

O quarto capítulo trata dos procedimentos metodológicos adotados. Na primeira seção, definimos quais são as técnicas de coleta e de análise dos dados. Após, na seção seguinte, descrevemos o processo de negociação para autorização de pesquisa junto às empresas-tipo analisadas. Com isso, visamos tornar explícitos os limites e possíveis vieses na realização dos quatro estudos de caso. Na última seção, elaboramos as hipóteses de pesquisa que balizaram a interpretação dos dados e as conclusões alcançadas.

Os capítulos de 5 a 8 estão organizados cada qual em quatro seções dedicadas para exposição dos resultados da análise de dados para cada um dos estudos de caso. No capítulo 5, intitulado "Caracterização dos Casos", como o próprio nome já diz, consiste numa descrição sistemática através de cinco dimensões: localização e história da empresa; produtos e organização do trabalho; posição de mercado e estratégias de negócios; tamanho e estrutura ocupacional da firma; e a estrutura e as práticas de gestão do trabalho que são encaminhadas pelo setor de recursos humanos da empresa. O sexto capítulo analisa e expõe os agentes humanos e não-humanos que compõem as redes sociotécnicas de cada caso estudado. Intitulado "Os Valores da Demanda da Firma no Mercado de Trabalho", o sétimo capítulo obviamente traz a definição dos tipos de 
valores que orientam e compreendem a demanda que a firma procura realizar no mercado de trabalho. O oitavo capítulo encerra a análise de dados dos estudos de caso e tem como título "A Capacidade de Cálculo de Valor das Firmas". Trata-se de um capítulo que disserta sobre a análise tanto da formação da demanda de trabalho em termos dos valores econômicos e economicamente relevantes, como das operações de cálculo econômico de valor que cada firma estudada executa ao comparecer no mercado de trabalho visando concretizar a sua demanda.

Ao final, no nono capítulo, vamos expor as conclusões alcançadas a partir das hipóteses aventadas e discorreremos sobre como o estudo contribui para refletir sobre o valor do trabalho como mercadoria no contexto da nova economia e da construção de uma abordagem sociológica sobre o cálculo econômico. 


\section{O CÁLCULO ECONÔMICO ENTRE A SOCIOLOGIA E A ECONOMIA}

Conforme mencionado na Introdução, a nova sociologia econômica (NSE) possui poucos estudos sobre o comportamento da firma no mercado de trabalho ${ }^{6}$ e, apesar do seu foco no funcionamento dos mercados, existem poucos estudos a respeito da capacidade de cálculo dos agentes; por outro lado, a própria noção de cálculo pode ser situada no debate que configura a relação entre a Nova Sociologia Econômica e a chamada teoria econômica ortodoxa ou neoclássica ${ }^{7}$. O objetivo deste capítulo será situar nossa pesquisa no debate teórico entre a NSE e a economia ortodoxa, mostrando como podemos contribuir nessa reflexão.

Ao final do século XX, o modo como a NSE se consolida como uma área específica do conhecimento sociológico ocorre através da crítica da chamada teoria econômica neoclássica ${ }^{8}$. O debate entre as duas disciplinas não é algo novo e ele se organizou mais ou menos dentro da seguinte forma: “[...] economists often view sociology as being too broad and diffuse and see the behavior that sociologists examine as being too complex (at least initially) for modeling. Similarly, [...] sociologists view economics as being too narrow and based on unrealistic assumptions" (WINSHIP; ROSEN, 1988, p. S5). A Nova Sociologia Econômica tem, portanto, sua formação e desenvolvimento marcados por essa postura.

${ }^{6}$ Se a firma é pouco estudada pela sociologia econômica no que diz respeito ao contexto do mercado de trabalho, já sobre outros aspectos não podemos dizer o mesmo, por exemplo, mudanças e modelos organizacionais (DIMAGGIO; POWELL, 2004; GUILLÉN, 2001; WHITLEY, 2004), relações e cooperação interfirmas (MIZRUCHI, 1996; POWELL, 2002), modelos de governança (DAVIS; DIEKMANN; TINSLEY, 2004; FLIGSTEIN; BRANTLEY, 1992), capacidade e estratégias de inovação (ARBIX, 2010; FERRARY; GRANOVETTER, 2009; SAXENIAN, 2000).

${ }^{7}$ A noção de ortodoxia é geralmente utilizada como um sinônimo de mainstream, isto é, para sinalizar a abordagem dominante na teoria econômica. A recorrente equivalência, especialmente na bibliografia de sociologia econômica, entre teoria neoclássica e ortodoxia precisa ser repensada. Davis (2006) e outros economistas defendem a tese de que, desde meados da década de 1980, a corrente neoclássica tem sido suplementada por outras abordagens. Assim, o mainstream ou ortodoxia econômica vem se tornando cada vez mais multiparadigmática. Por uma questão de diálogo com a literatura de sociologia econômica, adotamos ainda a perspectiva que considera teoria econômica ortodoxa e neoclássica como praticamente sinônimos, pois queremos chamar a atenção para certa interpretação do pensamento econômico. Contudo, adiante deixaremos claro nossa posição de que a sociologia econômica deva repensar o que são ortodoxia e teoria neoclássica.

${ }^{8}$ Outro elemento que perpassa a constituição da NSE como uma especialidade da Sociologia, sobretudo no contexto acadêmico norte-americano, é a relação com a abordagem sociológica clássica sobre os fenômenos econômicos. Alguns autores da NSE irão postular uma distinção com a tradição clássica (GRANOVETTER, 1990; ZELIZER, 1988), enquanto que outros irão enfatizar pontos de continuidade (STEINER, 2006; SWEDBERG, 1991). 
No chamado manifesto fundador de Mark Granovetter (1985) esse posicionamento é assumido quando o autor caracteriza como uma abordagem "subsocializada" aquilo que, na sua interpretação, pode ser considerado a teoria econômica ortodoxa. Com essa caracterização, Granovetter procura chamar a atenção para o suposto caráter irrealista do postulado neoclássico de considerar a ação econômica como socialmente atomizada, isto é, livre da influência da estrutura de relações sociais. Essa postura é tão presente na NSE que na introdução da segunda edição de um dos mais importantes manuais de sociologia econômica, os autores contrapõem essa última à teoria econômica ortodoxa através dos seguintes pontos: o conceito de ator, o conceito de ação econômica, constrangimentos da ação econômica, relação economia e sociedade, objetivos de análise, modelos empregados e tradições intelectuais (SMELSER; SWEDBERG, 2005, p. 4-6). Ao passarem por cada um desses pontos, os autores fazem questão de demarcar as diferenças entre Sociologia e Economia mais ou menos dentro da lógica explicitada na citação acima ${ }^{9}$. É verdade que Smelser e Swedberg (2005, p. 3-4) fazem a ressalva, relativizando tal contraposição, que ambas as ciências desenvolveram variações e refinaram seus postulados e pressupostos teóricometodológicos básicos. Entretanto, mesmo assim, os autores adotam uma postura que procura mais contrapor Sociologia e Economia, destacando como a primeira possui uma perspectiva mais abrangente (e por isso mais completa) a respeito dos fenômenos da vida econômica.

A noção de cálculo econômico talvez seja o exemplo mais claro dessa tendência dicotômica. Em Smelser e Swedberg identificamos uma postura recorrente entre os sociólogos da economia em considerar que, primeiro, essa noção é característica da abordagem neoclássica e seu reducionismo e, segundo, que a sociologia seria portadora de uma perspectiva mais abrangente, pois ela reconhece a existência do cálculo, porém afirmando que o comportamento econômico somente se torna explicável levando consideração outros elementos, ou seja, esse conceito seria insuficiente para compreender a ação econômica.

Por parte de economistas ortodoxos, Edward Lazear (2000a), por exemplo, sustenta a tese que a diferença entre a ciência econômica e as demais ciências sociais

\footnotetext{
${ }^{9}$ Podemos citar autores que fazem de outras maneiras essa contraposição entre Sociologia e Economia. Por exemplo, Beckert (1996) que defende a tese de que a sociologia econômica estaria melhor "equipada" para lidar com a questão da incerteza na ação econômica. Assim, Sociologia e Economia se contraporiam ao tratamento e profundidade com que ambas abordam o problema da incerteza na ação econômica. Sobre diferentes maneiras e graus de influência das teorias econômicas na sociologia contemporânea, ver Baron e Hannan (1994).
} 
residiria, entre outras coisas, no uso do construto teórico-metodológico de indivíduos racionais calculando como maximizar utilidade. Lazear chega a afirmar que esse construto, mais as ideias de equilíbrio e de eficiência, proporcionariam à Economia um status de ciência mais próximo ao que encontramos na Física, especialmente do ponto de vista do grau de predições que suas teorias oferecem.

Alternativamente, partimos de outra postura com relação a esse debate que pode ser sintetizada através da seguinte pergunta: e se o sociólogo considerasse a ação econômica como essencialmente o exercício de cálculo? Trata-se, então, de esboçar uma perspectiva sociológica sobre a agência econômica calculadora, visando indiretamente à formulação de outro tipo de relação e leitura da teoria econômica por parte da sociologia.

Tal como explicitamos na Introdução, estudamos o cálculo de valor que a firma exercita no mercado de trabalho; assim, cabe mostrar como essa dualidade entre Economia e Sociologia se manifesta no estudo desse tipo de mercado e de seus agentes para melhor situar nosso estudo no debate teórico.

\subsection{0 mercado de trabalho entre a sociologia e a economia}

Para compreender a manifestação da contraposição entre Sociologia e Economia no tema do mercado de trabalho é preciso entender o debate sobre o valor heurístico da noção de "mercado de concorrência perfeita" e os pressupostos comportamentais que essa noção implica. Grosso modo, afirma-se que a teoria econômica ortodoxa estabelece que os mercados sejam dotados das seguintes propriedades: são espaços portadores de uma dinâmica própria, são livres da influência do contexto social e possuem agentes tomando decisões de maneira racional e motivados pelo interesse pessoal. Essas propriedades são possíveis dentro das condições presentes no chamado mercado de concorrência perfeita, quais sejam: 1) a existência de um número suficientemente grande de indivíduos e firmas de modo que nenhum deles possa sozinho manipular os resultados das transações no mercado; 2) produtos e serviços homogêneos para que nenhum consumidor ou demandante prefira outro vendedor ou ofertante por razões que não seja o preço; 3) indivíduos e firmas socialmente isolados (atomização) e independentes para que não haja conluio ou coerção; 4) indivíduos e firmas conscientes do seu interesse e com nível suficiente de informação para tomar decisões de maneira racional (BEAMISH; BIGGART, 2006, p. 244). 
Diversos cientistas sociais e economistas heterodoxos afirmam que essas condições são exceções, não a regra, na realidade empírica dos mercados. Os economistas ortodoxos contra-argumentam arguindo que o modelo de mercado de concorrência perfeita importa por seu valor heurístico e não empírico, já que, se construíssemos uma teoria que retivesse todas as situações e condições observadas empiricamente nos mercados, tal teoria seria inútil já que será tão complexa quanto à realidade que deveria descrever abstratamente. Nesse sentido, o modelo de mercado de concorrência perfeita ofereceria uma teoria parcimoniosa e elegante com capacidade preditiva satisfatória (BORJAS, 2010, p. 8).

Desde meados da década de 1930, a economia do trabalho vive um debate entre abordagens neoclássicas e abordagens institucionalistas (BOYER; SMITH, 2001). Os partidários dessas últimas defendem que a economia do trabalho deva ser uma ciência empírica e indutiva, centrada em reunir dados através de estudos de casos concretos que possam construir uma base para análise da realidade do trabalho dentro das suas particularidades históricas e contextuais. Os institucionalistas defendiam que a teoria econômica convencional não dava conta da complexidade e particularidades observadas nos mercados de trabalho e que, ao reunirem dados que contradissessem as predições e pressupostos do modelo teórico ortodoxo, os economistas teriam que mudar esse último para comportar o estudo do mercado de trabalho.

Por sua vez, os economistas neoclássicos do trabalho defendem a utilização de modelos teóricos dedutivos, a-históricos e centrados no nível dos comportamentos individuais de firmas e trabalhadores, vistos como agentes racionais e maximizadores ${ }^{10}$. Seguindo a perspectiva epistemológica de Alfred Marshall, esses economistas afirmam que através da análise teórica, não da coleta de dados, que devem ser logicamente deduzidas as hipóteses e conclusões a respeito do funcionamento e resultados econômicos no mercado de trabalho ${ }^{11}$ (BOYER; SMITH, 2001, p. 201). O empírico serve, então, para testar a capacidade preditiva dos modelos teóricos construídos a partir de pressupostos acerca do comportamento dos agentes econômicos e do funcionamento dos mercados.

\footnotetext{
${ }^{10}$ Grosso modo, dizer que um agente é maximizador é afirmar que frente a um conjunto de possíveis escolhas, o agente vai preferir aquela que lhe trará maior retorno, maior bem-estar possível visà-vis ao esforço/custos necessários para obtê-lo. Assim, do ponto de vista teórico-metodológico, os conteúdos das escolhas não são tão relevantes quanto saber que as escolhas serão sempre consistentes com essa lógica de maximização de resultados.

${ }^{11}$ Essa mesma visão é até hoje sustentada nos manuais de economia do trabalho escritos por autores de perspectiva ortodoxa. Nesse sentido, ver Borjas (2010, p. 2-10).
} 
Tal como mencionado acima, os economistas neoclássicos do trabalho também defendiam que o propósito dos modelos teóricos não era representar a realidade na sua complexidade, mas o de torná-los capazes de extrair os elementos essenciais dessa complexidade, de modo a possibilitar predições sobre os fenômenos observados.

Posto a discussão nesses termos, aparentemente estaríamos presos ao seguinte dilema: ao reconhecermos que em geral os mercados de trabalho apresentam características que fogem ao modelo de concorrência perfeita, somos levados a desacreditar as capacidades racionais e calculadoras dos agentes no mercado de trabalho. Por outro lado, reconhecer a capacidade explicativa e preditiva dos modelos teóricos que assumem que firmas e trabalhadores tomam decisões racionais, calculando como maximizar seus ganhos, implicaria em fechar os olhos para o fato de que os mercados de trabalho funcionam a partir de outras condições que não aquelas previstas no modelo de concorrência perfeita.

Portanto, ambas as perspectivas são incompletas. A sociológica se limita, na maior parte das vezes, em denunciar o caráter empiricamente fíctício do cálculo econômico e da noção de mercado de concorrência perfeita. A econômica insistindo na utilidade heurística desses conceitos. As duas perspectivas perdem de vista, então, a possibilidade de refletir acerca de um importante problema teórico, qual seja: quais condições empiricamente verificáveis dotam os agentes econômicos de capacidade de cálculo? Essa pergunta evita a armadilha de adotar apenas uma visão, a crítica da noção de cálculo ou a "doutrinária" tomando-a como um pressuposto. Implícita na pergunta formulada acima, a proposição de que uma perspectiva sociológica deva tomar a capacidade de cálculo econômico como um objeto empírico de análise, evitando a posição de crítica ou doutrinária. Tal perspectiva deve desenvolver conceitos capazes de identificar empiricamente essa capacidade e de compreender as suas condições de possibilidade. Esta tese deu alguns passos nessa direção.

Talvez seja a firma o agente que melhor ilustra esse dilema e, portanto, seja o caso mais adequado para refletirmos a respeito da questão mencionada acima. É difícil negar que ela é um ator cuja raison d'être é gerar ganhos econômicos crescentes e que suas tomadas de decisões não sigam uma lógica de cálculo visando à maximização da produtividade e do lucro. É, portanto, quase evidente que não faz nenhum sentido dizer, por exemplo, que uma firma irá contratar trabalhadores se isso não lhe trouxer ganhos. Mas, também, perguntamos: o cálculo econômico da firma é compreensível somente nesses termos? Se reconhecermos que, na maior parte das vezes, os mercados de 
trabalho apresentam condições diferentes (ou até mesmo opostas) às do modelo de concorrência perfeita, como incorporar à explicação o reconhecimento de que as firmas exercem sua capacidade de cálculo? Ou seja, como ela é capaz de calcular o valor das ofertas disponíveis no mercado de trabalho? Pensamos que a perspectiva sociológica desenvolvida aqui consegue superar esse impasse analítico e conceitual.

Assim, a perspectiva adotada nesta tese reconhece que as firmas são agentes que calculam visando maximizar seus ganhos, isto é, elas calculam o valor relativo das ofertas no mercado de trabalho; e, ao mesmo tempo, que os mercados de trabalho apresentam características que fogem às do modelo de concorrência perfeita. Veremos adiante na primeira seção do Capítulo 2, as especificidades da mercadoria e do mercado de trabalho, mas antes, para melhor compreender o significado da abordagem sociológica do cálculo econômico, cabe melhor definir a abordagem econômica ortodoxa que diz respeito ao comportamento da firma no mercado de trabalho.

\subsection{0 comportamento da firma no mercado de trabalho, segundo a visão econômica ortodoxa}

$\mathrm{Na}$ perspectiva ortodoxa é a "teoria da produtividade marginal" (TPM) que descreve e explica o comportamento da firma no mercado de trabalho, ou seja, a demanda de trabalho (BOYER; SMITH, 2001; BORJAS, 2010). O principal objetivo desta teoria é compreender o processo de tomada de decisão das firmas no que respeita a contratar mão de obra; nesse sentido, ela não se interessa pela maneira através da qual as firmas demandam trabalho, mas apenas por determinar quanto ela irá demandar e quando irá parar de demandar. Dito de maneira diferente, a TPM visa compreender a decisão de uma firma sobre demandar e contratar trabalhadores, mas não através de que práticas ela recruta, seleciona e contrata esses trabalhadores.

A TPM está baseada numa concepção do mercado de trabalho como um mercado de concorrência perfeita ${ }^{12}$. Disso decorre representá-lo como um espaço onde interagem dois tipos de agentes, que ali exercem a sua capacidade de cálculo, são eles, os trabalhadores e as firmas. No entanto, eles exercem essa capacidade a partir de interesses conflitantes, ou seja, os trabalhadores vão querer vender sua força-de-trabalho

\footnotetext{
${ }^{12}$ Reiterando o que foi sublinhado antes, isso não quer dizer que não se reconheça que, do ponto de vista empírico, os mercados de trabalho apresentem condições opostas às do modelo de concorrência perfeita, e nem que outros fatores deixem de ter influência no funcionamento desses mercados. Significa apenas que, diante da complexidade da realidade empírica, assume-se que os mercados de trabalho são mercados de concorrência perfeita, pois isso permite fazer predições consistentes com ao que se observa no mundo real. Nesse sentido, ver BORJAS (2010, p. 2-10).
} 
ao maior preço possível enquanto as firmas vão querer comprá-la ao menor custo. Sendo um mercado de concorrência perfeita, à medida que trabalhadores procuram emprego e firmas procuram trabalhadores, "[...] these conflicting desires are 'balanced out' and the labor market reaches an equilibrium" (BORJAS, 2010, p. 4, grifos do autor).

Essa perspectiva ainda reconhece o governo como um ator importante, pois impõe regulações que ajudam a definir "as regras do jogo" das transações que ali têm lugar. Exemplos dessas regulações é a fixação de um salário mínimo, os impostos incidentes sobre os salários ou sobre a folha de pagamento, as leis que limitam ou favorecem o trabalho de imigrantes, as regulações que definem a contratação segundo critérios raciais, de gênero ou de idade, protegendo minorias ou grupos sociais específicos, ou criando barreiras de ingresso ou de permanência no mercado, só para citar algumas iniciativas onde fica evidente o poder regulador das instituições governamentais ${ }^{13}$. "All these actions will change the equilibrium that will eventually be attained in the labor market" (BORJAS, 2010, p. 5).

Segundo a TPM, a firma é um agente que busca maximizar seu lucro e o faz através de decisões de produção que maximizem a sua sintonia com os desejos e necessidades do consumidor ${ }^{14}$. Entre tais decisões estão incluídas as escolhas no que concerne contratar e demitir trabalhadores. Portanto, "[...] the firm's demand for labor is a derived demand, a demand derived from the desires of consumers" (BORJAS, 2010, p. 4, grifos do autor).

Assim, para compreender a demanda de trabalho de uma firma é preciso considerar o trabalho como um dos insumos que compõem a sua função de produção; essa, por sua vez, pode ser entendida como a quantidade de empregados/horas e de capitais (terra, máquinas, ferramentas, matérias-primas e energia) que a firma utiliza para produzir bens ou serviços e, assim fazendo, atender os desejos dos consumidores dos seus produtos finais.

Essa abordagem do trabalho como um insumo implica na adoção de dois pressupostos. Primeiro, a decisão sobre o número de empregados/horas numa função de

${ }^{13}$ Sindicatos, segundo essa perspectiva, podem ser considerados como um ator relevante para análise desde que representem uma parcela significativa da força-de-trabalho.

${ }_{14}$ Cabe destacar que, para a economia do trabalho ortodoxa, no caso da análise do comportamento da demanda de trabalho, toma-se a estratégia de negócios da firma como apenas composta pelas decisões de produção, isto é, escolhas sobre a quantidade empregada de trabalhadores e capital (BORJAS, 2010, p. 89). Nessa questão reside uma importante crítica da Nova Economia Institucional à teoria neoclássica, a saber, a firma seria muito mais do que simplesmente uma função de produção, mas uma estrutura de governança (WILLAMSON, 2000, p. 602-604). 
produção tomará sempre em conta a produtividade dos mesmos; assim, por exemplo, 10 trabalhadores contratados por oito horas deverão ser equivalentes em produtividade a 20 trabalhadores contratados por quatro horas. Visando a simplificação, considera-se essa proporcionalidade e, para TPM, apenas é considerado o número de trabalhadores contratados pela firma. Segundo, apesar de se reconhecer que os trabalhadores são heterogêneos em termos de qualificação, experiência e função, contribuindo desigualmente para produtividade da firma, o outro pressuposto adotado é que diferentes tipos de trabalhadores produzem um mesmo insumo para firma, chamado "trabalho". Deste modo, considerando o trabalho como um insumo homogeneamente ofertado, o que importa para análise são apenas as decisões em termos da quantidade deste insumo que irá ser contratada.

Um dos conceitos mais importantes para se compreender a demanda da firma pelo insumo trabalho é o de "produtividade marginal do trabalho" (PMT). A PMT é definida como o acréscimo de produtividade que uma firma consegue ao contratar mais um trabalhador, mantidos constantes os outros insumos da função de produção. A PMT, por sua vez, está submetida à "lei dos rendimentos decrescentes" que estabelece: "As more and more workers are added to a fixed capital stock (that is, to a fixed number of machines and a fixed amount of land), the gains from specialization decline and the marginal product of workers declines" (BORJAS, 2010, p. 91). Se a lei dos rendimentos decrescentes não fosse verdadeira, a firma, sendo um agente maximizador, continuaria contratando trabalhadores indefinidamente.

Outro conceito muito importante para compreender a TPM é o de "firma perfeitamente competitiva". Isso quer dizer que, a TPM pressupõe que a demanda desse tipo de firma tem um peso suficientemente pequeno no seu segmento econômico, de tal modo que "[...] the price of the output [...] is unaffected by how much output this particular firm produces and sells, and the price of labor [...] and capital [...] are also unaffected by how much labor and capital the firm hires" (BORJAS, 2010, p. 91). Uma vez que uma firma perfeitamente competitiva não possui meios para influenciar os preços, só pode maximizar seu lucro e produtividade empregando a correta quantidade de seus insumos, o trabalho entre eles.

Apoiando-se nos pressupostos antes indicados e nas condições que os conceitos acima mencionados estabelecem, a teoria da produtividade marginal afirma que o comportamento da firma no mercado de trabalho respeita e é compreensível nos termos da seguinte lógica: "[...] a profit-maximizing firm is posited to stop hiring when the 
value of labor's marginal product falls below the cost of hiring this extra labor" (BOYER; SMITH, 2001, p. 206). Dito de maneira de outra maneira, a demanda de trabalho de uma firma depende dos ganhos em produtividade que ela adquire ao empregar certa quantidade de trabalhadores vis-à-vis ao custo que assume ao adquirir essa quantidade no mercado de trabalho; quando os custos superam os ganhos, a firma vai parar de demandar mão de obra.

O que chama atenção nessa proposição aparentemente simples é a quantidade de pressupostos e condições que se precisa levar em conta para que ela seja verdadeira. Em particular, dois deles se destacam: o da "firma perfeitamente competitiva" e o que prevê que o trabalhador oferece um insumo (ou mercadoria) homogêneo, o trabalho. Poderíamos citar uma série de casos empíricos nos quais a firma tem condições de influenciar os preços seja no mercado de produtos, seja no mercado de trabalho. Poderíamos ainda elencar inúmeras razões que confirmam que a mercadoria trabalho é tudo menos um insumo homogeneamente ofertado pelos trabalhadores, de tal modo que o custo (preço) desse insumo é um dos fatores que determinam a demanda de trabalho de uma firma, ou seja, diferentes valores entram no cálculo da firma.

Entretanto, nenhuma dessas ressalvas consegue desacreditar completamente a simples e poderosa proposição da teoria da produtividade marginal de que uma firma irá empregar trabalhadores na medida em que isso represente ganhos para ela, isto é, algum valor. É nesse aspecto que nosso interesse analítico se torna relevante: se a lógica de cálculo da firma não é refutável completamente em razão da diferença entre a realidade empírica e os pressupostos comportamentais que a TPM assumi para compreender o cálculo econômico da firma nas transações que têm lugar no mercado de trabalho; então, é preciso compreender que outros elementos dão condições e moldam essa capacidade de cálculo. Em outros termos, concordamos com a TPM que a firma calcula o valor do insumo trabalho para ela, mas pensamos que esta perspectiva não fornece uma adequada compreensão sobre quais condições e como a firma calcula (sendo essa uma forma de descrever o interesse analítico desta tese).

Cabe destacar que, segundo a perspectiva ortodoxa, é possível compreender o comportamento das firmas em posição de monopsônio (isto é, firmas que não são perfeitamente competitivas nos mercados onde são demandantes) em termos de um cálculo maximizador de ganhos de produtividade marginal (VARIAN, 2006, p. 503510). Se por um lado, esse aspecto relativiza nossa afirmação sobre a quantidade de pressupostos que a TPM se baseia para descrever o comportamento da firma no 
mercado de trabalho, por outro lado, isso reforça nosso argumento de que a noção de cálculo é analiticamente poderosa. Portanto, nossa pergunta permanece pertinente: o que faz com que as firmas exerçam sua capacidade de calcular valor no mercado de trabalho? O fato que tanto em condições de perfeita competição como em condições imperfeitas, a lógica do comportamento da firma seja passível de ser descrita em termos de cálculo econômico de valor, indica que em qualquer uma dessas condições exista algo que faça a firma se portar com base nessa capacidade de agência. Cabe, então, a nossa pergunta sobre quais são os elementos que permitem a firma exercer essa capacidade.

Pode-se ainda contra-argumentar que a teoria da produtividade marginal e os pressupostos e conceitos ortodoxos que ela adota, apenas fornecem um modelo de explicação para um dos aspectos da demanda de trabalho das firmas, a saber, o da quantidade de força-de-trabalho a ser demandada ou dispensada. Outros aspectos relevantes estariam, assim, sendo deixados de lado, por exemplo, como explicar as escolhas que elas fazem sobre como remunerar os trabalhadores? (salário fixo ou remuneração por desempenho?); ou as escolhas que se referem ao regime de tempo sob o qual a firma irá demandar o trabalho? (por jornada fixa ou variável? por vínculo indeterminado ou por tempo determinado?); ou ainda sobre as qualidades e critérios que a firma deve valorizar nos ofertantes de força-de-trabalho e que definirão o processo de seleção dos candidatos a uma vaga de emprego.

Frente a essas e outras questões, poder-se-ia argumentar que para compreender o modo como firmas escolhem realizar a sua demanda de trabalho seria necessário afastar-se dos pressupostos que descrevem as suas escolhas em termos de cálculo de valor. Todavia, a chamada "Personnel Economics" (PE) tenta oferecer respostas a perguntas dessa natureza, mantendo-se fiel aos pressupostos ortodoxos da teoria econômica sobre o comportamento dos agentes.

A PE estuda diferentes práticas de gestão de recursos humanos das firmas (LAZEAR; SHAW, 2007), mas, para fins do enfoque desta pesquisa, vamos tratar dessa perspectiva através do modo como ela analisa uma dessas práticas que mais diretamente se refere ao comportamento da firma no mercado de trabalho, as formas e sistemas de remuneração elegidas ${ }^{15}$.

15 Sobre o modo como a PE compreende outras práticas de gestão de recursos humanos, ver Lazear (2000b) e Lazear e Shaw (2007). 
Ao examinar as escolhas das firmas sobre formas de remunerar seus empregados, a PE o faz a partir de quatro pressupostos da teoria econômica ortodoxa:

First, personnel economics assumes that both the worker and the firm are rational maximizing agents, seeking utility and profits. Of course, the economic approach allows for constraints or imperfections, such as imperfect information and transaction costs, and permits an individual's utility to be influenced by a variety of factors such as personal identity, competition, and peer pressure. Second, personnel economists assume that labor markets and product markets must reach some price-quantity equilibrium [...]. Third, efficiency is a central concept of personnel economics. [...] Fourth, personnel economists emphasize the use of econometrics and experimental design to identify underlying causal relationships (LAZEAR; SHAW, 2007, p. 91-92).

Novamente chama a atenção a quantidade de condições e pressupostos que precisam ser assumidos para que as proposições acerca do comportamento da firma no mercado de trabalho sejam formuladas. É verdade que, como se lê na citação acima, os autores fazem uma ressalva com relação ao pressuposto de agentes que calculam como maximizar utilidade ou lucros. Porém, admitir a existência de todos aqueles elementos que interferem na capacidade de cálculo não diminui a força e a centralidade analítica deste pressuposto para PE:

Constrained maximization is the basic building block of all theories in personnel economics. Our empirical analyses in the field are attempts to test models that are based on maximizing behavior. Even when evidence suggests that the theories are wrong, we do not drop the assumption of maximization. Instead, our approach is to think more carefully about the nature of the model set up, but not about the rationality of the individuals making choices. Economists are rarely willing to assume that individuals simply do not know what they are doing (LAZEAR, 2000b, p. F612).

Portanto, os autores da PE não abdicam do pressuposto teórico-metodológico do cálculo maximizador de valor, mesmo reconhecendo que há elementos que interferem. Porém, a manutenção desse e outros pressupostos permitem à PE, segundo seus autores, desfrutar da principal vantagem da ciência econômica frente às demais ciências sociais, qual seja: produzir modelos abstratos e parcimoniosos com alto poder de predição. Essa capacidade é central porque, segundo Lazear (2000b, p. F612-F616), fornece condições à $\mathrm{PE}$ se tornar uma ferramenta útil aos gestores de empresas, ou seja, oferecer medidas cientificamente embasadas de caráter prescritivo.

Desse modo, a PE procura explicar as escolhas das empresas entre, por exemplo, pagar seus funcionários um salário fixo ou uma remuneração variável por desempenho. Tal decisão é uma função dos seguintes fatores: 
1) é provável que uma firma escolha remunerar seus funcionários pelo desempenho, quando forem baixos os custos de medir o desempenho dos trabalhadores. Por exemplo, é mais fácil medir o desempenho de um vendedor do que o de um contador;

2) a escolha entre as formas de remuneração é realizada em função do interesse da firma em selecionar trabalhadores com o perfil "certo", ou seja, firmas interessadas em funcionários com habilidade de atrair novos clientes ou produzir inovações serão mais propensas a adotar sistemas de remuneração por desempenho para atrair empregados com essas capacidades, sabedores de que terão rendimentos maiores e crescentes;

3) a adoção de sistemas de remuneração por desempenho é mais provável em firmas que demandem profissionais com capacidades escassas e valorizadas no mercado de trabalho. Assim, em vez de uma empresa competir com outras oferecendo salários maiores, ela atrai esses trabalhadores garantindo uma remuneração de acordo com o desempenho desse profissional. Assim, a diferença de rendimentos do trabalhador passa a depender do seu desempenho na firma;

4) firmas em mercados de trabalho com boa parte dos ofertantes (trabalhadores) com baixa qualificação, provavelmente irá adotar sistemas de remuneração por desempenho como meio de selecionar aqueles trabalhadores mais dispostos em se comprometer com a produtividade da firma.

Em suma, "the choice between pay-for-performance and salary is determined by concerns of economic efficiency in different employment settings, including the level of measurement costs and the value of screening out workers to specific employers" (LAZEAR; SHAW, 2007, p. 100). Em outros termos, a PE entende que as firmas escolhem um ou outro sistema de remuneração em função de um cálculo maximizador de valor (sendo esse valor a maior eficiência ou a produtividade) frente às características da oferta no mercado de trabalho.

Tanto na PE como na TPM, a capacidade de cálculo é tomada como um pressuposto comportamental dos agentes e o que é estudado são os resultados de escolhas conduzidas a partir desse pressuposto frente a certos tipos de condições de mercado, ou seja, não é o como e nem o porquê dos agentes tomarem decisões através ou não do exercício da capacidade de cálculo que essa perspectiva se preocupa, mas são 
os resultados das escolhas (em que momento e em que quantidade uma firma irá contratar?) ou quais decisões são tomadas frentes a certas condições de mercado; tal como o Nobel de economia, Hebert Simon, afirma ao se referir ao modo particular como a economia ortodoxa estuda o comportamento humano: "[...] economics has largely been preoccupied with the results of rational choice rather than the process of choice" (1978, p. 2).

Assim, esta tese se situa num esforço para mostrar como uma abordagem de sociologia econômica pode contribuir ao analisar um aspecto deixado para trás pela economia ortodoxa quando essa toma o cálculo como um pressuposto comportamental, a saber, o estudo das condições de possibilidade e das formas pelas quais as firmas exercerem a capacidade de cálculo econômico de valor no mercado de trabalho. Em suma, em vez de tomar o cálculo como pressuposto comportamental, fazemos dele um objeto de investigação.

Tal objetivo não pode ser alcançado se adotarmos aquela perspectiva tradicional da NSE que se contenta em denunciar o caráter reducionista e fictício do modelo de interpretação da economia neoclássica baseado na escolha racional através do cálculo maximizador. Simultaneamente, não devemos descartar as ferramentas de análise da sociologia econômica e nem simplesmente transpor os conceitos e métodos da Economia; pois, se fizéssemos assim, não teríamos meios de constituir o cálculo econômico como objeto de análise.

\subsection{0 cálculo econômico entre a atomização e a rede social}

Grosso modo, a economia ortodoxa assume os pressupostos da teoria da escolha racional ao entender o comportamento dos agentes como o resultado de escolhas calculadas visando à maximização de valores relativos ao interesse pessoal - no caso das firmas lucro e ganho de produtividade são os valores. A realização dessas capacidades dos atores na ação econômica dependeria em boa parte da existência de condições oferecidas pelo modelo de "mercado de concorrência perfeita" 16 . Entretanto, uma vez que assumimos que essas condições são empiricamente raras, como poderíamos explicar que os agentes exerçam a capacidade de cálculo, sem incorrermos na posição ingênua que afirma que é da natureza do indivíduo calcular e maximizar valores? No seminal artigo de 1985, Mark Granovetter irá defender a tese que as

\footnotetext{
${ }^{16}$ Cabe lembrar que, a teoria econômica ortodoxa também descreve o comportamento dos agentes econômicos em termos de escolhas racionais em mercados em condições imperfeitas, por exemplo, com a presença de agentes em posição do monopsônio.
} 
transações de mercado são realizadas a partir das condições estruturadas pelas redes de relações sociais, não pelas condições previstas no modelo de concorrência perfeita. Assim, compreender as condições de possibilidades para o cálculo econômico através das redes sociais configura uma alternativa para constituir tal capacidade como objeto de análise e não como simplesmente um pressuposto.

O referido artigo de Granovetter pode ser considerado como fundador na consolidação da chamada perspectiva de análise de redes sociais na Nova Sociologia Econômica. Essa perspectiva é um tipo de sociologia estrutural que estuda os efeitos das relações sociais sobre o comportamento individual e grupal. Ela defende que as estruturas sociais, através de restrições e oportunidades, afetam mais o comportamento humano que as normas culturais e outros fatores subjetivos. Nesse sentido, a identidade das pessoas e seu comportamento não são o resultado de seus atributos culturais, demográficos e/ou cognitivos, mas da morfologia da rede social na qual estão inseridas (MIZRUCHI, 2009).

$\mathrm{Na}$ Nova Sociologia Econômica, a perspectiva de redes situa-se em contraposição à concepção da teoria econômica ortodoxa no que diz respeito à concepção da última sobre os mercados como espaços onde agentes, socialmente atomizados, fazem escolhas e se engajam em transações impessoais e anônimas. A abordagem de redes contra-argumenta que esses espaços são constituídos de atores (firmas, trabalhadores, consumidores, etc.) em relações sociais, sendo afetados por essas últimas nos seus comportamentos.

Ronald S. Burt (2004), Mark Granovetter (2005), Joel M. Podolny (2001), Brain Uzzi (1996), Harrison C. White (1981) e outros pesquisadores de sociologia econômica e acólitos desse tipo de abordagem, procuraram evidenciar como as características e morfologia das redes de relações sociais, a posição do agente na rede e as qualidades dos laços sociais ali tecidos afetam o comportamento dos agentes e o decurso dos processos econômicos ${ }^{17}$. Assim sendo, mostram como essas redes influenciam aspectos do funcionamento dos mercados (confiança, circulação de informações, hierarquias, sistemas de classificação, reprodução de normas, etc.) e como elas determinam os resultados econômicos como preços, salários, acesso à tecnologia e inovação, entre

${ }^{17}$ Os autores da NSE situados na perspectiva de redes possuem, também, discordâncias a respeito do papel e como as relações sociais afetam os fenômenos da vida econômica. A título de exemplo sobre essas diferenças, ver Granovetter (1985, nota 2, p. 487) ou Ioannides e Loury (2004, p. 1062-66). 
outros (FOURCADE, 2007; FLIGSTEIN; DAUTER, 2007; BEAMISH; BIGGART, 2006).

Tanto na NSE como na teoria social, a abordagem de redes possui diferenças e aproximações com a chamada teoria da escolha racional cujos pressupostos são largamente adotados pela teoria econômica ortodoxa. Um ponto comum entre as duas perspectivas é presumir "[...] que, em geral, as variações do comportamento individual são explicadas por diferenças entre as estruturas de oportunidade com que se deparam os agentes e não por variações da sua composição interna [...]” (HEDSTRÖM ${ }^{18}$ apud MIZRUCHI, 2009, p. 144).

A análise de redes sociais não assume nenhum tipo de premissa quanto à racionalidade dos agentes, mas, ao mesmo tempo, não há nada nela que exclua a racionalidade.

As principais diferenças entre o modelo estrutural e o modelo de escolha racional são que, no primeiro (1), as preferências humanas são consideradas endógenas, ou seja, a formação das preferências é tida como algo a ser explicado, e no segundo (2), a ação humana é tida como sendo afetada por estruturas sociais explicitamente definidas (MIZRUCHI, 2009, p. 145).

Em contrapartida, a perspectiva econômica ortodoxa não exclui a possibilidade de inserir o papel das redes sociais no comportamento humano. Vejamos essa questão.

Segundo Granovetter (1985), a perspectiva ortodoxa da economia - que ele denomina de subsocializada - só pode manter o pressuposto da atomização em função da forma como ela utiliza a noção de mercado de concorrência perfeita para resolver o "problema hobbesiano da ordem", que é por ele definido nos seguintes termos: a realização de transações econômicas e sociais necessita de ordem promovida pela confiança entre indivíduos e pela ausência de maleficência; mas, se os indivíduos são atomizados, não há nada que os faça confiar uns nos outros e nem evitar que se engajem em condutas oportunistas. Ainda segundo Granovetter, para Thomas Hobbes, o problema da ordem poderia ser resolvido através de uma forma de autoridade autocrática, que fizesse os indivíduos respeitar as regras em função da ameaça e execução da coerção e, assim, findasse por promover a confiança. Já a resposta da economia neoclássica para esse dilema, tal como compreende Granovetter, afirma que:

repressive political structures are rendered unnecessary by competitive markets that make force or fraud unavailing. Competition determines the terms of trade in a way that individual traders cannot

${ }^{18}$ HEDSTRÖM, P. Introduction to this special issue on rational choice theory. Acta Sociologica, v. 36, n. 3, p. 167-169, 1993. 
manipulate. If traders encounter complex or difficult relationships, characterized by mistrust or malfeasance, they can simply move on to the legion of other traders [...]; social relations and their details thus become frictional matters (GRANOVETTER, 1985, p. 484)

Assim, para Mark Granovetter, os pressupostos da atomização e do mercado de concorrência perfeita são mutuamente complementares. Alternativamente, ele desenvolve a perspectiva do "enraizamento social dos mercados e da ação econômica" que "[...] stresses instead the role of concrete personal relations and structures (or 'networks') of such relations in generating trust and discouraging malfeasance" (GRANOVETTER, 1985, p. 490). É, então, nas redes sociais que se encontram as bases para que as transações econômicas de mercado se desenrolem; assim, as escolhas dos agentes nos mercados e os resultados econômicos observados nesses dependem das estruturas sociais nas quais estão inseridos. A partir de Granovetter pensamos que as condições produzidas pelas redes sociais são elementos fundamentais para explicar a capacidade de e o modo como os agentes econômicos exercem o cálculo de valor.

Cabe destacar que Granovetter alerta para o risco de se incorrer num certo "funcionalismo otimista" que conferiria às relações sociais um papel de produtoras da ordem necessária ao funcionamento dos mercados. Para evitar esse equívoco é preciso reconhecer dois pontos: 1) que as redes de relações sociais não estão generalizadas de modo uniforme pelos diferentes âmbitos da vida econômica, já que elas penetram em diferentes graus nos vários setores da economia, abrindo espaço para ocorrência de desconfiança, oportunismo e desordem; 2) que relações sociais também podem ser meios para emergência de disputas, oportunismo e maleficência porque, ao confiarmos numa pessoa, nos colocamos sempre numa posição vulnerável. Além disso, o conluio só é possível através de uma estrutura de relações pessoais. A perspectiva do enraizamento, por conseguinte, “[...] makes no sweeping (and thus unlikely) predictions of universal order or disorder but rather assumes that the details of social structure will determine which is found" (GRANOVETTER, 1985, p. 493) ${ }^{19}$.

Portanto, para Granovetter (1985, p. 505-06), o criticável na perspectiva ortodoxa da economia não é o reducionismo psicológico e comportamental que ela incorpora ao assimilar a teoria da escolha racional e, sim, é que, ao fazê-lo, desconsidera o papel das relações sociais e pressupõe a atomização dos agentes econômicos.

19 Adiante ao retomarmos alguns estudos sobre a relação entre redes e discriminação e desigualdades no mercado de trabalho, veremos que o alerta para não se incorrer num otimismo funcionalista com relação ao papel das redes na economia é válido para racionalidade, ou seja, as redes sustentam tanto comportamentos e escolhas econômicas racionais como irracionais, por exemplo, a discriminação de gênero ou racial. 
Portanto, não há nada nessa perspectiva teórica que impeça o que estamos propondo: compreender o exercício do cálculo de valor das firmas no mercado de trabalho, analisando as condições produzidas pelas redes sociais das quais elas fazem parte. Em outros termos, propomos que a capacidade de cálculo da firma depende do modo como sua ação econômica está socialmente enraizada.

Todavia, antes de esboçar um modelo de análise baseado na perspectiva de redes sociais, precisamos repensar a crítica de Granovetter ao conceito sub-socializado de ação econômica, porque já encontramos desenvolvido na Economia um conjunto de pesquisas e modelos teóricos de análise de redes, baseados em muitos dos principais pressupostos neoclássicos.

Alguém familiarizado quase exclusivamente com a literatura de sociologia econômica se surpreenderá ao constatar que exista uma tradição (inicialmente dispersa) de estudos na economia a respeito do papel das redes sociais de informação no processo de procura/obtenção de emprego. A revisão bibliográfica feita por Ioannides e Loury (2004) deixa claro esse fato logo no início do artigo, mostrando a existência de uma primeira geração de estudos em economia (que começa nos meados da década de 1970 e se estende à de 1990) a respeito da relação entre redes sociais e o processo de procura/obtenção de emprego.

Segundo esses dois autores, essa primeira geração de estudos evidenciou o que eles chamam de alguns "fatos estilizados": 1) o uso de amigos, familiares e conhecidos para procurar trabalho é ubíquo entre as populações e tem crescido ao longo do tempo; 2) o uso dessas relações sociais para procurar emprego é variável em função de características demográficas e no espaço; 3 ) geralmente procurar emprego através de relações sociais é mais produtivo e vantajoso; 4) parte da variação de sucesso na procura de emprego entre grupos demográficos é devido ao uso de redes sociais; 5) em contraposição ao quarto fato, algumas pesquisas mostraram que nem toda variação no sucesso da procura de emprego entre grupos demográficos pode ser explicada em função do uso de redes sociais; 6) há um crescente uso da Internet como um método de procura de emprego que interfere e até mesmo vem substituindo o uso de redes sociais para esse fim; 7) há diferenças entre países no que concerne ao uso de redes sociais tanto por parte de trabalhadores como de firmas (IOANNIDES; LOURY, 2004, p. 1057-61).

Todos esses fatos são até hoje alvo de debates e pesquisas no campo da análise de redes em sociologia econômica e em economia do trabalho; mostrando, portanto, que 
uma contraposição entre Sociologia e Economia precisa ser reavaliada e que seja aberto o caminho para maior intercâmbio disciplinar.

Conforme Ioannides e Loury (2004, p. 1060-61), essa primeira geração de estudos de redes sociais não possuía uma clara orientação e embasamento nas teorias econômicas. Entretanto, as pesquisas mais recentes reverteram essa característica, estruturando por meio dos pressupostos e conceitos da economia neoclássica, a análise dos papéis das redes sociais no funcionamento do mercado de trabalho. As pesquisas têm utilizado os postulados ligados às noções de eficiência, escassez e equilíbrio, junto ao recurso do modelamento matemático, para precisar o impacto de aspectos $\mathrm{e}$ características específicas das redes sociais no funcionamento e resultados econômicos observados nos mercados e organizações econômicas ${ }^{20}$ (JACKSON, 2007). A utilização dessas noções é mais evidente num grupo de estudos de análise de redes que Ioannides e Loury (2004, p. 1076-78) denominaram de pesquisas sobre "formação estratégica de rede e redes endógenas de informação de emprego". O principal objetivo e contribuição dessa linha de pesquisa é a construção axiomática de modelos sobre processos relacionados a certas características e propriedades (densidade, forma topológica, etc.) das redes e, também, a respeito da formação e extinção dessas últimas como uma função de escolhas de agentes estratégicos.

Ainda mais surpreendente é que, utilizando conceitos e pressupostos ortodoxos, os economistas de análise de redes reconheceram um fato diretamente relacionado à crítica de Granovetter sobre a noção subsocializada de ação econômica da teoria neoclássica, tornando essa crítica um tanto quanto anacrônica frente ao desenvolvimento dos modelos teóricos econômicos de redes:

The rise of what might called "social economics" comes very much from the realization by economists that there are many economic interactions where the social context is not a second-order consideration, but is actually a primary driver of behaviors and outcomes. [...]

Although the widespread realization of the importance of the embeddedness of economic activity in social settings has been fundamental to sociologists for some time, [...] it was largely ignored by economists until the last decade. The recent interest comes from many economic models having been pushed to their limits, and the consequent discovery that social circumstances can help explain observed economic phenomena [...] (JACKSON, 2007, p. 19).

${ }^{20}$ Além de uma questão de espaço, a utilização de modelos matemáticos impossibilitou fazermos uma resenha dos principais achados e modelos teóricos dessa literatura de análise econômica de redes. Nesse sentido, ver Ioannides e Loury (2004, p. 1066-84), Calvó-Armengol (2006), Jackson (2007; 2010). 
Economistas chegaram a essa conclusão sem abrir mão de postulados ortodoxos como o de equilíbrio, eficiência, recursos escassos e do uso de modelamento matemático. Portanto, eles encontraram uma forma de absorver uma tese advinda da sociologia econômica sem abandonar aspectos teórico-metodológicos característicos da sua disciplina, ou seja, enriqueceram os tradicionais modelos teóricos econômicos com a noção de enraizamento social das atividades econômicas.

Ademais, essa literatura da economia de análise de redes faz uso do postulado ortodoxo do agente racional (cálculo) maximizador para explicar algo que a sociologia pouco vem se debruçando: as razões do surgimento e término de redes sociais (IOANNIDES; LOURY, 2004, p. 1063; PODOLNY; RAUCH, 2007, p. 4-6). Matthew Jackson (2007, p. 20-21) elucida esse ponto ao afirmar:

[...] much of the economic study of interactions in a social context lies within a "rational choice" framework. [...] One of the basic presumptions that underlies much of the economic modeling of network formation is the view that the individuals involved in networks choose whom to interact with. [...] This choice perspective traces the structure and the properties of networks back to the costs and benefits that they bestow upon their participants.

Em suma, o que essa perspectiva econômica de análise de rede afirma é que a emergência, reprodução e desestruturação de redes sociais são uma função do cálculo maximizador de utilidade dos agentes, isto é, uma rede só surge e permanece se ela representa ganhos marginais em relação aos custos que os indivíduos assumem ao participarem dela.

Nesse ponto é que reside uma diferença entre Sociologia e Economia que adotamos e, por meio dela, construímos o cálculo econômico como objeto de investigação. Essa diferença não se refere às concepções atomizadas ou não de ação econômica, mas de considerar as redes como constitutivas das preferências, interesses e da racionalidade dos agentes (abordagem sociológica) ou se as redes são formadas de acordo com o cálculo maximizador de preferências e interesses dados (abordagem econômica). Em outros termos,

Economic conceptions of networks also seemed to treat an actor's links within a network as something apart from the actor's self, a fact that seemed increasingly to trouble sociologists from the mid-1990s on, as they came to conceptualize networks as constituent elements of identity. Because the sociologists believed that networks informed and shaped preferences, they thought it made little sense to treat networks as a form of capital that is analytically separate from an actor and thus something in which an actor chooses to make or not make investments (PODOLNY; RAUCH, 2007, p. 3) 
É essa diferença que estrutura a abordagem sociológica desenvolvida nesta tese, ou seja, ela incorpora um elemento importante da teoria econômica ortodoxa, a saber, que a ação econômica comporta um elemento de cálculo no processo de escolha visando maximizar utilidade ou lucro (valores). Se a economia toma esse elemento como um pressuposto para explicar a rede, nossa abordagem sociológica adota-o como objeto de investigação incorporando o seu pressuposto de enraizamento social da ação econômica. Portanto, alternativamente à noção de mercado de concorrência perfeita, o cálculo econômico passa ser uma capacidade de agência explicável em função da rede na qual essa última está inserida. 


\section{MODELO SOCIOLÓGICO DE ANÁLISE DO CÁLCULO ECONÔMICO}

\subsection{Valores na economia e o trabalho como mercadoria}

Praticamente ninguém seria capaz de negar que vivemos em uma economia na qual os mercados desempenham um papel central e crescente na organização das relações econômicas. Vimos no capítulo anterior que a perspectiva econômica ortodoxa compreende os mercados a partir de uma série de elementos, condições e características que formariam o chamado "mercado de concorrência perfeita", mas essa definição não pode ser considerada como uma definição dos mercados per se, ela consiste em um modelo teórico que diz mais sobre alguns postulados sobre o sistema de preços, os bens transacionados, o comportamento e a racionalidade dos atores. Em outras palavras, não são concretamente os mercados que estão sendo definidos, mas o funcionamento de um modelo de trocas econômicas que é definido em termos de pressupostos abstratos sobre o comportamento humano frente a determinadas condições e regras.

Assim, essa perspectiva se preocupou principalmente em desenvolver provas matemáticas e dedutivas sobre a eficiência de alocação das transações levadas ao cabo por meio das empiricamente improváveis condições estabelecidas pelo modelo teórico de "mercados de concorrência perfeita", em vez de realmente definir os mercados a partir da análise do seu funcionamento concreto (BERCKERT, 2009, p. 245-246).

O reconhecimento dessa limitação não pode servir de justificativa para nos furtar de adotar uma definição dos mercados e, nesse sentido, entendemos que a Nova Sociologia Econômica apresenta alguns elementos para uma definição analítica dos mercados com base em um sólido arcabouço de conhecimentos empíricos e teóricos (FLIGSTEIN; DAUTER, 2007; SWEDBERG, 2005).

Justamente por estar fundamentada nesse acúmulo da produção do conhecimento e também por tratar de definir os mercados com base no funcionamento que de fato eles apresentam é que escolhemos adotar aqui a conceituação desenvolvida por Patrik Aspers: "A market is a social structure for the exchange of rights in which offers are evaluated and priced, and compete with one another, which is shorthand for the fact that actors - individuals and firms - compete with one another via offers" (2011, p. 4, grifos do autor). Nessa definição podemos identificar elementos fundamentais que diferenciam os mercados de outros modelos de intercambio econômico existentes na 
sociedade. Segundo essa perspectiva, as trocas mercantis seriam aquelas que são realizadas a partir da existência de direitos de propriedade sobre o que está sendo transacionado, de indivíduos e firmas exercitando capacidade de avaliação para decidir entre diferentes ofertas, da competição entre os agentes na condição de ofertantes e da precificação de bens e serviços. Entre esses elementos, o interesse analítico desta tese repousa sobre um deles, a saber, o cálculo de valor (processo de avaliação) que os agentes exercitam diante de um conjunto de ofertas acessíveis em um mercado, isto é, quais valores orientam a sua demanda por certo tipo de mercadoria e como eles calculam esses valores na oferta disponível desses bens. Mais especificamente, estamos interessados no cálculo de valor de firmas quando comparecem, a partir do papel de demandantes, no mercado de trabalho.

Como os bens adquirem valor no mercado é uma questão seminal na fundação da ciência econômica e do pensamento social moderno. Assim, por exemplo, a economia política clássica, com Adam Smith ([1776] 1904) e David Ricardo ([1817] 2004), propôs a teoria do valor-trabalho que defendia a ideia de que o valor de um produto era determinado pelo trabalho necessário para produzi-lo. Karl Marx ([1867] 2006) tomou de empréstimo essa tese e, a partir dela, formulou sua teoria da exploração do trabalho. Essa teoria postula que, sendo a quantidade de trabalho a origem do valor dos bens, seria na exploração do trabalho, através do processo e relações de produção, que o empresário retiraria seu ganho, ou seja, o lucro advindo do processo de maisvalia, que consiste em quantidade de trabalho não paga pelo empresário ao trabalhador. Nesse sentido, cabe esclarecer que Marx fala em quantidade socialmente necessária de trabalho, que seria formada nas interações de troca que têm lugar nos mercados. Entretanto, mesmo remetendo ao mercado uma parte do processo de definição do valor, esse último ainda é objetivamente determinado pelos processos de produção que definem as quantidades necessárias de trabalho para produção de bens por parte de cada firma concorrente. É com posse desse valor que as firmas vão ao mercado e nele concorrem em termos de valor de troca e, simultaneamente, determinam a quantidade socialmente necessária de trabalho (MARX, 2006, p. 53-172). Portanto, a crítica que será explicitada adiante, ainda se mantém mesmo considerando esse aspecto da teoria da exploração e do valor-trabalho de $\operatorname{Marx}^{21}$.

${ }^{21}$ Para uma fascinante crítica à teoria do valor-trabalho e da exploração, ver Eugen Von BöhmBawerk (2010). 
Smith, Ricardo e Marx partilham da noção de que os produtos possuiriam um valor intrínseco, determinado pela quantidade de trabalho necessária para sua produção. Nesse sentido, a teoria do valor-trabalho ignora que o valor dos bens é formado extrinsecamente ao objeto, isto é, "[t] his theory misses the essential point that economic value expresses a relationship between the qualities of products offered in the market and the wants of customers and seller" (ASPERS; BECKERT, 2011, p. 9, grifo do autor).

A partir da ideia de que o valor de um bem ou serviço não é objetivamente, mas subjetivamente determinado, estabeleceu-se a base da moderna teoria econômica; mais especificamente a chamada Revolução Marginalista, ancorada na ideia de utilidade marginal (valor como a utilidade do último produto adquirido), que foi desenvolvida separada, mas contemporaneamente por William Jevons ([1871] 1996), Carl Menger ([1871] 2007) e Léon Walras ([1874] 1953). Uma vez que o valor não é ancorado num critério objetivo como a quantidade de trabalho, a esfera, o "espaço" no qual ele é determinado deixa de ser o das relações de trabalho e de produção para ser, em última estância, a das relações que têm lugar no mercado entre os agentes (firmas e indivíduos, ora na condição de ofertantes, ora na de demandantes) e as com os produtos demandados e suas qualidades. Portanto, para entender o funcionamento dos mercados é necessário, dentre outras coisas, compreender esse processo no qual as ofertas de produtos ou de serviços recebem um valor, ou seja, as transações de mercado ocorrem quando os agentes são capazes de responder à pergunta: quanto vale isso?

É nesse sentido que Patrick Aspers e Jens Beckert entendem a questão do processo de definição de valores como uma das condições para existência e funcionamento dos mercados - o que eles chamam de "ordem social dos mercados" (ASPERS, 2011; ASPERS; BECKERT, 2011; BECKERT, 2009). Em primeiro lugar é preciso ter em mente que os mercados não existem porque simplesmente os seres humanos teriam uma natural propensão para realizarem trocas de produtos. Para os mercados existirem é necessário que alguns "problemas de coordenação" sejam resolvidos, isto é, "[h]ow is it possible that economic activities can be coordinated through markets despite the heterogeneous and partly antagonistic motives and interests of the participants?" (BECKERT, 2009, p. 246).

Pensamos que, de certo modo, o que essa dupla de sociólogos faz é desenvolver teoricamente na sociologia econômica, a linha de reflexão que Mark Granovetter (1985) inaugura ao mencionar o "problema hobbesiano da ordem" nos mercados, tal como 
vimos na seção 3 do capítulo 1. Nesse sentido, entendemos que Aspers e Beckert avançam em relação à Granovetter ao estabelecer que as condições de existência do mercado e, por conseguinte, do seu funcionamento, não estão restritas somente a um problema de confiança e de risco de maleficência entre os agentes, que, segundo a perspectiva de Granovetter, sua resolução passaria pelo enraizamento social da ação econômica $^{22}$. Ambos (ASPERS, 2011; BECKERT, 2009) tratam das condições extraeconômicas na formação dos mercados e no seu funcionamento através de um conjunto mais extenso de ferramentas de análise; por exemplo, eles não apenas consideram as influências das redes de relações sociais na formação e funcionamento dos mercados, mas também tentam articular no modelo de análise os condicionantes advindos das instituições, cultura, cognição e poder.

Não é nossa ambição compreender por completo a formação e funcionamento do mercado de trabalho relacionado à área das atividades econômicas das tecnologias da informação. Parcimoniosamente escolhemos por analisar um dos processos ligado a essa realidade porque, tal como expusemos na introdução desta tese, pensamos que articule uma faceta analítica ainda pouco explorada pela literatura sociológica, a saber, a firma como demandante no mercado de trabalho. Assim sendo, destacamos que nosso interesse analítico reside em examinar através das condições de possibilidade engendradas por redes sociotécnicas, a capacidade das firmas de tecnologias da informação exercerem o cálculo econômico de valor quando comparecem como demandantes no mercado de trabalho.

Retomando, o que é, então, o "problema do valor" como condição para a formação e funcionamentos dos mercados? De maneira geral, esse problema se refere ao lado da demanda em um mercado - isso não quer dizer que ele não seja influenciado pelos agentes que ofertam - e à questão da formação e dos modos de realização das preferências dos demandantes. Para que as transações de mercados se concretizem, o demandante se vê na posição de ter que estabelecer critérios que liguem as suas preferências e interesses (que, ao seu turno, conformam a sua demanda) às inúmeras qualidades que uma sorte de produtos poderá conter e, desse modo, possa ser capaz de julgar entre quais das ofertas concorrentes no mercado é a melhor para ele, isto é, tomar uma decisão.

\footnotetext{
${ }^{22}$ Para melhor compreender a relação crítica entre a perspectiva do enraizamento social da ação econômica de Granovetter com a da ordem social dos mercados, ver Beckert (1996).
} 
Basicamente esse é o processo de cálculo de valor que se refere ao problema da constituição e funcionamento dos mercados, pois ele não ocorre automaticamente por alguma força natural. Tal como se sabe desde a Revolução Marginalista na Economia, o valor de uma mercadoria não se encontra objetivamente determinado em alguma propriedade do objeto ou da produção desse objeto que representa um tipo de mercadoria; assim sendo, cabe àquele que demanda estabelecer qual é o valor de um produto ou serviço. Nesse sentido, o problema reside no fato de que os bens e os serviços não possuem um valor objetivamente determinado, os indivíduos demandantes são sempre chamados para decidir o que é e o que não é fonte de valor nas inúmeras qualidades de um bem ou um serviço (ASPERS, 2011; ASPERS; BECKERT, 2011; BECKERT, 2009).

Estamos lidando, em última análise, com um problema que a ciência econômica ortodoxa não considera, qual seja, a formação de preferências. Nos modelos teóricos ortodoxos, as preferências já estão dadas e são estáveis. Tal como vimos no caso do mercado de trabalho na seção 1.2, através do pressuposto de que as preferências são exógenas ao modelo é também justificável considerar que os bens e serviços em um mercado são homogeneamente ofertados, isto é, as decisões são tomadas apenas em função de considerações de quantidade e de preços relativos, uma vez que as preferências sobre os mesmos já estão formadas. O que a perspectiva de sociologia econômica destaca é que para haver essa homogeneidade, indivíduos e firmas na posição de demandantes precisam decidir o(s) critério(s) que conferem valor a uma sorte de bens ou serviços e, dessa maneira, dando sentido à comparação em termos de preços relativos e quantidades.

Para não sermos injustos com a literatura, cabe destacar dois autores, incluindo um economista, que também abordaram essa questão de como os agentes econômicos exercem o procedimento de cálculo de valor. O economista Lucien Karpik (2010) elabora uma teoria sobre o que ele denomina "mercados de singularidades", isto é, mercados que envolvem a transação de produtos e serviços nos quais atribuir um valor e, principalmente, um preço é um processo complexo, pois são demasiadamente únicos e, por isso, não possuem critérios claros e estabelecidos sobre como avaliá-los. Em outros termos, "[s] ingularities are multidimensional, uncertain, and incommensurable; the consumer is searching for the 'right' or a 'good' singularity; quality competition prevails over price competition; and the market is opaque" (KARPIK, 2010, p.20). 
Singularidades são, portanto, serviços que, nos seus respectivos mercados, não há um sistema de sinais pré-estabelecido para acessar de antemão a qualidade dos que ofertam esses serviços, por exemplo, médicos, psicólogos, advogados, restaurantes de luxo; ou seja, serviços nos quais os consumidores tomam decisões através de julgamentos em termos de o "bom" ou de o "melhor". Singularidades são também produtos como obras de arte, vinhos, roupas de alta-costura, entre outros; pois esses produtos apresentam a particularidade de que determinar as suas qualidades que o fazem valiosos seja incerta e difícil para os seus consumidores.

Consideramos que o limite que essa perspectiva representa em relação ao nosso interesse analítico é que ela é elaborada explicitamente para uma modalidade específica de mercado cujas características poucos se relacionam com as do mercado de trabalho; especialmente quando o autor menciona que nos mercados de singularidade os preços têm pouca ou nenhuma influência no comportamento da demanda. Ademais, a economia das singularidades trata, segundo Karpik (2010, p. 3-31), de mercados que a economia neoclássica ignora; ora, tal como vimos no capítulo anterior, o mercado de trabalho não somente é considerado pelos modelos teóricos neoclássicos como tem sido fonte de importantes inovações teórico-metodológicas, por exemplo, a incorporação da análise de redes para explicar o seu funcionamento (CALVÓ-ARMENGOL, 2006; IOANNIDES; LOURY, 2004).

David Stark (2009) também apresenta uma interessante contribuição a respeito do modo como bens e serviços adquirem valor. Entretanto, esse sociólogo analisa esse processo de geração de valor a partir de uma perspectiva bem específica, a saber, o modo como firmas descobrem o que é valioso (STARK, 2009, p. 3-19). Assim, apesar de Stark focalizar, tal como este estudo, no cálculo de valor das firmas; ele está lidando com um enfoque diferente, qual seja: enquanto procura-se nesta tese saber como as firmas calculam o valor de coisas que já estão no seu horizonte de demanda, Stark está mais interessado sobre como as firmas descobrem o valor de coisas que elas ainda não conheciam. Simplificando, enquanto esta pesquisa trata do cálculo de valor da firma como demandante, a perspectiva de Stark "dá um passo atrás" para compreender como firmas descobrem e produzem o valor de um bem ou um serviço. Portanto, o estudo de Stark está então lidando mais com questões relacionadas à produção de inovações mercadológicas.

Por fim, cabe destacar que apesar de a literatura estabelecer diferentes termos que podem ser traduzidos como "processo de avaliação", "definição de valor", 
“julgamento do valor" e "qualificação de valor", aqui esses termos são usados como sinônimos para denotar o cálculo econômico de valor, que consiste no conjunto de operações nas quais os agentes no mercado confrontam e formam suas preferências visà-vis qualidades e atributos das mercadorias para, então, estabelecerem um valor a elas e tomar uma decisão econômica (ASPERS; BECKERT, 2011; CALLON, MÉADEL; REBEHARISOA, 2002; KARPIK, 2010; STARK, 2009).

Portanto, o contraste entre nosso interesse analítico e essas duas perspectivas, ajuda-nos a melhor esclarecer o foco desta tese, a saber, compreender quais valores as firmas de tecnologia da informação calculam quando demandam ao comparecer no mercado de trabalho. Assim sendo, quais são exatamente os valores que podem estar sendo usados pela firma no exercício da sua capacidade de cálculo na demanda de trabalho?

Mesmo não adotando a perspectiva de Lucien Karpik (2010) no que diz respeito a postular um papel secundário às considerações sobre os preços nos cálculos dos agentes, isso não quer dizer que incorremos no extremo oposto de que o cálculo se faz apenas tomando como referência os sinais do sistema de preços. Em outras palavras, mesmo no contexto de mercado (de trabalho), não devemos reduzir à formação dos preços a resposta à pergunta que nos interessa - como os agentes calculam o valor de bens e serviços? Ou seja, os agentes econômicos precisam considerar, além do preço, quais produtos têm valor para eles e o que eles precisam saber acerca dos produtos, ou seja, quais informações precisam obter sobre um produto para calcular seu valor. $\mathrm{O}$ agente demandante, portanto, toma decisões também a partir de considerações sobre a qualidade do produto e o classifica em relação a outras mercadorias. Nesse ponto, só se discorda de Karpik (2010) na ideia de que esse processo estaria restrito a determinadas formas particulares de mercados e mercadorias.

Entendemos então nesta tese que o valor no mercado não é somente valor monetário (preço). Tal como demonstra Aspers e Beckert (2011, p. 5-8), o processo de avaliação no mercado pode utilizar outros tipos de valores, por exemplo, moral e político, estético e cultural. Cada tipo de valor tem a sua "escala" e, portanto, estabelece critérios próprios de avaliação sobre pessoas, objetos, organizações ou eventos. Muitas vezes estas escalas de valor se chocam com o valor econômico; isso indica o quanto é equivocado reduzir-se a lógica dessas escalas à racionalidade econômica, através de conceitos como o de capital e o de utilidade. Ao contrário, esses diversos tipos de 
valores relacionam-se reciprocamente e, na sua interação, definem processos e decisões econômicas que têm lugar nos mercados.

Nesse sentido, Marion Fourcade (2011) esclarece como valores culturais que estão presentes na sociedade norte-americana, permitiram a formatação de um cálculo econômico sobre recursos naturais em casos de desastres ambientais. Viviana Zelizer (1994), por outro lado, analisou um processo inverso ao de Fourcade, ou seja, mostrou como a formação e definição de valores morais a respeito da infância e da criança estiveram na base da proibição do trabalho infantil e do mercado de adoções nos Estados Unidos na virada do século XIX para o século XX. Podemos ainda citar a proliferação de mercados social e/ou ambientalmente responsáveis nos quais o cálculo do valor econômico dos produtos está diretamente baseado em considerações sobre valores éticos, morais e políticos; o funcionamento de tais mercados é examinado por Gourevitch (2011). Em suma, "[...] what is valued in markets correlates with what is valued outside of markets. Moral values are distinct from economic values; they are, however, economically relevant" (ASPERS; BECKERT, 2011, p. 8, grifo do autor).

Ademais, os valores econômicos possuem diferentes dimensões na sua formação, pois existem diferentes parâmetros (materiais ou imateriais) através dos quais um bem se torna economicamente valioso para um indivíduo ou firma. Aspers e Beckert (2011, p. 11-13) conceituam três dimensões para a definição do valor econômico de uma mercadoria, baseadas na contraposição dos seguintes critérios:

1. valor de uso e valor de investimento - o primeiro se refere ao ganho que o proprietário vai obter em função das qualidades do produto através de seu uso. Valor de investimento se refere à expectativa de lucro monetário que vai ser gerado pela aquisição de um bem ou serviço. E essa é uma distinção feita pelo agente econômico, ou seja, não há qualidades objetivamente inerentes às mercadorias que estabelecem essas distinções de valor;

2. valor individual e relacional - valor individual é a satisfação do desejo do comprador através da aquisição de um produto, independentemente de qualquer interação social associada à compra. O valor do produto é individual, mas isso não quer dizer que a formação do desejo que leva à aquisição do produto não seja socialmente moldada. Relacional, então, quer dizer que o valor do produto para o comprador é uma função de considerações a respeito do que terceiros iram pensar ou mesmo quando 
a aquisição do produto toma em consideração o comportamento de outros consumidores desse mesmo produto;

3. valor funcional e valor simbólico - funcional quer dizer que o produto é valorizado porque ao utilizá-lo é produzida uma mudança na realidade baseada em um efeito físico gerado pelo produto. Valor simbólico, em contraste, refere-se ao significado que um bem tem para o seu dono, que transcende os efeitos físicos gerados pela sua posse e uso.

Assim sendo, um mesmo bem pode ter simultaneamente valor funcional e simbólico; por exemplo, um carro pode ter seu valor funcional em razão de utilizar menos combustível e, também, a economia de combustível pode ter o valor simbólico de comprometimento com o meio ambiente; por sua vez, tal valor simbólico pode estar relacionado com uma satisfação (valor) individual ou relacional para o proprietário do veículo. Essa justaposição dos critérios de valor no mesmo bem ou serviço vai ao encontro da proposição de que a formação de valores situa-se no agente econômico, não em um critério objetivo ligado à mercadoria, como o processo de sua produção, tal como afirma a teoria do valor-trabalho.

O cálculo de valor é então o exercício de uma capacidade do demandante relacionar certas propriedades e características da oferta de um bem ou serviço com valores que formam a sua preferência, a sua demanda sobre este bem ou serviço ofertado em condição de competição.

Nesse sentido, tal como foi argumentado anteriormente, o trabalho não pode ser considerado uma "mercadoria de singularidade" (KARPIK, 2010); entretanto, ele não deve ser tomado como uma mercadoria sem as suas particularidades. Senão vejamos.

Robert Salais (1989) afirma que o trabalho como mercadoria possui três aspectos que lhe são peculiares: 1) ele não existe independentemente da pessoa que o oferta, o trabalhador; 2) a firma adquire essa mercadoria mesmo ela não estando presente de fato no mercado, ou seja, a firma precisa decidir por contratar o trabalhador antes da realização, da produção daquilo que ela está adquirindo, uma atividade laboral; 3) as duas partes que compõem o mercado de trabalho (firmas e trabalhadores) não somente têm interesses antagônicos (tal como em qualquer mercado, o ofertante tem o interesse de vender ao maior preço possível e o demandante comprar pelo menor preço disponível) como, também, seus interesses são de natureza diversa, a saber, o trabalhador está interessado em receber uma remuneração para fazer algo que julga ser capaz de fazer e a firma está interessada por pagar pelo produto que venha a ser gerado 
pelo o que o trabalhador seria capaz de fazer. Podemos, então, afirmar que essas particularidades do trabalho como mercadoria conferem ao seu mercado e, por consequência, às operações de cálculo realizadas nesses últimos, condições que podem ser denotadas através do termo "opacidade". São condições de opacidade porque as transações no mercado de trabalho são realizadas em função de um objeto que não está disponível no momento da transação e também não é a mesma coisa para as partes envolvidas - para o empregador é mais um produto e para o empregado é mais o tempo que está sendo transacionado.

É frente a essas particularidades que a firma precisa realizar a capacidade de cálculo valor, ou seja, ela precisa decidir o que deve examinar e extrair de informação do ofertante, uma vez que o objeto da sua demanda é indissociável da pessoa do ofertante. Ela precisa, ainda, calcular o valor de uma mercadoria que somente será entregue após a realização da transação no mercado de trabalho. E, por fim, ela precisar calcular o valor de algo que, para o ofertante, possui uma natureza diferente daquela que a firma considera.

É por isso que, seguindo a distinção marxista entre "trabalho" e "força-detrabalho", Salais (1989) estabelece um elemento analítico importante para a formação do modelo de análise desta tese: o que a firma acaba por calcular o valor e transacionar no mercado de trabalho é a força-de-trabalho do ofertante. Em outros termos, uma vez que o trabalho como mercadoria não está disponível enquanto tal no mercado de trabalho, a firma só pode exercitar o cálculo de valor da sua demanda sobre a capacidade do ofertante em entregar essa mercadoria, isto é, sobre a sua força-detrabalho. Nesse sentido, o cálculo de valor da firma quando comparece ao mercado de trabalho tem como objeto não o trabalho em si, mas a força-de-trabalho ofertada. Portanto, a firma precisa decidir quais características e aspectos formam essa oferta de força-de-trabalho e que corresponderiam aos valores que conformam e orientam a sua demanda no mercado de trabalho.

Com base no exposto até aqui, o cálculo econômico de valor da firma é compreendido como processos de avaliação no mercado de trabalho. Esses processos de avaliação, por sua vez, se voltam para características e aspectos que definem a força-detrabalho demandada pela firma. Esses processos de avaliação se escudam, assentandose, nos diferentes tipos de valores aludidos acima, tanto os econômicos como os economicamente relevantes. 
Por fim, se esse cálculo de valor é executado pelo agente econômico (neste caso, a firma), mas não é produto de uma propensão natural de calcular; então cabe a pergunta: como a capacidade de cálculo de valor é possível? Essa indagação se torna ainda mais pertinente se considerarmos que essa é uma capacidade que é exercida em condições que denominamos de opacidade. As duas seções seguintes tratam de fornecer os elementos para responder a essa pergunta. Veremos adiante que essa é uma capacidade de agência socialmente construída por condições de possibilidade engendradas por redes de relações sociais e sociotécnicas.

\subsection{A perspectiva de redes sociais para uma abordagem do cálculo econômico}

Há poucas pesquisas em sociologia econômica sobre o papel das redes sociais no comportamento da firma no mercado de trabalho ${ }^{23}$. Sendo que praticamente nenhuma trata especificamente do papel das redes na capacidade de cálculo das empresas. Ademais, um dos temas mais frequentes nessa literatura de redes é sobre algo que poderia ser considerado o lado irracional do comportamento da firma no mercado de trabalho, a discriminação de gênero ou racial.

A discriminação pode ser tomada como um comportamento irracional se lembrarmos das teorias ortodoxas da economia do trabalho (teoria da produtividade marginal e a Personnel Economics) nas quais a demanda de trabalho da firma seria determinada por critérios ligados à eficiência e à produtividade. Uma leitura superficial sobre essa questão poderia afirmar, então, que o papel das redes sociais seria restrito à explicação dos aspectos irracionais da ação econômica. Essa possível interpretação é equivocada porque, primeiro, leva em consideração apenas uma parte das pesquisas de redes que analisam aspectos irracionais como a discriminação e, segundo, ignora o já mencionado alerta de Granovetter (1985) de que a perspectiva de enraizamento social da ação econômica não incorre em um "funcionalismo otimista" e, consequentemente, nem em um de tipo "pessimista", ou seja, essa perspectiva explica tanto aspectos ligados à ordem, confiança e racionalidade nos mercados como o seu reverso, no qual se podem incluir questões como a discriminação.

\footnotetext{
${ }^{23}$ Ioannides e Loury (2004, p. 1075) também identificam essa mesma escassez de estudos na tradição econômica de análise de redes.
} 
Ademais, quando verificamos como as pesquisas de análise de redes compreendem o processo de discriminação no mercado de trabalho, concluímos que esse último não pode ser totalmente explicado em termos de irracionalidade dos agentes, mas como uma decorrência de certas características da rede social na qual a firma está inserida como demandante no mercado de trabalho. Vejamos esse ponto mais detidamente.

Podemos identificar na literatura dois modelos de explicação sobre discriminação no processo de contratação de trabalhadores por parte das firmas. $\mathrm{O}$ primeiro modelo explica a discriminação em função de efeitos homofílicos das redes sociais utilizadas pela firma para obter indicações na hora de recrutar, selecionar e/ou contratar trabalhadores (McDONALD; LIN; AO, 2009; PETERSEN; SAPORTA; SEIDEL, 2000; FERNANDEZ; SOSA, 2005; SEIDEL; POLZER; STEWART, 2000). Esses estudos evidenciam que as firmas preferem contratar candidatos que são recomendados por seus atuais funcionários ou por organizações e instituições (headhunters, agências de emprego, instituições de ensino, etc.) com as quais possuem relações de confiança. Considerando esse fato, as pesquisas demonstram que a maior parte dos recomendantes é inclinada a indicar pessoas (candidatos) de características demográficas iguais ou semelhantes. Desse modo, as redes sociais de recomendação tendem a ser homofílicas, fazendo com que as firmas contratem mais ou ofereçam propostas de emprego melhores aos candidatos de um dado grupo social que estrutura o caráter homofílico dessas redes. Esses estudos ainda demonstram que os vários grupos sociais têm redes com probabilidades diferentes de fornecer uma recomendação para uma vaga de trabalho.

O segundo modelo indica que muitos grupos sociais acabam formando uma espécie de nicho em determinado tipo de ocupação ou empresa (BARR, 2009; WALDINGER $^{24}$ apud IOANNIDES; LOURY, 2004, p. 1066; GRANOVETTER; TILLY $^{25}$ apud GRANOVETTER, 1994, p. 156). A firma, ao seu turno, acaba baseando sua estratégia de controle e treinamento da sua força-de-trabalho nessas redes, ou seja, ela apela aos laços de lealdade e solidariedade na rede desses grupos que se transformam em lealdade à firma em função de ela privilegiar a contratação de membros desse grupo.

\footnotetext{
${ }^{24}$ WALDINGER, R. D. Still the Promised City? Cambridge: Harvard University Press, 1996.

25 GRANOVETTER, M.; TILLY, C. Inequality and Labor Process. In: SMELSER, N. (Ed.). Handbook of Sociology. Newbury Park: Sage Publications, 1988. p. 175-221.
} 
Podemos concluir que em ambos os modelos, o processo de discriminação não é explicado em função de aspectos irracionais do comportamento da firma no mercado de trabalho; ao contrário, é justamente em função do fato de que as redes sociais atuam fornecendo recursos e critérios informacionais relevantes para a firma realizar de maneira racional e eficiente sua demanda no mercado de trabalho, que parte do fenômeno da discriminação neste contexto se torna explicável.

O tema da discriminação deixa evidente um postulado central dessa perspectiva de redes em sociologia econômica: padrões de comportamento e capacidades de agência, como a discriminação, não são compreensíveis em termos de um arbítrio cultural incorporado pelos agentes e nem por suas características demográficas, mas em função de certa característica da estrutura social (definida em termos de redes de relações) na qual a ação está enraizada. Esse postulado fornece uma pista analítica importante para esta tese: tal como as redes estruturam condições de possibilidade para o exercício da capacidade de agência discriminatória, ela também pode atuar no mesmo sentido para outras capacidades de agência como a de cálculo de valor.

Granovetter, em Getting a Job (1994), ao contrário de nosso foco, debruça-se sobre o papel das redes no lado da oferta no mercado de trabalho, ou seja, a influência das relações sociais no comportamento dos trabalhadores ao procurar e obter emprego. Entretanto, no posfácio da segundo edição dessa obra, o autor revisa algumas pesquisas que examinaram a influência das redes sociais na ação das firmas no mercado de trabalho, sendo que, dessa revisão da escassa literatura sobre redes e firma, podemos extrair um importante elemento para análise que será desenvolvida aqui.

O primeiro ponto que o autor destaca é que, dependendo de como as firmas concebem o seu modelo de relações de emprego, diferentes serão os impactos no tipo de estratégias, e diferentes serão as estratégias que podem ser tidas como bem sucedidas para se conseguir emprego (por exemplo, através de redes de contatos pessoais ou por meio de instituições como agências de emprego). Ilustrando esse argumento, ele cita pesquisas sobre o emprego vitalício japonês, que evidenciaram que o estabelecimento desse último determinou o sucesso de se conseguir emprego através das instituições de ensino. Em contraste, estudos concluíram que em outros contextos, como o Vale do Silício na Califórnia (EUA), onde firmas do setor de tecnologia da informação usam um pequeno grupo de empregados permanentes e um maior número de trabalhadores temporários, essa situação, que produz uma alta rotatividade no setor, torna as redes de contatos pessoais um mecanismo importante na aquisição de informações de 
oportunidades de emprego. Portanto, "within a particular regime of industrial organization, different kinds of employers have different goals under different circumstances, and these variations also are key in shaping what works or does not for job seekers" (GRANOVETTER, 1994, p. 155-56).

Ademais, as formas de recrutamento das firmas podem variar conforme as estratégias que elas adotam para o controle da força-de-trabalho - como mostra a pesquisa publicada por Granovetter e Charles Tilly em $1988^{26}$ (apud GRANOVETTER, 1994, p. 156). Os empregadores podem recorrer ao estímulo à lealdade do trabalhador à empresa como forma de controle. Nesse caso, essa lealdade pode ser construída a partir de redes sociais de grupos de trabalhadores de identidades profissionais, étnica e/ou familiar. Assim, o recrutamento é feito fazendo circular a informação sobre oportunidades ocupacionais através dessas redes de grupos que se mantêm leais à firma. Empregadores que utilizam como política de disciplina da força-de-trabalho o controle que os próprios trabalhadores de um mesmo grupo exercem uns sobre os outros, adquirem a tendência de contratar através de laços fortes, isto é, tecidos nesses grupos.

Por fim, Granovetter cita um estudo de Paul Windolf ${ }^{27}$. Este faz uma tipologia de firmas segundo seus objetivos e nicho comercial e, então, pergunta: quais tipos de empregados as firmas precisam recrutar para atingir seus objetivos? Dependendo das respostas, os métodos de recrutamento das firmas irão variar, especialmente, no que se refere à propensão da firma a usar redes sociais. A hipótese geral deste estudo sustenta que o recrutamento deve ser visto como parte da estratégia corporativa das firmas num particular nicho de mercado (GRNOVETTER, 1994: 157) ${ }^{28}$.

Essa pequena revisão de Granovetter leva a concluir que o uso de redes sociais no mercado de trabalho, por parte das firmas, está relacionado à maneira como essas concebem o perfil de trabalhador e o seu modelo de gestão de recursos humanos, tidos como adequados para colocar em curso suas estratégias no mercado de produtos. A rede passa, então, a oferecer as condições e recursos necessários para as firmas calcularem

${ }^{26}$ GRANOVETTER, M.; TILLY, C. Inequality and Labor Process. In: SMELSER, N. (Ed.). Handbook of Sociology. Newbury Park: Sage Publications, 1988. p. 175-221.

${ }^{27}$ WINDOLF, P. Recruitment, Selection, and Internal Labour Markets in Britain and Germany. Organization Studies, v. 7, n. 3, p. 235-254, 1986.

${ }^{28}$ Essa hipótese é análoga àquela da teoria da produtividade marginal que diz que a demanda por trabalho da firma é derivada das decisões produtivas que ela toma para maximizar sua sintonia com os desejos do consumidor do seu produto final. A diferença é que para Windolf, as estratégias das empresas com relação ao seu mercado de produtos não se resumem às decisões de alocação de insumos de produção. 
visando o retorno desse interesse ${ }^{29}$. Essa perspectiva amplia aquele postulado da Teoria da Produtividade Marginal que afirma que a demanda da firma no mercado de trabalho é uma demanda derivada. A rede passa a ser uma espécie de correia de transmissão produtora do elo entre o comportamento da firma no mercado de trabalho e a realização de suas estratégias no mercado de produtos.

Assim, a noção de demanda por força-de-trabalho aqui adotada, ao contrário da perspectiva econômica ortodoxa, não se restringe ao aumento da produtividade via a contratação do trabalho como insumo; mas de todo um entendimento por parte da firma em termos de gestão de recursos humanos e suas estratégias comerciais, tecnológicas e mercadológicas - incluindo, então, os ganhos de produtividade. Portanto, o interesse que a firma visa maximizar no mercado de trabalho não é meramente os resultados mensuráveis de aumento marginal da produtividade para atender as demandas do consumidor no mercado de produtos; são também, por exemplo, concepções e expectativas que as firmas assumem ao estabelecer um modelo de gestão de recursos humanos inserido em uma estratégia no mercado de produtos. O cálculo de valor se realiza por meio das operações de recrutamento, seleção e contratação capazes de atenderem ao interesse da firma definido em termos de demanda por força-de-trabalho formado por uma combinação de diferentes critérios, ou melhor, valores econômicos e economicamente relevantes.

As redes sociais estruturam, então, condições e recursos que moldam a capacidade de cálculo da firma em cada uma dessas etapas (recrutamento, seleção e contratação) que conformam o "caminho" a ser percorrido para calcular a oferta disponível no mercado de trabalho vis-à-vis os valores que formam o planejamento da sua demanda. Portanto, assim como a discriminação torna-se explicável a partir de condições engendradas pela rede social na qual a ação da firma está enraizada, pensamos que o mesmo ocorre com a capacidade de cálculo de valor. Vejamos, então, como as redes sociais, segundo estudos da sociologia econômica, oferecem condições de possibilidade para o exercício da capacidade de cálculo da firma.

O estudo de Fernandez, Castilla e Moore (2000) oferece um modelo de análise mais detalhado sobre o modo como as redes sociais afetam a capacidade de cálculo de firmas no mercado de trabalho. Segundo esses autores, o sistema de contratação via referências de funcionários é uma das principais formas por meio da qual as redes

\footnotetext{
${ }^{29}$ Adiante se argumentará como essa lógica se expressa quando as firmas estudadas nesta tese calculam o valor econômico de investimento na sua demanda no mercado de trabalho.
} 
sociais modelam o cálculo da firma no mercado de trabalho. Nesse sentido, empresas que usam esse método de contratação são "[...] quintessential 'social capitalists', viewing workers' social connections as resources in which they can invest in order to gain economic returns in the form of better hiring outcomes" (FERNANDEZ; CASTILLA; MOORE, 2000, p. 1288). Os autores identificam cinco mecanismos por meio dos quais as redes oferecem recursos e condições para as etapas de recrutamento e seleção, que compõem o cálculo de demanda da firma ao comparecer no mercado de trabalho.

O primeiro mecanismo é o de "ampliação do conjunto de candidatos" à vaga de emprego $^{30}$. A firma, por meio desse mecanismo, maximiza sua capacidade de recrutamento para um grupo de candidatos que ela não teria acesso sem o recurso da rede dos empregados cuja mobilização ocorre em função de programas de referências ${ }^{31}$. O segundo mecanismo é a tendência que "redes de referências sejam homofílicas". Empregados são mais propensos a referirem pessoas parecidas com eles, uma vez que esses empregados recomendantes já passaram pelo processo de seleção da firma, é provável que essa tendência faça com que os candidatos com referência sejam mais adequados do que aqueles sem recomendação. O terceiro mecanismo é o de "proteção da reputação", ou seja, se os recomendantes percebem que sua reputação na firma depende da qualidade das pessoas que recomendam, a tendência será que esses funcionários irão se esforçar para indicar bons candidatos. Esses três mecanismos produzem condições e recursos para que a firma amplie o grupo de candidatos e, deste modo, melhore as condições para o cálculo na operação de recrutamento (FERNANDEZ; CASTILLA; MOORE, 2000, p. 1291-92).

O quarto mecanismo é a obtenção, por parte das firmas, de "vantagens informacionais" através das redes de referência. O empregado recomendante passaria à firma informações sobre qualidades do candidato difíceis de serem acessadas via meios tradicionais de informação como o currículo. Ademais, o recomendante pode passar ao candidato informações que façam com que esse tenha maior nível de conhecimento sobre a firma e a vaga ocupacional, assim aumentando a probabilidade da firma obter candidatos mais bem preparados e adequados para o cargo de uma vaga. $\mathrm{O}$ quarto

${ }^{30}$ Cabe destacar que, não estamos usando uma tradução literal dos termos e nomes que os autores dão aos mecanismos e resultados econômicos. Isso se deve ao fato de optarmos em transmitir as ideias presentes neste estudo utilizando os termos que adotamos para construir nosso modelo analítico.

${ }^{31}$ Programas de referências são sistemas de incentivos que as firmas estabelecem para motivar seus funcionários a recomendarem candidatos para vagas de empregos na empresa. Esses incentivos podem ser explícitos ou implícitos, monetários ou simbólicos. 
mecanismo, portanto, influencia positivamente a capacidade de cálculo da firma na etapa de seleção de candidatos, isto é, as redes de recomendação aumentam o nível e a qualidade das informações que a firma utiliza para selecionar o conjunto de candidatos que foram recrutados para preencher a(s) vaga(s) de emprego (FERNANDEZ; CASTILLA; MOORE, 2000, p. 1292-96).

O quinto e último mecanismo é o de produção de "vantagens no processo social de adaptação e treinamento" do candidato contratado. A rede de recomendação ofereceria ao candidato um amigo ou conhecido na firma, o que facilitaria o processo de transição e adaptação ao local de trabalho. Do ponto de vista do interesse da firma, esse recurso oferecido pela rede de recomendação pode resultar na maximização de resultados visados por ela ao buscar contratar novos empregados, por exemplo, diminuição da rotatividade e do absenteísmo ou, ainda, maior produtividade (FERNANDEZ; CASTILLA; MOORE, 2000, p. 1296-98). Apesar desse mecanismo não influenciar diretamente o cálculo da firma no mercado de trabalho, é preciso reconhecer que ele pode estar relacionado a valores/objetivos que orientam a demanda da firma no mercado de trabalho. Desse modo, se esse mecanismo for eficaz, isso pode fazer com que a firma invista mais no uso de redes de recomendação para a operação de recrutamento no mercado de trabalho ${ }^{32}$.

Este estudo de Fernandez, Castilla e Moore mostra que a rede social produz condições e recursos que moldam duas operações de cálculo de valor quando a firma comparece ao mercado de trabalho, a saber, o recrutamento e a seleção. Contudo, a pesquisa de Seidel, Polzer e Stewart (2000) oferece evidências sobre a influência da rede na etapa da contratação, isto é, mais do que a decisão da firma contratar ou não certo candidato é o tipo e condições de contrato que a firma está disposta a ofertar para esse candidato.

Estudando o caso de uma empresa high-tech norte-americana, esses autores encontram uma série de evidências mostrando que, por um lado, minorias raciais obtêm menor sucesso na negociação de salários iniciais ${ }^{33}$, mas, por outro, esses efeitos discriminatórios são drasticamente reduzidos quando se controla pela existência ou não

${ }^{32}$ Esse argumento poderia ser utilizado para explicar as evidências encontradas por Chapple (2006). A autora observou que, no setor de Tecnologias da Informação de três metrópoles norteamericanas, a recomendação de candidatos via instituições de treinamento com relações de confiança com certas empresas desse setor, era um critério mais decisivo no processo de seleção do que o nível de escolaridade formal e a experiência profissional do candidato.

${ }^{33}$ Os autores definem o sucesso na negociação salarial em termos de porcentagem negociada do aumento salarial que consiste no produto da subtração da oferta inicial de salário pelo salário inicial alcançado, dividindo-se o produto dessa subtração pela oferta inicial de salário e multiplicando por cem. 
de laços sociais entre candidatos e a firma. Esse laço social, promovido por uma rede que liga candidato e empresa, aumenta significativamente o sucesso da negociação salarial. Contudo, as minorias raciais (basicamente, definidas como indivíduos nãobrancos) têm menor probabilidade de ter esse tipo de laço na sua rede (SEIDEL; POLZER; STEWART, p. 2000) $)^{34}$.

Tendo em vista o interesse analítico desta tese, o estudo de Seidel, Polzer e Stewart aponta para o fato que redes produzem certas condições e recursos que permitem à firma aceitar pagar salários iniciais mais altos para os candidatos que possuem laços sociais com a empresa ${ }^{35}$. Entretanto, esse mesmo estudo não especifica qual mecanismo na rede produz esse fenômeno; mas, a partir do estudo de Fernandez, Castilla e Moore (2000), nós podemos cogitar que o mecanismo de rede responsável seria o seguinte: considerando que as redes podem fornecer para empresa melhores níveis de informação sobre os candidatos e, para esses últimos, laços sociais com pessoas da firma tonando-os mais produtivos e menos sujeitos à rotatividade e ao absenteísmo; podemos deduzir que possivelmente esses dois aspectos diminuam o nível de incerteza da firma a respeito do candidato possuir um perfil adequado para vaga de emprego e, por conseguinte, fazendo com que ela valorize mais a contratação dele e esteja mais aberta a oferecer um salário inicial mais alto do que aquele inicialmente ofertado.

Outra explicação possível de ser retirada da literatura de sociologia econômica de redes é através da discussão sobre a maior eficiência dos "laços fracos" (isto é, contatos que não sejam de familiares ou amigos próximos) em proporcionar mais e melhores informações sobre oportunidades de emprego (GRANOVETTER, 2005, p. 36-38; 1994, p. 146-154; 1983). Há uma vasta discussão formada desde o notório estudo de Granovetter (1973) sobre a eficiência (ou, nos termos do autor, força) dos laços fracos em promover melhores resultados econômicos em função de sua maior probabilidade de produzir informações não redundantes. No caso do mercado de trabalho, a discussão gira em torno do papel desses laços em proporcionar acesso a informações sobre oportunidades de emprego, mobilidade profissional ascendente intra e interfirmas e melhor status profissional e salário (MONTGOMERY, 1992; BIAN, 1997; WEGENER, 1991; YAKUBOVICH, 2005; TASSIER, 2006; LIN; ENSEL;

\footnotetext{
${ }^{34}$ Petersen, Saporta e Seidel (2000) encontram evidências que corroboram com essa mesma ideia a respeito das diferenças de sucesso nas negociações salariais entre raças.

${ }^{35}$ Em nenhum dos casos estudados nesta tese, há relatos sobre negociação salarial.
} 
VAUGHN, 1981; FRANZEN; HANGARTNER, 2006; PODOLNY; BARON, 1997). Mesmo não havendo consenso na literatura, podemos usar o argumento da força dos laços fracos para explicar o fenômeno de desigualdade racial de sucesso na negociação salarial da seguinte forma: uma rede com maior número de laços fracos permitiria ao agente maior acesso a informações de oportunidade de emprego, também a contatos que o liguem a uma firma. Minorias étnicas possuíram redes pobres em laços fracos e, por isso, diminuindo a sua probabilidade de ter na sua rede um contato que as liguem às empresas e, por conseguinte, diminuindo sua chance de sucesso na negociação salarial.

É preciso destacar que essa possível explicação via o argumento da força dos laços fracos, está centrada na rede dos trabalhadores e não da firma. Todavia, para que esse argumento seja verdadeiro, é preciso compreender o papel da rede no comportamento da firma, ou seja, é preciso verificar se a rede social da empresa fornece condições e recursos que a façam privilegiar e valorizar mais a contratação de candidatos recomendados ou conhecidos pelos membros dessa rede. De maneira geral, o que estamos argumentando é que para compreendermos certas capacidades de agência (discriminação ou cálculo de valor) da firma no mercado de trabalho, é preciso analisar os condicionantes que a sua rede social estabelece nas operações de cálculo (recrutamento, seleção e contratação) para realizar a sua demanda por força-de-trabalho.

Podemos, então, extrair algumas dimensões para análise do papel da rede social na capacidade de cálculo da firma no mercado de trabalho: 1) é preciso considerar o modo como a empresa enxerga suas necessidades e interesses, isto é, os critérios que definem a sua demanda por força-de-trabalho como demanda derivada de sua estratégia no mercado de produtos; 2) as redes sociais oferecem condições e recursos mais ou menos favoráveis às operações de cálculo de valor. Essas condições, no caso da abordagem da NSE, são definidas em termos de características das redes (por exemplo, grau de homofilía) e do nível e qualidade das informações que lá circulam; 3) ter em mente que essas condições e recursos atuam nas três operações de cálculo.

Se, por um lado, essa literatura fornece elementos importantes de análise para bem responder nosso problema de pesquisa (compreender o cálculo econômico de valor realizado por firmas de tecnologia da informação quando estas comparecem no mercado de trabalho) por outro lado, há duas lacunas importantes que ela deixa tendo em vista esse interesse de pesquisa. A primeira lacuna diz respeito ao fato que, mesmo na escassa bibliografia sobre redes e firma, o que está em jogo na análise não é propriamente a rede da firma. Por exemplo, no caso do estudo de Fernandez, Castilla e 
Moore (2000), a rede analisada é as dos funcionários da firma, que passa ter influência no comportamento dessa última no mercado de trabalho na medida em que é apropriada através de programas de contratação via referências.

$\mathrm{Na}$ verdade, essa interpretação da literatura é possível porque há nela uma carência de uma melhor definição da distinção entre redes da firma e a dos trabalhadores. Em função desse déficit conceitual, pode-se ainda indagar se as redes são dos agentes ou elas contêm os agentes e modelam seu comportamento. Nesse último caso, a análise não é direcionada para a rede da firma, mas para a influência da rede no comportamento da firma. É uma diferença sutil, porém fundamental do ponto de vista teórico e metodológico porque, apesar da literatura até aqui revisada não apresentar essa discussão, compreendemos que essa última interpretação esteja em maior sintonia com o argumento do enraizamento da ação econômica. Uma vez que, como se argumentou no capítulo 1, a noção de mercado de concorrência perfeita envolve condições empiricamente improváveis, a noção de redes e de enraizamento social oferecem uma maneira mais adequada de analisar as condições presentes no mercado de trabalho, que modelam capacidades de agência como a de discriminação ou a de cálculo. Portanto, ao tratarmos em termos de "redes da firma/redes de trabalhadores", abandonamos esse sentido da rede como estrutura que estabelece recursos e condicionantes que caracterizam as condições de mercado.

A segunda lacuna pode ser definida através desta pergunta: será que podemos resumir a influência da rede na capacidade de cálculo de valor em termos de recursos informacionais e condições estabelecidas por características como homofilia, número de laços fracos, etc.? Essas condições e recursos, apesar de importantes, não são capazes de explicar o modo como a rede constitui a firma como agente dotado de capacidade de cálculo, ou seja, essas condições e recursos ajudam-nos a compreender o modo como a rede modela essa capacidade, mas não como dota o agente dessa capacidade. Nesse sentido, para superar essa lacuna é preciso incorporar uma perspectiva de redes que a relaciona mais diretamente à capacidade de cálculo.

Argumentaremos adiante que, através da perspectiva do ator-rede em sociologia econômica, especialmente na figura de Michel Callon, podemos superar essas lacunas e, por conseguinte, definir um modelo de análise mais adequado para o estudo sociológico da capacidade de cálculo de valor da firma no mercado de trabalho. 


\subsection{A rede sociotécnica e a capacidade de agência calculadora das firmas}

Michel Callon é um dos representantes mais conhecidos da chamada perspectiva da performatividade ou da teoria do ator-rede em sociologia econômica. O principal objetivo quando autores ligados a essa corrente estudam os mercados, especialmente o financeiro, é demonstrar o papel da rede de relações entre agentes humanos, conhecimentos, instrumentos e tecnologias na estruturação e reprodução destes espaços sociais (BEUNZA; SATRK, 2004; COCHOY, 1998; DOGANOVA; EYQUEMRENAULT, 2009; HARDIE; MACKENZIE, 2007; GAO, 1998; MILLER, 1998). Nesse sentido, a própria economia como ciência é um agente na rede que performa, formata e modela a vida econômica, isto é, a economia, de certa maneira, cria o próprio fenômeno que ela descreve (CALLON, 1998a; FOURCADE, 2007, p. 1024-25; FLIGSTEIN; DAUTER, 2007, p. 108; HARDIE; MACKENZIE, 2007).

Essa perspectiva amplia o conceito de redes sociais para o de "redes sociotécnicas", incluindo na análise não somente as relações interpessoais como, também, as tecidas com conhecimentos científicos e técnicos e com artefatos materiais. Em suma, para usar a terminologia dessa corrente, as redes sociotécnicas são compostas por relações entre agentes não-humanos e humanos. Portanto, artefatos, tecnologias e conhecimentos são compreendidos não como meros instrumentos que indivíduos usam na sua ação, mas como entidades com capacidade de agência que, por conseguinte, modelam a estrutura da qual fazem parte.

Essa perspectiva situa-se na chamada "teoria do ator-rede" (CALLON, 1998a, 2004; LATOUR, 1999, 2006; LAW, 1999) que toma como pressuposto a total indeterminação das capacidades de agência dos atores, ou seja, esses não possuem $a$ priori uma lógica de ação. É a rede na qual o agente humano ou não-humano está inserido que o dota de certa capacidade de agência. Além disso, nessa perspectiva, a rede fornece referência ontológica ao agente, ou seja, não é possível estabelecer a identidade do agente desencarnada da rede. É importante ter isso em conta para que se perceba uma diferença entre a abordagem sociológica e a econômica sobre o comportamento da firma no mercado de trabalho.

Mesmo tendo em conta a pluralidade de escolas de pensamento econômico, não há uma visão que reconheça que a identidade da firma como demandante é socialmente construída, isto é, essa identidade é tomada como um dado. Todavia, a perspectiva da 
teoria do ator-rede permite compreender que essa identidade é uma construção social, que a firma só incorpora essa identidade a partir da referência constitutiva da rede de relações sociotécnicas.

Para ficarmos no campo de interesse desta tese, tomemos como exemplo o caso da demanda de trabalho de empresas de tecnologias da informação: a identidade da firma de demandante nesse espaço e as variações discretas nessa identidade dependem, no mínimo, de uma estrutura básica de relações, a saber, uma empresa do setor de TI pode ser, simultaneamente, ofertante e demandante de atividades de trabalho nesse setor. Se olharmos do ponto de vista da sua relação com empresas que contratam seus serviços, ela é uma ofertante, pois ela atende a demanda de trabalho de atividades de TI de outras empresas sob a forma da oferta de serviços. Por outro lado, se tomarmos a relação dessa mesma empresa com profissionais dessa área, ela, então, assume a identidade de demandante ao contratar esses profissionais. Mesmo num exemplo básico como esse, que se refere apenas a um tipo de relação, podemos ver como a rede exerce esse papel, tal como previsto pela teoria do ator-rede, de produtora de ontologias, isto é, de identidades e lógicas de ação.

Nesse sentido, a ação ou a capacidade de agência não é exercida individualmente pelo agente, mas pelo o que Callon chama de coletivos híbridos, que são coletivos compostos de dispositivos materiais e técnicos, conhecimentos e seres humanos (CALLON, 2004, 2007, 2008; HARDIE; MACKENZIE, 2007). Em suma, é a rede sociotécnica (formada por coletivos híbridos) que estrutura certo espaço de ação e, ao fazê-lo, dota os atores sociais de certas capacidades de agência.

Esse processo no qual a rede dota o agente humano ou não-humano de certa capacidade de agência é denominado de agenciamento $^{36}$ (CALLON, 2008; DOGANOVA; EYQUEM-RENAULT, 2009; HARDIE; MACKENZIE, 2007; MUNIESA; MILLO; CALLON, 2007). Cabe destacar que, nessa perspectiva da teoria do ator-rede, agente e estrutura são "faces da mesma moeda", então, um agente numa rede sociotécnica também é um agenciamento, por exemplo, um artefato como um currículo, numa rede sociotécnica de um mercado de trabalho, é, simultaneamente, agente dotado pela rede de capacidade de agência (estrutura a circulação de informações sobre esse mercado) e agenciamento quando faz com que trabalhadores e empregadores executem operações de cálculo de seleção.

In Callon's analysis, therefore, an economic actor is not an individual

\footnotetext{
${ }^{36}$ Adaptação do original em francês agencement.
} 
human being, nor even a human being 'embedded in institutions, conventions, personal relationships or groups'. For Callon, an actor is 'made up of human bodies but also of prostheses, tools, technical devices, algorithms, etc'. - in other words is made up of an agencement. [...] an agencement is thus an assemblage, arrangement, configuration or lay-out (HARDIE; MacKENZIE, 2007, p. 58).

Os agentes, para essa corrente, não possuem ontologias fixas e nem lógicas de ação pré-determinadas. Isso permite que Callon (1998a, p. 22; 2004, p. 92; 2007, p. 150-151) afirme categoricamente que o homo economicus não é uma ficção teórica, mas que existe no contexto de uma dada configuração de rede sociotécnica que dota os agentes de capacidade de cálculo de valor ${ }^{37}$. Assim, essa capacidade não é algo resultante da natureza do cérebro humano e nem produto de um arranjo cultural, mas decorre de uma estrutura muito específica de relações entre humanos e não-humanos. Em outros termos, é possível compreender a capacidade de cálculo de valor de uma firma no mercado de trabalho como um produto do agenciamento de uma dada configuração de rede sociotécnica composta pelas relações entre humanos e nãohumanos (instrumentos, teorias, especialistas, procedimentos técnicos, etc.).

Nesta perspectiva, os agentes não-humanos que produzem agenciamentos de cálculo econômico são chamados de "dispositivos de mercado" ${ }^{8}$ (MUNIESA; MILLO; CALLON, 2007) ou de "dispositivos ou ferramentas de cálculo" 39 (CALLON; MUNIESA, 2005, p. 1242; CALLON, 1998a, p. 23-32). Esses agentes não-humanos nada mais são que configurações materiais e discursivas que influenciam tanto na formação de um mercado quanto nas modalidades de cálculo que os agentes nele realizam. "An analysis that fails to take these tools into account would be unable to understand the emergence and logic of calculative agencies, for all decisions are the outcomes of this complex calculating system" (CALLON, 1998a, p. 24). Assim, esses dispositivos têm capacidade de agência e são agenciamentos, ou seja, eles agem moldando uma rede de relações e direcionam a lógica de ação dos agentes.

Moreover, these objects can be considered as objects with agency: whether they might just help (in a minimalist, instrumental version) or force (in a maximalist, determinist version), devices do things. They articulate actions; they act or they make others act (MUNIESA; MILLO; CALLON, 2007, p. 2).

No caso da empresa no mercado de trabalho, podemos trazer a título de exemplo que os dispositivos podem ser testes lógicos, técnicas de entrevistas, sistemas

\footnotetext{
${ }^{37} \mathrm{O}$ que chamamos aqui de capacidade de cálculo de valor, Callon denomina de capacidade de calculative agency.

${ }^{38}$ No original, market devices.

${ }^{39}$ No original, calculative devices ou accounting tools.
} 
informáticos e intranet, conhecimentos advindos da formação universitária dos profissionais de $\mathrm{RH}$, bancos de currículos, concepções de cultura da empresa, sites de redes sociais e profissionais e as páginas eletrônicas de vagas de empregos. Todos esses dispositivos, tal como se verá especialmente no capítulo 8, em relação sociotécnica com agentes humanos, eles executam operações de cálculo ao coordenar e coletar informações utilizadas para o cálculo de valor que a empresa executa no mercado de trabalho.

No nosso entender, os dispositivos de mercado são conceitos que servem para analisar dois processos inter-relacionados: de um lado, quando os consideramos como agentes, estamos focando a análise na formação e transformação do mercado, isto é, na dimensão propriamente estrutural; por outro lado, quando aprendemos seu papel numa configuração de rede sociotécnica que promove uma modalidade de agenciamento como o é a de cálculo de valor, estamos centrando a análise na dimensão da agência. É preciso lembrar que, dentro da perspectiva da teoria do ator-rede, estrutura e agência são "faces de uma mesma moeda"; portanto, essa separação tem razão de ser meramente analítica, ela serve para melhor delimitar o interesse de análise desta tese.

Nessa direção, ao se definir como uma das questões de pesquisa desta tese, compreender como as condições engendradas pelas redes sociotécnicas das firmas de tecnologias da informação estruturam as suas capacidades de cálculo econômico de valor; situa-se o interesse analítico deste estudo no nível da agência, ou seja, não se está especialmente interessado em compreender a formação, transformação e funcionamento do mercado de trabalho - apesar da análise sobre a agência colocar luz sobre essa dimensão estrutural. A perspectiva calloniana, portanto, remete a explicação da agência à noção de agenciamento, isto é, à dimensão estrutural dos mecanismos, componentes e características da rede sociotécnica que produziram as condições de possibilidade para modalidades de cálculo de valor, quando as firmas comparecem no mercado de trabalho.

Assim sendo, o cálculo econômico não é uma capacidade exercida individualmente pelo agente (a firma), mas é realizado na e por causa da rede; vale dizer, não há possibilidade de cálculo desencarnada da rede, até porque não é possível reconhecer um ator senão embebido na rede que lhe dá referência constitutiva. Esse é o argumento da teoria do ator-rede, que Callon se mantém fiel. Em outros termos, ator e estrutura (rede) são "faces da mesma moeda", eles são partes do mesmo processo que gera capacidades de agência como a de cálculo de valor. Cabe ainda sublinhar que, para 
essa perspectiva, cada mercado apresenta variações de tipo contextual e histórico nessa estrutura da rede, as quais geram variações discretas ou modalidades de agência calculadora (CALLON; MUNIESA, 2005; CALLON, 1998a, 2008). Em suma, para se analisar as diferentes formas de comportamento e racionalidade dos agentes econômicos é preciso analisar a composição das redes sociotécnicas que produzem tais variações de agenciamentos.

Conforme a teoria do ator-rede em sociologia econômica, o que é exatamente o cálculo econômico? Destacamos na Introdução que Callon nos fornece uma definição de cálculo econômico que não se limita à habilidade de fazer operações matemáticas e quantitativas. Para esse autor, afirmar que um agente calcula é dizer que ele é capaz dos seguintes procedimentos mentais: 1) a de listar possíveis cenários sobre a realidade (sendo cada cenário composto por uma lista de atores e produtos e uma distribuição dos últimos entre os primeiros); 2) a de hierarquizar esses possíveis cenários (o que evidencia o objeto da preferência dos agentes, e lhes confere conteúdo); 3) a de identificar e descrever as ações necessárias para a produção de cada um dos cenários possíveis (CALLON, 1998a; 2004; CALLON; MUNIESA, 2005). Denomina-se aqui essas três operações como, respectivamente, classificar, julgar e planejar.

Cabe lembrar que, segundo essa perspectiva, esses procedimentos não são feitos individualmente pelo ator e, sim, realizados na e pela rede sociotécnica que produziu o agenciamento que torna possível o agente exercer essa capacidade. Assim, para Callon e Muniesa, "markets are collective devices that allow compromises to be reached, not only on the nature of the goods to produce and distribute but also on the value to be given to them" (2005, p. 1229, grifos nossos).

Por um lado, essa definição de cálculo econômico de valor, por ser abstrata, permite compreender que existem variações discretas nas maneiras como agentes econômicos executam essa capacidade. Não é apenas por considerações numéricas que é possível realizar esses procedimentos necessários ao cálculo de valor. Por outro lado, no caso da firma no mercado de trabalho, quais são as formas concretas desses procedimentos do cálculo econômico de valor?

Para responder a essa pergunta, cabe destacar que os estudos empíricos, especialmente os de matriz sociológica, que estudam o modo como empresas realizam a sua demanda no mercado de trabalho (FERNANDEZ; CASTILLA; MOORE, 2000; FERNANDEZ; SOSA, 2005; MARCHAL; RIEUCAU, 2010; MARSDEN, 1994; 
PETERSEN; SAPORTA; SEIDEL, 2000) afirmam que essa demanda é realizada por meio de três operações: recrutamento, seleção e contratação.

Recrutar consiste definir um cenário no mercado de trabalho para a realização da demanda da firma; trata-se de saber quais são os trabalhadores e o que eles ofertam. Ao fazer isso, a firma está identificando quais são os cenários possíveis de realização de sua demanda. Já selecionar trata justamente de hierarquizar esses conjuntos de trabalhadores e o que eles são capazes de ofertar em termos de força-de-trabalho vis-à-vis ao interesse da firma como demandante. Por último, a contratação é quando a firma estabelece o curso de ação ou o conjunto de procedimentos necessários para produção de um dos cenários possíveis em termos de realização da sua demanda.

Para que a firma possa executar essas três operações de cálculo de valor no mercado de trabalho, é necessário certo nível de organização das informações e sinais no mercado de trabalho, que somente são possíveis de serem captados e processados pelas condições engendradas pela rede sociotécnica; especialmente em razão da opacidade que cerca o mercado e o trabalho como mercadoria. Assim, para o cálculo de valor ser exercitado pelo agente, "[...] there have to be not only calculative agents but also agents with information on all the possible states of the world, on the nature of the actions which can be undertaken and on the consequences of these different actions [...]" (CALLON, 2004, p. 184). Portanto, Callon (1998a; 2004) destaca que, para que os agentes se tornem capazes do que ele chama de "agência calculadora" ${ }^{40}$, é preciso que os mercados apresentem certa organização das informações que torne possível para os atores construírem alguma previsibilidade em relação ao futuro e, desse modo, realizarem os três passos que compõem o cálculo econômico. Todavia, uma vez que a realidade empírica dos mercados é permeada de incertezas e, no caso do mercado de trabalho, das condições de opacidade; cabe, então, a pergunta: "how can agents calculate when no stable information or shared prediction on the future exists?" (CALLON, 1998a, p. 6).

A resposta do autor com relação a essa pergunta é análoga àquela desenvolvida por Mark Granovetter com relação ao "problema hobbesiano da ordem" ${ }^{41}$. São as redes

\footnotetext{
${ }^{40}$ A tradução literal de calculative é calculista. Pensamos que essa não é uma tradução adequada, pois o significado dessa palavra, no português, é frequentemente associado a uma pessoa sem escrúpulos. Esse sentido não é o que é dado pelo uso da expressão em inglês por Callon.

${ }^{41}$ O próprio Callon (1998: 7-12; 2004: 185-86) reconhece que é influenciado pelos argumentos de Granovetter nesse aspecto.
} 
sociotécnicas que organizam a realidade empírica dos mercados de tal forma que permitem aos atores exercerem o cálculo econômico, ou seja, "if agents can calculate their decisions, irrespective of the degree of uncertainty concerning the future, it is because they are entangled in a web of relations and connections [...]" (CALLON, 1998a, p. 7-8).

Como condição de emergência da agência calculadora, a rede sociotécnica deve ser capaz, então, de fazer o processo de "enquadramento" (framing), que estabelece as relações que devem ser tomadas em conta, pelos agentes, com vistas à realização das transações em um mercado. Por meio desse processo, definem-se os tipos de laços/relações a serem considerados, sejam eles tecidos entre os atores sejam entre os entes que circulam neste espaço. Em suma, é pelo enquadramento dos laços que se estabelece a possibilidade de calculabilidade por parte dos agentes; é que ele torna a rede de relações calculável para aqueles que comparecem a um mercado (CALLON, 1998a, p. 16-23; 2004, p. 187-88).

Entretanto, Callon afirma que, entre ele e Granovetter, a sua abordagem possui diferenças importantes com relação às implicações teóricas na maneira de compreender os mercados através das redes:

Markets are not embedded in networks. In other words, it is not a question of adding social, interpersonal, or informal relations in order to understand their functioning. [...] To understand a market it is necessary first to agree to take what it does seriously; that is to say, the construction of calculative actors who consider themselves to be quits once the transaction has been concluded. [...] it is one thing to see these links and relations as having been voluntary and actively rejected from the framework of market relations [...]; it is quite another to say that the market is possible and functions only because these relations are present and form, in a sense, the substratum of market exchange (CALLON, 2004, p. 192-193).

Portanto, para Callon, o mercado e as redes de relações sociotécnicas são equivalentes, ou seja, o primeiro é um tipo de rede que define um espaço de ação cujo funcionamento e comportamento dos que nele participam seguem características previstas pela economia, por exemplo, a capacidade de calcular. A rede, nesta perspectiva, não é meramente um contexto de relações e conexões que interfere e molda a ação dos agentes; a rede, nessa acepção, configura ontologias, produz agenciamentos, ou seja, o que os agentes fazem e suas identidades dependem da morfologia e do que circula nas relações da rede sociotécnica. "This means that the agent is neither immersed in the network nor framed by it; in other words, the network does not serve as a context. Both agent and network are, in a sense, two sides of the same coin" 
(CALLON, 1998a, p. 8). Já para Granovetter, seguindo a leitura que faz Callon das suas ideias, a rede é uma espécie de infraestrutura sobre a qual o funcionamento do mercado está assentado ${ }^{42}$.

Portanto, através da perspectiva de análise de redes sociais de sociologia econômica e a da teoria do ator-rede é possível a construção de um modelo de análise sobre a capacidade de a firma executar o cálculo econômico. Com base nos estudos de redes cuja referência é Mark Granovetter, verificamos que o uso das redes como recurso para firma realizar sua demanda no mercado de trabalho depende do modo como ela define seu interesse em termos de modelo de gestão de recursos humanos e das estratégias comerciais, tecnológicas e mercadológicas que, por sua vez, compõem sua estratégia no mercado de produtos. Além disso, essa abordagem permite vislumbrar que as redes organizam certos condicionantes que modelam o cálculo, por exemplo, elas determinam o nível e a qualidade das informações disponíveis.

A partir da perspectiva da teoria do ator-rede em sociologia econômica foi possível, então, melhor esclarecer o vínculo entre redes e capacidade de cálculo de valor. As redes, segundo essa perspectiva, são responsáveis por processos que estruturam as informações no mercado - o processo de enquadramento - tornando o cálculo possível. Além disso, elas são compostas de elementos que instituem ontologias, isto é, identidade e lógicas de ação; sendo que, no caso examinado, as redes instituem a identidade de demandante da firma no mercado de trabalho e a capacidade de cálculo de valor que pauta seu comportamento nesse espaço. Por fim, a partir de Callon é possível formular uma concepção de cálculo empiricamente operacionalizável, permitindo ao pesquisador identificar em processos empíricos - recrutamento, seleção e contratação a manifestação dessa capacidade. Desse modo é elaborado o modelo de análise desta tese que permite identificar e compreender as modalidades de cálculo econômico e de explicar as condições de possibilidade do exercício desse último por parte das firmas.

\footnotetext{
${ }^{42}$ Sobre outras diferenças teóricas e metodológicas entre a abordagem de Callon e a de análise de redes sociais, ver Callon (2008: 308-11). Uma vez que o nosso argumento se sustenta no que há em comum nas duas abordagens - as redes são um conceito chave para compreender as modalidades de cálculo de valor encontradas nos mercados - não vamos nos debruçar mais sobre essas diferenças.
} 


\section{NOVA ECONOMIA E TECNOLOGIAS DA INFORMAÇÃO}

\subsection{Transformações econômicas recentes e o protagonismo das tecnologias da informação}

É um truísmo na literatura de Ciências Sociais a afirmação de que as últimas décadas são marcadas por um profundo processo de transformação social, político e econômico, que atingiu todos os países, porém de formas e intensidades variadas. Essas observações, que se iniciaram em meados da década de 1970, abriram caminho para uma discussão sobre se estaríamos presenciado uma nova etapa histórica, a PósModernidade. Essa noção remete então para um amplo debate de periodização histórica que se estrutura em interpretações holísticas organizadas a partir da consideração da inter-relação de fatores de natureza cultural, política, econômica, etc.

De maneira geral, temos autores como o filósofo Fredric Jameson (1985) ou o geógrafo marxista David Harvey (1996) que defendem a ideia de que a chamada Terceira Revolução Industrial ou Científico-Tecnológica, a globalização nas suas diversas dimensões, o surgimento no campo político do neoliberalismo e uma economia centrada no consumo e nas empresas multi ou transnacionais, representam a ruptura com as características e lógica de funcionamento econômico, político e cultural que marcaram as sociedades modernas. Por outro lado, pesquisadores como os sociólogos Anthony Giddens (1991) Krishan Kumar (1997) analisam basicamente os mesmos processos, porém interpretam que eles não foram suficientes para a consolidação de uma etapa histórica que rompesse com a Modernidade. Para eles, o que estamos presenciando consistiria no desdobramento e intensificações de processos constituintes das sociedades de tipo moderno.

Por mais que possa ser interessante o debate colocado nesses termos, não é possível, no espaço desta tese, explorá-lo com a atenção devida, além do risco de se perder enfoque analítico. Esse último está mais diretamente relacionado às mudanças tecnológicas e organizacionais que tiveram impacto no funcionamento da economia e no âmbito do trabalho. Basicamente, o interesse analítico desta pesquisa se liga às analises sobre o surgimento de uma nova economia capitalista que tem sido denominada de diferentes formas, conforme as chaves interpretativas e tradições intelectuais que cada autor utiliza para compreender esse processo em tela. Assim, o objetivo aqui é 
apenas trazer, a partir da leitura de alguns autores, os traços reconhecidos como mais ou menos comuns dessa nova economia, especialmente aqueles que impactam mais diretamente nas firmas, pois estas constituem a unidade de análise desta tese.

Já na década de 1970, o sociólogo Daniel Bell (1973) defendia a tese da formação de uma nova economia capitalista baseada na predominância das atividades de serviços em relação às industriais e assentada numa lógica econômica na qual o uso e produção de conhecimento e informação seriam estratégicos em razão da maior importância da inovação em relação ao investimento em capital e energia visando ganhos de produtividade em escala.

Para esse sociólogo norte-americano havia uma clara tendência de mudança para uma nova etapa do capitalismo, isto é, um movimento de mudança que partia do capitalismo industrial para o pós-industrial. No primeiro (que estaria sendo crescentemente substituído em razão de uma terceira revolução tecnológica) o desenvolvimento e lógica de funcionamento da economia estavam baseados na produção em massa de bens industriais, na qual era estratégico para empresas fazer mais com menos custos nos insumos de matéria-prima, energia e trabalho (ganho de produtividade em escala). A economia industrial, então, teria o setor secundário (a indústria e a manufatura) como setor econômico líder do desenvolvimento. Esse setor estruturava-se ao redor de grandes empresas organizadas hierárquica e burocraticamente, que predominante empregavam trabalhadores semiqualificados.

Em contraste, na economia pós-industrial é a inovação, baseada no conhecimento e na informação, o determinante estratégico para as empresas e para geração de riqueza e crescimento econômico. Com os avanços tecnológicos, especialmente nas áreas da informática e da telecomunicação, Bell apontava para o aumento do emprego de mão de obra mais qualificada e, portanto, mais adequada para lidar com as novas tecnologias e a produção de inovação. Esse processo produziria uma mudança profunda na estrutura ocupacional das sociedades na direção do aumento dessa classe de profissionais mais qualificados (especialmente os com formação de nível universitário e experiência em pesquisa científica) em relação aos trabalhadores semiqualificados da economia industrial. Por fim, o setor de serviços tomaria o lugar do tradicional setor industrial, ou seja, a Revolução Tecnológica, que estaria alavancando 
todo esse processo de mudança, traria consigo a tendência de colocar no centro do desenvolvimento econômico capitalista a produção de serviços e bens intangíveis ${ }^{43}$.

Daniel Bell produziu sua teoria em meio a um contexto ainda embrionário de desenvolvimentos das principais tecnologias que dariam "o tom" para o surgimento e estruturação de uma nova economia. Entretanto, muitos de seus insights ainda permanecem e inspiram as analises de outros autores contemporâneos. Entre esses insights queremos aqui destacar a ascensão da importância das atividades econômicas de serviços; o aumento da demanda por uma força-de-trabalho mais qualificada; mudanças nas empresas no sentido de se afastarem cada vez mais de modelos marcados pela gestão centralizada, hierarquizada e burocratizada; e o aumento de importância estratégica das atividades de inovação e das tecnologias de informação e comunicação.

Com relação a esse último aspecto, alguns anos depois de Daniel Bell, mas seguindo uma linha mais próxima ao determinismo tecnológico na economia, nós encontramos a teoria de Yoneji Masuda (1982). Para ele são as inovações tecnológicas as principais responsáveis pelas mudanças macroscópicas nos modelos econômicos das sociedades, pois as novas tecnologias são difundidas e combinadas constituindo o que ele chama de "sistemas tecnológicos" que, por sua vez, consolidam novas maneiras e um novo nível de produtividade, assim transformando a sociedade e a economia como um todo.

Nessa perspectiva, a sociedade e a economia industrial seriam frutos principalmente das inovações tecnológicas - inicialmente através da máquina a vapor e após pelas máquinas eletromecânicas - atuantes na ampliação da capacidade produtiva do trabalho humano voltado para produção de bens industriais tangíveis e do consumo de massa. Já a nova etapa econômica e social, denominada por Masuda como "sociedade da informação", seria fruto do surgimento das tecnologias de informação e comunicação (o que o autor chama de "teleinformática") que direcionariam os padrões de produtividade econômica para a ampliação do trabalho mental humano. Essas tecnologias formariam um sistema tecnológico baseado na computação, bancos de dados e redes de informação e comunicação. As forças produtivas formadas por esse sistema tecnológico estariam, então, voltadas para a produção de bens intangíveis e serviços informacionais.

${ }^{43}$ Cabe destacar que, Daniel Bell não estava defendendo a ideia do fim do industrialismo, mas apenas que o crescimento da economia capitalista não seria mais determinado pela produção de bens industriais, mas pela produção de serviços e bens intangíveis através de processos produtivos baseados no uso do conhecimento e da informação visando à inovação e não mais o descobrimento empírico. 
Por mais esquemática e adesista ao determinismo tecnológico, a perspectiva de Masuda fornece a este estudo uma pista analítica com "tintas mais fortes", mas que Daniel Bell (1973) já mencionava sobre a nova economia: a competição e a produtividade estão crescentemente orientadas por tecnologias que são baseadas e simultaneamente atuam na produção e distribuição de conhecimento e informação. É esse vínculo entre um novo paradigma tecnológico baseado nas tecnologias de informação e comunicação e a formação de uma nova economia capitalista que interessa à tese, pois desse modo se torna compreensível o significado de mudanças importantes que operam nas esferas dos diferentes mercados, nas experiências laborais de trabalhadores e profissionais e também nas estratégias comerciais e nos modelos de gestão desenvolvidos pelas firmas em meio a esse cenário de profunda transformação econômica e social. Em outros termos,

Este processo desencadeado por mudanças no paradigma tecnológico, em grande parte decorrente da difusão das tecnologias de informação e comunicação (TICs), foi acompanhado de mudanças em outras dimensões como: elevação do nível de escolaridade da força de trabalho, do crescimento do setor de serviços, em especial, serviços intensivos em conhecimento, da crescente participação feminina no mercado de trabalho. Em consequência, o mundo do trabalho é afetado de forma significativa, tanto no que se refere à produção propriamente dita, quanto às formas de organização do trabalho, às relações de trabalho, às demandas do mercado de trabalho (GUIMARÃES, 2009, p. 8).

Portanto, essas mudanças provocadas pelas tecnologias de informação e comunicação têm consequências profundas e dinâmicas nos mercados, nas empresas e no trabalho. No caso desta tese, mais especificamente, pretende-se contribuir na compreensão dessa nova economia, olhando o cálculo econômico de valor que as firmas realizam ao comparecer no mercado de trabalho. Desse modo, torna-se analiticamente estratégico destilar, a partir dos autores que se debruçaram sobre o processo de surgimento da nova economia capitalista, as principais características e forças que impactam e simultaneamente são transformadas pela ação dos agentes econômicos na nova economia.

Dentre os autores contemporâneos, destacam-se os estudos de Manuel Castells que conferem centralidade a essa relação entre mudança econômica e transformações nos paradigmas tecnológicos. Para esse sociólogo, a nova economia ou, nos seus termos, o "capitalismo informacional" é constituído por processos provocados e sustentados pelas mudanças no paradigma tecnológico das sociedades através da emergência, desenvolvimento e disseminação das tecnologias de informação e 
comunicação. Para Castells essa transformação tecnológica não somente conferiu ao capitalismo um novo modelo de desenvolvimento (o "informacionismo") como também operou transformações profundas em várias esferas, configurando uma nova estrutura social (a "Sociedade em Rede") e um novo período histórico (a "Era da Informação").

By Information Age I refer to a historical period in which human societies perform their activities in a technological paradigm constituted around microelectronics-based information/communication technologies, and genetic engineering. It replaces/subsumes the technological paradigm of the Industrial Age, organized primarily around the production and distribution of energy (CASTELLS, 2000, p. 5-6).

Cabe destacar que, para Castells, uma estrutura social é o modelo de organização das sociedades nas diversas fases do desenvolvimento histórico humano. Essa estrutura é composta pelas relações de produção e consumo (economia), pelas experiências e identidades (sociedade) e pelas relações de poder (política), todas elas expressas por interações dotadas de sentidos e, assim, influenciadas pela cultura (CASTELLS, 2007, p. 50-54). Cabe destacar novamente, que interessa aqui os aspectos mais ligados à economia e ao mundo do trabalho associados ao desenvolvimento da Sociedade em Rede e da Era da Informação - para usar a terminologia de Castells. Nesse sentido, um dos primeiros elementos que se deve destacar é a tese do autor sobre como o novo paradigma tecnológico, centrado nas tecnologias de informação e comunicação, encontra-se amalgamado com a maneira como o desenvolvimento se processa na nova economia.

No novo modo informacional de desenvolvimento, a fonte de produtividade acha-se na tecnologia de geração de conhecimentos, de processamento da informação e de comunicação de símbolos. Na verdade, conhecimento e informação são elementos cruciais em todos os modos de desenvolvimento [...]. Contudo, o que é específico ao modo informacional de desenvolvimento é a ação de conhecimento sobre os próprios conhecimentos como principal fonte de produtividade. $\mathrm{O}$ processamento da informação é focalizado na melhoria da tecnologia do processamento da informação como fonte de produtividade, em um círculo virtuoso de interação entre as fontes de conhecimentos tecnológicos e a aplicação da tecnologia para melhorar a geração de conhecimentos e o processamento da informação (CASTELLS, 2007, p. 53-54).

Neste momento, Castells se alinha com Daniel Bell (1973) e Yoneji Masuda (1982) ao destacar que, no que ele chama de "modo informacional de desenvolvimento", o funcionamento da economia passa a estar centrado na capacidade de geração de novas tecnologias que atuem na produção, processamento e circulação do conhecimento e da informação; diferente do capitalismo industrial movido pelos 
investimentos em fontes de energias e pelo incremento no uso de capital físico no processo produtivo. Por isso mesmo, ressalta Castells, se antes o conhecimento só tinha valor por sua aplicação em tecnologias que maximizassem a produtividade, no capitalismo informacional, ele importa por sua capacidade de desenvolver tecnologias propulsoras da produção e processamento da própria informação e conhecimento; daí a centralidade e protagonismo das tecnologias da informação e comunicação. Esse modelo de desenvolvimento, associado pela emergência de um paradigma tecnológico baseado nas tecnologias de informação e conhecimento, produz uma nova economia, porém essa é ainda essencialmente uma economia capitalista, "but it is a new brand of capitalism, in which rules for investment, accumulation, and reward, have substantially changed" (CASTELLS, 2000, p. 11).

A nova economia do modo informacional de desenvolvimento, segundo Castells (2007, p. 119-203) apresenta as seguintes características no seu funcionamento:

1. O sucesso e a produtividade de qualquer agente econômico (indivíduos, firmas, países e regiões) estão atrelados a sua capacidade de gerar conhecimentos e processar informações eficientemente.

2. O núcleo da economia passa a residir nas atividades financeiras, pesquisa em ciência e tecnologia, comércio eletrônico e internacional, serviços intensivos em conhecimento voltados para gestão de negócios, logística de cadeias produtivas multinacionais, serviços de redes de telecomunicação, produção de conteúdo em mídias e nos serviços e produtos no campo da saúde e biotecnologia.

3. A economia, principalmente as atividades econômicas mencionadas no item anterior, passam a operar dentro da lógica dinâmica e variável da globalização. Trata-se de uma economia global, ou seja, “[...] uma economia com capacidade de funcionar como uma unidade em tempo real, em escala planetária" (CASTELLS, 2007, p. 142, grifo do autor).

4. Rápidas transformações culturais, tecnológicas e institucionais, exigindo dos agentes econômicos flexibilidade para adaptar seus recursos e modos de trabalho a essas constantes mudanças.

5. A inovação como principal arma competitiva nos mercados em vez do aumento da capacidade produtiva.

Como não poderia ser diferente, esse novo funcionamento da economia do capitalismo informacional também exige uma nova forma organizacional para se operar 
dentro dela, a saber, a "empresa em rede" (CASTELLS, 2007, p. 209-259). As firmas, segundo essa perspectiva, afastam-se do modelo fordista-taylorista, que basicamente consiste em processos mecanizados de produção padronizada em linhas de montagens que são geridas a partir dos princípios da integração vertical e da alta fragmentação e especialização técnica do trabalho. Esse modelo fundamentou-se na busca por ganhos de produtividade em economias de escala (PEREIRA; OLIVEIRA, 2001).

A nova economia põe em xeque esse modelo porque a sobrevivência nos mercados passa estar mais ligada ao atendimento de demandas mundialmente diversificadas, baseadas na qualidade dos produtos e na rápida transformação tecnológica. Assim sendo, a empresa em rede é antes de tudo uma empresa que busca a flexibilidade dos seus processos produtivos e da gestão. Castells mostra como essa flexibilidade foi planejada e implantada por diferentes maneiras a depender dos contextos institucionais, culturais e históricos em que estão situadas as organizações que buscaram se adaptar aos novos condicionantes da nova economia.

Entretanto, correndo o risco da simplificação, pode-se afirmar que a flexibilidade foi buscada nas organizações através das reduções de hierarquias administrativas e da descentralização da gestão, por meio do trabalho em grupo e por projetos e da focalização nos processos diretamente relacionados à atividade-fim. Ainda cabe mencionar que as empresas elaboraram suas estratégicas comerciais visando a nichos de mercado, também seus modelos de gestão buscam por maior envolvimento por parte dos trabalhadores nas diferentes atividades exercidas dentro da firma. Tudo isso foi propiciado e se relacionou com o uso, aperfeiçoamento e integração das tecnologias de informação e comunicação. Desse modo, a empresa em rede é o resultado desse complexo processo de mudança e reestruturação organizacional, ocorridos especialmente nas décadas de 1980 e 1990, que moldou e foi moldado pelas tecnologias de informação e comunicação.

Antes de definir o que é uma empresa em rede é necessário definir o que são, de maneira geral, organizações? Elas são um sistema de meios estruturados com a finalidade de atingir objetivos específicos. Nessa perspectiva, a empresa em rede é uma forma particular de organização cujo sistema de meios é composto por segmentos de sistemas autônomos de objetivos (CASTELLS, 2007, p. 232). A eficiência da rede, por conseguinte da empresa em rede, é determinada por duas capacidades: a de comunicação sem ruídos entre seus componentes (conectividade) e a de compartilhar e coordenar os objetivos da rede com os de seus componentes (coerência). 
Acompanhando a lógica de funcionamento econômico do modo informacional de desenvolvimento e a emergência desse novo modo de organização que é a empresa em rede, operaram-se mudanças profundas no funcionamento do mercado de trabalho e nas relações de emprego (AOYAMA; CASTELLS, 2002; CARNOY; CASTELLS; BENNER, 1997; CASTELLS, 2007, p. 265-351) que podem ser resumidas através dos seguintes pontos ${ }^{44}$ :

1. Disseminação e consolidação de arranjos flexíveis de relações de emprego, por exemplo, contrato de trabalho temporário, de trabalho em tempo parcial, por projeto, trabalho autônomo, teletrabalho ou em domicílio, terceirização, etc. Cabe ressaltar que, essas formas de relações de emprego apresentam níveis de remuneração, estabilidade e condições de trabalho bastante diversas, tornando impossíveis generalizações nesse sentido.

2. Eliminação gradual dos empregos rurais e retração significativa dos mesmos nas industriais tradicionais, por exemplo, automobilística.

3. Aumento da participação das mulheres em ocupações de melhor qualidade e nos empregos de jornada integral do trabalho.

4. Ampliação do número de ocupações no setor de serviços em razão da sua diversificação em novas atividades.

5. Aumentos dos empregos em segmentos de serviços prestados para outras empresas (ênfase naqueles relacionados à produção) e dos serviços de cunho social (com destaque para aqueles relacionados ao setor de saúde e cuidado).

6. Maior participação das ocupações ligadas à gestão e à administração.

7. Formação de empregos de baixa qualidade em atividades "de escritório", por exemplo, vendas, marketing e relacionamento com o cliente. Nesse sentido, os centros de teleatendimento são emblemáticos.

8. Aumento da demanda por profissionais mais qualificados com destaque para aqueles com escolaridade de nível universitário.

\footnotetext{
${ }^{44}$ Cabe destacar que essas tendências foram extraídas por Castells através do exame extensivo e profundo de estatísticas referentes aos países do G-7 (Estados Unidos, Japão, Alemanha, França, Itália, Reino Unido e Canadá). Por isso, é preciso cautela ao usá-las, especialmente quando examinamos contextos econômicos e sociais distintos como o brasileiro. Por isso que, na última seção deste capítulo, será exposta a análise de alguns dados sobre as empresas e o mercado de trabalho brasileiro e gaúcho, justamente para identificar semelhanças e diferenças com as tendências apontadas por Castells com base no exame dos países do G-7.
} 
9. Individualização das carreiras e diminuição das filiações em organizações coletivas como os sindicatos.

10. Aumento da duração do desemprego, especialmente no nível inferior da estrutura ocupacional.

11. Altos índices de rotatividade voluntária e involuntária, principalmente nas ocupações situadas naqueles setores tidos como estratégicos e peculiares à nova economia, por exemplo, as atividades de produção e de serviços de tecnologias da informação e comunicação.

Para esta tese é importante ter em mente essas tendências do mercado de trabalho na nova economia para melhor compreender o comportamento e a demanda das empresas estudadas, quando comparecem ao mercado de trabalho. Todavia, três aspectos interessam particularmente porque são facilmente associados quando se pensa nas empresas de tecnologias da informação: (1) modelos flexíveis de gestão e relações de trabalho; (2) maior ocupação nas atividades de serviços prestados a empresas; (3) maior demanda por profissionais mais bem qualificados.

Por fim, Michel Callon destaca um aspecto da nova economia que foi pouco ou nada analisado pelos atores mencionados até aqui, a saber, o papel estratégico para as empresas na nova economia de desenvolverem a habilidade de se relacionarem e colaborarem com um conjunto cada vez maior, numérica e qualitativamente, de agentes humanos e não-humanos externos à empresa. Esse autor denomina a nova economia como "economia de qualidades" (CALLON, 2007; CALLON; MÉADEL; RABEHARISOA, 2002) cujo aspecto distintivo é a importância crescente que assumem a inovação e a interação entre empresas e consumidores no funcionamento dos mercados. Ambos têm exigido das empresas a capacidade de envolver agentes externos a elas nos processos de produção e comercialização dos seus bens. Por um lado, a necessidade de inovação constante e acelerada, imposta pelo novo contexto econômico, exige dos agentes, especialmente empresas, a maior mobilização de recursos de conhecimento e informação que dificilmente encontram-se acessíveis internamente. Nesse sentido, o segmento de software é exemplar como podemos ver por essa citação do artigo de Judy Wajcman, que analisa justamente as conexões possíveis entre os "estudos sociais da ciência e tecnologia" (corrente que tem como um de seus representantes Michel Callon) e a sociologia do trabalho.

According to one estimate, there are 18 million amateur programmers worldwide, or about three times the number of professional 
programmers. For example, as I write, approximately 10,000 volunteers around the world are testing the latest version of computer software, the new Vista platform, for Microsoft (2006, p. 782).

Eis um exemplo de uma das formas na qual a inovação constante exige das empresas saber mobilizar agentes externos a elas. Assim, para inovar, os agentes econômicos precisam estrategicamente "se abrir" para um número crescente de relações sociotécnicas com outros agentes em projetos de interesse comum entre seus participantes (CALLON, 2007).

De outro lado, o aumento da competição e da segmentação das demandas dos consumidores, ambos gestados pela globalização da economia, fazem com que os mercados se tornem crescentemente organizados em torno do processo que Callon denomina de "qualificação dos bens" (CALLON; MÉADEL; RABEHARISOA, 2002). Tal processo consiste em sucessivas operações e interações entre ofertantes e consumidores para estabelecer as qualidades (objetificação) que fazem de um bem ter valor no mercado e, ao mesmo tempo, se diferenciar (singularização) dos seus equivalentes. Portanto, o processo de qualificação dos bens transacionados no mercado nada mais é que o resultado de operações de cálculo de valor sobre esses bens, baseados em critérios (qualidades) em constante mutação a depender das relações sociotécnicas que são travadas para realizar esse cálculo.

Em suma, o argumento dessa perspectiva (CALLON, 2007; CALLON; MÉADEL; RABEHARISOA, 2002) consiste em afirmar que quanto mais estratégico se torna o processo de inovação assim como o de qualificação de bens transacionados nos mercados, tanto mais os agentes econômicos precisam estabelecer relações sociotécnicas extensas e complexas com diferentes tipos de agentes. Esse processo no qual as relações sociotécnicas são incluídas para depois gerar a necessidade da inclusão de outras relações é denominado por Callon (1998b; 2007), respectivamente, como "enquadramento" 45 e "transbordamento" 46.

Nesse sentido, as tecnologias de informação e comunicação, tal como nas demais perspectivas vistas, assumem uma posição de destaque e estratégica. Para Michel Callon, elas serviriam justamente para ampliar essa capacidade de interação e coordenação entre diferentes tipos de agentes (CALLON, 2007; CALLON; MÉADEL; RABEHARISOA, 2002).

\footnotetext{
${ }^{45}$ No original em inglês, framing.

${ }^{46}$ No original em inglês, overflow.
} 
O que se pretende nesta tese é justamente verificar como se processam e quais relações sociotécnicas as firmas estabelecem em ordem de poder calcular o valor do insumo que demandam (a força-de-trabalho) quando comparecem no mercado de trabalho. E é também por essa importância que assumem as tecnologias da informação em praticamente todas as perspectivas que se propuseram em compreender a nova economia, que se elegeu tomar como objeto empírico de análise, as firmas que desenvolvem produtos e serviços referentes a essas tecnologias. Portanto, a análise empírica dessas empresas pode proporcionar um ponto de vista analiticamente privilegiado para compreender o funcionamento, os condicionantes e as formas que assumem o cálculo econômico de valor na nova economia, sobre um dos insumos indispensáveis para qualquer atividade econômica, o trabalho.

\subsection{Firmas de tecnologias da informação: uma definição e os} seus papéis no mercado de trabalho

As tecnologias da informação (TI), principalmente nas últimas décadas, têm sido marcadas por intensas e rápidas inovações e por sua integração a outras tecnologias como a de comunicação, biológicas e audiovisuais. Isso faz com que seja uma tarefa complexa estabelecer uma noção de TI. A definição de Castells é, nesse sentido, ilustrativa com relação ao caráter integrado dessa tecnologia: "Entre as tecnologias da informação, incluo [...] o conjunto convergente de tecnologias em microeletrônica, computação (software e hardware), telecomunicações/radiodifusão, e optoeletrônica" (2007, p. 67, grifos do autor). O autor ainda considera como parte da TI a engenharia genética, pois ela lida com os códigos de informação da matéria viva e por ter interagido com a eletrônica e informática ao longo da década de 1990.

É ainda em função dessa convergência com outras tecnologias que, frequentemente, a TI é definida como tecnologias de informação e comunicação $(\mathrm{TICs})^{47}$. Nesse sentido,

A convergência configura-se, assim, como o conectivo tecnológico de base digital que possibilita a comunicação entre diversos tipos de aparelhos e equipamentos compreendidos no conjunto das TICs, permitindo, a migração de dados, textos, sons e imagens entre diferentes aparelhos e equipamentos de informação e até mesmo a conjunção de diferentes formas de comunicação em um mesmo aparelho ou equipamento (SALDANHA, 2006, p. 65).

\footnotetext{
${ }^{47} \mathrm{O}$ aparelho celular é talvez o símbolo mais expressivo dessa convergência. Num mesmo dispositivo há funções de telefonia, Internet, televisão, vídeo, música, texto, jogos, GPS, etc.
} 
Essa convergência entre TI e tecnologias de comunicação é tão intensa, especialmente após o advento da Internet, que a OCDE (Organização para a Cooperação e Desenvolvimento Econômico) também formula uma definição de TI como TICs, qual seja:

Os produtos TIC devem ter o propósito de realizar a função de processamento da informação e comunicação por meios eletrônicos, inclusive a transmissão e divulgação ou o uso do processamento eletrônico para detectar, mensurar e/ou registrar um fenômeno físico ou controlar um processo físico.

Os serviços TIC devem ter o propósito de capacitar a função do processamento da informação e comunicação, por meios eletrônicos (OCDE apud IBGE, 2009, p. 13).

Nota-se que essa definição se faz pela ótica dos produtos e serviços nos quais as TICs se materializam. Também se percebe que mesmo falando em tecnologias de informação e comunicação estão excluídos, nessa definição da OCDE, os produtos e serviços que criam conteúdos, por exemplo, publicidade e jornalismo.

O IBGE (Instituto Brasileiro de Geografia e Estatística) seguiu as orientações da OCDE de definição das TICs e, na CNAE (Classificação Nacional de Atividades Econômicas) 2.0, estabeleceu o setor de "Informação e Comunicação" 48, conforme tabela abaixo:

Tabela 1 - Setor de TICs segundo CNAE 2.0

\section{Hierarquia}

\section{Seção: J Informação e Comunicação}

\section{DIVISÕES:}

58 - Edição e edição integrada à impressão.

59 - Atividades cinematográficas, produção de vídeos e de programas de televisão; gravação de som e edição de música.

60 - Atividades de rádio e de televisão.

61 - Telecomunicações.

62 - Atividades de serviços de tecnologia da informação.

63 - Atividades de prestação de serviços de informação.

Fonte: Comissão Nacional de Classificação.

Percebe-se que as atividades de produção de conteúdos estão incluídas nessa classificação e que foram excluídas as atividades industriais de fabricação de máquinas e equipamentos de $\mathrm{TICs}^{49}$.

${ }^{48}$ A CNAE 1.0 não apresentava um setor específico de informação e comunicação. Era preciso, então, construir uma classificação satélite na forma de agregados alternativos. Em IBGE (2009) podemos ver um exemplo desse esforço de classificação.

${ }^{49}$ Essas atividades constam na seção C (Indústria de Transformação), divisão 26 (Fabricação de equipamentos de informática, produtos eletrônicos e ópticos). 
Essa plêiade de definições e elementos acontece em razão do fato que, normalmente, as tecnologias da informação são definidas ou como um setor econômico, ou um grupo de produtos e serviços ou um paradigma tecnológico (EISCHEN, 2000). Essas diferentes "portas de entrada" para definição de TI produzem, então, uma cacofonia conceitual que, nos parágrafos acima, apenas se arranhou a superfície.

Tendo em mente que esta tese utiliza a noção de TI principalmente para localizar empresas que representem casos-tipo da nova economia, elaborou-se uma definição de tecnologias da informação como um gênero de produtos e serviços que constituem a atividade-fim de certo grupos de empresas. A intenção, portanto, é alcançar uma definição que permita identificar os tipos de empresas que estão produzindo aqueles produtos ou serviços que se constituem, tal como visto na seção anterior, referência ubíqua nos processos que configuram o surgimento e funcionamento de uma nova etapa da economia capitalista. Assim sendo, nesta pesquisa compreendemos por TI o conjunto de produtos e serviços que lidam com a produção, tratamento e/ou circulação da informação (seja na forma de texto, imagem, dado ou som) através de meios eletrônicos ou digitais. Portanto, os estudos de caso desta tese foram feitos em empresas cujo objeto de sua atividade-fim é a oferta de alguma forma de produto e/ou serviço de tecnologia da informação, entendida dentro dessa definição.

Delimitar pelo o critério de atividade-fim é ainda mais importante quando temos em vista os resultados de pesquisa de Hualde e Micheli (2009). Segundo esses autores, no segmento de serviços relacionados às tecnologias da informação se constituem duas realidades que, frequentemente, são tratadas indistintamente e amalgamadas dentro daquilo que se pode chamar de "setor econômico de tecnologias da informação", quais sejam: "serviços de tecnologia da informação" e os "serviços propiciados pelas tecnologias da informação". No primeiro estão situadas as firmas que têm como atividade-fim a prestação de serviços genuinamente de TI como empresas de desenvolvimento de software. No segundo se constata a presença de empresas bastante distintas das do primeiro grupo, por exemplo, os centros de teleatendimento que prestam serviços de marketing, suporte técnico e/ou vendas.

A definição do setor de tecnologia da informação elaborada para esta tese se mostra pertinente, pois através dela se podem distinguir essas duas realidades de segmentos do setor de serviços de tecnologia da informação, que como demonstram Hualde e Micheli (2009), possuem um perfil diferente de mão de obra empregada do ponto de vista de níveis de remuneração, modalidade de contrato de trabalho, nível de 
escolaridade, etc. Portanto, esta tese se propõe em examinar empresas que justamente são as que estão mais diretamente relacionadas com as tecnologias da informação, não somente porque utilizam essas últimas como ferramentas de trabalho e gestão, como também são essas tecnologias o que elas ofertam no mercado de produtos.

Entretanto, a definição de TI como um tipo de produto e/ou serviços que constitui a atividade-fim de um conjunto de empresas, refere-se a um campo da realidade no qual também existem definições "nativas" de TI, isto é, a compreensão que as empresas têm ao delimitar o seu setor de atuação, seu nicho no vasto campo que é o mercado de produtos na área de tecnologia da informação. Por vezes, essas definições e classificações nativas se baseiam em categorias e esquemas que não são os mesmo que movem o pesquisador. Assim, por exemplo, cabe citar a variedade de autoclassificações encontradas nos sites das empresas estudas nesta tese: 1) Indústria eletrônica de produtos de telecomunicação e informática; 2) empresa de desenvolvimento de software e serviços relacionados a softwares para gestão empresarial; 3) empresa fabricante de softwares, serviços e tecnologia para empresas; 4) empresa de desenvolvimento de softwares e consultoria de TI para empresas e organizações. Nessas definições é possível identificar palavras como serviços, produção, consultoria, software, TI e eletrônica, que nem sempre correspondem às categorias utilizadas pelo pesquisador para elaborar suas definições. A principal razão disso são interesses distintos em pauta desses agentes, levando a linguagens e compreensões distintas.

Assim sendo, esta tese toma em consideração essa dissonância e escolhe por submeter uma primeira redação do capítulo cinco, que trata justamento desse esforço de caracterização e classificação, à leitura dos profissionais gestores das empresas estudadas. Através desse procedimento foi possível cotejar as categorias e classificações adotadas nesta pesquisa com as do conhecimento "nativo", e, então, ancorar nosso conhecimento à riqueza da realidade empírica.

Até aqui a definição adotada de TI serviu para justamente delimitar o foco sobre quais tipos de empresas interessa estudar, a saber, as empresas de tecnologia da informação compreendidas como um grupo definível em termos de um mesmo gênero de atividade-fim. Portanto, é o cálculo de valor desse tipo de empresa, quando comparece no mercado de trabalho, que constitui o interesse analítico desta tese. Em outros termos, empreendeu-se o esforço de compreender o cálculo de valor da demanda no mercado de trabalho de empresas cujas atividades-fim são produtos e/ou serviços que 
lidam com a produção, tratamento e/ou circulação da informação (seja na forma de texto, imagem, dado ou som) através de meios eletrônicos ou digitais.

Todavia, a demanda de trabalho que nos interessa dessas firmas é aquela dos profissionais que exercem atividades ligadas diretamente a essa atividade-fim, ou seja, aquilo que podemos denominar genericamente como "profissionais de tecnologia da informação". Neste aspecto também se manifestam diversos critérios e, por conseguinte, diferentes classificações sobre quem são esses profissionais. Poder-se-ia delimitar esse grupo de profissionais aos trabalhadores com formação superior ou técnica na área de informática e eletrônica ou profissionais das engenharias. Entretanto, como demonstra Adams e Demaiter (2008), as pesquisas apontam para o fato que, em diversos países, contingentes significativos dos trabalhadores empregados em firmas de tecnologia da informação têm diplomas de cursos superior ou técnico em áreas diversas das engenheiras e da informática.

Outra maneira de abordar essa questão é aquela adotada pelos estudos do Observatório da SOFTEX (2009; 2012). Esses estabelecem que o conjunto dos profissionais de tecnologias da informação consiste em um agregado de ocupações constantes na CBO (Classificação Brasileira de Ocupações). Nesse sentido, os profissionais de TI seriam formados pelos diretores de serviços de informática, gerentes de TI, engenheiros da computação, analistas de sistemas computacionais, operadores de equipamentos de entrada e transmissão de dados, etc. Entretanto, essas classificações oficiais nem sempre se correspondem àquelas que as empresas de TI utilizam para definir o grupo de profissionais por elas demandados, ou seja, aqui também existem definições "nativas". Muitas vezes as definições "oficiais" como as da CBO preveem separações, divisões que as firmas não levam em consideração, tornando essas classificações um instrumento não muito adequado para caracterizar a demanda por força-de-trabalho de TI das empresas. Ou, ainda, algumas das atividades de TI que aparecem na CBO podem ou não ser demandadas no mercado de trabalho, por exemplo, a atividade de gerenciamento e aquisição de softwares pode ser demandada no mercado de produtos através da contratação de empresas de consultoria ou no de trabalho através da contratação de profissionais.

Tendo em vista também essas disparidades e diversidades conceituais, elegeu-se por compreender a demanda por profissionais de TI no mercado de trabalho em termos dos tipos de demandantes e não através de "quem" é demandado. Essa postura tem 
como vantagem evitar as confusões acima citadas e estar ancorada na unidade de análise desta tese, a firma no mercado de trabalho.

Nesse sentido, as empresas responsáveis pela demanda de profissionais de TI no mercado de trabalho podem ser divididas em duas categorias - empresas usuárias e as produtoras de TI. As primeiras são todas e quaisquer empresas que fazem uso intensivo e abrangente das tecnologias da informação nos seus processos de gestão e comercialização. Em princípio, empresas usuárias podem estar situadas em qualquer setor econômico - comércio, serviços, indústria, agropecuária - dada a centralidade dessas tecnologias no cotidiano das empresas atualmente. Portanto, essas não correspondem ao grupo de empresa que interessa para esta pesquisa, isto é, elas não têm como atividade-fim produtos e/ou serviços de TI. Assim sendo, esta tese lida com o segundo grupo de demandantes, empresas produtoras de TI.

Dentro do grupo de empresas produtoras de TI podemos delimitar três modalidades: 1) empresas que prestam serviços de tecnologias de informação para usuários individuais; 2) empresas que prestam serviços de TI para outras empresas ou organizações; 3) indústrias e manufaturas de equipamentos de TI. Portanto, as empresas produtoras de TI são tanto aquelas que prestam serviços como as que fabricam produtos desta área. Essa divisão é necessária para identificar uma diferença de papéis no mercado de trabalho dessas empresas: enquanto as de serviços podem atuar tanto como ofertante e como demandante no mercado de trabalho, as indústrias estão restritas ao papel de demandantes. Uma firma de serviços de TI precisa demandar profissionais dessa área como, também, atuar como ofertante no mercado de trabalho ao prestar serviços de terceirização e consultoria; enquanto que indústrias oferecem apenas equipamentos de TI em mercados de produtos.

Pretende-se, então, apontar para o fato de que o mercado de trabalho do segmento de TI é constituído não somente pela oferta individual de mão de obra de profissionais, mas também pela oferta de atividades sob a forma de prestação de serviços por parte de empresas ou pessoas jurídicas individuais. Todavia, os casos estudados aqui são de empresas de tecnologia da informação propriamente ditas, ou seja, a sua demanda de trabalho se concentra na contratação de profissionais de TI; portanto, nenhum dos casos pesquisados apresentou a realização da demanda de 
trabalho de TI através da contratação de outras empresas ou mesmo pessoas jurídicas individuais ${ }^{50}$.

O mercado de trabalho de atividades de TI é, portanto, composto pelos seguintes agentes: 1) Ofertantes Exclusivos que são profissionais de TI e pessoas jurídicas individuais; 2) Ofertante/Demandante que são as empresas de serviços de $\mathrm{TI}$; 3) Demandantes Exclusivos que são as empresas usuárias de TI e as empresas de fabricação de equipamentos de tecnologias da informação. Cabe destacar que a identidade de demandante de uma firma está ligada ao tipo de relação que ela estabelece tanto com a tecnologia como também com outros agentes econômicos - reforçando a ideia de que redes sociotécnicas são produtoras de ontologias. Isso é especialmente válido para firmas que são Ofertante/Demandante, pois quando inseridas apenas numa relação com uma Demandante Exclusiva, elas devem ser compreendidas como ofertantes no mercado de trabalho de TI.

A presente pesquisa toma como unidade de análise empírica as firmas de serviços a empresas (Demandantes Exclusivas) e de fabricação de equipamentos de informática (Demandantes Exclusivas). O objetivo é identificar as modalidades de cálculo de valor que elas exercem ao comparecerem no mercado de trabalho. A escolha por somente firmas em condição de Demandantes Exclusivas foi feita em razão de delimitar o recorte de análise, ou seja, ao tomar firmas de TI com a mesma identidade de papel no mercado de trabalho, evita-se a necessidade de abordar uma variedade de casos que seria impossível de abarcadas no escopo temporal de uma tese. Então, sendo o problema de pesquisa desta tese centrado na capacidade de cálculo das firmas na sua demanda de trabalho, escolheram-se justamente casos nos quais as empresas somente exerçam esse papel no mercado de trabalho.

\subsection{Contextualização e caracterização das firmas e da demanda}

\section{de trabalho de tecnologia da informação - Brasil e Rio Grande do Sul.}

Esta seção do capítulo apresenta uma análise descritiva da demanda de trabalho $^{51}$ no setor de tecnologias da informação no que diz respeito às características das firmas, vínculos de trabalho utilizados e à força de trabalho por elas empregadas. empresas.

${ }^{50}$ Pessoas Jurídicas Individuais nada mais são que profissionais que prestam serviços a outras

${ }^{51}$ Escolhemos a definição dos papéis no mercado de trabalho tal como consta nos principais manuais de Economia do Trabalho: empregadores formam o lado da demanda e empregados o lado da oferta. 
Essa análise será feita, primeiro, com dados para o nível nacional e, depois, para o Estado do Rio Grande do Sul. Nosso objetivo é contextualizar os estudos de casos realizados.

Utilizamos como fonte de dados a Relação Anual de Informações Sociais (RAIS) do Ministério do Trabalho e Emprego (MTE). Essa fonte fornece informações do universo nacional de empresas com um ou mais vínculos de trabalho no ano-base, sendo que também podemos vislumbrar o número de estabelecimentos empresariais sem vínculos no ano, ou seja, a chamada declaração de "RAIS negativa". Todavia, a RAIS apresenta algumas limitações: ela compreende somente o chamado mercado de trabalho formal, não nos possibilitando vislumbrar vínculos e firmas que atuem de modo informal; e o MTE obtém esses dados através de formulários preenchidos pela própria empresa, então, distorções podem ocorrer. Sendo assim, consideram-se aqui os dados da RAIS como um Proxy da demanda formal de trabalho do setor de TI.

Para classificar o tipo de atividade exercida pela empresa, a RAIS utiliza a Classificação Nacional de Atividades Econômicas (CNAE). Foi utilizada a CNAE 2.0 porque é a versão que define especificamente um setor de tecnologia da informação e, também, porque os dados mais recentes da RAIS estão estruturados nessa versão.

Conforme representa a tabela abaixo, o setor de tecnologia da informação é definido pela CNAE junto às atividades ligadas às tecnologias de comunicação:

Tabela 2 - Setor de Tecnologia da Informação e Comunicação. Hierarquia

\section{Seção: J Informação e Comunicação}

\section{DIVISÕES:}

58 - Edição e edição integrada à impressão.

59 - Atividades cinematográficas, produção de vídeos e de programas de televisão; gravação de som e edição de música.

60 - Atividades de rádio e de televisão.

61 - Telecomunicações.

62 - Atividades de serviços de tecnologia da informação.

63 - Atividades de prestação de serviços de informação.

Fonte: Comissão Nacional de Classificação.

Como o interesse desta tese reside em firmas cuja atividade-fim seja produção ou prestação de serviços de tecnologia da informação, na seção $\mathrm{J}$ da CNAE se considerou como pertencentes ao setor de tecnologia da informação, apenas as firmas que exercem atividades compreendidas na divisão 62: 
Tabela 3 - Serviços de Tecnologia da Informação.

\section{Hierarquia}

SEÇÃO

J - Informação e Comunicação.

\section{DIVISÃO:}

62 - Atividades de serviços de tecnologia da informação.

\section{GRUPO}

620 - Atividades de serviços de tecnologia da informação.

\section{CLASSES}

6201-5 Desenvolvimento de Programas de Computador sob Encomenda.

6202-3 Desenvolvimento e Licenciamento de Programas de Computador

Customizáveis.

6203-1 Desenvolvimento e Licenciamento de Programas de Computador Não-

Customizáveis.

6204-0 Consultoria em Tecnologia da Informação.

6209-1 Suporte Técnico, Manutenção e Outros Serviços em Tecnologia da

Informação.

Fonte: Comissão Nacional de Classificação.

Entretanto, percebe-se que se está excluindo a divisão 63, "Atividades de Prestação de Serviços de Informação". A razão principal é que os tipos de caso que se teve acesso são aquelas que exercem atividades que compreendem apenas a divisão 62 . Ademais, esse grupo específico de atividades lida mais diretamente com $\mathrm{o}$ desenvolvimento de serviços de tratamento e/ou circulação da informação nas formas de texto, imagem, dado ou som, através de meios eletrônicos ou digitais. Nesse sentido, é possível compreender a diferença entre as divisões 62 e 63 da seção J da CNAE como aquela mencionada entre, respectivamente, "serviços de tecnologia da informação" e "serviços possibilitados por tecnologia da informação" (HUALDE; MICHELI, 2009). Portanto, a seleção dos estudos de caso acabou por privilegiar firmas do setor de tecnologia da informação que desenvolvem serviços dessas tecnologias e não por meio delas.

A seção J não compreende as atividades de fabricação de equipamentos de TI. Como se vê na tabela abaixo, na CNAE 2.0, elas são classificadas na seção C "Indústria de Transformação": 
Tabela 4 - Indústria de Tecnologia da Informação.

Hierarquia

SEÇÃO

C - Indústria de Transformação.

DIVISÃO:

Ópticos.

26 - Fabricação de Equipamentos de Informática, Produtos Eletrônicos e

GRUPO

262 - Fabricação de Equipamentos de Informática e Periféricos.

\section{CLASSES}

2621-3 Fabricação de Equipamentos de Informática.

2622-1 Fabricação de Periféricos de Equipamentos de Informática.

Fonte: Comissão Nacional de Classificação.

Assim, nesta pesquisa o setor de TI está delimitado como as atividades diretamente envolvidas na fabricação ou em serviços de tecnologias da informação, isto é, firmas pertencentes ao grupo 262 da Seção C mais à divisão 62 da seção J da CNAE 2.0. Cabe destacar que, como a adoção da CNAE 2.0 se refere somente aos dados da RAIS entre os anos de 2006 a 2010, optou-se por esse recorte temporal na análise que segue, evitando, assim, possíveis distorções nos dados em função de adaptações entre diferentes versões da CNAE.

A unidade de análise consiste na demanda da firma porque esse é o objeto desta tese. Assim, além das características das firmas de TI, coletaram-se dados que dizem respeito à frequência e intensidade da sua demanda, características dos vínculos e mão de obra por elas demandadas. Portanto, o interesse não é compreender "quem são" e como circulam os trabalhadores e, sim, o comportamento da demanda das empresas de tecnologias da informação. Por essa razão, nos dados que se seguem estão inclusos os vínculos ativos e inativos em 31 de dezembro do ano base. Poder-se-ia argumentar que, ao fazer isso, consideram-se duas ou mais vezes o mesmo trabalhador; entretanto, esse problema não se aplica porque esta análise se estrutura para compreender a demanda e não a oferta, ou seja, o que se está "contando" é a ação de demandar da firma de TI no mercado de trabalho.

Entretanto, mais uma limitação da RAIS se revela neste ponto da demanda da firma como unidade de análise, a saber, a RAIS somente registra aquelas demandas que resultaram em estabelecimento de vínculos de trabalho, excluindo vagas de trabalho abertas (demandas) não preenchidas. Ademais, trata-se da demanda apenas por vínculos de trabalho contratados com indivíduos, uma firma pode, por exemplo, demandar certas funções ou atividades através de contrato com outras firmas. Portanto, reitera-se aqui 
que a análise dos dados da RAIS é um Proxy do comportamento da demanda das firmas de TI no mercado de trabalho.

Por meio da realização de algumas entrevistas com representantes de organizações de empresas, sindicatos e consultores da área de tecnologias da informação, foi apontada a seguinte tendência no mercado de TI: a presença dos chamados PJI, ou seja, pessoas jurídicas individuais. Trata-se de profissionais que individualmente se constituem como empresas através do registro de pessoa jurídica e normalmente prestam serviços de TI no mercado; concorrendo, em alguns casos, com as demais empresas de TI que possuem funcionários. Segundo os entrevistados, os PJI têm uma presença ubíqua no mercado de TI e possuem perfis profissionais bastante diferentes - desde o programador sem formação técnica ou superior na área e cujas habilidades foram adquiridas de maneira autodidata até consultores de alta formação e especialização que são muito valorizados no mercado.

Uma maneira indireta e aproximada para compreender a representatividade dos PJI no setor de tecnologia da informação é comparar o número de RAIS negativas com os demais estabelecimentos; pois, se a característica comum aos PJI é ser uma empresa sem vínculos de trabalho, estes devem fazer a declaração de RAIS negativa. Contudo, encontramos nessa declaração, por exemplo, estabelecimentos que suspenderam suas atividades naquele ano, ou seja, nem toda declaração de RAIS negativa é PJI. Além disso, podemos considerar PJI pequenas empresas que possuem funcionários, porém nenhum deles exerce ocupação ligada à atividade-fim da firma de TI. Assim, o gráfico a seguir é apenas uma estimativa da representatividade dos PJI no setor de TI: 
Gráfico 1 - \% de Estabelecimentos RAIS Negativa - Brasil.

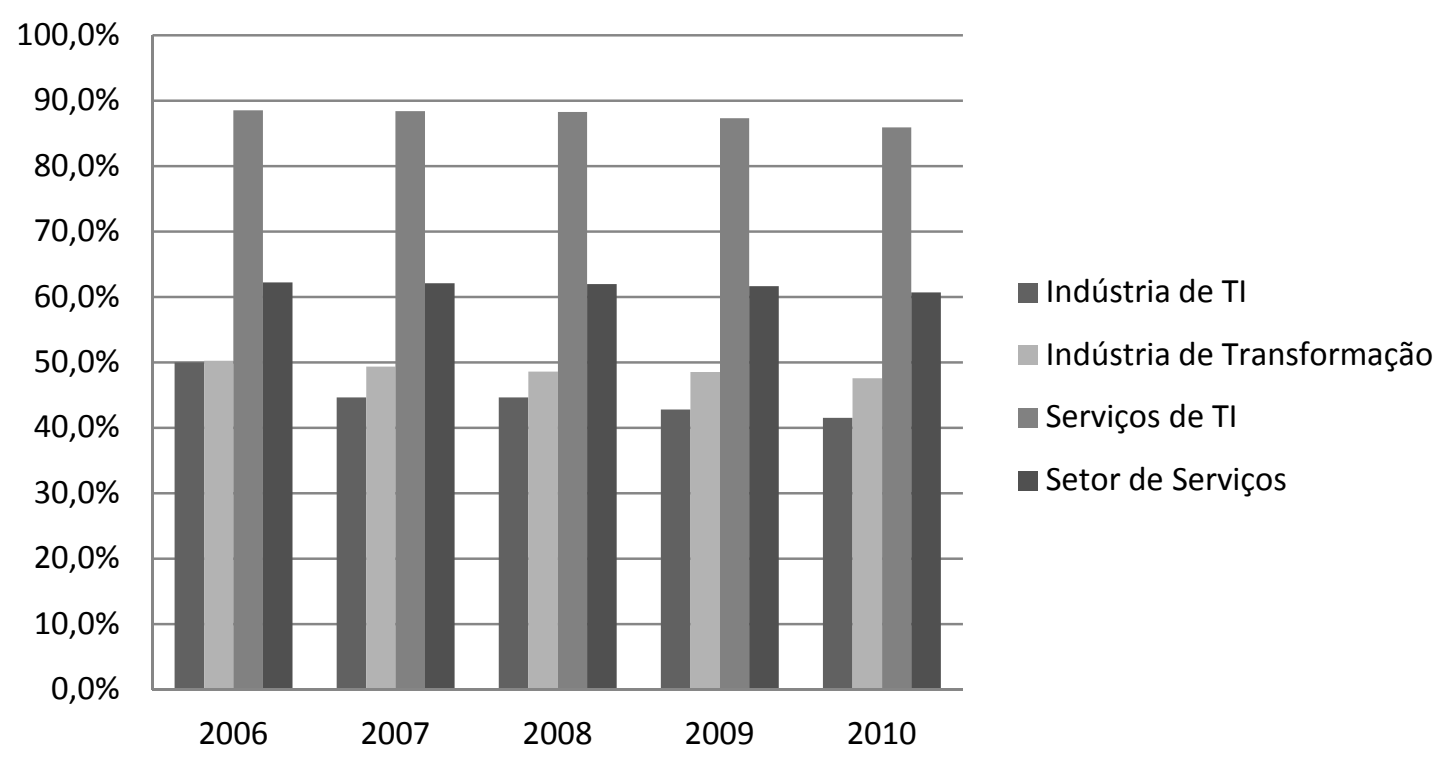

Fonte: RAIS - MTE.

Consistente com as informações obtidas através das entrevistas, atividades de serviços de TI apresentam uma concentração muito maior de RAIS negativas do que no setor de serviços como um todo ou mesmo nas atividades de fabricação de equipamentos de TI ou no setor da indústria de transformação. É possível somente cogitar que nos outros casos, a maior parte dos registros de RAIS Negativa não é de PJI, mas de empresas que não apresentaram nenhum vínculo de trabalho naquele ano ou mesmo suspenderam suas atividades ${ }^{52}$. Todavia, apesar de representarem uma grande parcela dos estabelecimentos do setor de TI, os PJI ou RAIS negativas não foram incluídos na análise por três razões: 1) porque dada as próprias regras da base RAIS, a declaração negativa exime o estabelecimento de fornecer qualquer outra informação, ou seja, não há dados disponíveis nessa base sobre eles; 2) o enfoque desta tese reside na compreensão da capacidade de cálculo econômico de valor de firmas de TI no mercado de trabalho; uma vez que, por definição, PJI não demandam no mercado de trabalho, não há prejuízos analíticos em excluí-los; 3) os estudos de caso que realizados, nenhuma das empresas declarou o uso de contratação de PJI. Portanto, os dados que seguem se referem apenas aos estabelecimentos que não fizeram declaração negativa nos anos em questão.

52 Ademais, ao contrário dos serviços, é difícil imaginar a fabricação de equipamentos, especialmente os de complexidade como são os de tecnologia da informação, através de um profissional. 
Como é possível de identificar no gráfico acima, está seção visa contextualizar os dois segmentos do setor de TI (serviços e indústria) comparando-os com seus respectivos setores econômicos mais amplos. Mas qual é o peso, nesses grandes setores, dos segmentos de tecnologia da informação?

Tabela 5 - Participação dos Estabelecimentos de TI nos Grandes Setores Brasil.

\begin{tabular}{c|c|c|c|c}
\hline & $\begin{array}{c}\text { Setor de } \\
\text { Serviços }\end{array}$ & Serviços de TI & $\begin{array}{c}\text { Indústria de } \\
\text { Transformação }\end{array}$ & $\begin{array}{c}\text { Indústria de } \\
\text { TI }\end{array}$ \\
\hline \multirow{2}{*}{2010} & 1.180 .213 & 13.711 & 337.651 & 693 \\
& $(100,0)$ & $(1,2)$ & $(100,0)$ & $(0,2)$ \\
\hline \multirow{2}{*}{2009} & 1.115 .205 & 11.975 & 331.359 & 644 \\
& $(100,0)$ & $(1,1)$ & $(100,0)$ & $(0,2)$ \\
\hline \multirow{2}{*}{2008} & 1.055 .859 & 10.685 & 320.769 & 640 \\
& $(100,0)$ & $(1,0)$ & $(100,0)$ & $(0,2)$ \\
\hline \multirow{2}{*}{2007} & 1.004 .166 & 9.639 & 306.682 & 619 \\
& $(100,0)$ & $(1,0)$ & $(100,0)$ & $(0,2)$ \\
\hline \multirow{2}{*}{2006} & 966.491 & 8.968 & 298.619 & 563 \\
& $(100,0)$ & $(0,9)$ & $(100,0)$ & $(0,2)$ \\
\hline
\end{tabular}

Fonte: RAIS - MTE.

Tanto indústria como serviços de tecnologias da informação têm uma baixa participação em termos de números de firmas nos grandes setores que participam respectivamente, setor industrial e de serviços. Cabe destacar que a participação do segmento de serviços de TI vem aumentando no período analisado. Isso se reflete, como se identifica no gráfico abaixo, no movimento ascendente e nas maiores taxas de crescimento anual no número de estabelecimentos desse segmento se comparadas às encontradas nos grandes setores ou mesmo à indústria de TI.

\section{Gráfico 2 - Taxa de Crescimento Anual do No. de Estabelecimentos - Brasil.}

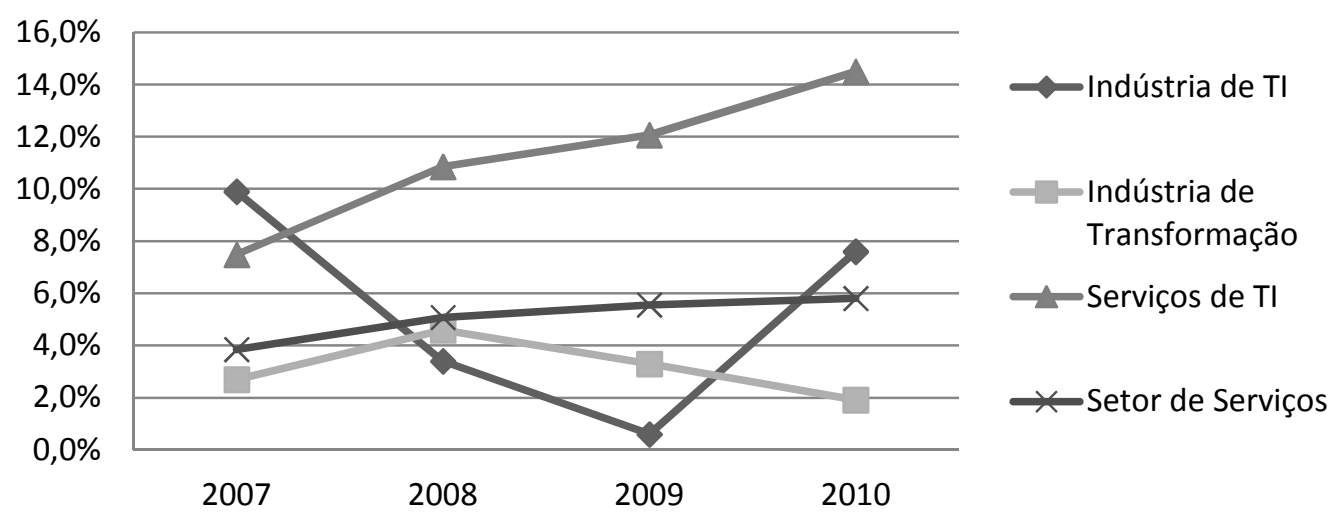

Fonte: RAIS - MTE. 
O segmento de serviços de tecnologia da informação permaneceu, em todo período, com exceção de 2007, com as maiores taxas de crescimento e numa trajetória crescente, refletindo, portanto, o crescimento constante da sua participação no setor de serviços. Por outro lado, a indústria de tecnologia inicia o período com uma trajetória de queda, recuperando-se somente em 2010. Em contraste, o setor industrial inicia o período com alta na sua taxa e finaliza com uma trajetória de queda; sendo que, a indústria de transformação a partir de 2008 apresenta uma trajetória de queda nas suas taxas, explicando porque a participação do número de estabelecimentos da indústria de TI permaneceu constante ao longo do período.

Se a participação dos números de estabelecimentos do setor de TI é pequena em relação aos grandes setores; o que é possível observar com relação ao número de vínculos de trabalho demandado?

Tabela 6 - Participação do No. de Vínculos de Trabalho por Estabelecimentos de TI nos Grandes Setores - Brasil.

\begin{tabular}{c|c|c|c|c}
\hline & $\begin{array}{c}\text { Setor de } \\
\text { Serviços }\end{array}$ & Serviços de TI & $\begin{array}{c}\text { Indústria de } \\
\text { Transformação }\end{array}$ & $\begin{array}{c}\text { Indústria de } \\
\text { TI }\end{array}$ \\
\hline \multirow{2}{*}{$\mathbf{2 0 1 0}$} & 22.329 .256 & 396.450 & 11.790 .367 & 46.318 \\
& $(100,0)$ & $(1,8)$ & $(100,0)$ & $(0,5)$ \\
\hline \multirow{2}{*}{2009} & 20.188 .554 & 334.276 & 11.014 .841 & 58.955 \\
& $(100,0)$ & $(1,7)$ & $(100,0)$ & $(0,6)$ \\
\hline \multirow{2}{*}{2008} & 19.562 .291 & 310.665 & 11.231 .676 & 64.587 \\
& $(100,0)$ & $(1,6)$ & $(100,0)$ & $(0,6)$ \\
\hline \multirow{2}{*}{2007} & 17.918 .553 & 253.026 & 10.374 .075 & 58.960 \\
& $(100,0)$ & $(1,4)$ & $(100,0)$ & $(0,5)$ \\
\hline \multirow{2}{*}{2006} & 16.688 .137 & 241.164 & 9.533 .565 & 68.750 \\
& $(100,0)$ & $(1,4)$ & $(100,0)$ & $(0,6)$ \\
\hline
\end{tabular}

Fonte: RAIS - MTE.

Assim como no caso do número de estabelecimentos, a participação da quantidade de vínculos de trabalho demandado pelos segmentos de TI é percentualmente baixa. Os serviços de TI apresentaram uma trajetória de crescimento na sua participação entre 2006 e 2010, mas a participação da indústria de tecnologia da informação permaneceu praticamente a mesma. Vejamos se esses movimentos também têm relação com as taxas de crescimento anual de vínculos de trabalho. 
Gráfico 3 - Taxa de Crescimento Anual dos Vínculos de Trabalho por Segmentos de TI e Grandes Setores - Brasil.

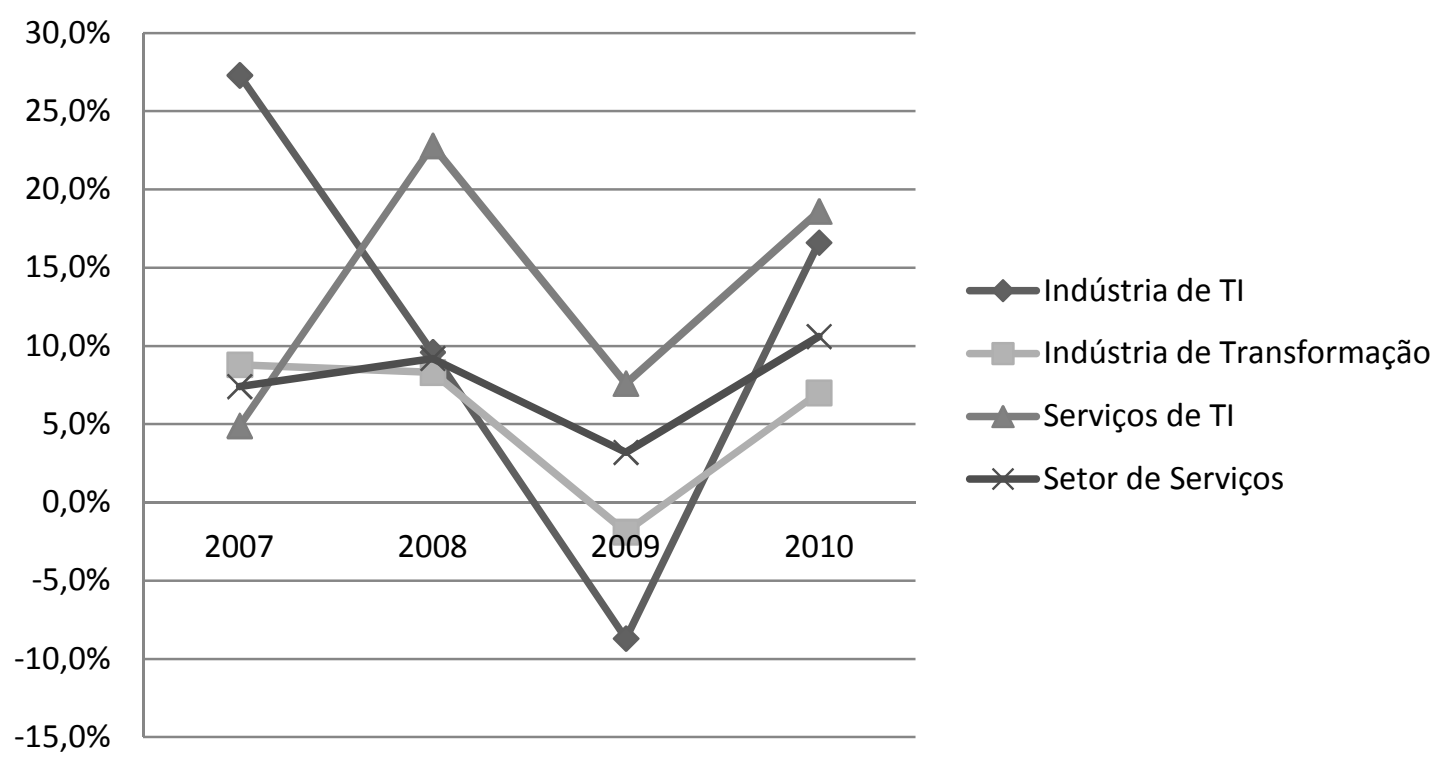

Fonte: RAIS - MTE.

A trajetória de crescimento da participação da demanda do segmento de serviços de TI no grande setor pode ser relacionada ao fato de suas taxas de crescimento, apesar de instáveis durante o período, serem maiores das que as registradas no setor de serviços. Já na indústria de $\mathrm{TI}$, constata-se uma trajetória de queda, tal como na indústria de transformação, apesar de nessa última tal trajetória ter sido menos intensa.

A base RAIS fornece poucas informações que dizem respeito à caracterização econômica da firma, centrando seus dados sobre as características da força-de-trabalho e dos vínculos. Todavia, é possível extrair uma descrição sobre o tamanho dos estabelecimentos e sua composição na demanda de trabalho. 


\section{Gráfico 4 - Distribuição de Estabelecimentos por Faixa de Vínculos de Trabalho - Brasil, 2010.}

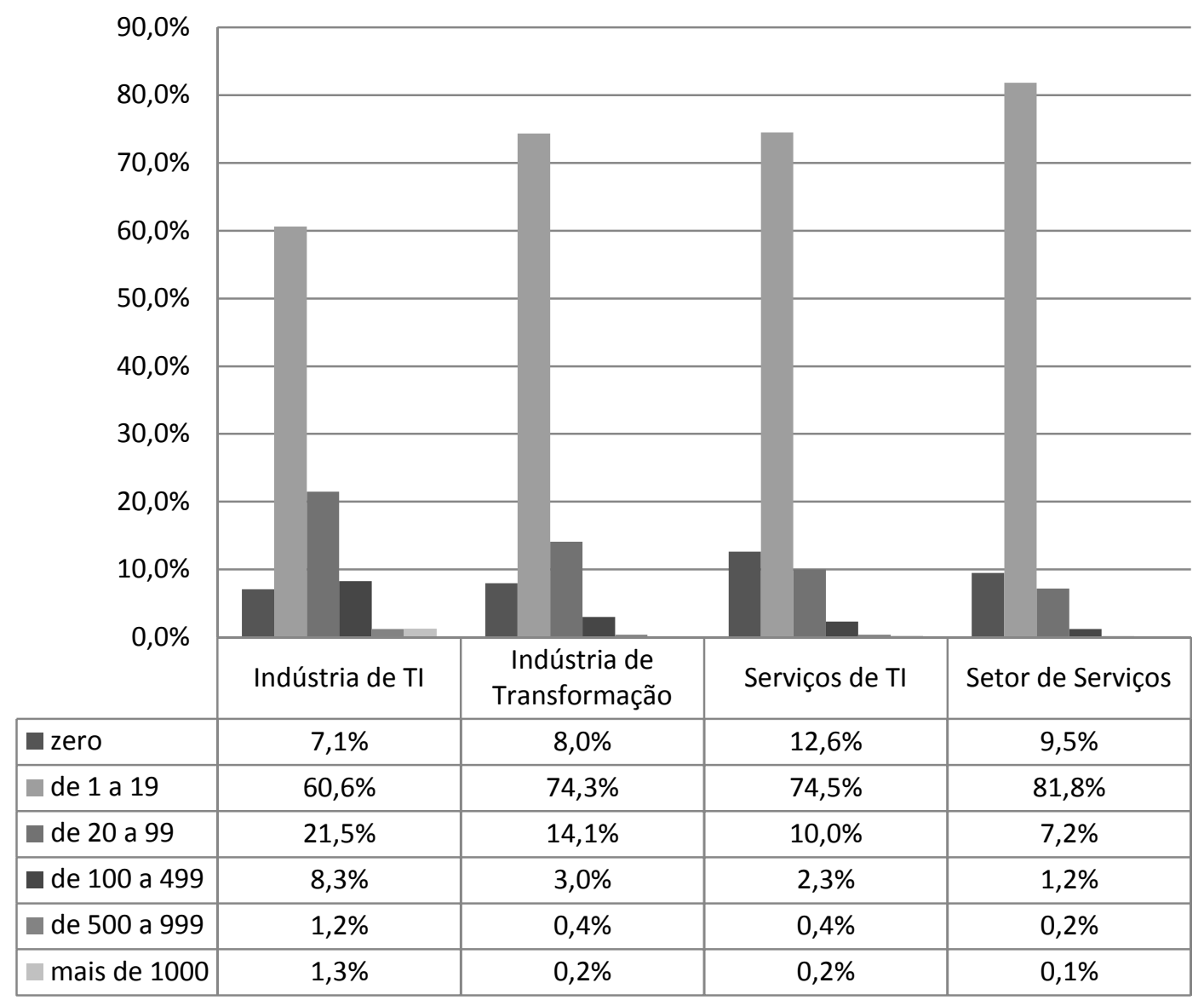

Fonte: RAIS - MTE.

Em ambos grandes setores e nos dois segmentos de TI, a maior parte dos estabelecimentos declarou ter entre 1 a 19 vínculos de trabalho. Também de maneira geral, segmentos e setores apresentam um predomínio de estabelecimentos de pequeno porte.

Essa maior concentração de estabelecimentos nas faixas com menores números de vínculos de trabalho se reflete na presença de uma maior concentração dos vínculos nesse tipo de estabelecimentos? 


\section{Gráfico 5 - Distribuição dos Vínculos de Trabalho por Tamanho de Estabelecimentos - Brasil, 2010.}

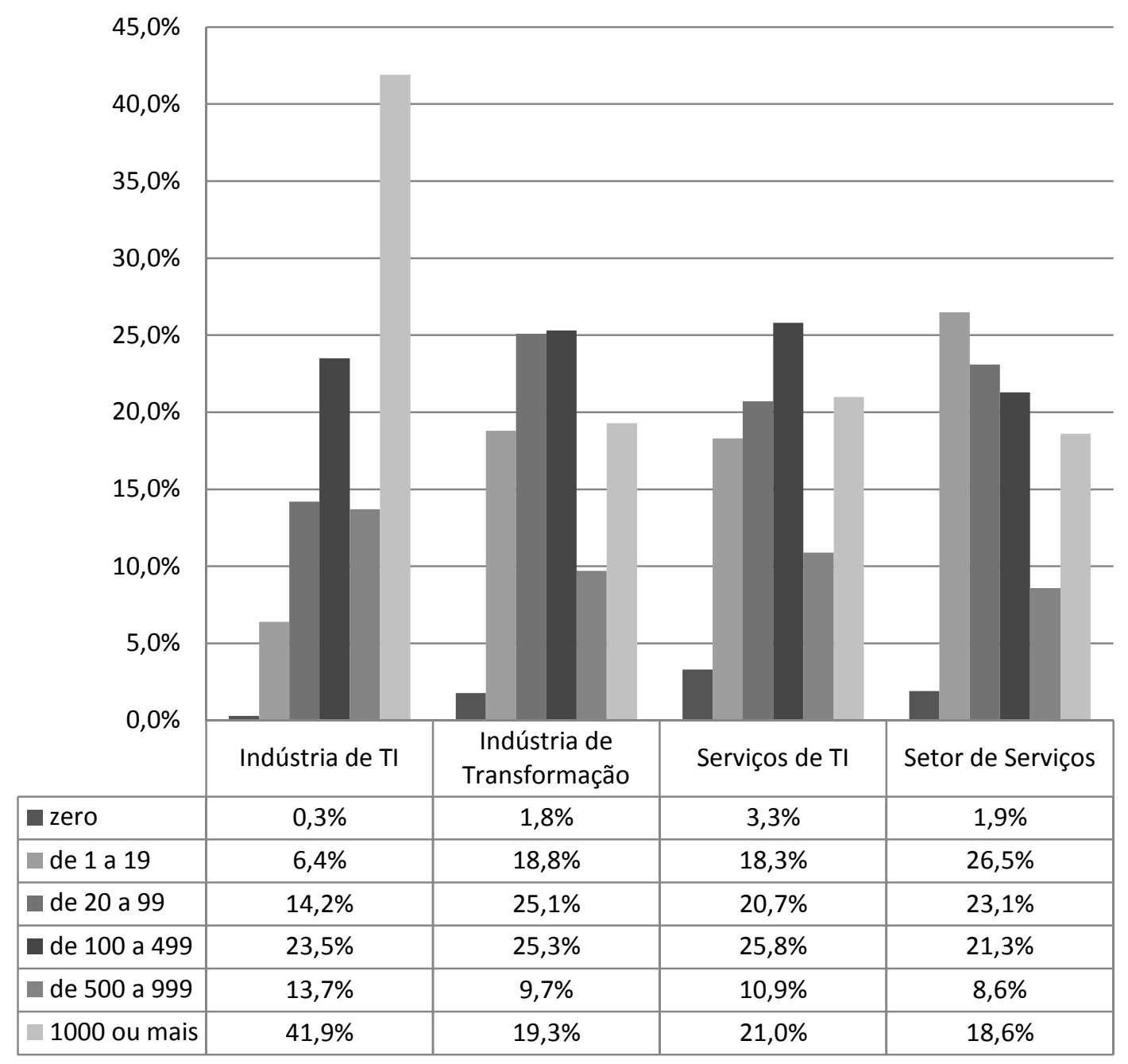

Fonte: RAIS - MTE.

O gráfico acima subsidia que a resposta é sim e não. A maior concentração de estabelecimentos nas menores faixas de números de vínculos (Gráfico 4), não foi suficiente para garantir que, no segmento de Indústria de TI, uma maior participação dos vínculos de trabalho nos menores estabelecimentos; em contraste, nos serviços de TI há uma distribuição quase uniforme entre estabelecimentos de diferentes tamanhos.

Até aqui foi caracterizada a demanda de trabalho em TI pelo tamanho das firmas, o que se pode observar a respeito dos vínculos nessa demanda? Cabe destacar que, a quase totalidade dos vínculos é CLT: na indústria de TI, eles representaram 99,99\% dos vínculos de trabalho em 2010 e nos de serviços de tecnologia de TI foram registrados $99,82 \%$. O que, então, é possível verificar sobre a duração desses vínculos? 


\section{Gráfico 6 - Distribuição dos Vínculos por Faixa de Tempo em \\ Meses - Brasil, 2010.}

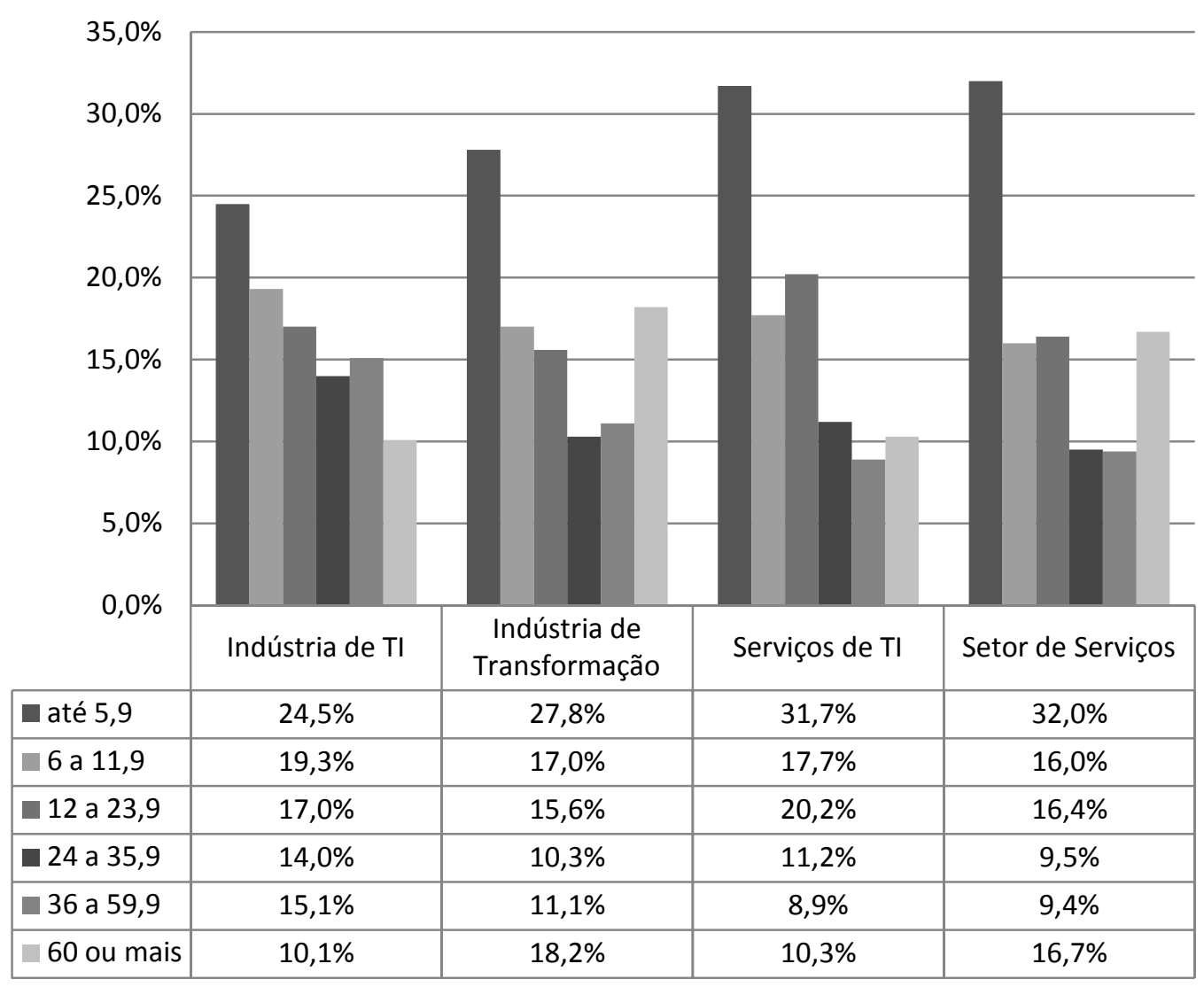

Fonte: RAIS - MTE.

Nos segmentos de TI existe uma tendência clara de diminuição do número de vínculos conforme a duração; porém, não há diferenças percentuais pronunciadas se compararmos aos respectivos grandes setores. Entretanto, considerando as médias de duração dos vínculos, a diferença entre segmentos de TI e setores é mais evidente:

Tabela 7 - Média de tempo em meses dos vínculos de trabalho - Brasil.

\begin{tabular}{c|c|c|c|c}
\hline & Serviços de TI & $\begin{array}{c}\text { Setor de } \\
\text { Serviços }\end{array}$ & $\begin{array}{c}\text { Indústria de } \\
\text { TI }\end{array}$ & $\begin{array}{c}\text { Indústria de } \\
\text { Transformação }\end{array}$ \\
\hline $\mathbf{2 0 1 0}$ & 28,8 & 34,9 & 25,6 & 36 \\
\hline $\mathbf{2 0 0 9}$ & 31,1 & 36,8 & 25,5 & 37,3 \\
\hline $\mathbf{2 0 0 8}$ & 31,9 & 37,8 & 22,8 & 37,5 \\
\hline $\mathbf{2 0 0 7}$ & 33,2 & 39,9 & 23,4 & 38,4 \\
\hline $\mathbf{2 0 0 6}$ & 35 & 40,7 & 25,9 & 39,7 \\
\hline
\end{tabular}

Fonte: RAIS - MTE.

As empresas de tecnologias da informação apresentam médias de tempo de vínculo tradicionalmente menores das registradas nos seus respectivos setores. Isso pode indicar que a "ida" das empresas de TI ao mercado de trabalho tem sido mais 
recorrente do que a de outras empresas do setor de serviços ou industrial. Apesar dessa diferença, as taxas anuais de não desligados são similares:

Tabela 8 - Participação (\%) de Vínculos Não Desligados - Brasil.

\begin{tabular}{c|c|c|c|c}
\hline & Serviços de TI & $\begin{array}{c}\text { Setor de } \\
\text { Serviços }\end{array}$ & $\begin{array}{c}\text { Indústria de } \\
\text { TI }\end{array}$ & $\begin{array}{c}\text { Indústria de } \\
\text { Transformação }\end{array}$ \\
\hline $\mathbf{2 0 1 0}$ & 64,5 & 64,1 & 69,0 & 67,7 \\
\hline $\mathbf{2 0 0 9}$ & 67,1 & 65,6 & 68,8 & 68,8 \\
\hline $\mathbf{2 0 0 8}$ & 63,1 & 64,3 & 62,9 & 65,1 \\
\hline $\mathbf{2 0 0 7}$ & 67,8 & 66,6 & 67,3 & 68,3 \\
\hline $\mathbf{2 0 0 6}$ & 65,8 & 67,3 & 71,5 & 69,2 \\
\hline
\end{tabular}

Fonte: RAIS - MTE.

Não somente não há diferenças significativas nas taxas constantes na tabela acima, mas também, ao longo do período, não se identifica grandes variações. Esse aparente paradoxo (demanda mais intensa das firmas de TI no mercado de trabalho com taxas estáveis e semelhantes aos setores de serviço e indústria de transformação) podem ser explicados pelo fato de que a média de duração dos vínculos é superior a 12 meses. Portanto, se o percentual de não desligados é anual, é possível que a maior frequência ou intensidade da demanda das firmas de TI vis-à-vis seus respectivos setores, não seja apreensível através desses dados.

Todavia, a hipótese de segmentos de TI possuírem uma demanda mais intensa no mercado de trabalho, pode ser reforçada se analisarmos as médias do valor nominal dos salários.

\section{Gráfico 7 - Valor Nominal Médio de Salários - Brasil.}

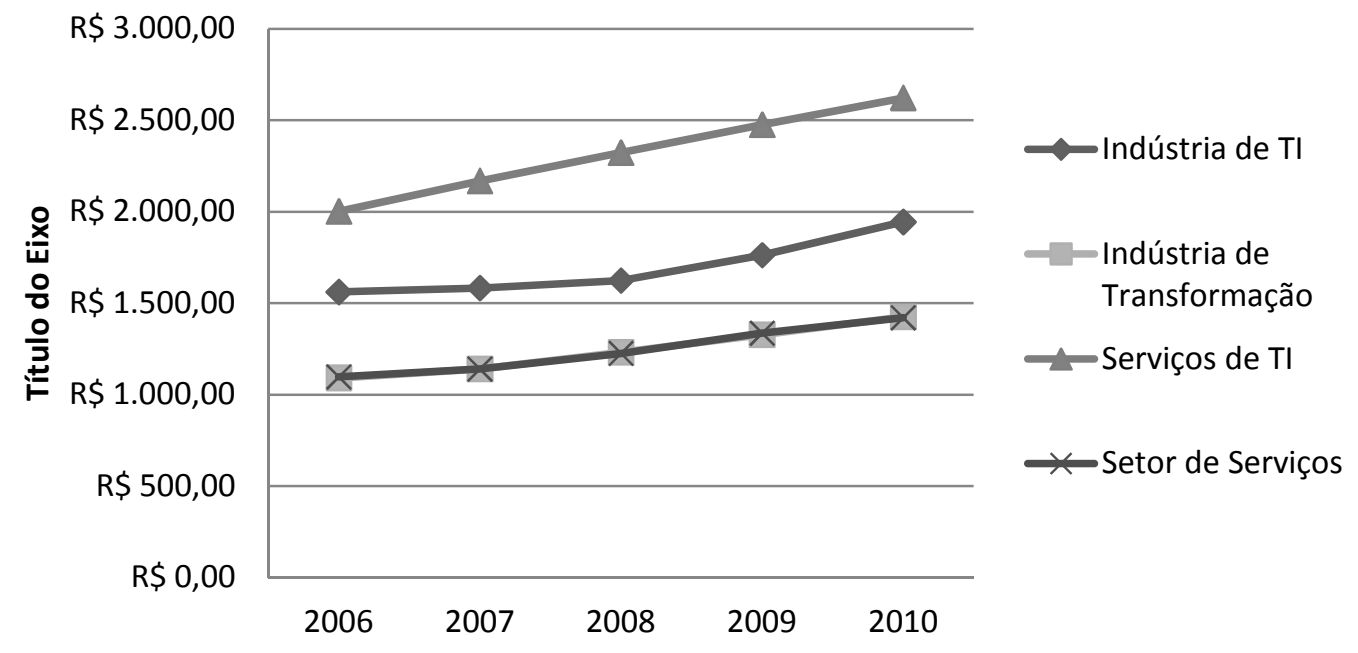

Fonte: RAIS - MTE. 
Em média, as empresas de TI oferecem salários maiores que os observados nos seus respectivos grandes setores, destacando nessa diferença o segmento de serviços de tecnologia da informação. Ademais, podemos observar uma tendência de crescimento nas médias salariais ao longo do período analisado. Pensamos que, a oferta de salários médios maiores pode apontar para a necessidade, consistente com uma demanda mais intensa, de atrair e contratar proporcionalmente mais trabalhadores.

O que, então, é possível concluir sobre as características da força de trabalho que está sendo demandada? Por exemplo, a maior intensidade de demanda dos segmentos de TI se reflete em um aumento da participação das mulheres?

Tabela 9 - Participação (\%) Feminina nos Vínculos de Trabalho Demandados - Brasil.

\begin{tabular}{c|c|c|c|c}
\hline & Serviços de TI & $\begin{array}{c}\text { Setor de } \\
\text { Serviços }\end{array}$ & $\begin{array}{c}\text { Indústria de } \\
\text { TI }\end{array}$ & $\begin{array}{c}\text { Indústria de } \\
\text { Transformação }\end{array}$ \\
\hline $\mathbf{2 0 1 0}$ & 36,4 & 45,4 & 44,3 & 31,0 \\
\hline $\mathbf{2 0 0 9}$ & 37,6 & 45,1 & 42,5 & 30,4 \\
\hline $\mathbf{2 0 0 8}$ & 38,2 & 44,4 & 43,4 & 29,8 \\
\hline $\mathbf{2 0 0 7}$ & 38,6 & 44,1 & 41,3 & 29,2 \\
\hline $\mathbf{2 0 0 6}$ & 40,3 & 43,8 & 40,8 & 29,1 \\
\hline
\end{tabular}

Fonte: RAIS - MTE.

Com exceção do segmento de serviços de TI, todos apresentaram aumento da participação feminina. Portanto, se não há diferenças nesse sentido entre indústria de TI e setor da indústria de transformação e o fato do segmento de serviços de TI registrar decréscimo da participação feminina, pode-se cogitar que essa participação depende de outros elementos e não da intensidade da demanda das firmas no mercado de trabalho.

Existem diferenças sobre quais faixas etárias os vínculos estão mais concentrados? 
Gráfico 8 - \% de Vínculos por Faixa Etária - Brasil, 2010.

\begin{tabular}{|c|c|c|c|c|}
\hline \multicolumn{5}{|l|}{$60,0 \%$} \\
\hline \\
\hline & & & & \\
\hline \multicolumn{5}{|l|}{$30,0 \%$} \\
\hline \multicolumn{5}{|l|}{$20,0 \%$} \\
\hline \multicolumn{5}{|l|}{$10,0 \%$} \\
\hline & & & & \\
\hline & Indústria de TI & $\begin{array}{l}\text { Indústria de } \\
\text { Transformação }\end{array}$ & Serviços de TI & Setor de Serviços \\
\hline$\square 10$ a 17 & $0,9 \%$ & $1,2 \%$ & $0,4 \%$ & $1,1 \%$ \\
\hline 18 a 29 & $54,4 \%$ & $44,6 \%$ & $53,6 \%$ & $40,5 \%$ \\
\hline 30 a 39 & $31,0 \%$ & $28,9 \%$ & $28,6 \%$ & $29,4 \%$ \\
\hline 40 a 49 & $10,8 \%$ & $17,1 \%$ & $11,2 \%$ & $18,3 \%$ \\
\hline 50 ou mais & $2,9 \%$ & $8,2 \%$ & $6,2 \%$ & $10,7 \%$ \\
\hline
\end{tabular}

Fonte: RAIS - MTE.

Comparando com os grandes setores, os segmentos de tecnologia da informação registram maiores concentrações nas faixas etárias mais jovens a partir dos 18 anos. Entretanto, todos apresentam maiores percentagens de vínculos de trabalho na faixa etária entre 18 e 29 anos.

Outro elemento importante para caracterizar a demanda de trabalho das firmas de TI diz respeito ao nível de escolaridade da força-de-trabalho contratada. Em entrevistas realizadas com representantes de organizações do setor de tecnologia da informação, todos mencionaram as dificuldades de se encontrar pessoas qualificadas no mercado de trabalho. Mesmo sendo verdadeira ou não essa escassez, essa percepção indica um demanda no segmento de TI que valoriza, entre outros aspectos, o nível de escolaridade. Assim, espera-se que na comparação com os grandes setores, os segmentos de TI apresentem maiores concentrações de vínculos nas faixas de maior escolaridade. 
Gráfico 9 - \% de Vínculos por Escolaridade - Brasil, 2010.

\begin{tabular}{|c|c|c|c|c|}
\hline \multirow{2}{*}{$80,0 \%$} & \\
\hline & \multicolumn{4}{|c|}{$70,0 \%$} \\
\hline \multicolumn{5}{|l|}{$60,0 \%$} \\
\hline \multicolumn{5}{|l|}{$50,0 \%$} \\
\hline \multicolumn{5}{|l|}{$40,0 \%$} \\
\hline $30,0 \%$ & & & & \\
\hline $20,0 \%$ & & & & \\
\hline $10,0 \%$ & & & & E \\
\hline $0,0 \%$ & Indústria de $\mathrm{TI}$ & $\begin{array}{l}\text { Indústria de } \\
\text { Transformação }\end{array}$ & Serviços de TI & $\begin{array}{l}\text { Setor de } \\
\text { Serviços }\end{array}$ \\
\hline Analfabeto & $0,1 \%$ & $0,8 \%$ & $0,0 \%$ & $0,3 \%$ \\
\hline Fundamental Incompleto & $1,8 \%$ & $21,1 \%$ & $1,3 \%$ & $12,4 \%$ \\
\hline Fundamental Completo & $2,8 \%$ & $15,9 \%$ & $1,9 \%$ & $12,6 \%$ \\
\hline Médio Incompleto & $4,7 \%$ & $11,1 \%$ & $2,4 \%$ & $7,9 \%$ \\
\hline Médio Completo & $68,1 \%$ & $41,5 \%$ & $32,2 \%$ & $44,9 \%$ \\
\hline Superior Incompleto & $7,7 \%$ & $3,3 \%$ & $16,4 \%$ & $5,4 \%$ \\
\hline Superior Completo & $14,8 \%$ & $6,3 \%$ & $45,8 \%$ & $16,5 \%$ \\
\hline
\end{tabular}

Fonte: RAIS - MTE.

Com exceção dos serviços de TI, todos registraram maior concentração dos vínculos de trabalho no nível de escolaridade "Médio Completo". Pode-se cogitar que a particularidade do caso dos serviços de tecnologia da informação está relacionada aos níveis mais altos de médias salariais ao longo do período de 2006 a 2010 (Gráfico 7). Mas nas respectivas comparações com os grandes setores, ambos os segmentos de tecnologia da informação registram maiores concentrações de vínculos nas faixas de escolaridade mais altas. Tal fato é consistente com a percepção de escassez dos entrevistados e pode ser reforçado observando nas tabelas abaixo, a evolução da participação da faixa de escolaridade "Superior Completo" e "Médio Completo" ao longo de 2006 a 2010. 
Tabela 10 - \% de Vínculos de Trabalho Demandados com Curso Superior Completo - Brasil.

\begin{tabular}{c|c|c|c|c}
\hline & Serviços de TI & $\begin{array}{c}\text { Setor de } \\
\text { Serviços }\end{array}$ & $\begin{array}{c}\text { Indústria de } \\
\text { TI }\end{array}$ & $\begin{array}{c}\text { Indústria de } \\
\text { Transformação }\end{array}$ \\
\hline $\mathbf{2 0 1 0}$ & $45,8 \%$ & $16,5 \%$ & $14,8 \%$ & $6,3 \%$ \\
\hline $\mathbf{2 0 0 9}$ & $40,4 \%$ & $16,4 \%$ & $13,1 \%$ & $5,9 \%$ \\
\hline $\mathbf{2 0 0 8}$ & $38,7 \%$ & $15,8 \%$ & $12,4 \%$ & $5,6 \%$ \\
\hline $\mathbf{2 0 0 7}$ & $38,8 \%$ & $15,5 \%$ & $14 \%$ & $5,4 \%$ \\
\hline $\mathbf{2 0 0 6}$ & $35,9 \%$ & $15,4 \%$ & $14 \%$ & $5,3 \%$ \\
\hline
\end{tabular}

Fonte: RAIS - MTE.

Tabela 11 - \% de Vínculos de Trabalho Demandados com Ensino Médio Completo - Brasil.

\begin{tabular}{c|c|c|c|c}
\hline & Serviços de TI & $\begin{array}{c}\text { Setor de } \\
\text { Serviços }\end{array}$ & $\begin{array}{c}\text { Indústria de } \\
\text { TI }\end{array}$ & $\begin{array}{c}\text { Indústria de } \\
\text { Transformação }\end{array}$ \\
\hline $\mathbf{2 0 1 0}$ & $32,2 \%$ & $45 \%$ & $68,1 \%$ & $41,6 \%$ \\
\hline $\mathbf{2 0 0 9}$ & $34,2 \%$ & $43 \%$ & $68,2 \%$ & $39,2 \%$ \\
\hline $\mathbf{2 0 0 8}$ & $32,9 \%$ & $41,7 \%$ & $70 \%$ & $37,2 \%$ \\
\hline $\mathbf{2 0 0 7}$ & $35,6 \%$ & $40,1 \%$ & $66,9 \%$ & $34,8 \%$ \\
\hline $\mathbf{2 0 0 6}$ & $38,1 \%$ & $38,1 \%$ & $65,1 \%$ & $32,4 \%$ \\
\hline
\end{tabular}

Fonte: RAIS - MTE.

Nos vínculos com curso superior completo, constata-se que não somente o segmento de serviços de TI apresenta as maiores percentagens como também houve um aumento significativo da participação desse tipo de vínculo. Além disso, comparando com o setor da indústria de transformação, o segmento de indústria de TI registrou percentuais significativamente maiores de vínculos com curso superior.

A intensidade da demanda do segmento de serviços de TI por vínculos com curso superior completo foi de tal ordem que se registrou uma diminuição da participação dos vínculos com ensino médio completo. A prevalência pela demanda de vínculos com ensino médio completo é observada na indústria de TI, registrando percentuais maiores aos da indústria de transformação. Em suma, é possível concluir que a demanda de segmentos de TI tem privilegiado cada vez mais o nível de escolaridade. Essa preferência pode ser notada através das médias salariais? 


\section{Gráfico 10 - Valor Médio do Salário Nominal para Trabalhadores} com Curso Superior Completo - Brasil.

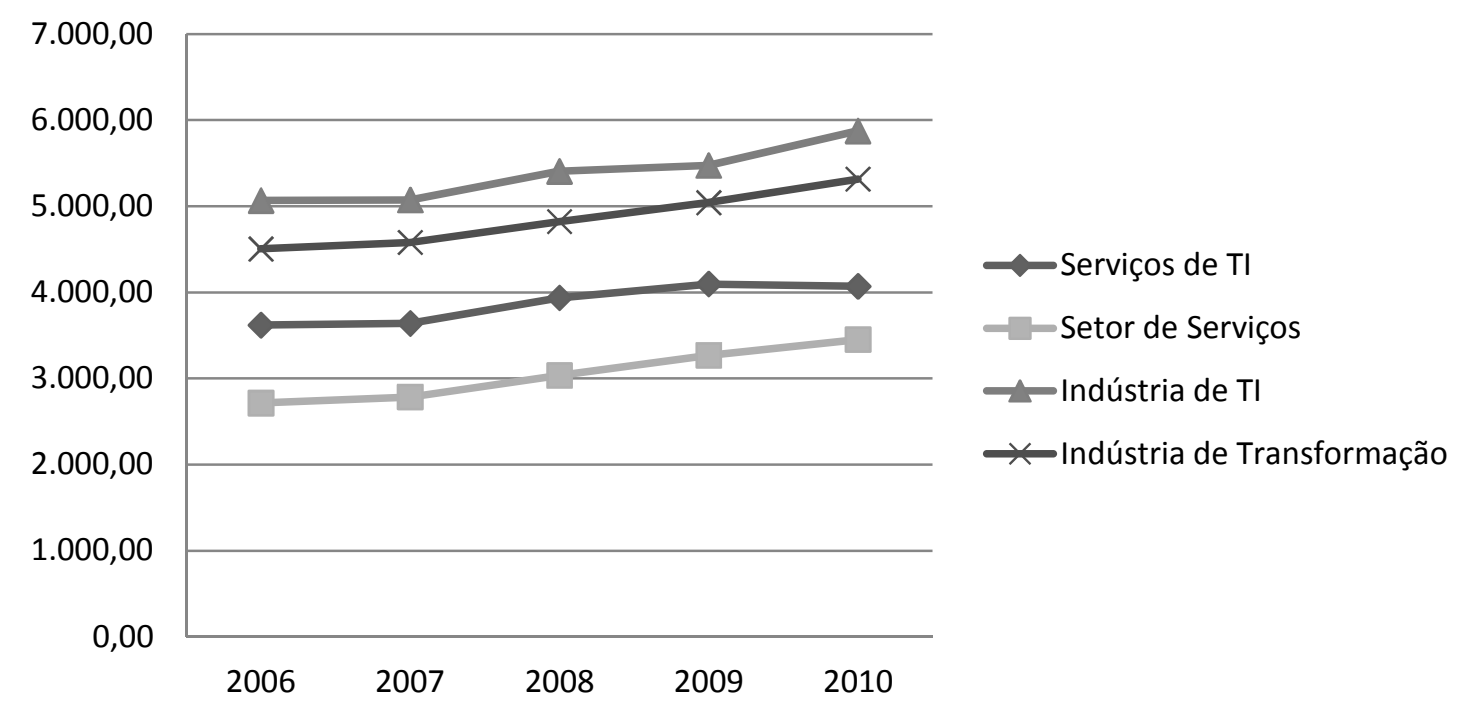

Fonte: RAIS - MTE.

\section{Gráfico 11 - Valor Médio do Salário Nominal para Trabalhadores com Ensino Medio Completo - Brasil.}

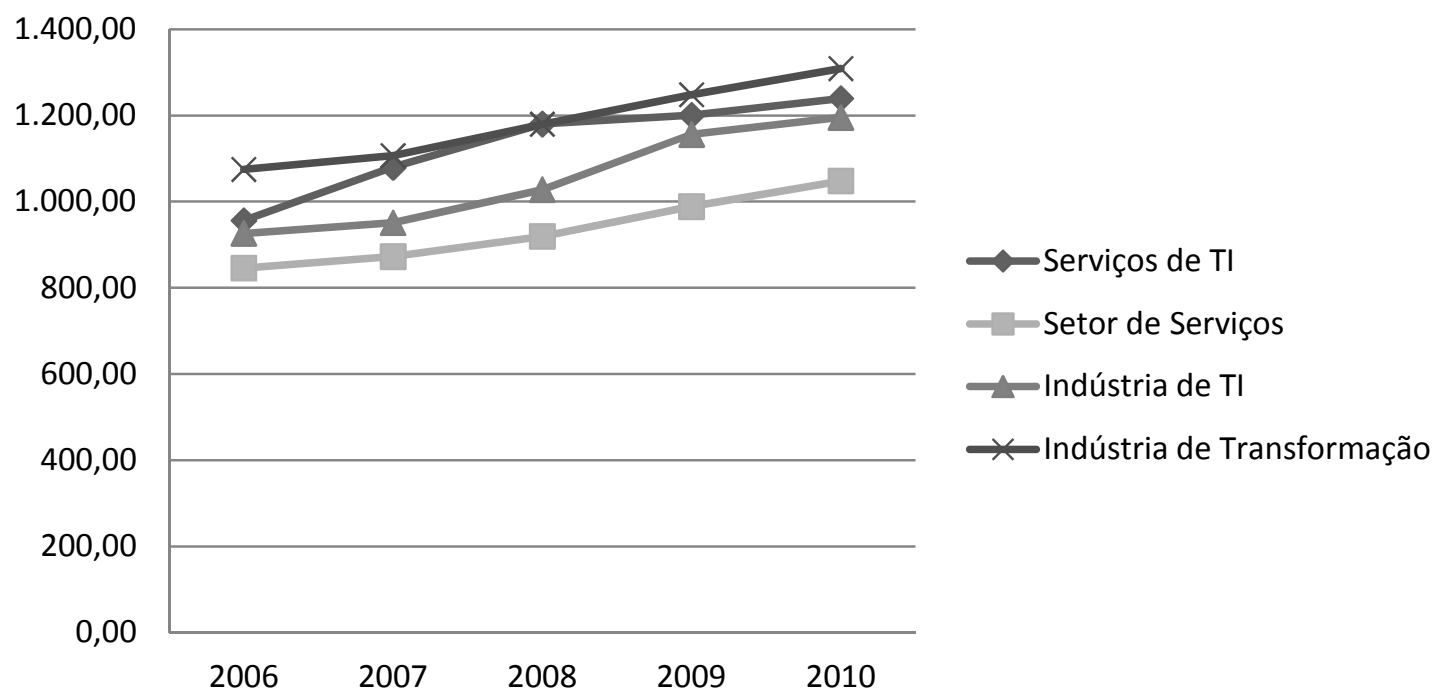

Fonte: RAIS - MTE.

Para os com ensino superior completo, ambos os segmentos de tecnologia da informação registram médias superiores aos seus respectivos setores - fato coerente com nossa hipótese de valorização da escolaridade na demanda das firmas de TI. Porém, se os serviços de TI apresentaram a maior demanda de vínculos com curso superior completo, as médias salariais estão abaixo do setor da indústria de transformação e da indústria de TI. Destaca-se, ainda, que as médias salariais para curso 
superior no setor de serviços de TI praticamente estabilizaram-se entre 2008 e 2010. Isso pode indicar que esse segmento chegou a certo limite na sua demanda por trabalhadores com esse nível de escolaridade.

No caso do ensino médio completo, cabe destacar a menor diferença nas médias salariais entre segmentos de TI e os setores econômicos. Observa-se que a Indústria de transformação apresenta um crescimento mais intenso, fazendo com que as suas médias salariais ultrapassem os demais. Constata-se que a indústria de TI, analogamente ao que se observou para a demanda por vínculos de curso superior nos serviços de TI, entre 2008 e 2010, tem suas médias estabilizadas. Assim, cabe cogitar que essas estabilizações de médias salariais nos segmentos de TI podem estar contribuindo para a mencionada percepção de escassez de trabalhadores com qualificação e escolaridade desejada, uma vez que a oferta de salários maiores pode transferir mão de obra para outros setores.

As características do contexto e do comportamento da demanda das firmas de TI no estado do Rio Grande do Sul (RS), onde foram realizados os estudos de caso desta tese, têm diferenças ou similitudes com o que foi visto no nível nacional? Antes de responder essa pergunta, cabe verificar o peso do setor de TI gaúcho em relação ao nacional.

Tabela 12 - Participação do No. de Estabelecimentos de TI do RS no Setor de TI Brasileiro.

\begin{tabular}{c|c|c|c|c}
\hline & STI-BR & STI-RS & ITI-BR & ITI-RS \\
\hline \multirow{2}{*}{2010} & 13.711 & 1.032 & 693 & 52 \\
& $(100 \%)$ & $(7,5 \%)$ & $(100 \%)$ & $(7,5 \%)$ \\
\hline \multirow{2}{*}{2009} & 11.975 & 870 & 644 & 48 \\
& $(100 \%)$ & $(7,3 \%)$ & $(100 \%)$ & $(7,5 \%)$ \\
\hline \multirow{2}{*}{2008} & 10.685 & 743 & 640 & 49 \\
& $(100 \%)$ & $(7 \%)$ & $(100 \%)$ & $(7,7 \%)$ \\
\hline \multirow{2}{*}{2007} & 9.639 & 701 & 619 & 44 \\
& $(100 \%)$ & $(7,3 \%)$ & $(100 \%)$ & $(7,1 \%)$ \\
\hline \multirow{2}{*}{2006} & 8.968 & 697 & 563 & 41 \\
& $(100 \%)$ & $(7,8 \%)$ & $(100 \%)$ & $(7,3 \%)$ \\
\hline
\end{tabular}

Fonte: RAIS - MTE.

No número de estabelecimentos, nota-se uma pequena, porém significativa participação do RS nos segmentos de TI do Brasil. Essa participação permaneceu praticamente estável ao longo do período. Qual é, então, essa participação do ponto de vista dos vínculos de trabalho demandados? 
Tabela 13 - Participação do No. de Vínculos de Trabalho Demandados em Estabelecimentos de TI do RS no Setor de TI Brasileiro.

\begin{tabular}{c|r|r|r|r}
\hline & STI-BR & STI-RS & ITI-BR & ITI-RS \\
\hline \multirow{2}{*}{2010} & 396.450 & 16.163 & 68.750 & 4.445 \\
& $(100 \%)$ & $(4,1 \%)$ & $(100 \%)$ & $(6,5 \%)$ \\
\hline \multirow{2}{*}{2009} & 334.276 & 12.195 & 58.960 & 3.787 \\
& $(100 \%)$ & $(3,6 \%)$ & $(100 \%)$ & $(6,4 \%)$ \\
\hline \multirow{2}{*}{2008} & 310.665 & 10.936 & 64.587 & 3.493 \\
& $(100 \%)$ & $(3,5 \%)$ & $(100 \%)$ & $(5,4 \%)$ \\
\hline \multirow{2}{*}{2007} & 253.026 & 9.329 & 58.955 & 3.146 \\
& $(100 \%)$ & $(3,7 \%)$ & $(100 \%)$ & $(5,3 \%)$ \\
\hline \multirow{2}{*}{2006} & 241.164 & 7.783 & 46.318 & 2.939 \\
& $(100 \%)$ & $(3,2 \%)$ & $(100 \%)$ & $(6,3 \%)$ \\
\hline
\end{tabular}

Fonte: RAIS - MTE.

Observa-se que percentualmente a participação dos segmentos de TI gaúchos em vínculos de trabalho demandados é menor do que a participação do número de estabelecimentos. Isso pode estar relacionado ao fato, registrado no gráfico abaixo, do RS apresentar percentuais mais altos no número de estabelecimentos de menor porte.

\section{Gráfico 12 - \% de Vínculos de Trabalho por Tamanho de Estabelecimentos - BR e RS, 2010.}

\begin{tabular}{|c|c|c|c|c|}
\hline \multicolumn{5}{|l|}{$50,0 \%$} \\
\hline \multicolumn{5}{|l|}{$45,0 \%$} \\
\hline \multicolumn{5}{|l|}{$40,0 \%$} \\
\hline \multicolumn{5}{|l|}{$35,0 \%$} \\
\hline \multicolumn{4}{|l|}{$30,0 \%$} & \\
\hline \multicolumn{5}{|l|}{$25,0 \%$} \\
\hline \multicolumn{5}{|l|}{$20,0 \%$} \\
\hline \multicolumn{5}{|l|}{$15,0 \%$} \\
\hline \multicolumn{5}{|l|}{$10,0 \%$} \\
\hline \multicolumn{5}{|l|}{$5,0 \%$} \\
\hline $0,0 \%$ & ITI-BR & ITI-RS & STI-BR & STI-RS \\
\hline zero & $0,3 \%$ & $0,1 \%$ & $3,3 \%$ & $3,4 \%$ \\
\hline de 1 a 19 & $6,4 \%$ & $9,8 \%$ & $18,3 \%$ & $31,8 \%$ \\
\hline de 20 a 99 & $14,2 \%$ & $6,3 \%$ & $20,7 \%$ & $31,8 \%$ \\
\hline de 100 a 499 & $23,5 \%$ & $7,9 \%$ & $25,8 \%$ & $29,3 \%$ \\
\hline de 500 a 999 & $13,7 \%$ & $30,6 \%$ & $10,9 \%$ & $3,7 \%$ \\
\hline 1000 ou mais & $41,9 \%$ & $45,3 \%$ & $21,0 \%$ & $0,0 \%$ \\
\hline
\end{tabular}

Fonte: RAIS - MTE. 
A explicação da menor participação do RS no setor de TI brasileiro em função do menor tamanho dos estabelecimentos gaúchos é reforçada quando se verifica a média de vínculos ativos ${ }^{53}$ por estabelecimentos.

Tabela 14 - Média do No. de Vínculos Ativos por Estabelecimentos de TI BR e RS.

\begin{tabular}{c|c|c|c|c}
\hline & STI-BR & STI-RS & ITI-BR & ITI-RS \\
\hline $\mathbf{2 0 1 0}$ & 19 & 11 & 69 & 66 \\
\hline $\mathbf{2 0 0 9}$ & 19 & 10 & 63 & 59 \\
\hline $\mathbf{2 0 0 8}$ & 18 & 10 & 64 & 53 \\
\hline $\mathbf{2 0 0 7}$ & 18 & 9 & 64 & 54 \\
\hline $\mathbf{2 0 0 6}$ & 18 & 8 & 59 & 53 \\
\hline
\end{tabular}

Fonte: RAIS - MTE.

As médias de número de vínculos são menores no RS daquelas registradas no Brasil; porém, essas diferenças são pequenas, não passando de 10. Assim sendo, é possível afirmar que no segmento da indústria de TI gaúcha, a maior parte da demanda está a cargo de empresas de grande porte (500 vínculos ou mais) e, no segmento de serviços de tecnologia da informação, há maior participação dos estabelecimentos de pequeno e médio porte.

A duração dos vínculos pode ajudar na explicação sobre a menor participação do RS em termos de vínculos vis-à-vis ao número de seus estabelecimentos no setor de TI brasileiro, pois uma maior duração dos vínculos pode apontar para uma menor necessidade de a firma demandar no mercado de trabalho.

${ }^{53}$ O sistema de consulta da RAIS somente permite coletar a média de vínculos ativos; por isso, não foi utilizado a média de vínculos demandados, i.e., ativos e inativos no dia 31 de dezembro do ano de referência. 
Gráfico 13 - \% de Vínculos por Faixa de Tempo em Meses - BR e RS, 2010.

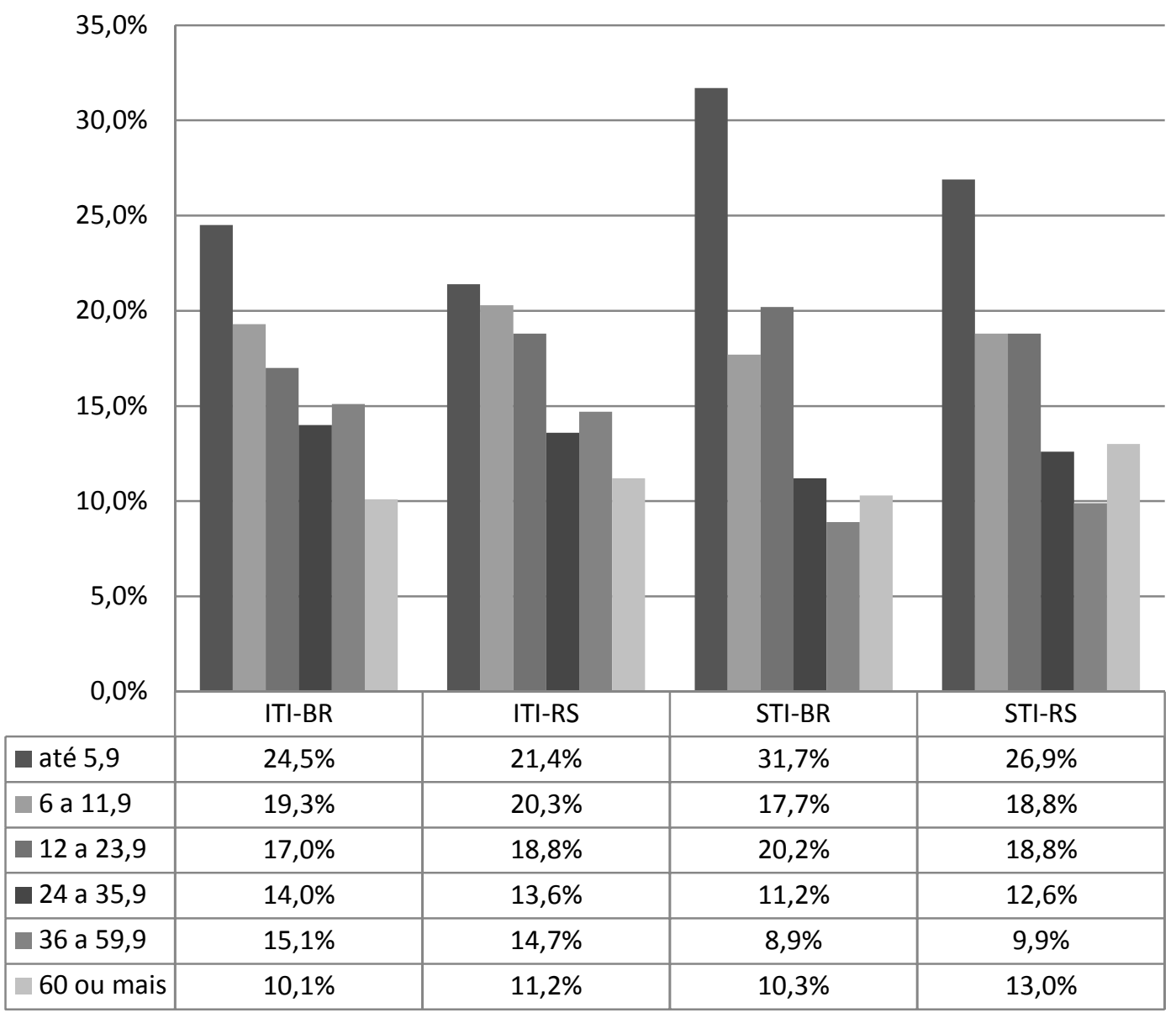

Fonte: RAIS - MTE.

A distribuição do número de vínculos por tempo de duração do RS é semelhante a da brasileira. Entretanto, cabe destacar que os segmentos de TI brasileiro apresentam maiores percentagens nos vínculos com até 5,9 meses. Cabe verificar se também não existem diferenças acentuadas nas médias de tempo de vínculos de trabalho entre RS e Brasil.

Tabela 15 - Média em meses de tempo dos vínculos de trabalho - BR e RS.

\begin{tabular}{c|c|c|c|c}
\hline & STI-BR & STI-RS & ITI-BR & ITI-RS \\
\hline $\mathbf{2 0 1 0}$ & 28,8 & 36,6 & 25,6 & 28,1 \\
\hline $\mathbf{2 0 0 9}$ & 31,1 & 36 & 25,5 & 28,5 \\
\hline $\mathbf{2 0 0 8}$ & 31,9 & 36,7 & 22,8 & 27,9 \\
\hline $\mathbf{2 0 0 7}$ & 33,2 & 40,4 & 23,4 & 28,5 \\
\hline $\mathbf{2 0 0 6}$ & 35 & 44,1 & 25,9 & 33,2 \\
\hline
\end{tabular}

Fonte: RAIS - MTE. 
É possível concluir que, no segmento de serviços de TI, as médias têm diferenças entre 5 a 9 meses, enquanto que, na indústria, elas não passam de 5 meses. Como tendência geral, constata-se que, no Rio Grande do Sul, os vínculos de trabalho têm uma maior duração dos que em nível nacional, apesar dessas diferenças serem menores que um ano.

Se os vínculos em média duram mais no RS, isso significa maiores taxas anuais de não desligados?

Tabela 16 - \% Anual de Vínculos Não Desligados - BR e RS.

\begin{tabular}{c|c|c|c|c}
\hline & STI-BR & STI-RS & ITI-BR & ITI-RS \\
\hline $\mathbf{2 0 1 0}$ & $64,5 \%$ & $68,6 \%$ & $69 \%$ & $77,1 \%$ \\
\hline $\mathbf{2 0 0 9}$ & $67,1 \%$ & $72 \%$ & $68,8 \%$ & $75,2 \%$ \\
\hline $\mathbf{2 0 0 8}$ & $63,1 \%$ & $67,3 \%$ & $62,9 \%$ & $74,4 \%$ \\
\hline $\mathbf{2 0 0 7}$ & $67,8 \%$ & $71,1 \%$ & $67,3 \%$ & $75 \%$ \\
\hline $\mathbf{2 0 0 6}$ & $65,8 \%$ & $70,6 \%$ & $71,5 \%$ & $74,1 \%$ \\
\hline
\end{tabular}

Fonte: RAIS - MTE.

A resposta é sim. Portanto, é cabível formular a hipótese de que o menor "peso" do RS em termos do número de vínculos demandados, deve-se ao fato de suas firmas de TI apresentarem menor rotatividade da sua mão de obra. Talvez, soma-se a esse fato, um cenário de pouca expansão do setor de TI gaúcho, ou seja, taxas menores de crescimento anual do número de estabelecimentos e de vínculos demandados, se comparados com o Brasil.

Gráfico 14 - Taxa (\%) de Crescimento Anual do No. de Estabelecimentos BR e RS.

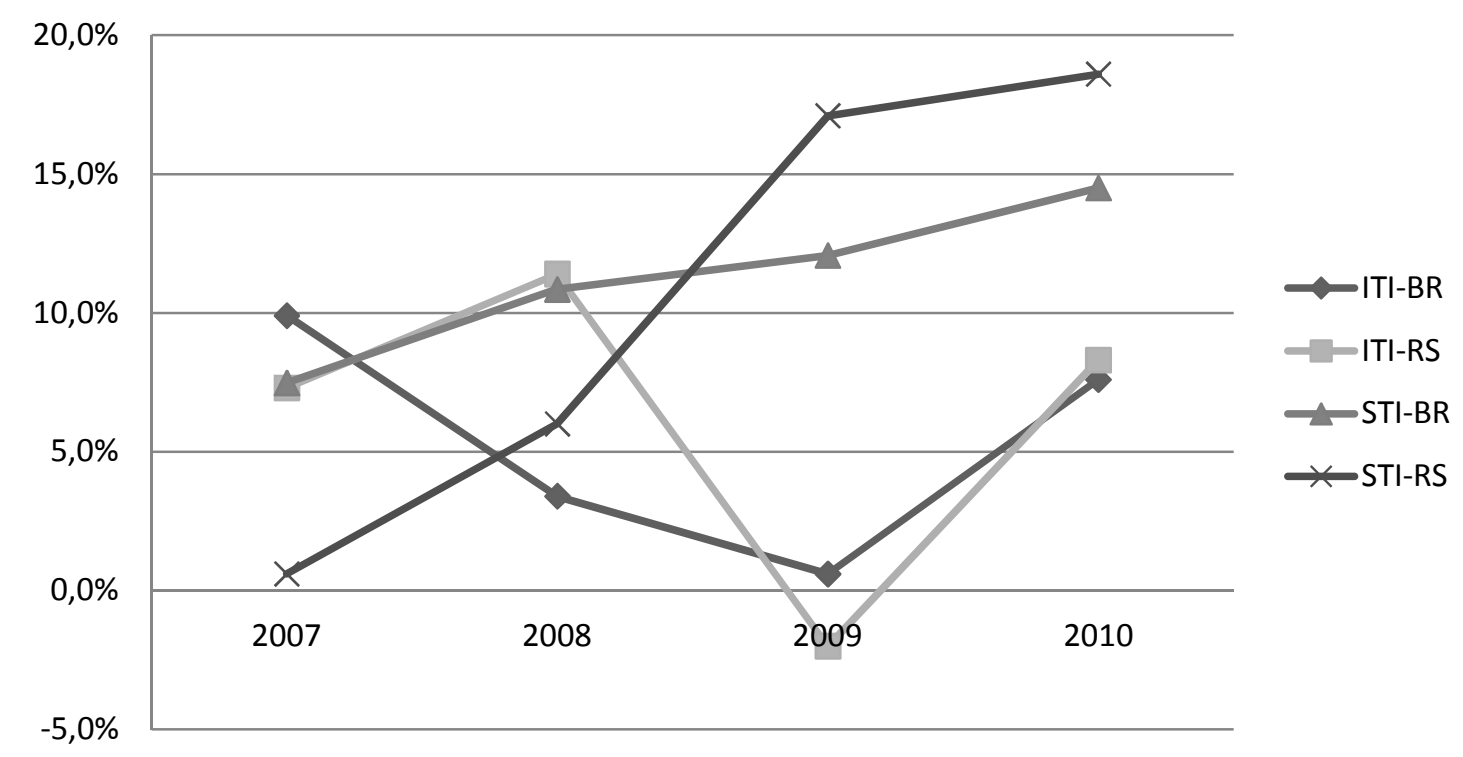


Fonte: RAIS - MTE.

Gráfico 15 - Taxa (\%) de Crescimento Anual do No. de Vínculos de Trabalho Demandados nos Segmentos de TI - BR e RS.

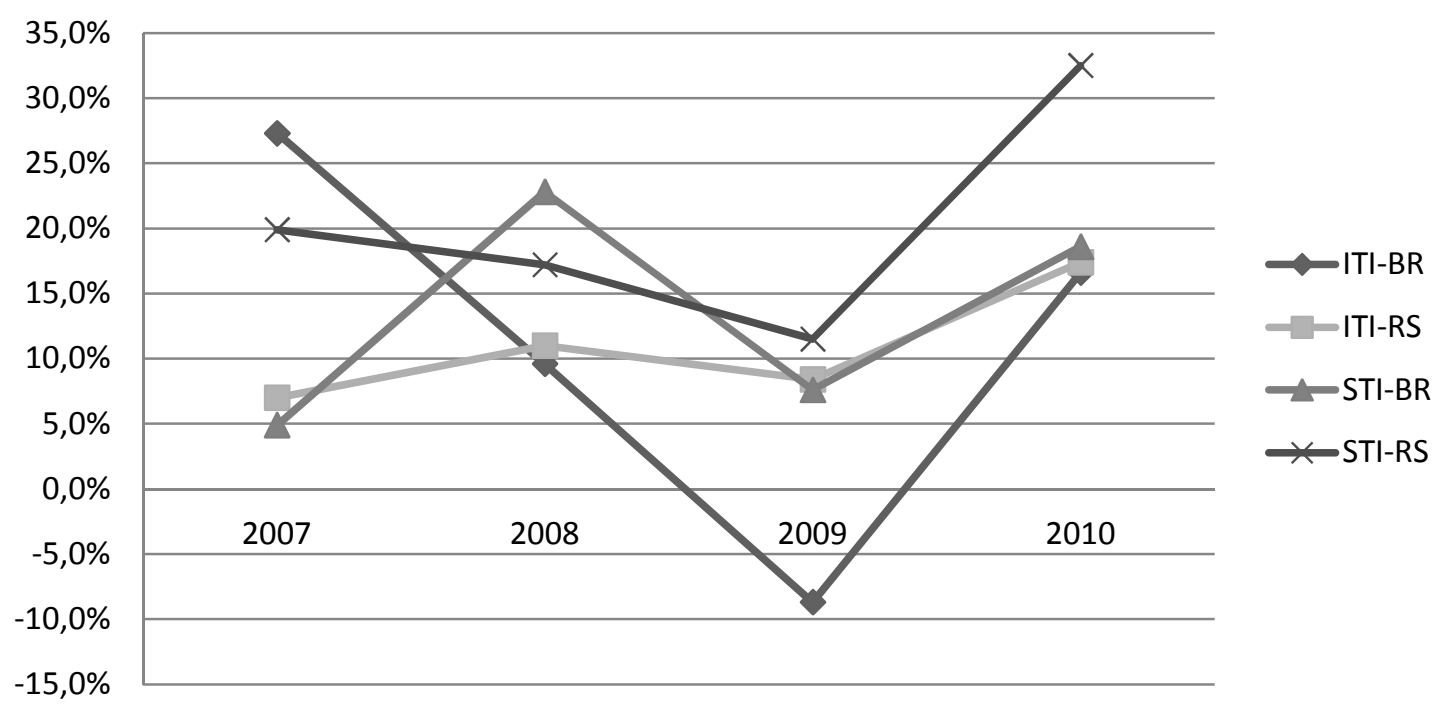

Fonte: RAIS - MTE.

No caso do número de estabelecimentos, no segmento da indústria de TI, o RS alternou entre taxas de crescimento maiores e menores do que as observados para o Brasil. No segmento de serviços de TI, o RS não somente encerrou o período com taxas maiores como, também, o movimento de crescimento foi mais intenso ao registrado no Brasil. No caso das taxas para vínculos demandados, a indústria gaúcha de tecnologias da informação apresentou crescimento constante nas taxas e em níveis maiores das observadas para o Brasil, durante boa parte do período. Nos serviços de TI, o RS, apesar de uma trajetória de queda das suas taxas, manteve percentuais mais altos daqueles registrados no Brasil. Assim sendo, compreende-se que a menor participação do RS em termos de número de vínculos demandados no setor de TI brasileiro, não se deve a um contexto estadual de baixa expansão do TI gaúcho; esse fato ocorre em razão da tendência das firmas gaúchas possuírem menor rotatividade da sua mão de obra.

Com relação às médias salariais, o que se pode verificar na comparação entre Brasil e RS? 
Gráfico 16 - Valor Nominal Médio de Salários - BR e RS.

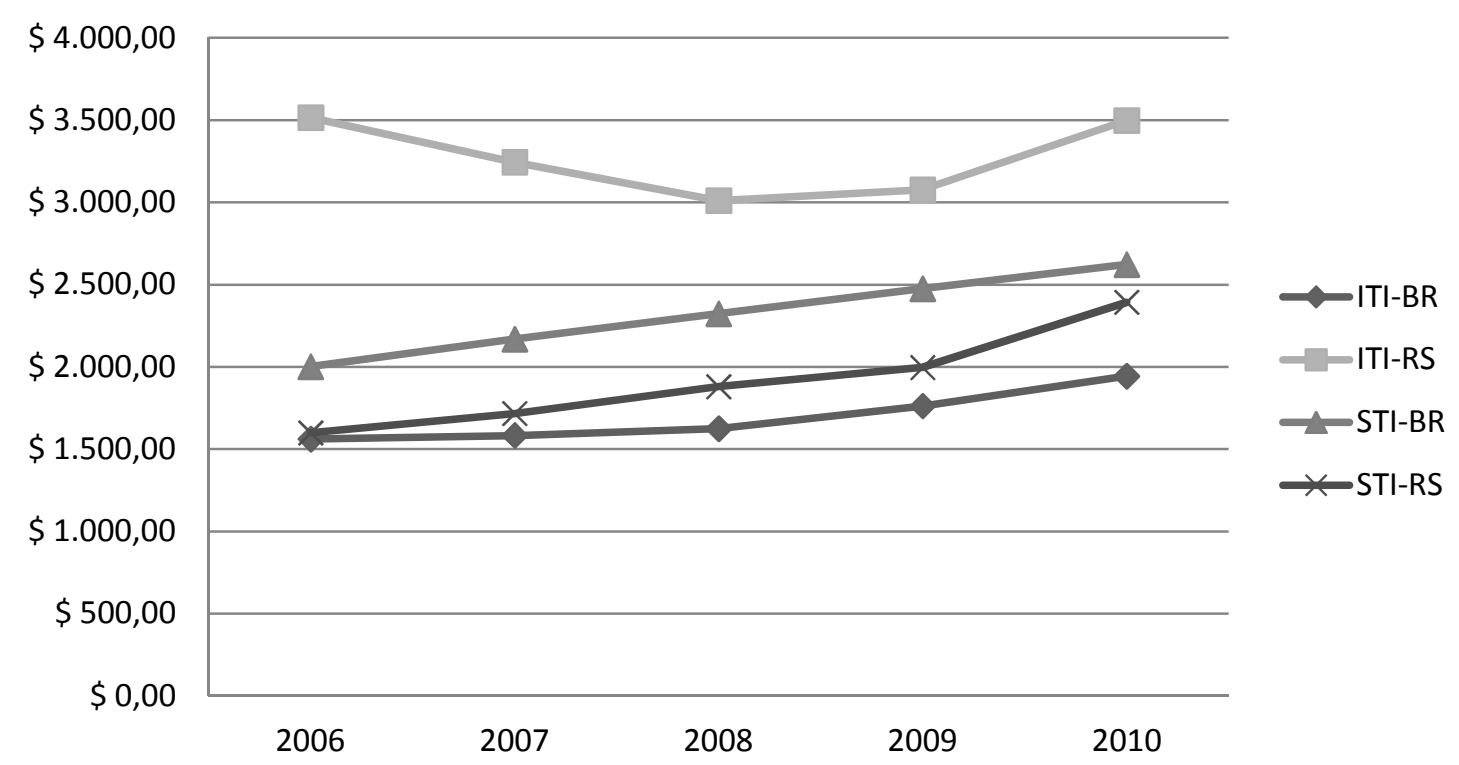

Fonte: RAIS - MTE.

Com exceção do segmento da indústria de TI gaúcha, os demais apresentaram trajetórias crescentes nas médias salariais durante o período. Em compensação, o ITIRS registrou as maiores médias salariais em todos os anos. Já o segmento de serviços de tecnologias da informação do RS, registrou médias salariais menores daquelas do mesmo segmento no Brasil.

O que é possível verificar sobre os profissionais que são demandados pelos segmentos de TI gaúchos comparados com os do Brasil? As taxas de participação feminina nos vínculos demandando, por exemplo, são semelhantes?

Tabela 17 - Participação Feminina nos Vínculos de Trabalho - BR e RS.

\begin{tabular}{r|c|c|c|c}
\hline & STI-BR & STI-RS & ITI-BR & ITI-RS \\
\hline $\mathbf{2 0 1 0}$ & $36,4 \%$ & $34,1 \%$ & $44,3 \%$ & $36,5 \%$ \\
\hline $\mathbf{2 0 0 9}$ & $37,6 \%$ & $34,8 \%$ & $42,5 \%$ & $33,3 \%$ \\
\hline $\mathbf{2 0 0 8}$ & $38,2 \%$ & $35,1 \%$ & $43,4 \%$ & $30,7 \%$ \\
\hline $\mathbf{2 0 0 7}$ & $38,6 \%$ & $35,7 \%$ & $41,3 \%$ & $30,5 \%$ \\
\hline $\mathbf{2 0 0 6}$ & $40,3 \%$ & $38,2 \%$ & $40,8 \%$ & $33,7 \%$ \\
\hline
\end{tabular}

Fonte: RAIS - MTE.

Tanto no Brasil como no RS, a participação feminina no segmento de serviços caiu ao longo do período e, no da indústria, cresceu. O setor de TI gaúcho registrou uma menor participação das mulheres com destaque para a diferença entre a indústria de tecnologias da informação do RS comparada com a brasileira. 
Se houve diferença na participação feminina entre Brasil e RS, o mesmo não se verifica para distribuição etária dos vínculos demandados.

Gráfico 17 - \% de Vínculos por Faixa Etária - BR e RS, 2010.

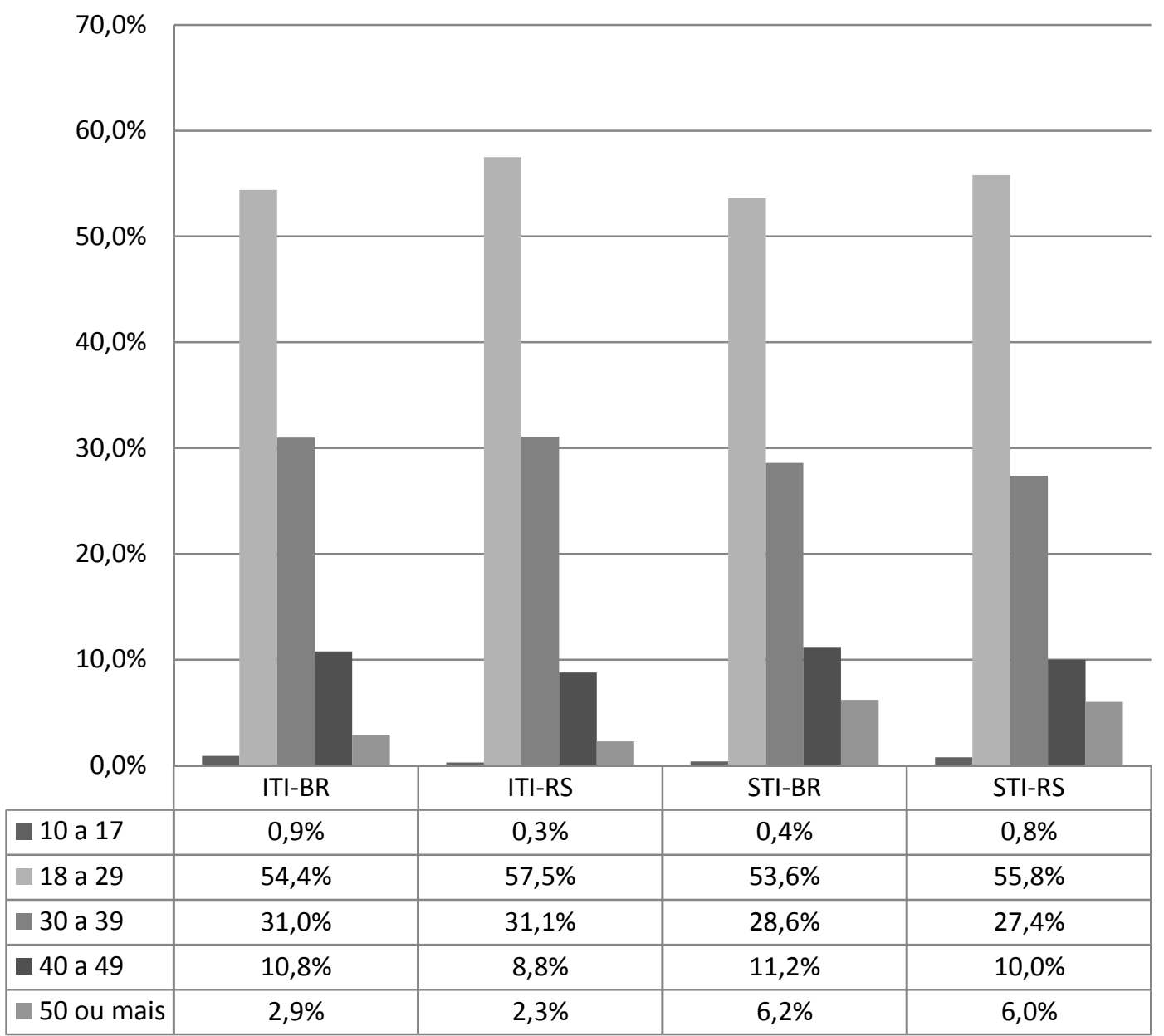

Fonte: RAIS - MTE.

Desse modo se pode constatar que as distribuições percentuais são equivalentes e o mesmo é registrado no caso das médias de idade.

Tabela 18 - Média de Idade em Anos - BR e RS.

\begin{tabular}{c|c|c|c|c}
\hline & STI-BR & STI-RS & ITI-BR & ITI-RS \\
\hline $\mathbf{2 0 1 0}$ & 31 & 31 & 30 & 30 \\
\hline $\mathbf{2 0 0 9}$ & 31 & 31 & 30 & 30 \\
\hline $\mathbf{2 0 0 8}$ & 31 & 30 & 30 & 29 \\
\hline $\mathbf{2 0 0 7}$ & 31 & 30 & 30 & 30 \\
\hline $\mathbf{2 0 0 6}$ & 31 & 31 & 30 & 31 \\
\hline
\end{tabular}

Fonte: RAIS - MTE. 
Conforme verificado anteriormente o setor de TI nacional registra uma demanda que valoriza graus maiores de escolaridade comparados ao setor de serviços e à indústria de transformação. Esse aspecto pode ser observado no caso gaúcho.

Gráfico 18 - \% de Vínculos por Escolaridade - BR e RS, 2010.

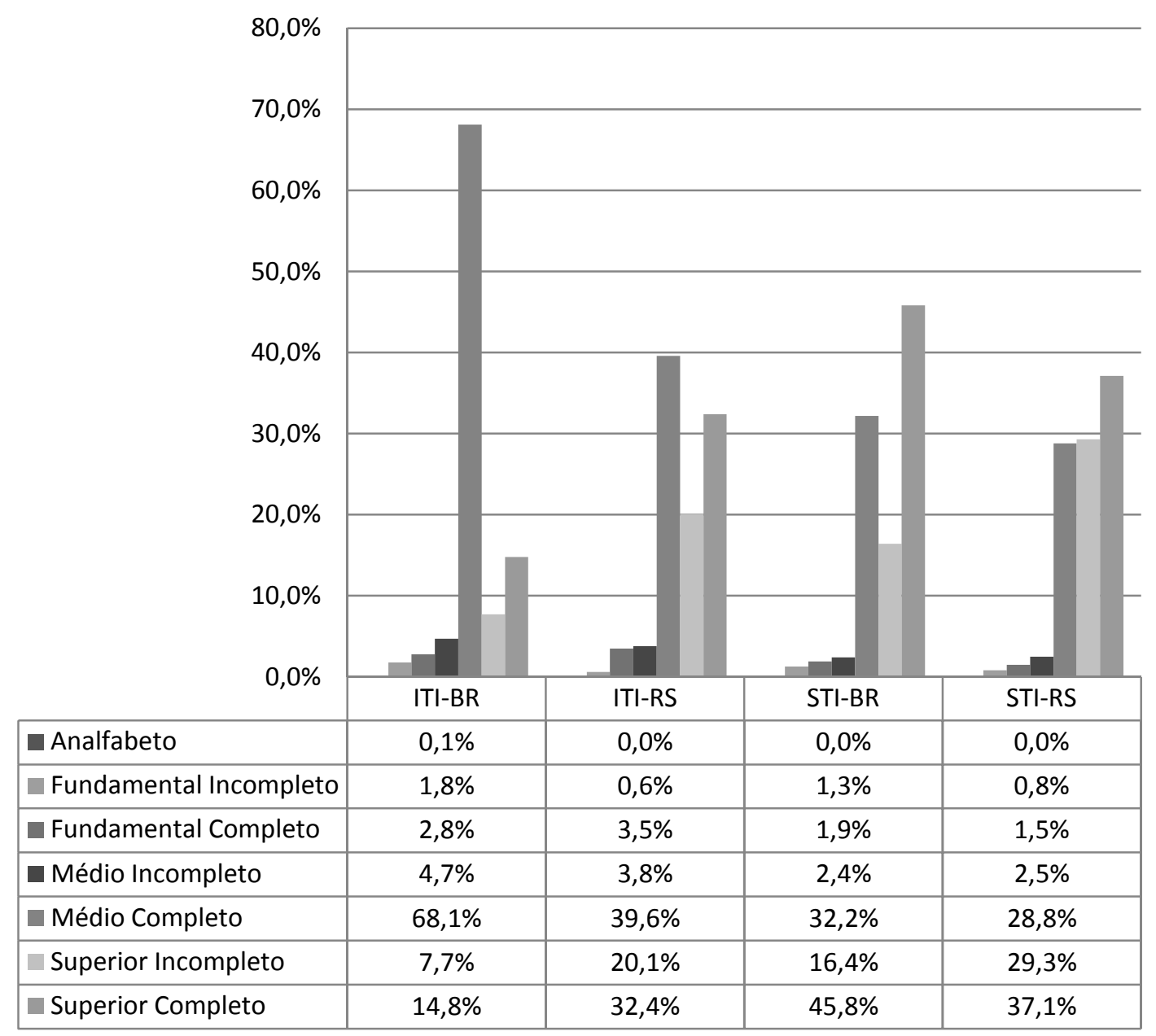

Fonte: RAIS - MTE.

Comparada à nacional, a indústria de TI gaúcho registra maior concentração de vínculos em níveis maiores de escolaridade. Já o segmento de serviços do RS, apesar de apresentar uma menor percentagem de vínculos com curso superior completo, registrou percentagens maiores na escolaridade "superior incompleto" comparativamente à brasileira. Conforme verificado na análise dos estudos de caso desta, esse fato pode ser produto da adoção de uma estratégia das firmas de serviços de TI gaúchas em recrutar profissionais cursando graduação ou recém-formados em curso de interesse das firmas de TI. 
Tabela 19 - \% de Vínculos de Trabalho com Curso Superior Completo - BR e RS.

\begin{tabular}{r|r|r|r|r}
\hline & STI-BR & STI-RS & ITI-BR & ITI-RS \\
\hline $\mathbf{2 0 1 0}$ & $45,8 \%$ & $37,1 \%$ & $14,8 \%$ & $32,4 \%$ \\
\hline $\mathbf{2 0 0 9}$ & $40,4 \%$ & $29,2 \%$ & $13,1 \%$ & $26,6 \%$ \\
\hline $\mathbf{2 0 0 8}$ & $38,7 \%$ & $27,8 \%$ & $12,4 \%$ & $24,1 \%$ \\
\hline $\mathbf{2 0 0 7}$ & $38,8 \%$ & $25,3 \%$ & $14 \%$ & $34,2 \%$ \\
\hline $\mathbf{2 0 0 6}$ & $35,9 \%$ & $26,5 \%$ & $14 \%$ & $35,6 \%$ \\
\hline
\end{tabular}

Fonte: RAIS - MTE.

Como é possível concluir através da tabela 19, essas diferenças entre os segmentos de TI do RS e os do Brasil, com relação à demanda por vínculos com curso superior completo, não é algo totalmente recente. Apesar de haver uma tendência de queda no período, a indústria de tecnologias da informação gaúcha registrou percentagens mais acima das nacionais. Essas diferenças se manifestam nas médias salariais para vínculos com curso superior completo.

\section{Gráfico 19 - Valor Médio do Salário Nominal para Trabalhadores com Curso Superior Completo - BR e RS.}

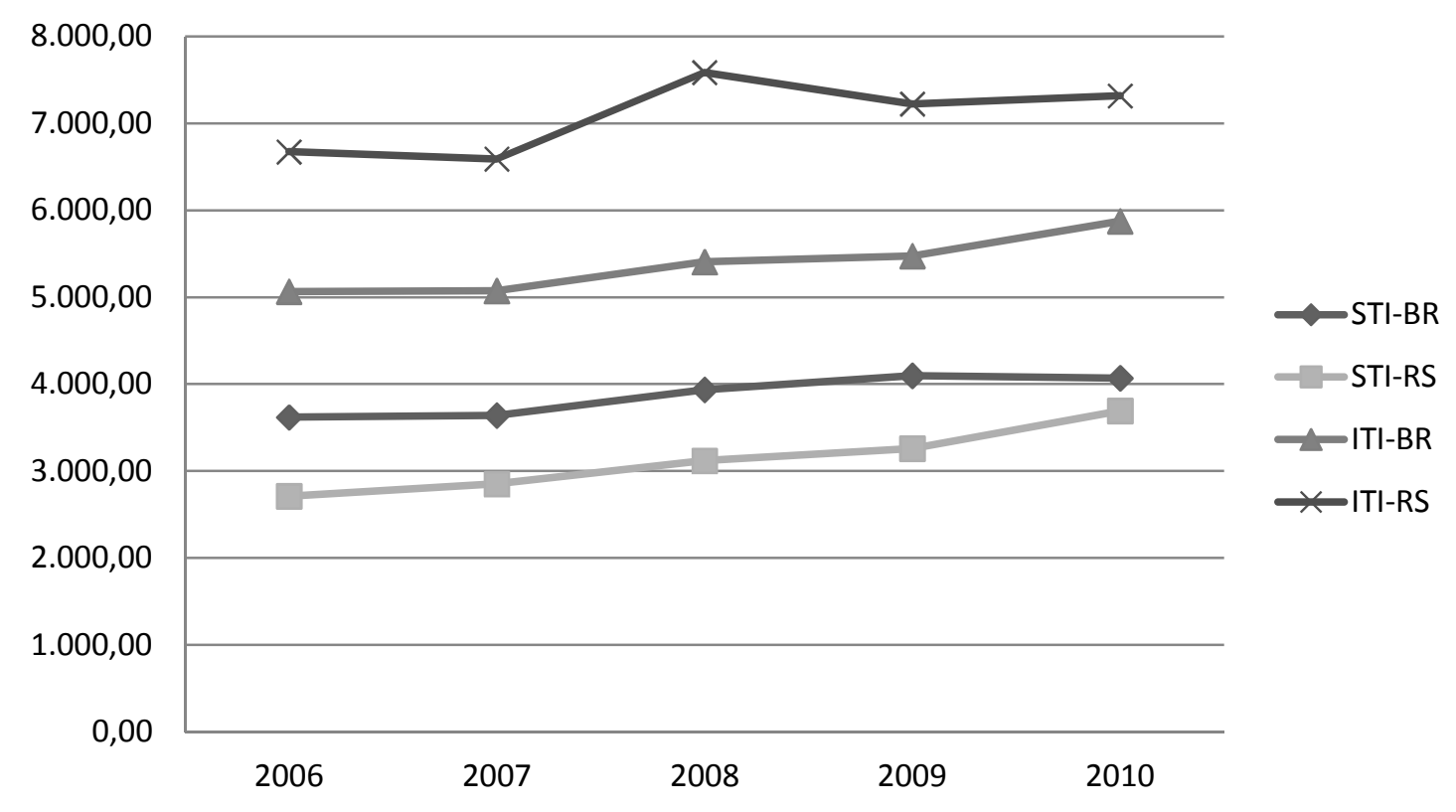

Fonte: RAIS - MTE.

A indústria de TI gaúcha registrou tanto as maiores médias para todo o período como uma tendência de crescimento. Esses dois fatos podem indicar uma política de demanda de trabalho desse segmento no RS centrada em profissionais com curso superior. Por outro lado, os serviços de TI no RS registraram as menores médias 
salariais, apesar de haver tendência de se igualar com as médias nacionais do segmento que, por sua vez, permaneceram praticamente estáveis no período.

Por fim, através da análise dos dados da RAIS feita nesta seção é possível extrair algumas conclusões vis-à-vis determinadas particularidades da estrutura ocupacional da nova economia (tal como foi exposta na primeira seção deste capítulo). Primeiramente, a nova economia seria marcada pela presença de relações de trabalho e de empregos flexíveis. A base RAIS registra algumas formas de vínculos de trabalho que poderiam ser consideradas como flexíveis, por exemplo, o vínculo por tempo determinado. Todavia, os dados acessados mostram a tendência das empresas, inclusive as de TI, de empregarem por vínculos CLT (mais de 99\%) que consistem em relações de emprego com jornada fixa de trabalho e por tempo indeterminado. Em contraposição, verificouse no inicio desta seção a alta representatividade das declarações de "RAIS Negativa", que podem indicar formas de atividades e de relações de emprego flexíveis, especialmente no segmento de serviços de tecnologias da informação.

Em segundo lugar, uma tendência apontada por Manuel Castells (AOYAMA; CASTELLS, 2002; CARNOY; CASTELLS; BENNER, 1997; CASTELLS, 2007, p. 265-351) é a maior participação das mulheres na estrutura ocupacional. Tal como demonstrado na análise, há uma leve tendência do incremento da participação das mulheres nos vínculos de trabalho, tanto nos grandes setores como na indústria de TI. Surpreendentemente, o segmento de serviços de TI registrou queda na participação de mulheres nos vínculos de trabalho.

Em terceiro, os dados claramente apontam para um crescimento e uma maior concentração do número de estabelecimentos e de vínculos de trabalho demandados nas atividades de serviços quando comparadas com as industriais. Tanto na comparação entre os grandes setores como entre os segmentos de TI, esta tendência de maior crescimento e concentração dos números de estabelecimentos e vínculos nas atividades de serviços, são confirmadas. Esses dados vão ao encontro, portanto, com as teses sobre a nova economia como uma economia de serviços.

Em quarto lugar, constata-se que no segmento de serviços de TI há uma tendência de crescimento da demanda por profissionais com curso superior completo; já no segmento industrial de TI, observa-se o predomínio da demanda por profissionais com ensino médio completo. Esses movimentos da demanda de trabalho em função do nível de escolaridade indicam uma tendência consistente com a tese de que a nova economia privilegiaria o emprego de profissionais mais qualificados. 
Por fim, em quinto lugar, em acordo com o que os autores sobre a nova economia afirmam, identificou-se aqui altos e crescentes índices de rotatividade, especialmente nos segmentos de tecnologias da informação. Não se pode afirmar com base nesta breve análise que essa é uma tendência estrutural da nova economia, pois o escopo dos dados apresentados aqui é demasiadamente limitado para tal inferência.

Em suma, tanto em nível nacional como estadual, os dados corroboram com algumas tendências da nova economia e simultaneamente apresentam aspectos idiossincráticos, que ao seu turno, indicam a persistência de trajetórias institucionais e culturais modelando a formação da nova economia em diversos contextos. 


\section{PROCEDIMENTOS METODOLÓGICOS}

\subsection{Procedimentos e técnicas de coleta e análise de dados}

A metodologia de pesquisa adotada é o estudo de caso (GERRING, 2007; HANCOCK; ALGOZZINE, 2006; ROESE, 1998; WOODSIDE, 2010) voltado para análise qualitativa de dados. Portanto, foi realizado um levantamento sistemático e aprofundado de dados sobre cada caso (no total quatro), limitado ao grau de autorização de acesso a documentos e pessoas concedido pelas firmas. Esse levantamento foi orientado visando a alcançar os seguintes objetivos de pesquisa: 1) compreender a demanda da firma no mercado de trabalho em termos dos valores que ela atribui ao trabalho como mercadoria; 2) identificar as práticas que a firma executa para recrutar, selecionar e contratar trabalhadores, isto é, suas operações de cálculo; 3) caracterizar e identificar os elementos que formam a rede sociotécnica que estruturam essas operações.

A escolha dessa metodologia foi feita em razão da sua adequação à natureza dos objetivos e do problema de pesquisa desta tese. Como já foi destacado, estamos analisando o cálculo econômico de uma firma na sua dimensão qualitativa, ou seja, não se trata de compreender quais os custos monetários a firma leva em consideração e determinar quando e em qual quantidade ela irá contratar trabalhadores; o interesse analítico reside no processo em si e nas condições de possibilidade para a firma executar a sua capacidade de cálculo de valor no mercado de trabalho. Em outros termos, o problema de pesquisa tal como está formulado, exige um nível de detalhamento na compreensão do cálculo econômico que impossibilita a condução de um estudo de maior escala dentro do escopo temporal de uma tese. Ademais, não se está visando obter generalizações para um universo relativo de fenômenos, mas procurando verificar concretamente como e se certas proposições teóricas se manifestam em realidades sociais concretas e, assim, cotejar com a teoria, fazendo avançar o conhecimento.

Os casos estudados são de firmas de tecnologias da informação. Esta pesquisa tem como interesse analítico o cálculo de valor executado pela firma no mercado trabalhado, a partir das condições engendradas pelas suas relações sociotécnicas. Nesse sentido, não se está estudando o mercado de trabalho, nem as relações de trabalho e tão pouco o processo produtivo no setor de TI, mas sim, o conjunto de relações e procedimentos que facultam a realização do cálculo de valor necessário para realização 
da demanda da firma no mercado de trabalho. Portanto, cada caso (firma) aqui é entendido como um conjunto de relações entre agentes humanos e não-humanos dentro e fora da empresa. Essas relações estruturam o cálculo econômico de valor da demanda da firma no mercado de trabalho. Portanto, a capacidade de cálculo não é executada individualmente por nenhum agente - humano ou não - da firma, mas se faz através dos conhecimentos, informações e práticas engendradas pelas relações sociotécnicas. Em razão dessa definição da firma como uma rede sociotécnica, compreende-se que o cálculo é exercitado também por meio de relações com agentes humanos e não-humanos que não estão localizados dentro da empresa, por exemplo, universidades, agência de emprego e seleção, sites de relacionamento da Internet, etc. Em suma, a identidade da firma como demandante no mercado de trabalho e como agente com capacidade de cálculo de valor é resultado do conjunto de relações estabelecidas na rede sociotécnica.

Os casos foram selecionados verificando se a empresa é uma demandante importante de mão de obra no mercado de trabalho, configurando-se, por isso mesmo, como uma organização de médio ou grande porte em termos de seus efetivos de funcionários. Outro elemento importante de seleção de casos é a preferência por firmas com atuação reconhecida e de peso no mercado de produtos de TI. Procuraram-se casos que também fossem diferentes em termos dos segmentos de atuação no setor de tecnologias da informação, para com isso ter em conta variações de uma mesma sorte de fenômeno. Assim se chegou ao estudo de um caso no segmento de indústria e manufatura e três tipos de empresas de serviços de software.

O próximo capítulo consiste numa descrição analítica detalhada dos casos e que teve uma primeira versão das seções que o compõem enviada para as respectivas empresas. Essas, então, ajudaram a fazer correções, adendos e até mesmo avaliar se certas informações deveriam ser divulgadas. De maneira geral, esse procedimento permitiu o apuramento de algumas informações técnicas e também no respaldo de certas interpretações. Os capítulos 6 e 7 também possuem um caráter mais descritivo, neles se discorre sobre os agentes humanos e os dispositivos de cálculos que compõem a rede sociotécnica de cada firma (capítulo 6) e os valores econômicos e economicamente relevantes que conformam a demanda por força-de-trabalho e, por conseguinte, orientam as operações de cálculo de cada empresa (capítulos 7). Finalmente, o capítulo 8 consiste em articular analiticamente todos os elementos que foram definidos e descritos nos capítulos de 5 a 7. O capítulo oitavo, portanto, assume o caráter de exposição da análise dos resultados de pesquisa visando deixar claro para o leitor como 
as relações tecidas nas redes sociotécnicas de cada empresa estruturam condições de possibilidade para o exercício do cálculo de valor no mercado de trabalho.

Todavia, vale aqui uma breve caracterização dos quatro casos escolhidos em cada um dos segmentos:

a) indústria e manufatura de hardware de transmissão de dados, voz e imagem. Firma localizada na região metropolitana de Porto Alegre (RMPA) que possui mais de 200 funcionários, sendo a quase totalidade dedicada à atividade-fim. Trata-se de uma empresa nacional e com atuação tradicional e pioneira no mercado brasileiro de TI. Para preservar o seu anonimato foi denominada nesta tese de "EC1";

b) empresa cuja atuação se faz no desenvolvimento de softwares personalizáveis de gestão empresarial e também exerce a função de suporte ao cliente. A unidade pesquisada está localizada na RMPA e conta com mais de 500 funcionários, sendo que a quase totalidade deles exerce funções diretamente ligadas à atividade-fim da empresa. Trata-se de uma empresa internacional com atuação global e posição predominante no mercado mundial e nacional no segmento do seu produto. Chama-se essa empresa de "EC2";

c) firma de desenvolvimento de softwares personalizáveis também para áreas de gestão de empresas. Localizada em Porto Alegre, a unidade conta com quase 300 funcionários, a maioria dos quais é envolvida na atividade-fim. Possui atuação nacional e na América Latina, principalmente tendo como clientes pequenas e médias empresas. Foi denominada aqui de "EC3";

d) consultoria e desenvolvedora de software por encomenda para empresas e organizações. Localizada em Porto Alegre, a unidade conta com pouco mais de 100 funcionários com a quase totalidade deles atuando na atividade-fim. A empresa possui atuação global com segmentação no mercado de projetos de software de alta complexidade para grandes clientes corporativos. Denominou-se de "EC4".

Em um primeiro momento foi feita a coleta de dados através de entrevistas semiestruturadas, privilegiando diretores de recursos humanos e pessoas atuantes nas funções de recrutamento e seleção. Com cada um desses, utilizou-se o procedimento de fazer em geral duas entrevistas, sendo a primeira, em todos os casos, realizada com base 
no mesmo roteiro de entrevista (em anexo) e, em seguida, com base em análise preliminar das respostas obtidas, foi confeccionado roteiros específicos para aprofundar pontos de maior interesse para esta pesquisa.

Através das entrevistas com os gestores de $\mathrm{RH}$ e recrutadores foram identificados quais outros funcionários estavam envolvidos na realização da demanda da empresa no mercado de trabalho; e, desse modo, foi solicitado, através do RH, o contato com uma parte desses funcionários para a realização de uma entrevista. A razão de se entrevistar apenas uma vez os funcionários que não são do departamento de recursos humanos ocorreu em função dos termos de negociação da autorização da nossa entrada nas empresas, isto é, a autorização foi dada com a condição de se perturbar minimamente a rotina dos funcionários da parte técnica.

A tabela a seguir mostra o número de entrevistas e de pessoas entrevistadas em cada caso:

Tabela 20 - No. de Entrevistados e de Entrevistas por Estudo de Caso.

\begin{tabular}{|c|c|c|}
\hline & Recursos Humanos & Área Técnica \\
\hline EC1 & $\begin{array}{l}\text { Entrevistado } 1=2 \text { Entrevistas } \\
\text { Entrevistado } 2=1 \text { Entrevista }\end{array}$ & $\begin{array}{l}\text { Entrevistado } 1=1 \text { Entrevista } \\
\text { Entrevistado } 2=1 \text { Entrevista } \\
\text { Entrevistado } 3=1 \text { Entrevista }\end{array}$ \\
\hline EC2 & $\begin{array}{l}\text { Entrevistado } 1=2 \text { Entrevistas } \\
\text { Entrevistado } 2=2 \text { Entrevistas } \\
\text { Entrevistado } 3=2 \text { Entrevistas }\end{array}$ & Entrevistado $1=1$ Entrevista \\
\hline EC3 & $\begin{array}{l}\text { Entrevistado } 1=2 \text { Entrevistas } \\
\text { Entrevistado } 2=2 \text { Entrevistas }\end{array}$ & - \\
\hline EC4 & $\begin{array}{l}\text { Entrevistado } 1=2 \text { Entrevistas } \\
\text { Entrevistado } 2=2 \text { Entrevistas } \\
\text { Entrevistado } 3=2 \text { Entrevistas } \\
\text { Entrevistado } 4=1 \text { Entrevista }\end{array}$ & $\begin{array}{l}\text { Entrevistado } 1=1 \text { Entrevista } \\
\text { Entrevistado } 2=1 \text { Entrevista } \\
\text { Entrevistado } 3=1 \text { Entrevista } \\
\text { Entrevistado } 4=1 \text { Entrevista }\end{array}$ \\
\hline
\end{tabular}

Fonte: Dados de Campo.

Como se podem notar, na EC2 só foi possível fazer uma entrevista com funcionários da área técnica em razão de problemas de agenda da empresa; na EC3, em determinado momento, não se obtive mais autorização para nenhuma entrevista além daquelas quatro, alegando-se que a empresa estava passando por um momento de alta atividade, mudanças operacionais e novas contratações para atender novos clientes; nessas condições a pesquisa perturbaria o ritmo de trabalho.

Este conjunto de entrevistas resultou em pouco mais de 22 horas de gravação (todas elas transcritas). Também através das entrevistas com as pessoas da parte de recursos humanos da firma, identificou-se os agentes não-humanos que faziam parte da organização do cálculo da firma no mercado de trabalho, isto é, quais eram os 
dispositivos de cálculo da empresa. Sendo assim, noções como "cultura da empresa", "planos de cargos e carreiras", "certificação ISO" e "qualificação técnica e comportamental" interessam e foram tratados na análise como dispositivos de cálculo (DOGANOVA; EYQUEM-RENAULT, 2009; MUNIESA; MILLO; CALLON, 2007); ou seja, examinaram-se os seus papéis na rede sociotécnica que confere à firma capacidade de cálculo de valor no mercado de trabalho. Isso implica, então, em não entrar na seara de questões caras aos estudos de sociologia do trabalho ou das organizações, como, dentre outras: a cultura de uma empresa realmente se concretiza em práticas reais de organização e gestão do trabalho? As certificações de qualidade como a ISO possuem relação com formas de controle e disciplina da mão de obra? Qualificações comportamentais são formas de controle da firma sobre a subjetividade do trabalhador? O interesse analítico desta tese, portanto, diz respeito apenas a pensar como agentes não-humanos assumem o papel de dispositivos de cálculo da firma no mercado de trabalho.

Esses dispositivos são materiais de apresentação da empresa em eventos (apresentações de PowerPoint e folhetos de divulgação); documentos que definem os valores e cultura da empresa; sítio eletrônico das firmas e o seu sistema de envio de currículos; testes e roteiros de entrevistas utilizados na seleção de candidatos; planos de cargos e carreiras; sistemas informáticos de banco de currículos e de comunicação entre os envolvidos no processo de seleção.

Com relação a esse tipo de dado, a coleta foi realizada seguindo dois tipos: a obtenção de cópia do material para ser analisado pelo pesquisador e a apresentação e observação in loco do material. Por razões de preservação do anonimato das fontes, nenhum desses materiais será reproduzido nesta tese.

Todo esse corpus de dados coletados foi submetido à técnica de análise de conteúdo categorial (BARDIN, 1979, 2003; BAUER, 2002; PEREIRA, 1998; WEBER, 1990). Esse processo de análise foi operacionalizado da seguinte maneira: primeiro, o corpus de dados foi separado e agrupado de acordo ao pertencimento a cada caso. A seguir, para cada grupo de dados de cada caso foi feito, separadamente e com auxílio do software NVivo (RICHARDS, 1999), a codificação de trechos de entrevistas e extratos dos documentos na seguinte grade de categorias:

- Rede Sociotécnica

- Relações entre pessoas do RH

○ Relações entre pessoas do RH e área técnica 
- Relações entre pessoas do RH e pessoas fora da firma

- Relações entre pessoas do RH e dispositivos de cálculo

- Relações entre pessoas de área técnica e dispositivos de cálculo

- Valores

- Estratégias e percepção da firma para o mercado de produtos

○ Organização e gestão do trabalho

- Estratégias e percepção da firma para o mercado de trabalho

- Perfil técnico de trabalhador demandado

- Perfil comportamental de trabalhador demandado

- Cálculo de Valor

○ Métricas do cálculo

○ Operações de recrutamento

○ Operações de seleção

○ Operações de contratação

Após a classificação dos trechos de entrevistas e dos documentos em cada uma das categorias da grade, foi feito o procedimento de leitura transversal, isto é, o conjunto de dados de cada caso foi analisado pela leitura dos trechos em cada categoria. Isso permitiu definir e compreender cada um dos elementos e relações que compõem a rede sociotécnica das empresas (Capítulo 6), os valores que elas utilizam nas operações de cálculo que têm lugar no mercado de trabalho (Capítulo 7) e as operações de cálculo que se estruturam a partir das combinações entre relações sociotécnicas e valores (Capítulo 8).

Todo esse conjunto de procedimentos de análise de dados serviu para verificar as hipóteses de pesquisas definidas adiante. Antes, contudo, é preciso considerar e descrever o processo de contato com as empresas nas quais se realizaram os estudos de caso. Assim é possível explicitar os limites e possíveis vieses nos dados analisados.

\subsection{Inserção nas empresas e limites da pesquisa}

No final de 2010 e início de 2011 foram realizadas entrevistas com representantes de entidades empresariais do setor de TI, no município de São Paulo. Num primeiro momento, elegeu-se São Paulo em razão de dados secundários apontarem a maior concentração de empresas de tecnologia da informação e de profissionais da área de TI nesse município. Desse modo, as entrevistas com organizações de representação de empresas desse setor serviriam para identificar as principais firmas e 
travar conhecimento com as mesmas através de indicações advindas de contatos nessas organizações de representação empresariais. Entretanto, no inicio de 2011, constatou-se que a permissão para a entrada nas empresas em São Paulo só seria possível através de indicações de alguém dentro das firmas, ou seja, o contato com as empresas através das organizações de representação empresarial não era suficiente. Além disso, as informações obtidas através das entrevistas com representantes de entidades empresariais do setor de TI e a consulta a dados secundários apontavam para a tendência a se abrigarem em São Paulo apenas as atividades financeiras e comerciais das grandes empresas de tecnologia da informação. Assim sendo, a demanda no mercado de trabalho das unidades paulistas dessas empresas estaria mais voltada para profissionais dessas atividades do que propriamente para as atividades de tecnologias da informação, desviando do foco desta pesquisa.

Elegeu-se, então, por realizar os estudos de casos em firmas do município de Porto Alegre e sua região metropolitana (RMPA), pois ali se tinha contatos com profissionais empregados em empresas de médio e grande porte. Tal como visto no capítulo anterior, essa região possui uma importância considerável no setor de atividades de serviços e de manufaturas de TI. Através de dados obtidos na base RAIS (Relação Anual de Informações Sociais) do Ministério do Trabalho e Emprego, constatou-se que, em 2010, o estado do Rio Grande do Sul, onde está situada a RMPA $^{54}$, abrigava 7,5\% dos estabelecimentos de serviços, assim como da indústria de TI nacional. Além disso, esses estabelecimentos eram responsáveis, respectivamente, por $4,1 \%$ e $6,5 \%$ dos vínculos de trabalho demandados pelas firmas de TI nacional ao longo do ano de 2010. Destaca-se ainda, a presença de três grandes parques tecnológicos universitários, onde nos quais estão sediadas grandes empresas multinacionais de tecnologias da informação. Em suma, trata-se de uma região com relativo peso no contexto nacional de TI.

Mesmo mobilizando essa rede de contatos pessoais e profissionais, o processo de negociação para autorização da nossa entrada nas empresas foi demorado. Tais negociações envolveram longos períodos de contato explicando o objetivo estritamente acadêmico desta tese de doutorado. Via de regra, esses contatos eram iniciados com o encaminhamento de documentos - resumo executivo da tese, roteiro de entrevistas,

\footnotetext{
${ }^{54}$ Consultando a base mencionada, identificamos que pouco mais de $90 \%$ dos estabelecimentos de serviços e industriais de TI estavam situados na RMPA. Porém, por uma questão de operação da base de dados RAIS-MTE, não se consegue coletar os demais dados somente para RMPA.
} 
carta de apresentação, lista de pessoas que planejávamos entrevistar, etc. -, a que se seguia a realização de conversas, por telefone e pessoais, com os funcionários encarregados de verificar se haveria, ou não, condições de realização da pesquisa na empresa. Para que se tenha ideia do grau de dificuldade, os quatro estudos de casos foram antecedidos por nada menos que cinco negativas de autorização para acesso às empresas, também inicialmente selecionadas.

Em meados do segundo semestre de 2011 é que se obteve a primeira autorização de entrada em uma das empresas. Uma vez concedida as autorizações de pesquisa, escolheu-se por começar entrevistando gerentes de recursos humanos, nossos informantes estratégicos, uma vez que detêm o conhecimento de conjunto tanto sobre as operações de gestão do trabalho como sobre as de recrutamento e seleção de pessoas. Essas primeiras entrevistas serviram também para identificar quais agentes se deveria tomar em conta na análise sobre o cálculo de valor que cada uma dessas firmas exerce no mercado de trabalho. Cabe notar que o adequado avanço na coleta de dados viu-se frequentemente obstaculizado pela (in)disponibilidade de agenda dos gestores de recursos humanos, recrutadores e gestores de áreas técnicas, fazendo com que o levantamento de dados e a realização de entrevistas durasse cerca de 16 meses.

Após essas primeiras entrevistas, foi iniciado um segundo processo de negociação com esses gestores, a saber, obter autorização sobre "quem" na empresa poderíamos entrevistas e que tipo de acesso seria concedido a certos documentos e procedimentos. Como se percebeu na Tabela 20, cada empresa permitiu certo número de entrevistas com profissionais técnicos que ocupavam, via de regra, a função de gestores de operações técnicas. Infelizmente, não nos foi facultada autorização para observação de processos de seleção, seja em razão de política de confidencialidade da empresa, seja porque os agentes encarregados pelas operações de seleção não disponham de tempo para adaptar esse evento à presença de um observador externo à empresa.

$\mathrm{O}$ acesso a materiais como roteiros de entrevista, relatórios, folder $\mathrm{e}$ apresentações em PowerPoint foi concedido em alguns casos e sob a condição de não reproduzi-los na impressão desta tese. Por fim, foi facultada apenas autorização para observar sistemas informáticos de gestão de $\mathrm{RH}$; porém, não se pode observar in loco o uso das aplicações que compreendem esses sistemas, por exemplo, pesquisa em banco de currículos; comunicação entre funcionários envolvidos na seleção e contratação de candidatos; consulta às informações constantes em planos de cargos, salários e carreiras. 
Tendo em vista esses limites na coleta de dados entre as empresas, alguns vieses podem ser cogitados. O primeiro deles advém do maior número de entrevistas com pessoas do RH, o que pode ter estruturado uma visão unidimensional das firmas; isto é, não se obteve acesso à visão da organização e de estratégias da empresa através do ponto de vistas de gestores de áreas como a financeira, a comercial ou mesmo por parte de diretores gerais ou executivos. Em segundo lugar, não sendo possível observar na prática os processos de recrutamento e seleção, esta tese está se respaldando apenas nas percepções e conhecimentos de algumas das pessoas encarregadas dessas práticas, conhecimentos e percepções provocados e formulados a partir das condições particulares de entrevistas semiestruturadas (GOODE; HATT, 1969, p. 237-268; POUPART, 2008). Em terceiro lugar, o acesso restrito ou a não autorização de entrevistas com profissionais técnicos que participam da seleção de candidatos a vagas de emprego na firma, pode ter conduzido a uma percepção acerca das qualificações e do perfil de funcionários demandados pela firma, restrita ao que pensam os profissionais de RH encarregados de avaliar no processo de seleção. Finalmente, em quarto lugar, o fato de não se ter conseguido uniformidade no grau de acesso, que deveria estar expresso no mesmo número de entrevistas e na variabilidade de tipos de entrevistados, faz correr o risco de que as conclusões alcançadas e a verificação de hipóteses que dizem respeito a diferenças entre as firmas resultem, na verdade, de diferenças nessa variabilidade de acesso aos dados.

A análise de dados e a verificação das hipóteses foram conduzidas observando rigorosa e sistematicamente esses limites nas condições da coleta de dados, tal como determinadas pela receptividade de cada uma das empresas.

\subsection{Hipóteses de trabalho}

Como já exposto, especialmente no capítulo 3, a nova economia tem como particularidade o seguinte conjunto de características a respeito de suas atividades econômicas, formas de organização, gestão das empresas e de suas relações de trabalho e emprego: 1) se na etapa econômica anterior o paradigma de organização era a indústria voltada para o consumo de massa, na nova economia são atividades de serviços do segmento de tecnologias da informação as que se tornam paradigmáticas; 2) mais do que eficiência no processo produtivo, voltada para os ganhos de escala, a dinâmica competitiva e as estratégias comerciais das firmas na nova economia estão direcionadas para o aprimoramento de suas capacidades e para o seu envolvimento 
sistemático em processos de inovação; 3) as relações de trabalho e as de emprego são mais flexíveis, por exemplo, ausência de jornadas fixas de trabalho com a adoção de regimes como o trabalho por projeto e a diminuição de hierarquias de gestão, conferindo e esperando-se maior autonomia decisória da parte dos trabalhadores e conduzindo a ambientes de trabalho mais informais; 4) adoção de formas de organização marcadas pelo trabalho em grupo e a polivalência; 5) maior valorização e nível de exigência de qualificações técnicas e comportamentais; 6) em contraste com o modelo de consumo de massa, há uma relação mais personalizada entre produtores e clientes gerando a customização de produtos e serviços.

Também vimos a importante pista analítica sobre a nova economia fornecida por Michel Callon (2007; CALLON; MÉADEL; RABEHARISOA, 2002), a saber, a tendência das atividades econômicas e transações nos mercados em envolverem redes sociotécnicas crescentemente complexas e diversificadas em termos do número e tipos de relações e de agentes humanos e não-humanos, ou seja, o que Callon denomina do processo de relação entre "enquadramento" e "transbordamento" (1998b; 2007).

Tendo em conta os elementos acima mencionados que configuram a especificidade da nova economia com essa perspectiva de Callon é possível formular a primeira hipótese de trabalho: as empresas que mais se aproximam no seu modelo de organização, de gestão do trabalho e de negócios em relação ao que é peculiar à nova economia, apresentaram redes sociotécnicas mais diversificadas em termos de relações e de agentes humanos e não-humanos mobilizados na execução do seu cálculo de valor no mercado de trabalho.

A segunda e terceira hipóteses de pesquisa envolvem a noção de valores desenvolvida por Aspers e Beckert (2011) e a já referida caracterização e perspectiva sobre a nova economia. Uma vez que essa última envolve novas formas de organização e gestão do trabalho e, por conseguinte, um perfil diferente de trabalhador que é valorizado pelas empresas, compreende-se que, quanto mais uma firma se aproximar das características peculiares à nova economia, mais o cálculo da sua demanda no mercado de trabalho envolverá uma diversidade maior de valores econômicos e economicamente relevantes. Relacionada a essa última e à primeira, a terceira hipótese prevê que quanto maior o número de valores que envolvem o cálculo da demanda de uma firma no mercado de trabalho, maior será a diversidade de relações sociotécnicas e de agentes humanos e não-humanos envolvidos nas operações de cálculo da firma. 
Essas hipóteses orientaram a coleta de dados da pesquisa de campo e também a análise de cada caso-tipo estudado. Simultaneamente, elas envolvem o procedimento analítico que requereu que, a partir da compreensão individual de cada caso, fosse necessário também compará-los em termos da complexidade de relações e de agentes humanos e não-humanos, da diversidade de valores econômicos e economicamente relevantes e do grau de adoção de aspectos peculiares à nova economia.

Cabe destacar entretanto, que a operação de comparação entre os casos não implicou na adoção da metodologia comparativa (LALLEMENT, 2003; SCHNEIDER \& SCHMITT, 1998), uma vez que o levantamento de dados e sua análise se voltaram para compreender em profundidade a manifestação empírica particular de processos referidos pelos quadros teóricos pertinentes. Em outros termos, as firmas não são concebidas nesta tese como unidades de análise a serem comparadas e referidas para compreensão de um fenômeno mais amplo, mas como realidades particulares que encerram em si mesmas processos empíricos que servem para refletir e melhor compreender proposições teóricas. 


\section{CARACTERIZAÇÃO DOS CASOS}

Neste capítulo é feita uma caracterização sistemática dos casos através das seguintes dimensões: 1) localização e história da empresa; 2) produtos e organização do trabalho; 3) posição no mercado de produtos e estratégias de negócios; 4) tamanho e estrutura ocupacional; 5) estrutura e políticas de recursos humanos. Algumas dessas dimensões podem apresentar dados que dizem respeito ao foco de análise desta pesquisa, isto é, valores, cálculo econômico e redes sociotécnicas; entretanto, o tratamento e o objetivo deste capítulo consistem em descrever analiticamente os casostipos, de maneira a classificá-los em termos do quanto eles se aproximam das seis características organizacionais tidas como típicas da nova economia. Retomando, essas seis características organizacionais são: 1) se na etapa econômica anterior o paradigma de organização era a indústria voltada para o consumo de massa, na nova economia são atividades de serviços do segmento de tecnologias da informação que se tornam paradigmáticas; 2) a dinâmica competitiva e as estratégias comerciais das firmas se voltam para o aprimoramento de suas capacidades e o envolvimento sistemático em processos de inovação; 3) as relações de emprego e a gestão do trabalho se tornam mais flexíveis e com ambientes mais informais; 4) adoção de formas de organização marcadas pelo trabalho em grupo e pela polivalência; 5) maior valorização e nível de exigência de qualificações técnicas e comportamentais; 6) em contraste com o modelo de consumo de massa, há uma relação mais personalizada entre produtores e clientes gerando a customização de produtos e serviços.

Nesse sentido, a análise descritiva dos casos, que será exposta nas seções seguintes, apresenta em detalhes o modo e se cada uma dessas seis características organizacionais está presente no caso estudado. A tabela abaixo expõe esquematicamente os resultados desse esforço analítico: 
Tabela 21 - Aproximação dos Casos em Relação às Características Organizacionais Típicas da Nova Economia.

\begin{tabular}{c|c|c|c|c}
\hline & EC1 & EC2 & EC3 & EC4 \\
\hline Serviços de TI & NÃO & SIM & SIM & SIM \\
\hline Inovação & POUCA & ALTA & ALTA & ALTA \\
\hline $\begin{array}{c}\text { Gestão Flexível } \\
\text { Trabalho em } \\
\text { Grupo, por } \\
\begin{array}{c}\text { Projeto e } \\
\text { Polivalência }\end{array}\end{array}$ & NÃO & ALTA & MẼDIA & ALTA \\
\hline $\begin{array}{c}\text { Qualificação } \\
\text { Demandada }\end{array}$ & $\begin{array}{c}\text { EENSINO } \\
\text { TÉCNICO }\end{array}$ & MÉDIO & MÉDIO & ALTO \\
\hline $\begin{array}{c}\text { Personalização } \\
\text { do Produto }\end{array}$ & POUCA & MÉDIA & ENSINO & $\begin{array}{c}\text { ENSINO } \\
\text { SUPERIOR }\end{array}$ \\
\hline
\end{tabular}

Fonte: Dados de Pesquisa de Campo.

Através da tabela acima, já se pode constatar que o caso que mais se aproxima das características organizacionais típicas da nova economia é o EC4. No "meio" podem ser classificados em ordem de maior para menor proximidade, respectivamente, o EC2 e o EC3. Por fim, o EC1 é o caso que mais distancia da nova economia em termos de características organizacionais.

\subsection{Estudo de caso 1: indústria de TI}

A EC1 é uma indústria de TI que atua no ramo de equipamentos para transmissão de dados, voz e vídeo. A empresa está localizada em um distrito industrial da RMPA desde 2001. Esse distrito industrial abriga empresas de diversos ramos e existe desde meados da década de 1970. A EC1 foi fundada em 1966 no município de Porto Alegre e, inicialmente, suas atividades eram voltadas para o desenvolvimento de produtos eletrônicos de telecomunicação e alarmes para o setor bancário. Em meados da década de 1970, a empresa desenvolveu em parceria com a Universidade Federal do Rio Grande do Sul (UFRGS) o primeiro aparelho de Modem nacional ${ }^{55}$. Assim, a empresa foi nacionalmente uma das pioneiras neste tipo de tecnologia e também no estabelecimento de uma parceria de Pesquisa \& Desenvolvimento (P\&D) com um estabelecimento de ensino superior. Esse pioneirismo se deve em grande parte ao perfil profissional do fundador da empresa, que foi professor universitário de Eletrônica na mesma instituição parceira. A partir de meados da década de 1980, a EC1 passou a se dedicar ao segmento de telecomunicações, produzindo aparelhos de transmissão de

${ }^{55}$ A palavra Modem é formada da união de palavras modulador e demodulador. Consiste em um aparelho utilizado principalmente para conexão à Internet e que modula um sinal digital numa onda analógica para depois demodular e reconverter o sinal analógico para o digital. 
dados e de rede. Na década de 1990, a empresa acompanhou o crescimento do setor de telecomunicações no Brasil, especialmente ao final da década quando começaram as privatizações e a quebra do monopólio estatal, participando ativamente no desenvolvimento de produtos de tecnologia ADSL (Asymmetric Digital Subscriber Line) ${ }^{56}$. Em 2007, a firma passa a produzir produtos utilizando tecnologia de transmissão de dados sem fio. No ano seguinte, ocorre o falecimento do fundador da empresa, passando a administração ser feita por um conselho de gestores e a presidência a ser ocupada pela filha do fundador. A história da EC1 aponta, assim, para um perfil de empresa com atuação tradicional no setor de tecnologias da informação no segmento de telecomunicações, com imagem e trajetória bastante ligadas ao seu fundador e atuação de destaque no mercado nacional.

Atualmente, a EC1 produz aparelhos para a transmissão de dados, voz e vídeo, como Modems, roteadores ${ }^{57}$ e multiplexadores ${ }^{58}$ para tecnologias de redes de fibra óptica e sem fio. Ela trabalha tanto com o desenvolvimento e manufatura de produtos dessa área como atua como electronic contract manufactured, ou seja, monta e testa produtos cuja concepção e componentes advêm de outras empresas. Ademais, a empresa conta com um serviço de assistência técnica.

O chão de fábrica é silencioso, aclimatizado por ar-refrigerado e com espaços separados para as seguintes operações: expedição e almoxarifado, teste e assistência técnica, produção e montagem de componentes e equipamentos, prototipagem, $\mathrm{P} \& \mathrm{D}$ e administração. Todas essas operações estão situadas na mesma construção de dois andares. No térreo estão localizadas as atividades de produção, assistência técnica e prototipagem e acima estão situados os escritórios da administração, as salas de reunião e a área de pesquisa e desenvolvimento.

Expedição e almoxarifado, também no pavimento térreo, executam as atividades de embalagem, separação e armazenagem de equipamentos e componentes eletrônicos. A área de teste e assistência técnica consiste de vários balcões nos quais os técnicos estão sentados em estações de trabalho contíguas porém individuais, realizando seja o teste de equipamentos que saíram da produção, seja o conserto de produtos que vieram

\footnotetext{
${ }^{56}$ Trata-se de um sistema de transmissão de dados via linhas de telefone. Foi largamente utilizado para o acesso à Internet, mas atualmente somente está presente entre alguns usuários residenciais.

${ }^{57}$ Aparelho usado para transmitir uma rede de Internet ou a comunicação entre diferentes redes de computadores.

${ }_{58}$ Dispositivo que serve para codificar informações de duas ou mais fontes de dados em um canal.
} 
com defeito de dentro ou de fora da fábrica. O setor de produção e montagem possui um espaço no qual estão máquinas dedicadas à produção de placas eletrônicas e outro espaço para colocação de componentes nas placas eletrônicas e para o processo de montagem dos produtos como um todo. Existe uma sala, próxima à área da produção e montagem, dedicada ao teste e desenvolvimento de protótipos. No segundo pavimento, além dos escritórios comerciais, de recursos humanos e do conselho gestor, há o laboratório de P\&D.

A EC1 foca comercialmente no mercado nacional, onde se defronta com outras empresas concorrentes. Tem na sua lista de clientes tanto empresas privadas de vários portes como instituições e empresas governamentais. Com o recente falecimento do fundador, a EC1 estava passando por transformações tanto na área comercial como na de gestão de recursos humanos e no processo produtivo. A entrada da nova presidente deflagrou uma iniciativa no sentido de reestruturar a relação entre os setores da empresa e seus respectivos gestores de área. Estava se promovendo um modelo que aumentasse a comunicação e articulação das iniciativas e ações de contratação, desligamento, avaliação e incentivo de funcionários. Até então, cada gestor de área técnica desenvolvia isoladamente essas iniciativas; após a entrada da nova presidente, estava-se implementando práticas para trabalhar em grupo essas ações. Como será visto nos capítulos seguintes, esse processo influenciou na organização da capacidade de cálculo de valor que a firma executa no mercado de trabalho.

Desde o início, a empresa tem uma preocupação em acompanhar ou mesmo liderar inovações tecnológicas no seu mercado de produtos. Tal estratégia é visualizada pela manutenção e aprimoramento de um departamento dedicado a P\&D e outro a prototipagem. Essas áreas são compostas por profissionais de nível superior da engenharia eletrônica e informática com experiência em pesquisa acadêmica. Essa estratégia visando à inovação é concretizada através de convênios com Universidades da região e a obtenção de financiamentos a projetos obtidos junto a instituições de fomento como a FINEP (Financiadora de Estudos e Projetos) vinculada ao Ministério de Ciência, Tecnologia e Inovação. Somada à estratégia para inovação, a EC1 possui a preocupação para o aumento da eficiência do processo produtivo visando à garantia de padrões de qualidade. Isso é fundamental para o atendimento ao mercado de electronic contract manufactured que requer padrões mínimos de qualidade, como as certificações ISO, com custo baixo na manufatura dos produtos. 
Nas entrevistas foi mencionado que o mercado de produtos de TI do segmento de telecomunicações possui variações intensas de demanda. Essas variações seriam determinadas, de um lado, pela presença ou não de grandes projetos governamentais ligados à infraestrutura de telecomunicações e, de outro, pelas decisões de predominância de certas tecnologias de transmissão de dados e de tipo de sinais, que causam a adoção de certos tipos de equipamentos; ou seja, uma vez que o mercado e/ou o governo definem a adoção de um padrão tecnológico de telefonia móvel como a $3 \mathrm{G}^{59}$, há uma expansão da demanda de equipamentos de transmissão de dados que utilizem esse padrão.

No momento em que foi realizada a pesquisa junto à EC1, ela contava com aproximadamente 230 funcionários, incluindo temporários (12) e estagiários (10). Desse total, cerca de 130 estão envolvidos nas atividades de fabricação, teste e assistência técnica dos produtos, além de 23 engenheiros envolvidos em $\mathrm{P} \& \mathrm{D}$. $\mathrm{Na}$ área de produção, o perfil de qualificação é o de nível de ensino médio ${ }^{60}$ (especialmente, o técnico na área de eletrônica) e/ou experiência profissional nos segmentos industriais de TI ou eletrônica. Constatou-se também nas atividades de produção, uma presença expressiva de mão de obra feminina ${ }^{61}$.

Até cerca de dois a três anos atrás, a EC1 contava apenas com um departamento de pessoal composto por duas pessoas que, basicamente, cuidavam de procedimentos burocráticos como folha de pagamento e registro de autorização de licença. Portanto, a existência de um setor dedicado à gestão de recursos humanos é algo recente na empresa, sendo que, antes, muito das decisões de contratação e avaliação de funcionários eram de responsabilidade dos gestores diretamente envolvidos no chão de fábrica. Assim, a EC1 estava consolidando o departamento de recursos humanos quando da pesquisa desta tese. O RH contava, então, com três profissionais: uma coordenadora de RH, uma analista de departamento de pessoal e uma técnica em segurança do trabalho. Somente a analista participava do modelo de gestão anterior; a atual coordenadora foi deslocada da área comercial e passou a implantar a estrutura e atuação de um setor de RH na empresa. Por isso mesmo a EC1 estava ainda formalizando um

${ }^{59} 3 \mathrm{G}$ significa a terceira geração de padrões e tecnologias de telefonia móvel.

${ }^{60}$ Isso é consistente com o que se identificou no capítulo 3, onde, na indústria de TI do Rio Grande do Sul, a maior parte dos vínculos de trabalho demandados eram com ensino médio completo, $39,6 \%$ em 2010.

${ }^{61}$ Conforme analisado nos dados da RAIS, a indústria de TI do RS registrou 36,5\% de participação feminina nos vínculos em 2010. Isso faz cogitar que o alto índice de mulheres na EC1 pode estar relacionado com algum aspecto no mercado de trabalho da região, pois nas entrevistas não foi mencionada uma política ou orientação para privilegiar a contratação de mulheres. 
plano de cargos e salários, criando programas de avaliação e de benefícios e estabelecendo procedimentos e técnicas para recrutamento e seleção de novos funcionários. Por fim, o setor de RH ainda recebia assessoria externa jurídica e contábil para a parte previdenciária e trabalhista e, por vezes, utilizava uma agência de recrutamento e seleção, especialmente para contratações de profissionais da área de segurança, limpeza e alimentação da firma. Portanto, mesmo sendo uma empresa tradicional e pioneira na área de TI no Brasil, ela apenas recentemente havia começado a por em execução um departamento e políticas de gestão de recursos humanos. Nas entrevistas foi relatado que essa situação ocorreu em função do perfil de liderança do fundador da empresa e do fato que, recentemente, houve uma grande ampliação da demanda no mercado de produtos e maior nível de exigência de atualização tecnológica. Por essas razões, a direção e a presidente da empresa identificaram a necessidade de ter uma política e um setor de gestão de RH na empresa para melhor lidar com essas mudanças externas e internas da EC1.

\subsection{Estudo de caso 2: empresa de software por encomenda e customizável62}

Empresa multinacional europeia, a EC2 foi fundada no início da década de 1970 por engenheiros e ex-funcionários de uma conhecida multinacional norte-americana da área de tecnologias da informação. Após um ano da sua fundação, a empresa lançou seu primeiro produto de software para contabilidade financeira e, desde então, vem desenvolvendo produtos voltados para gestão de negócios em tempo real. Mas foi no final da década de 1970 que a EC2 cria seu primeiro produto de destaque, um conjunto de módulos de software para computação de mainframes ${ }^{63}$ e que, até meados de 1995 , esse produto era utilizado por cerca de duas mil empresas ao redor do mundo. Nos anos de 1980, a empresa cresce rapidamente no seu segmento, conquistando grandes clientes da área corporativa, ou seja, empresas multinacionais europeias. Como resultado dessa expansão, a empresa passa se preocupar em adaptar seu software para trabalhar em diferentes idiomas e com diferentes moedas e realidades econômicas.

\footnotetext{
${ }^{62}$ Nesta pesquisa, a diferença entre software customizável e por encomenda é compreendida da seguinte maneira: no primeiro caso, a empresa já tem uma plataforma de software própria e/ou de outrem e adapta essa plataforma conforme as necessidades do cliente ou ramos de atividades econômicas ou a realidade nacional; em contraste, o software por encomenda é um programa criado única e exclusivamente para cada cliente.

${ }^{63}$ Computadores mainframes são equipamentos de grande porte dedicados ao processamento de grandes volumes de dados.
} 
No meio da década de 1980, a EC2 funda a sua primeira central de vendas, ainda na Europa, mas fora de seu país de origem ${ }^{64}$. Também nesse período, a EC2 se torna multimilionária e, ao final daquela década, suas ações passam a ser negociadas em bolsas de valores europeias e mantém uma forte expansão de abertura de filiais nas principais cidades da Europa e dos Estados Unidos.

No início da década de 1990, a EC2 lança um novo produto, abandonando a tecnologia de computação em mainframes para "arquitetura cliente-servidor" ${ }^{65}$, que é utilizada no setor de softwares até hoje. Esse novo produto reúne diversas aplicações que lidam com quase todas as atividades de gestão de uma grande empresa, ou seja, contabilidade, finanças, vendas e recursos humanos. Cada módulo é responsável por cerca de mil processos de negócios, processando informações em tempo real e configuráveis através de mais de oito mil tipos de tabelas, responsáveis pela organização desde a estrutura financeira da empresa até a política de descontos aos clientes. Em 1995, a empresa abre sua primeira subsidiária no Brasil e, ao final da década, a EC2 aparece pela primeira vez no pregão da Bolsa de Valores de Nova York, além de iniciar o desenvolvimento de produtos na área de comércio eletrônico.

No início dos anos 2000, a EC2 torna-se uma entre as três maiores empresas do mundo fornecedoras independentes de softwares e foca no desenvolvimento de tecnologias para a Internet. No meio da década de 2000 é inaugurada a unidade da EC2 na qual foi realizado o levantamento para o estudo de caso. Essa unidade é a primeira na América Latina dedicada ao serviço de suporte ao cliente e ao desenvolvimento de softwares. Em 2011, através da aquisição de outra empresa, a EC2 se torna uma das maiores empresas no mundo no segmento de "computação em nuvem ${ }^{66 "}$.

A EC2 está presente em mais de 100 países, com faturamento multibilionário e mais de 200 mil clientes no mundo. Desse modo, a empresa exerce uma posição de liderança global no mercado de softwares para gestão de negócios. Suas ações são negociadas nas principais bolsas de valores do mundo e atualmente conta com mais de 60 mil funcionários. A unidade na qual foi realizado o estudo de caso está localizada em um parque tecnológico da uma grande universidade privada da região metropolitana de

\footnotetext{
${ }^{64}$ Não é mencionado o país de origem para não violar o compromisso de pesquisa de sigilo com a empresa.

${ }^{65}$ Modelo computacional que funciona através da separação entre usuários e servidores numa rede de computadores. Os servidores são requisitados por cada cliente (usuários) da rede para o processamento de dados ou o compartilhamento de recursos como impressão e arquivamento de dados.

${ }^{66}$ Tecnologia que utiliza a capacidade de memória, processamento e cálculo de computadores e servidores interligados pela Internet.
} 
Porto Alegre, onde ocupa um prédio construído em meados dos anos 2000. Essa construção possui a característica de ter sido um projeto arquitetônico que segue padrões internacionais de certificação ambiental. Localizar-se numa universidade tem permitido à EC2 firmar convênios com a instituição na qual está sediada e outras de ensino superior de Porto Alegre e região metropolitana. As ações em parceria com as universidades abrangem desde a participação em feiras, organização de eventos, palestras e cursos, assim como a manutenção de programas de estágios.

A EC2 é responsável por três tipos de atividades ligadas aos produtos de softwares para gestão de empresas: suporte e assistência técnica aos clientes, desenvolvimento de software sob medida e customização para clientes, principalmente mas não restrito à América Latina. Essa última atividade se refere não somente às modificações e adaptações feitas no software segundo as necessidades de um cliente, mas também à adaptação segundo legislações, moedas e idiomas da região dos clientes (o que eles chamam de "localização do produto"). Cada uma dessas atividades conta com profissionais de diferentes níveis de senioridade, trabalhando em equipe com um gerente. Com exceção das operações de suporte, todas as áreas técnicas possuem flexibilidade de horário, liberdade para trabalhar em casa e o ritmo de trabalho é determinado por projeto. Portanto, trata-se de uma unidade voltada para atividades técnicas e menos para atividades comerciais.

Essa unidade e a EC2 de maneira geral possuem foco na relação com clientes de empresas de grande porte, mas através de parcerias com outras empresas, ela fornece suporte e treinamento para revendedoras que atuam com clientes de menor porte. Os clientes são empresas atuantes em diferentes áreas de atividades econômicas: desde indústrias de processos e de base, passando pelos serviços do setor público e pelo setor bancário e financeiro, chegando até grandes redes do comércio varejista. Além disso, a empresa possui ações de responsabilidade social e ambiental com a comunidade local e regional da unidade.

No Brasil, a EC2 possui cerca de 1.500 funcionários. A sede da subsidiária brasileira está localizada no município de São Paulo e a unidade pesquisada na RMPA, abriga por volta de um terço do total de funcionários sediados no Brasil. Do seu efetivo total, que alcança poucos mais de 500 funcionários, a unidade da EC2 aloca mais de $90 \%$ nas suas atividades-fim. Isso é coerente com uma firma que define seu modelo de gestão como flexível, "lean and flat", isto é, com reduzidas hierarquias de gestão. Todos os funcionários da unidade são fluentes em inglês, uma vez que precisam lidar com 
clientes ao redor do globo e interagir com outras unidades da EC2. Por ter atividades com foco na América Latina, o espanhol é considerado como segundo idioma na empresa, porém nem todos os funcionários têm essa proficiência. Há um foco na contratação de profissionais jovens e recém-formados em curso superior na área de TI (apesar disso, a média de idade da força-de-trabalho é por volta de 28 anos, isto é, próxima à média brasileira e à gaúcha que giram em torno de 30 anos para o segmento de serviços de TI). Menos de 1\% das contratações ocorrem via agências de empregos, sendo a grande maioria através da atividade de recrutamento feita por uma parte do setor de recursos humanos da EC2, dedicada a essa função ${ }^{67}$.

Por ser uma empresa de capital aberto, o RH da unidade pesquisada está subordinado a uma estrutura de gestão que chega ao Conselho Executivo Geral da empresa. No capítulo 7 é analisado esse fluxograma e a rede de agentes que estabelecem as decisões de recursos humanos da EC2; por enquanto, cabe apenas descrever a organização do RH da unidade pesquisada. Esse setor é composto por: uma Diretora de Recursos Humanos da unidade ${ }^{68}$ cuja função consiste lidar com a articulação das ações de gestão de pessoas com as demais gerências de dentro e fora da unidade, visando à atração, motivação e retenção de profissionais; uma equipe de Operações de Departamento de Pessoal com quatro funcionários que cuidam da parte de folha de pagamento, benefícios e de registro de transferência, desligamento e contratação; um grupo de três pessoas dedicadas às operações de treinamento, de avaliação, de incentivos e de carreiras; mais duas pessoas encarregadas da parte de recursos e equipamentos, por exemplo, definição da aquisição e modelos de mesas, notebooks e celulares, etc.; e duas recrutadoras encarregadas das ações de atração de candidatos para preenchimento de vagas e da organização do processo de seleção desses candidatos. Cabe destacar que foram realizadas entrevistas com a Diretora de Recursos Humanos e com as duas recrutadoras.

No memento da pesquisa junto à EC2, as operações de RH estavam visando à ampliação das contratações em razão da expansão da unidade através da construção de outro prédio. Essa ampliação dobraria o número de funcionários da unidade gaúcha.

${ }^{67}$ Cabe mencionar que as contratações de atividades periféricas - serviços de limpeza, segurança e transporte - não são de responsabilidade da equipe de RH da unidade da EC2. Estas contratações são definidas na matriz da subsidiária brasileira da empresa em São Paulo.

${ }^{68}$ É digno de nota que os cargos têm nomes em inglês na EC2 que lhe são bem característicos, incluindo adjetivações baseadas no nome da empresa. Para a melhor compreensão do leitor e para manter o anonimato da empresa, escolheu-se fazer uma tradução livre e não literal desses nomes. Ainda importante notar é que o uso de nomes em inglês denota uma padronização global da EC2 nas suas políticas e atividades de recursos humanos. 
Também havia a preocupação de alcançar as primeiras posições de um ranking de melhores empresas para se trabalhar na área de tecnologia, classificação essa estabelecida por uma revista da área de tecnologias da informação.

Por fim, a EC2 tem como política de atração e retenção de funcionários a disponibilidade de uma "cesta" de benefícios, que é composta conforme as preferências pessoais do profissional. Nesta cesta há vale-refeição, previdência privada, plano de saúde e odontológico, vale transporte, estacionamento ou ônibus da empresa, convênio de descontos com academias de ginástica ou cursos de línguas, bônus anual, etc. Além disso, a EC2 disponibiliza ações para o bem-estar dos seus empregados como, por exemplo, a visita e atendimento de um consultor financeiro pessoal.

\subsection{Estudo de Caso 3: empresa de software customizável}

A EC3 é uma empresa pioneira no Brasil e na América Latina na área de produção de softwares customizáveis para gestão de negócios. Criada no início da década de 1980 no Brasil, ela era um empreendimento submetido a uma tradicional empresa nacional de hardware e fruto da iniciativa de um executivo dessa mesma empresa. Inicialmente a EC3 era voltada para o desenvolvimento de softwares de gestão para pequenas e médias empresas e, ao longo da década de 1980, ela desenvolveu produtos próprios, conquistando clientes e crescendo ao ponto que, no final daquela década, a EC3 incorpora a empresa na qual ela tinha começado.

Nos anos 1990, a EC3 direciona suas atividades para a expansão, consolidação de certificação de qualidade e busca de capitalização. A expansão ocorreu por meio de uma estratégia inédita no setor de software, a saber, a abertura de novas unidades através da criação de franquias. Em meados da década de 1990, a EC3 consegue a certificação ISO e abre sua primeira unidade no exterior. Ao final daquela década, a empresa desenvolve a sua própria linguagem de programação e estabelece parceria com um fundo de investimento estrangeiro. Nesse momento, a EC3 já era uma empresa multimilionária, sua estratégia de expansão via franquias havia dado certo e também conseguiu se tornar a holding de diversas empresas do setor de tecnologias da informação no país.

Nos anos 2000, a empresa continua com a estratégia de expansão via franquias e aquisições, mas em meados da década, encerra a sociedade com o fundo de investimento estrangeiro. A estratégia de expansão por franquias e aquisições estabeleceu um processo de concorrência entre as empresas nacionais de software, no 
qual a EC3 foi bem sucedida a ponto de conseguir comprar as suas duas principais concorrentes. Uma dessas aquisições ficou conhecida por ter sido feita em parceria com o Banco Nacional do Desenvolvimento (BNDES) que também ajudou a empresa a se tornar um grande empreendimento de nível internacional na área de software para empresas (nesse sentido, cabe destacar que, ao final da década de 2000, a EC3 abriu sua primeira unidade na Europa). Além disso, outro elemento que permitiu o crescimento de empresa multimilionária para bilionária foi o lançamento das negociações de ações da EC3 na Bolsa de Valores de São Paulo. Esse crescimento provocou a mudança para o nome atual da empresa.

Ao fim dessa história, a EC3 atualmente conta com quase 30 mil clientes, sendo a empresa com a maior participação no mercado de software no Brasil. Possui cerca de 10 mil funcionários em pouco mais de 20 países, ocupando posição de destaque no mercado mundial e latino americano de software para gestão de negócios, sendo considerada a maior empresa de países emergentes desse setor. No estado do Rio Grande do Sul, a empresa conta com cerca de 300 empregados, divididos em duas unidades, e por volta de 800 clientes. A unidade pesquisada foi fundada em 2010 e está localizada no parque tecnológico de uma universidade privada em Porto Alegre. Ela possui mais de 250 funcionários, dos quais cerca de 20 deles não estão envolvidos na atividade-fim da EC3.

Nacionalmente, a empresa desenvolve softwares e oferece serviço de suporte para clientes provenientes de doze setores de atividades: agricultura, construção civil, arquitetura, logística, transporte, educação, serviços financeiros, serviços jurídicos, indústria, saúde, serviços e varejo. A estratégia de negócios está direcionada para pequenas e médias empresas, porém a EC3 possui clientes de grande porte. No caso estudado, prioriza-se o desenvolvimento de softwares para empresas de serviços financeiros e de saúde. Por isso, as atividades e carreiras concentram-se em dois grandes grupos de profissionais, quais sejam: aqueles com experiência e conhecimento comercial e de gestão dos ramos de negócios de saúde e finanças e, assim, relacionamse mais diretamente com os clientes da EC3; e o segundo grupo, composto de profissionais mais diretamente ligados à área técnica de desenvolvimento de software. Essa divisão não é absoluta, isto é, os profissionais que lidam com os clientes devem ter conhecimentos da área técnica e vice-versa. O trabalho é realizado em grupo, porém 
cada profissional possui seu espaço próprio de trabalho em mesas com divisórias, denominadas de "baias" 69.

Conforme descrevemos, a EC3 investiu na estratégia de expansão via aquisições de outras empresas na área de tecnologias da informação e abertura de franquias. Uma vez que o desenvolvimento de software como atividade econômica depende quase que exclusivamente do conhecimento produzido pelas equipes de profissionais que compõem as empresas, a EC3 teve que desenvolver a habilidade de também incorporar as equipes de profissionais das empresas adquiridas e não perder esse conhecimento acumulado. Adiante será visto que o caso estudado por ser uma franquia aberta em razão da compra de duas empresas locais, a retenção dos profissionais das antigas empresas teve impacto nas estratégias de gestão de recursos humanos desta unidade que pesquisada.

Também cabe mencionar que, na unidade estudada, o setor de recursos humanos estava em fase de consolidação e tinha efetivamente começado suas atividades em meados de 2011. Assim, especificamente nessa unidade de Porto Alegre, estava-se iniciando um processo de conscientizar os gestores das áreas técnicas para a necessidade de comunicação e de articulação com o RH, planejando e combinando ações de relacionamento com as suas respectivas equipes. Ademais, foi somente a partir de 2012 que a empresa começou a elaboração de uma política de recursos humanos unificada para todas as unidades. Até então, a gestão de RH estava sendo adaptada muito em função das especificidades de cada unidade, especialmente no que se refere ao desafio de lidar com as equipes de profissionais das empresas adquiridas ${ }^{70}$. Também estava em fase de elaboração a definição de um plano de cargos e carreiras. Todo esse processo de padronização tem tido como objetivo principal consolidar práticas e atitudes visando à inovação, entre os funcionários da empresa.

Por ser um setor novo na unidade estudada, o RH também assumiu a função de administração de suprimentos de equipamentos e materiais de escritório, manutenção predial e registro e encaminhamento de hospedagem e viagens. Além disso, a equipe de RH cuida de operações de avaliação, treinamento, recrutamento, seleção, programa de estágio, promoção, carreira e gestão de clima e comunicação organizacional. Por fim, realiza também as atividades típicas de um departamento de pessoal, ou seja, elaboração

\footnotetext{
${ }^{69}$ Importante destacar essa denominação porque representa uma empresa com políticas de gestão e ambiente de trabalho mais tradicionais, formais e menos flexíveis.

${ }^{70}$ Nos últimos dez anos, a EC3 adquiriu quase 50 empresas.
} 
de folha de pagamento, relação com o sindicato, registro e autorização de férias e licença. Assim, quando do período das entrevistas, o RH da unidade pesquisada era composto por um coordenador e duas analistas, sendo que uma delas tinha como função, entre outras coisas, a parte de recrutamento e seleção; subordinas às duas analistas existiam ainda três assistentes, e planejava-se a contratação de um estagiário. A unidade apenas utilizou agência de emprego para recrutar profissionais portadores de deficiência física. Por fim, estava se consolidando um programa de benefícios composto por vale-refeição, programa de participação nos lucros e plano de saúde e odontológico.

\subsection{Estudo de Caso 4: empresa de consultoria e desenvolvimento de software por encomenda}

Fundada nos Estados Unidos no final da década de 1980, a EC4 assumiu o nome que tem hoje no início dos anos de 1990, quando sofreu uma aquisição. Desde então, a empresa tem sido internacionalmente reconhecida por sua liderança em projetos Open Source e de "métodos ágil" de desenvolvimento de softwares. Open Source são projetos nos quais o código-fonte de um programa de computador é aberto para o uso, cópia, distribuição e estudo. O método ágil é uma proposta que reúne diversas metodologias de desenvolvimento de software fornecendo uma estrutura conceitual para reger projetos. Durante a década de 1990, a EC4 também se dedicou a ser uma referência no desenvolvimento de softwares utilizando as linguagens de programação "C++", "Forte 4GL" e "Java". A década de 1990 também foi marcada pela consolidação comercial e financeira da EC4 e, ao final daquela década, deu-se a abertura do seu primeiro escritório regional de operações nos Estados Unidos; ou seja, até então a empresa somente funcionava numa sede.

Os anos 2000 foram um período de vertiginoso crescimento financeiro e de operações para EC4. Com a reputação de empresa inovadora já consolidada, a EC4 abriu, nesse período, escritórios em diferentes países de todos os continentes, começando pela Oceania. Expandiu sua capacidade tecnológica utilizando as seguintes plataformas para desenvolvimento de software e aplicações: “Dot Net Framework", "Ruby" e "Ruby on Rails". Também iniciou um processo de abertura de unidades dedicadas à criação, ao suporte e à venda de produtos para projetos de método ágil e ferramentas e aplicações para o desenvolvimento de softwares. Nesse período entraram para a EC4 as suas principais lideranças em nível global nas áreas de gestão financeira, comercial e tecnológica. Ao final da década de 2000, a empresa lança um programa 
global de responsabilidade social que, como será exposto nos capítulos seguintes, está fortemente integrado ao modelo de negócios da EC4. Esse programa inclui ações de desenvolvimento de software e de consultoria com preços reduzidos para organizações filantrópicas e missões de ajuda internacional, serviços Pro Bono tanto para organizações sociais como para organizações humanitárias com projetos Open Source de software ${ }^{71}$.

Atualmente a EC4 é uma empresa que oferece serviços de consultoria de projetos de software, desenvolve softwares por encomenda e atua na produção de aplicações e plataformas para desenvolvimento de softwares. É uma empresa que pertence a um grande grupo com mais de mil clientes corporativos no mundo. $\mathrm{O}$ grupo possui escritórios em mais de dez países, empregando mais de dois mil funcionários. Seus clientes são empresas nas áreas de comércio eletrônico, educação, saúde, varejo, tecnologia da informação, transporte, turismo, mídia e entretenimento. Além disso, atende organizações sem fins lucrativos e governos. Especializou-se em clientes com projetos de alta complexidade e de fronteira tecnológica. Todavia, tem por preferência em não travar relações comerciais com empresas que exercem ações que desrespeitem valores de responsabilidade social e ambiental.

A unidade na qual foi realizado o estudo de caso fica em um parque tecnológico universitário na cidade de Porto Alegre. Foi fundada ao final da década de 2000, sendo a primeira unidade da EC4 na América Latina e possui pouco mais de cem funcionários, sendo cerca de $80 \%$ deles dedicados à atividade-fim da empresa. Recentemente, a EC4 está ampliando suas operações para o Norte e Nordeste brasileiro com a abertura de um escritório em Recife.

A EC4 tem uma forte cultura voltada a manter escritórios com estruturas organizacionais horizontalizadas, evitando a hierarquização. Da mesma forma adota globalmente uma orientação segundo a qual nenhuma unidade deve ter mais que cerca de 150 funcionários, mantendo assim um senso de "comunidade". O processo de trabalho é realizado em grupos e por projetos. Para viabilizar essas orientações, nas unidades, inclusive na que foi pesquisada para esta tese, as mesas de trabalho são coletivas e sem estações individuais, equipamentos como notebooks e computadores são

\footnotetext{
${ }^{71}$ Observa-se neste momento uma abertura da empresa para a multiplicação e adensamento de relações externas à EC4 com vistas ao processo contínuo e sistemático de inovação tecnológica. Em suma, a EC4 é, entre os casos estudados, a que melhor expressa aquela tendência de adensamento e aumento de complexidade das redes sociotécnicas apontada por Michel Callon a respeito da nova economia (CALLON, 2007; CALLON; MÉADEL; RABEHARISOA, 2002).
} 
frequentemente divididos por duplas, as salas existentes servem apenas para reuniões e há a presença de espaços de convivência informal, por exemplo, para jogar vídeos games.

Seguindo ainda o princípio de redução de hierarquias e divisões, a EC4 está organizada em apenas uma divisão de dois grandes grupos: o de "Serviços Profissionais" e o de "Operações", a saber, os que realizam as atividades técnicas e os que se dedicam a questões operacionais tais como a seleção e o gerenciamento de pessoal, finanças, suporte técnico, consultoria jurídica, marketing, entre outros. Essas divisões e os seus respectivos cargos recebem nomes bem particulares à empresa, inclusive havendo a orientação de não nominar o setor de recursos humano como tal em razão da sua estrutura reticular e descentralizada com gestores alocados fora da unidade. Na parte técnica, os funcionários trabalham em grupos formados para um projeto de um cliente específico, ou seja, assim que o projeto termina, o profissional poderá trabalhar com pessoas diferentes, formando um grupo diferente e inclusive utilizando linguagens de programação e tecnologias diferentes - esse modelo de trabalho implica em um alto grau de polivalência nas tarefas técnicas, comercial e de gestão. A parte de recursos humanos opera com duas divisões: uma voltada para atividades relacionadas ao recrutamento e seleção e outra para desenvolver ações e rotinas ligadas à gestão de pessoas e procedimentos de departamento de pessoal.

A alocação de pessoas que estruturam a parte de RH da unidade está, então, distribuída da seguinte maneira: um Diretor Geral para cada unidade do Brasil; uma Coordenadora de Recrutamento que, no momento da pesquisa, estava no recém-aberto escritório de Recife; duas recrutadoras da unidade de Porto Alegre; uma estagiária atuante na organização do processo de seleção; e uma equipe para as atividades de gestão de pessoas e de departamento de pessoal, que é formada por um analista e um "people lead".

As políticas de recursos humanos são definidas globalmente numa estrutura em rede de gestores, mas profundamente adaptada para cada realidade local e para as preferências dos profissionais das unidades. Portanto, a EC4 possui várias características que a colocam inserida na lógica da nova economia. Relembrando, essa lógica pode ser definida a partir dos seguintes seis pontos: 1) se na etapa econômica anterior o paradigma de organização era a indústria voltada para o consumo de massa, na nova economia são atividades de serviços do segmento de tecnologias da informação as que se tornam paradigmáticas; 2) mais do que eficiência no processo produtivo, 
voltada para os ganhos de escala, a dinâmica competitiva e as estratégias comerciais das firmas na nova economia estão voltadas para o aprimoramento de suas capacidades e para o seu envolvimento sistemático em processos de inovação; 3) as relações de trabalho e de emprego são mais flexíveis, por exemplo, pela ausência de jornadas fixas de trabalho com a adoção de regimes como o trabalho por projeto e a diminuição de hierarquias de gestão, conferindo e esperando-se maior autonomia decisória de parte dos trabalhadores, formando ambientes de trabalho mais informais; 4) adoção de formas de organização marcadas pelo trabalho em grupo e pela polivalência; 5) maior valorização e nível de exigência de qualificações técnicas e comportamentais; 6) em contraste com o modelo de consumo de massa, há uma relação mais personalizada entre produtores e clientes gerando a customização de produtos e serviços. Por fim, tendo em vista esses seis pontos e as descrições dos casos feitas até aqui, podemos classificá-los do mais longe ao mais próximo das tendências da nova economia, da seguinte maneira: EC1, EC3, EC2 e EC4. 


\section{AS REDES SOCIOTÉCNICAS DAS FIRMAS}

Este capítulo é dedicado ao esforço em definir as redes sociotécnicas das quatro empresas nas quais foram realizados os estudos de caso. Tal esforço foi guiado por duas perguntas:

1) Quais são os agentes humanos e os dispositivos de cálculo (agentes nãohumanos) que compõem a rede sociotécnica da firma?

2) Quais são as combinações de relações entre esses agentes e dispositivos?

A primeira pergunta visa a identificar e descrever os agentes em relação na rede sociotécnica, os quais podem ser pessoas, organizações, conhecimentos, artefatos tecnológicos, protocolos e técnicas. É importante destacar que tanto os agentes (humanos ou não) como os tipos e as combinações de relações existentes são definidos em termos de suas funções na capacidade de cálculo de valor das firmas no mercado de trabalho, isto é, não se trata de definir e identificar todos os agentes e relações que ocorrem na firma, mas somente as que formam essa capacidade de agência no mercado de trabalho. A segunda pergunta, basicamente, trata de examinar "quem se relaciona com quem".

Ao responder às perguntas referidas acima, ao longo deste capítulo será inevitável não mencionar a que operações de cálculo as relações e agentes da rede sociotécnica se referem. Portanto, neste capítulo é apenas aludida essa correspondência entre certas relações sociotécnicas da rede e as operações de cálculo, pois este é o foco e objetivo do capítulo oitavo.

\subsection{Estudo de Caso 1: uma rede sociotécnica em transição e instável}

A EC1 é o caso que apresentou o menor número de agentes humanos e de dispositivos de cálculo na sua rede sociotécnica. A tabela abaixo lista os agentes identificados e que compõem a rede da EC1. 
Tabela 22 - Agentes humanos e dispositivos de cálculo na rede sociotécnica da EC1.

\begin{tabular}{|c|c|c|}
\hline & Agentes Humanos & Dispositivos de Cálculo \\
\hline $\begin{array}{l}\text { Direção Executiva e } \\
\text { Comercial }\end{array}$ & $\sqrt{ }$ & \\
\hline Gestores de Áreas Técnicas & $\sqrt{ }$ & \\
\hline Coordenadora de RH & $\sqrt{ }$ & \\
\hline $\begin{array}{c}\text { Técnica de Departamento } \\
\text { de Pessoal }\end{array}$ & $\sqrt{ }$ & \\
\hline Tabela de Salários & & $\sqrt{ }$ \\
\hline Programa de Benefícios & & $\sqrt{ }$ \\
\hline $\begin{array}{c}\text { Entrevista } \\
\text { Técnica/Profissional } \\
\end{array}$ & & $\sqrt{ }$ \\
\hline Entrevista Comportamental & & $\sqrt{ }$ \\
\hline Site da Empresa & & $\sqrt{ }$ \\
\hline Currículos & & $\sqrt{ }$ \\
\hline Banco de Currículos & & $\sqrt{ }$ \\
\hline Universidades & & $\sqrt{ }$ \\
\hline Site de Vagas de Emprego & & $\sqrt{ }$ \\
\hline
\end{tabular}

Fonte: Dados de Pesquisa de Campo.

Conforme visto no capítulo anterior, a EC1 estava passando por um processo de transformação na sua gestão, desencadeado pelo falecimento do fundador da empresa, que se manifestava, entre outras coisas, na formação e consolidação de um setor de recursos humanos responsável por tarefas além daquelas ligadas às de departamento de pessoal, isto é, montagem de folha de pagamento, registro e autorização de licenças e férias, etc.

O RH da EC1, a área [responsável pelo planejamento e execução das ações] de recursos humanos mesmo! É uma área que ainda está nova. A EC1 tem 45 anos, mas ela tinha o RH só como setor de departamento de pessoal, era uma área bem burocrática, que fazia basicamente a folha de pagamento. Não era o setor que lidava com a questão dos benefícios, nem do plano de carreira, nem de avaliação do funcionário. Com a chegada da [nome próprio] na presidência e com todas as mudanças de cultura que está acontecendo na EC1, nós montamos uma área de recursos humanos e dentro dos recursos humanos tem o departamento de pessoal, como uma das atribuições (Coordenadora de RH).

Assim sendo, a formação do RH acaba por ser também a reestruturação da rede sociotécnica da firma, construindo novas formas de relacionamento entre agentes e (novos) dispositivos de cálculo. Em outros termos, operações como recrutamento, seleção e contratação de novos funcionários passam a ter alteradas as relações sociotécnicas que lhes são subjacentes, com a entrada em cena do RH, pautado agora por uma atuação para além das funções de um mero departamento de pessoal.

Resumidamente, o sentido dessa transformação se configura da seguinte forma: operações ligadas ao cálculo econômico da firma no mercado de trabalho eram feitas 
autonomamente por cada gestor das áreas técnicas da EC1 por meio de uma relação direta com os membros da direção, ou seja, o processo de recrutamento e seleção era feito pelos gestores, cabendo à direção apenas aprovar ou não as novas contratações. A entrada do RH simboliza a alteração da rede sociotécnica da EC1 no sentido de maior interação entre esse setor, a direção e os gestores das áreas técnicas de produção e de P\&D. Simultaneamente, a construção desse processo de maior interação passa pela inserção de novos dispositivos de cálculo, como será visto a seguir.

O primeiro agente na nova rede é, obviamente, o RH, formado por três pessoas: a coordenadora, uma técnica de departamento de pessoal e outra técnica de segurança do trabalho. Entre essas três pessoas, a coordenadora é basicamente a responsável pelas operações de recrutamento, seleção e contratação. Formada em administração de empresas e cursando uma especialização em gestão de departamento de pessoal, a relação com esses conhecimentos orienta, em primeiro lugar, o projeto de formação do RH dentro da empresa.

Quando você assumiu o RH, que tipo de conhecimentos ou técnicas teve que aprender? E da sua formação, o que você teve que aplicar para exercer esta função?

Eu tive que, primeiro, começar a entender e me especializar na área de departamento de pessoal, porque o RH da EC1 é junto RH e DP, então eu tive que aprender bem como funciona a parte do departamento de pessoal. Então, eu tive que fazer... eu estou fazendo uma especialização em departamento de pessoal porque ele é muito burocrático. É folha de pagamento, é legislação, é benefícios... então, esse conhecimento eu tinha muito superficial. Com a especialização, eu agora começo mais a me aprofundar. O próximo! A pós-graduação mesmo eu quero fazer na área de gestão de pessoas mesmo. Para me aprofundar na área de $\mathrm{RH}$... porque na parte de $\mathrm{RH}$, eu tive que conhecer os cargos que a empresa tem... Então, um cargo de engenheiro júnior... O que ele faz? Que habilidades? Que conhecimentos ele precisa? Para eu recrutar? $\mathrm{Eu}$ recruto um engenheiro júnior numa faculdade ou num curso técnico? Um engenheiro júnior pode ser um técnico com seus quatro ou seis anos de carreira? O que a gestão prefere? Curso técnico ou recém-formado? Enfim, eu precisei entender como cada perfil, por exemplo, do P\&D funciona. Então, conhecer o perfil de engenheiro júnior, pleno, sênior... Os técnicos, saber o que eles fazem, que qualidades e competências eles precisam ter para cada um desempenhar o seu papel (Coordenadora de RH).

A formação acadêmica da coordenadora e a sua experiência prática dentro da empresa promoveram a participação de conhecimentos na rede sociotécnica da empresa, que, ao seu turno, configura o papel do RH como responsável por executar as políticas e a gestão das relações de trabalho, além da execução dos processos de recrutamento, 
seleção e contrato, sendo que antes eram basicamente levados a cabo pela relação de cada gestor de área técnica com a direção da empresa.

Além disso, a coordenadora e o conhecimento advindo da sua formação estão por trás da inserção de dois novos dispositivos de cálculo, ainda em formação no momento das entrevistas. O primeiro é a "nova cultura da empresa", que estava sendo concebida a partir da relação entre a coordenadora de RH e a direção da empresa. Portanto, a cultura passa a ser formada a partir do conjunto de práticas de gestão das relações de trabalho que, por sua vez, são concebidas com base no conhecimento advindo da formação acadêmica e experiência profissional da coordenadora que, então, responde às demandas dos membros da direção e dos gestores de área da EC1.

A nova cultura que está se formando na EC1 é bem legal porque está permitindo que as pessoas se sintam mais à vontade em sentar, conversar, ser atendidos. Então o RH está tendo um trabalho muito mais presente com os funcionários, com a diretoria e com as gerências, fazendo com que o retorno que a gente tem dos funcionários, seja um retorno melhor, positivo. Estamos começando a trabalhar com questões de ergonomia, de ginástica laboral, que antes... ou talvez as diretorias não tinham esta cultura ou o tempo do setor não era suficiente para fazer. Então a cultura está mudando bastante e o RH está ficando cada vez mais presente (Coordenadora de RH).

Assim sendo, a cultura da empresa acaba por ser mais um dispositivo em formação no sentido da sua influência no cálculo da firma no mercado de trabalho.

O outro dispositivo de cálculo elaborado através da relação entre coordenadora, conhecimentos acadêmicos e direção da empresa é o "plano de carreiras, cargos e salários".

Hoje, eu ainda estava falando com a presidente... porque às vezes a gente almoça juntas para justamente alinhar algumas questões do RH. A EC1 foi sempre muito departamento de pessoal e aí a empresa cresceu e o mercado está a mil com a questão de tecnologia! A gente precisa trabalhar com recrutamento e seleção, com recursos humanos. Então, a gente está buscando fazer plano de carreira, a gente está iniciando... a nosso ideia principal é isso: é trabalhar primeiro o $\mathrm{P} \& \mathrm{D}$, os engenheiros... fazendo o plano de carreira, estruturando cada cargo, estruturando setores internos do $\mathrm{P} \& \mathrm{D}$, para depois passar para a área industrial... essa é a ideia. [...] Porque chegou um momento que a gente viu que o nosso salário está abaixo do de mercado! Que a nossa estrutura física de prédios, não comporta mais a nossa quantidade de funcionários. Os nossos benefícios e atividades internas já não são mais suficiente para motivar. Por isso teve funcionários que saíram e falaram isso em entrevista de desligamento. Então, a diretoria começou a também a ser dar conta - "Não! Espera aí! Se eles estão saindo por causa disso, a gente está falhando". Então, a gente chegou à conclusão que era preciso desenvolver as carreiras dos funcionários e falar mais com eles. Então, nós estamos buscando fazer o plano de carreira, fazer melhor recrutamento... agora a gente está começando 
com tudo isso. [...] A direção aqui não tem o costume de impor e cobrar metas, mas hoje o que eu sou cobrada é o Plano de Carreiras, isso eu sou cobrada todos os dias (Coordenadora de RH).

Esse é um dispositivo que deve definir o cálculo da firma em termos de qualificações técnicas desejadas e de salários. O dispositivo "plano de carreiras" poderia definir orientações de recrutamento como, por exemplo, a questão mencionada sobre onde recrutar um engenheiro júnior, se em cursos técnicos ou em universidades? Já o dispositivo "plano de cargos e salários" poderia servir para direcionar operações de cálculo de seleção e contrato que ligam as qualificações, sobretudo técnicas, do candidato à faixa salarial dentro da empresa em que ele se encaixa ou mesmo se ele apresenta condições para preencher os requisitos da vaga que se pretende contratar na empresa.

Todavia, esse dispositivo, como mostrará mais claramente o extrato de entrevista abaixo, ainda não estava elaborado e plenamente em uso na EC1:

Como você percebe esse processo de elaboração do Plano de Carreiras, Cargos e Salários?

Olha eu não sei o que a [coordenadora de $\mathrm{RH}$ ] está estruturando. Porque pelo conhecimento que eu tenho agora, tu tem que começar a avaliar o perfil... tu tem que tentar entender as responsabilidades, por exemplo, de um engenheiro ou um projetista júnior, um sênior, assim por diante... Ela tem uma base que já passaram para ela sobre o que os funcionários desses cargos fazem, mas eu acho que ela teria que apagar tudo aquilo e fazer entrevistas, questionário para entender a responsabilidades e as habilidades e a partir disso começar aplicar! O quanto realmente esse profissional nesse cargo deve ganhar? Ah! Deve ganhar tanto porque a competência dele é essa. É preciso fazer avaliações de competências pra saber se eles estão adequados. Hoje, eu não vejo nada disso (Técnica de DP).

Portanto, dado esse status em formação do dispositivo de cálculo "Plano de Carreiras, Cargos e Salários", não há meios de se afirmar com segurança a sua participação na rede sociotécnica da firma que executa o cálculo de valor no mercado de trabalho.

Essa situação permanece, mesmo considerando um agente não-humano que o RH travava relação e, deste modo, adquire parte do conhecimento necessário à formação do plano de carreiras, cargos e salários, a saber, a "certificação ISO".

Agora no final do ano, a gente está sendo avaliado pela ISO. Então tem toda a documentação que a gente precisa colocar em dia. A [técnica de DP] está fazendo isso junto com os demais setores como uma auditoria da qualidade. E isso eu acho que vai ajudar muito entender o processo dos setores, ajudando a gente entender, então, como é que funciona... que tipo de pessoa a gente precisa na empresa naquele setor. Então é saber como é que eles trabalham? Como é o 
processo? Que tipo de profissional para cada área (Coordenadora de $\mathrm{RH})$.

Portanto, esse conhecimento adquirido que, em um momento seguinte seria materializado num dispositivo de cálculo como o plano de carreiras, cargos e salários, serve antes como dispositivo de cálculo para o RH determinar as qualificações técnicas demandadas pela EC1.

Cabe agora tratar de definir os dispositivos de cálculo com os quais a coordenadora do RH está em relação e que, ao contrário dos que foram abordados até aqui, já são consolidados e atuam mais diretamente nas operações de recrutamento e seleção. O primeiro deles é o "Banco de Currículos" que, no momento das entrevistas, consistia em pastas de arquivo no computador da coordenadora, na qual os currículos recebidos eram classificados pelos cargos que podiam ser ocupados pelos candidatos. Entretanto, já havia planos para adquirir uma aplicação para o software de gestão de recursos humanos que já era utilizado pela EC1. Essa aplicação possibilitaria melhor armazenar os currículos recebidos e as informações ligadas à seleção dos currículos em si e dos candidatos.

Nós recebemos por e-mail os currículos e... por exemplo, esses currículos aqui [aponta para uma pilha de currículos impressos em papel na mesa] nós recebemos lá na portaria, a pessoa passa e entrega pra gente. $\mathrm{E}$ os currículos que a gente recebe pelo site, a gente armazena pelo sistema da EC1 e fica guardado no nosso banco de currículos. Então, todos os currículos que nós recebemos [começa a mostrar as pastas na tela do computador] a gente coloca aqui nas pastas por áreas: P\&D, produção... Também pôr os processos que estão em aberto, em análise... E isso fica aqui no banco para que depois a gente possa consultar. A intenção é que a gente tenha controle de abertura de vagas... a intenção é ter um controle bem melhor disso. A gente está vendo com a nossa atual empresa do software de folha de pagamento, se têm e como são as aplicações de administração de pessoas, salários e de banco de currículos. Para, então, a gente ter armazenado e poder fazer uma pesquisa mais rápida (Coordenadora de RH).

Ao mesmo tempo, na EC1, esse dispositivo entra na relação do $\mathrm{RH}$ com os gestores das áreas técnicas na operação de seleção, pois é a partir dele que a coordenadora faz uma pré-seleção de currículos de acordo com os requisitos indicados pelo gestor da área em que a vaga foi aberta e, então, com base na leitura desses currículos, o gestor planeja as entrevistas com os candidatos.

Outro dispositivo de cálculo que se relaciona somente de modo direto com a coordenadora de recursos humanos são os sites de anúncio de vagas de emprego e de currículos - adiante apenas referido como "sites de emprego". 
Uma das maneiras que a gente recebe currículo é pelos sites. Nós temos acesso à Catho ${ }^{\circledR}$, InfoJobs ${ }^{\circledR}$, o Vagas ${ }^{\circledR}$... esse tipo de site que é banco de dados, né? E o baguete ${ }^{\circledR}$ que é mais da área de tecnologia (Coordenadora de RH).

Foram analisados os sites mencionados pela coordenadora e se constatou que esses são dispositivos que se diferenciam em dois tipos: 1) a firma apenas anuncia uma ou mais vagas em aberto em um espaço semelhante a um classificado de jornal. São sites voltados para o público de profissionais de tecnologias da informação e, portanto, não somente anunciam vagas de empregos, mas apresentam conteúdo de notícias do setor, agenda de eventos, colunistas escrevendo sobre tendências mercadológicas e tecnológicas, etc. O principal site deste tipo acessado pela EC1 é o baguete ${ }^{\circledR}$; 2) sites voltados para o anúncio de vagas de emprego por parte das empresas e/ou de currículos por parte de profissionais. Cada qual escolhe cobrar ou da empresa ou do trabalhador para anunciar. Normalmente, o candidato ou a empresa acessam ferramentas de busca com critérios geográficos, nível de qualificação educacional, área profissional ou de negócios, etc. Alguns desses sites apresentam seções específicas para o segmento de TI. A EC1 faz uso do InfoJobs.com.br ${ }^{\circledR}$, Catho ${ }^{\circledR}$ e o Vagas.com.br®.

As universidades são organizações que entram em relação na rede sociotécnica da coordenadora com vistas ao recrutamento. Essa relação ocorre através das seguintes formas.

E ainda,

Nós não tínhamos relacionamento com universidades, mas agora estamos procurando fazer. Uns dias atrás, eu fiz contato com a PUC [Pontifícia Universidade Católica de Porto Alegre] e cadastrei a EC1 para participar da feira de profissões. Justamente para colocar a EC1 no mercado, para colocar na "vitrine". Ano passado, os gestores de P\&D foram para UERGS [Universidade Estadual do Rio Grande do Sul] para também participar da feira de profissões e, de lá, eles trouxeram uma estagiária. Nós temos também os bolsistas na PUC, que são ou estudantes da engenharia elétrica ou da ciência da computação, e eles trabalham em projetos específicos com a EC1. Então, cada vez mais a intenção é aumentar mais o contato com as universidades.

Como funciona esse programa com bolsistas?

Os bolsistas trabalham lá dentro da PUC. Eles desenvolvem projetos específicos que o $\mathrm{P} \& \mathrm{D}$ usa para diversos produtos. Agora, eles estão trabalhando num projeto, eu acho, de VOIP [Voice over Internet Protocol] para integrar na nossa linha de produtos de GPON [Gigabitcapable Passive Optical Networks]. Então, eles recebem uma bolsa pelo trabalho realizado e também eles vêm aqui para, por exemplo, apresentar esse projeto pra toda equipe (Coordenadora de RH).

Que estratégias tu desenvolve na concorrência com outras empresas pelos profissionais das áreas de engenharia e da computação? 
Eu tinha falado que nós temos uma "salinha" lá na PUC, onde ficam os bolsistas. E é uma sala muito pequena! E do lado da nossa "minissala" tem a "megassala" da [nome de uma empresa concorrente da EC1]. Então, qual é a nossa estratégia? Vamos para dentro da PUC, dentro do centro tecnológico da PUC e mostrar a EC1. Mas aí a diretoria [da EC1] diz: "Nós somos tão pequenos perto deles. Eles vão nos engolir!”. Não! A nossa estratégia é engolir eles! Então, a gente quer ir lá e montar uma sala com todos os equipamentos necessários e chamar estagiário, chamar bolsista pra mostrar a EC1. E agora, também, estamos pensando em fazer isso em Santa Catarina. A gente está com o contato de uma universidade lá pra colocar uma "salinha" no polo tecnológico lá da universidade. Então é isso que nós estamos fazendo em relação aos nossos concorrentes que estão buscando os nossos funcionários (Coordenadora de $\mathrm{RH}$ ).

Observa-se, então, que essa é uma relação sociotécnica de recrutamento voltada para um perfil específico de profissional valorizado pela empresa, a saber, os engenheiros jovens e recém-formados. Essa relação tem como objetivo viabilizar uma estratégia para concorrer com outras empresas que demandam esses profissionais, empresas até mesmo maiores do que a EC1.

Apesar de não haver um programa formal de indicações, essas acontecem espontaneamente tanto para a coordenadora como para os gestores.

Muitas vezes quando nós não estamos conseguindo preencher uma vaga, nós pedimos indicações aos funcionários através de e-mail e por aviso no mural. E aí nós colocamos que a vaga é pra tal área, precisamos de tal perfil com essas qualificações... Não colocamos questões de remuneração! Botamos que a vaga estará aberta até tal dia. E o pessoal normalmente indica um familiar, um amigo ou um vizinho e deixa o currículo com a gente e a gente analisa.

As indicações são eficientes?

Sim, bastante. O pessoal deixa muitos currículos. Mesmo não tendo um programa com bônus e tudo mais... Claro que tem aquelas indicações do tipo: "Ah... minha filha completou 18 anos e nunca trabalhou e precisa trabalhar" [risos]. Bom, aí... se nós temos uma oportunidade do tipo um auxiliar no financeiro, só para ficar digitando "notinhas"... Tranquilo! Pode chamar a menina. Mas tem vezes que eles indicam currículos bem legais, com experiência boa (Coordenadora de RH).

Eu recebo, eu recebo indicações dos funcionários de gente pra vir trabalhar na minha área, mas... O problema é que vem indicação de gente sem experiência e aqui, na produção, tem que ter experiência, não adianta! Ou então, indica família, por exemplo, marido ou esposa... e aí eu também não aceito, mesmo com experiência. Por quê? Porque se tu tem um desafeto em casa com a tua mulher, vocês vão vir do trajeto de casa pra cá no mesmo ônibus, vão trabalhar na mesma área... e daqui a pouco vocês vão está trazendo problema de vocês pra cá. E também daqui a pouco tu está no trabalho falando, reclamando sobre a tua esposa pro teu colega... E eu não quero esse problema! Nem teu irmão, nem tua filha... não quero! Teve uma funcionária minha que foi lá falar com um dos diretores para eu contratar a filha 
dela. E aí... eu disse que não pro diretor. Expliquei: "Se um dia eu tenho que chamar a atenção da filha dela? A mãe dela pode querer ir lá, na minha frente, tomar partido da filha e aí?" É problema, sabe? (Gestor da Área de Produção).

Se vier uma indicação, a indicação para o meu time de engenheiro, a indicação eu dou alguma preferência. A indicação é sempre uma indicação, tá? Claro, eu nem sempre contrato a indicação porque ela passa pelo mesmo processo de entrevistas como qualquer outro candidato. Mas assim: é uma tranquilidade a mais saber que eu estou pegando alguém que foi indicado pra mim.

Com qual frequência você recebe indicações?

Olha... eu não saberia dizer com exatidão, mas o que acontece? Por exemplo, hoje eu entrevistei um profissional... na realidade, hoje eu fiz uma proposta para um profissional que a gente entrevistou faz 30 dias e que foi uma indicação. A gente entrevistou outros candidatos para mesma vaga, mas ele era do perfil que queríamos. Então, eu tenho vários profissionais no meu time que foram indicados. Teve um doutor em Física que trabalhou comigo aqui e depois saiu pra virar professor. E aí, depois, teve uma época que eu tive que contratar vários estagiários e ele me indicava só os melhores alunos dele para ser estagiário aqui (Gestor da Área de P\&D).

Em razão de não ser um programa de indicações, não se pode considerar como um dispositivo de cálculo, mas como uma forma de relação entre, de um lado, trabalhadores da EC1 indicando e, de outro, os gestores e o RH recebendo as indicações. Essa relação entre agentes humanos acontece tanto porque o RH toma a iniciativa de divulgar por e-mail e mural as vagas em aberto como, também, as indicações ocorrem espontaneamente, isto é, especialmente no caso dos gestores, os trabalhadores tomam a iniciativa de verificar a possibilidade de contratar amigos ou familiares. Uma vez que essa é uma relação sem a formatação de um dispositivo como um "programa de recomendação" (tal como os que foram identificados em alguns dos outros casos estudados) trata-se de uma relação que pode ou não estruturar a operação de cálculo de recrutamento e seleção. A razão para que isso ocorra é que a utilização das indicações depende da postura dos agentes, isto é, tal como se podem constatar na leitura dos extratos de entrevistas dos dois gestores de área técnica, as indicações são avaliadas de forma positiva ou negativa, determinado se elas são usadas ou não na hora de recrutar e selecionar.

Ainda no RH, além da coordenadora, a técnica em departamento de pessoal entra em relação com a direção da empresa formando condições de possibilidade para certas operações de cálculo. A partir da sua formação acadêmica na área de administração e especialmente a sua experiência profissional junto ao $\mathrm{RH}$, quando exercia apenas as atividades de departamento de pessoal; ela organiza e transmite 
métricas para direção da empresa subsidiando operações de cálculo no âmbito da contratação.

Ou, ainda,

Geralmente, eu sou chamada [pela direção e gestores] para dar informações sobre salários, férias... Mas eu não tenho um envolvimento de criar estratégias de, por exemplo, retenção de talentos e... não, não tenho esse envolvimento. Eu trabalho mais o operacional. É só informações de folha mesmo (Técnica de DP).

Como são definidas as faixas de salários, uma vez que vocês não têm um Plano de Carreiras pronto?

A empresa tem uma tabela de salário, mas ela é muito antiga. Eu até nem sei quem fez essa tabela que é de 2006. Essa tabela só é reajustada conforme o dissídio! Agora como foi criada e com que base ela foi criada, eu não sei. Então, essa tabela já estava pronta quando eu entrei na EC1. Só que a EC1, mesmo com essa tabela, a EC1 paga acima do mercado. $\mathrm{O}$ que a gente às vezes fazemos e nos basear numa pesquisa nos sites de vagas de emprego. Então, o que aconteceu? Teve um ano que a gente assinou a Catho ${ }^{\circledR}$ e aí eu fiz o levantamento nas empresas do mesmo setor da gente, o quanto elas estavam pagando para cada um dos cargos que a gente tem aqui na EC1. E aí quando a diretoria queria decidir o aumento de salário de um cargo, eles me pediam os dados dessa pesquisa que eu tinha feito. Hoje, a [coordenadora de $\mathrm{RH}$ ] não quis mais assinar porque acha que é muito caro. Então, essa pesquisa serviu para quando a gerência me solicitar, eu ter essa informação pronta. Mas ela não serviu como base para reajuste de salários (Técnica de DP).

Portanto, a sua formação e experiência profissional escudam sua relação com um dispositivo de cálculo, a folha de pagamento e também, durante certo período, a pesquisa de salários. Dessa relação, ela estrutura a sua com a direção da empresa, através do fornecimento de métricas, que oferecem condições de possibilidade para a EC1 executar operações de cálculo de contratação como a definição de salários.

Até aqui foram definidas as relações sociotécnicas que se formam na rede da EC1 a partir do RH. A partir desse ponto é preciso prosseguir definindo as relações produzidas a partir da direção da empresa e dos gestores de áreas técnicas.

A direção da empresa é formada pela presidente (filha do fundador da empresa), um diretor de produção (cônjuge da presidente) e uma diretora comercial. Em razão de não ter havido acesso para entrevistas com os membros da direção da empresa, não há condições de discernir (tal como foi feito no caso do RH) quais relações especificamente partem de cada um dos membros da direção. Assim sendo, serão abordadas apenas as relações sociotécnicas que partem da direção como um grupo e também essas relações estão sendo figuradas a partir do modo como elas são representadas pelo $\mathrm{RH}$ e os gestores de áreas técnicas. É importante destacar tal 
limitação na coleta de dados porque somente foram identificadas as relações que justamente são travadas entre direção e RH e/ou gestores.

Uma vez que no modelo de gestão anterior, o RH exercia somente a função de departamento de pessoal, ele não travava relações sociotécnicas com a direção da empresa para execução do cálculo da EC1 no mercado de trabalho. Atualmente, a direção cobra do RH metas e resultados que justamente estruturam o começo de uma relação sociotécnica na qual o RH produza condições de possibilidade para as operações de cálculo de valor da EC1 no mercado de trabalho. Isso foi conotado quando acima foi abordada a elaboração do Plano de Carreiras, Cargos e Salários e, também, sobre a relação da técnica de DP com a direção.

Todavia, essa inclusão do RH na rede sociotécnica como participante dessa capacidade de cálculo de valor da firma é ainda instável e em processo de consolidação. Por vezes, os gestores voltam ao modelo anterior, ou seja, eles executam por conta própria as operações de cálculo (recrutamento, seleção e contratação) e, a seguir, legitimam sua decisão junto à direção. Quando isso ocorre, os gestores se relacionam com o RH somente para os procedimentos de departamento de pessoal, ou seja, para o encaminhamento e efetivação burocrática e contábil do novo funcionário.

Qual momento o RH é consultado na hora de abrir uma vaga e contratar alguém?

Isso para mim, ainda está problemático. Muitas vezes, o RH é comunicado só do início do funcionário. Justamente porque a EC1 não tinha essa filosofia de RH. No meu ver, o RH deve fazer parte de todo esse processo - será que precisa contratar mais uma pessoa? OK, então será que a gente pode contratar alguém interno, uma recolocação? Ou então, se temos que trazer alguém de fora, já temos alguém em mente pra trazer pra essa vaga? - hoje o RH não se envolve tanto nisso. Hoje é direto entre a diretoria e os gestores. Então, essa é uma prática que precisamos mudar para justamente o $\mathrm{RH}$ estar envolvido (Coordenadora de RH).

Quando uma pessoa é indicada pelo gestor de área, a seleção do candidato acaba sendo diferente ou acaba não ocorrendo com vocês do $R H$ ?

É... algumas vezes a seleção nesses casos é quase nula.

É frequente esse tipo de situação?

Ela é bem frequente. Desde que eu estou no $\mathrm{RH}$, já houve várias situações desse tipo. O que a gente faz? Claro que a gente pode conversar com a pessoa [o candidato indicado e selecionado pelo gestor], mas a gente não vai poder dizer nada contra! Porque, no final, a pessoa já está sabendo que vai ser contratada, né? Então, a gente faz uma conversa bem informal com ela na hora que ela está entregando a documentação. [...] E aí, como numa entrevista, a gente começa pescar algumas coisas... e falamos pro gestor: "Legal tu ter contratado, mas quem sabe tu cuida isso e isso... Ele me falou tal coisa, então dá uma 
olhada melhor nisso...". A gente procura fazer isso (Coordenadora de $\mathrm{RH})$.

Portanto, a rede sociotécnica da EC1 encontrava-se instável em razão da existência de dois modelos das operações de cálculo da firma no mercado de trabalho, quais sejam: o anterior estruturado a partir de relações sociotécnicas realizando o cálculo através da relação exclusiva entre gestores e a direção e o recente, e ainda em formação, que visa à interação entre direção, gestores e RH com vistas a exercitar as operações necessárias ao cálculo da empresa no mercado de trabalho.

O modelo recente, mais interativo e munido de maior número de agentes e de relações sociotécnicas, pode ser definido na análise feita acima das relações formadas a partir do RH. Já no modelo menos interativo e menos adensado de agentes humanos e não-humanos, constata-se que as operações de cálculo econômico de valor eram praticamente feitas pelo gestor somente. Essa era uma capacidade de cálculo basicamente estruturada pelos seguintes elementos: o planejamento comercial e de produção advindo da interação entre direção e gestores que, por seu turno, gerava uma demanda de contratação ou de demissões, sendo que as operações de recrutamento, seleção e contratação para executar o que foi planejado eram feitas através de relações sociotécnicas entre os gestores de área, seu conhecimento e experiência profissional, que informam o perfil técnico para as vagas, e assentadas em apenas dois dispositivos de cálculo - currículos e técnicas de entrevistas.

Eu realizo hoje uma diversidade grande de tarefas, mas já foi maior a minha diversidade! Inclusive a participação no planejamento... participei do PCP [planejamento e controle da produção], né? Fracionava lotes de produção e... enfim, eu fazia toda essa gerência da produção. De um ano e meio para cá, isso se desvinculou de mim. O que eu absorvi! Não porque alguém mandou, mas porque eu quis! Isso é da autonomia, entendeu? A demanda é tão grande e a diversidade de clientes também. Há clientes que tem 30 tipos de produtos, entendeu? $\mathrm{Eu}$ cheguei a comandar 86 pessoas diretamente em dois turnos, o diurno e o noturno. Então, eu que fazia a tarefa de contratar pessoal, né? Seleção de currículos, entrevistas... Tudo isso passava por mim! Eu fazia tudo! Até o preenchimento da folinha da contratação da pessoa era eu que fazia. Aí, nesse período, isso era diretamente conectado ao diretor, né? Todos os gestores da área industrial... era direto com o diretor, não havia intermediários, sabe?

Já que tu tens essa experiência na contratação de pessoas, eu queria saber como funciona no dia-a-dia da empresa essa decisão de que precisa contratar mais gente?

A identificação da necessidade é por demanda, né? Já teve momento que, assim... na semana que vem tinha que começar 10 pessoas a trabalhar! Então, isso dificulta porque às vezes tu vai no mercado de trabalho procurar e não tem 10 pessoas qualificadas. Por que assim, cada gestor contrata o seu profissional de acordo com a necessidade 
da sua área, né? Cada gestor tem o seu perfil de profissional que precisa. Não é uma coisa que a empresa é quem diz e direciona. Eu tenho, então, autonomia para decidir os meus critérios para selecionar o tipo de profissional que eu preciso. E isso é muito desgastante porque chega 10 currículos e tu tiras somente três que vale a pena entrevistar, sabe? [...] Então, chega perto do momento que tu tinha que ter 10 e tu via que não ia dar e tinha que dizer pro diretor. Então tem que ter um banco de currículos, onde tu tem os currículos que não são os melhores ou o ideal, mas tu tem os médios pra esses apertos (Gestor de Área de Produção).

No caso de currículos, não havia propriamente um banco dos mesmos; o departamento de pessoal guardava os currículos recebidos pela firma e os repassava aos gestores quando se fazia necessário contratar. Essa situação evidencia que, naquele período, a firma não tinha relações sociotécnicas para realizar plenamente uma das operações de cálculo de valor, o recrutamento. Não havia práticas ativas para buscar currículos e seleciona-los para, então, serem repassados aos gestores de áreas técnicas para selecionar novos trabalhadores. Nesse sentido, pode-se concluir um ponto que será tratado mais detidamente no capítulo oitavo, qual seja: a capacidade de agência dos dispositivos de cálculo, isto é, neste caso, a existência do dispositivo "banco de currículos" fornece à firma uma das condições para executar a operação de recrutamento e, simultaneamente, produz uma relação sociotécnica entre RH e gestores de área. Em suma, sem o banco de currículos, não há operação de recrutamento ativo por parte da empresa e nem a relação sociotécnica entre RH e gestores para executar essa operação.

O dispositivo de técnica de entrevista é constituído por meio da experiência profissional e de trabalho que formam um arcabouço de conhecimentos tácitos e individual de cada gestor para fazer a entrevista.

A entrevista eu avalio a parte técnica. E o candidato tem que mostrar pra mim que sabe, ele tem que desenhar pra mim... Porque, assim, uma coisa é dizer que sabe e outra saber de verdade e saber desenhar pra mim. Você solda? Que tipo de solda tu usa? Que ferramental que usa? Tu solda SMD? Então, eu faço um desenho no verso do currículo dele de um componente e coloco situações práticas ali e peço para descrever qual o ferramental, tipo de solda, técnica... pergunto, enfim, sobre como ele executaria isso que eu desenhei. [...] Então, eu procuro saber toda a habilidade, toda a técnica que o candidato consegue usar pra ver se é dentro do que nós fazemos aqui (Gestor da Área de Produção).

Existem dois processos: recebeu indicação ou eu to com meu banco de currículos lá e tal... Aí eu vejo, eu tenho a liberdade de ver quem eu vou entrevistar e peço para o RH me marcar as entrevistas. Aí chega o profissional aqui, eu entrevisto ele. Vejo se ele tem condições de acompanhar o projeto; se sim, o RH faz uma entrevista com ele. Não 
tem condições, eu faço o RH nem perder tempo com ele. E aí nisso, eu tenho três bons candidatos, por exemplo. Eu já recebi uma resposta do RH sobre o perfil desses caras e aí eu chamo eles para ver quem eu prefiro e tal...

Pelo que eu percebi, então, tu seleciona o candidato com base na capacidade técnica dele e, com a ajuda do RH, o que tu chamou de "perfil profissional"; é isso?

Sim. Assim, como funciona? A avaliação técnica é a mais fácil porque é matemático o processo: eu já li o currículo do cara, então, eu já sei o que eu vou perguntar na entrevista. Então, eu elenco pontos no currículo que eu acho relevantes e aí eu peço para o cara descrever o currículo dele com as próprias palavras. Ele me conta a experiência profissional dele. E conforme ele vai falando... eu - "OK. Mas aqui tu falou que fez tal coisa..." - eu faço uma pergunta relacionada àquilo e... vou ti dar um exemplo: tinha um profissional que tinha experiência em hardware e tal... Aí eu pergunto que ferramentas ele usava para desenhar o esquemático e ele não se lembra do nome de nenhuma e... e daí tu começa assim e tu vai vendo que na realidade ele não tinha aquela experiência toda que disse que tinha no currículo. Tecnicamente é muito fácil de tu ver isso. Mesmo partes técnicas que eu não domino, eu tenho profissionais no meu time que dominam (Gestor de Área de P\&D).

Ao contrário do que será visto adiante nos outros casos, não há relação estruturada com o RH em função desses dispositivos de cálculo que são as técnicas e tipos de entrevistas. Os extratos de entrevistas demonstram que, na EC1, essa relação sociotécnica depende do gestor, não do dispositivo de cálculo.

A inclusão ou não do RH na rede sociotécnica do cálculo de valor da EC1 no mercado de trabalho é a chave interpretativa para entender as relações sociotécnicas que são formadas e a dinâmica das mesmas. Tal como foi exposto até aqui, a inclusão ou não do RH na rede sociotécnica faculta a inserção de novos dispositivos que exercitam operações de cálculo. Portanto, a formação e instabilidade da rede sociotécnica da EC1 está relacionada à inclusão ou não do RH como agente na rede. Sua inclusão traz um adensamento de relações sociotécnicas e um aumento no número de agentes nãohumanos na rede da EC1. Resumindo, a rede sociotécnica da EC1, quando incluído o RH nas operações de cálculo que têm lugar no mercado de trabalho, é composta da seguinte forma: 1) agentes humanos - direção executiva e comercial, gestores de áreas técnicas, coordenadora de RH, técnica de departamento de pessoas e trabalhadores através de indicações sem um programa; 2) agentes não-humanos - tabela de salários, banco de currículos, currículos, agências de emprego, sites de emprego, universidade, dois tipos de entrevistas, site da EC1. 
6.2. Estudo de Caso 2: uma rede sociotécnica compartimentada e rotinizada

A EC2 é o caso que apresentou o segundo maior número de agentes humanos e de dispositivos de cálculo na sua rede sociotécnica. A tabela abaixo lista os agentes identificados e que compõem a rede da EC2.

Tabela 23 - Agentes humanos e dispositivos de cálculo na rede sociotécnica da EC2.

\begin{tabular}{|c|c|c|}
\hline & Agentes Humanos & Dispositivos de Cálculo \\
\hline $\begin{array}{c}\text { Direção Executiva e } \\
\text { Comercial }\end{array}$ & $\sqrt{ }$ & \\
\hline Gestores de Áreas Técnicas & $\sqrt{ }$ & \\
\hline Coordenadora de RH & $\sqrt{ }$ & \\
\hline Recrutadoras & $\sqrt{ }$ & \\
\hline Diretor de Escritório & $\sqrt{ }$ & \\
\hline Conselho de Acionistas & $\sqrt{ }$ & \\
\hline Funcionários Técnicos & $\sqrt{ }$ & \\
\hline Pesquisa Salarial & & $\sqrt{ }$ \\
\hline Programa de Benefícios & & $\sqrt{ }$ \\
\hline Plano de Cargos e Carreiras & & $\sqrt{ }$ \\
\hline Plano de Cargos e Salários & & $\sqrt{ }$ \\
\hline $\begin{array}{c}\text { Sistema Informático de } \\
\text { Gestão de RH }\end{array}$ & & $\sqrt{ }$ \\
\hline Teste de Exercício Técnico & & $\sqrt{ }$ \\
\hline $\begin{array}{l}\text { Testes Lógicos } \\
\end{array}$ & & $\sqrt{ }$ \\
\hline $\begin{array}{c}\text { Teste Psicológico de Perfil } \\
\text { Profissional }\end{array}$ & & $\sqrt{ }$ \\
\hline $\begin{array}{c}\text { Entrevista } \\
\text { Técnica/Profissional }\end{array}$ & & $\sqrt{ }$ \\
\hline Entrevista Comportamental & & $\sqrt{ }$ \\
\hline Cultura da Empresa & & $\sqrt{ }$ \\
\hline $\begin{array}{c}\text { Programa de } \\
\text { Recomendação }\end{array}$ & & $\sqrt{ }$ \\
\hline Site da Empresa & & $\sqrt{ }$ \\
\hline Formulários de Assessment & & $\sqrt{ }$ \\
\hline Currículos & & $\sqrt{ }$ \\
\hline Banco de Currículos & & $\sqrt{ }$ \\
\hline Sites de Redes Profissionais & & $\sqrt{ }$ \\
\hline Sites de Redes Sociais & & $\sqrt{ }$ \\
\hline Universidades & & $\sqrt{ }$ \\
\hline Técnica de Entrevistas & & $\sqrt{ }$ \\
\hline Site de Vagas de Emprego & & $\sqrt{ }$ \\
\hline
\end{tabular}

Fonte: Dados de Pesquisa de Campo.

Ao contrário do caso anterior, o RH na EC2 possui uma estrutura bem definida, funções e tarefas bem claras dentro da empresa. No que concerne às operações de cálculo da firma que têm lugar no mercado de trabalho, destaca-se que todo o processo é coordenado pelo RH, ou seja, existe uma rotina bem definida dos procedimentos que 
vão desde o recrutamento, passando pela seleção, até a contratação de funcionários. $O$ fato de o RH se relacionar separadamente com certo grupos de agentes humanos e nãohumanos específicos para cada operação de cálculo (recrutamento, seleção e contratação) fez com que se caracterizasse como "compartimentada" essa rede sociotécnica.

No que diz respeito ao cálculo de valor da EC2 no mercado de trabalho, os agentes humanos do RH que se inserem nas relações sociotécnicas que compõem esse cálculo são as duas recrutadoras, a coordenadora de recursos humanos da unidade, o diretor executivo da unidade e a coordenadora de recrutamento dos escritórios da EC2 nos continentes americanos ${ }^{72}$. Com exceção das recrutadoras, esses agentes humanos estabelecem relações sociotécnicas entre si, com dispositivos de cálculo e com a direção executiva da empresa. Esse primeiro conjunto de relações estabelece as metas de demanda da unidade pesquisada da EC2.

O diretor geral de uma área, lá na [país onde fica a matriz da empresa], ele depois de todo um planejamento, ele chega à conclusão que terá a necessidade de aumentar o time dele em cem pessoas. $\mathrm{Ou}$ seja, houve um aumento de demanda, foram vendidos " $\mathrm{x}$ " softwares a mais, a gente vai precisar de mais gente no suporte, por exemplo. $\mathrm{E}$ esse diretor geral vai fazer uma análise de onde ele vai alocar, entre os escritórios da EC2 no mundo, essas cem pessoas a mais pra suporte. Então, ele vai ver o seguinte: quanto é o custo de alguém no cargo de suporte no Brasil? É “x”. E quais são os benefícios? Por exemplo, o inglês do brasileiro é melhor do que é falado pelo indiano ou o chinês. Porque esses são os dois países que mais competem com a gente entre escritórios da EC2 no mundo. E eles têm um custo de mão de obra mais baixo que a gente, mas também a gente vê que a decisão não é só pelo critério financeiro, existe essa questão de qualidade que pesa na satisfação do cliente, que é muito importante para EC2. Até porque não adiante ele economizar mil Dólares por mês se o atendimento na China, por exemplo, é pior do que no Brasil. Então, esse diretor geral faz essa análise para ver onde ele vai locar esses cem nesses países. Ele submete essa decisão, tanto a de local como a da necessidade de cem a mais, para o conselho executivo da EC2. Ele recebendo a aprovação do Conselho, ele avisa para o diretor executivo da unidade que, dessas cem vagas, vão vir 25 pro escritório dele. O diretor executivo em posse dessa informação vai lá no sistema e vai abrir uma solicitação de 25 pessoas. E também ele vai colocar lá o nível de senioridade que ele acha adequado para essas 25 vagas. Esse material chega pelo sistema pra mim, a coordenadora de $\mathrm{RH}$, e eu analiso pra ver se ele está correto na questão da descrição de senioridade para as 25 vagas. Se eu acho que não está correto, eu falo e discuto com ele sobre as dúvidas que tenho de perfil e... e vou aí arrumar aquelas vagas no sistema para realmente como deve ser a descrição delas para aquela função. As recrutadoras recebem isso pelo sistema, mas claro

\footnotetext{
${ }^{72}$ Somente foi autorizado fazer entrevistas com as duas recrutadoras e com a coordenadora de RH da unidade.
} 
que a gente conversa sobre isso porque estamos na mesma sala [risos]. E então, as recrutadoras vão lá e vão ver as informações sobre quais são as vagas e o perfil de profissional pra elas e então as recrutadoras vão ver para qual área da empresa essas vagas são porque elas acessam no sistema a estrutura de carreiras e áreas e comparam a descrição dos cargos com a descrição do perfil para as vagas. Uma vez que elas sabem a área, elas marcam para conversar com o gerente daquela área para acertar os detalhes sobre os cargos daquela área que as vagas vão entrar; por exemplo, elas discutem com ele: "Ah! $\mathrm{Na}$ descrição do sistema esse cargo diz que tem de 0 a $30 \%$ de ter que viajar, você acha que está mais para zero ou mais para $30 \%$ ?". E a partir daí, as recrutadoras vão fazer os processos para preencher as vagas (Coordenadora de $\mathrm{RH}$ ).

Constata-se, então, que há um planejamento do número de contratações e em quais cargos essas contratações serão distribuídas; tudo isso para atender decisões corporativas de cunho comercial. Além disso, esses agentes em relação estabelecem as métricas através das quais as recrutadoras terão que cumprir e serão avaliadas, a saber, tempo médio para preenchimento de uma vaga e número mensal de processos de seleção concluídos.

Travando relação com esse primeiro grupo de agentes, há o dispositivo de cálculo "Pesquisa Salarial". Através da relação com esse dispositivo, esses agentes conseguem tomar decisões sobre faixas salariais pagas pela empresa e da necessidade ou não de corrigir salários.

Como funciona a decisão sobre os salários que a EC2 paga?

Bom, a gente tem hoje aqui na EC2... são dois fatores que agente considera! [...] Assim, a EC2 considera dois "equity", como a gente chama, o interno e o externo. Então, a EC2 utiliza todos os anos uma pesquisa salarial de uma empresa de consultoria multinacional. Essa pesquisa tem uma amostra de 90 empresas brasileiras do ramo tecnológico. Ela é a mais consistente porque ela é especializada em TI. Então, se a gente pegar todas as grandes empresas de TI e mais as Telecom, todas essas empresas utilizam essa pesquisa. Então com isso, todos os anos, nós temos uma ideia muito clara do mercado! Quanto ganha um profissional júnior, um pleno, um sênior... um coordenador, um gerente, um diretor... Em cada uma das áreas dessas empresas: suporte, desenvolvimento, administrativo... E então, na EC2, a gente passa a ter para cada um dos nossos níveis de senioridade, né? Para cada um desses níveis a gente calcula uma faixa salarial que o funcionário daquele nível tem que estar naquela faixa! (Coordenadora de $\mathrm{RH}$ ).

É dedutível do extrato acima que essa definição de salários ainda é feita com a participação de outro agente não-humano, o "plano de cargos e carreiras" da EC2. A coordenadora menciona que há uma estrutura de níveis de senioridade nas carreiras de cada área da EC2. Esse plano assume a forma de uma aplicação dentro do programa informático de gestão de recursos humanos da empresa e é acessado através de uma 
intranet $^{73}$. As carreiras ligadas à atividade-fim da empresa estão organizadas a partir de uma carreira inicial chamada "funcional"; depois que o profissional passa do nível máximo de senioridade da área funcional, ele pode escolher três carreiras: gestão de pessoas, de projetos e gerência funcional. Em cada uma dessas carreiras, há diferentes cargos divididos em cinco níveis de senioridade. Assim sendo, cada cargo na empresa é vinculado a um nível de senioridade dentro de uma das quatro carreiras.

No sistema informatizado é disponibilizado o acesso às seguintes informações relativas a cada um dos cargos existentes nessa estrutura: tarefas e resultados esperados; nível de qualificação técnica, educacional e profissional para ocupar o cargo; salário e benefícios. Portanto, o número de contratações ou de vagas de empregos disponíveis na unidade da EC4 é distribuído segundo uma clara estrutura fornecida pelo Plano de Cargos e Carreiras. O sistema informatizado do Plano, por sua vez, fornece às recrutadoras as informações de salários e o perfil de competências técnicas e profissionais que o candidato deverá ter para ser considerado para a vaga de determinado cargo. Ademais, essa definição do perfil de profissional para vaga é aprimorada através da relação entre recrutadora e o gestor da área técnica na qual o cargo da vaga está lotado.

Você, então, recebe a vaga no sistema com a descrição dela dentro do Plano de Carreiras e depois faz uma adaptação da definição do perfil dessa vaga, isso?

O que acontece? A gente tem que seguir um "working flow"! Então, a vaga chega pra mim no sistema com o código do "job description" do Plano. O que eu faço? Eu agendo uma reunião para falar com o gestor de área daquela vaga. E, então, com o gestor, eu monto uma estratégia. Por exemplo, um gestor só quer receber candidato interno, do "pipeline" da empresa. Outro gestor quer anunciar no jornal. Outro quer... Então, a gente monta junto essa estratégia. Essa estratégia depende de cada área e de cada gestor. E aí também cada área tem uma estratégia de seleção: pra umas precisa de teste de lógica pra outras não; pra uma área tem teste de programa de uma linguagem, outra o candidato não precisa saber disso.

[...] Então há muito interação tua com os gestores.

Muita!

Eu queria saber que tipo de demanda um gestor ti passa?

É tudo uma relação de confiança. Ele tem que confiar em mim, que eu vou encontrar a pessoa certa pro cargo. Que tipo de demanda que eu tenho? "Eu quero uma pessoa com tais e tais características". Exemplo: inglês fluente, espanhol fluente, saiba programar em Java... estou dando exemplo, tá? Então, um cara que tenha conhecimentos

73 Em somente uma ocasião foi concedida a oportunidade de visualizar brevemente a representação gráfica desse plano de cargos e carreiras, tal como aparece na intranet da EC2. É, portanto, com base nessa visualização e dos relatos sobre esse plano nas entrevistas que se conseguiu nesta tese a elaboração da definição descritiva que se segue no corpo do texto. 
técnicos " $x$ ", um candidato que tenha expectativa de salário dentro de uma faixa de salário "x" e... A demanda é o seguinte: que ele vá entrevistar alguém que não esteja totalmente fora da "casinha". Então, é uma relação de confiança (Recrutadora 1).

Eu queria que você descrevesse como é aprimorado o perfil de uma vaga para, então, partir para o recrutamento?

Quando a gente recebe a confirmação da vaga pelo sistema, a gente normalmente marca uma reunião com o gestor de área da vaga. Conversamos com ele sobre o perfil da vaga e a descrição dessa posição, né? Então para alinhar com ele alguns detalhes. Então, algumas vezes é preciso modificar um pouco a descrição do perfil pra se encaixar com a necessidade do momento. Pra alinhar como vai ser a questão do nível do idioma. Como vai ser a questão de graduação? Recém-formado ou não? Se... Qual é previsão, a necessidade de tempo para contratação? Quais estratégias de recrutamento e seleção que a gente vai usar? Então é assim que a agente aprimora a definição da vaga (Recrutadora 2).

Retomando, o primeiro grupo de agentes humanos e não-humanos é aquele que é responsável, entre outras coisas, por indicar em quais cargos da empresa há vagas em aberto, sendo que os cargos são definidos de acordo com um Plano de Cargos e Carreiras. Esse último assume a forma de uma aplicação em um programa informático de gestão de recursos humanos, que opera através de uma intranet. Esse mesmo programa alerta às recrutadoras das vagas em aberto, que, por sua vez, através de reunião com gestores de área, aprimora as definições de perfil de candidato desejado para ocupar a vaga e quais estratégias de recrutamento e seleção serão usadas. Portanto, esse sistema informático articula boa parte do fluxo de comunicação e interação entre os agentes humanos ligados ao RH, gestores de áreas técnicas da empresa e os diretores administrativos e executivos.

Para a operação de recrutamento, esse dispositivo "sistema informático de gestão de RH" trava relação com as recrutadoras ao oferecer um banco de currículos. Por sua vez, esse banco é alimentado pelos currículos cadastrados no site da EC2. Cada uma das recrutadoras ainda tem um banco de currículos feito por elas numa planilha de Excel.

O currículo do candidato chega no sistema. Eu vou no sistema, vou na vaga " $x$ " e aparece ali, por exemplo, 17 currículos. E aí eu abro os currículos e começo analisar.

Esse banco de currículos é permanente?

Não! No momento que tu fecha a vaga, ele sai dali porque senão fica como se a vaga não foi preenchida.

Então para cada vaga que abre, se abre um banco de currículos? Isso! Mas normalmente assim... eu tenho, por exemplo, uma planilha de Excel com os currículos de candidatos que não foram selecionados para aquela vaga, mas que são bons currículos. A gente tem um banco de currículos nosso, que a gente mantém no Excel (Recrutadora 1). 
A partir dos canais de recrutamento é formado então um banco de currículos?

Assim, a gente está tentando melhorar essa questão, mas... A minha maneira de trabalhar, na verdade, eu tenho um Excel, onde eu coloco todos os candidatos que chegam até mim e para quais posições eles se candidataram, sejam eles dentro do perfil ou não! Vou salvando os currículos e ali eu vou colocando quem foi contratado, quem avançou no processo de seleção, quem foi rejeitado, quem foi para uma entrevista pessoal e assim por diante... Mas é uma maneira minha de trabalhar e cada um tem um Excel e uma maneira de colocar numa planilha. Deveria ser feito tudo através do nosso sistema, mas como não são todos que se candidatam através do sistema, não tem como a gente controlar só por ali. Por isso que eu mantenho esse recurso extra para controlar quem passou pelo processo ou não (Recrutadora 2).

Desse modo, identifica-se o mesmo dispositivo de cálculo assumindo duas formas diferentes em função do agente não-humano com que ele se relaciona: currículos cadastrados no site da empresa para primeira forma e currículos recebidos em mãos ou por e-mail das recrutadoras para a segundo forma do banco de currículos. Para alimentar esses bancos de currículos, as recrutadoras se relacionam com dispositivos de cálculo que são seus canais de recrutamento. Primeiro, o site da EC2 que disponibiliza uma seção de oportunidades de emprego em todas as unidades da empresa no mundo. $\mathrm{O}$ candidato acessa, então, uma área com uma representação do mapa mundial com pontos vermelhos dando a localização dos escritórios da EC2. Ao clicar em um dos pontos vermelhos, o candidato é informado sobre quantas vagas estão abertas naquela unidade e para quais cargos. Selecionando um cargo é aberta uma janela informando as tarefas desempenhadas naquele cargo e o nível de qualificação educacional, técnica e de experiência profissional exigida. O candidato, então, pode escolher se candidatar para aquela vaga, cadastrando-se no sistema e enviando o seu currículo (se o candidato já é cadastrado, ele apenas marca que quer se candidatar para a vaga e seu currículo é automaticamente enviado para recrutadora responsável). Portanto, esse é um dispositivo que alimenta apenas o banco de currículos na forma que assume dentro do sistema informático de gestão de RH.

O segundo canal de recrutamento ou dispositivo de cálculo é o programa de recomendações da EC2, que é considerado o meio mais eficiente para recrutamento.

Por que o Programa de Indicações é tão valioso para nós? O funcionário que está aqui, ele sabe o perfil da empresa e sabe quem fecha com esse perfil. E ele tem o "networking" de pessoas dele da... da mesma linguagem [de programação], que trabalham com a mesma coisa. Então, a EC2, eu acredito, que hoje ela dá 600 Reais para as indicações ou até mesmo mil Reais para vagas que estamos tendo mais dificuldade de preencher. Então, com isso, a EC2 tem uma resposta das indicações com candidatos com potencial de serem 
nossos funcionários, que têm a "cara" da empresa! Porque o funcionário sabe quem é que pode fechar com a nossa empresa. Então, hoje é a nossa principal fonte de recrutamento. É um programa fundamental para nós! [...] Para tu ter uma ideia, cerca de um pouco mais da metade das contratações - não dos candidatos como um todo! - são de profissionais que foram indicados pelos funcionários da EC2 (Coordenadora de $\mathrm{RH}$ ).

O programa funciona da seguinte forma.

Vamos supor que tu é funcionário da EC2 e indica alguém. Então, a pessoa que tu indicou é contratada. Depois de três meses, se a pessoa que tu indicou permanece na EC2, tu vai ganhar 500 Dólares. Mas se a pessoa entrou em cargos sênior, tu recebe 1.000 Dólares (Recrutadora 1).

Além disso, as recrutadoras relataram que recebem as recomendações de duas maneiras: através dos seus e-mails ou por meio de candidatura via site da EC2, que oferece um espaço para o candidato dizer se está ou não e por quem está sendo indicado. As recrutadoras relatam que normalmente ocorrem as duas coisas: o funcionário que indica manda o currículo para o e-mail da recrutadora e a pessoa que é indicada se candidata pelo site da empresa, marcando no formulário eletrônico o nome da pessoa que está indicando ela.

Em terceiro lugar estão os sites de vagas de emprego: baguete ${ }^{\circledR}$, InfoJobs.com.br ${ }^{\circledR}$ e $C a t h o \circledR$, que já foram definidas as suas características na seção anterior. A partir desses sites o candidato é levado diretamente ao espaço do site da EC2 para se cadastrar e se candidatar à vaga neles divulgada.

Quarto, ao contrário do que veremos no caso da EC4, as redes sociais virtuais, especialmente o Linkedin ${ }^{\circledR}$, são utilizadas pelas recrutadoras como dispositivos para divulgar vagas e não pra fazer o recrutamento ativo de profissionais, isto é, procurando profissionais com perfil para vaga e fazendo contato direto com eles. Mas por que foi mencionado em especial o Linkedin ${ }^{\circledR}$ ? Porque essa é uma rede virtual exclusiva para relações profissionais. $\mathrm{O}$ usuário preenche um perfil que muitas vezes é o seu próprio currículo. Pode receber e fazer recomendações de outros profissionais. E há grupos definidos de acordo com áreas profissionais ou setor de atividade econômica. Além do Linkedin ${ }^{\circledR}$, as recrutadoras divulgam as vagas no perfil da unidade da empresa no Twitter ${ }^{\circledR}$ e no Facebook ${ }^{\circledR}$.

O quinto canal de recrutamento é o anúncio de jornal, um dispositivo de cálculo menos usado porque representa custo à empresa e não tem tido uma boa eficiência em recrutador candidatos de bom nível educacional e profissional. 
Por fim, há um sexto canal, o relacionamento da EC2 com universidades de Porto Alegre e região metropolitana. As universidades tornam-se dispositivo de cálculo para a operação de recrutamento através de quatro tipos de relações com a EC2: 1) programa de estágios; 2) divulgação de vagas nas páginas eletrônicas das faculdades; 3 ) realização de eventos; 4) participação em eventos ou feiras de profissões.

Uma vez que os candidatos chegam através de um desses seis canais, eles são selecionados pela recrutadora através de outro dispositivo, os currículos.

Como são analisados os currículos?

Dependendo do perfil da vaga, o currículo é analisado de uma forma; por exemplo, uma vaga a pessoa tem que estar se formando no final do ano ou tem que ser já graduada? Então, eu olho no currículo. Tem que ver no currículo se vale a pena iniciar o processo de seleção dessa pessoa, entendeu? Se a pessoa tem 15 anos de experiência e eu tenho uma vaga com um salário para um profissional com três anos de experiência, eu nem vou ligar para essa pessoa. Eu vejo, então, se o currículo se encaixa com os pré-requisitos da vaga. A análise é feita muito rápida (Recrutadora 1).

Ah... Eu olho para ver se o currículo se encaixa com a descrição dos pré-requisitos da vaga, com o "job description". Se encaixa, eu faço algumas anotações no currículo para quando eu entrevistar o candidato pelo telefone e eu falar esses e esses pontos que eu achei que ficou meio "assim" no currículo (Recrutadora 2).

Por meio dos currículos, a recrutadora avalia se o candidato merece ou não ser contatados e entrevistados por telefone. Essa última e as demais entrevistas são realizadas através de uma técnica que se constitui como um dispositivo de cálculo da rede sociotécnica da empresa.

Nós temos um processo chamado "Target Selection", que é uma consultoria que faz um treinamento de... todos os anos a gente tem esse treinamento! Onde as pessoas são treinadas em fazer seleção baseada em competências. Então, a gente tem um padrão. Então, treinamento para ser apto! Mesmo sendo gerente, ele vai passar pelo treinamento para fazer entrevistas. E hoje nós temos 70 funcionários, entre gerentes e não gerentes, preparados para fazer seleção nessa metodologia. Obviamente não é rígido, não precisa fazer toda entrevista naquele modelo, mas pelo menos tu tens uma noção de como entrevistar um candidato. E a gente normalmente faz as entrevistas em par, um par formado por um gerente e um técnico, que é um técnico que normalmente desempenha aquela função da vaga que o candidato está sendo selecionado. Então, eles vão entrevistar juntos porque normalmente o gerente fica com uma dúvida e, então, ele tem uma pessoa que ele pode conversar sobre aquela dúvida que ficou da entrevista (Coordenadora de $\mathrm{RH}$ ).

Então, as entrevistas são realizadas através da técnica de entrevista por competências. Todos os entrevistadores recebem treinamento sobre como fazer essa entrevista por competência. E assim... Ah! Tem uma vaga que precisa da competência de relação com o cliente. Então 
através de perguntas, a gente é capaz de dar uma nota sobre essa competência no candidato. As perguntas da entrevista de competência são sempre formuladas buscando uma experiência passada da pessoa relacionada àquela competência que se quer medir no candidato. Então, a entrevista por competência é a entrevista baseada em comportamentos passados, não o que você faria se... Por exemplo, a gente pergunta: "O que você fez quando um gestor ou teu chefe ti xingou?". Então é... competência é: tu tem uma situação "x", o que tu fez e qual foi o resultado. É assim que se avalia a competência. Por exemplo: "Me dá um exemplo de quando tu teve um cliente insatisfeito, o que tu fez?" - "Ah! Eu liguei pro cliente pra ver o que estava acontecendo" - "OK. E daí? Qual foi o resultado?" - "A gente reconquistou o cliente e vendemos mais um milhão pra ele". Então, esse candidato terá uma avaliação da competência de relação com cliente muito boa (Recrutadora 1).

Eu fiz o treinamento para fazer entrevista faz bastante tempo, eu acho que em final de 2007. E o curso, o treinamento se chama "Target Selection". Que é fazer entrevistas baseado em fatos, tá? E não em impressões, vida pessoal da pessoa, enfim... É: Qual era situação? Qual foi a ação desenvolvida pela pessoa? E qual foi o resultado ou atividade que ela fez? Então é sempre nessa estrutura: situação, ação e resultado (Gestor de Área de Desenvolvimento de Software).

Seguindo essa técnica e preparada através de uma análise de currículo, a entrevista por telefone visa verificar se o profissional apresenta os requisitos mínimos de qualificação para vaga e ela é feita em inglês para justamente avaliar se o candidato é suficientemente proficiente nesse idioma - que é uma condição para todos os cargos da EC2.

Passando por essa entrevista, a recrutadora utiliza os seguintes testes para selecionar o candidato: 1) teste de raciocínio lógico G36 - consiste em teste com questões de múltiplas escolhas que mede a capacidade de raciocínio do candidato e é aplicado e avaliado por um profissional da área de psicologia. Na EC2, esse teste é usado como critério eliminatório no caso de baixa pontuação e classificatório; 2) Professional Profile Assessment (PPA) - teste desenvolvido por uma empresa de consultoria, Thomas International. Consiste em identificar como o profissional trabalha através de três critérios: grau e tipo de motivação para o trabalho, o valor que possui para o negócio e como se comporta sob pressão. A EC2 aplica esse teste para algumas vagas, especialmente as que envolvem tarefas de contato com clientes; 3) teste de linguagens de programação - são exercícios elaborados pelos gestores de áreas técnicas que visam medir a habilidade do candidato em trabalhar em código escrito em determinada linguagem de programação.

Após ou até mesmo entre esses testes, a recrutadora marca uma data com o gestor da área correspondente à vaga e com os profissionais daquela área que passaram 
pelo já mencionado treinamento de técnica de entrevistas por competências, para entrevistarem o candidato. Então, os seguintes tipos de entrevistas são executados pelos gestores e profissionais da área técnica.

Existem dois modelos de entrevistas. Um é o modelo com duas entrevistas, uma comportamental e outra mais técnica, que são realizadas por duas pessoas, normalmente um gerente de área e um profissional. O outro modelo é realizado por um grupo de pessoas, não todas juntas, elas vão se revezando, tá? Para saber essas mesmas competências técnicas e comportamentais, mas o que acontece? Esse modelo é usado quando temos que selecionar muita gente num período curto de tempo em função da necessidade de um novo projeto. Então, a gente se reúne em grupo e faz essas entrevistas com vários candidatos no mesmo dia. Mas é o primeiro modelo que é o mais frequente, esse que é feito em dupla entre um gestor e um profissional do time que o candidato vai trabalhar. Mas também acontece da vaga envolver um conhecimento muito específico que ninguém da minha área conhece. Então, aí nós chamamos alguém de fora com esse conhecimento; por exemplo, nós conseguimos como cliente um banco russo e eu precisava de alguém que conhecia o mercado bancário da Rússia e, então, eu precisei chamar uma pessoa que já tinha trabalhado na Rússia e essa pessoa fez a entrevista junto comigo (Gestor de Área de Desenvolvimento de Software).

Trata-se, como pode deduzir, de entrevistas que compõem uma seleção na qual os gestores são responsáveis por determinar qual dos candidatos à vaga da sua área deve ser contratado, utilizando critérios de qualificação técnica e comportamental. Os gestores comunicam a sua decisão ao RH e também preenchem, no sistema informático de gestão de recursos humanos, uma avaliação chamada de "assessment" para cada um dos candidatos. O "assessment" é um dispositivo de cálculo que trava relação com gestores de área, profissionais que entrevistam e recrutadoras, estabelecendo a estrutura para avaliação de um candidato. Ao se ter conseguido acesso ao formulário de "assesment", pode-se identificar que esse dispositivo formata a avaliação do candidato pelo entrevistador em duas grandes áreas:

1) perfil de qualificação técnica e profissional - dividido por sete grupos de critérios que devem estar em sintonia com as definições de níveis que o cargo da vaga requer, segundo consta no Plano de Cargos e Carreiras da EC2. Os sete grupos são: conhecimento profissional e técnico da área de expertise, habilidade de comunicação, perspicácia de negócios ${ }^{74}$, criatividade, foco nos resultados, sabe colaborar e

${ }^{74}$ Seria a habilidade de o profissional encarar suas atividades, responsabilidades e metas como se a empresa fosse seu cliente. Em outros termos, o profissional apresenta iniciativa para exercer sua função sem que seja diretamente supervisionado em todo o processo. 
trabalhar em grupo e, por último, habilidade para lidar com problemas complexos;

perfil de qualificação comportamental - são seis critérios de avaliação relacionados à cultura da empresa, a saber, se a pessoa avalia seu sucesso pelo sucesso e satisfação do cliente; ser responsável e mantém a palavra nos compromissos profissionais que assume; profissionalismo no sentido de sempre buscar se aperfeiçoar, fazer o máximo no seu trabalho e tratar com respeito a todos; integridade $\mathrm{e}$ sinceridade ao tratar com colegas de trabalho e clientes; dá valor ao trabalho em equipe; é uma pessoa confiável que assume responsabilidades e se compromete com o sucesso da sua equipe.

No assessment, a cultura da empresa é expressa em critérios que aludem a um modelo de gestão do trabalho, sendo que os agentes humanos definem essa cultura das seguintes maneiras:

Baseado na cultura da EC2, a gente faz perguntas para ver se o candidato tem: motivação e entusiasmo, capacidade de aprender por conta própria, sabe trabalhar em equipe e se trata todo mundo bem. Essas competências comportamentais são avaliadas e são ranqueadas (Gestor de Área de Desenvolvimento de Software).

A cultura da EC2 é uma cultura assim... Bem flexível! Em geral, flexível é a palavra que melhor define, né? O pessoal tem bastante liberdade, mas claro! Quem trabalha com suporte precisa cumprir horários, porque precisa estar disponível pro cliente, né? Mas em geral é bastante tranquilo, assim em termos de poder levantar, sair, tomar um café... Não tem aquela rigidez de empresas que cada vez que você vai sair, vai ao banheiro, você precisa está avisando para um supervisor. É bem informal também, né? O pessoal aqui é totalmente diferente do pessoal da EC2 em São Paulo. Como lá o foco é mais consultoria, vendas e atendimento ao cliente, né? O pessoal lá se veste muito mais formal do que aqui. Aqui tem gente que vem de bermuda no verão, então... De forma geral, eu diria que a cultura é de um ambiente de trabalho flexível e informal (Recrutadora 2).

A cultura da empresa, por exemplo, quando a gente faz eventos, nós definimos a cultura da empresa como um ambiente informal de trabalho. Um ambiente que valoriza pessoas que pensem "fora da caixa", né? Um ambiente "flat", onde há poucas hierarquias e as pessoas são cobradas não por obedecerem a pessoas, mas cobradas por resultados. Um ambiente de horário flexível, onde não tem cartãoponto. Então, a EC2 acredita muito no funcionário! No momento que ele entrega o resultado, ele está OK. Então é uma meritocracia! Um ambiente super jovem, mas que também as pessoas recém-formadas estão trabalhando ao lado com pessoas de 40 anos... É o ambiente onde a pessoa tem que trazer inovação pra empresa (Recrutadora 1). 
A EC2 é a primeira empresa que eu trabalho que vive a cultura, que vive aquilo que está escrito no papel. Sabe que toda empresa tem aquela coisa: valores, princípios, missão... Só que, em geral, quando a gente vai vivenciar o dia-a-dia da empresa, não tem nada daquilo que está lá escrito! Claro que eu não vou dizer que todas as pessoas, o dia inteiro atuam conforme todos os padrões da EC2, não é isso! Mas o que eu sinto é que a cultura que permeia a empresa, ela tem a ver com respeitar o ser humano, ela tem a ver com buscar o desenvolvimento das pessoas que trabalham aqui! Valorizar as pessoas que estão na empresa. Então, isso acontece realmente. [...] Por exemplo, a gente teve um caso de um gerente aqui que não se adaptou a essa cultura, que veio de uma outra empresa de TI americana que tinha uma cultura extremamente agressiva, onde a forma de motivar era pressionar as pessoas! Isso não é a nossa cultura de gerenciamento de pessoas. E aí, houve o conflito e... Com ele mesmo a gente fez todo um trabalho de desenvolvimento para que ele conseguisse entrar na cultura, mas depois de dois anos, não tinha como! Isso era uma coisa que ele trazia muito forte de uma experiência numa empresa que não batia com nosso perfil. Então, eu vejo a cultura da EC2 como uma cultura onde se valoriza muito os funcionários, né? Valoriza que as pessoas ficam um bom tempo na empresa, que se desenvolva dentro... Assim, aqui, a gente não vai chegar pra você e dizer - "Ah! Tu vai ser demitido!". Uma pessoa aqui não vai ser demitida sem antes ter tido a oportunidade de ter participado de um plano de desenvolvimento de no mínimo três meses! Onde ela acompanhou com a gente se ela estava melhorando ou não. Se ela tava chegando perto daquelas metas. Então, isso são coisas que eu acredito que são extremamente importantes. A pessoa se sente protegida, mas ao mesmo tempo ela tem obrigações a cumprir, mas ela tem essa contrapartida. Toda essa questão de flexibilidade... Nós não temos ponto aqui! Nós não controlamos horários das pessoas aqui. As pessoas são responsáveis, elas vêm aqui e fazem seu trabalho. Então, as pessoas sabem que se qualquer um dos nossos funcionários precisar sair agora, porque aconteceu alguma coisa, por exemplo, o filho se machucou no colégio e precisa pegar ele! A pessoa sabe que ela pode sair sem problema. Então, esse tipo de coisa não há como a gente mensurar o impacto na motivação, atração e retenção das pessoas (Coordenadora de RH).

Constata-se que a cultura da empresa aparece em termos de ambiente e de modelo de gestão do trabalho (com exceção da fala do Gestor de Área). A cultura da empresa, neste caso, materializa-se num instrumento que é o "assessment" e, ao fazê-lo, é constituída como um dispositivo de cálculo poderoso.

A EC2 possui, portanto, uma rede com relações sociotécnicas bem definidas e estáveis entre agentes humanos e não-humanos. Há uma separação clara entre combinações de relações entre agentes e dispositivos para cada uma das operações de cálculo de valor - recrutamento, seleção e contratação. O desenvolvimento dos dispositivos conectados a uma política e modelo de gestão de recursos humanos globais confere à rede sociotécnica da EC2 estabilidade e organização. 


\subsection{Estudo de Caso 3: rede sociotécnica em formação e estável}

A EC3 é o caso que apresentou o terceiro maior número de agentes humanos e de dispositivos de cálculo na sua rede sociotécnica. A tabela abaixo lista os agentes identificados e que compõem a rede da EC3.

Tabela 24 - Agentes humanos e dispositivos de cálculo na rede sociotécnica da EC3.

\begin{tabular}{|c|c|c|}
\hline & Agentes Humanos & Dispositivos de Cálculo \\
\hline $\begin{array}{c}\text { Direção Executiva e } \\
\text { Comercial }\end{array}$ & $\sqrt{ }$ & \\
\hline Gestores de Áreas Técnicas & $\sqrt{ }$ & \\
\hline Coordenador de RH & $\sqrt{ }$ & \\
\hline Recrutadora & $\sqrt{ }$ & \\
\hline Pesquisa Salarial & & $\sqrt{ }$ \\
\hline Programa de Benefícios & & $\sqrt{ }$ \\
\hline $\begin{array}{c}\text { Sistema Informático de } \\
\text { Gestão de RH }\end{array}$ & & $\sqrt{ }$ \\
\hline Teste de Exercício Técnico & & $\sqrt{ }$ \\
\hline $\begin{array}{c}\text { Testes Lógicos } \\
\end{array}$ & & $\sqrt{ }$ \\
\hline $\begin{array}{c}\text { Teste de Redação em } \\
\text { Português }\end{array}$ & & $\sqrt{ }$ \\
\hline $\begin{array}{c}\text { Entrevista } \\
\text { Técnica/Profissional }\end{array}$ & & $\sqrt{ }$ \\
\hline Entrevista Comportamental & & $\sqrt{ }$ \\
\hline Cultura da Empresa & & $\sqrt{ }$ \\
\hline Site da Empresa & & $\sqrt{ }$ \\
\hline Formulários de Assessment & & $\sqrt{ }$ \\
\hline Currículos & & $\sqrt{ }$ \\
\hline Banco de Currículos & & $\sqrt{ }$ \\
\hline Sites de Redes Profissionais & & $\sqrt{ }$ \\
\hline Sites de Redes Sociais & & $\sqrt{ }$ \\
\hline Universidades & & $\sqrt{ }$ \\
\hline Técnica de Entrevistas & & $\sqrt{ }$ \\
\hline Site de Vagas de Emprego & & $\sqrt{ }$ \\
\hline
\end{tabular}

Fonte: Dados de Pesquisa de Campo.

Neste terceiro caso, a rede sociotécnica encontrava-se em formação no sentido de ser recente naquela unidade a presença do RH.

Qual diferença você percebe entre a EC3 e as outras empresas que você trabalhou no que diz respeito ao $R H$ ?

As duas empresas que eu trabalhei em RH foram a AMBEV e a EC3. Elas têm características bem diferentes pro RH, apesar de nas duas se chamar essa parte de RH. [...] O que difere uma da outra? Na EC3 é um RH em formação, isso não somente aqui como em todas as unidades da EC3. Um RH em formação significa assim: a maturidade do RH na EC3 não é ainda tão avançada... isso quando a gente fala em maturidade do $\mathrm{RH}$, não só o $\mathrm{RH}$, por exemplo, o processo de avaliação de desempenho, ele começou ano passado. Na AMBEV, um processo de avaliação já tem muitos anos! Então, lá se você falar em um processo de avaliação de desempenho pras pessoas, não só do $\mathrm{RH}$, 
mas as pessoas de maneira geral, elas entendem a metodologia, importância, o retorno que isso pode ter, a complexidade, as diferentes formas de avaliação... $\mathrm{Na} \mathrm{EC3,} \mathrm{tu} \mathrm{fala} \mathrm{em} \mathrm{um} \mathrm{processo} \mathrm{de} \mathrm{avaliação,}$ as pessoas imaginam muito mais um "feedback" que acontece uma vez por ano, mas sem perceber o impacto que isso pode ter, todas informações positivas que isso pode ti agregar na tua carreira. [...] Então, o RH da EC3 não é maduro! (Coordenador de RH).

Ao mesmo tempo, também influencia no seu status de uma rede ainda "em formação", o fato de que só recentemente a EC3 vem elaborando políticas e uma cultura de recursos humanos para todas suas unidades.

A EC3 é o seguinte... Imagina só! A EC3 adquiriu mais de 40 empresas ao longo de 10 anos. São mais de 40 empresas diferentes, de segmentos de mercado diferentes em TI, de sistemas diferentes, de modelagem de programação diferente e de culturas diferentes. Esse ano [2012] é o primeiro ano que a EC3 está trazendo de forma única e coesa o sentimento de uma única cultura! [...] Implementação de cultura, ela não pode ser impositiva, a gente não pode chegar e dizer assim: "A nossa cultura é essa!". Ela tem que ser vivenciada. As pessoas devem perceber que aquilo é vivido! Principalmente pelos seus principais líderes! E eu não estou dizendo chefes, eu estou dizendo líderes para justamente que as pessoas se espelhem naquilo e comprem essa ideia (Coordenador de $\mathrm{RH}$ ).

Ao contrário da EC1, a inserção do RH já se encontra definida na EC3, ou seja, não foram relatadas a presença de operações de recrutamento, seleção e contratação que não fossem encaminhadas e articuladas com envolvimento do RH. Aliás, boa parte da rede sociotécnica que sustenta essas operações de cálculo estava sendo desenvolvida a partir da relação entre o coordenador de RH daquela unidade e o conhecimento que ele trouxe da sua formação acadêmica.

Qual é a estrutura do RH, hoje na EC3?

A nossa estrutura hoje, ela é... Na verdade, o RH, o conceito dele, ele não deveria ser diferente entre as empresas. $O$ que deveria ser diferente? A quantidade de processos que o teu RH absorve. Porque assim: "Ah! Todo RH, ele gerencia uma avaliação de desempenho". Avaliação de desempenho pra mim, tanto faz se é em papel de pão, se é em "Four Box", se é em "Nine Box", se é por competência, se é por resultados, se é por uma análise de 360 graus... Não interessa! Toda avaliação de desempenho tem o mesmo objetivo que é: avaliar e dar um feedback, que vai produzir um plano de desenvolvimento individual que vai ti ajudar a crescer na empresa. Então, eu entendendo que os processos de RH, eles deveriam ser comuns. Eu me apoio sempre no chamado "ciclo de gente" para montar a estrutura do RH. [...] Essa estrutura do ciclo, ela é dividida em caixas de processos. A primeira caixa é a do ciclo da atração, e o que entra nessa caixa? Por exemplo, um programa de estágio, eu posso colocar uma forma de captação de mercado, etc. Mas são formas de atrair pessoal pra empresa. Essa atração vai me gerar um recrutamento e seleção. A pessoa pode entrar por um processo de recrutamento interno ou externo. E a prioridade é sempre o recrutamento interno para que os funcionários da empresa se sintam com possibilidade de crescimento, 
de mudança de carreira; e aí, se eu não achar ou já supri tudo pelo interno, eu vou pro externo. Aí vem uma fase de integração! E a integração tem duas partes: uma na empresa e uma na função. Geralmente, o RH olha mais para integração na empresa. [...] Depois da integração vem uma fase que a gente chama de treinamento. É diferente da integração porque as pessoas, na empresa, estão em constante treinamento que pode ser treinamento formal, informal, com o colega do lado... Não importa! Ela sempre vai estar em treinamento. Depois chega na fase que a pessoa tem que ser avaliada. Isso é a avaliação de desempenho, que eu tinha ti falado, né? Isso tudo vai me gerar o quê? Vai me gerar um gerenciamento de carreiras! Por quê? Qual o nome disso na verdade? Isso é um ciclo de gente, ciclo de pessoas, ciclo de como você quiser chamar! Mas é o ciclo do RH.

$[\ldots]$

Essa estrutura que você definiu, ela vem de conhecimentos técnicos da tua formação?

Sim. Assim, uma das coisas que eu acho que se aplica a não só o RH, mas poderia ser aplicado em outras áreas é a questão do modelo mental com relação ao modelo de pensamento sobre o PVCA! Que é planejamento, execução, o "check" e uma ação corretiva, se for o caso. Porque é uma questão de todo um ciclo que vai do planejamento à execução. E aí aquela coisa do checar e aí depois tu age de maneira corretiva. Isso é uma coisa que eu tive bem forte quando eu fiz a faculdade [de administração], né? Mas também ao longo da minha carreira profissional, isso veio se repetindo! Então, isso que descrevi pra ti [a estrutura do RH como "ciclo de pessoas"] é um dos conceitos que eu mais utilizei. É um modelo mental que tu utiliza! (Coordenador de $\mathrm{RH}$ ).

Portanto, esse conhecimento se materializa numa estrutura organizacional de $\mathrm{RH}$

e em suas funções na empresa; por seu turno, esse processo de formação do RH desencadeia a inserção de agentes humanos e não-humanos na rede sociotécnica relacionada às operações de cálculo de valor da EC3 no mercado de trabalho. Nesse sentido, uma relação importante neste processo de formação do $\mathrm{RH}$ e da rede sociotécnica é ainda o inicial envolvimento entre coordenador de RH e a direção da empresa, o chamado "corporativo" e "lideranças da empresa".

O normal numa empresa com RH maduro, como era quando eu trabalhei na AMBEV, é uma vez por mês o RH se reunir com as lideranças e apresentar uma série de indicadores e... Indicadores de entrevistas de desligamento, do "turnover" ou "attrition", do absenteísmo, quantidade de horas-extras, talvez algumas informações referentes à utilização do plano médico porque ali tu consegue abstrair se tu tem um extrato do que as pessoas estão procurando mais, por exemplo, fisioterapia e isso pode ser algum sinal de questões do ambiente de trabalho. Então tem uma série de coisas que você pode trazer. Isso é uma apresentação que ocorre muito naturalmente numa outra empresa, mas na EC3 isso não é uma realidade ainda, as pessoas não entendem ainda nem que tem que fazer isso! Mas muito pela maturidade do RH. Quando eu falo da maturidade do RH, não é só daqui, mas é do corporativo! $\mathrm{Na} A M B E V$, o RH é uma área estratégica da empresa! Por exemplo, quando no início do ano se faz 
uma reunião para se estabelecer metas para aquela unidade, quem monta, quem coordena, quem é o "carro-chefe" dessa reunião é o RH! Aqui na EC3 ainda não existe esse movimento. Então, ainda não está muito claro pra empresa onde se quer posicionar o $\mathrm{RH}$, inclusive estrategicamente. Por exemplo, quando eu cheguei aqui, o RH era visto muito como aquele setor do "evento", da folha de pagamento, sabe? E isso é muito pouco pra mim! Eu quero ver um RH que é e é percebido como uma área estratégica, que influencia no resultado final, que pode trazer uma série de informações ou que ti dá um apoio necessário na tomada de decisão. [...].

Então, quando tu falas em consolidar o RH na EC3, a dificuldade, o desafio está na relação de convencer as pessoas no nível corporativo, na direção da empresa?

Sim. Eu acho que, na realidade, são várias camadas, por exemplo, aqui na unidade a gente consegue comparar com algumas outras unidades, tá? Então assim, aqui nessa unidade, o RH tem uma função estratégica muito boa. Por quê? Porque na unidade, talvez pelo trabalho que a gente está fazendo e pela forma como já tem uma visão de $\mathrm{RH}$ estratégico! Tu consegue cada vez mais levar um RH pra dentro da unidade com importância. Mas isso também vem partindo do corporativo, mas de uma forma muito tímida ainda. Aí quando tu vai pra uma outra unidade, o RH já não tem o mesmo peso, sabe? [...] Então, tu não tem ainda corporativamente, vamos dizer assim, um peso de RH! Tu pode ter um RH local com uma importância maior ou menor, mas quando eu falo dessa visão estratégica do RH é muito melhor quando tu tem um alinhamento corporativo, que daí a estratégia vem descendo, sabe? Isso na EC3 está começando acontecer! Mas o que ainda não é tão disseminado? Os diretores locais não têm essa visão ainda. Eles têm muito mais uma visão formada do que vem do RH local pra cima do que vem de cima pra baixo (Coordenador de RH).

Percebe-se, entretanto, que ao contrário do que se constatou no caso anterior, na

EC3 ainda não há uma relação sociotécnica consolidada entre agentes do $\mathrm{RH}$, direção da unidade e direção executiva ou corporativa da empresa. Apesar desse fato, o desenvolvimento dessas relações determina o grau de inserção e participação de dispositivos de cálculos na rede sociotécnica, por exemplo, a cultura da empresa que é definida formalmente no site da EC3 e está presente nas falas do coordenador do RH e da recrutadora.

A EC3 está trazendo uma cultura de inovação baseada nos seus profissionais que devem ter a capacidade de fazer e de não somente se preocupar com aquela sua tarefa, sabe? Eu acho que essa é uma cultura que tem um direcionamento muito legal. A percepção que a gente vê é: Poxa! Pessoas que vão além da sua caixa! Que são [um nome que é utilizado pela EC3 para definir esse profissional que se preocupa com o negócio da empresa como um todo]. Que cuidam do seu lugar de trabalho! Que buscam inovação, que buscam algo novo que vai agregar algo diferente, que vai potencializar a forma como a EC3 vai buscar o crescimento e a sua sustentabilidade de negócio. Tudo isso é uma cultura baseada em pessoas, ou seja, valorizar nosso principal ativo, né? Mas eu acho que nós ainda temos dificuldade de 
vivenciar isso na prática, talvez por sermos muito novos, talvez porque nós ainda não temos o mesmo nivelamento de conhecimento da própria cultura. Eu acredito muito em cultura da empresa. Eu acho que o que faz a empresa mover é a cultura. [...] Então, eu acho que a empresa que se destaca no mercado é aquela que tem uma cultura marcante e bem definida. Mas daí podem dizer: "Ah! Mas se uma empresa tem uma cultura assim tão forte, ela não vai atrair pessoas no mercado que também não têm aquela mesma cultura". Não tem problema! Por quê? Porque uma empresa precisa ter pessoas que acreditem e que joguem o jogo daquela cultura, por exemplo, a EC3 não é aquele tipo de empresa que a gente vê no mundo de TI, que o funcionário para estimular a criatividade foi vestido de galinha! Não estou falando de forma pejorativa, eu estou dizendo que de fato o funcionário entrou na empresa vestido de galinha pra explorar a mente criativa que ele tinha! A EC3 não é essa empresa. Então, se eu tiver no mercado pessoas que gostem disso e vierem pra cá, elas vão se frustrar. Então, é muito importante que a EC3 deva mostrar pro mercado e pros seus funcionários quem ela é! (Coordenador de RH).

A EC3 ainda está em processo de consolidação da sua cultura. A cultura da EC3 é muito baseada em pessoas, tá? Então, a gente procura pessoas que busquem muito a questão da inovação, né? A empresa fala muito nessa questão de ser [um nome que é utilizado pela EC3 para definir esse profissional que se preocupa com o negócio da empresa como um todo]. Então, a cultura da empresa busca esse tipo de pessoas que ela entende serem capazes de provocar inovações (Recrutadora).

Apesar de estar "em processo de consolidação", a cultura da empresa encontrase bem definida e uma vez que ela se reflete numa definição de um perfil de profissional valorizado, ela se insere como um dispositivo de cálculo na rede sociotécnica da EC3.

Outro dispositivo de cálculo que apresenta essa condição de estar em fase de consolidação, mas não o suficiente para participar nas relações sociotécnicas das operações de cálculo da EC3 no mercado de trabalho, é o Plano de Cargos e Carreiras.

\section{Vocês têm um Plano de Cargos e Carreiras?}

Bom, nós ainda não temos descrição de cargos. A gente tem uma ferramenta que é a [?], que tem algumas descrições de alguns cargos, mas é bem... Como eu vou ti dizer? Simples, né? Não completa. Mas já está sendo feito um trabalho pelo corporativo para ter todas as descrições dos cargos. Tanto que, na abertura de uma vaga, ainda é o gestor da área da vaga que descreve o perfil. [...] Mas claro! A gente já tem uma tabela salarial, onde tem os salários de acordo com os perfis e... Mas uma política forte, nesse sentido, ainda não temos (Recrutadora).

A EC3 ainda não tem um Plano de Cargos e Carreiras bem definido. A EC3 está criando e está para lançar isso! Mas por exemplo, a gente tem hoje algumas definições de papéis, tá? O que é um analista de desenvolvimento de software? O que é um arquiteto de soluções? Isso a gente não tem ainda bem definido, mas nós temos uma intranet que a gente pode acessar e ver essas informações mínimas, mas não para todas as funções. E mesmo nesses papéis que tem lá, eu ainda não 
tenho os níveis de senioridade. Então, por exemplo, hoje é muito difícil eu chegar para um analista e avaliar qual senioridade ele se encaixa. [...] Então, eu não tenho um local, uma ferramenta que eu posso consultar e me dizer isso. O que existe, nesse sentido, é o conhecimento da experiência prática dos gestores e que acaba passando pra gente aqui [do RH]. Então, através dessa relação com os gestores, tu vai tendo um direcionamento. Mas quem descreve a vaga com os conhecimentos e habilidades específicas mesmo é o gestor (Coordenador de RH).

Pelos extratos de entrevista se constata que o Plano de Cargos e Carreiras ainda não entra como dispositivo de cálculo; assim, ele é substituído pela relação entre agentes humanos do RH e os gestores de áreas técnicas. É também através dessa relação com os gestores que acontece o planejamento do número e para quais funções serão necessárias novas contratações.

A demanda de contratação depende muito mais do escopo de projeto. É o projeto que vai definir se eu preciso contratar pessoas pro desenvolvimento ou pra prestação de serviços ou pra qualidade ou... E isso é a área do projeto que me passa e aí a gente vai buscando as pessoas.

Essas informações chegam pra ti dos gestores?

Geralmente, $[. .$.$] elas chegam primeiro como um sinal de alinhamento$ do tipo: "Olha, nós estamos fechando um projeto e esse projeto vai precisar desse número de contratações". E aí eu pergunto para que áreas são essas contratações. Aí o gestor passa a descrição dessas contratações e aí eu repasso pro nosso time. Mas por exemplo, a gente tem uma reunião todas as sextas-feiras, onde a gente consegue abordar todos os assuntos que estão acontecendo na unidade, desde eventos, contratações que estão pra vir, desde... Então, é essas contratações novas dali que eu abordo com o time (Coordenador de RH).

Se o planejamento de abertura de vagas e as definições de cargos e carreiras ainda dependem de uma relação sociotécnica estabelecida somente entre agentes humanos, a definição de faixas salariais passa pela participação de um dispositivo de cálculo, a "Pesquisa Salarial de Mercado".

Como vocês fazem para definir salários?

A gente tem uma pesquisa de salários bianual feita pelo corporativo da empresa. Nela é feita uma média de mercado. Nessa média de mercado, a gente vai definir, por exemplo, hoje a EC3 tem seis tetos salariais por níveis de carreira e... Então, um analista I, ele tem seis tetos salariais.

Nessa pesquisa, vocês selecionam empresas que são as principais concorrentes?

A pesquisa de fato, ela não é feita pela gente. A pesquisa é feita por uma empresa terceira e aí, geralmente, eles direcionam a pesquisa pro mundo de TI, né? Eles não comparam com outros segmentos, mas se a gente pedir eles... Por exemplo, quando eles fizeram pela última vez a pesquisa pro mundo de TI, a gente pediu pra eles incluir banco, cooperativas de crédito e algumas grandes empresas de varejo. Por quê? Porque eu posso perder profissionais pra esses caras! Então, é importante ter uma visão deles também (Coordenador de RH). 
O coordenador de recursos humanos, a recrutadora e os gestores de área ainda travam relação com outro dispositivo de cálculo, a saber, técnicas de entrevista. Esse dispositivo assume a forma de um roteiro de entrevista que é utilizado na seleção de candidatos, tanto pela recrutadora como pelo gestor da área técnica. O roteiro de entrevistas organiza certo número de perguntas abertas segundo os seguintes grupos de informação que se quer extrair do candidato: 1) perguntas pessoais como hobbies, idade, família, história de vida, etc.; 2) questões sobre a formação de ensino superior ${ }^{75}$ do candidato e de fluência em línguas estrangeiras; 3) relato da trajetória e experiência profissional; 4) perguntas para relatar desafios profissionais experimentados pelo candidato; 5) remuneração e benefícios do último emprego e pretensão salarial; 6) verificação da disponibilidade e vontade do candidato em trabalhar na EC3. Gestores e recrutadora aplicam esse roteiro de entrevista para verificar e avaliar tanto competências e qualificações técnicas como comportamentais, sendo essas últimas definidas por meio da relação sociotécnica com a cultura da empresa. A concepção por de trás da elaboração do questionário e do seu uso é a chamada técnica de entrevistas por competências.

Toda técnica de entrevista aqui é baseada em perguntas abertas, nunca perguntas fechadas. Nunca é pergunta de "sim ou não". São perguntas que avaliam competências como trabalhar em equipe, através de perguntas que o candidato vai contar uma experiência que ele passou. Então, o nosso roteiro de entrevistas, ele é todo baseado nisso (Coordenador de RH).

A gente faz entrevistas baseada em competências comportamentais. Então, no que a gente se apoia? Nas experiências anteriores do candidato. Então, eu faço umas perguntas para ele e eu vou entendendo como ele agia nas outras empresas. Então, é questão de estar conhecendo o candidato mesmo (Recrutadora).

Ao contrário da EC2, a técnica de entrevistas por competências é uma prerrogativa do RH da unidade, especialmente para avaliar as chamadas competências comportamentais. Não é uma técnica na qual os gestores e os funcionários da EC3 tenham sido treinados, mas se constitui em um dispositivo de cálculo que participa das relações sociotécnicas com os agentes humanos do $\mathrm{RH}^{76}$.

75 A EC3 somente contrata profissionais com curso superior completo com exceção dos estagiários, que ainda estão cursando o ensino superior.

${ }^{76}$ Cabe destacar que não houve autorização para a realização de entrevistas com gestores de área técnica da EC3. 
Outro dispositivo de cálculo na rede sociotécnica da EC3 é o "plano de benefícios". Trata-se de um dispositivo que trava uma relação sociotécnica com o RH (coordenador e recrutadora) para executar a contratação como operação de cálculo.

Como tu vê o programa de beneficios que a EC3 oferece? Eu me refiro tanto os beneficios mais tradicionais como aqueles mais ligados ao ambiente e ao modelo de gestão de trabalho?

$\mathrm{Eu}$ acho que a EC3 tem que dar um passo maior nisso, por exemplo, nós fizemos uma pesquisa e vimos que o nosso vale-refeição está abaixo da média das grandes empresas. Então, isso é um indicativo que ele não tem tanta atratividade de mercado. A gente tem um PLR [Participação no Lucro e nos Resultados] e eu até nem sei como é exatamente o PLR nas outras empresas de tecnologias, mas o nosso não é um PLR muito grande... Então, ele varia entre meio até um salário e meio. Mas esses são aqueles benefícios mais clássicos! Por exemplo, plano de saúde e odontológico, eu acho que é igual ao mercado. Mas eu acho que a gente tem que evoluir naqueles benefícios que não aparecem tanto, sabe? Que são os benefícios de rotina. Por exemplo, todo dia, em tal hora, passa um carrinho de fruta. Não é um benefício que tu coloca num contrato, sabe? Mas são benefícios que são interessantes! Coisas diferentes! E quando eu falo nessas coisas diferentes é que eu acho que a EC3 precisa andar mais!Ter ideias mais inovadoras. Coisas que podem tornar o ambiente mais agradável e que quando tu comente numa entrevista, as pessoas pensem - "Poxa! Que legal!" - sabe? Nesse sentido que a EC3 precisa evoluir mais (Coordenador de RH).

Olha, eu acredita que os benefícios têm potencial de atrair os candidatos. A EC3 é uma empresa que oferece previdência privada, PLR e... A empresa também oferece algumas facilidades! A gente traz um professor para dar aulas de inglês aqui, por exemplo. A gente ter parcerias com clubes e universidades pra dar descontos. Tudo isso são diferenças que atraem, né? (Recrutadora)

Esse dispositivo, portanto, entra nas relações sociotécnicas que executar a capacidade de cálculo de contratação dos profissionais demandados pela EC3.

Apesar de ainda não estabelecer um Plano de Cargos e Carreiras, os agentes humanos do RH da EC3, em suas operações de recrutamento e seleção, travam relação com um agente não-humano, o "sistema informático de gestão de recursos humanos".

A gente tem um sistema no qual eu consigo visualizar as vagas que são abertas. O gestor acessa esse sistema, ele abre a vaga no sistema e, na verdade, ele solicita a abertura de vaga para o coordenador dele, tá? E lá no sistema, quando ele solicita, ela passa as informações do perfil da vaga, qual salário, etc. E aí o coordenador pelo sistema aprova ou não a solicitação. $\mathrm{O}$ coordenador aprovando, o sistema encaminha para aprovação do diretor! O diretor aprovando, já vem pelo sistema pro RH, pra mim no caso. Tudo isso para uma vaga de substituição. Se for uma vaga de aumento de quadro, isso ainda passa pela vicepresidência da EC3 (Recrutadora).

Nesse sistema, os gestores, o coordenador de RH e a direção da empresa comunicam e organizam as vagas para serem preenchidas na empresa. Também 
constam as informações sobre os requisitos de qualificação para diferentes vagas de acordo com as descrições fornecidas pelos gestores da área. O sistema ainda possui um banco que reúne todos os currículos recebidos pelos canais de recrutamento mobilizados para preencher as vagas em aberto da EC3.

Temos um banco de currículos permanente que, assim, a gente tem uma ferramenta que é um sistema corporativo que, como eu disse, a gente divulga a abertura de vagas pelo sistema. Quando a vaga foi aprovada pra ser aberta, o sistema divulga a vaga no site da EC3 e as pessoas, através do site, já se candidatam. Então, o sistema me permite acessar esses currículos das pessoas que se candidataram pra vaga no site da EC3 e, também, a gente guarda os currículos que se recebe por e-mail. Então, a agente acessa esses currículos via sistema (Recrutadora).

Além do banco de currículos, os canais de recrutamento estabelecem outros agentes na rede sociotécnica da EC3. O primeiro deles, já mencionado no extrato de entrevista acima, é o site da empresa, que possui um espaço no qual os candidatos cadastram seus currículos numa plataforma determinada. Essa plataforma, por seu turno, alimenta o banco de currículos no sistema informático acessado pela recrutadora. O segundo seria o "programa de indicações", mas ainda se encontrava em fase de elaboração e, por isso, não participava como agente na rede sociotécnica da empresa. Além do site da EC3, algumas vagas são divulgadas igualmente nos sites de emprego Catho ${ }^{\circledR}$ e baguete ${ }^{\circledR}$, que já foram definidos na seção deste capítulo referente ao caso da EC1. Também é utilizado o site Linkedin ${ }^{\circledR}$ cujo funcionamento e definição se trataram na seção sobre a EC2, mas ao contrário dessa última, na EC3, essa rede virtual de profissionais é usada para recrutamento ativo, ou seja, a empresa vai atrás de profissionais que lhe interessam, pesquisando e travando contato com eles através do Linkedin ${ }^{\circledR}$.

A gente usa bastante o Linkedin $®$. Ele é uma das grandes fontes que a gente tem pra buscar pessoas, né?Eu até acho que o Linkedin ${ }^{\circledR}$ não é tão disseminado como deveria ser! Tem muito profissional bom que não está lá (Coordenador de RH).

O Likendin ${ }^{\circledR}$ é hoje uma fonte bem forte de recrutamento. Tem muito profissional que está lá. Então, a gente divulga vagas no nosso perfil lá e também busca profissionais por lá. Profissionais de alta qualificação, a gente busca por lá e faz contato com ele direto por lá (Recrutadora).

Por fim, ainda como dispositivo de cálculo que se insere em relação sociotécnica com o RH na operação de recrutamento, há a presença das universidades.

Nosso foco é a UNISINOS [Universidade do Vale do Rio dos Sinos] e a PUC [de Porto Alegre]. São as universidades que a gente mais divulga. Nós mandamos e-mails pros professores com as vagas, né? [...] A gente vai também e faz palestras e fala da empresa também, do 
site com as vagas, né? Mas até agora, nós fizemos apenas uma palestra na PUC e uma na UNISINOS. E a PUC nos procurou e a gente participou de uma feira de carreiras (Recrutadora).

Constata-se que essa é uma relação ainda em formação na EC3, pois se limita mais a divulgar vagas de emprego através de e-mails para professores dessas universidades e esporadicamente fazer ou participar de eventos. Em contraste, cabe lembrar a relação mais consolidada da EC2, que inclui não somente a divulgação de vagas, mas a realização frequente de eventos de divulgação da empresa junto às universidades de Porto Alegre e região metropolitana e um programa de estágios consolidado.

Por último, mas não menos importante, há os dispositivos de cálculo que se inserem em relações sociotécnicas com os gestores e com o RH, os "testes técnicos". Infelizmente não foi permitido o acesso a nenhum deles, porém foi mencionada nas entrevistas a utilização dos seguintes testes: 1) teste de lógica elaborado pela EC3, pois não há muitos psicólogos em RH da empresa para aplicar testes padrões; 2) teste de programação que os gestores de área elaboram e aplicam em candidatos para vagas que envolvem a habilidades de desenvolver e testar códigos de programação; 3) um teste na forma de redação em português que serve para verificar o nível de expressão escrita do candidato.

Todos esses testes são utilizados como critérios de exclusão e classificação de candidatos. Os testes mais dedicados a medir capacidades de proficiência dos candidatos em linguagens de programação estão em relação e aplicados pelos gestores de área; já aqueles que se referem a habilidades mais genéricas como capacidade de raciocínio lógico e de expressão escrita, esses estão em relação com o RH.

Em suma, a rede sociotécnica da EC3 se encontrava em formação no sentido de ser recente a atuação do RH na unidade da empresa; assim, por exemplo, dispositivos de cálculo como o programa de indicações ou o Plano de Cargos e Carreiras não participavam como dispositivos na rede sociotécnica da EC3. A rede era estável apesar de ainda em formação, pois as relações sociotécnicas se encontravam bem definidas, isto é, constatou-se a atuação do RH em todas as operações de cálculo de valor da empresa no mercado de trabalho.

Assim sendo, tem-se uma rede sociotécnica com a presença de três grupos de agentes humanos em relação entre si - direção da empresa, gestores de áreas técnicas e recursos humanos - e vários dispositivos de cálculo - cultura da empresa, pesquisa de salários, técnicas de entrevistas, plano de benefícios, universidades, sites de vagas de 
empregos e redes online de relacionamento profissional, site da EC3, sistema informático de gestão de recursos humanos, banco de currículos e os próprios currículos, testes para seleção e metas e métricas de contratação. Todos esses agentes humanos e não-humanos travam relações em pelo menos uma das operações de cálculo de valor da firma no mercado de trabalho.

\subsection{Estudo de Caso 4: rede sociotécnica complexa e adensada}

A EC4 é o caso com o maior número de agentes humanos e de dispositivos de cálculo na sua rede sociotécnica. A tabela abaixo lista os agentes identificados e que compõem a rede da EC4.

Tabela 25 - Agentes humanos e dispositivos de cálculo na rede sociotécnica da EC4.

\begin{tabular}{|c|c|c|}
\hline & Agentes Humanos & Dispositivos de Cálculo \\
\hline Direção Executiva e Comercial & $\sqrt{ }$ & \\
\hline Gestores de Áreas Técnicas & $\sqrt{ }$ & \\
\hline Coordenadora de RH & $\sqrt{ }$ & \\
\hline Recrutadoras & $\sqrt{ }$ & \\
\hline Diretor de Escritório & $\sqrt{ }$ & \\
\hline $\begin{array}{l}\text { Coordenadora de } \\
\text { Recrutamento }\end{array}$ & $\sqrt{ }$ & \\
\hline Organizadora de Seleção & $\sqrt{ }$ & \\
\hline Funcionários Técnicos & $\sqrt{ }$ & \\
\hline Pesquisa Radar Tecnológico & & $\sqrt{ }$ \\
\hline $\begin{array}{c}\text { Reunião de Decisão de } \\
\text { Contratação }\end{array}$ & & $\sqrt{ }$ \\
\hline Programa de Benefícios & & $\sqrt{ }$ \\
\hline Plano de Cargos e Carreiras & & $\sqrt{ }$ \\
\hline Plano de Cargos e Salários & & $\sqrt{ }$ \\
\hline $\begin{array}{c}\text { Sistema Informático de Gestão } \\
\text { de RH }\end{array}$ & & $\sqrt{ }$ \\
\hline Teste de Exercício Técnico & & $\sqrt{ }$ \\
\hline Testes Lógicos & & $\sqrt{ }$ \\
\hline $\begin{array}{c}\text { Entrevista } \\
\text { Técnica/Profissional }\end{array}$ & & $\sqrt{ }$ \\
\hline Entrevista Comportamental & & $\sqrt{ }$ \\
\hline Entrevista de Valores & & $\sqrt{ }$ \\
\hline Cultura da Empresa & & $\sqrt{ }$ \\
\hline Programa de Recomendação & & $\sqrt{ }$ \\
\hline Site da Empresa & & $\sqrt{ }$ \\
\hline Formulários de Assessment & & $\sqrt{ }$ \\
\hline Currículos & & $\sqrt{ }$ \\
\hline Banco de Currículos & & $\sqrt{ }$ \\
\hline Sites de Redes Profissionais & & $\sqrt{ }$ \\
\hline Sites de Redes Sociais & & $\sqrt{ }$ \\
\hline $\begin{array}{c}\text { Eventos em Comunidades de } \\
\text { TI }\end{array}$ & & $\sqrt{ }$ \\
\hline Universidades & & $\sqrt{ }$ \\
\hline Site de Vagas de Emprego & & $\sqrt{ }$ \\
\hline
\end{tabular}

Fonte: Dados de Pesquisa de Campo. 
O aspecto particular da rede sociotécnica da EC4 é o fato dela apresentar uma alta interatividade em todo o processo de cálculo de valor, entre os agentes humanos que, por sua vez, estão em relação sociotécnica com diversos dispositivos de cálculo (agente não-humanos). O símbolo desse alto grau de interatividade entre os agentes é a reunião final na qual todas as pessoas que tiveram contato com um candidato (cerca de 10 entrevistadores) tomam a decisão em conjunto e por consenso de contratá-lo ou não. Esse procedimento é bem diferente daquele identificado nos outros estudos de caso, onde esse tipo de decisão era feita por etapas, tendo a última palavra o gestor da área técnica na qual a vaga de emprego do candidato estava aberta. Para melhor entender este caso é preciso começar por definir os agentes humanos que participam da rede sociotécnica e que são encarregados das operações de cálculo da EC4 no mercado de trabalho.

A unidade estudada da empresa possui três pessoas encarregadas especificamente das atividades de recrutamento e organização da seleção: duas delas fazem a busca ativa de profissionais para ser entrevistados pela EC4 e uma terceira organiza todo o processo de seleção dos candidatos, por exemplo, agendamento com as pessoas da empresa que vão ser entrevistadores. Conforme descrito no capítulo anterior, a EC4 possui uma área de recursos humanos dividida em dois times: o de recrutamento e o encarregado de tarefas como departamento de pessoal e financeiro, avaliação e desenvolvimento de carreiras. Os dois times possuem um diretor de recursos humanos. O recrutamento possui, ainda, uma coordenadora que, no momento das entrevistas, estava sediada em Recife. Toda essa estrutura ainda se relecionada com o diretor do escritório de Porto Alegre. Cabe destacar que todos esses agentes foram entrevistados ${ }^{77}$.

Esses agentes do RH interagem com os profissionais da parte técnica da empresa nos processos de seleção e de decisão de contratação de um candidato. Chama atenção que na EC4, não somente gestores técnicos, mas profissionais de diferentes níveis da empresa são chamados a participar da seleção e contratação de um candidato. Todavia, a escolha de quem, entre os profissionais da empresa, irá participar do processo seletivo de um candidato é feita pelas recrutadoras.

\footnotetext{
${ }^{77}$ Ao contrário do que se constatou na EC1 e na EC3, os conhecimentos advindos da formação acadêmica e da experiência profissional dos agentes humanos ligados ao RH da EC4, não influenciam o modo como o RH está organizado e nem a estrutura composta pelos procedimentos de recrutamento, seleção e contratação. Esses aspectos já se encontram globalmente definidos pela direção corporativa da EC4. Portanto, tais conhecimentos somente têm uma fraca influência no modo como cada um desses agentes executa suas tarefas.
} 
Quando tem um candidato, eu vejo no sistema quem na empresa tem conhecimento e pode entrevistar o candidato; por exemplo, o candidato tem um conhecimento em Java? Então, eu vou ter que ver quem tem um conhecimento nessa linguagem para entrevistar essa pessoa. Então, a gente vai jogando assim. A gente tem todas as informações de todos os funcionários, o que eles sabem e o que não sabem, quanto tempo estão na EC4 (Recrutadora 1).

Um elemento peculiar à EC4 é que as recrutadoras não buscam profissionais do mercado de trabalho tendo em vista preencher um grupo definido de vagas em aberto na empresa. Elas trabalham com um modelo de recrutamento constante.

$\mathrm{O}$ que acontece? A gente não tem uma vaga em aberto, tipo: “Ah! Eu preciso de dois desenvolvedores que saibam linguagem de programação Python". A gente tem todas as vagas praticamente sempre abertas. As únicas vagas que abrem e fecham com candidatos específicos são as vagas administrativas. O resto, a gente está sempre contratando. Então, a gente está sempre online procurando, estamos sempre fazendo eventos (Recrutadora 1).

A EC4 não é uma empresa que contrata por vagas abertas em específico. Claro! Algumas vezes nós buscamos contratar profissionais específicos com habilidades muito específicas, tá? Mas em geral, a gente está sempre contratando. Estamos sempre procurando candidatos com potencial para trabalhar com a gente (Coordenadora de Recrutamento)

A gente está sempre com vagas no nosso site em aberto. Vagas que sempre vão estar lá: desenvolvedor, analista de teste e analista de negócios. Essas vagas estão sempre abertas e, então, o foco é sempre nelas. E depois são as vagas de operacional, por exemplo, alguém para trabalhar em contabilidade. Mas aquelas vagas técnicas estão sempre abertas (Organizadora de Seleção).

Nós não contratamos para vagas específicas. Nós não temos aquela coisa do tipo: "Esse projeto vai precisar de tantos mais desenvolvedores". Até porque depois o projeto terminar e a tecnologia, as habilidades podem ser bem diferentes para outro projeto. Então, nós contratamos pessoas que encaixam com a empresa porque quando termina um projeto, a pessoa não vai embora da empresa. O que acontece normalmente é que os diretores sabem quantas pessoas nós precisaremos no futuro, baseado no número de clientes, de expectativas de crescimento... E eles falam esse número pro recrutamento e o recrutamento faz o planejamento também, por exemplo, o recrutamento vê a capacidade de contratar tantas pessoas em tanto tempo. E aí o recrutamento e o direto geral da unidade vão chegar e vão conversar para acertar isso. [...] Agora, a média é oito novas contratações por mês! Mais do que isso é impossível [risos] (Recrutadora 2).

Esse modelo, ao mesmo tempo, não quer dizer que as recrutadoras não tenham metas que as orientem em priorizar certos perfis técnicos de profissionais.

A gente sabe que, por exemplo, uma das metas da empresa é dobrar o número de funcionários até 2015. E aí, no início do ano, a gente recebe, nós recrutadoras, uma meta mensal de número de contratações 
em cada escritório no Brasil. E aí a cada quatro meses, vai revisando, acompanhando essas metas, né?

Esses números que vocês recebem, já vêm com uma definição da distribuição dele por tipo de cargo, profissional?

Não. A gente tem um tipo de pirâmide, né? Uma pirâmide em termos de senioridade, né? Então, a gente já sabe que essas contratações têm que seguir esse sentido de pirâmide. Eu não posso contratar todo esse número em desenvolvedores júnior, entendeu? $\mathrm{O}$ time de recrutamento em específico, então, recebe esses números e de duas em duas semanas, ele se reúne com o nosso diretor de RH. Nessas reuniões, ele diz assim - "Ah! Quem sabe tu prioriza Java porque tá vindo esse cliente aqui e a gente vai precisar de mais gente que sabe Java do que "C Sharp" - ou - "Nós estamos prevendo que essas três pessoas vão sair, então foca para substituir elas". Além disso, comigo em específico, agora eu cuido do recrutamento de candidatos júnior. Então, eu recruto todo mundo que irá fazer o programa da Universidade EC4. Então são pessoas que não têm experiência de ter trabalhado em grandes corporações e a gente contrata para passar cinco semanas na Índia em treinamento. Pra esse programa em específico são sete sessões por ano e em cada sessão são sete pessoas. Então, essa meta, no início do ano, eu já sei que é ponto final (Recrutadora 1).

É claro que a gente tem número de recrutamento que a gente trabalha, Lucas. A gente, então, tem um número de contratações, mas esse não é um número fixo, tá? A gente tem uma flexibilidade nesse número, mas o que mais importa pra gente é a qualidade das contratações. Então assim, eu preciso atingir nesse número um "level mix" de senioridade dessas contratações, por exemplo, se eu estou promovendo muitas pessoas para os níveis mais seniores, eu provavelmente vou focar mais em contratar gente para os níveis mais júnior. Portanto, eu preciso estar alinhada com o programa de desenvolvimento interno de carreiras também (Coordenadora de Recrutamento).

Ao mesmo tempo, e isso também é algo peculiar à EC4, são as metas de perfil não-técnico que orientam não somente o trabalho das recrutadoras, mas que se configuram numa política de $\mathrm{RH}$ da empresa a qual é passada também para os funcionários da área técnica.

Nós temos metas de inclusão! Então, nas nossas contratações, eu não quero ter somente homens no setor de tecnologia. Eu também não quero ter somente homens brancos, né? Heterossexuais! Então, nós temos metas de inclusão. Então, eu procuro contratar mais mulheres, negros, gays... Enfim, a gente trabalha priorizando grupos que são tradicionalmente descriminados (Coordenadora de Recrutamento).

Atualmente, a gente está tentando trazer pra empresa pessoas que não tiveram tanta oportunidade. Negros, mulheres... Enfim, profissionais que não são a massa dos profissionais da TI. Então, a gente está focando esse perfil de pessoas que não tiveram muitas oportunidades, para justamente trazer diversidade pra dentro da empresa (Organizadora de Seleção). 
A gente tem metas para pessoas - como a gente chama - altamente discriminadas. Aí entram negros, gays, mulheres... Então, a gente desmembra isso para metas no ano no Brasil. Então assim, por exemplo, a gente prevê crescer " $x$ ", então, isso vai precisar de mais " $x$ " profissionais e que tantos por centos serão de contratações de pessoas altamente discriminadas. Por isso, também, que a gente foi para Recife - a população lá é mais negra que em Porto Alegre e tem também tem o impacto na região, que é mais pobre do que aqui. Então, a gente tem essas metas (Diretor de RH).

A EC4 é conhecida pela excelência técnica. Então, antigamente, ela tinha poucos consultores e todos os consultores eram muito excepcionais tecnicamente! Eram os melhores do mercado! [...] Faz uns cinco anos que a EC4 vem mudando um pouco a filosofia dela, pra uma coisa mais voltada pro social. Então, isso fez com que em vez de contratar somente pessoas excepcionais, que isso envolve um grupo muito seleto e elitista de pessoas que tiveram a oportunidade de estudar nas melhores faculdades e... Então, a EC4 hoje, dá oportunidades pra quem não teve muita oportunidade, sabe? (Analista de Qualidade).

Assim sendo, o dispositivo de cálculo "metas de recrutamento" assume um papel mais flexível do que nos demais estudos de caso, pois, nesses últimos, esses dispositivos estabeleciam quais vagas deveriam ser preenchidas e as métricas sobre os processos de seleção abertos pela recrutadora durante determinado período de tempo.

Outro dispositivo que direciona o cálculo da empresa nas contratações é a chamada "Pesquisa Tendências Técnicas e Tecnológicas".

Todo ano sai a nossa pesquisa, a "Pesquisa Tendências Técnicas e Tecnológicas". Nela, a EC4 fala com as pessoas que são muito sênior e aí vê quais são as linguagens [de programação] que serão as melhores para se trabalhar. O que é novo, o que está ultrapassado, o que está bom e o que não está. Então, todo ano a gente lança um release dessa pesquisa e muitas vezes até várias pessoas seguem essa pesquisa da EC4 para saber o que é bom usar. E isso acaba impactando no que a gente vai buscar para contratar (Recrutadora 1).

Esse dispositivo de cálculo estabelece, assim, parâmetros com base em tendências tecnológicas do mundo de TI, que servem para orientar a EC4 sobre que tipos de qualificações técnicas ela deve buscar desenvolver nos seus funcionários e verificar a presença das mesmas nos profissionais que contrata.

Uma vez que prevalece a orientação de que a demanda da EC4 por profissionais é continua, o recrutamento se torna ativo, isto é, os canais de recrutamento utilizados se envolvem mais na busca por todo e qualquer profissional que podem ser interessantes para a empresa. Em outros termos, nos demais estudos de casos, os canais de recrutamento serviam para receber candidatos na forma de currículos; em contraste, na EC4, os canais de recrutamento são usados mais para buscar profissionais. 
O canal de recrutamento que melhor ilustra essa particularidade são os "eventos".

Que estratégias tu desenvolve para atingir as tuas metas?

O que a gente faz bastante é eventos. Então, a gente cria eventos ou mesmo copia certos tipos de eventos e faz em várias regiões. Por exemplo, nós temos os eventos de "boot camp". Que são eventos nos quais a gente faz todas as etapas do processo seletivo em dois dias! A gente sai pelo Brasil e passa vários finais de semana fora [risos]. Nesses eventos, a gente sabe que vai acabar contratando de três a quatro pessoas do primeiro nível de senioridade, o "consultant". Então, eu vou já sabendo, porque todos os eventos tiveram esse resultado. Então, eu já sei, se eu estou apertada, eu tenho esta carta na manga. [...] Nós fazemos também eventos aqui no escritório, eventos para mulheres. Então, nesses eventos a gente ensina as gurias a codificar, escrever código, né? Fazemos isso aqui e em outros lugares. Fazemos palestras mais técnicas pra atrair pessoas mais seniores. Então, a gente é muito de evento, a gente adora eventos! (Recrutadora $1)$.

Nossa estratégia de recrutamento é muito focada em eventos, Lucas. Por isso é até difícil ti dizer aonde começa o recrutamento e aonde começa a ação de divulgação da empresa, de "branding", né? Nós temos uma marca muito forte dentro do país e, essa marca, nós construímos com muito envolvimento na comunidade de tecnologia. Não só no Brasil, mas em todo mundo, né? Nós estamos sempre promovendo eventos em todo mundo. Então, a gente viaja muito para vários estados do Brasil e até países da América Latina e, nesses eventos, a gente coloca o processo de seleção junto. Então, num evento, todo o processo de seleção é realizado em dois dias. Então, nos trabalhamos muito com eventos e temos uma marca muito forte por isso (Coordenadora de Recrutamento).

Organizar eventos é o canal mais eficiente para conseguir pessoas. Eu faço no mínimo um evento por mês. Em várias cidades, por exemplo, em agosto [2012], eu fui para Belém e já fui para São Paulo, Rio, Curitiba, vários lugares. Com esses eventos, eu consigo contratar pessoas muito rápido, porque eu faço o recrutamento e seleção num final de semana. [...] É um processo muito rápido e também muito bom para as pessoas conhecerem a empresa (Recrutadora 2).

Constata-se que, primeiro, não é a EC4 que participa de eventos, mas é ela que promove e organiza eventos visando buscar profissionais para serem candidatos a trabalhar na empresa. E, segundo, como os eventos partem de uma lógica de recrutamento ativo, eles servem também como um modo pelo qual a EC4 estabelece uma interação com as comunidades de TI e, assim, torna-se uma fonte de recomendações e de visibilidade entre os profissionais da área. Nesse sentido, a escolha de onde fazer eventos, também mobiliza outro tipo de canal de recrutamento e, por conseguinte, outro agente não-humano, a saber, os fóruns e “mail listing” na Internet, 
para discussão e relacionamento entre profissionais e pessoas interessados em temas das áreas de tecnologias da informação, especialmente desenvolvimento de softwares.

Além disso, os próprios funcionários da EC4 fazem indicações de lugares interessantes para fazer eventos.

Quem escolhe onde fazer os eventos é o time de recrutamento. Nós pesquisamos onde tem comunidades fortes de... Por exemplo, uma comunidade forte em metodologia ágil, que é uma metodologia de desenvolvimento que a gente usa, né? Ou uma comunidade forte de desenvolvedores de uma linguagem que a gente usa. Ou até comunidades que nós vemos que têm muitas mulheres na área de tecnologia. Por exemplo, Belém! Belém ninguém dá nada, mas é ótima a comunidade de tecnologia em Belém. Então, a gente pesquisa na Internet ou alguém nos diz! (Recrutadora 1).

Os lugares onde vamos fazer os eventos é sempre decidido com o time de recrutamento e a gente sempre procura trabalhar com os nossos colegas da parte técnica. É um ciclo continuo de comunicação com eles, aonde eles vão nos falando o que está acontecendo nas comunidades e a partir disso, a gente começa desenvolver uma estratégia. Os lugares dos eventos variam: universidades, sala em hotel, numa empresa parceira, colégios... Isso vai variar muito.

Outro dispositivo de cálculo na Internet e que é utilizado para o recrutamento ativo, é o site Linkedin ${ }^{\circledR}$ cujo funcionamento já foi tratado na seção dois deste capítulo. A EC4 utiliza esse dispositivo como uma forma de recrutamento ativo, mas o que lhe é peculiar é a utilização do mesmo como um dispositivo para operação de cálculo de seleção.

Principalmente nesses currículos que vem do Linkedin ${ }^{\circledR}$, o que eu faço é: eu olho as recomendações que o candidato tem lá no perfil dele. Eu olho lá -“Ah! O fulano é um cara muito bom porque ele conseguiu nos ajudar numa fase de um projeto muito difícil" - então, depois eu pergunto para ele - "Que fase foi essa? Por que esse cara escreveu essa recomendação pra ti?" - eu tento validar esse tipo de feedback pra extrair um pouco mais de informação dali. Eu até faço isso pra ver se aquele feedback foi sincero, se foi alguma coisa relevante ou se foi aquele tipo de coisa: tu me dá um feedback e eu ti dou outro. E também tentar procurar algumas coisas ali do tipo: ela colocou ali que é especialista em gestão de riscos. E aí vou perguntar pra ela porque ela se considera um especialista em gestão de risco, né? $\mathrm{Eu}$ pego coisas que a própria pessoa escreveu! $\mathrm{Eu}$ parto do pressuposto de que se ela escreveu, ela sabe do que ela está falando. Então, eu leio lá, faço umas anotações pra ter um material de antemão pra conversar com essa pessoa (Diretor de Escritório).

Por fim, o foco no recrutamento ativo através de eventos com as "comunidades

de tecnologia", acaba por acarretar uma relação fraca e pouco desenvolvida com as Universidades.

Nós estamos começando a ficar mais forte na relação com as universidades. O que a gente tem? A gente tem alguns professores que 
são nossos amigos, são professores da PUC [de Porto Alegre], da UFRGS [Universidade Federal do Rio Grande do Sul], da UNISINOS, que estão sempre com a gente conversando. Então, a gente pergunta o que os alunos querem, né? $\mathrm{O}$ que tu acha que os teus alunos vão gostar? Será que vão gostar de uma palestra ou de uma atividade? E daí, a gente vai lá e faz! Então, nós vamos bastante nessas universidades e faz alguma coisa com os estudantes e... Também não só aqui, a gente foi na USP [Universidade de São Paulo] no ano passado! Então, geralmente a gente tem relação com os professores e quando a gente quer fazer um evento, a gente liga antes, conversa, né? Vê o que está acontecendo na universidade, que tipo de aluno tem lá, se a universidade gostaria que a EC4 fosse e o que a universidade gostaria que a gente fizesse. Então, por exemplo, eles vão me dizer que os alunos deles não têm inglês! Então, eu não vou lá fazer uma coisa em inglês, né? A gente quer fazer parceria, mas a gente quer que a universidade nos guie sobre qual é o perfil de alunos deles e o que eles gostariam que a gente fizesse. [...] E a gente participa de algumas feiras de carreiras também (Recrutadora 1).

Nós temos relação de recrutamento em universidades, mas eu ti diria que não é nossa principal fonte de contratações. Não é porque a gente acaba com contratações bastante júnior, né? Então, é importante, a gente tem, mas nós não nos restringimos a isso (Coordenadora de Recrutamento).

Todavia, a EC4 tem uma linha de recrutamento ativo de recém-formados, principalmente em cursos da área de TI, para participarem do já mencionado programa "EC4 Universidade".

Com esse programa de vocês da EC4 Universidade, tu acha que a empresa está tendo um foco no recrutamento e contratação de recémformados ou o que vocês procuram mais é o profissional com experiência no mercado?

Não! Assim, isso é um balanço, tá? Não é uma prioridade da empresa, mas é a minha prioridade, porque eu fui encarregada desse programa, tá? Mas a gente tem muito orgulho desse programa! [...] O aluno da universidade que conhece o programa, ele fica louco pra ir! Então é um programa que nós temos muito orgulho e damos muito valor, mas isso não faz ser uma prioridade nas contratações, porque ele entra naquele sistema de distribuição de pirâmide de senioridade (Recrutadora 1).

Para as pessoas recém-formadas, a gente tem um programa que é a EC4 Universidade. Esse programa é na realidade um programa de imersão, de treinamento, tá? É um treinamento de cinco semanas, realizado na Índia. E a agente seleciona pra esse programa, pessoas recém-formadas. Então, são pessoas com pouca experiência, bem "verdezinhas", né? Então, eles fazem esse programa de imersão e, então, voltam pra trabalhar com a gente (Coordenadora de Recrutamento)

Há ainda dois canais de recrutamento que são utilizados, mas não através da lógica ativa. Primeiro, as agências de emprego que foram pouco acionadas e somente para vagas de estágios. 
Eu sou estagiária, tá? Então, eu vim de uma agência de estágio que fez o "screen" inicial e, depois, eles aqui me selecionaram. Mas são estágios pra área operacional. Então, a EC4 usa agência somente pra vagas de estágio. Ah! Para recepcionista estavam cogitando usar agência (Organizadora de Seleção).

Não usamos agência para nossos funcionários CLT. Mas de vez em quando, nós precisamos de estagiários e aí utilizamos agência pra isso. Mas é muito, muito pouco! Nós temos estagiários somente na parte de recrutamento e financeiro (Recrutadora 2).

O segundo canal de recrutamento, utilizado fora da lógica ativa, é o site da EC4.

Nesse há um espaço para envios de currículos para vagas, divididas segundo os escritórios da empresa espalhados pelo mundo. Nesse espaço do site constam informações sobre a EC4, seus escritórios (inclusive sobre a cidade na qual essa ou aquela unidade está sediada) e sobre as lideranças globais e regionais da empresa. $\mathrm{O}$ candidato preenche um cadastro nesse espaço do site e envia seu currículo, que é, então, armazenado em um sistema informático, o qual será definido adiante.

A EC4 tem um programa de recomendações que é utilizado tanto numa lógica de recrutamento ativo como passivo, ou seja, as recrutadoras recebem espontaneamente ou estimulam as indicações vindas dos funcionários.

Nós temos dois tipos de recomendações. Uma é se você conhece bem a pessoa, se você pode falar dela pra gente, e a outra é a pessoa que você conhece somente um pouco. Você ganha um valor se a pessoa é contratada. [...] E daí nós temos os eventos de indicações. Esses eventos são feitos aqui no escritório e nós reunimos pessoas que querem indicar e [...] fazemos tipo um jogo, uma competição pra indicar pessoas, e depois segue a mesma coisa: se a pessoa que você indicou for contratada, você recebe um bônus (Recrutadora 2).

A ferramenta de indicações é muito útil pra gente [recrutadoras]. Nós temos um programa de indicações que dá um bônus. Então, a gente tem uma vaga que está com dificuldade e divulga pro pessoal: "Alguém conhece um desenvolvedor que sabe Ruby [linguagem de programação]?”. E daí as pessoas que conhecem, indicam. Também, nós fazemos um "Crazy Referral Competition"! Um dia, na hora do almoço, todo mundo que está interessado em indicar, vem e senta numa sala com a gente. Então, a gente pede pizza e começa fazer "brainstorm" de nomes. Escrevemos todos os nomes que as pessoas conseguem lembrar de pessoas que querem trabalhar aqui. Então, tem essa ferramenta que também funciona super bem aqui dentro.

Vocês divulgam as vagas por e-mail e pedem indicações, isso?

É. A gente divulga uma vaga por e-mail e, por exemplo, nós temos a vaga de recepcionista; então, nós mandamos um e-mail sobre essa vaga - que é uma vaga nova aqui, né? - e pergunta se alguém tem uma pessoa pra indicar. Também, nós pedimos que o pessoal divulgue as vagas nas redes sociais deles. [...] No primeiro dia de trabalho da pessoa, ela passa por todos os setores para saber como a empresa funciona, quem são as pessoas lá, e quando ela passa pelo time de 
recrutamento, a gente já diz pra essa pessoa sobre o programa de recomendações, que dá um bônus e tal... E aí, as indicações vêm de tudo que é jeito: nos passam contato da pessoa por e-mail, falam comigo e deixam o currículo, passam o Likendin ${ }^{\circledR}$ de alguém ou, a gente também tem um quadro com o mapa do Brasil, e a pessoa pode ir ali e colocar o nome de alguém que conhece numa cidade, por exemplo, em Minas Gerais!

As indicações, então, são estimuladas não somente quando tem uma vaga em especifico aberta?

Não! É sempre. A gente sempre quer indicações.

Como funciona o bônus?

O funcionário só recebe o bônus, se a pessoa indicada é contratada e passa pelo período de experiência, que é noventa dias. Daí tem duas formas de indicação: uma é a que tu me dá somente o nome de alguém, e aí o bônus é de 250 Reais, a outra é se tu conhece a pessoa e me diz porque tu acha que essa pessoa pode trabalhar aqui, o que ela faz, como ela é... A gente considera uma indicação muito mais rica, e daí o bônus é 500 Reais (Recrutadora 1).

Constata-se que, nas duas lógicas, as recomendações são utilizadas como dispositivos de cálculo para operação de recrutamento, através daquela orientação da EC4 em estar demandando constantemente profissionais.

Conforme mencionado, os gestores de $\mathrm{RH}$, em relação com a direção corporativa da empresa, estabelecem algumas metas de contratação que, através da relação sociotécnica com o dispositivo de cálculo "Radar Técnico e Tecnológico", permitem identificar as competências técnicas que devem ser priorizadas pela empresa na hora de buscar novos trabalhadores. Além desses parâmetros, essa relação entre gestores de RH e a direção da EC4 (que não se teve acesso direto por meio de entrevistas com seus integrantes) trava relação sociotécnica com outros dispositivos de cálculo para estabelecer os sistemas de salários e de benefícios concedidos pela empresa ${ }^{78}$.

Um dos dispositivos que participa dessas relações sociotécnicas é o "plano de cargos e salários” da empresa. Os cargos são definidos por níveis de senioridade "consultant", "senior consultant", "lead consultant" e "principal consultant" - e, ainda, subdivididos em oito níveis de graus de habilidades (classificados em termos de competências técnicas), que hierarquizam as faixas de remuneração da EC4. Essa estrutura se distribui, na área técnica, nos seguintes tipos de atividades.

Nós temos o desenvolvedor de códigos, que desenvolve toda a parte de programação de códigos. Nós temos o analista de teste, que testa o software para ver problemas, erros, tá? $\mathrm{O}$ analista de negócios que, geralmente, é a pessoa que tem mais contato com o cliente, ele é um representante do cliente dentro do projeto [...]. Temos os

\footnotetext{
${ }^{78}$ No capítulo 7 será analisado sobre como funciona a definição dos salários e dos benefícios. No momento, cabe apenas identificar e definir os agentes humanos e não-humanos que, através de relações sociotécnicas, definem essas questões.
} 
desenvolvedores da parte de "front end", eles lidam com a experiência do usuário daquele software [...]. Temos os gerentes de projeto e tem o gerente de interação, que é um gerente de projeto, mas mais voltado pra parte técnica, não a parte gerencial das pessoas do projeto (Recrutadora 1).

O Plano de Cargos e Salários é, portanto, um instrumento de cálculo que entra em relação sociotécnica com os agentes humanos do RH para definir questões de cálculo e perfil de qualificação técnica que um candidato deve ter para ocupar um cargo. Entretanto, esse plano é separado do modo como se organizam as carreiras dentro da EC4. Essas se inserem em um modelo personalizado e flexível, que, portanto, difere-se do modelo mais hierárquico, padronizado e fechado do Plano de Cargos e Salários.

$\mathrm{Na}$ verdade, nós não usamos muito esse nome "Plano de Carreiras" porque ele implica de você ter cargos pré-definidos, né? De a empresa ter a hierarquia de analista um, dois, três e assim por diante... Não é assim que a gente trabalha. $\mathrm{Na}$ verdade, a gente possui um programa de desenvolvimento contínuo de competências. Então, nesse programa, cada pessoa na EC4 tem um mentor, que trabalha diretamente com esse mentor pra identificar o que é o crescimento pra ele, né? E a partir do que o crescimento é pra ele, ele vai definir com seu mentor o que ele precisa aprender, conhecer e que competências precisa adquirir pra chegar aonde ele quer (Coordenadora de Recrutamento).

Em relação a carreiras, a gente tem uma coisa bem peculiar. Aqui você não tem ninguém que vai ti puxar pela mão e dizer qual é o caminho pra crescer dentro da empresa. A gente dá muita liberdade e autonomia para as pessoas com relação à sua atitude. Nós temos vários casos de analistas de negócios querendo passar para área de testes, por exemplo. Então, a gente deixa isso muito pra pessoa escolher. Não existe uma fórmula certa. A única coisa que a gente tem certeza é que pra pessoa crescer na EC4, ela não precisa virar gerente. Isso é uma coisa que eu vejo nas grandes empresas. Nelas têm muitos desenvolvedores excepcionais que, por causa de salário, viraram gerentes. [...] Então, elas perdem excelentes desenvolvedores e ganham gerentes medíocres. A gente tem desenvolvedores na EC4 que estão a 17, 20 anos! E provavelmente ganham mais do que eu e vão sempre ganhar mais do que eu porque merecem em função do nível de excelência que apresentam na sua função (Diretor de $\mathrm{RH}$ ).

Portanto, o dispositivo de plano de carreira não entra na rede sociotécnica da empresa que executa as operações de cálculo sobre salários. Essas últimas, ao seu turno, são executadas nas relações que envolvem o Plano de Cargos e Salários.

Já o programa de benefícios, esse é definido em parceria com funcionários da empresa e o pacote é o mesmo para todos os funcionários. Obviamente que a empresa concede aqueles benefícios previstos por Lei no Brasil, por exemplo, vale-transporte e vale-refeição; mas, no caso da EC4, constatou-se que, como os benefícios são definidos pelos funcionários e não houve menção sobre isso ser pensado estrategicamente para 
atuação da empresa no mercado de trabalho, o programa de benefícios não é um dispositivo de cálculo inserido na rede sociotécnica da EC4.

Um dos principais dispositivos que orientam as operações de cálculo da EC4 no mercado de trabalho é a "cultura da empresa". O conteúdo desse agente não-humano está diretamente ligado à visão de mundo do fundador da $\mathrm{EC} 4{ }^{79}$.

Esse final de semana ainda, ele [o fundador da empresa] teve aqui para participar de um evento de todos os funcionários da EC4 no Brasil, que aconteceu em Bento Gonçalves ${ }^{80}$. Então, o evento teve confraternização, palestras e tudo mais... E ele fez uma palestra e ele é uma pessoa muito idealista, muito pelos direitos humanos e pela justiça social. Então, o discurso que ele fez lá foi muito assim: pela democracia! Falou sobre os países que estão vivendo modelo de democracia... Quem ele acha, por exemplo, quem são os responsáveis por saúde, né? Como no Haiti, que recentemente nos últimos desastres, foram destruídos $80 \%$ dos hospitais, e estão reconstruindo. Então, ele diz que através da mão do povo que a saúde pode ser feita lá e... Ou, por exemplo, ele falou também que o governo dos Estados Unidos tem a maior arma de todo mundo, que é o exército americano! Como que o povo tem que se colocar em relação a isso e não permitir que isso aconteça. Então, quase todo discurso dele foi em termos de justiça social (Recrutadora 1).

A cultura da empresa está muito atrelada ao perfil do [nome do fundador da empresa]. Lá no nosso site, você vai ver os três pilares da EC4 e que orientam até nosso trabalho de recrutamento e contratação de pessoas. Nós buscamos contratar pessoas que se identifiquem com esses três pilares, né? Então, eles são realmente o quê? Entender como funciona um negócio, como funciona uma organização; entender da excelência técnica daquilo que você faz, né? Então, é sempre aprender e buscar perceber aquilo que tem de melhor dentro da área que você trabalha; e a gente fala muito em justiça econômica e social. Então, a gente trabalha muito com organizações que são mais progressivas de pensamento, nesse sentido de justiça econômica e social. Procuramos contratar pessoas que são alinhadas com esse pensamento. Procuramos cliente que sejam alinhados com esse pensamento. Então, essa cultura permeia todas as nossas ações, né? (Coordenadora de Recrutamento).

Nosso fundador é uma pessoa que enfatiza muito esse ponto da justiça social! Isso é algo que é muito importante pra ele. Ele é uma pessoa que conhece e viajava pra todo lugar do mundo. Então, quando acontece alguma coisa em algum país, ele manda e-mail para todas as pessoas da empresa, pra que elas se sensibilizem também, e dizendo onde podemos ajudar. Ele fala pra gente da importância de usarmos nosso conhecimento para ajudar a melhorar o mundo. Mudar o mundo começando pela comunidade onde nós moramos, mas pensando também como podemos ajudar outros lugares (Recrutadora 2).

\footnotetext{
${ }^{79}$ Não foi realizada nenhuma entrevista com o fundador.

${ }^{80}$ Cidade localiza na região serrana do Rio Grande do Sul.
} 
Portanto, o ativismo político e moral do fundador estabelece uma dimensão de valores na definição da cultura da empresa.

Eu nunca vi uma empresa com esse nosso "mind set". Isso vem desde lá do nosso fundador, que faz questão de dizer que ele não criou a empresa só pra ter lucro, ele quer realmente mudar o mundo com a tecnologia. Então, esses três pilares - "sustainable business", "revolutionize IT", "social justice" - são os "drivers" do nosso dia-adia. Fazemos todas nossas decisões pensando nisso. E em cada pessoa que a gente contrata, nós valorizamos três coisas: integridade, aptidão e atitude. Isso é o que vale mais do que uma experiência de dez anos ou um $\mathrm{PhD}$. A gente valoriza muito a atitude das pessoas e é isso que a gente procura. E isso está enraizado na cultura da EC4. Isso se propaga do fundador para todos os escritórios, de revolucionar e questionar o "mainstream". [...] Então, a gente fala que os nossos desenvolvedores, analistas de testes ou analistas de negócios, eles são muito mais que isso! Eles são consultores que levam essa cultura pra frente! (Diretor de RH).

A gente tem uma questão de cultura muito forte na EC4. Uma cultura onde, basicamente, a gente valoriza três coisas: integridade, aptidão e atitude. Então, a gente quer pessoas que tenham uma atitude semelhante à nossa! Que sejam íntegras no sentido que sejam comprometidas não somente com o negócio, mas principalmente com uma série de valores que a gente compartilha. E que ela tenha aptidão para exercer seu trabalho na melhor forma possível (Diretor de Escritório).

A cultura da empresa, ela é formada por valores, mas são valores que não ficam só lá, nos escritos, num quadro, sabe? Inclusive, durante o processo de seleção tem uma entrevista que é só pra isso! São valores que são voltados pra justiça social, pra ser o melhor, pra ser honesto, pra ser íntegro... Valores nesse sentido. Então, a empresa tá muito voltada pra fazer uma mudança real no mundo! Então, ao mesmo tempo que a gente tem vários clientes, a gente cobra muito caro pra fazer projetos pra eles. A gente investe muito em projeto social! Agora, a gente abriu escritório na África do Sul com a intenção de estar desenvolvendo as pessoas lá, né? A gente vai trabalhar com um hospital no Haiti que está sendo construído e que vai ser cobrado só o valor de custo. [...] Então, a gente trabalha também pra pagar as contas, pra fazer o negócio crescer, mas também a gente trabalha pra EC4 ser um lugar diferente, informal, onde as pessoas se sintam à vontade, se sintam acolhidas, se sintam unidas - tanto que o escritório não tem divisões! Muito nesse sentido, ser uma família com pessoas que tenham o interesse de fazer a diferença no mundo (Recrutadora 1).

Por outro lado, a adoção da EC4 pelos chamados "métodos ágeis" de desenvolvimento de softwares, fundamentam a dimensão da cultura da empresa definida como modelo de gestão do trabalho ${ }^{81}$.

${ }^{81}$ Os métodos ágeis são uma proposta de desenvolvimento de softwares baseadas em princípios que visam a dar a maior flexibilidade e interação/colaboração com os clientes, em contraposição aos modelos de desenvolvimento de softwares que possuem processos mais rígidos e técnicas de planejamento mais tradicionais. Em suma, é uma proposta que põe mais peso na interação entre pessoas 
Eu recomendo que, para tu conhecer a cultura da EC4, tu pesquisar um pouco sobre métodos ágeis. Que é uma forma que a gente utiliza para desenvolvimento de software, né? O método é muito mais uma filosofia de trabalho e de relacionamento no dia-a-dia do que propriamente uma técnica! Então, tu pode aplicar esses fundamentos em qualquer área do negócio. É um modelo que fala muito de colaboração. É um modelo muito horizontal, onde a hierarquia é mínima e ela é flexível. A gente não trabalha com chefia, a gente trabalha com lideranças. Então, é uma cultura que a gente espera que todo mundo conheça, né? E é justamente por isso que a gente não tem escritórios maiores do que 150 pessoas, porque a gente sabe que esse número é um número chave pra a gente manter a nossa cultura, pra não criar processos, pra não criar burocracia, que todo mundo consiga se conhecer ou pelo menos se sentir confortável para conversar com qualquer um. Então, o nosso suporte físico corrobora muito com a nossa cultura. $\mathrm{O}$ nosso suporte físico é aberto, sem divisórias, sem escritórios... Ninguém tem escritórios! Nem o fundador da empresa tem escritório! Então, se ele chegar aqui, ele vai sentar numa mesa como qualquer outra pessoa. A gente se importa muito com essa igualdade. Todo mundo tem voz na empresa, todo mundo tem o direito de discordar. Então tem essa liberdade e essa liberdade requer muita maturidade e responsabilidade. Então, no processo de seleção, a gente procura avaliar isso: se a pessoa consegue ser funcional num ambiente com tão poucas regras (Coordenadora de Recrutamento).

Nosso modelo de gestão é bem flexível, tá? É difícil de explicar porque a gente não tem muitas políticas, né? No caso, as pessoas vão se adaptando à situação do momento. Nós temos muito a parte de desenvolvimento de carreira, mas que é voltado para o que o funcionário quer fazer, não o que a gente espera dele. Claro que tem certos níveis de expectativa pra todo mundo, né? Mas é a pessoa que vai dizer se quer trabalhar com desenvolvimento ou um analista de teste. Então, é bem flexível nesse sentido. A gestão vai ser sempre voltado pros interesses da pessoa. O que ela quer ser e fazer da vida dela na EC4! E dentro disso, vai ser visto qual é o melhor projeto pra ela e até qual seria a melhor localidade! Porque daqui a pouco pode até não ser no Brasil! Então é tudo muito personalizado! A gestão de pessoas aqui é muito personalizada, né? (Recrutadora 1).

$\mathrm{Eu}$ acho que cada pessoa que entra aqui não sabe realmente o grau de autonomia que vai ter aqui dentro. Então, tu tem total autonomia pra trabalhar do jeito que tu bem entender, desde que tu entregue aquilo que tu se comprometeu e o que está sendo esperado de ti. Então, eu acho que todo mundo aqui é muito aberto pra mudar o jeito de trabalhar. Todo mundo é muito aberto pra dar uma ideia e tentar melhorar. Eu acho que é um clima sempre leve. Óbvio que tem estresse, que tem prazo e tudo mais... Mas a gente está sempre indo na direção do lado mais simples e leve das coisas, sabe? (Organizadora de Seleção).

É muito diferente das empresas em que eu já trabalhei. A EC4 é uma empresa que quase não tem hierarquias. Não tem assim, uma pessoa

no desenvolvimento de softwares do que no uso de processos, aplicações e ferramentas técnicas. Sobre

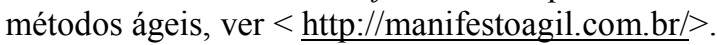


que eu mando um "report" do que me foi mandado; então, nós sempre planejamos tudo em equipe. Então, nós queremos manter uma cultura de quase não ter hierarquia. Claro que temos gerente e tudo mais... Mas a função dele é mais planejar as coisas do que mandar. Todos nossos escritórios, então, não tem mais do que 150 pessoas pra justamente manter essa cultura mais sem hierarquia. Não sei o quanto você conhece a área de TI, mas aqui nós trabalhamos com uma metodologia de desenvolvimento que são os métodos ágeis. São métodos para manter equipes de projetos quase sem hierarquias. Então, as equipes de projetos têm, todos os dias de manhã, uma reunião "stand up" entre eles, pra ver o que se fará naquele dia. Então, eles planejam juntos e ninguém trabalha sozinho, todo mundo trabalho em duplas. Todo mundo têm comunicação com o cliente pra ter mais interação com cliente, né? $\mathrm{E}$ tudo isso impacta no recrutamento (Recrutadora 2).

Como será analisada em detalhe no próximo capítulo, a cultura da empresa, através dessas duas dimensões que a compõem, torna-se um dispositivo de cálculo que participa nas relações sociotécnicas que definem a demanda no mercado de trabalho em termos do perfil de competências comportamentais que o candidato deve ter para ser funcionário da EC4.

Após o recrutamento de um candidato, agentes humanos do $\mathrm{RH}$ e os funcionários técnicos da empresa entram em relação sociotécnica entre si, e com uma série de dispositivos de cálculo, e então exercitam o cálculo econômico através das operações de seleção e contratação. Uma vez que já se identificou os agentes humanos, cabe definir os dispositivos de cálculo que participam dessas relações.

Em primeiro lugar, há o sistema informático de gestão de recursos humanos da EC4. Esse programa armazena e torna disponível para pesquisa, os currículos dos candidatos, os resultados que obtiveram nos testes que a EC4 aplicou com ele e os relatórios de avaliação (o que é chamado na empresa ou de "review" ou de “assessment"), preenchidos por aqueles que entrevistaram o candidato. $\mathrm{O}$ acesso ao conjunto completo das informações sobre os candidatos é somente possível às recrutadoras. Assim sendo, esse sistema é um dispositivo que coordena as relações sociotécnicas entre agentes humanos e agentes não-humanos, por exemplo, currículos e relatórios de avaliações.

A gente tem um sistema completo, um sistema que é excelente, ele é completo. No perfil do candidato vai ter o currículo dele; todos os emails que a gente trocou com ele e todos os contatos que ele tem; se ele é indicação de alguém, quem indicou e o que a pessoa falou dele; todas as entrevistas que ele fez e com quem; os assessment das entrevistas; os exercícios de código que eles nos mandam; se ele é contratado, o salário dele e de quando ele pode começar. Tem tudo que a gente precisa saber daquela pessoa.

E como o perfil e os currículos estão agrupados no sistema? 
Por vaga. Pela vaga que a pessoa aplicou com aquele currículo. Se a gente recebeu o currículo, a gente "linka" ele com a vaga; se não, a pessoa pelo site da EC4 clica naquela vaga e manda o currículo que vai direto pro sistema, daí ele já entra como novo. Daí, pelo menos uma vez por semana, a gente vai lá no sistema e vê os currículos novos. Se agente gostar do currículo, a gente entra em contato e, se a gente não gostar, a gente rejeita (Recrutadora 1).

Ao contrário do que foi relatado na EC2, aqui as recrutadores não mencionaram que têm em paralelo um banco de currículos na forma de uma planilha de Excel. Através desse sistema, as recrutadoras agendam e se comunicam com os funcionários que farão as entrevistas com o candidato, repassando para eles links com acesso ao currículo.

Após cada entrevista, os entrevistadores preenchem um relatório de avaliação do candidato.

Normalmente, a gente revisa os assessment que as pessoas nos deram. Então, além de nos falarem sobre como foi com o candidato em reuniões rápidas com a gente, eles ainda escrevem esses assessment. Esses assessment ficam lá no sistema junto com o perfil da pessoa. E aí agente vai vendo durante o processo de seleção como as pessoas avaliaram o candidato. E os assessment avaliam, então, se o candidato tem os valores da empresa, tem atitude boa, tem um bom inglês, se tem uma parte de habilidade consultoria desenvolvida, tem habilidade de comunicação e de relação com o cliente, e a parte técnica. Então assim, tem vários níveis que tu tem no critério técnico, desde o mais básico até o mais complexo. Isso tudo é avaliado pela gente; por exemplo, a pessoa teve uma ótima avaliação técnica, mas em termos de valores... Passou por situações que ela passou por cima do colega, sabe? Então, nem se cogita contratar essa pessoa.

Então é durante o processo de seleção que o sistema vai sendo atualizado?

Sim. Mas o que acontece? É só o time de recrutamento que tem acesso a todo esse sistema, a todas essas informações. Mas os entrevistadores recebem um link por e-mail junto com todo material da pessoa, antes da entrevista. Daí, quando termina a entrevista, ele entra nesse link e preenche, e quando ele dá o "OK", isso aparece pra mim. E aí, dependendo do como o candidato foi avaliado, a gente vê se ele avança ou não para as próximas etapas. [...].

Esse link que o entrevistador preenche é um tipo de formulário padrão?

Sim. É assim: se estou mandando o exercício de código que o candidato já fez, então é um link que tem um formulário pra aquilo ali - o que foi bom no código? O que não foi? Que nota daria para o exercício? - e se é entrevista, aí é diferente - o que achou dessa pessoa? O que ela tem que desenvolver? Então, é tipo um roteiro. (Recrutadora 1).

Portanto, esses relatórios fornecem informações para recrutadora decidir se um candidato continua ou não pelas etapas de entrevistas. Nesse sentido, cabe examinar como os entrevistadores se relacionam com esse dispositivo de cálculo. 
Sim, nós temos o review. O review pode ser de um exercício que a pessoa fez em casa. Então, esse review gera um input para depois nas entrevistas. Porque muitas vezes quem fez esse review dos exercícios é uma pessoa que não vai falar com o candidato (Analista de Qualidade).

Os review, eu faço baseado no que eu anoto durante a entrevista, né? Mas no sistema, a gente tem lá uma avaliação final do tipo pra marcar: "passou" ou "não passou". A gente também dá uma nota. E eu costumo detalhar bem os tópicos, tipo: "O candidato é nisso e não naquilo". E aí depende se é entrevista técnica ou de valores. Mas é sempre difícil tomar aquela decisão final, se o candidato deve passar ou não. Então, agora tem três opções: "prossegue", "rejeitado" ou "prossegue fraco" (Analista de Teste e de Negócios).

Outros dispositivos de cálculo que participam nas relações sociotécnicas de seleção de um candidato são três modalidades de testes ${ }^{82}$. O primeiro que o candidato faz é um "exercício de código". Quem avalia o desempenho do candidato nesse teste são dois funcionários técnicos que podem ou não realizar uma entrevista com $o$ candidato. Após, há mais dois testes de lógica, que são aplicados inclusive em candidatos a cargos que de administração e gestão.

São dois testes de lógica que é aplicado pra todo mundo, pra qualquer vaga. Um é mais de lógica mesmo e outro de raciocínio geral. Então, o pessoal que não é técnico se apavora, por exemplo, galera que vem pra vaga de recepção - "Meu Deus! Que isso?" - mas não é um teste técnico! Todas as pessoas podem fazer, mas claro que se tu tiver uma afinidade maior com lógica, tu vai melhor. Mas sempre a gente deixa claro que a gente espera coisas diferentes, tipo: uma pessoa que é desenvolvedor é esperado que vá melhor do que a pessoa que é recepcionista (Organizadora de Seleção).

Esses testes são usados apenas como critério eliminatório de candidatos.

Ao contrário do identificado na EC2 e na EC3, as entrevistas não se tornam dispositivos de cálculo em função de uma metodologia ou uma técnica de entrevista (relembrando, a chamada técnica de entrevistas por competências), mas, na EC4, as entrevistas se tornam dispositivos de cálculo em razão de haver tipos de entrevistas, que são desenvolvidas através de conhecimentos advindos da prática dos agentes humanos.

Como foi que tu aprendeste a fazer entrevistas aqui na EC4?

Sabe que pra mim, isso foi uma surpresa! Porque quando eu participei do processo seletivo, quando eu fui selecionado, eu vi que o processo seletivo era bem diferente de todos os outros que eu tinha participado. Principalmente pela questão da informalidade. $O$ fato de não ser aquele sistema tradicional de um entrevistador de um lado da mesa e um entrevistado do outro, né? $O$ entrevistador só pergunta e o entrevistado só responde. Eram geralmente conversas e eram conversas muito leves. Aí, ao longo dessa conversa, começavam a fazer perguntas pertinentes pra ver qual o conhecimento da pessoa, se

\footnotetext{
${ }^{82}$ Não foi possível o acesso direto a nenhum desses testes.
} 
ela encaixa no perfil da empresa... Então, isso, pra mim, foi bem curioso. [...] Então, eu me lembro que, quando eu comecei a participar do processo seletivo, no início eu ficava meio de ouvinte pra saber direito como a coisa funciona, ou seja, quais os tipos de perguntas e quais são as etapas desse processo. Mas com o tempo, e num tempo super curto, tu já se senti a vontade pra falar com o candidato, pra começar expor alguns aspectos da empresa e até alguns aspectos da tua vida pessoal! Porque, no final das contas, [...] a gente não quer simplesmente selecionar uma pessoa! A gente quer que isso seja mais ou menos como um casamento! No sentido de que, nós queremos conhecer o candidato, mas a gente quer que o candidato nos conheça! Porque se não tem essa via de mão-dupla, a relação não funciona!

Então, o processo de aprendizagem foi na prática?

Sim. Na verdade, a gente acredita muito numa coisa que, no inglês, é "pairing"! Na verdade é fazer com que as pessoas pareiem, né? Que as pessoas em duplas ou em grupos troquem experiência. A gente não tem um processo de empresas tradicionais, por exemplo, que tem uma documentação, manuais extensos falando de recrutamento e seleção. Uma documentação extensa que as pessoas precisem fazer um treinamento. Aqui é justamente na prática que a gente vai pegando como é o jeito de entrevistar (Diretor de Escritório).

Logo que eu fui contratado! Logo em seguida, eu virei entrevistador [risos]. Isso foi uma surpresa e isso me fez entender que a empresa é bem diferente porque, em outras empresas, tu não é entrevistado por pessoas que tu vai trabalhar com elas, né? Geralmente é pelo pessoal de RH, pelo pessoal mais gerencial... Eu lembro que, eu iniciei no dia 4 de janeiro e, no próprio mês de janeiro, eu já fui fazer entrevistas pra selecionar pessoas! Eu fui aprendendo a fazer entrevistas na prática. $\mathrm{O}$ que eles fazem muito, que é muito interessante, é fazer sempre entrevista pareando! E obviamente, no início, tu vai fazendo com uma pessoa mais experiente e tu vai aprendendo aquilo. Depois, então, tu que vai fazer isso com as outras pessoas (Analista de Teste e de Negócios).

A gente não tem um treinamento. Nós até estamos pensando em fazer um treinamento formal, mas por enquanto não tem. O que a gente tem é trabalhar com pareamento, né? Então, se tu vai fazer entrevistas, tu vai fazer com alguém que é mais experiente. Aos poucos, então, a gente vai pegando experiência e também ensinando os mais novos. [...] Então, você vai aprendendo como, ao longo de uma conversa, você vai abordando os pontos que você quer saber de um candidato. Não tem um roteiro fechado, você vai conversando... (Desenvolvedor).

Assim sendo, a EC4 faz quatro tipos de entrevistas.

Primeiro tem as entrevistas técnicas. Uma dessas é trabalhar num código pareando. A outra são perguntas técnicas e sobre tecnologia. Uma entrevista com base nos valores da EC4. Então, nessa são perguntas mais polêmicas pra ver questões como, por exemplo, racismo, homofobia... Essas coisas assim. Por último, uma entrevista com o diretor do escritório.

Essas entrevistas de valores, vocês veem questões comportamentais?

Sim, essa entrevista é pra ver se ele é um bom ser humano! São perguntas que cada um aqui faz de um jeito, mas é pra saber se a 
pessoa vai corromper os valores da cultura da EC4. Então são perguntas pra ver a honestidade, integridade e a atitude da pessoa (Recrutadora 1).

Eu faço basicamente entrevistas de valores e as entrevistas gerenciais. A entrevista de valores é pra ver se o candidato compartilha dos mesmos valores da gente. São valores... Voltando um pouco! O nosso objetivo como empresa é bem agressivo: a gente quer pouca coisa, a gente quer mudar o mundo [risos]. A gente quer mudar o mundo através do software. Então, o que a gente procura são pessoas que tenham entusiasmo pra fazer isso. [...] A entrevista que nós chamamos de gerencial, ela é também um bate-papo e também acaba por tocar em aspectos da entrevista de valores, só que ela acaba tendo uma... Como eu posso dizer? Ela acaba se sobrepondo também com as entrevistas técnicas, porque uma das coisas que eu vejo como diretor de escritório é a senioridade dos candidatos. Então, quero saber se a pessoa é mais júnior ou uma senioridade maior, ou seja, se ela é uma pessoa que vai poder conduzir um projeto por si só ou se ela vai poder liderar uma iniciativa, né? Se eu posso largar ela com um cliente e ela vai saber lidar com esse cliente de como propor coisas novas, como tratar assuntos delicados de maneira apropriada... Então, essa entrevista gerencial é mais pra ver o nivelamento dentro das faixas de senioridade que a EC4 tem (Diretor de Escritório).

Deste modo, cada entrevista se torna um dispositivo de cálculo na rede sociotécnica em função do seu foco em termos do tipo de competência que se pretende avaliar no candidato - basicamente, técnica ou comportamental. Resumindo, além da pré-entrevista realizada normalmente por telefone com a recrutadora, o candidato passa por outras quatro: 1) entrevista cultural ou de valores, que busca identificar se o candidato compartilha ou não das preocupações sociais da empresa e tem entusiasmo para com o mundo da tecnologia; 2) entrevista técnica na qual o candidato responde perguntas para verificar o seu nível de proficiência em certas competências tecnológicas e a sua atitude de trabalho, por exemplo, se é um profissional aberto para aprender novas linguagens de programação, o seu nível de familiaridade com métodos ágeis, etc.; 3) entrevista técnica de codificação na qual o candidato vai trabalhar em um código de programação junto com o entrevistador, que, ao seu turno, vai avaliar não somente a sua competência nessa atividade, mas também se sabe ou não trabalhar dentro do modelo de pareamento e em grupo da EC4; 4) entrevista gerencial que é feita normalmente pelo diretor do escritório e que verifica o perfil profissional do candidato em relação aos níveis de senioridade e os tipos de carreiras constantes no "plano de cargos e salários" da empresa.

Por fim, a contratação como operação de cálculo tem o seu conjunto de relações sociotécnicas entre agentes humanos e não-humanos reunidos no chamado dispositivo "huddle". 
Então a decisão de contratar um candidato em específico, ela é feita numa reunião com todos os que entrevistaram o candidato?

Sim. As pessoas se reúnem para discutir as suas percepções sobre o candidato. Até porque, Lucas, cada entrevistador faz um tipo de entrevista, né? Então, eles não têm uma visão do conjunto daquela pessoa.

Então, ocorrem discordâncias de opiniões sobre contratar ou não?

Sim, bastante.

E como se resolve esses impasses?

A gente está permeada por aqueles três pilares da cultura da empresa, tá? Então, a gente vai discutir e avaliar o entendimento de "business" que a pessoa tem, ou seja, o quanto ela conhece do nosso negócio, o quanto ela gosta do que a gente faz, né? Excelência técnica: qual a solidez técnica que essa pessoa trás?! E qual é o alinhamento cultural que essa pessoa trás também. E a gente vai conversar sobre essas três coisas e vai tomar uma decisão juntos. Se a pessoa não é contratada é porque ela não está alinhada com pelo menos um desses pilares. Então, assim, não adianta ter uma pessoa super alinhada com o pilar dois e ser super individualista, preocupada apenas com seu lucro individual. Ao mesmo tempo, não adianta você ter uma pessoa super socialmente ativa, mas ter um conhecimento raso em tecnologia. Então, a gente se preocupa sempre avaliar nesses três pilares (Coordenadora de Recrutamento).

Como tu coordenas essa reunião final?

Eu sou a facilitadora da reunião. Então, eu começo perguntando para cada um: "Você quer trabalhar com essa pessoa?". Então é uma avaliação sem a influência dos comentários das pessoas. Se todo mundo fala sim, a reunião acaba. Normalmente não é fácil assim [risos]. Então, eu normalmente começo a perguntar o que aconteceu nas entrevistas. Depois, eu peço para a pessoa falar sobre os motivos dela não querer trabalhar com a pessoa. Aí, os motivos podem ser, por exemplo, da pessoa achar que o candidato não estar tecnicamente pronto. $\mathrm{E}$ aí as pessoas discutem se o candidato não pode aprender, por exemplo. E depois de discutir tudo, nós fazemos a decisão novamente. Algumas vezes, depois da discussão, a pessoa muda de opinião e outras não. Aí senão mudou, a pessoa não é contratada (Recrutadora 2).

Nessa reunião final é comum haverem discordâncias de avaliações?

Sim, é muito comum. Por exemplo, recentemente teve um caso de uma pessoa que era praticamente somente uma ativista da tecnologia em um país da América do Sul. Então, algumas das pessoas queriam muito que ela fosse contratada porque essa pessoa era muito conhecida na comunidade e tudo mais... Mas, do ponto de vista técnico, $[. .$.$] eu e o meu par e mais duas outras pessoas que fizeram as$ entrevistas técnicas, nós chegamos à conclusão que essa pessoa é provavelmente, ela é uma pessoa que faz uma propaganda muito boa, mas que, ou ela não está capacitada naquele nível que ela julga estar, né? Ou ela não consegue mostrar isso! [...] É o que eu ti falei: na hora de conversar com o cliente, não adianta você ser o Bam-Bam-Bam do código, mas não saber entender o problema do cliente, resolver o problema daquele cliente e explicar pra ele. Então, ela era uma pessoa que não conseguiria fazer esse tipo de coisa. Mas também é difícil pra gente, porque a gente também gostaria que esse tipo de pessoa 
entrasse, mas infelizmente, do ponto de vista de negócios, não seria interessante porque teria que treinar muito tempo ee uma pessoa com esse tempo de experiência, ela não deveria ter que receber esse treinamento todo. Então, acontece de todas as formas: comportamental, valores... Valores barra! Já teve muitos casos de pessoas excepcionais tecnicamente, mas foram barradas por valores, isso acontece. E quando isso acontece, a gente tenta entender e ver se aquele problema que ele tem pode ser transformado pela gente. E se mesmo assim, a gente não chega num consenso, a gente barra $o$ candidato (Analista de Qualidade).

Acontece discordância de avaliações e aí depende do caso. Algumas vezes tem uma pessoa apenas dizendo "não" pro candidato, tá? E aí a gente pede pra explicar o motivo de ela não querer. Por exemplo, eu fiz um entrevista técnica e todo mundo que fez as técnicas dão "sim" pro cara! E o pessoal de valores, não! Aí explicaram do por que não, que do ponto de vista de valores e tal... Quando terminaram de explicar! Todo mundo concordou que não! Cada um vê um aspecto diferente, ninguém vê o candidato como um todo. Por isso tem essa reunião (Desenvolvedor).

Em suma, consiste numa reunião entre todos aqueles que participaram do processo de seleção, expondo a sua avaliação sobre se a empresa deve ou não contratar o candidato que foi submetido ao processo de seleção que eles participaram. A decisão de contratar deve ser alcançada por consenso. E as discordâncias, portanto, mostram que a relação com o dispositivo de cálculo "tipo de entrevista" molda esse processo. Ao mesmo tempo, outro dispositivo que está presente é a cultura da empresa, pois o candidato é avaliado de acordo com os "três pilares" que agem na formação do consenso, pois esse é obtido a partir de uma avaliação positiva do todos esses critérios que envolvem os três pilares da cultura da empresa. Por isso mesmo, a rede sociotécnica da EC4 caracteriza-se pelo seu alto grau de interações e pelo amplo leque de agentes humanos e não humanos envolvidos ao longo das operações de cálculo.

Este capítulo tratou de definir e identificar os agentes da rede sociotécnica de cada um dos quatro casos. No próximo capítulo, o objetivo é a definição dos valores econômicos e economicamente relevantes ligados ao cálculo econômico executado por essas redes de cada uma das quatro firmas. No Capítulo 8, de natureza mais analítica, dois elementos serão relacionados - rede sociotécnicas e valores - para analisar as operações de cálculo (recrutar, selecionar e contratar), isto é, as relações sociotécnicas que estruturam o agenciamento (CALLON, 2007; HARDIE; MACKENZIE, 2007; MUNIESA; MILLO; CALLON, 2007) da capacidade de cálculo de valor das firmas estudadas, quando elas comparecem no mercado de trabalho. 


\section{OS VALORES NA DEMANDA DA FIRMA NO MERCADO DE}

\section{TRABALHO}

Este capítulo trata de definir e descrever analiticamente quais valores econômicos e economicamente relevantes estão por trás da demanda das firmas para contratação de trabalhadores. Essa descrição revelou que, entre os casos, num mesmo conjunto de relações sociotécnicas e de dispositivos de cálculo das firmas, podem estar materializados determinados valores econômicos e economicamente relevantes. Relembrando, esses últimos podem ser valor morais, estéticos, políticos, etc. (ASPERS; BECKERT, 2001). Já os valores econômicos, esses podem ser classificados em:

1. valor de uso e valor de investimento - o primeiro se refere ao ganho que o proprietário vai obter em função das qualidades do produto através de seu uso. Valor de investimento se refere à expectativa de lucro monetário que vai ser gerado pela aquisição de um bem ou serviço. E essa é uma distinção feita pelo agente econômico, ou seja, não há qualidades objetivamente inerentes às mercadorias que estabelecem essas distinções de valor;

2. valor individual e relacional - valor individual é a satisfação do desejo do comprador através da aquisição de um produto, independentemente de qualquer interação social associada à compra. O valor do produto é individual, mas isso não quer dizer que a formação do desejo que leva à aquisição do produto não seja socialmente moldada. Relacional, então, quer dizer que o valor do produto para o comprador é uma função de considerações a respeito do que terceiros iram pensar ou mesmo quando a aquisição do produto toma em consideração o comportamento de outros consumidores desse mesmo produto;

3. valor funcional e valor simbólico - funcional quer dizer que o produto é valorizado porque ao utilizá-lo é produzida uma mudança na realidade baseada em um efeito físico gerado pelo produto. Valor simbólico, em contraste, refere-se ao significado que um bem tem para o seu dono, que transcende os efeitos físicos gerados pela sua posse e uso.

Em posse dessas definições, analisar-se-ia como (1) a cultura da empresa materializa o valor de uso e/ou o valor simbólico e/ou físico, (2) a percepção da firma 
sobre e o compromisso com a inovação materializa valor físico e/ou valor de uso, (3) a presença ou ausência da preocupação para com a rotatividade e o absenteísmo apontam para o valor de investimento, (4) as definições de perfis de competências técnicas expressam o valor de uso, (5) as definições de perfis de competência comportamentais materializam valor de uso e/ou físico e/ou simbólico, (6) as escolhas da firma em termos de salários e sistemas de beneficios revelam valor de investimento e/ou relacional e (7) o planejamento para atender às demandas dos clientes materializa o valor de investimento. Assim sendo, ao longo das análises de casos que compõem este capítulo, serão definidas essas modalidades de valores através do que revelam os dispositivos de cálculo e as relações sociotécnicas a que estão materializadas.

\subsection{Estudo de Caso 1: “tradicionais" valores econômicos}

A tabela abaixo expõe, esquematicamente, os valores econômicos que foram identificados como sendo calculados na demanda por força-de-trabalho da EC1 e as relações sociotécnicas e/ou dispositivos de cálculo que materializam esses valores.

Tabela 26 - Valores Econômicos Calculados pela EC1.

\begin{tabular}{c|c|c|c}
\hline & Valor de Uso & $\begin{array}{c}\text { Valor de } \\
\text { Investimento }\end{array}$ & Valor Relacional \\
\hline Cultura da Empresa & & & \\
\hline $\begin{array}{c}\text { Estratégia de } \\
\text { Inovação }\end{array}$ & $\sqrt{ }$ & \\
\hline $\begin{array}{c}\text { Rotatividade e } \\
\text { Absenteísmo }\end{array}$ & & $\checkmark$ & \\
\hline $\begin{array}{c}\text { Perfil de } \\
\text { Competências } \\
\text { Técnicas }\end{array}$ & $\sqrt{ }$ & & \\
\hline $\begin{array}{c}\text { Perfil de } \\
\text { Competências } \\
\text { Comportamentais }\end{array}$ & $\sqrt{ }$ & & \\
\hline Salários & & $\sqrt{ }$ \\
\hline $\begin{array}{c}\text { Programa de } \\
\text { Benefícios }\end{array}$ & & & $\sqrt{ }$ \\
\hline $\begin{array}{c}\text { Planejamento para } \\
\text { o Atendimento à } \\
\text { Demanda }\end{array}$ & & $\sqrt{ }$ \\
\hline Fonte: Dos & & & \\
\hline
\end{tabular}

Fonte: Dados de Pesquisa de Campo.

Refletindo sua condição de empresa que menos encarna as particularidades que tipificam a nova economia (Capítulo 5) e de conter uma rede sociotécnica instável (Capítulo 6), a demanda de trabalho da EC1 é organizada em torno de valores econômicos cujos conteúdos são os que mais se distanciam do que se pode chamar de lógica econômica da nova economia. Por exemplo, mesmo assumindo a "inovação" 
como um elemento importante na sua estratégia comercial, essa é adotada a partir de uma lógica mais tradicional se comparada às outras firmas estudadas. $\mathrm{Na} \mathrm{EC1,} \mathrm{a}$ inovação é compreendida menos como o desenvolvimento de novas tecnologias e mais como a capacidade da firma assimilar tendências tecnológicas definidas no mercado de produtos.

Sou o diretor ou gestor da área de $\mathrm{P} \& \mathrm{D}$, que possui, assim, uma equipe de engenheiros da computação, engenheiros eletrônicos e profissionais com vínculos com a ciência da computação e sistemas digitais. Essa equipe desenvolve equipamentos de telecomunicação e transmissão de dados. Como diretor dessa equipe, eu sou responsável em acompanhar a equipe comercial em reuniões com os gestores de tecnologia dos clientes. Os clientes são as principais Telecom do país, tá? Então, a gente acompanha de perto os clientes pra definir que caminhos a gente vai tomar, porque a gente tem que pensar o produto hoje que a gente vai vender daqui a dois ou quatro anos. E hoje em dia, tu não tem mais aquele gap de tecnologia que tu olhava pro o que o pessoal estava fazendo lá fora e simplesmente tu sabia que daqui 5 anos isso estaria aqui. Hoje é tudo mais rápido em função dessa questão da globalização, né? Agora, quando o pessoal estava conversando em $4 \mathrm{G}$ lá, a gente estava conversando sobre $4 \mathrm{G}$ aqui também. O gap é muito menor hoje, tá? Então, essa é basicamente a nossa função. Hoje, no $\mathrm{P} \& \mathrm{D}$, eu tenho gerente de projeto e abaixo dele, os projetistas e os engenheiros (Gestor da Área de P\&D).

A contratação desse grupo específico de profissionais demandados pela EC1, não é orientada pelo valor da inovação propriamente dita - o que seria um valor físico, uma vez que o significado desse valor está atrelado ao objetivo de se produzir um efeito na realidade, isto é, tornar-se uma firma inovadora. O valor calculado nessa demanda é um valor de uso, ou seja, a EC1 precisa contratar esses profissionais para desenvolver produtos que correspondem às demandas em termos de tecnologias dos seus grandes clientes. Portanto, o valor dos engenheiros para firma reside no desempenho de uma tarefa em específico, a de atualização tecnológica. Dito de outra forma, se a EC1 assumisse a inovação como uma capacidade ou uma estratégia para competir no mercado de produtos e atrair clientes, então se poderia concluir que se estaria calculando o valor físico na contratação de engenheiros; entretanto, como essa contratação está voltada para o desenvolvimento de uma atividade específica, o que está sendo calculado é o seu valor de uso.

Outro elemento, mais especificamente um dispositivo de cálculo, que se insere nas relações sociotécnicas da EC1, através também de uma concepção menos inserida na lógica da nova economia, é a cultura da empresa. Relembrando o trecho de entrevista que trata desse aspecto e que foi citado no capítulo anterior. 
A nova cultura que está se formando na EC1 é bem legal porque está permitindo que as pessoas se sintam mais à vontade em sentar, conversar, ser atendidos. Então, o RH está tendo um trabalho muito mais presente com os funcionários, com a diretoria e com as gerências, fazendo com que o retorno que a gente têm dos funcionários, seja um retorno melhor, positivo. Estamos começando a trabalhar com questões de ergonomia, de ginástica laboral, que antes, ou talvez as diretorias não tinham esta cultura ou o tempo do setor não era suficiente para fazer. Então, a cultura está mudando bastante e o RH está ficando cada vez mais presente (Coordenadora de RH).

De modo geral, a cultura da empresa como um dispositivo em relação sociotécnica na rede de uma firma poderá servir a calcular dois valores econômicos: o de uso e o simbólico. O último se revela quando a firma contrata um trabalhador com certo perfil visto que neste se expressa, vale dizer que ele simboliza, a cultura como identidade da firma. Em contraste, a cultura da empresa pode materializar um valor de uso no sentido de apenas definir características que o trabalhador deve ter e que são valorizadas pela empresa por corresponderem ao modelo de gestão do trabalho e/ou às necessidades do seu processo produtivo.

Destaca-se no extrato acima o reconhecimento do caráter "em formação" da cultura da EC1. O reconhecimento desse fato faz com que a cultura da EC1, de um lado, não possa ser considerada um dispositivo plenamente desenvolvido para servir na capacidade de cálculo de um valor simbólico, pois, nesse caso, o principal encarregado em fazer a conexão entre um perfil de trabalhador e a identidade da firma, o RH, não está em relação com uma noção de cultura da empresa plenamente formada. Por outro lado, se a cultura da empresa materializa o valor de uso em termos de um perfil de trabalhador adequado ao seu modelo de gestão de trabalho e ao seu processo produtivo, esse elemento, ou seja, o valor de uso materializado no perfil de trabalhador adequado transparece nas falas dos gestores de área técnica.

Quando eu seleciono um trabalhador, eu vejo, primeiro, onde ele mora em razão da possibilidade de segundo turno - nós ainda não temos segundo, mas dependendo onde morar fica difícil contar para segundo turno de produção, o noturno, né? Vejo também se tem segundo grau e a empresa onde trabalhou pra ver a experiência, né? E, algumas vezes, eu olho pra ver a quantidade de filho. Eu vejo tudo isso porque aqui falta muita gente, né? Então, pela minha [...] experiência, né? Pela minha experiência, essas coisas influenciam nessa questão (Gestor da Área de Produção).

Em função do pessoal está faltando muito ou rotando muito entre empresas, infelizmente nós gestores estamos adquirindo uma espécie de pré-conceito! Terrível essa palavra, muito ruim! Mas infelizmente [...] não dá mais pra acreditar em currículo e em indicação. Então, nós temos que testar o candidato de tudo que é jeito! Fazemos uma 
inquisição com a pessoa, mas mesmo assim, não garante que... Repara no seguinte: nós não temos problema no perfil técnico, no currículo ou no conhecimento ou até na experiência da pessoa! Não é isso! Ela sabe e tem condições de fazer, mas por algum motivo, ela não faz aquilo. Então, é uma questão de atitude, de caráter, sabe? (Gestor da Área de Planejamento Industrial).

Constata-se, assim, que, na fala dos gestores, há um cálculo de valor de uso cujo conteúdo é expresso no perfil de um trabalhador (pelo menos na escassez desse perfil) comprometido com a função que desempenha no processo produtivo. Portanto, há uma forte preocupação sobre os níveis de rotatividade e absenteísmo na $\mathrm{EC}^{83}$.

Principalmente nos currículos do pessoal da parte da produção - isso a gente nota bastante quando lê os currículos, que o pessoal fica pouco nas empresas, no máximo um ano, sabe? A gente acredita que, o que acontece? Por incrível que pareça, o pessoal ali troca de emprego por causa de uma diferença de 50 Reais! E como as empresas grandes, essas industriais maiores têm muitos períodos de baixa e alta, então elas cortam o pessoal que chegou faz dois meses, quando era um período de alta produtividade. Então, a gente acha que por isso o pessoal tem essa trajetória com experiências bem curtas. Aqui na EC1, a gente procura manter os funcionários tanto na alta como na baixa, né? Então, a gente não tem essas demissões. Então, eles acabam trazendo isso com eles pra cá, sabe? E fora isso, tem essa coisa: "Ah! Aqui na EC1 eu to ganhando 700, mas lá na outra empresa estão oferecendo 750; então, eu vou pra outra empresa". Então tem muito funcionário que entra aqui e continua procurando outras empresas pra saber, né? Eles não nos falam diretamente isso, mas a gente sabe que eles continuam procurando. Mas o clima da EC1, a forma de trabalhar e as atividades na EC1 são diferentes das outras empresas que eles estão acostumados a trabalhar. A gente dá um número bom de benefícios, sabe? Então, por mais que eles saiam daqui, eles acabam querendo voltar... Então, isso tem sido um problema, apesar de que, se tu for olhar, o nosso índice de rotatividade é mais baixo que o das outras empresas daqui da região (Coordenadora de $\mathrm{RH}$ ).

$\mathrm{Eu}$, o RH, a direção e a presidente têm conversado sobre essa questão [rotatividade e absenteísmo]! E eu falo que eu entrevisto uma pessoa e pergunto se ela tem realmente vontade de trabalhar aqui - "Sim! Eu tenho muito vontade de trabalhar na ECl". E aí, dois dias depois tu liga e ela - "Ah! Não quero mais". E aí tu vê que ela arranjou às vezes uma vaga de temporário, mas foi por causa de 50 Reais. Mas tem muita gente que tenta vir trabalhar aqui porque a EC1 é uma empresa diferentes das empresas da região.

E mais especificamente do absenteísmo?

Isso agora é nosso maior problema! Por exemplo, até meados de 2007, nosso absenteísmo não chegava a quatro por cento. Hoje, já está chegando a dez por cento! Mais do que dobrou! Já teve dias que deu dezessete por cento! E o diretor geral novo, que entrou faz pouco, está fazendo um acompanhamento semanal disso! E agora isso está

\footnotetext{
${ }^{83}$ As entrevistas revelam que esses são problemas apenas identificados entre os trabalhadores da área produtiva. Engenheiros, gestores e o pessoal da parte administrativa não foram citados como apresentado níveis tidos como problemáticos de rotatividade e/ou de absenteísmo.
} 
virando um critério pra demissão. Mas assim, isso aumentou muito, mas o que fazer? Nós nos perguntamos e nos perguntamos... Mas ainda de prático mesmo! Nós nada fizemos! (Gesto da Área de Produção).

A mão de obra está muito diferente! Nós sentimos uma mudança da água pro vinho. Então, como hoje nós precisamos tratar a nossa equipe que é pouco mais de 100 pessoas? Nós podemos dividir em dois: nós temos um grupo que é o das pessoas mais antigas, que é de gente muito responsável! Gente que produz! Está aí todos os dias e está preocupada com o negócio! E tem o outro grupo, o do pessoal mais recente, que é triste! O cara não quer trabalhar e exige muito direitos pra poucos deveres! É complicado! E o quê que acontece? Qual o maior problema nesse sentido? Durante o contrato de experiência, a pessoa é uma! No dia seguinte, do final do contrato de experiência, ela se transforma! Se transforma de um jeito que nos faz ter que demitir ela! A maioria que tem chegado aqui tem sido assim, sabe? Pra aquilo que a EC1 precisa, está bem difícil! [...] Mesmo depois de ter eliminado os piores casos nesse sentido, as pessoas que a gente tem contratado, pelo que eu vejo, tem vindo só nesse perfill E isso é um problema porque a gente gasta tempo com a pessoa, sabe? A gente treina e tal, mas passou o período de experiência, a pessoa é outro funcionário (Gestor da Área de Planejamento Industrial).

A partir da rotatividade e do absenteísmo, o valor de investimento é compreensível através de duas instâncias: 1) da questão do tempo de permanência do trabalhador na firma, especialmente após o período de experiência; 2) e da incerteza sobre se o profissional contratado, após esse período, ainda apresentará uma atitude consistente ao nível de produtividade que se espera dele, não começando, por exemplo, um ciclo de absenteísmo. A primeira é mais diretamente vista pelo RH da EC1, já a segunda, a manutenção de um nível de produtividade após o período de experiência, é mais diretamente percebida pelos gestores de área.

Sendo que o valor de investimento se refere à expectativa de lucro ou retorno que poderá ser gerado da aquisição de um bem ou serviço (ASPERS; BECKERT, 2011, p. 11-12); no caso da EC1, então, o que está em jogo é a expectativa de ganho de produtividade da firma que se prevê alcançar ao contratar determinado número de trabalhadores. O valor de investimento revela-se, assim, nesse planejamento de ganho de produtividade para atender a um nível esperado de demanda dos clientes.

Nós temos hoje uma contradição! Que contradição é essa? Nós temos uma carteira [de clientes] baixa, mas um potencial alto! Nada acontecendo, essa carteira vai baixar e vai sobrar gente. Por outro lado, a coisa pode mudar e nós termos que entrar com segundo turno de produção! Nós podemos estar na beira de um sobressalto! Que pode ser um vale como pode ser um pico. Isso está indefinido por questões comerciais e de tecnologias, enfim... Porque o que está havendo nesse momento é uma migração de tecnologia, uma migração de equipamentos para fio de cobre e passamos também por um 
momento de wireless, né? E agora, o que vai pegar é fibra óptica! Então, o que acontece? Tem aquela coisa do modismo: todo mundo correndo pra fibra óptica e aí nós vamos precisar dobrar o número de pessoas aqui! Por outro lado, não está ainda bem na moda, o mercado, os nossos clientes não sabem pra onde bem vão ir (Gestor da Área de Planejamento Industrial).

Vai entrar um cliente novo, tá? Então, geralmente esse cliente novo vai gerar um produto novo, que requer uma linha nova e daí isso requer que, eu, o diretor e o gestor de planejamento industrial, nós tenhamos que nos reunir e ver as coisas, por exemplo, o cálculo de mão de obra em função do número de componentes/hora, número de placas/hora e aí placas/dia e demanda/mês que o cliente necessitar, né? Então - "Nós vamos precisar de tantas pessoas!" - e aí a gente sai à cata dessas pessoas! (Gestor da Área de Produção)

Portanto, os problemas da rotatividade e do absenteísmo também revelam o valor de investimento porque comprometem essa expectativa de ganho de produtividade.

Salários na EC1 são definidos por uma relação sociotécnica entre gestores de áreas e o dispositivo de cálculo "Tabela Salarial”.

Existe uma política de salários da empresa, mas ela está pra ser refeita também. O que nós temos hoje? Nós temos uma tabela de salários por cargos, né? Com um salário de admissão e depois mais cinco faixas. E aí, o gestor é que vai ver a faixa que o candidato pode ser colocado. Essas faixas são atualizadas pelo dissídio, né? Mas nós queremos montar o "cargos e salários" mesmo! Então, isso a gente, o RH e a direção, nós vamos fazer (Coordenadora de RH).

Lá no $\mathrm{P} \& \mathrm{D}$, a gente tem, por exemplo, o projetista júnior, pleno e sênior, tá? Quando eu entrevisto o profissional, eu procuro ver a experiência, o nível de conhecimento e tal... E vou tentar encaixar ele num desses níveis. O que acontece é assim: o candidato está me pedindo um salário de um cara que já está aqui, mas esse cara daqui já está em outro nível, entendeu? E aí esse fator complica. Então, nós os gestores - é nós que tentamos arrumar isso, é nós que vemos se o que o cara está pedindo é muito fora, sabe? Se não for, eu tenho que ver se aquele meu cara, eu não posso subir ele, sabe? Então, a gente vai discutindo isso com a direção (Gestor de Área de P\&D).

Em primeiro lugar, os extratos de entrevistas acima evidenciam que os salários materializam o cálculo do valor de uso, pois ele é decidido pelo gestor ao avaliar o nível de senioridade de um candidato através da relação sociotécnica com a tabela de salários. Em segundo lugar, especialmente nas falas sobre a capacidade da EC1 atender a demanda dos seus clientes, os salários materializam o cálculo de um valor de investimento no sentido de ser um entre outros custos que a empresa terá que arcar para comprar insumos necessários à obtenção de lucro; que, por sua vez, depende do 
aumento de produtividade que se planeja ser necessário para atender a certo nível de demanda esperada no mercado de produtos.

Ademais, a relação com esse instrumento de cálculo "tabela salarial", revela também a materialização do valor relacional sendo calculado na questão dos salários.

A empresa tem uma tabela de salário, mas ela é muito antiga. Eu até nem sei quem fez essa tabela que é de 2006. Essa tabela só é reajustada conforme o dissídio! Agora como foi criada e com que base ela foi criada, eu não sei. Então, essa tabela já estava pronta quando eu entrei na EC1. Só que a EC1, mesmo com essa tabela, a EC1 paga acima do mercado. O que a gente às vezes fazemos e nos basear numa pesquisa nos sites de vagas de emprego. Então, o que aconteceu? Teve um ano que a gente assinou a Catho ${ }^{\circledR}$ e aí eu fiz o levantamento nas empresas do mesmo setor da gente, o quanto elas estavam pagando para cada um dos cargos que a gente tem aqui na EC1. E aí quando a diretoria queria decidir o aumento de salário de um cargo, eles me pediam os dados dessa pesquisa que eu tinha feito. Hoje, a [coordenadora de $\mathrm{RH}$ ] não quis mais assinar porque acha que é muito caro. Então, essa pesquisa serviu para quando a gerência me solicitar, eu ter essa informação pronta. Mas ela não serviu como base para reajuste de salários (Técnica de DP).

Portanto, o valor relacional é revelado através do dispositivo de cálculo "tabela salarial" que promove o reajuste conforme os dissídios. Ao contrário dos outros casos, o cálculo do valor relacional não ocorre tendo como referência principal o mercado de trabalho, isto é, o quanto as outras empresas pagam para profissionais que a EC1 também demanda. $\mathrm{O}$ extrato acima evidencia que já houve a tentativa de algo nessa direção através da pesquisa pelo site da Catho ${ }^{\circledR}$, mas isso não foi levado adiante. Todavia, o cálculo de valor relacional tendo como referência o salário pago por outras empresas, não está totalmente ausente, isto é, ele se materializa na preocupação da EC1 em reter profissionais das engenharias ou altamente qualificados. Essa consideração do cálculo do valor relacional nos salários dos profissionais mais qualificados é expressa junto com o sistema de benefícios da EC1.

Os profissionais de fábrica, apesar de várias questões, é mais fácil pra a gente contratar, porque o que a gente vê é que eles têm aquilo da pouca estabilidade ao longo da carreira, porque as empresas da região contratam e demitem muito, e aqui, a gente procura manter os funcionários. Mas na parte de $\mathrm{P} \& \mathrm{D}$, nós temos uma concorrência muito grande com as outras empresas, que são os nossos concorrentes! Então a [principal concorrente da EC1] está sempre em cima da gente querendo os nossos engenheiros. E ainda, se a gente comparar o tamanho da [principal concorrente da EC1] com o tamanho da EC1, ela tem mais de 300 engenheiros na área de $P \& D$ e nós pouco mais de 30. Então, a gente tem que ver bem essa questão de pagamentos e benefícios pra essa parte. Isso é um desafio pra gente! Com o nosso tamanho, né? A gente conceder benefícios e salários condizentes pra 
que a gente não perca esses profissionais pra essas grandes empresas concorrentes (Coordenadora de RH).

Tu achas que os beneficios oferecidos pela empresa, eles atraem ou ajudam a manter os funcionários aqui?

Sim, bastante, até porque os benefícios contam ponto na hora deles decidirem se querem ou não sair da empresa. Então, tudo isso - plano de salários, de carreira, alimentação, auxílio pra estudos - tudo isso é ponto que conta na decisão deles.

E você acha que os beneficios contam mais para o pessoal da parte de produção ou do $P \& D$ ?

Depende do benefício, eu acho. O pessoal da parte de fábrica, né? Vale-alimentação e vale-transporte pesam mais pra eles. No P\&D, um auxílio educação, auxílio de viagem pra palestras, oportunidades de treinamento, isso pesa mais pra eles (Coordenadora de RH).

Como tu vês a questão das contratações na tua área de $P \& D$ ?

Isso é um problema. Até saiu um estudo assim: hoje, o Brasil está formando 55 mil engenheiros por ano e a demanda atual seria de aproximadamente 80 mil engenheiros por ano. E assim: claro que eu não sei se isso mudou em função da crise na Europa, mas a previsão é de se o país crescesse de 4 a $5 \%$ por ano, mais ou menos em 2017, nós estaríamos precisando mais ou menos de 400 mil engenheiros por ano. E a gente não tem de onde tirar tantos profissionais assim! Então, hoje aqui no Rio Grande do Sul, nós enfrentamos uma concorrência muito forte! Porque tem outras empresas do mesmo ramo da EC1 e todas demandam engenheiros. Então é um processo complicado, nós vamos ter que disputar esses profissionais com empresas grandes de tecnologia. E também assim, essa falta por óbvio vai acontecer de ter que aumentar o salário desses engenheiros (Gestor da Área de P\&D).

O que se percebe é que para os perfis de profissionais de maior qualificação, principalmente engenheiro, a necessidade de contratações e o planejamento das contratações que, ao seu turno, implica na definição de salários e benefícios, o cálculo leva em consideração um valor relacional mais diretamente vinculado ao mercado de produtos e ao de trabalho. Já a demanda pelos trabalhadores da área de "chão de fábrica", a questão de salários e benefícios materializa o cálculo do valor relacional, não tanto orientado pelos mercados, mas pelo dissídio sindical.

Nas entrevistas, o dispositivo "perfil comportamental" e o "perfil técnico" se misturam. Constatou-se que a principal razão disso se encontra no fato de que a empresa ainda não havia definido um plano de carreiras (agente não-humano) e também o dispositivo "cultura da empresa". Esses elementos contribuíram para essa situação na qual o dispositivo "perfil comportamental" e o "perfil técnico" se misturem nas operações de cálculo da demanda da empresa no mercado de trabalho.

A EC1 busca dois perfis de profissionais bem diferentes: o perfil de pessoal de $\mathrm{P} \& \mathrm{D}$ que são engenheiros que, principalmente, a gente procura os que tenham alguma vivência na parte de Telecom e TI, que é uma área que muda muito tecnologicamente, né? Então, a gente 
procura profissionais jovens e que tenham vontade de desenvolver coisas novas, que tenham aquele gás, né? Nesse sentido, a gente está com uma equipe legal de trainees que são profissionais recémformados, que entraram na EC1 sem experiência nenhuma e, então, a EC1 está formando eles. Então, ela não tem um perfil assim: eu quero um profissional com tantos anos de formado, tanto anos de experiência e que tenha trabalhado com isso, isso e isso! Não! A gente quer uma pessoa que tenha vontade de fazer! Claro que tem cargos específicos que a gente precisa de uma experiência maior em alguma ferramenta ou algum conteúdo. E outro perfil que a gente precisa é a área industrial. Daí é pessoal pra auxiliar técnico, auxiliar de produção. A formação máxima que a gente pede é o nível técnico em eletrônica, né? Mas muitos ali, não têm nível técnico, mas têm segundo grau completo ou técnico em administração [...]. Enfim, a gente exige pelo menos segundo grau completo. Ali também, a experiência também é muito valorizada porque, na parte de produção, [...] é um trabalho que não é simples de se fazer e a pessoa precisa ter um conhecimento sobre como funciona aquela linha de produção, como funciona uma montagem de placa pra poder trabalhar aqui com a gente (Coordenadora de RH).

Eu vou começar pelos nossos estagiários pra ti dizer os perfis de gente que a EC1 precisa, tá? Os nossos estagiários, então, tanto a área de P\&D como na de produção, a gente procura jovens que pelo menos esteja cursando o nível técnico, especialmente técnico em eletrônica. Esse profissional pode entrar tanto na parte de assistência técnica como na parte de $\mathrm{P} \& \mathrm{D}$, isso vai depender. O trainee, que são profissionais já formados ou quase formados, não tem experiência profissional nenhuma, que não sabe como a coisa funciona na prática, né? Esses são profissionais que só têm aqui na parte de $P \& D$ e os gestores de equipes envolvem eles dentro de todas as áreas - parte de teste, software, hardware, gerência de projetos - e, assim, pra que no final de tudo isso, eles possam estar preparados pra ser projetistas júnior. Depois disso, os engenheiros júnior, pleno e sênior, que ainda a gente não tem muito bem definido o nível de experiência e as habilidades técnicas de cada um e isso é o plano de carreiras que a gente tem que fazer ainda. [...] A parte de produção é praticamente uma função: auxiliar técnico e os técnicos. Os técnicos são todos formados em eletrônica, né? Mas é diferente daqui do $\mathrm{P} \& \mathrm{D}$, por que o que eles vão fazer? Eles vão montar a peça! [...] Então, eles precisam ter conhecimento em componentes, em solda, operar e programar máquinas... Então, esse pessoal, a gente busca aqueles que já trabalharam em empresas do mesmo ramo. Quem não trabalhou em empresas do mesmo ramo, a gente procura botar primeiro na área de testes pra depois ir pra produção, pra saber operar máquinas e montar uma placa. E o auxiliar é aquele que está ali no dia-a-dia na mão de obra mesmo! (Coordenadora de RH).

O perfil [comportamental], pra mim, ele tem um peso maior que o conhecimento técnico. Quando eu vejo assim - "Esse conhecimento ele pode absorver aqui dentro, mas tem esse profissional que já tem esse conhecimento, mas o perfil [comportamental] não se enquadra" eu tendo a escolher pelo perfil [comportamental]. Porque eu corro menos risco de perder um profissional porque teve um problema de clima lá $[\mathrm{P} \& D]$, sabe? Porque é aquilo que eu já ti falei: o perfil 
técnico é simples de saber - ou o cara sabe aquilo lá ou não sabe - e eu sei que perguntas eu tenho que fazer pra ver isso. Então, como eu ti disse, é matemático! Agora, o perfil [comportamental] é mais difícil e aí o RH também ainda não tem isso bem claro. Eu acho que de repente um psicotécnico... Por isso quando eu sinto que o perfil [comportamental] do candidato é legal, [...] eu valorizo (Gestor da Área de P\&D).

Quando eu seleciono um trabalhador, eu vejo primeiro, onde ele mora em razão da possibilidade de segundo turno [...]. Vejo também se tem segundo grau e a empresa onde trabalhou, pra ver a experiência, né? E, algumas vezes, eu olho pra ver a quantidade de filho. Eu vejo tudo isso porque aqui falta muita gente, né? Então, pela minha experiência [...] essas coisas influenciam nessa questão. [...] Depois, na entrevista, eu foco a parte técnica! Na entrevista, a pessoa tem que mostrar pra mim, o que ela conhece. Com desenho e com explicação descrevendo, né? Por exemplo, sabe soldar? Com o quê que tu solda? Quais ferramentas tu vai usar pra essa solda? [...] Eu quero saber se tu sabe tirar um curto de solda. Eu pergunto todo o passo a passo das coisas que a pessoa tem que fazer pra trabalhar lá comigo, lá naquele cargo que eu preciso. Eu pergunto tudo isso pra saber toda a técnica e a habilidade da pessoa. E com isso, [...] eu tenho sentir confiança na pessoa, naquilo que ela tá falando pra $\mathrm{mim}$ ! Se eu vejo que ela responde muito rápido e muito curto, eu já fico meio assim, porque as perguntas que eu faço não são pra ser respondidas assim, entende? Eu quero que a pessoa me diga especificações técnicas daquilo, por exemplo, um resistor! Eu quero que ela diga pra mim, qual é o encapsulamento, a resistência... Enfim, características dos componentes. Peço daí pra desenhar e aí a pessoa na me sabe desenhar... E o cara já trabalha dois, três anos e não sabe! Aí, eu começo ficar em dúvida! (Gestor da Área de Produção).

Normalmente, eu lido com o pessoal da produção mesmo, né? E nosso produto ele é feito uma parte em máquina e outra manualmente. Então, dentro dessa última parte, que é de manufatura, a gente tem um pessoal sem o técnico, mas que daí a gente seleciona porque tem experiência em manufatura eletrônica. E aí tem um grupo menor que a gente precisa com uma formação com curso técnico, técnico em eletrônica principalmente. Então, esse é os dois tipos gerais que a gente tem ali na fábrica, né? [...] E aí tem aquilo que eu ti falei da atitude, do caráter, que está difícil ver se a pessoa não vai fazer mais ou menos o trabalho depois do período de experiência. Então, isso, a gente ainda não conseguiu definir muito bem ou verificar pra ver se a pessoa tem caráter, sabe? Talvez o psicotécnico tenha que ser aplicado, porque quando eu comecei a trabalhar era diferente, a gente tinha vergonha de não entregar uma coisa que tinha prometido na entrevista! A seleção era mais dura! Eu vejo que esse lado, a gente precisa desenvolver. De repente nós nos acostumamos com aquele perfil antigo de trabalhador comprometido e o perfil mudou e o nosso processo seletivo não! (Gestor da Área de Planejamento Industrial).

Constatam-se através de todos esses estratos de entrevistas que os perfis de competências técnicas e comportamentais materializam o cálculo do valor de uso, pois essas competências permitem à firma calcular se, ao contratar certo perfil de 
trabalhador, ela conseguirá satisfazer a necessidade de execução de uma atividade no seu processo produtivo. Nesse caso, então, há a materialização do cálculo do valor de uso em função de um amálgama entre o perfil técnico e o comportamental demandado e valorizado pela EC1. Todavia, por não haver os dispositivos de cálculo "plano de carreiras" e "cultura da empresa", o perfil de competências comportamentais não materializa completamente um cálculo de valor de uso, isto é, os agentes humanos do RH e da gestão de áreas técnicas possuem um alto grau de incerteza sobre como verificar e selecionar os candidatos nesse aspecto.

\subsection{Estudo de Caso 2: valores econômicos estruturados da nova}

\section{economia}

A tabela abaixo expõe, esquematicamente, os valores econômicos que foram identificados como sendo calculados na demanda por força-de-trabalho da EC2 e as relações sociotécnicas e/ou dispositivos de cálculo que materializam esses valores.

Tabela 27 - Valores Econômicos Calculados pela EC2.

\begin{tabular}{c|c|c|c|c|c}
\hline & $\begin{array}{c}\text { Valor de } \\
\text { Uso }\end{array}$ & $\begin{array}{c}\text { Valor de } \\
\text { Investimento }\end{array}$ & $\begin{array}{c}\text { Valor } \\
\text { Relacional }\end{array}$ & $\begin{array}{c}\text { Valor } \\
\text { Físico }\end{array}$ & $\begin{array}{c}\text { Valor } \\
\text { Simbólico }\end{array}$ \\
\hline Cultura da Empresa & $\sqrt{ }$ & & & & $\sqrt{ }$ \\
\hline Estratégia de Inovação & & & & $\sqrt{ }$ & \\
\hline $\begin{array}{c}\text { Rotatividade e } \\
\text { Absenteísmo }\end{array}$ & & & & & \\
\hline $\begin{array}{c}\text { Perfil de Competências } \\
\text { Técnicas }\end{array}$ & $\sqrt{ }$ & & & & \\
\hline $\begin{array}{c}\text { Perfil de Competências } \\
\text { Comportamentais }\end{array}$ & $\sqrt{ }$ & & & $\sqrt{ }$ & \\
\hline Salários & & $\sqrt{ }$ & & & \\
\hline Programa de Benefícios & & $\sqrt{ }$ & & & \\
\hline $\begin{array}{c}\text { Planejamento para o } \\
\text { Atendimento à } \\
\text { Demanda }\end{array}$ & & $\sqrt{ }$ & & & \\
\hline
\end{tabular}

Fonte: Dados de Pesquisa de Campo.

Por ser uma empresa multinacional com atuação consolidada no mercado de produtos de softwares de gestão empresarial e a sua unidade pesquisada nesta tese se encontrar também estabelecida nas suas operações, os valores econômicos calculados na sua demanda no mercado de trabalho apresentam uma definição clara e estável entre os agentes que compõem a rede sociotécnica da EC2. Também cabem destacar que, apesar da EC2 compartilhar de alguns dos mesmos tipos de valores econômicos identificados na EC1, os conteúdos dessas modalidades de valores é que determinam a maior proximidade da EC2 com aspectos que caracterizam a nova economia. Portanto, são menos as diferenças entre as modalidades de valores econômicos que determinam a 
diferença entre as empresas em termos de se aproximarem mais ou menos da nova economia, mas mais a forma como são definidos e, por conseguinte, transformados esses valores econômicos nessa nova economia.

Nesse sentido, o conjunto de relações sociotécnicas que conformam a definição de cultura da empresa na EC2, também se materializa no cálculo do valor de uso. Nesse sentido, no capítulo anterior foram expostos os extratos de entrevistas que definem a cultura da empresa, mas cabe destacar alguns trechos:

A cultura da EC2 é uma cultura assim, bem flexível! Em geral, flexível é a palavra que melhor define, né? [...] Mas em geral é bastante tranquilo [...] em termos de poder levantar, sair, tomar um café... Não tem aquela rigidez de empresas que cada vez que você vai sair, vai no banheiro, você precisa está avisando para um supervisor. É bem informal também, né? [...] Aqui tem gente que vem de bermuda no verão, então, de forma geral, eu diria que a cultura é de um ambiente de trabalho flexível e informal (Recrutadora 2).

[...] nós definimos a cultura da empresa como um ambiente informal de trabalho. Um ambiente que valoriza pessoas que pensem "fora da caixa", né? Um ambiente "flat", onde há poucas hierarquias e as pessoas são cobradas não por obedecerem a pessoas, mas cobradas por resultados. Um ambiente de horário flexível, onde não tem cartãoponto (Recrutadora 1 ).

Mas o que eu sinto é que a cultura que permeia a empresa, ela tem a ver com respeitar o ser humano, ela tem a ver com buscar o desenvolvimento das pessoas que trabalham aqui! Valorizar as pessoas que estão na empresa. Então, isso acontece realmente. [...] Então, eu vejo a cultura da EC2 como uma cultura onde se valoriza muito os funcionários, né? Valoriza que as pessoas ficam um bom tempo na empresa, que se desenvolva dentro [...]. A pessoa se sente protegida, mas, ao mesmo tempo, ela tem obrigações a cumprir, mas ela tem essa contrapartida. Toda essa questão de flexibilidade... Nós não temos ponto aqui! Nós não controlamos horários das pessoas aqui. As pessoas são responsáveis, elas vêm aqui e fazem seu trabalho (Coordenadora de RH).

Constata-se que o valor de uso se manifesta por aspectos ligados a um modelo de gestão do trabalho identificado com características típicas da nova economia e, tal como foi analisado na seção anterior, estão ausentes na EC1. A caracterização da cultura da empresa em termos de um modelo de gestão de trabalho flexível, com poucas hierarquias, informal e sem controle de horários, definem um valor de uso em termos do cálculo do perfil de trabalhador que se adéqua a essa cultura.

O nosso perfil aqui sempre foi assim: a gente não foca muito em pessoas com grandes experiências! Até porque não existe essa pessoa, é difícil encontrar pessoas que tenham grande experiência no de desenvolvimento de linguagem de Java e de [linguagem de programação própria da empresa]. [...] Então, buscar aquele 
profissional com o conhecimento mesmo das nossas linguagens, não é muito possível! A gente procura, então, profissionais potenciais! Aquela pessoa que quando a gente entrevista, a gente sente que tem grande potencial de aprendizado, tá? Que está motivada para vir trabalhar na EC2 e que, assim, a gente pode desenvolver ela aqui dentro. Então, assim, o perfil dos nossos funcionários é jovem! [...] Hoje, 26\% dos nossos funcionários são estudantes de universidade! Os que já se formaram, uns $20 \%$ se formaram não faz nem dois anos! Então, a gente procura esse profissional: aquela pessoal que vem com vontade e com muita capacidade! (Coordenadora de RH).

O que nós buscamos? O que nós valorizamos? Então, boa faculdade! Inclusive as notas que teve na faculdade, isso é importante! Nível de inglês - isso pra todos! Porque todo material da EC2 é em inglês do início ao fim. Hoje em dia, o espanhol já é um diferencial. [...] Pessoas que tenham ideias diferentes, pessoas inteligentes! Então, todas as entrevistas aqui, a gente avalia o candidato por competências e competência que tem a ver com a vaga do candidato, mas também competências que tem a ver com a empresa, sabe? Pessoas que tenham ideias, que sejam criativas, que gostem daquilo que fazem - é isso que a gente procura. Pessoas que sejam flexíveis, que, por exemplo, gostem de trabalhar com times virtuais porque aqui o teu chefe, o teu colega de projeto pode não estar aqui na unidade! Então, reunião virtual é o que mais tem aqui com gente na Índia, Europa, Estados Unidos... Então, é um ambiente muito dinâmico! Então tem que ser uma pessoa que saiba se adaptar a esse ambiente (Recrutadora 1).

Portanto, a cultura da empresa materializa um cálculo de valor de uso no sentido de competências que a pessoa deve ter para bem desempenhar seu papel dentro da organização. Interessante notar também que, essa relação sociotécnica, conformada pela cultura da empresa, o modelo de gestão do trabalho e o perfil de trabalhador, materializa o valor simbólico no sentido de exprimir uma identidade da empresa. Tal como é escrito no site da EC2, a sua cultura é definida em termos de um modelo de trabalho que faz com que ela seja (identidade) uma empresa inovadora, líder e capaz de mudar a forma como as outras empresas (suas clientes) fazem negócios. A cultura da empresa é, então, um modelo de trabalho capaz de mudar o mundo dos negócios através da inovação tecnológica. Sendo essa a identidade da empresa, isso expressa um valor simbólico a ser calculado no mercado de trabalho, pois serve para mobilizar e selecionar profissionais com vocação para o mundo de TI e identificados com a cultura da empresa.

A inovação não aparece diretamente nas falas das entrevistas realizadas na EC2. Entretanto, tal como argumentado acima, a inovação faz parte da identidade da empresa e, por conseguinte, de sua cultura como modelo de trabalho. Na seção do site da EC2 sobre informações institucionais, há frases que reforçam o compromisso da empresa, 
seus executivos e funcionários em valorizar e buscar "novas ideias" ${ }^{84}$. Também, tal como exposto no capítulo sexto, o dispositivo de cálculo "roteiro de entrevista" contemplava, como critério de avaliação do candidato, a sua capacidade de produzir e se engajar em projetos de inovação.

Assim, a inovação é algo que perpassa a empresa, isto é, que faz parte do modelo de negócios e de gestão de trabalho na EC2; com isso, compreende-se que a noção de inovação materializa o cálculo do valor físico. Cabe notar que, essa interpretação se justifica quando se considera em contraste com o caso da EC1, onde a inovação é tida como uma atividade específica de um grupo de profissionais da empresa.

O valor físico, portanto, é justamente adquirir um bem ou serviços que tenham em si a capacidade de produzir um efeito e alterar o estado de coisas (ASPERS; BECKERT, 2011, p. 13). No caso da EC2, o bem cuja aquisição é valorizada nesse sentido, são os trabalhadores identificados com a cultura da empresa e capazes de tornala uma firma inovadora.

Foi relatado que a unidade pesquisada da EC2 possui índices baixos de rotatividade e nem se quer foi mencionado o absenteísmo.

O que acontece aqui nesse sentido [da rotatividade]. Nós temos uma situação bem atípica: nós fechamos o ano [2011] com 2,8\% de rotatividade. $\mathrm{E}$ a gente sabe que tem empresa de TI que a rotatividade chega aos 20\%! Quer dizer, então, que a diferença é gritante! Claro, nós já tivemos uma rotatividade mais alta: por exemplo, em 2010, ela chegou em 7\%. E provavelmente esse ano [2012], nós vamos ficar na faixa de $4 \%$ - e que igual é uma rotatividade baixa pro setor de TI. E a gente sabe assim: obviamente a concorrência aqui, no Rio Grande do Sul, em termos de empresas que oferecem o que a gente oferece pro empregado, ela é menor que em São Paulo, por exemplo! Em São Paulo, eu tenho inúmeras grandes empresas que oferecem o mesmo tipo de faixa salarial, os mesmos tipos de benefícios e outras coisas positivas, como o ambiente de trabalho, possibilidade de crescimento, possibilidade de ambiente intercultural... No Rio Grande do Sul, isso não é tão comum! Então, isso obviamente conta a favor da nossa rotatividade. Nós fomos por dois anos consecutivos, uma das empresas melhores pra trabalhar no Brasil, segundo a EXAME S/A. Nosso engajamento no escritório, que é um índice que a agente mede, [...] essa unidade tem o segundo melhor índice no mundo de todas unidades da EC2. Uma diferença de 1\% do primeiro lugar. [...] Mas mesmo assim, apesar dessa situação favorável, nós ficamos de olho nisso (Coordenadora de RH).

\footnotetext{
${ }^{84}$ Em razão do compromisso ético da tese de compromisso com o anonimato das fontes, não foi possível transcrever as frases constantes do site da EC2.
} 
A rotatividade é uma preocupação, mas dado o seu nível baixo na unidade, ela acaba por não subsidiar o cálculo de ações e decisões que têm lugar no mercado de trabalho. O que ocorre no caso da EC2 é o que a coordenadora de RH da empresa chamou de "iniciativas de retenção", isto é, políticas de gestão de recursos humanos para aumentar o nível de satisfação dos empregados para com a empresa (foi relatado o uso de pesquisas anuais, aplicadas em todas as unidades no mundo da empresa, para medir a satisfação dos funcionários em trabalhar na EC2) e, simultaneamente, há uma percepção das características do mercado de empresas de TI gauchas, que seriam favoráveis para obtenção de uma baixa rotatividade. Portanto, constata-se que, no caso da EC2, a rotatividade não expressa nenhum valor econômico que oriente as operações de cálculo da empresa no mercado de trabalho.

O perfil de competências técnicas encontra-se forte e claramente materializado como cálculo de valor de uso numa série de relações sociotécnicas bem estabelecidas na EC2. O primeiro conjunto de relações se estabelece a partir do dispositivo de cálculo "plano de cargos e carreiras". Retomando o que foi exposto no capítulo anterior, esse dispositivo consiste num sistema informático, disponível para todos na empresa através de uma intranet, no qual constam definições de níveis de qualificação técnica para cada cargo daquela unidade da EC2. Cada cargo é organizado em hierarquias de níveis de competências divididas em cinco níveis de senioridade que, por sua vez, estão distribuídos em quatro carreiras: funcional, gerência de pessoas, gerência de projetos e gerência funcional. O cálculo do valor de uso se expressa nessas definições de cargos por perfil de competências técnicas, isto é, quais características profissionais o candidato deve ter em ordem de realizar a tarefa estabelecida para aquele cargo dentro da empresa.

Ainda no que se refere ao perfil técnico materializando o valor de uso no cálculo da EC2 no mercado de trabalho, temos uma competência que é tida pela empresa como necessária para executar qualquer atividade laboral dentro da mesma falar e compreender a língua inglesa. Além de estar presente nas falas dos entrevistados, essa competência técnica também é divulgada nas apresentações da EC2 em Universidades $^{85}$. Essa proficiência como competência do perfil técnico da empresa expressando um valor de uso, torna-se ainda mais evidente quando se analisa as falas

\footnotetext{
${ }^{85}$ Foi concedido o acesso ao material de apresentação da EC2 nas Universidades, mas por razões de acordo de confidencialidade com a empresa, não é possível reproduzi-los aqui. Trata-se de panfletos e apresentações em PowerPoint $\AA$.
} 
que dizem que a principal razão de escassez no mercado de trabalho é achar profissionais que saibam falar, compreender e ler em inglês.

Qual é a maior dificuldade que tu encontra no recrutamento e seleção de pessoas?

Inglês! Disparado! A gente perde muita gente boa por causa de inglês. Porque, pra ser contratada, a pessoa precisa saber conversar em inglês. Muitas vezes, então, eu vejo currículos muito bons, que chegam colocar inglês avançado e tal... E aí vou fazer a entrevista por telefone e muitas vezes o candidato não consegue se expressar em inglês.

E vocês fazem algum tipo de estratégia para contornar esse problema?

Assim, a gente viu esse "gap", né? E ano passado, eu montei um projeto que, os melhores alunos de nove cursos de tecnologia da UNISINOS, que estão passando pro segundo semestre, a gente está dando uma bolsa de um ano de curso de inglês. É ainda um projeto piloto [...]. Um ano de curso pra os melhores, que são os que nos interessam! As pessoas com potencial (Recrutadora 1).

Qual é a maior dificuldade que tu encontra no recrutamento e seleção de pessoas?

Eu acho que é o inglês, a questão de idiomas, né? Aqui, nessa unidade, $100 \%$ dos funcionários falam inglês. Não tem como a gente contratar uma pessoa com pelo menos um nível intermediário de inglês. [...] Pra algumas vagas, o inglês fluente já é indispensável! Porque muitas vezes o gestor daquela área, não fala nada de português ou porque a vaga é para atender clientes que estão no exterior (Recrutadora 2).

Por fim, outra competência técnica que está inserida na concepção de valor de uso da EC2 são as principais linguagens de programação utilizadas - Java e uma linguagem que não é possível revelar o nome porque é própria da empresa e, portanto, comprometeria o nosso compromisso ético de anonimato das fontes. Assim, os níveis de domínio dessas linguagens entram como uma das competências que definem os perfis técnicos correspondentes para cada cargo das áreas ligadas às operações da atividadefim da EC2. Como expresso no extrato de entrevista da Coordenadora do RH (p. 214) sobre o perfil de profissional valorizado pela empresa, a escassez de trabalhadores com familiaridade nessas linguagens tem levado a EC2 focar em profissionais jovens que podem ser treinados dentro da empresa nessas linguagens de programação.

O valor de uso também está relacionado ao perfil de competências comportamentais.

Baseado na cultura da EC2, a gente faz perguntas para ver se o candidato tem motivação e entusiasmo, capacidade de aprender por conta própria, sabe trabalhar em equipe e se trata todo mundo bem. Essas competências comportamentais são avaliadas, são ranqueadas. Como exatamente tu avalias essas competências comportamentais? A gente, assim, nós temos algumas perguntas que chamamos de killers, tá? Eu particularmente, eu avalio desde como o candidato 
tratou com o pessoal da portaria até o final da entrevista, né? Então, eu sempre falo com o pessoal da recepção pra ver se o candidato foi cordial e tudo mais... Algumas coisas que eu também avalio, por exemplo, como é o comportamento dele frente à entrevista. Nesse sentido, eu considero a entrevista um momento tão especial, quanto ir fechar um negócio com o cliente! Então, se o candidato faz coisas que os clientes não gostariam que ele fizesse na frente deles, eu considero aquilo um killer. Chegar atrasado! Se o celular tocar até tudo bem, mas não mostrar nenhum tipo de embaraço e atender, eu considero um killer. [...] Clareza na hora de responder as perguntas também, porque tem candidatos com experiências muito boas, mas não é estruturado na hora de responder. São coisas, então, que são indiretas e que também estão nas perguntas (Gestor de Área de Desenvolvimento de Software).

Qual o perfil de competências comportamentais, a EC2 valoriza em um candidato?

$\mathrm{Ah}$ ! Uma pessoa que gosta de inovar em primeiro lugar. Uma pessoa que proponha ideias, que seja pró-ativa, né? Que não fique esperando as coisas acontecerem. Tem que ser uma pessoa com boa índole, que tu sintas confiança. Claro que índole não tem como muito saber antes de contratar, mas muitas pessoas aqui são indicadas por outras, então mais de $50 \%$ das contratações que a gente faz são através de indicações. Não é porque a pessoa indicada é que tenha preferência no processo seletivo - aquela coisa do QI ["quem indica"], né? - mas claro que, por ela ter sido indicada, a gente já imagina que a outra pessoa conhece em relação de comportamento e índole, né? De maneira geral, nós queremos em termos de comportamento, uma pessoa honesta, inovadora e que tome a iniciativa (Recrutadora 2).

Nessas falas descrevendo esse perfil, o valor de uso é expresso em termos de competências necessárias ao profissional para bem desempenhar suas atividades dentro das características e práticas que conformam o ambiente de trabalho da EC2 como um todo. Simultaneamente, o perfil de competências comportamentais materializa o valor físico. Conforme visto nesta seção, quando se fez a análise sobre a cultura da empresa e a questão da inovação, a EC2 entende que para se tornar uma empresa inovadora, no sentido de ser capaz de transformar o mundo dos negócios, faz-se necessário que ela contrate profissionais que têm atitudes e comportamento em sintonia com a sua cultura corporativa. Essas atitudes, ao mesmo tempo, traduzem a cultura da empresa que a torna capaz de ser inovadora (valor físico) e, também, no estabelecimento de um perfil de competências comportamentais, definido nos extratos acima. A relação entre esses elementos - cultura da empresa, perfil comportamental e valor físico - fica mais clara na seguinte instrução de preenchimento do roteiro de entrevistas utilizado pela EC2:

A cultura corporativa da EC2 é o nosso principal diferencial e nos ajudou a alcançar a posição de liderança. A cultura da EC2 continuará a ser o guia para que possamos atingir nossa meta e responsabilidade de nos tornarmos líderes. Nossa cultura é baseada num conjunto de paixões. Por favor, avalie o candidato(a) para saber se você acredita 
que ele/ela possui um comportamento alinhado às paixões da EC2. Essas paixões aplicam-se em trabalhar com clientes, parceiros e com o ambiente dentro da EC2.

As "paixões" são justamente as competências que definem o perfil comportamental demandado e calculado como valor de uso e como valor físico, pois tal como diz o extrato acima, é o que torna possível a EC2 se tornar líder no seu segmento de mercado. No roteiro, as competências ou paixões são definidas em termos do quanto o candidato apresenta as seguintes qualidades: comprometimento com o sucesso pessoal, dos clientes e da própria empresa; ser responsável e mantém a palavra nos compromissos profissionais que assume; profissionalismo no sentido de sempre buscar o seu aperfeiçoamento, esforçar-se ao máximo no seu trabalho e tratar com respeito a todos; integridade e sinceridade ao tratar com colegas de trabalho e clientes; valorizar e saber trabalhar em equipe; ser uma pessoa confiável que assume responsabilidades e participa para alcançar o sucesso do grupo.

O cálculo do valor de investimento na questão dos salários pagos pela EC2 é constatado através do seguinte relato sobre como a direção executiva da empresa define o número de contratações a ser feitas no ano ou semestre.

O diretor geral de uma área, lá na [país onde fica a matriz da empresa], ele depois de todo um planejamento, ele chega à conclusão que terá a necessidade de aumentar o time dele em cem pessoas. Ou seja, houve um aumento de demanda, foram vendidos " $\mathrm{x}$ " softwares a mais, a gente vai precisar de mais gente no suporte, por exemplo. E esse diretor geral vai fazer uma análise de onde ele vai alocar, entre os escritórios da EC2 no mundo, essas cem pessoas a mais pra suporte. Então, ele vai ver o seguinte: quanto é o custo de alguém no cargo de suporte no Brasil? É "x". E quais são os benefícios? Por exemplo, o inglês do brasileiro é melhor do que é falado pelo indiano ou o chinês. Porque esses são os dois países que mais competem com a gente entre escritórios da EC2 no mundo. E eles têm um custo de mão de obra mais baixo que a gente, mas também a gente vê que a decisão não é só pelo critério financeiro, existe essa questão de qualidade que pesa na satisfação do cliente, que é muito importante para EC2. Até porque não adiante ele economizar mil Dólares por mês, se o atendimento na China, por exemplo, é pior do que no Brasil. Então, esse diretor geral faz essa análise para ver onde ele vai locar esses cem nesses países. Ele submete essa decisão, tanto a de local como a da necessidade de cem a mais, para o Conselho Executivo da EC2. Ele recebendo a aprovação do Conselho, ele avisa para o diretor executivo da unidade que, dessas cem vagas, vão vir 25 pro escritório dele. O diretor executivo em posse dessa informação, vai lá no sistema e vai abrir uma solicitação de 25 pessoas. E também ele vai colocar lá o nível de senioridade que ele acha adequada para essas 25 vagas. Esse material chega pelo sistema pra mim, a coordenadora de $\mathrm{RH}$, e eu analiso pra ver se ele está correto na questão da descrição de senioridade para as 25 vagas. Se eu acho que não está correto, eu falo e discuto com ele 
sobre as dúvidas que tenho de perfil e aí vou arrumar aquelas vagas no sistema [...] (Coordenadora de RH).

Como são aprovadas aberturas de vagas em função de pessoas que deixam a empresa?

O que acontece nesse caso? Por exemplo, eu tenho um funcionário que pede demissão e, então, eu como gerente vou pedir via sistema, o que chamamos de replacement. Esse pedido vai passar por uma aprovação e que assim, na EC2, a gente tem um sistema de linha de diretores, tá? Nós temos o linha zero, que é um membro do "board" [de acionistas] da empresa; então, o linha 1 é um diretor que reporta pro linha zero e assim por diante é até o linha 5, que é um diretor local de unidade. Então, no caso de um replacement, não vai passar pela aprovação de um linha zero ou um linha 1 , mas geralmente, isso é decidido por um linha 2 ou 3. Então, é um que já está num nível abaixo daquele que se reporta pro board. Por quê? Porque tudo isso impacta no número de pessoas que a gente tem na empresa, que é um dos fatores importantes pra resultados anuais da empresa! Então, quando chega no final de ano, lá pro acionista da EC2, é importante pra ele saber com quantos recursos aquele resultado anual foi atingido! Então, a gente não pode ficar criando indiscriminadamente vagas. Em geral, a gente tem aprovação dos replacement, exceto em situações que nós estamos buscando redução de pessoas, porque em determinados trimestres, a gente vê que não está atingindo o lucro operacional, $[. .$.$] eu precisava entregar pro acionista, ao final do$ trimestre, um lucro de um bilhão e eu estou em 99 milhões e 800 mil em dado momento; então, o que eu posso fazer? Para tirar despesa, eu corto o replacement até o próximo trimestre! Com isso, eu diminuo o custo, porque tu está pensando em termos da EC2 globalmente com dezenas de milhares de funcionários, [...] isso, então, não é tão comum, mas acontece de um trimestre ruim, o board dizer: "Trancou! Congelamento de contratações". (Coordenadora de RH).

Constata-se que esse cálculo é feito tendo em relação com o planejamento para

$o$ atendimento das demandas dos clientes, assim como, também, algo que somente

apareceu na EC2, que são as demandas dos acionistas da empresa. Os salários são, então, o custo de investimento que a EC2 terá que pagar em função da expectativa de um retorno em termos de produtividade para satisfazer a demanda dos clientes como também de lucro para os acionistas.

O salário materializando o cálculo em termos de valor de investimento, também

fica evidente neste relato sobre a contabilidade de custos em torno da substituição de um funcionário que pede demissão.

Uma substituição de funcionário, quando a gente coloca na ponta do lápis, o custo de reposição é um salário anual! Como a gente chega nisso? A gente pega um funcionário que está produzindo $100 \%$ da sua capacidade, tá? Então, ele conhece a empresa, ele conhece sua função, ele sabe fazer suas atividades... Então, ele está ali produzindo! Se ele sair da EC2, a empresa tem uma série de custos com ele: vai ter o custo de procurar no mercado uma reposição (o custo de horas de trabalho das recrutadoras), tem o custo de horas de trabalho do gerente 
dele em buscar um profissional para substituí-lo, tem o custo de horas das pessoas que tiveram que me substituir provisoriamente, tem o custo de contratação desse novo funcionário que virá com o salário de mercado, tem o tempo que esse novo funcionário vai ter que ser treinado, tem o custo das pessoas que treinam esse funcionário e, ainda, tem o custo de um período da pessoa não estar plenamente produtiva por um período " $x$ "! Então, quando a agente coloca tudo isso no papel, a conclusão é a seguinte: a reposição de um funcionário é um salário dele anual, ou seja, pega o salário dele mensal e multiplica por treze! (Coordenadora de RH).

Além do valor econômico de investimento, os salários materializam o cálculo do valor relacional. Como mencionado, a EC2 faz uso do dispositivo "pesquisa de salários". O valor relacional é calculado a partir do momento que as definições dos salários pagos pela EC2 levam em consideração outras empresas do setor de tecnologias da informação através desse dispositivo. Simultaneamente, também o valor econômico relacional é calculado nos salários tendo em vista uma dimensão relacional interna à empresa.

A política salarial da EC2 é determinada, então, pela pesquisa salarial do mercado e o equity interno. Então, por exemplo, eu tenho a pesquisa, mas eu não posso deixar de levar em conta o time interno, né? A pesquisa pode até me dizer que eu posso pagar três mil pra alguém, mas se internamente eu pago dois e oitocentos... Então, assim, é sempre os dois componentes! Eu olho a pesquisa e todo ano eu tento colocar as pessoas que estão aqui dentro no patamar adequado indicado pela pesquisa. E assim, eu tenho condições de buscar as pessoas no mercado sem prejudicar meu equity interno. Porque se eu contrato uma pessoa e ela ganha mais do que aquelas pessoas do time que ela vai trabalhar, essas pessoas vão me questionar: "Pô! Eu faço a mesma coisa que ele, eu to aqui faz mais tempo, por que ele ganha mais do que eu?". Isso gera um problema interno, entende?

Como exatamente vocês reformulam a política salarial anualmente? Todo ano, então, a gente revisa a pesquisa de salários. Todo ano, a gente faz um levantamento de todos os salários pagos na empresa. Para, então, a gente trazer o maior número possível dos salários dos nossos funcionários para ficar de acordo com aquilo que a gente traçou como objetivo de política salarial a partir daquela pesquisa.

E esse objetivo formulado com base na pesquisa, ele é formulado localmente ou globalmente?

Globalmente. A EC2 globalmente busca estar num determinado ponto de mercado salarial no mundo todo! Por exemplo, o valor muda porque cada país tem a sua realidade de mercado, né? Mas a EC2 quer que no mundo inteiro, ela estar pagando num determinado ponto daquela curva normal de salários que é gerada pelos dados da pesquisa (Coordenadora de $\mathrm{RH}$ ).

Portanto, o cálculo dos salários é feito através do valor relacional levando em consideração outras empresas e os próprios funcionários da EC2. Ademais, o programa de benefícios da empresa também materializa um cálculo de valor relacional. 
Tem uma questão geracional que faz com que os benefícios sejam pensados de formas diferentes. Por exemplo, a geração mais antiga, de 35 ou 40 anos de idade pra cima - estamos falando da "geração x" - o que essa geração valoriza? Valoriza ter um emprego com segurança, antes de mais nada. Então, assim, ter um emprego numa empresa que tenha um status, conhecida, né? [...] Empresas que têm nome e que as pessoas possam identificar onde ele trabalha. Empresas, então, que tenham um pacote de benefícios bem tradicional, por exemplo, um bom plano de saúde e odontológico, seguro de vida, vale-alimentação e que eu posso lentamente crescer nessa empresa e me estabelecer! Esse é um modelo de "geração x", né? Onde a segurança vinha antes de outros quesitos. Quando é uma empresa como essa unidade da $\mathrm{EC} 2$, que tem uma média de idade de 28 anos - isso porque tem pessoas mais velhas na gerência que puxam a média pra cima - mas temos muitos, então, abaixo dessa média e ainda estudando, a gente percebe que aquele pacote de benefícios não segura ninguém! Não adianta um plano de saúde e odontológico maravilhoso! Não é isso que atrai essas pessoas! Atrai essas pessoas o seguinte: qual é a minha possibilidade de ganhar conhecimento ao longo desse ano e do próximo? É uma coisa mais curto prazo, entende? Eles pensam: "estou parado aqui ou estou gerando um desenvolvimento pra mim?". Claro que isso junta carreira e experiência profissional, mas também experiência de vida! Por exemplo, oportunidade de viajar, oportunidade de exercitar o inglês, oportunidade de conhecer outras culturas, oportunidade conhecimentos novos pra vida, entende? Então, essa coisa do desenvolvimento mais imediato da carreira, sabe? Mas da carreira não mais restrita à empresa, mas ao desenvolvimento do conhecimento da pessoa. E isso é bem mais importante pra geração mais nova do que um plano de saúde ou o que for... [...] Então, traduzindo isso na prática pros benefícios: nós temos que ter benefícios flexíveis na empresa! Porque não adianta achar que um plano de saúde pra toda família vai ter o mesmo valor pra esse recémformado, que está sozinho e quer viajar! Essa pessoa quer muito mais que parte de seu valor de benefício esteja voltado pra fazer um curso de línguas do que pagar um plano de saúde fantástico! Claro que nós temos que garantir um plano bom pra todos, mas com essa flexibilidade de escolher diminuir o plano e voltar isso pra outras coisas (Coordenadora de $\mathrm{RH}$ ).

Na tua opinião os benefícios oferecidos pela EC2 aos funcionários, eles têm atratividade para os profissionais no mercado?

Assim, atrai quando a gente pensa nos benefícios num sentido menos tradicional, por exemplo, a flexibilidade de horário aqui. A pessoa vê que é uma empresa voltada para o bem-estar do funcionário, sabe? Mas tem uma coisa que a gente peca: a previdência privada! Ela é muito baixa comparada com outras empresas. Mas mesmo assim, eu acho que o conjunto de benefícios atrai, mas também atrai o ambiente informal, o produto da EC2 que é conhecido no mundo de TI... Eu acho que são vários fatores. Os benefícios são importantes, especialmente quando tu pega pessoas que vêm de empresas menores (Recrutadora 1).

Na tua opinião os beneficios oferecidos pela EC2 aos funcionários, eles são atrativos para os profissionais no mercado? 
Sim, especialmente entre aqueles que vêm de empresas menores. Mas em relação a outras empresas de TI do mesmo porte da EC2, o nosso pacote de benefícios é equivalente. Mas, no final das contas, o nosso pacote de benefícios está bem competitivo (Recrutadora 2).

Por fim, ao compreender que os benefícios são um aspecto importante no recrutamento e na permanência do trabalhador na empresa, esses são calculados levando em consideração o quanto os profissionais se sentem satisfeitos com esses benefícios. Esse cálculo é feito, como se pode ler acima, tendo em vista perfis de profissionais definidos por faixas etárias ou por trajetórias com experiência anterior ou não em grandes empresas.

\subsection{Estudo de Caso 3: valores econômicos em formação da nova}

\section{economia}

A tabela abaixo expõe, esquematicamente, os valores econômicos que foram identificados como sendo calculados na demanda por força-de-trabalho da EC3 e as relações sociotécnicas e/ou dispositivos de cálculo que materializam esses valores.

Tabela 28 - Valores Econômicos Calculados pela EC3.

\begin{tabular}{c|c|c|c|c|c}
\hline & $\begin{array}{c}\text { Valor de } \\
\text { Uso }\end{array}$ & $\begin{array}{c}\text { Valor de } \\
\text { Investimento }\end{array}$ & $\begin{array}{c}\text { Valor } \\
\text { Relacional }\end{array}$ & $\begin{array}{c}\text { Valor } \\
\text { Físico }\end{array}$ & $\begin{array}{c}\text { Valor } \\
\text { Simbólico }\end{array}$ \\
\hline Cultura da Empresa & $\sqrt{ }$ & & & & $\sqrt{ }$ \\
\hline Estratégia de Inovação & & & & $\sqrt{ }$ & \\
\hline $\begin{array}{c}\text { Rotatividade e } \\
\text { Absenteísmo }\end{array}$ & & & & & \\
\hline $\begin{array}{c}\text { Perfil de Competências } \\
\text { Técnicas }\end{array}$ & $\sqrt{ }$ & & & & \\
\hline $\begin{array}{c}\text { Perfil de Competências } \\
\text { Comportamentais }\end{array}$ & $\sqrt{ }$ & & $\sqrt{ }$ & \\
\hline Salários & & & $\sqrt{ }$ & & \\
\hline Programa de Benefícios & & & & & \\
\hline $\begin{array}{c}\text { Planejamento para o } \\
\text { Atendimento à } \\
\text { Demanda }\end{array}$ & & $\sqrt{ }$ & & & \\
\hline
\end{tabular}

Fonte: Dados de Pesquisa de Campo.

Conforme mencionado, a EC3 estava passando um momento de consolidação de práticas de gestão de recursos humanos e, com isso, enfrentando uma transição entre o modelo de trabalho consolidado nas firmas adquiridas e o modelo que a EC3 queria estabelecer. Nesse sentido, é preciso considerar que na unidade pesquisada, o setor de recursos humanos era recente e, então, estava em plena fase de formação de suas tarefas e funções dentro da empresa. Relembrando.

$\mathrm{Na}$ EC3, o RH está em formação, isso não somente aqui como em todas as unidades da EC3. Um RH em formação significa assim: a 
Ou, ainda,

maturidade do RH na EC3 não é ainda tão avançada. Isso quando a gente fala em maturidade do $\mathrm{RH}$, não só o $\mathrm{RH}$, por exemplo, o processo de avaliação de desempenho, ele começou ano passado. [...] $\mathrm{Na} \mathrm{EC} 3$, tu fala em um processo de avaliação, as pessoas imaginam muito mais um "feedback" que acontece uma vez por ano, mas sem perceber o impacto que isso pode ter, todas informações positivas que isso pode ti agregar na tua carreira. E isso é uma coisa que falta maturidade do RH e de também as pessoas perceberem assim. Então, o RH da EC3 não é maduro! (Coordenador de RH).

O que aconteceu aqui foi a compra de duas empresas. Então era outros RH e outras culturas, outro jeito de trabalhar. E agora que a gente está formando a cultura da EC3.

Tiveram adaptações que vocês tiveram que fazer nesse processo?

$\mathrm{Na}$ verdade, toda essa unidade foi reformada fisicamente para atender a cultura da EC3. Então assim, você pode já ver os adesivos nas paredes, os banners... Todos com lembretes da cultura da EC3. Também, quando entramos aqui, a gente fez toda uma apresentação, o nosso presidente falando sobre a cultura e ele veio aqui na unidade. Então houve um processo pro pessoal começar a se integrar na cultura (Recrutadora).

Ao contrário do identificado na EC1, apesar de também recente neste caso, o RH tem uma atuação e inserção bem estáveis na rede sociotécnica da EC3. Esse contexto de maior estabilidade da rede sociotécnica e as características da firma (Capítulo 5) colocam-na mais próxima às particularidades da nova economia. Tal proximidade se refletirá nos valores econômicos calculados na sua demanda no mercado de trabalho.

A definição da cultura da empresa reflete o seu modo específico de cálculo, tanto do valor de uso como do valor simbólico na EC3.

Por exemplo, a gente é uma empresa de desenvolvimento de software que não é $100 \%$ formal, mas ao mesmo tempo, ela está longe de ser informal. Por exemplo, o informal que a gente vê em algumas empresas que o pessoal vai trabalhar de bermuda, de chinelo, tem sinuca no escritório, tem poltrona relax e trabalham sem horário rígido. Já aqui na EC3, não é assim. Nós temos mesas com baias, tem um horário que não é tão flexível, tem uma certa informalidade, por exemplo, a gente pode vir de camisa polo, pode vir de calça jeans... Isso é tranquilo! Mas tem uma formalidade! Então tem pessoas que não vão se adaptar. E aí, assim, as empresas anteriores, elas não eram muito diferentes da EC3. Então, nós não perdemos tanta gente nessa aquisição (Coordenador de RH).

A EC3 ainda está em processo de consolidação da sua cultura. A cultura da EC3 é muito baseada em pessoas, tá? Então, a gente procura pessoas que busquem muito a questão da inovação, né? A empresa fala muito nessa questão de ser [um nome que é utilizado pela EC3 para definir esse profissional que se preocupa com o negócio da empresa como um todo]. Então, a cultura da empresa busca esse tipo de pessoa que ela entende ser capaz de provocar inovações.

Como isso se reflete no dia-a-dia e na prática de gestão de pessoas? 
O que a empresa tem de práticas: a gente tem um processo de recrutamento interno. Sempre que surgi uma oportunidade, a gente prefere dar pra quem está dentro da empresa. Então, isso é uma forma da empresa sinalizar pro funcionário que ela aposta nele, que ele tem perspectiva de crescer dentro da empresa. A gente tem uma premiação do funcionário destaque do trimestre, né? Esse programa tem um nome, mas agora me deu um branco [risos]. Mas é um programa do funcionário destaque do trimestre, os gestores mesmos indicam as pessoas que fizeram uma coisa diferente, provocaram inovação numa atividade da EC3 e ,enfim, que foram [nome que é utilizado pela EC3 para definir esse profissional que se preocupa com o negócio da empresa como um todo]. Então, essas pessoas são premiadas. Tem ainda a festa junina e a festa de início de ano. São festas de confraternização da empresa (Recrutadora).

Constata-se nos extratos que a cultura da EC3 é definida em termos das características de seu modelo de gestão do trabalho (valor de uso). Todavia, esse mesmo modelo remete a uma identidade como firma dedicada à inovação. Isso se reflete especialmente quando, na fala da Recrutadora, essa definição de cultura engloba uma denominação que amalgama a empresa como um lugar que reúne um tipo especial de profissional (valor simbólico), ou seja, tal como também aparece no site da EC3: "Cultura: uma empresa de [nome que se dá aos profissionais comprometidos com a gestão e o negócio como um todo, não somente com suas tarefas] $]^{86}$, baseada em pessoas [capacitadas para] inovação". Portanto, os trabalhadores da EC3, segundo essa definição da cultura da empresa, estariam investidos de um status especial que se constitui na própria imagem ou identidade da empresa no mercado. Não se trata apenas de profissionais que se adaptam ao modelo de gestão do trabalho da firma (valor de uso), mas indivíduos que compartilhariam de um "espírito" que une a identidade da EC3 com a dos próprios profissionais que trabalham nela. Esse sentido que adquire, neste caso, a noção de cultura da empresa pode ser ainda identificado na seguinte fala:

Cultura de empresa não é, assim, "vou me adaptar ou não"! Assim, até esses dias, a gente teve um evento em São Paulo que era sobre cultura mesmo. Falamos sobre rotatividade por não aceitação da cultura e tal... Então, nós acabamos por falar do Schein [Professor e Pesquisador do Massachusetts Institute of Technology na área de gestão] que fala sobre cultura da empresa. Então, ele fala sobre as camadas da cultura. Imagina um iceberg: tem a camada externa que tu vê e tem a camada do meio que tu vê somente fazendo uma entrevista e depois de um tempo na empresa e tem aquelas questões que são da origem mesmo! Então tem pessoas que não se adaptam já ao ver aquela situação, depois de um tempo naquela empresa, e tem pessoas

\footnotetext{
${ }^{86}$ Não é citada a denominação que a EC3 utiliza para transmitir essa ideia de profissional envolvido e interessado com a empresa como um todo, porque identificaria a empresa e, então, infringiria o compromisso ético desta pesquisa sobre o anonimato das fontes.
} 
que não vão se adaptar pela própria origem do negócio e de como a empresa funciona, de como ela é! (Coordenador de RH).

Uma vez que a inovação serve como eixo que define a cultura da empresa faz sentido que ela não materialize o cálculo do valor de uso, isto é, ela não é tida pela empresa como uma tarefa específica realizada por um grupo particular de seus profissionais. Na EC3, a inovação materializa o valor físico. Retomando.

A EC3 está trazendo uma cultura de inovação baseada nos seus profissionais que devem ter a capacidade de fazer e de não somente se preocupar com aquela sua tarefa, sabe? Eu acho que essa é uma cultura que tem um direcionamento muito legal. A percepção que a gente vê é: Poxa! Pessoas que vão além da sua caixa! Que são [um nome que é utilizado pela EC3 para definir esse profissional que se preocupa com o negócio da empresa como um todo]. Que cuidam do seu lugar de trabalho! Que buscam inovação, que buscam algo novo que vai agregar algo diferente, que vai potencializar a forma como a EC3 vai buscar o crescimento e a sua sustentabilidade de negócio. Tudo isso é uma cultura baseada em pessoas, ou seja, valorizar nosso principal ativo, né? (Coordenador de RH).

Portanto, não se trata de entender a inovação como uma atividade, mas de se tornar uma empresa inovadora, reconhecida por essa capacidade, o que define seu modelo de negócios. A inovação não se liga a um perfil de competências técnicas para calcular um valor de uso, ou seja, ao contrário da EC1 que buscava profissionais com formação superior nas áreas de engenharia, por entendê-los capazes de cumprir a tarefa de desenvolver produtos em função de padrões tecnológicos adotados pelos clientes. Em razão de na EC3 a inovação materializar o valor físico em vez do valor de uso, a inovação está relacionada principalmente com um perfil de competências comportamentais, o qual, por seu turno, remete-se à estratégia comercial da firma como um todo e à sua cultura.

O que nós esperemos de todos que contratamos na EC3? Por exemplo, não é porque eu trabalho com recrutamento e seleção que eu não vou me preocupar com algo que eu vejo que está acontecendo lá no atendimento ao cliente. Se eu tenho uma ideia que pode melhorar aquilo, a pessoa vai lá e conversa com quem está trabalhando com aquilo, sabe? Pessoas que tenham um olhar pro todo, né? Uma visão sistêmica! E não só olhar pra minha "caixa", sabe? [...] Isso é um profissional que a gente valoriza que vai lá e faz sua contribuição, mesmo que não esteja dentro daquilo que ele faz, mas que faz a sua contribuição para empresa melhorar, inovar e crescer. Tanto que no site da empresa, se tu fores lá e ler, ela diz que esse profissional é o que provoca a inovação, sabe? (Recrutadora).

Em suma, não se trata da inovação como uma dentre outras tarefas do processo produtivo (valor de uso), mas se trata de contratar trabalhadores que tornem a EC3 uma empresa inovadora (valor físico). 
Assim entendida a questão da inovação, tornar-se possível depreender que o perfil de competências comportamentais materialize o valor físico, pois a partir dele é calculada a capacidade da firma de se tornar inovadora. Então, qual é esse perfil de competências comportamentais?

A gente busca muito aquela pessoa que tenha o brilho nos olhos, né? Pessoa que realmente tenha vontade! Isso eu acho que é o mais importante. O principal: a pessoa tem que querer trabalhar na EC3! Uma pessoa que a gente vê na entrevista que ela já olhou e gostou do ambiente da empresa. Também não pode ser aquela pessoa centralizadora, ela tem que saber trabalhar em equipe. Até porque, aqui dentro, todo mundo trabalha em conjunto, não tem aquela coisa do individual. Nós temos um lema dentro da empresa que é o "Let's share!", né? Então, tudo é compartilhado e todo mundo vai adquirindo conhecimento um do outro. E compartilhando, a pessoa vai montando o seu conhecimento também. Como a empresa está crescendo, a gente busca muito o espírito de liderança. Esse espírito é aquela pessoa que toma iniciativa, que corre atrás de objetivos. Até porque se a empresa quer dobrar de tamanho nos próximos anos, nós temos que ter pessoas que tragam pra si a liderança em direção a esses objetivos. Então é liderança, trabalho em equipe e espírito de inovação são as principais competências comportamentais que a empresa procura nos candidatos. Essas competências comportamentais, vocês buscam em todos os candidatos para todos os cargos?

Sim, mas claro que dependendo do nível do cargo, as exigências, nesse sentido, elas são maiores. A empresa tem as competências comportamentais definidas: foco em resultado, visão estratégica, orientação para com o cliente (atender bem o cliente tanto externo como interno) e as outras são as que eu ti falei, liderança, saber colaborar e espírito de inovação (Recrutadora).

O perfil tem que refletir parte do que a empresa busca e parte do que o gestor é! Então, por exemplo, quando eu procuro um perfil da EC3, que é conforme a cultura da empresa, eu tenho que buscar uma pessoa que queira crescer, que não busque se acomodar, mas que busque sempre se desenvolver. Então, isso me faz olhar muitas vezes para o mercado mais jovem, né? Isso não quer dizer que eu não possa buscar um cara de 30 ou 40 anos com esse perfil! Mas de fato, eu preciso de pessoas que tenham esse interesse de ampliar seu tamanho enquanto profissional! E não ficar somente na sua "caixa"! Então, essa é uma das características. A outra é uma pessoa que tenha muito o sentimento de dono do negócio, de se importar muito com aquilo que está fazendo, $[\ldots]$ não vou dizer que é um perfil de perfeccionista, mas uma pessoa que tenha muito interesse de que o seu produto, a sua área, seja a melhor e que ele vá crescer quando isso se refletir em verdade! Isso é um perfil! Pessoas com muita pegada, com muita vontade! Com muito desejo de trazer alguma coisa nova! Só que a gente sempre tenta alinhar com o perfil do gestor. E o que isso quer dizer? Por mais que eu busque essas características... [...] Eu posso ter um gestor que prefira trabalhar com homens e outros com mulheres, por exemplo. Outro ainda, que queiram equilibrar a sua área nesse sentido. Um gestor que prefira um cara mais agitado, mais expansivo e outro gestor um cara mais calmo, mais introvertido - mas ser calmo, 
ser introvertido, não quer dizer que tu não queira crescer, que tu não queira trazer algo novo e que tu não queira ser reconhecido por isso. Então, eu tenho gestores que trabalham melhor com essa pessoa porque também têm certo nível de introspecção. Então, eu tenho que sempre codificar isso aí, ou seja, eu tenho que pegar um perfil que é o da EC3 e pegar o perfil que se adapta com o gestor da vaga. É assim que a gente tenta compor o grupo, a equipe! Porque a EC3 entende, enquanto empresa, que ela precisa investir nas pessoas (Coordenador de RH).

Compreende-se que, além do valor físico, esse perfil materializa o valor de uso, isto é, além desse perfil produzir as condições para a EC3 se tornar uma firma inovadora, ele também determina se o profissional tem capacidades para se adaptar ao modelo de gestão de trabalho da EC3 e, mais especificamente, com o gestor da área na qual a vaga do candidato está alocada.

Também se identifica uma definição de perfil de competências técnicas expressando o valor de uso calculado pela EC3.

Na parte técnica vai depender muito da atividade, né? Porque a gente tem uma divisão na unidade em termos de "torres". Então, eu tenho a torre que é focada na parte de desenvolvimento [de softwares] mesmo. Então, nessa torre, tu tens as atividades de upgrade de programa, ela pega aplicativos de desktop e adapta para tablets, aplicativos para transmitir dados via SMS... Então assim, eu preciso de pessoas que realmente conheçam muito tecnicamente. Aí eu posso, dependendo do segmento, eu preciso gente que mexa com "dot Net", Java... Então assim, tecnicamente, essa torre é de pessoas que precisam conhecer mais da área técnica de desenvolvimento de software. A outra torre é a área de engenharia. Essa torre faz praticamente todos os testes de qualidade. Então, as pessoas não precisam conhecer muito codificação, mas elas precisam conhecer análise de teste, casos de testes. $\mathrm{O}$ que é um teste? $\mathrm{O}$ teste não entra na parte de programação. $\mathrm{O}$ teste entra em todas as funcionalidades daquilo que alguém criou. [...] Então, eu tenho que ter pessoas com conhecimento em análise de teste. Essas pessoas também acabam criando toda a padronização dos sistemas pra enviar pros clientes e, também, elas vão treinar pessoas de uma outra torre, que é a torre de "helpdesk". Essa torre dá o prontoatendimento pra clientes e também faz pequenos reparos. Então, geralmente são pessoas mais novas que estão começando na carreira. Eu também ainda tenho a "fábrica", que são as pessoas que fazem as customizações. O cliente recebe um produto da EC3, mas quer que se alterem coisas dentro daquele produto. Então, nessa área, eu tenho que ter profissionais que saibam de inovação e desenvolvimento também, mas com uma abordagem de cliente muito maior. Porque no desenvolvimento, eu posso ter aquele cara introspectivo e fechado, mas o profissional da "fábrica", esse profissional não pode ser assim porque ele tem que conversar com cliente. Eu também tenho meus produtos voltados para programas na área financeira. Então, aí eu tenho que ter profissionais que saibam também muito de negócios! Porque, nesse caso, o cliente pode, por exemplo, dizer que está entrando no sistema pra fazer um empréstimo e ele acha que o problema é que o sistema não está "conversando" com o BACEN 
[Banco Central]. Então, eu tenho que ter pessoas com conhecimento técnico, mas também de negócios (Coordenador de RH).

Vocês, então, têm dois perfis técnicos de profissionais: um mais ligado à parte de desenvolvimento de software e outro que seria um analista de negócios?

Então assim, nós temos dos segmentos de clientes: o de saúde e o financeiro. Então, o perfil de negócios é de profissionais que já trabalharam em um desses segmentos. Então, é um profissional de TI que, por exemplo, já trabalhou numa cooperativa de crédito. Ou, então, alguém que já trabalhou num grande hospital, convênios médicos... Então são profissionais que têm conhecimento no negócio, mas são pessoas do TI. Depois tem os profissionais da área técnica mesmo: desenvolvedor, analista de teste, analista de qualidade e assim vai... (Recrutadora).

Esses perfis materializam um valor de uso porque determinam quais são as competências técnicas que o profissional deve ter para exercer um dos dois grandes grupos de atividades que organizam a produção dos softwares da EC3. Um dos perfis de competências técnicas tem como valor de uso a capacidade de realizar atividades mais voltadas ao relacionamento com o cliente e, no outro perfil, o valor de uso reside em desempenhar atividades diretamente relacionadas à tecnologia. Ainda sobre esse último perfil técnico, cabe destacar a necessidade da EC3 em termos de proficiência em linguagens de programação utilizadas por ela, quais sejam: Java e Dot Net Framework. Neste ponto o valor de uso é bem evidente: para a firma desenvolver os softwares que desenvolve, é preciso ter profissionais que saibam programar nas linguagens em que esses softwares são concebidos.

A rotatividade revelou-se uma preocupação apenas moderada para EC3, em que pese o seu nível fosse maior que o mencionado nas outras empresas estudadas.

Vocês se preocupam com a questão da rotatividade?

A gente trabalha com dois itens de controle: "Turnover" e "Attraction". O primeiro, pra EC3, é a rotatividade. E o segundo é quantidade de pessoas que saíram da empresa e a gente precisa repor. Então, a gente está sempre observando isso aí porque, desculpa a palavra [risos], o mercado está meio prostituído; não é bem essa palavra que eu ia usar, mas vamos lá, porque você tem pessoas sem muita experiência, formação e conhecimento pedindo salários ou recebendo propostas muito grandes. E aí o mercado acaba por ficar inflacionado, né? $\mathrm{E}$ isso acaba gerando uma certa rotatividade. A questão é: no mundo da TI, tu tem empresa de três, de 10 , de 20 , de 200, de 1.000 funcionários! Essa rotatividade, eu acredito, que ela não vai cessar, porque tem cada vez mais pessoas entrando no mercado, mas eu acredito que ao longo da carreira as pessoas vão estabilizando. Por quê? Muitos caras que saíram da EC3, eles querem voltar! E eu por política da empresa, eu não posso trazer de volta. Eu tenho pelo menos 18 meses pra poder trazer de volta. Então, o que acontece? É um mercado que está em alta, principalmente na área técnica, e a rotatividade acontece muito em função disso, né? Então, a gente tem 
essa preocupação e a gente acompanha é claro! A gente tenta manter as ações de clima em dia, por exemplo. Tentamos trazer pra unidade um sentimento de qualidade de vida. Tudo isso pra tentar evitar ao máximo a rotatividade porque ela significa que mais treinamento e mais conhecimento técnico vão embora da empresa. Então, a gente tenta controlar essa questão, tanto via corporativo com via unidades.

Tu tens uma ideia qual é a taxa de rotatividade na unidade?

Na nossa unidade hoje, ela tem uns $20 \%$ de rotatividade, eu acredito. Não é baixa, ela é alta, né? Mas isso na área de programas financeiros; já na saúde, a rotatividade está bem baixa, uns $5 \%$. Por quê? Porque possivelmente, a área financeira, o cliente e o tipo de negócio sejam mais estressantes. Então, nós estamos ainda analisando pra ver o quê que é (Coordenador de RH).

Eu não sei dizer como está a nossa rotatividade com relação ao mercado, mas nós temos uma rotatividade.

E ela é o suficiente para vocês se preocuparem?

Sim, sim! Nós estamos analisando o porquê das pessoas que estão saindo da empresa (Recrutadora)

Se a rotatividade é uma preocupação na empresa, ela não orienta um cálculo em

termos de recrutamento e seleção de funcionários. O coordenador menciona que essa é uma questão importante porque ela significa a perda de custo de investimento em treinamento feito pela empresa e também de conhecimento, da expertise que o profissional leva ao deixar a firma. Essa visão sobre a rotatividade como perda de um investimento, também pode ser identificada nas falas que tratam da perda dos funcionários que estavam nas empresas adquiridas.

Como ficou a questão de funcionários que eram das empresas que foram adquiridas para formar essa unidade? Houve funcionários que não se adaptaram?

Teve, teve funcionários que saíram. Esse ano [2012], a gente deve ter tido uma rotatividade bem expressiva. A gente divide os desligamentos voluntários e os involuntários, tá? O primeiro é o funcionário que pede demissão e o outro é a empresa que demite. Os involuntários são muito mais com relação a fatores de desempenho do funcionário que é um processo natural de qualquer empresa. Mas o voluntário, a gente também tem! E no voluntário, muitos é por causa de não adaptação ao modelo novo ou não aceitação do novo modelo! Porque quando eram as empresas menores, elas acabavam sendo um pouco mais informais, conversar com gestores ou diretores era mais fácil, a resolução de problemas talvez fosse mais rápida! Mas isso é natural em empresas menores, né? Em empresas grandes como a EC3, tu tem mais processos definidos, maior padronização e com certeza alguns não se adaptaram. Aí entra também, as diferenças de cultura de empresa, que eu já ti falei. [...] Mas, em termos de cultura, de ambiente nem tanto informal de trabalho como existe em algumas empresas de TI, as empresas adquiridas, como eu já disse, não era tão diferentes da gente. Então é por isso que não perdemos tanta gente assim. $\mathrm{O}$ lado negativo disso é que a empresa perde um ativo, alguém com experiência que não precisa ir lá e buscar no mercado, sabe? (Coordenador de RH). 
Assim sendo, constata-se que há uma presença, mesmo se ainda pouco definida, da rotatividade expressando o valor de investimento. Talvez a baixa clareza com que esse problema aparece para os agentes humanos do RH ocorra por ser este um setor recente na unidade e, por isso mesmo, os dispositivos de cálculo que medem a rotatividade não estarem completamente desenvolvidos. Ademais, como as relações sociotécnicas que lidam com a rotatividade não estão plenamente formadas, essa questão ainda não materializa o cálculo desse valor de investimento nas operações que têm lugar no mercado de trabalho.

Na EC3, o valor de investimento calculado pela firma no mercado de trabalho está materializado antes no planejamento da capacidade da firma em atender à demanda de clientes.

O número de pessoas dentro de uma unidade é definido no começo de cada ano, né? Claro que se eu tive um crescimento em função de um novo negócio que me exija mais pessoas, aí isso muda. De fato, hoje é assim, eu, o coordenador de RH, não posso abrir uma vaga nova, eu posso suprir substituições. Para abrir uma vaga nova, é assim que funciona: o gestor da área que identifica a necessidade de mais uma pessoa e fala com seu coordenador; esse coordenador vai falar com um diretor corporativo que, então, fala com um vice-presidente sobre a necessidade de se ter mais essa vaga. Vai lá em cima mesmo! Eles não abrem vagas por qualquer motivo. Eles avaliam mesmo o impacto financeiro, sabe? (Coordenador de RH).

Tu mencionaste que a intenção da EC3 é quase dobrar o número de funcionários até o ano que vem nessa unidade...

Isso! Contratar mais gente, e principalmente da área técnica, para quase dobrar o tamanho da unidade. É que assim, a gente fechou contrato com dois clientes bem grandes, né? Um deles é uma grande empresa de varejo, então somente nesse projeto, serão quarenta novas contratações! Aí tem mais uns bancos que estamos fechando projeto, aí já são mais vinte contratações. Então, a projeção para o ano que vem [2013] é crescer bastante mesmo. A demanda de contratação depende muito mais do escopo de projeto. É o projeto que vai definir se eu preciso contratar pessoas pro desenvolvimento ou pra prestação de serviços ou pra qualidade; e isso é a área do projeto que me passa e aí a gente vai buscando as pessoas (Coordenador de RH).

Constata-se o valor de investimento sendo calculado em função da expectativa de ganhos de produtividade com a contratação de determinados tipos de profissionais que, por sua vez, são avaliados como capazes de desempenhar as atividades necessárias ao atendimento das demandas de novos clientes em termos de projetos.

Provavelmente a questão salarial entre nesse planejamento de contratações compreendido como necessário para a firma atingir certo nível de produtividade de acordo com a demanda dos clientes; porém, na EC3, obteve-se autorização para 
realização de poucas entrevistas e, por isso, é prudente apenas cogitar essa hipótese em vez de verificar esta questão.

Mesmo assim, verifica-se que a questão salarial, através da menção do dispositivo de cálculo "pesquisa salarial”, revelou a presença do valor relacional sendo calculado pela firma nas suas operações no mercado de trabalho.

\section{Como vocês fazem para definir salários?}

A gente tem uma pesquisa de salários bianual feita pelo corporativo da empresa. Nela é feita uma média de mercado. Nessa média de mercado a gente vai definir, por exemplo, hoje a EC3 tem seis tetos salariais por níveis de carreira, então, um analista I, ele tem seis tetos salariais.

Nessa pesquisa, vocês selecionam empresas que são as principais concorrentes?

A pesquisa de fato, ela não é feita pela gente. A pesquisa é feita por uma empresa terceira e aí geralmente, eles direcionam a pesquisa para o mundo de TI, né? Eles não comparam com outros segmentos, mas [...], por exemplo, quando eles fizeram pela última vez a pesquisa pro mundo de TI, a gente pediu pra eles incluírem bancos, cooperativas de crédito e algumas grandes empresas de varejo; por quê? Porque eu posso perder profissionais pra esses caras! Então, é importante ter uma visa deles também (Coordenador de RH).

Tal como constatado no caso anterior, a utilização do dispositivo da pesquisa salarial revela o cálculo do valor relacional por parte da rede sociotécnica da EC3. Ao contrário da EC2, aqui não foi identificado nas falas dos entrevistados, o cálculo do valor relacional voltado para dentro da firma e, sim, apenas a dimensão relacional sendo considerada fora da empresa, no mercado de trabalho.

Por fim, a definição do programa de benefícios da EC3 também apresenta a perspectiva relacional a respeito dos profissionais que ela busca contratar e reter dentro da firma. Conforme tratado no capítulo anterior, as entrevistas mostram que os valores de itens que compõem o programa de benefícios da EC3, especialmente vale-refeição, são avaliados pelos agentes humanos do RH em relação ao que é pago por outras empresas. Ademais, benefícios não tradicionais, mais ligados ao ambiente de trabalho, são calculados em termos de valor relacional, mas não tendo como referência o mercado de trabalho e, sim, a capacidade desses benefícios reterem os funcionários da EC3.

\subsection{Estudo de Caso 4: valores econômicos e economicamente}

\section{relevantes}

A tabela abaixo expõe, esquematicamente, os valores econômicos e o economicamente relevante que foram identificados como sendo calculados na demanda 
por força-de-trabalho da EC4 e as relações sociotécnicas e/ou dispositivos de cálculo que materializam esses valores.

Tabela 29 - Valores Econômicos Calculados pela EC4.

\begin{tabular}{c|c|c|c|c|c}
\hline & $\begin{array}{c}\text { Valor de } \\
\text { Uso }\end{array}$ & $\begin{array}{c}\text { Valor de } \\
\text { Investimento }\end{array}$ & $\begin{array}{c}\text { Valor } \\
\text { Físico }\end{array}$ & $\begin{array}{c}\text { Valor } \\
\text { Simbólico }\end{array}$ & $\begin{array}{c}\text { Valor } \\
\text { Moral }\end{array}$ \\
\hline Cultura da Empresa & $\sqrt{ }$ & & & $\sqrt{ }$ & $\sqrt{ }$ \\
\hline Estratégia de Inovação & & & $\sqrt{ }$ & \\
\hline $\begin{array}{c}\text { Rotatividade e } \\
\text { Absenté́smo }\end{array}$ & & & & & \\
\hline $\begin{array}{c}\text { Perfil de Competências } \\
\text { Técnicas }\end{array}$ & $\sqrt{ }$ & & & & $\sqrt{ }$ \\
\hline $\begin{array}{c}\text { Perfil de Competências } \\
\text { Comportamentais }\end{array}$ & $\sqrt{ }$ & & $\sqrt{ }$ & & \\
\hline Salários & & $\sqrt{ }$ & & & \\
\hline Programa de Benefícios & & $\sqrt{ }$ & & \\
\hline $\begin{array}{c}\text { Planejamento para o } \\
\text { Atendimento à } \\
\text { Demanda }\end{array}$ & & $\sqrt{ }$ & & & \\
\hline
\end{tabular}

Fonte: Dados de Pesquisa de Campo.

Conclui-se que a EC4 nas suas operações de cálculo no mercado de trabalho, orienta-se tanto por valores econômicos identificados com a nova economia como por uma modalidade de valor economicamente relevante. Dada essa particularidade em relação às demais empresas pesquisadas, primeiro serão analisadas quais relações sociotécnicas materializam o cálculo na demanda da EC4 no mercado de trabalho, desse valor economicamente relevante.

Como valor economicamente relevante foi identificado um valor moral na forma de justiça social. No que se refere diretamente às operações de cálculo da EC4 que têm lugar no mercado de trabalho, esse valor se materializa no "perfil comportamental".

Baseado nessa cultura da empresa que tu descreveste, existe ou qual é o perfil de profissional que vocês procuram contratar?

Eu acho que assim, não pode ser uma pessoa muito presa a processos porque isso aqui muitas vezes é uma bagunça. Então, tu tem que saber ti organizar da tua forma. Então, tem que ser uma pessoa que não precisa de alguém dizendo o que ela tem que fazer ou de normas ou rotinas a serem seguidas. Ela tem que ser mais aberta para as coisas, entendeu? Tem que ser uma pessoa com um cunho social! Não adiante tu chegar aqui e dizer que não está nem aí, porque tu não vai passar no nosso processo seletivo. [...] claro! Não é algo que a gente cobre das pessoas, mas é algo que aqui todo mundo tem seu projeto, mas também se envolve com algo mais, por exemplo, toda semana, nós temos o "lunch and learn", que é um almoço onde as pessoas dão espécie de palestras para os próprios funcionários; e tem gente que organiza isso sem serem da parte da gestão, sabe? [...] Também se envolver com nossos projetos sociais. [...] Comportamentalmente, a gente espera contratar pessoas que tenham um olho que enxergue não somente o seu redor, sabe? Aquilo que eu ti disse sobre que a gente 
até tem um termo, que é "não queremos estúpidos" [risos]. Então, o cara não pode ser tipo - "Ah! Eu me acho o tal, o melhor..." - ou "Não to nem aí pro mundo". Ela tem que ser uma pessoa bacana! (Organizadora de Seleção).

A entrevista comportamental, vocês chamam de valores e cultural, não é?

Sim.

Como você avalia o candidato nessa entrevista?

[...] Bom, nós temos um problema grande na área de TI que é não ter muitas mulheres e negros. Aí, eu pergunto como ele acha que a gente pode resolver esse problema. E tem pessoas que falam que não estão nem aí com isso, entendeu? E isso, pra mim, isso não bate com os valores da empresa. Outro exemplo de pergunta que eu faço: "Você é um desenvolvedor que está trabalhando num projeto pra urna eletrônica que rodou as eleições no Brasil. Depois que saiu o resultado das eleições, tu descobriu que tinha um erro muito grave, que mudaria o resultado da eleição. O que você faria?". Tem muitos que ficam "sabonetiando", sabe? Falaria com o chefe, mas se ele não falasse, eles deixariam assim. E tem outros que não! Que dizem que se o chefe não falar, eles vão pra mídia, vão botar a boca no trombone, entendeu? Então, isso é uma postura que a gente avalia numa pessoa! Então, a gente coloca esse tipo de cenário pra avaliar como é a pessoa. Outro exemplo, a EC4 tem um grupo de valores e a gente pede pro candidato descartar um deles e explicar o porquê que tu escolheu tirar esse valor. E aí tu tenta ver o "racional" que a pessoa utilizou pra escolher tirar aquele valor. Até assim: "Quais livros, não vale técnicos, tu tem lido ultimamente?". Pra ver se a pessoa é ambientado com a realidade, sabe? (Analista de Teste e de Negócios).

O valor moral de justiça social é um dos elementos que definem a cultura da empresa e ele é, por isso mesmo, avaliado no candidato. Constata-se que a cultura incorpora princípios morais de responsabilidade social que orientam o modelo de trabalho e as estratégias de negócios da EC4, ou seja, não se trata de uma atividade em separado que a empresa faz e que poderia ser dominada como "responsabilidade social". Os extratos evidenciam que a justiça social é um valor moral que orienta as operações de cálculo da EC4 no mercado de trabalho, especialmente na seleção.

É tão orgânica essa relação entre valor moral de justiça social, como um dos elementos que definem a cultura da empresa, e o tipo de profissional demandado e valorizado pela empresa, que ela se expressa utilizando-se um nome para o profissional da empresa: o "EC4Worker" 87 . Portanto, o EC4Worker é o profissional comprometido com o valor moral assumido pela empresa de "mudar o mundo".

A cultura da empresa, especialmente em função da presença do valor moral, também materializa o cálculo do valor econômico simbólico, isto é, a demanda por

\footnotetext{
${ }^{87}$ Para preservar o anonimato da empresa, não é citado o termo de fato, mas ele é formado pelo nome da empresa amalgamado com a palavra "trabalhador" em inglês.
} 
profissionais da empresa também tem que simbolizar essa identidade da firma como socialmente responsável através, de um lado, pela contratação de pessoas identificadas com a causa da empresa de melhorar e mudar o mundo através do software e, de outro, nas metas de contratar "minorias" e "excluídos".

O mercado no Brasil está bem aquecido. A gente tem sempre clientes entrando em contato com a empresa. Então é difícil fazer, como a empresa fez nos Estados Unidos, de parar de contratar totalmente homens brancos, mas a gente sempre tenta balancear aqui. Por exemplo, a gente tem a meta de aumentar o número de mulheres e de negros. Então, nos eventos que a gente faz, a gente procura fazer com que essas estratégias aconteçam. Por exemplo, a gente tem feito muitos eventos pra mulheres! A gente fez um evento de programa de código só para mulheres, por exemplo. E nesses eventos, elas são chamadas a se candidatarem na EC4. Então, a gente toma certas iniciativas pra que essas estratégias se convertam em pessoas recrutadas, né? Também tem a questão de a gente ir para regiões aonde tem uma diversidade maior! Então, a gente está fazendo um tour por todo Nordeste agora, fazendo eventos seguidos de recrutamento. Então, no planejamento de onde fazer esses eventos entra a questão de ir para regiões que tragam maior diversidade. [...] Por exemplo, em relação à exigência de inglês - aí entra a questão da empresa ser revolucionária [...] - a gente tem que contratar pessoas que não tiveram o privilégio de estudar numa escola que tinha inglês. A gente tem que ir em comunidades pobres e vê que essas pessoas podem ser o nosso futuro. Então, a gente tem um plano de no ano que vem [2013] trazer mais diversidade e quebrar alguns paradigmas de que tem que contratar pessoas que saibam inglês (Diretor de RH).

A cultura da empresa também acaba por materializar o cálculo do valor de uso.

Nesse sentido, os chamados "métodos ágeis" definem o modelo de gestão de trabalho que, ao seu turno, implicam no cálculo do valor de uso, pois o profissional deve ser capaz de desempenhar suas funções nessa metodologia.

Constata-se que esse perfil comportamental materializa o cálculo tanto do valor de uso para EC4 - características que o trabalhador deve ter para se adaptar e desempenhar suas atividades dentro das condições do modelo de gestão de trabalho como do valor físico e do simbólico, no sentido desse perfil permitir a empresa ter pessoas comprometidas com a meta de "mudar o mundo através do software". Portanto, tal relação entre cultura da empresa e um tipo de profissional adequado para essa cultura em termos de valores de uso, simbólico e moral, é, então, expressa em um perfil de competências comportamentais.

Esta meta de "mudar o mundo" também implica na ideia de inovação, basta compreender que o próprio desenvolvimento de software capaz de produzir tal alteração na realidade, já é em si uma inovação. Entretanto, isso somente se materializa no cálculo do valor físico nas operações da EC4 que têm lugar no mercado de trabalho, 
quando se analisa que a inovação implica em demandar trabalhadores com interesse no continuo aprendizado e com experiência e familiaridade nas tecnologias de desenvolvimento de software.

\section{Qual o perfil comportamental que a empresa valoriza?}

A empresa tem três pilares que são coisas que ela também procura nos candidatos. Os pilares são: "negócio sustentável", "excelência em tecnologia" e "justiça social". Então, nós precisamos de pessoas que tenham esse pensamento de consultoria, como comunicar com o cliente, essas coisas... Segundo, nós sempre procuramos pessoas que tenham muito interesse nas tecnologias! Que sempre estão procurando as novidades no mundo da tecnologia. Que vive sempre experimentando as linguagens de programação. Porque aqui, nós sempre temos treinamentos tecnológicos feitos por funcionários para outros funcionários. Então, pessoas pró-ativas na área de tecnologia. $\mathrm{O}$ terceiro pilar é a justiça social; então, tem que ser pessoas que têm interesse em usar seu conhecimento para melhorar o mundo, por exemplo, na sua cidade ou no país. Porque nosso fundador fez a empresa para que os conhecimentos das pessoas ajudem a sua comunidade. Então, as entrevistas são feitas para avaliar se o candidato encaixa nesses pilares da EC4 (Recrutadora 2).

É esse envolvimento do profissional com as tecnologias que serve para EC4 calcular o valor físico, ou seja, se a empresa está contratando trabalhadores que produziram inovação.

Além do perfil comportamental, a EC4 também tem perfis de competências técnicas para os seus cargos. Esses perfis estão distribuídos entre as quatro modalidades de carreiras existentes na empresa - relembrando, dois tipos de desenvolvedores, analista de teste, analista de negócios, gerente de projeto e gerentes de interação. Não se teve o acesso ao sistema informático que define exatamente as competências técnicas e os níveis de experiência profissional para os diferentes cargos de cada carreira, mas constata-se que esses perfis materializam um cálculo de valor de uso porque, quando examinado o "Plano de Cargos e Salários" da EC4, identifica-se que cada nível de senioridade dos cargos, nas diferentes áreas de carreiras da empresa, determinam níveis e tipos de competências técnicas para exercer atividades que a EC4 espera do profissional. Essas competências técnicas estavam diretamente ligadas ao valor de uso, isto é, às competências que o profissional deveria ter para desempenhar o que a empresa necessita e espera daquela pessoa, naquele cargo. Isso ficou evidente quando mencionado que o aumento do nível salarial ocorre em função do acúmulo de competências técnicas, não da passagem para um cargo de gestor.

A única coisa que a gente tem certeza é que pra pessoa crescer na $\mathrm{EC} 4$, ela não precisa virar gerente. Isso é uma coisa que eu vejo nas grandes empresas. Nelas têm muitos desenvolvedores excepcionais 
que, por causa de salário, viraram gerentes. [...] Então, elas perdem excelentes desenvolvedores e ganham gerentes medíocres. A gente tem desenvolvedores na EC4 que estão 17, 20 anos! E provavelmente ganham mais do que eu e vão sempre ganhar mais do que eu porque merecem em função do nível de excelência que apresentam na sua função (Diretor de RH).

Contudo, tal como as outras empresas estudadas, a EC4 também apresenta uma relação entre o planejamento da empresa para atender a demanda de clientes e as contratações de funcionários calculando o valor de investimento. Todavia, o diferencial da EC4 em relação ao demais caso é a menção de que o planejamento para atender a demanda dos clientes, não deve comprometer o nível de exigência da empresa em termos de qualidades técnicas e comportamentais que ela espera dos profissionais para trabalhar na EC4.

O perfil que a gente procura por si só, ele já é um perfil difícil de ser encontrado no mercado! Porque, uma coisa até que eu sinto bastante orgulho daqui da EC4, é o fato de que agente não contrata por contratar. Eu já vi várias empresas, especialmente empresas desse segmento de consultoria, que as empresas vendem um projeto e após a venda desse projeto, elas saem à caça de consultores. Aquela coisa: "Ah! Eu vendi o projeto pra dez pessoas e eu preciso de dez pessoas aqui dentro! E eu só achei seis! Então, eu vou contratar quatro de qualquer jeito porque isso vai me dar lucro de qualquer jeito no final do mês!". E eu já vi várias situações aqui, onde projetos foram adiados porque a gente não achou pessoas que realmente se encaixassem com o nosso perfil! A gente inclusive achou pessoas que, do ponto de vista técnico, eram boas, mas só que elas não se encaixavam com nosso perfil de empresa. E aí a gente falou com o cliente que não poderíamos fazer esse trabalho. Então, a gente não está aqui pra fazer no mercado o que se chama de "body shopping", ou seja, contratar uma pessoa pra simplesmente gerar uma receita pra gente por um tempo determinado e, depois desse tempo, a gente simplesmente descarta a pessoa. Não é esse o nosso modelo! Por causa disso, o nosso processo de seleção acaba sendo bem mais criterioso e ele tem uma participação das pessoas muito maior. Também a expectativa em torno do candidato é maior! Então, a gente acaba rejeitando muitos candidatos que, mesmo do ponto de vista técnico sejam bons, mas do ponto de vista de valores, eles não são compatíveis com a empresa (Diretor de Escritório).

Entretanto, há um cálculo que implica em considerar contratar trabalhadores cujo valor de investimento remete ao planejamento comercial da empresa.

Como a empresa, apesar desse sistema de demanda permanente, planeja as metas de contratação?

$\mathrm{Na}$ EC4, qualquer decisão, ela precisa ser bem socializada, antes de ela ser implementada. Então tem todo um processo de venda interna, quando a pessoa quer fazer alguma coisa. Mas então, nós temos já um histórico de planejamento que a gente já viu o quanto de pessoas a gente pode contratar por mês. Então, a gente sabe que temos um histórico de que nós conseguimos contratar entre cinco a oito pessoas por mês. Então, o planejamento usa esse histórico também. A gente 
usa isso para ver assim: "Bom, nós temos 200 ou 300 pessoas nessa região, nesses escritórios, e nós precisamos chegar a ter tanto mais pessoas". Então, com esse histórico de contratações, a gente vai demorar uns três ou quatro anos para atingir esse número a mais de pessoas na empresa. Então, a gente faz as projeções com base nas lições aprendidas. Isso também é decidido com o pessoal de RH, pois a gente precisa saber quantas pessoas estão pra sair - é o que a gente chama de "attrition", né? O recrutamento também entra nisso aí. Entra também a parte de demanda e oferta, ou seja, a gente vê quais projetos vão entrar e o que eles vão precisar em termos de pessoas com essas e essas senioridades. Aí entra saber não só quem vamos contratar, mas também quem pode mudar de nível de senioridade - isso é o RH que passa pra gente. O pessoal entra com as informações todas de custos de pessoal, escritórios, equipamentos... [...] A [equipe de] finanças dá bastante subsídios pra ver o que já aconteceu de gastos reais, que a gente precisa pra projetar o custo fixo. $O$ recrutamento também trás as projeções sobre as pessoas que se está conseguindo trazer. Mobilidade também entra: ver as pessoas da EC4 que a gente está trazendo e, também, mandando pra fora do Brasil! Porque isso impacta também. [...] Então, isso é bem socializado! (Diretor de RH).

O que diferencia a EC4 das demais empresas nesse aspecto é que por ela ser uma consultoria e desenvolvedora de software por encomenda, cada cliente é um projeto e um tipo de demanda. Assim sendo, o retorno do investimento que representa contratar um profissional não é medido em termos de aumento de produtividade para atender aos níveis de demanda no mercado de produtos; o valor de investimento é calculado no mercado de trabalho em termos de profissionais capazes de trabalhar, aprender e se adaptar a um maior número de tecnologias e técnicas e, deste modo, levar a EC4 a ganhar na sua capacidade de se adaptar às necessidades de cada cliente.

Por conseguinte, os salários também se inserem nessa lógica do cálculo do valor de investimento; mas, ao contrário das demais empresas estudadas, os salários não se materializam num cálculo de valor econômico relacional. A razão disso está na ênfase da empresa pagar de acordo com o número e o nível de senioridade que o candidato possui em termos de competências técnicas. Portanto, na EC4, no que se refere aos salários e ao programa de benefícios, esses materializam apenas o cálculo do valor econômico de investimento.

A gente até tem um sistema de cargos e salários, nós até fizemos a revisão esse ano das faixas, mas a EC4 não paga acima do mercado! Isso já é conhecido de todo mundo que entra! Porque a gente propõe um ambiente diferenciado. Então, essa experiência de aprendizado, a oportunidade de trabalhar junto com pessoas que são referência no mercado, isso é mais valioso que um contracheque. A gente não distribui bônus no final do ano porque a gente pega o lucro e investe em iniciativas como "business development" ou projetos sociais de clientes que não podem pagar (Diretor de RH). 
Os salários são definidos de acordo com as expectativas para cada nível de senioridade da empresa. São as entrevistas técnicas que vão nos dar a resposta de onde a pessoa está em termos de conhecimento de tecnologia e de metodologia e, a partir do feedback das entrevistas técnicas, a gente vê em que nível de senioridade ela está e, portanto, qual o salário. Lembrando que esse nível é determinado de acordo com o nosso Plano de Cargos e Salários (Coordenadora de Recrutamento)

A EC4 não faz negociação de salários com o candidato. A gente vê no processo de seleção onde a pessoa está no nível de competências técnicas, tá? E aí a gente vê qual o salário que a empresa paga pra aquele nível de competência (Recrutadora 1).

Para decidir o salário do candidato, depois que a contratação dele foi aprovada na reunião dos entrevistadores, a recrutadora e o Diretor de Escritório se reúnem pra decidir o salário. A decisão é feita com base na competência técnica avaliada do candidato.

Vocês, então, têm pré-definido faixas salariais de acordo com as competências?

Sim. Nós temos o Plano de Cargos e Salários que diz quando ganha cada nível técnico (Recrutadora 2).

Por fim, a EC4 não apresenta na questão dos salários aquela dimensão relacional interna à empresa, identificada na EC2. Todavia, o programa de benefícios é definido junto com os funcionários da empresa que traz a essa questão certa dimensão relacional interna, porém ela não é voltada para um cálculo que tem lugar no mercado de trabalho.

Este capítulo tratou de evidenciar e analisar quais os valores que as firmas estudadas calculam ao comparecer no mercado de trabalho. Para bem ilustrar as diferenças quantitativas e qualitativas dos valores calculados pelas empresas, cabe a exposição da seguinte tabela: 
Tabela 30 - Valores Econômicos e Economicamente Relevantes Calculados pelas Empresas de TI.

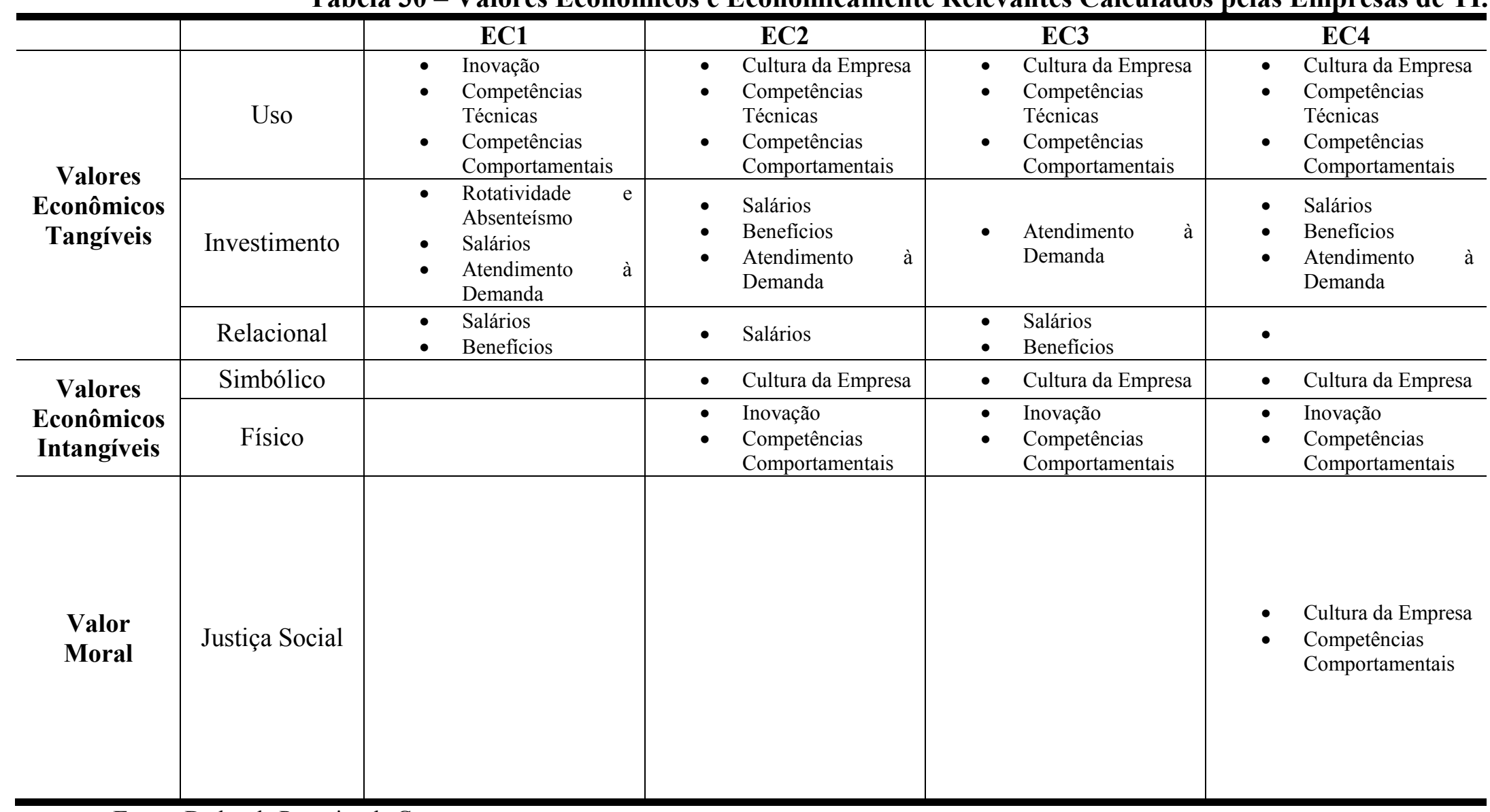

Fonte: Dados de Pesquisa de Campo. 
Com base na tabela 30 é possível constatar que as empresas estudadas se diferenciam em termos do número de valores calculados e conformando as suas demandas por força-detrabalho, assim como nas modalidades de valores - os econômicos tangíveis, os econômicos intangíveis e o economicamente relevante (moral). Também se observa que uma mesma relação sociotécnica e/ou dispositivo de cálculo possui valores diferentes para as firmas; por exemplo, na EC1, a inovação tem um valor econômico de uso, mas nos demais casos, ela tem um valor econômico físico. Portanto, a tabela acima ilustra que há tanto diferenças quantitativas como qualitativas nos valores calculados pelas empresas de TI estudadas nesta tese. 


\section{A CAPACIDADE DE CÁLCULO DE VALOR DAS FIRMAS}

Neste capítulo será descrito e analisado a capacidade de cálculo de valor no mercado de trabalho das firmas estudadas. Os capítulos anteriores abordaram os elementos que compõem essa capacidade: as características das empresas (Capítulo 5), agentes humanos e não-humanos que formam a rede sociotécnica (Capítulo 6), e os valores econômicos e economicamente relevantes calculados nas demandas das empresas no mercado de trabalho (Capítulo 7). De certo modo, a análise dos dados empíricos realizada nesta tese, remete à montagem de um quebra-cabeça, isto é, nos capítulos de 5 a 7 foram definidos quais são as peças desse quebra-cabeça e, neste capítulo, será feita a "descrição da imagem" que é formada quando são relacionadas essas peças. Por isso que aqui não serão trazidos extratos de entrevistas, uma vez que estes são as peças do quebra-cabeça; mas vai ser exposta a imagem que é formada a partir do modo como cada uma dessas peças se relaciona em cada estudo de caso. Em outros termos, o objetivo deste capítulo é apresentar a compreensão a que se chegou sobre a capacidade de cálculo de valor (a imagem formada pelas relações entre as peças) e o seu agenciamento (CALLON, 2007; HARDIE; MACKENZIE, 2007; MUNIESA; MILLO; CALLON, 2007).

Para auxiliar na leitura das seções que compõem este capítulo, cabe listar as peças, ou seja, os agentes humanos, os dispositivos de cálculo e os valores econômicos e economicamente relevantes identificados em cada estudo de caso. Senão vejamos.

$>$ Estudo de Caso 1 - agentes humanos dentro da firma: a coordenadora de $\mathrm{RH}$, a técnica de departamento de pessoal, os gestores de áreas técnicas, o gestor de planejamento industrial e a direção executiva e comercial da empresa; dispositivos de cálculo internos à empresa foram identificados os conhecimentos acadêmicos e profissionais, tabela de salários, cultura da empresa em formação, o plano de cargos e carreiras em elaboração, banco de currículos e os currículos, site da empresa, tipos de entrevistas e as indicações; agentes externos (humanos e não-humanos) são as agências de emprego, as universidades e os sites de vaga de emprego; valores econômicos tem-se o valor de uso, o de investimento e o relacional. 
Estudo de Caso 2 - agentes humanos internos: coordenadora de RH, o diretor geral da unidade, duas recrutadoras, direção executiva, gestores de áreas técnicas e os funcionários técnicos; dispositivos de cálculo internos são a pesquisa de salários, o plano de cargos, salários e carreiras, sistema informático de gestão de $\mathrm{RH}$, duas formas de bancos de currículos e os próprios currículos, assessments de avaliação de candidatos, site da empresa, programa de indicações, tipos de entrevista, técnica de entrevista por competências, testes lógicos e exercícios técnicos, cultura da empresa e linguagens de programação; agentes externos são os sites de vagas de emprego, sites de redes sociais e profissionais, as universidades e os anúncios em jornais; valores econômicos foram constatados o valor de uso, o simbólico, o físico, o de investimento e o relacional.

Estudo de Caso 3 - agentes humanos internos: coordenador de RH, recrutadora, direção corporativa e os gestores de áreas técnicas; dispositivos de cálculo internos são formados pelo conhecimento acadêmico e profissional, a cultura da empresa em consolidação, os planos de cargos e carreiras em formação, a pesquisa de salários, as técnicas de entrevistas por competências, os tipos de entrevistas, o sistema informático de gestão de RH, o site da empresa, o banco de currículos e os currículos, as linguagens de programação, os testes lógicos, a redação e os exercícios técnicos; agentes externos são as universidades, sites de vagas de emprego, sites de redes sociais e profissionais e agências de emprego; valores econômicos foram identificados o valor de uso, o simbólico, o físico, o relacional e o de investimento.

Estudo de Caso 4 - agentes humanos internos tem-se o diretor geral de escritório, a coordenadora de recrutamento, o diretor de $\mathrm{RH}$, a direção corporativa, duas recrutadoras, a organizadora de seleção e os funcionários de áreas técnicas; dispositivos de cálculo internos são os eventos, banco de currículo e currículos, assessments de avaliações de candidatos, sistema informático de gestão de RH, plano de carreiras, plano de cargos e salários, site da empresa, programa de recomendações, cultura da empresa, tipos de entrevistas, testes lógicos e exercícios de 
programação de códigos, pesquisa radar técnico e tecnológico, reunião de decisão de contratação, métodos ágeis e linguagens de programação; agentes externos: universidade, comunidades de TI e sites de redes sociais e profissionais; valores economicamente relevantes tem-se o valor moral de justiça social e valores econômicos são o valor de uso, o simbólico, o físico e o de investimento.

Cabe destacar que o objetivo não foi analisar e definir todos os agentes humanos e não-humanos das redes sociotécnicas das firmas estudadas, mas somente aqueles que entram nas relações sociotécnicas que formam a capacidade de cálculo de valor quando comparecem no mercado de trabalho. Por exemplo, na EC2 e na EC4, os profissionais de TI da empresa foram identificados como agentes humanos na rede sociotécnica dessas firmas; porém, na EC1 e na EC3, esses mesmo agentes não estão incluídos porque não estão inseridos nas relações sociotécnicas por meio das quais se exerce a capacidade de cálculo de valor da empresa no mercado de trabalho.

Através das análises dos dados, concluiu-se que essa capacidade de cálculo é exercida em dois momentos: planejamento da demanda (em primeiro lugar) e operações de cálculo que a firma executa quando comparece no mercado de trabalho (em segundo lugar). No primeiro momento, a firma define a sua motivação e o objeto de sua busca no mercado de trabalho; já no segundo, a firma estabelece o modo como ela faz essa busca no mercado de trabalho.

Como discorrido no capítulo 2, o estudo sobre como a firma demanda no mercado de trabalho se volta para observar três procedimentos: recrutamento, seleção e contratação. Também se dissertou como esses três procedimentos correspondem respectivamente às três operações que compõem a capacidade de cálculo econômico, segundo Michel Callon (1998; 2004). Ocorre que, antes dessas operações, a firma precisa estabelecer o quê ela vai calcular. Ainda conforme o capítulo 2, o trabalho como mercadoria possui certa opacidade, isto é, aquilo que é transacionado no mercado de trabalho não é um objeto, ou seja, a pessoa do trabalhador; mas sim, a construção de qualidades e características de que o trabalhador seria portador e que configurariam a sua força-de-trabalho - que é exatamente o que se transaciona no mercado de trabalho. Portanto, em termos mais simples, o planejamento da demanda consiste na etapa durante a qual a firma define se precisa e qual tipo de força-de-trabalho irá demandar ao comparecer no mercado de trabalho. 
É neste momento de planejamento da demanda que a firma define o que ela precisa/valoriza em um trabalhador para contratá-lo. Assim sendo, por ser a demanda de trabalho da firma uma demanda derivada, ela precisa definir a primeira à luz das necessidades postas pela segunda, isto é, ela precisa definir questões como, por exemplo, quantos trabalhadores, qual preço deverá (ou poderá pagar) e que tipos de trabalhadores e profissionais ela irá precisar vis-à-vis os requisitos de atividades do seu processo produtivo. Contratar certa quantidade de força-de-trabalho a um determinado preço (salários e benefícios) esperando um retorno (demanda de trabalho como demanda derivada) é justamente a definição de valor econômico de investimento. Por outro lado, saber e planejar que tipos de trabalhadores e profissionais a firma precisa para executarem as atividades que compõem o seu processo produtivo é justamente definir uma valor de uso. Como serão demonstrados adiante, esses dois valores econômicos estão presentes no planejamento da demanda de todas as empresas estudadas nesta tese; exatamente porque eles se referem a condições sine qua non para firma estabelecer o objeto da sua demanda e, por conseguinte, comparecer ao mercado de trabalho.

Também será analisado e exposto neste capítulo que, apesar de condições essenciais para a construção da demanda da firma, especialmente nas empresas que se aproximam mais do modelo da nova economia, esses dois valores econômicos não são suficientes para compor o planejamento da demanda de trabalho das firmas.

Se os valores econômicos e economicamente relevantes são os "materiais" por meio dos quais a firma constrói o planejamento da sua demanda, isto é, o quê será calculado quando ela comparecer no mercado de trabalho; então, o que exatamente é construído nesse processo? Tal como será argumentado, os valores operacionalizam ou “constroem" perfis de trabalhador valorizados pela firma e que, portanto, serão demandados por ela no mercado de trabalho, através das operações que conformam a capacidade de cálculo econômico - recrutamento (classificar), seleção (julgar) e contratação (planejar). Em razão de que, no mercado de trabalho, o que é transacionado é a força-de-trabalho, os perfis de trabalhador são formados por competências técnicas e comportamentais que, ao seu turno, dão conteúdo a demanda de força-de-trabalho da firma. Em outros temos, a força-de-trabalho é definida pela empresa como perfis de competências técnicas e comportamentais que o trabalhador deverá ter. Uma vez isso definido, ou seja, uma vez que o planejamento da demanda é realizado, a firma 
comparece ao mercado de trabalho para calcular na oferta disponível nesse espaço, a realização da sua demanda.

Assim, a análise feita nas seções que se seguem, estará dividida em duas partes. Primeiro será identificado e descrito o conjunto de relações sociotécnicas da firma encarregadas de executar o planejamento da sua demanda e, também, a demanda de trabalho em termos dos valores econômico e economicamente relevantes. Segundo serão descritos analiticamente como essa demanda é realizada através das operações de cálculo que a firma executa no mercado de trabalho. Nesse sentido, também serão definidas essas operações em termos das relações sociotécnicas que as formatam e que estruturam as condições de possibilidade para serem executadas. Por fim, cabe destacar que as relações sociotécnicas nada mais são que o conjunto de agentes humanos e dispositivos de cálculo que, uma vez postos em relação, executa tanto o planejamento da demanda como as operações de cálculo que têm lugar no mercado de trabalho.

\subsection{Estudo de Caso 1: o cálculo de valor mais longe da nova economia}

A tabela abaixo esquematicamente apresenta a alocação dos agentes humanos e dos dispositivos de cálculo, que entram em relação sociotécnica em cada operação da capacidade de cálculo de valor da demanda por força-de-trabalho da EC1.

Tabela 31 - Rede Sociotécnica e Operações de Cálculo de Valor da EC1.

\begin{tabular}{|c|c|c|c|c|c|}
\hline & & $\begin{array}{l}\text { Planejamento } \\
\text { da Demanda }\end{array}$ & Recrutamento & Seleção & Contrato \\
\hline \multirow{4}{*}{$\begin{array}{l}\text { Agentes } \\
\text { Humanos }\end{array}$} & $\begin{array}{c}\text { Direção Executiva e } \\
\text { Comercial }\end{array}$ & $\sqrt{ }$ & & & $\sqrt{ }$ \\
\hline & $\begin{array}{c}\text { Gestores de Áreas } \\
\text { Técnicas }\end{array}$ & $\sqrt{ }$ & $\sqrt{ }$ & $\sqrt{ }$ & $\sqrt{ }$ \\
\hline & Coornadora de $\mathrm{RH}$ & $\sqrt{ }$ & $\sqrt{ }$ & $\sqrt{ }$ & $\sqrt{ }$ \\
\hline & $\begin{array}{c}\text { Técnica de } \\
\text { Departamento de } \\
\text { Pessoal }\end{array}$ & $\sqrt{ }$ & & & \\
\hline \multirow{9}{*}{$\begin{array}{l}\text { Dispositivos de } \\
\text { Cálculo }\end{array}$} & Tabela de Salários & $\sqrt{ }$ & & & $\sqrt{ }$ \\
\hline & Programa de Benefícios & $\sqrt{ }$ & & & $\sqrt{ }$ \\
\hline & $\begin{array}{c}\text { Entrevista } \\
\text { Técnica/Profissional }\end{array}$ & & & $\sqrt{ }$ & \\
\hline & $\begin{array}{c}\text { Entrevista } \\
\text { Comportamental }\end{array}$ & & & $\sqrt{ }$ & \\
\hline & Site da Empresa & & $\sqrt{ }$ & & \\
\hline & Currículos & & $\sqrt{ }$ & $\sqrt{ }$ & \\
\hline & Banco de Currículos & & $\sqrt{ }$ & $\sqrt{ }$ & \\
\hline & Universidades & & $\sqrt{ }$ & & \\
\hline & $\begin{array}{l}\text { Sites de Vagas de } \\
\text { Emprego }\end{array}$ & & $\sqrt{ }$ & & \\
\hline
\end{tabular}

Fonte: Dados de Pesquisa de Campo. 
O planejamento da demanda da EC1 envolve três tipos de valores econômicos: o de uso, o de investimento e o relacional. A seguir serão descritas analiticamente as relações sociotécnicas através das quais se executam o planejamento da demanda, escudadas naqueles três valores econômicos.

Basicamente, o valor de uso se traduz numa série de competências técnicas e comportamentais de que o trabalhador deverá ser possuidor para exercer uma das atividades (cargos e carreiras) que compõem as etapas de produção do(s) produto(s) final(is) da empresa. Como o leitor deve estar lembrado, a EC1 é uma empresa de TI do setor industrial e manufatureiro, que produz equipamentos para transmissão de dados, voz e vídeo. A produção desses produtos exige basicamente a presença de dois tipos de trabalhadores, cujos perfis de competências técnicas são bem distintos ${ }^{88}$ : profissionais das engenharias e das ciências da computação que lidam com a elaboração e projeto dos produtos da EC1 (setor de P\&D) e profissionais que lidam com a manufatura desses mesmos produtos (chão de fábrica). Portanto, não são, tal como nos demais casos, perfis de profissionais que se diferenciam por níveis de proficiência e experiência em determinadas competências técnicas, mas trata-se, na EC1, de dois tipos distintos de profissionais. Por isso mesmo, a EC1 atribui valor de uso distinto aos mesmos: no primeiro grupo, alocado no setor de $\mathrm{P} \& \mathrm{D}$, o processo de atribuição de valor consiste em saber se os profissionais serão capazes de traduzir as principais tendências tecnológicas do setor em produtos de que seus clientes precisam; já no segundo grupo, situado no chão de fábrica, o desafio consiste em planejar o número de trabalhadores necessários para cada tarefa e etapa do processo de produção dos produtos.

Assim sendo, a EC1 precisa calcular duas modalidades de valor de uso no planejamento da demanda de acordo com os seus dois perfis de profissionais. Os da parte de P\&D estão mais ligados ao que a firma entende como inovação, isto é, são os profissionais capazes de traduzir certas tendências tecnológicas do mundo de TI e das telecomunicações (por exemplo, adoção da fibra óptica) em equipamentos de transmissão de dados, voz e imagem, destinados aos clientes ligados a essas tendências tecnológicas. O valor de uso, então, resulta basicamente da habilidade e do conhecimento dos engenheiros e profissionais, todos eles com curso superior nas áreas

\footnotetext{
${ }^{88} \mathrm{O}$ perfil de competências comportamentais é basicamente o mesmo para os dois.
} 
de informática e eletrônica, no que respeitam a esses novos paradigmas tecnológicos e à sua aplicação nos tipos de produtos que a EC1 comercializa.

Uma vez que os instrumentos de cálculo que estabelecem esse perfil de competências técnicas - basicamente, planos de cargos e carreiras - não estavam estabelecidos e devidamente implantados dentro da EC1, o valor de uso desses profissionais é definido exclusivamente por agentes humanos, munidos de seus conhecimentos mercadológicos e tecnológicos. São, portanto, as relações entre membros da direção e da administração da EC1, gestores da área de P\&D e o gestor de planejamento industrial, que identificam a necessidade ou não de contratar novos quadros para essa área (principalmente, após reunião com gestores de tecnologia das empresas que são as principais e potenciais clientes da EC1), e definem o perfil de competências técnicas requeridas desses novos quadros (valor de uso).

Ao mesmo tempo, o número de clientes determina o número de projetos de pesquisa e desenvolvimento de produtos que, ao seu turno, provoca, especialmente a partir da avaliação do gestor da área de $\mathrm{P} \& \mathrm{D}$, a necessidade de planejar a contratação de certos números de profissionais de uma dada área e com o perfil técnico exigido pelos conteúdos tecnológicos dos projetos. Essa avaliação ainda passa pelo aval dos membros da direção comercial e executiva da EC1. Os agentes humanos do RH são incluídos nesse planejamento da demanda de profissionais de P\&D apenas no momento das decisões sobre salários e benefícios a serem pagos para esses profissionais. A coordenadora de RH, em relação com a técnica de departamento de pessoal, então, fornece informações de tempo estimado para conseguir contratar esse profissional e a expectativa de salário que teria que se pagar. Neste último aspecto, o dispositivo de cálculo "tabela de salários" entra em cena, participando dessa parte do planejamento de contratações.

No caso dos trabalhadores do setor de chão de fábrica, os agentes humanos e não-humanos envolvidos no planejamento da sua demanda, são os mesmos. Contudo, destaca-se a participação dos gestores de áreas da produção, que fornecem informações específicas sobre o chão de fábrica em termos de necessidade ou não de mais trabalhadores e para quais atividades, por exemplo, montagem de placas eletrônicas ou programação de máquinas-ferramenta, teste de componentes eletrônicos, expedição e organização de almoxarifado, etc. O planejamento dessa demanda ocorre mais em função da avaliação acerca do volume de clientes e da demanda e menos em razão da questão tecnológica, como no caso dos profissionais de P\&D. Isso porque os valores de 
uso para a demanda de um e de outro são diferentes; a saber, os de chão de fábrica advêm da capacidade de produção e os de P\&D do conhecimento sobre tecnologias e desenvolvimento de projetos de equipamentos de TI.

Portanto, o planejamento da demanda dos trabalhadores da área de produção da EC1 ocorre a partir das relações entre gestores de produção, gestor de planejamento industrial e direção executiva e comercial da empresa. O RH, neste caso também, é chamado para prestar o mesmo subsídio de informações do caso dos profissionais de P\&D.

Relembrando, constatou-se uma instabilidade da inserção do RH na rede sociotécnica da EC1 e essa instabilidade também se reflete no planejamento da demanda. Tal instabilidade se manifesta através das duas formas pelas quais o planejamento da demanda pode se materializar na empresa. A primeira, na qual há lugar a interveniência do RH, é a que foi descrita acima e que se materializa em reuniões com os supracitados agentes humanos e o dispositivo de cálculo "tabela de salários"; a segunda ocorre quando um dos gestores técnicos (produção ou P\&D) identifica por conta própria a necessidade de nova contratação e leva o nome do candidato que será contratado diretamente à direção da empresa; nesta segunda forma, o RH é apenas utilizado para conduzir os trâmites de registro burocrático de entrada do novo funcionário na EC1. Portanto, na segunda forma, o planejamento da demanda é feito exclusivamente pelo gestor de área técnica.

Na EC1, o planejamento da demanda também é feito com referência ao valor de investimento. De certo modo, já havia sido possível identificar esse aspecto na descrição feita acima sobre o planejamento e o valor de uso. Ambos os perfis de competências técnicas e, portanto, de tipos de valor de uso, estão relacionados a duas capacidades que a firma deve alcançar para atender os clientes e, deste modo, obter lucro, a saber, a expectativa de retorno em termos de ganhos de produtividade (trabalhadores do chão de fábrica) ou de capacidade de desenvolver novos equipamentos em sintonia com as tendências tecnológicas (profissionais de $\mathrm{P} \& \mathrm{D}$ ). $\mathrm{O}$ valor de investimento se revela exatamente na expectativa, assumida quando do planejamento da demanda, de que a contratação de certa quantidade de um desses dois perfis de trabalhadores representaria, para a empresa, a obtenção seja de ganhos de produtividade, seja de aumento da sua capacidade de inovação, o que, por sua vez, permitiria à EC1 atender as demandas no mercado de produtos e, assim, ampliar o seu lucro. 
O planejamento da demanda tendo em vista o valor de investimento é feito na EC1 com os mesmos agentes humanos envolvidos quando do valor de uso, isto é, membros da direção comercial e executiva, gestores de áreas técnicas, o gestor de planejamento industrial e o RH. Tal planejamento ocorre por meio de relações sociotécnicas estabelecidas nas reuniões entre esses agentes humanos, tendo em vista a decisão sobre quais profissionais a EC1 deve contratar de modo a ser capaz de atender e conquistar clientes. Quando o RH é incluído, ele traz consigo a inserção dos seguintes agentes não-humanos nessas relações sociotécnicas: métricas sobre absenteísmo, rotatividade e salários. É na relação com esses dispositivos que os agentes humanos envolvidos nas relações sociotécnicas de planejamento de demanda de trabalho serão capazes de definir o valor de investimento de novas contratações, pois esses dispositivos fornecem justamente as informações sobre os custos requeridos para realizar tal investimento. Também neste caso, o gestor de área técnica pode fazer quase que isoladamente esse planejamento de contratação sobre o valor de investimento. Neste caso, o gestor avalia se mais contratações irão trazer uma produtividade ao seu setor para níveis mais satisfatórios.

Por último, o planejamento da demanda passa por definir quanto a EC1 irá pagar (salários mais benefícios) para contratar os trabalhadores que encarnariam os dois perfis básicos de profissionais que ela necessita e valoriza. Como já mencionado, a EC1 não utiliza uma pesquisa de médias salariais de mercado $^{89}$; ao invés disso, ela utilizava um dispositivo chamado "tabela salarial" que é atualizado pelo dissídio trabalhista. Portanto, o planejamento da demanda em termos de salários é feito mais em relação aos valores econômicos de uso e de investimento, encarnados no dispositivo "tabela de salário" que o valor relacional. Em suma, as relações sociotécnicas formadas entre agentes humanos e a tabela salarial para o planejamento da demanda da EC1, estruturam decisões que dizem respeito ao valor de uso - consultando a tabela que se vê quanto será pago para certo perfil de profissional adequado para determinado cargo - e ao valor de investimento - a tabela é usada como um guia para os agentes humanos anteverem o custo de contratação de novos funcionários ${ }^{90}$.

\footnotetext{
${ }^{89}$ Foi relatado, por parte da técnica de departamento de pessoal, que se havia feito uma pesquisa de salários via um site de vagas de empregos. Porém, a entrevistada menciona que essa pesquisa não estava sendo utilizada para definições acerca dos salários pagos aos funcionários da EC1.

90 Somente muito indiretamente a tabela de salário é usada em relações sociotécnicas para planejar a demanda em termos de valor econômico relacional. A dimensão relacional, tal como mencionada no capítulo anterior, estaria presente na atualização da tabela pelo dissídio trabalhista. Porém,
} 
Até aqui, o planejamento se desenrola mais em termos da definição dos perfis de competências técnicas de dois grandes grupos de trabalhadores demandados pela EC1, os de P\&D e os de produção. Entretanto, o planejamento da demanda em termos de valor econômico de investimento requer a definição de um perfil comportamental. Esse último é definido a partir de relações sociotécnicas entre os agentes humanos já mencionados, aos quais se soma o agente não-humano "cultura da empresa". Essa última (tal como foi tratada nos capítulos 6 e 7) não se encontrava plenamente elaborada na EC1, sendo concebida mais em termos de possíveis políticas de gestão de recursos humanos a serem desenvolvidas pela empresa. Isso significa que, para o $\mathrm{RH}$, a cultura da empresa ainda não estabelecia as condições para bem definir um perfil de competências comportamentais que se refere a um valor de uso, ou seja, competências comportamentais que se encaixariam ao ambiente e ao modelo de gestão do trabalho da EC1, que, ao seu turno, seriam definidos pela cultura da empresa.

O que está presente para o $\mathrm{RH}$ e para os gestores de áreas técnicas é mais propriamente uma cultura da empresa que valoriza funcionários que permaneçam o maior tempo possível na EC1 e que se comprometam em manter a produtividade no seu trabalho. Assim sendo, o planejamento da demanda em termos de perfis de competências comportamentais se refere ao valor de investimento, pois o trabalhador com um perfil comportamental inclinado à rotatividade e/ou ao absenteísmo põem em risco a possibilidade de realização do retorno esperado pela firma ao contratá-1o ${ }^{91}$.

No planejamento da demanda, o valor relacional somente está presente nas definições sobre o programa de benefícios que deve ser dado pela empresa aos trabalhadores com esses perfis de competências técnicas e comportamentais que ela valoriza. Esse planejamento é feito através de relações sociotécnicas entre membros da direção executiva da empresa (especialmente a presidente) e a coordenadora de RH. Para essa última, norteada pelo conhecimento de que mesmo pequenas diferenças salariais afetam a decisão de trabalhadores saírem da empresa, o programa de benefícios é visto, especialmente no caso dos trabalhadores de chão de fábrica, como um incentivo para esses permanecerem na EC1 e continuarem produtivos. Assim, o valor relacional se revela no planejamento da demanda quando esses agentes humanos se dispõem a

esse procedimento não está presente no momento mesmo do planejamento da demanda por força-detrabalho na EC1.

${ }^{91}$ As métricas de absenteísmo e rotatividade são dispositivos de cálculo que servem para firma selecionar o trabalhador com base no perfil comportamental desejado. 
melhorar, a tornar mais atraente o seu programa de benefícios frente a outras empresas e, deste modo, diminuir a rotatividade e o absenteísmo de seus funcionários.

Em suma, as relações sociotécnicas mobilizadas na EC1 para o planejamento da sua demanda por força-de-trabalho definem dois perfis de competências técnicas e um perfil de competências comportamentais que expressam os valores econômicos de uso, de investimento e o relacional. Esse trio de valores, e o conteúdo que eles assumem na $\mathrm{EC} 1$, reflete a maior distância dessa empresa face àquilo que se pode considerar como sendo os valores do trabalho na nova economia ${ }^{92}$.

Uma vez definida a demanda de trabalho nos termos desses perfis de competências técnicas e comportamentais, como a EC1 calcula a oferta disponível no mercado de trabalho tendo em vista a satisfação da sua demanda? Quais são as relações sociotécnicas e quais agentes humanos e não-humanos entram em cena para que a EC1 exercite as operações de cálculo necessárias à realização da sua demanda no mercado de trabalho?

Quando uma firma comparece no mercado de trabalho, a primeira operação de cálculo que ela executa é o recrutamento. Retomando, o recrutamento é uma operação de cálculo no sentido que, nele, a firma irá buscar saber quais são as possibilidades de realização de sua demanda no mercado de trabalho; ou seja, é recrutando trabalhadores que ela irá ver se há disponibilidade de oferta de mão de obra vis-à-vis os perfis de competências técnicas e comportamentais que definem a sua demanda. Na EC1, essa operação se materializa por dois modelos de relações sociotécnica que, novamente, refletem a instabilidade da inserção do RH.

Conforme exposto nos capítulos anteriores, na EC1 os gestores de áreas técnicas recebem indicações de seus funcionários a respeito de pessoas para trabalharem na EC1. Através dessas indicações que chegam diretamente ao gestor de área é estruturada uma modalidade de relação sociotécnica entre o coordenador e a indicação que produz uma forma de operação de recrutamento. É por meio do recrutamento via indicações que o gestor de área técnica pode acessar o conhecimento sobre a oferta disponível de profissionais no mercado de trabalho e avaliar a possibilidade de realização da sua demanda, calculando o perfil técnico e comportamental dos que representam essa oferta disponível no mercado de trabalho, através das informações obtidas nas relações indicações. Cabe destacar que, essas informações obtidas na relação de indicações,

\footnotetext{
${ }^{92}$ Esse ponto será aprofundado nas conclusões desta tese.
} 
assumem duas formas: a de um currículo entregue no ato da indicação ou a de uma conversa entre o gestor e o funcionário que está indicando. Nos capítulos 6 e 7 foi evidenciado e descrito que os gestores de áreas têm avaliações distintas sobre a eficiência das recomendações, sendo que justamente essa avaliação é obtida através do cálculo que se faz do perfil técnico e comportamental nesta oferta de mão de obra disponível no mercado de trabalho.

O segundo modelo de relações sociotécnicas que tornam possível aos agentes da firma exercer a operação de recrutamento e calcular o perfil da oferta de força-detrabalho disponível no mercado de trabalho, tem lugar por meio da inserção do RH nessas relações. Neste caso, a operação de cálculo é feita a partir da alimentação do "banco de currículos" (agente não-humano) que ocorre por meio da relação do RH com os seguintes dispositivos que se constituem em canais de recrutamento: as indicações, agências de emprego e seleção, anúncios e procura em sites de vagas de empregos, programa de bolsa e eventos em universidades e recebimento de currículos através do site da EC1 ou na portaria da empresa. Conforme a demanda por contratações é planejada com e informada ao RH, esse irá calcular através da relação sociotécnica com o dispositivo de cálculo "banco de currículos", a oferta disponível no mercado de trabalho em termos do perfil de competência técnica e comportamental valorizado pela firma. Se o banco não oferece currículos de candidatos em número suficiente para atender a demanda da empresa, o RH estabelece relações sociotécnicas com agentes (humanos e não-humanos) que oferecem condições de possibilidade para operação de recrutamento de maneira ativa. Esses agentes são basicamente os que travam relação com o banco de currículos com exceção do programa de bolsas em universidades e o site e portaria da empresa. Além disso, a coordenadora de RH ainda trava relação com os gestores das áreas técnicas que têm contratações a serem feitas ("vagas em aberto") para definir melhor o perfil de competências técnicas dos trabalhadores considerados necessários para serem contratados pela EC1. Portanto, essa relação entre RH e gestores de áreas técnicas fica na fronteira entre o planejamento da demanda e a operação de recrutamento.

Uma vez que a operação de recrutamento fornece à firma o conhecimento a respeito da oferta disponível no mercado de trabalho, em termos de força-de-trabalho com as competências técnicas e comportamentais valorizadas pela empresa, o cálculo sobre essa oferta disponível será aprofundado por meio da operação de seleção. Nesta, a finalidade é julgar e classificar os que representam a oferta disponível no mercado de 
trabalho em função da verificação da presença e grau de posse das competências técnicas e comportamentais demandadas.

Esta operação de cálculo, que é a seleção, se divide em dois momentos: o de seleção de currículos e o de seleção de candidatos. No primeiro momento, normalmente a coordenadora de RH irá selecionar os currículos no banco, de acordo com a classificação que se deu a cada um deles em termos dos tipos de cargos em que os currículos se encaixariam na EC1. Uma vez reunidos os currículos pertinentes à demanda de contratação para preencher certo tipo de cargo na empresa, a coordenadora de RH lê os currículos e os seleciona de acordo com as competências técnicas desejadas para aquele cargo. Nesse momento, os critérios de competências técnicas irão variar de acordo com o tipo de cargo sobre o qual a demanda de contratações da firma se destina; porém, basicamente, verifica-se nível de escolaridade, experiência profissional, tempo de permanência em empregos anteriores e o que foi denominado nesta tese de características demográficas, por exemplo, sexo, estado civil, número de fillhos, idade e local de residência ${ }^{93}$. O currículo como dispositivo de cálculo em relação sociotécnica com a coordenadora de RH fornece, portanto, as condições iniciais para selecionar-se a oferta de trabalhadores disponível à empresa, calculando o perfil de competências desses ofertantes conforme critérios que se materializam nas informações lidas nos currículos. Os candidatos dos currículos selecionados a partir dessa operação de cálculo são chamados para fazer uma entrevista com o RH e outra com o gestor da área técnica que o candidato irá trabalhar se contratado.

$\mathrm{Na}$ entrevista com a coordenadora do RH, o valor do candidato é calculado mais em função de um perfil de competências comportamentais do que técnicas. Uma vez que não foi mencionado nenhum uso de técnica de entrevista, essa não se constitui em um dispositivo de cálculo propriamente dito, porém uma modalidade de relação sociotécnica para operação de cálculo de seleção, formada entre candidato, coordenadora do RH, currículo do candidato e a cultura da empresa. Essa última, tal como já foi exposto, consiste na valorização de um perfil comportamental de trabalhador que permanece um bom tempo na empresa e que se comprometa em manter a produtividade no seu trabalho. Assim sendo, na relação sociotécnica com o currículo e a cultura da empresa, na situação de entrevista, a coordenadora do RH elabora perguntas

\footnotetext{
${ }^{93}$ Compreende-se que essas características demográficas não são propriamente competências profissionais. Porém, elas foram consideradas como tal porque, para a empresa, elas configuram critérios para seleção do currículo do candidato.
} 
para avaliar/calcular o candidato segundo esse perfil comportamental valorizado. Por exemplo, uma vez que através do currículo a coordenadora do $\mathrm{RH}$ notava que o candidato possuía uma trajetória marcada por baixo tempo de permanência nos empregos, ela elaborava perguntas para verificar se isso ocorria mais em função de um comportamento do candidato ou em razão de características das empresas que o contratavam.

$\mathrm{Na}$ entrevista com o coordenador de área técnica, além do cálculo desse perfil comportamental feito a partir da relação sociotécnica com a cultura da empresa, esse agente humano estabelece relações com dispositivos como o currículo do candidato e o conhecimento que o próprio gestor detém sobre o funcionamento das atividades realizadas na sua área. Em relação a esse último dispositivo, ele é formado através de conhecimentos tácitos e também explícitos a respeito das competências técnicas que o trabalhador deve possuir para exercer determinado cargo ou atividade no processo produtivo. É na relação com esse conhecimento adquirido, que o gestor de área técnica elabora perguntas e até mesmo testes para verificar o nível de proficiência e se realmente o candidato possui as competências técnicas que declarou possuir no currículo $^{94}$. É no momento da entrevista, portanto, que a operação de seleção é realizada para calcular as competências comportamentais e técnicas dos candidatos e, assim, poder classificá-los e hierarquizá-los tendo em mente o quanto eles satisfazem e se aproximam do perfil elaborado no planejamento da demanda no que concerne a essas competências.

Por fim, selecionados os trabalhadores constantes na oferta disponível no mercado de trabalho para EC1 através da seleção como operação de cálculo, o gestor de área técnica e a coordenadora de RH estabelecem entre si relação sociotécnica para calcular aspectos referentes à operação de contratação. Em posse da avaliação e classificação de candidatos é que eles calculam em maior profundidade e comparativamente as competências técnicas e comportamentais daqueles que foram avaliados positivamente na seleção. Esses dois agentes humanos - gestor de área técnica e coordenadora de $\mathrm{RH}$ - decidem qual/quais dentre os candidatos a EC1 irá contratar e para qual cargo (cada um deles) será contratado. Portanto, neste momento, a operação de cálculo de contratação se materializa não somente na decisão de contratar ou não, como também, no cargo que o candidato poderá exercer. Definido o cargo, o RH, em

\footnotetext{
${ }^{94} \mathrm{~A} \mathrm{EC1} \mathrm{não} \mathrm{possui} \mathrm{uma} \mathrm{política} \mathrm{de} \mathrm{testes} \mathrm{técnicos} \mathrm{ou} \mathrm{de} \mathrm{qualquer} \mathrm{outra} \mathrm{natureza.} \mathrm{O} \mathrm{que} \mathrm{ocorre}$ é mais uma ação de testar o candidato do que propriamente aplicar um teste padronizado.
} 
relação sociotécnica com o dispositivo "tabela de salários", irá verificar qual será a oferta de salário ao candidato e, assim, concretizar a demanda da empresa, ou seja, contratar o trabalhador. Em resumo, o cálculo na operação de decisão de contratação estabelece um cargo que o candidato poderá ocupar na EC1 que, por sua vez, é relacionado à "tabela de salários" da empresa.

\subsection{Estudo de Caso 2: o cálculo de valor estruturado da nova}

\section{economia}

A tabela abaixo esquematicamente apresenta a alocação dos agentes humanos e dos dispositivos de cálculo, que entram em relação sociotécnica em cada operação da capacidade de cálculo de valor da demanda por força-de-trabalho da EC2.

Tabela 32 - Rede Sociotécnica e Operações de Cálculo de Valor da EC2.

\begin{tabular}{|c|c|c|c|c|c|}
\hline & & $\begin{array}{l}\text { Planejamento } \\
\text { da Demanda }\end{array}$ & Recrutamento & Seleção & Contrato \\
\hline \multirow{7}{*}{$\begin{array}{l}\text { Agentes } \\
\text { Humanos }\end{array}$} & $\begin{array}{l}\text { Direção Executiva e } \\
\text { Comercial }\end{array}$ & $\sqrt{ }$ & & & \\
\hline & Gestores de Áreas Técnicas & $\sqrt{ }$ & $\sqrt{ }$ & $\sqrt{ }$ & $\sqrt{ }$ \\
\hline & Coornadora de RH & $\sqrt{ }$ & & & $\sqrt{ }$ \\
\hline & Recrutadoras & & $\sqrt{ }$ & $\sqrt{ }$ & $\sqrt{ }$ \\
\hline & Diretor de Escritório & $\sqrt{ }$ & & & \\
\hline & Conselho de Acionistas & $\sqrt{ }$ & & & \\
\hline & Funcionários Técnicos & & & $\sqrt{ }$ & \\
\hline \multirow{21}{*}{$\begin{array}{l}\text { Dispositivos de } \\
\text { Cálculo }\end{array}$} & Programa de Benefícios & $\sqrt{ }$ & & & $\sqrt{ }$ \\
\hline & Plano de Cargos e Carreiras & $\sqrt{ }$ & & & $\sqrt{ }$ \\
\hline & Plano de Cargos e Salários & $\sqrt{ }$ & & & $\sqrt{ }$ \\
\hline & $\begin{array}{l}\text { Sistema Informático de } \\
\text { Gestão de RH }\end{array}$ & $\sqrt{ }$ & $\sqrt{ }$ & $\sqrt{ }$ & $\sqrt{ }$ \\
\hline & Pesquisa de Salários & $\sqrt{ }$ & & & \\
\hline & Teste de Exercício Técnico & & & $\sqrt{ }$ & \\
\hline & Testes Lógicos & & & $\sqrt{ }$ & \\
\hline & $\begin{array}{l}\text { Testes Psicológicos de } \\
\text { Perfil Profissional }\end{array}$ & & & $\sqrt{ }$ & \\
\hline & $\begin{array}{l}\text { Entrevista } \\
\text { Técnica/Profissional }\end{array}$ & & & $\sqrt{ }$ & \\
\hline & Entrevista Comportamental & & & $\sqrt{ }$ & \\
\hline & Cultura da Empresa & & & $\sqrt{ }$ & \\
\hline & $\begin{array}{l}\text { Programas de } \\
\text { Recomendação }\end{array}$ & & $\sqrt{ }$ & & \\
\hline & Site da Empresa & & $\sqrt{ }$ & & \\
\hline & Formulários de Assessment & & & $\sqrt{ }$ & \\
\hline & Currículos & & $\sqrt{ }$ & $\sqrt{ }$ & \\
\hline & Banco de Currículos & & $\sqrt{ }$ & & \\
\hline & Sites de Redes Profissionais & & $\sqrt{ }$ & & \\
\hline & Sites de Redes Sociais & & $\sqrt{ }$ & & \\
\hline & Universidades & & $\sqrt{ }$ & & \\
\hline & Técnica de Entrevista & & & $\sqrt{ }$ & \\
\hline & Sites de Vagas de Emprego & & $\sqrt{ }$ & & \\
\hline
\end{tabular}

Fonte: Dados de Pesquisa de Campo. 
Cinco tipos de valores econômicos foram identificados no planejamento da demanda da EC2: o de uso, o de investimento, o relacional, o físico e o simbólico. Primeiro serão definidas analiticamente as relações sociotécnicas formadas por agentes humanos e dispositivos de cálculo que executam o planejamento da demanda calculando o valor econômico de uso.

A EC2 desenvolve principalmente softwares customizáveis para gestão de empresas. $\mathrm{Na}$ unidade pesquisada são desenvolvidas as seguintes atividades relacionadas a esses softwares: suporte e assistência técnica aos clientes, adaptações de aplicações para realidades nacionais e customização para os clientes. Em cada uma dessas atividades possuem cargos definidos no dispositivo "Plano de cargos e carreiras". Relembrando, esse plano consiste em uma aplicação dentro do programa informático de gestão de recursos humanos da empresa. As carreiras ligadas às atividades mencionadas estão organizadas a partir de uma carreira inicial chamada "funcional" que, depois do seu maior nível de senioridade, há três carreiras: gestão de pessoas, gestão de projetos e gerência funcional. Por sua vez, nessas carreiras há diferentes cargos divididos em cinco níveis de senioridade. Por fim, cada cargo na empresa é vinculado a um nível de senioridade dentro de uma das quatro carreiras.

O planejamento da demanda, desse modo, acontece em termos de perfis de competências técnicas e é feito a partir de relações sociotécnicas entre os agentes humanos do RH, os diversos níveis de direção corporativa da EC2, o dispositivo "Plano de cargos e carreiras" e o sistema informático de gestão de recursos humanos. Ademais, esse planejamento é ainda aprimorado por meio da relação entre os agentes humanos do RH e os gestores de áreas técnicas.

O valor de uso é expresso nas definições de perfil de competências técnicas para cada um dos cargos da EC2; ou seja, essas definições de perfis correspondem às características profissionais tidas como necessárias à realização das tarefas estabelecidas para os cargos dentro da empresa. No que se refere ao planejamento da demanda em termos de competências técnicas, há ainda uma competência técnica considerada como necessária para qualquer um dos cargos da empresa, a saber, falar e compreender a língua inglesa. A proficiência de inglês é calculada pelo seu valor de uso, pois a unidade possui clientes que falam essa língua e todos os materiais técnicos utilizados para qualquer uma das atividades de desenvolvimento de software e de suporte técnico, estão redigidos nesse idioma. Por último, a outra competência técnica inserida no planejamento da demanda por força-de-trabalho da EC2, que também possui valor de 
uso, é a proficiência em duas linguagens de programação utilizadas pela empresa: Java e uma linguagem desenvolvida pela EC2.

Há ainda um grupo de competências que ficam na fronteira entre técnicas e comportamentais, e cuja demanda no mercado de trabalho, advém do seu valor de uso. Esse grupo é formado por: habilidade de comunicação, perspicácia de negócios ${ }^{95}$, criatividade, foco nos resultados, saber colaborar e trabalhar em grupo e a habilidade para lidar com problemas complexos.

Através da relação entre o dispositivo "cultura da empresa" e os agentes humanos do RH, o planejamento da demanda é realizado tomando em consideração esse grupo de competências técnico-comporamentais, mencionadas no parágrafo anterior, e as competências comportamentais. Essas competências comportamentais e técnicas expressam também valor de uso porque estabelecem um perfil de profissional considero compatível com o ambiente e o modelo de gestão do trabalho da EC2. Esse ambiente e o modelo de gestão, por seu turno, expressam a cultura da empresa.

Nesse sentido, trata-se de um trabalhador capaz de se adaptar a um ambiente de trabalho informal, com poucas hierarquias e sem controle de horários. As competências comportamentais ainda incluem o comprometimento com a satisfação do cliente; ser responsável e manter a palavra nos compromissos profissionais assumidos; profissionalismo no sentido de sempre buscar se aperfeiçoar e de se esforçar ao máximo no seu trabalho; tratar com respeito a todos; integridade e sinceridade ao lidar com colegas de trabalho, parceiros e clientes; valorizar o trabalho em equipe; ser uma pessoa confiável que assume responsabilidades e ativamente participa para alcançar o sucesso da sua equipe. Essa definição de perfil comportamental, estabelecida através das relações sociotécnicas entre $\mathrm{RH}$, gestores de áreas técnicas e o dispositivo "cultura da empresa", materializa o planejamento da demanda de trabalho em termos de valores de uso.

Interessante notar também que, a relação sociotécnica entre agentes humanos e a cultura da empresa no planejamento da demanda através de competências comportamentais e técnicas, são ainda valorizadas simbolicamente. A cultura da EC2 proporciona um ambiente e um modelo de gestão do trabalho que são tidos como responsáveis por tornar a EC2 uma empresa inovadora e uma líder capaz de mudar a

${ }^{95}$ Seria a habilidade de o profissional encarar suas atividades, responsabilidades e metas como se a empresa fosse seu cliente. Em outros termos, o profissional apresenta iniciativa para exercer sua função sem que seja diretamente supervisionado em todo o processo. 
forma como outras empresas (suas clientes) fazem negócios. O planejamento da demanda por competências comportamentais e técnicas, que encarnam à cultura da empresa, simboliza a aquisição de um perfil especial de profissional, que faria da EC2 uma empresa líder e inovadora. Ao mesmo tempo, essa noção de inovação remete em produzir um "estado de coisas" almejado, ou seja, as competências comportamentais e técnicas, no planejamento da demanda, também são procuradas pelo seu valor fisico, pois seriam capazes de trazer para dentro da firma, profissionais com atitudes e capacidades que levariam a EC2 a se tornar uma empresa inovadora e líder no seu segmento de mercado (estado de coisas).

Esse conjunto de competências técnicas e comportamentais é, portanto, valorizado pelo seu valor de uso, simbólico e físico. O planejamento da demanda dessas competências ocorre através de relações sociotécnicas entre agentes humanos do RH, gestão corporativa, gestores de áreas técnicas e os dispositivos "cultura da empresa", "plano de cargos e carreiras" e o sistema informático de gestão de RH.

Além das características dos profissionais que a empresa calcula contratar, o planejamento da demanda envolve definições sobre quantos funcionários serão contratados durante determinado período de tempo, em quais cargos da EC2 e quanto será pago de salário e benefícios. No número de contratações, o planejamento é feito através de relações entre os seguintes agentes humanos: conselho de acionistas, diretores comerciais e executivos de nível corporativo, equipe do RH e os gestores de áreas técnicas, sendo que a interação e comunicação entre esses agentes são mediadas pela intranet fornecida no sistema informático de gestão de recursos humanos. Nesse planejamento é calculado o valor de investimento, pois novas contratações são aprovadas considerando-se as necessidades para o atendimento do volume de clientes e as metas de "lucro operacional". O planejamento de salários é também executado pelas relações sociotécnicas entre os agentes humanos e o não-humano acima mencionados, calculando ainda o custo de investimento que a EC2 terá que pagar visando alcançar tanto o retorno em aumento de produtividade para atender a demanda dos seus clientes como para alcançar o lucro definido pelos acionistas.

A distribuição das contrações entre cargos/perfis profissionais é planejada através das relações entre gestores de área técnica, coordenadora do RH e o diretor geral da unidade. Os gestores identificam a necessidade de contratação de certos cargos em razão de alcançar resultados de produtividade esperados em sua área. A definição do perfil de profissional adequado para as contratações é aprimorada pela relação 
sociotécnica entre gestor, RH e o aplicativo de "Plano de Cargos e Carreiras" (agente não-humano).

O planejamento da demanda que envolve as questões de salários é feito pelo mesmo conjunto de agentes humanos no planejamento de contratações, porém com a inserção de outro dispositivo de cálculo, a "pesquisa de salários". Nessa o planejamento em termos de salários se escuda calculando o valor econômico relacional, porque a pesquisa expressa a definição dos salários pagos pela EC2 considerando outras empresas do setor de tecnologia da informação. Simultaneamente, o valor econômico relacional também se expressa de outra forma na EC2, a saber, o chamado critério de "equity" interno. Esse critério estabelece que os salários para os diferentes cargos da EC2, que são também comparados pela média salarial formada no mercado e expressa no dispositivo "pesquisa de salários", não pode se afastar dos salários que já são pagos dentro da empresa. Portanto, o planejamento da demanda acerca de salários é feito calculando o valor relacional.

Por fim, o planejamento da demanda na questão do programa de beneficios, segue a mesma estrutura de relações entre agentes humanos e não-humanos, mas apenas considerando o valor econômico relacional, não o de investimento.

Portanto, na EC2, o planejamento da demanda estabelece as vagas para contratações de cargos, que possuem diferentes perfis de competências técnicas, mas o mesmo conjunto de competências comportamentais. Uma vez realizado esse planejamento, a EC2 irá calcular a disponibilidade para realização dessa demanda no mercado de trabalho; ou seja, ela executa operações de cálculo de recrutamento, seleção e contratação. Analisemos a partir de quais relações sociotécnicas essas operações são possíveis.

As informações e decisões produzidas no momento do planejamento da demanda tomam forma em um sistema informático de gestão de recursos humanos. Neste sistema, por exemplo, um gestor de área técnica comunica a necessidade de contratação para certo tipo de cargo cujo perfil de competências técnicas e comportamentais, descrição da função, resultados esperados na atividade e a faixa salarial paga, estão registrados em um aplicativo desse sistema, o "Plano de Cargos e Carreiras". Esse pedido de contratação é transmitido, via esse sistema, para os diretores corporativos de diferentes níveis, que irão aprovar ou não esse pedido conforme critérios financeiros e comerciais da empresa. Sendo aprovada a abertura da vaga, a informação é repassada à coordenadora de RH, que vai ajustar a descrição dos requisitos 
para preenchimento da vaga. A coordenadora, então, repassará também via sistema, o aviso de abertura da vaga para as recrutadoras. Uma delas se reunirá com o gestor da área técnica correspondente à vaga e, com ele, vão acertar detalhes de tempo para o preenchimento da vaga, dúvidas sobre o perfil de competências requeridas e estratégias de recrutamento.

Uma vez que ocorre esse processo acima descrito, a recrutadora responsável pela vaga dá início à operação de recrutamento. Tal operação de cálculo é feita pela relação sociotécnica entre a recrutadora e o dispositivo "banco de currículos", que assumi duas formas: uma aplicação disponibilizada pelo sistema informático de gestão de RH e uma planilha de Excel mantida pela recrutadora. Quando a vaga para algum cargo é aberta, esse sistema automaticamente anuncia essa vaga na seção de oportunidades de emprego do site da EC2. Neste caso, os candidatos se cadastram no sistema do site da empresa e se candidatam anexando seu currículo ao link da vaga ${ }^{96}$. Esses currículos são, então, armazenados pelo banco conforme correspondem a determinadas vagas. Além disso, esse sistema informático, através de uma intranet, anuncia a vaga em aberto para os funcionários da EC2. Esses últimos podem se candidatar à vaga ou indicar pessoas para ela. O candidato indicado se cadastra no site da empresa, marcando no formulário eletrônico uma opção que informa quem é o funcionário que o indicou.

Além das candidaturas via o site, os bancos de currículos são alimentados por outros canais de recrutamento: anúncios de vagas em aberto no perfil da empresa e da recrutadora no Linkedin $\AA$, Facebook ${ }^{\circledR}$ e Twitter $\AA$, e, também, por meio de divulgação nos sites de oportunidades de carreiras das principais universidades da RMPA.

Até este momento, o recrutamento não é feito de maneira ativa, ou seja, a recrutadora não está buscando, pesquisando a existências de profissionais que se encaixem aos requisitos de uma vaga. À medida que os bancos de currículos são formados por esses canais de recrutamento, a recrutadora calcula a oferta disponível no mercado de trabalho através da análise dos currículos armazenados nos bancos vis-à-vis requisitos básicos de competências para a vaga em aberto, por exemplo, proficiência em inglês, formação acadêmica, nível de experiência profissional, familiaridade com linguagens de programação e/ou de ferramentas de teste. Se a qualidade dos currículos disponível nos bancos não é satisfatória, a recrutadora vai mobilizar relações sociotécnicas com agentes de recrutamento ativo: anúncios em jornal e em sites de

\footnotetext{
96 Nos eventos que a EC2 participa e palestras que promove dentro de Universidades, as recrutadoras solicitam aos presentes que, se tiverem interesse, façam a candidatura via o site.
} 
vagas de emprego. Se ainda não der resultados, a recrutadora pede auxílio de head hunters que são funcionários da própria EC2 e estão localizados no escritório de São Paulo $^{97}$. Através desses meios, os currículos dos candidatos são armazenados pela recrutadora no banco do sistema informático de gestão de RH e na sua planilha de Excel.

Portanto, as condições de possibilidade da operação de recrutamento são estruturadas por meio de relações sociotécnicas entre, de um lado, dispositivos de cálculo como os canais de recrutamento e os bancos de currículos e, de outro, a recrutadora. É especialmente por meio do armazenamento e visualização dos bancos de currículos pela recrutadora, que a firma pode calcular a oferta disponível no mercado de trabalho, considerando a natureza da sua demanda por força-de-trabalho, isto é, verificando a disponibilidade do perfil de competências valorizadas pela empresa.

A operação de recrutamento é seguida pela operação de cálculo de seleção. Essa consiste em hierarquizar os possíveis cenários de realização da demanda de trabalho da EC2, que estão representados na oferta disponível no mercado de trabalho, na forma de currículos selecionados no recrutamento. Na operação de seleção, os seguintes agentes estabelecem relações sociotécnicas: os candidatos, a recrutadora, um gestor e um funcionário de área técnica, testes lógicos, exercícios técnicos, técnica de entrevista, assessments e o roteiro de entrevistas.

Em primeiro lugar, o candidato é entrevistado ao telefone pela recrutadora. Nessa entrevista, a recrutadora verifica o nível de inglês do candidato e, através da técnica de entrevista por competências, as competências comportamentais. Além dessa entrevista, a recrutadora utiliza os seguintes testes para selecionar o candidato: 1) teste de raciocínio lógico G36 para medir a capacidade de raciocínio do candidato. Esse teste é aplicado e avaliado por um profissional da área de psicologia. Na EC2, tal teste é usado como critério eliminatório no caso de baixa pontuação e como classificatório; 2) Professional Profile Assessment (PPA) que verifica as seguintes competência comportamentais: grau e tipo de motivação para o trabalho, orientação para gerar valor para o negócio e o comportamento sob pressão. A EC2 aplica esse teste para algumas vagas, especialmente as que envolvem tarefas de contato com clientes; 3) exercícios de códigos de programação ou de teste de software que são elaborados pelos gestores de áreas técnicas, visado medir a habilidade nessas competências técnicas.

\footnotetext{
${ }^{97}$ Não foi possível fazer entrevistas com nenhum desses head hunters da EC2.
} 
Os candidatos ainda passam por uma entrevista presencial realizada em dupla pelo gestor da área técnica e um profissional técnico, ambos com treinamento na técnica de entrevistas por competências. Conforme já exposto, essa entrevista visa avaliar tanto competências técnicas como as comportamentais ligadas à cultura da empresa - as chamadas "paixões da EC2". Os entrevistadores elaboram um roteiro de perguntas, baseado nessa técnica de entrevistas e nos parâmetros estabelecidos pelo assessment de avaliação do candidato. Relembrando, esses parâmetros correspondem às competências comportamentais definidas pela cultura da empresa e as competências técnicas definidas pelo "plano de cargos e carreiras" e o conhecimento sobre área e as preferências do gestor.

É por meio, então, das relações sociotécnicas entre a recrutadora, gestor e funcionário de área técnica, testes, exercícios técnicos, técnica de entrevista, assessment e o roteiro de entrevistas, que a operação de cálculo de seleção é executada; ou seja, nela os possíveis cenários de realização da demanda de trabalho da firma, representados pelos candidatos recrutados, são hierarquizados conforme o perfil para a vaga em aberto.

Ao final, inicia-se a operação de contratação. No caso da EC2, o gestor de área técnica é o responsável por tomar a decisão a respeito de quem, entre os candidatos selecionados, será contratado. Cabendo ao RH apenas verificar, e se necessário ajustar com o gestor, a sugestão de salário e senioridade que foi atribuída ao candidato, e verificando principalmente se não vai haver conflito com o critério de equity interno.

Portanto, no caso da EC2, as operações de cálculo - planejamento da demanda, recrutamento, seleção e contratação - são executadas através das condições de possibilidade de uma rede sociotécnica bem estruturada, resultando em funções e processos bem claros de inserção dos agentes humanos e não-humanos que compõem essa rede. Através dessas operações são calculadas as ofertas de força-de-trabalho em termos de perfis de competências técnicas e comportamentais valorizadas pela empresa. Justamente através dessas operações, a EC2 consegue verificar a presença dessas competências e, por conseguinte, a qualidade das ofertas disponíveis no mercado de trabalho. Por fim, esses perfis de competências técnicas e comportamentais materializam para a EC2 os valores econômicos de uso, simbólico, físico, relacional e de investimento - portanto, são esses valores que são calculados pelas operações executadas a partir da rede sociotécnica da EC2. 


\subsection{Estudo de Caso 3: o cálculo de valor em formação da nova}

\section{economia}

A tabela abaixo esquematicamente apresenta a alocação dos agentes humanos e dos dispositivos de cálculo, que entram em relação sociotécnica em cada operação da capacidade de cálculo de valor da demanda por força-de-trabalho da EC3.

Tabela 33 - Rede Sociotécnica e Operações de Cálculo de Valor da EC3.

\begin{tabular}{|c|c|c|c|c|c|}
\hline & & $\begin{array}{c}\text { Planejamento } \\
\text { da Demanda }\end{array}$ & Recrutamento & Seleção & Contrato \\
\hline \multirow{4}{*}{$\begin{array}{c}\text { Agentes } \\
\text { Humanos }\end{array}$} & $\begin{array}{l}\text { Direção Executiva e } \\
\text { Comercial }\end{array}$ & $\sqrt{ }$ & & & \\
\hline & Gestores de Áreas Técnicas & $\sqrt{ }$ & & $\sqrt{ }$ & $\sqrt{ }$ \\
\hline & Coornador de RH & $\sqrt{ }$ & & & $\sqrt{ }$ \\
\hline & Recrutadores & & $\sqrt{ }$ & $\sqrt{ }$ & $\sqrt{ }$ \\
\hline \multirow{18}{*}{$\begin{array}{l}\text { Dispositivos de } \\
\text { Cálculo }\end{array}$} & Programa de Benefícios & $\sqrt{ }$ & & & $\sqrt{ }$ \\
\hline & $\begin{array}{l}\text { Sistema Informático de } \\
\text { Gestão de RH }\end{array}$ & $\sqrt{ }$ & $\sqrt{ }$ & $\sqrt{ }$ & $\sqrt{ }$ \\
\hline & Pesquisa de Salários & $\sqrt{ }$ & & & \\
\hline & Teste de Exercício Técnico & & & $\sqrt{ }$ & \\
\hline & Testes Lógicos & & & $\sqrt{ }$ & \\
\hline & $\begin{array}{l}\text { Teste de Redação em } \\
\text { Português }\end{array}$ & & & $\sqrt{ }$ & \\
\hline & $\begin{array}{l}\text { Entrevista } \\
\text { Técnica/Profissional }\end{array}$ & & & $\sqrt{ }$ & \\
\hline & Entrevista Comportamental & & & $\sqrt{ }$ & \\
\hline & Cultura da Empresa & & & $\sqrt{ }$ & \\
\hline & Site da Empresa & & $\sqrt{ }$ & & \\
\hline & Formulários de Assessment & & & $\sqrt{ }$ & \\
\hline & Currículos & & $\sqrt{ }$ & $\sqrt{ }$ & \\
\hline & Banco de Currículos & & $\sqrt{ }$ & & \\
\hline & Sites de Redes Profissionais & & $\sqrt{ }$ & & \\
\hline & Sites de Redes Sociais & & $\sqrt{ }$ & & \\
\hline & Universidades & & $\sqrt{ }$ & & \\
\hline & Técnica de Entrevista & & & $\sqrt{ }$ & \\
\hline & Sites de Vagas de Emprego & & $\sqrt{ }$ & & \\
\hline
\end{tabular}

Fonte: Dados de Pesquisa de Campo.

Nas operações de cálculo da demanda de trabalho da EC3 são calculados cinco tipos de valores econômicos: o de uso, o de investimento, o relacional, o físico e o simbólico. Tal como nas demais seções, inicia-se com a definição das relações sociotécnicas formadas por agentes humanos e não-humanos que fazem o planejamento da demanda calculando o valor econômico de uso.

A EC3 é uma empresa de software customizável. Isso quer dizer que ela produz programas de computador que servem para gestão de empresa e esses programas podem ser adaptados conforme especificações de cada um de seus clientes. Na unidade pesquisada são produzidos softwares para empresas do segmento da saúde e do 
segmento de atividades financeiras. A produção desses produtos basicamente exige dois tipos de perfis de competências técnicas e comportamentais. Em primeiro lugar, no campo das competências técnicas, há os profissionais que exercem cargos que requerem maior nível de conhecimento no desenvolvimento de códigos de linguagens de programação e os outros que exigem menor conhecimento em programação, porém mais competências em outras áreas necessárias à produção do software, por exemplo, análise de teste e qualidade, suporte ao usuário e analista de negócios. Em segundo lugar, no campo das competências comportamentais, a variação se organiza entre profissionais com habilidades para lidar com os clientes e aqueles descritos como "mais introvertidos" e que lidam diretamente com a tecnologia. Assim sendo, a EC3 calcula quatro modalidades de valores de uso no planejamento da demanda para dois pares de competências.

Uma vez que o dispositivo de cálculo que estabelece esse perfil de competências técnicas - basicamente, planos de cargos e carreiras - não está plenamente formado dentro da EC3, o cálculo do valor de uso dos perfis de competências técnicas é executado na relação entre agentes humanos do $\mathrm{RH}$ e os gestores de áreas técnicas, que possuem conhecimentos sobre habilidades técnicas necessárias aos diferentes cargos e níveis de senioridade da sua área. Portanto, por meio dessa relação que se aprimoram os perfis de competências técnicas, que estão fracamente definidos em um plano de cargos e carreiras em formação, que somente estabelece em linhas gerais alguns cargos e competências técnicas dentro da EC3. Essa definição é necessária ao planejamento da demanda para o cálculo do valor de uso.

Apesar de ser considerada em formação e também recente, o dispositivo "cultura da empresa" exerce relação sociotécnica com os agentes humanos do RH, fornecendo definições sobre competências comportamentais. Essas competências comportamentais, no planejamento da demanda, expressam um valor de uso no sentido de definirem um perfil de profissional compatível com o ambiente e o modelo de gestão do trabalho da EC3. Esses elementos são justamente informados na relação entre RH e o dispositivo "cultura da empresa". Nesse sentido, trata-se de um trabalhador capaz de se adaptar a um ambiente de trabalho com algum grau de formalidade, tanto na maneira de se vestir como em processos ligados a menor flexibilidade no horário de trabalho, que se acostume à comunicação com os diferentes níveis de hierarquia dentro da empresa. Além disso, as competências comportamentais incluem o saber trabalhar em equipes, o interesse em produzir inovação e a capacidade de olhar o negócio da empresa como um 
todo, não se prendendo apenas na tarefa e cargo que exerce. Por fim, os cargos que requerem maior contato com clientes requerem obviamente essa capacidade comportamental; mas, também, por meio da relação entre RH e gestores de áreas técnicas, esses últimos informam sua preferência em ter na equipe um profissional com certo perfil comportamental como ser mais ou menos extrovertido. Todas essas definições dos perfis comportamentais alcançadas a partir das relações sociotécnicas entre $\mathrm{RH}$, gestores de áreas técnicas e o dispositivo "cultura da empresa" materializam, na EC3, boa parte do planejamento da demanda de trabalho em valores de uso.

A cultura da empresa, então, como dispositivo em relação com RH e gestores, define, quando do planejamento da demanda, um perfil de competências comportamentais. Esse perfil, por sua vez, é valorizado pela empresa por seu valor de uso; mas, também, por seu valor simbólico.

O valor simbólico é expresso no fato de que essas competências comportamentais são valorizadas por simbolizarem um perfil especial de profissionais, que seriam capazes de provocar inovação dentro da empresa. Conforme exposto no capítulo anterior, na EC3 a inovação é compreendida a partir de uma concepção abrangente, isto é, ela não é tida como uma tarefa específica realizada por um grupo de profissionais dentro da empresa. Por isso, a inovação está ligada a um perfil de competências comportamentais que são comuns para todos os funcionários contratados pela EC3. Simultaneamente, essa concepção mais abrangente de inovação é concebida também como um "estado de coisas" almejado pela empresa; ou seja, as competências comportamentais, no planejamento da demanda, são calculadas pelo seu valor físico por serem capazes de trazer para dentro da empresa, aqueles profissionais com atitudes e comportamentos cujo resultado seria tornar a EC3 uma firma inovadora (estado de coisas). Basicamente, essas competências são valorizadas pelo seu valor de uso, simbólico e físico, que devem ser demandadas para todos os profissionais contratados pela EC3. Essas competências são o saber trabalhar em equipe, importar-se e colaborar com soluções para processos da empresa além daqueles da sua área de trabalho, ter iniciativa e buscar exercer papel de liderança, manter o foco e buscar o melhor resultado na sua atividade profissional, interesse genuíno em desenvolver novas ideias e no aprendizado contínuo.

Até aqui foi analiticamente exposto o planejamento da demanda que diz respeito às competências técnicas e comportamentais que a EC3 buscará demandar no mercado de trabalho. Todavia, há ainda o conjunto de relações sociotécnicas que estabelecem o 
planejamento da demanda sobre quantos funcionários serão contratados, para quais cargos e qual será o salário oferecido nessas contratações.

No caso do planejamento do número de contratações, ele é feito através das relações entre os seguintes agentes humanos: diretores comerciais e executivos do nível corporativo, equipe do RH e gestores de áreas técnicas. Esse planejamento passa pelo cálculo do valor de investimento, pois as novas contratações são aprovadas, por esse grupo, se elas representarem ganhos de produtividade necessários ao atendimento do número e da natureza dos projetos de desenvolvimento de software para clientes. Simplificando, uma vez que a EC3 estabelece contrato para o fornecimento de software para, por exemplo, uma cadeia de lojas de varejo, novas contratações são planejadas por esses agentes, sendo que os gestores de áreas técnicas fornecem as informações referentes aos tipos de perfis técnicos de profissionais que serão requeridos - analistas de teste, desenvolvedores, técnicos de suporte, etc. Portanto, o planejamento da demanda por novos funcionários é feito calculando o valor de investimento, expresso através da expectativa de ganhos de produtividade. Tal como constatado no capítulo anterior, a questão salarial provavelmente é uma das considerações que entram nesse planejamento de novas contratações; portanto, os salários pagos pela empresa representariam o custo de novas contratações cujo planejamento da sua demanda é feito tendo como referência o valor de investimento.

Ademais, esse cálculo dos salários no planejamento da demanda é executado pelo mesmo conjunto de agentes humanos no planejamento de contratações, porém também se insere aí um dispositivo de cálculo, a "pesquisa de salários". O planejamento da demanda em termos de salários se escuda no valor econômico relacional porque a pesquisa expressa justamente a tomada em consideração dos salários pagos por empresas que competem com a EC3 na contratação de profissionais de TI. Já a definição do programa de benefícios da EC3 também apresenta a consideração de valor relacional no planejamento da demanda. Conforme o exposto no capítulo seis, as entrevistas mostram que os valores de itens que compõem o seu programa de benefícios, especialmente vale-refeição, são avaliados pelos agentes humanos do RH em relação ao que são pagos por outras empresas.

No planejamento da demanda por força-de-trabalho, na EC3, identificou-se, então, que nas relações sociotécnicas há a inserção de agentes humanos como diretores corporativos da empresa, gestores de áreas técnicas e membros do RH e, também, dispositivos de cálculo como a cultura da empresa, um plano de cargos e carreiras em 
formação e a pesquisa de salários. O planejamento calcula cinco valores econômicos em diferentes tipos de decisões, sendo esses valores o de uso, de investimento, o simbólico, o físico e o relacional. A partir desse planejamento, a EC3 estabelece perfis de competências técnicas e comportamentais que ela irá calcular a sua disponibilidade, quando decidir comparecer ao mercado de trabalho. Sendo assim, cabe agora descrever analiticamente as operações de cálculo e suas respectivas relações sociotécnicas, que a EC3 lança mão para concretizar a sua demanda no mercado de trabalho.

As informações e decisões produzidas no processo de planejamento da demanda são materializadas em um sistema informático de gestão de recursos humanos. Neste sistema, por exemplo, um gestor de área técnica comunica a necessidade de contratação para certo tipo de cargo e também descreve o perfil técnico que o profissional deverá ter para esse cargo. Esse pedido de contratação é transmitido, via sistema, aos diretores corporativos que irão aprovar ou não esse pedido conforme critérios financeiros e comerciais da empresa. Sendo aprovada a abertura dessa vaga, a informação é repassada ao RH que irá iniciar as operações de cálculo com vista ao preenchimento dessa vaga.

Além dessa articulação de informação que ocorre no sentido de baixo para cima, há outra na qual os diretores corporativos planejam a estratégia da empresa como um todo, e nesta estratégia, elaboram metas de contratações de certos tipos profissionais de TI para as unidades da EC3. Essa informação é repassada, então, no sistema tanto para os gestores de áreas técnicas como para o coordenador de RH, que juntos irão melhor definir o perfil de competências técnicas requeridas para essas vagas abertas por decisão da direção corporativa da empresa. Enfim, por um ou outro caminho, a decisão de abertura de vagas e as informações sobre os perfis de competências técnicas dos cargos, ambos circulam e ocorrem por meio desse agente não-humano que é o sistema informático de gestão de RH da EC3.

Uma vez realizado o processo acima descrito, o time de $\mathrm{RH}$, especialmente a recrutadora, dá início à operação de recrutamento. Essa operação de cálculo é feita a partir da relação sociotécnica entre a recrutadora e o dispositivo "banco de currículos" (agente não-humano), sendo que esse dispositivo é também disponibilizado pelo sistema informático de gestão de RH. Quando a vaga para algum cargo é aberta no sistema, este automaticamente anuncia na seção de oportunidades de emprego do site da EC3. Neste caso, os candidatos se cadastram no sistema do site da empresa e se candidatam a uma vaga por meio do anexo do seu currículo no link da vaga em aberto. Esses currículos 
são armazenados pelo banco conforme a correspondência entre uma vaga e os currículos que se candidataram para ela.

Ademais, a recrutadora, antes de buscar candidatos de fora da empresa, ela verifica no mercado de trabalho interno da empresa, os funcionários que poderiam ocupar essa vaga e que teriam interesse nela. Se isso não for possível, ou seja, se a contratação interna não é viável, então a recrutadora irá verificar o banco de currículos para visualizar a oferta disponível de profissionais para o cargo da vaga em aberto. Além das candidaturas via o site da empresa, o banco é alimentado por outros canais de recrutamento: as indicações ${ }^{98}$, anúncios das vagas no perfil da empresa no Linkedin ${ }^{\circledR}$ e pedido por e-mail aos professores de universidades para divulgarem a vaga. Nota-se que até este momento, o recrutamento não é feito de maneira ativa por parte da empresa e recrutadora.

Uma vez que o banco de currículos é formado pelos canais de recrutamento acima descritos, a recrutadora avaliará essa oferta disponível no mercado de trabalho através dos currículos armazenados no banco vis-à-vis requisitos básicos de competências técnicas para o cargo da vaga em aberto. Se a qualidade dos currículos, ou mesmo a quantidade dos mesmos no banco, não forem satisfatórias, a recrutadora trava relações sociotécnicas com agentes não-humanos de recrutamento ativo, quais sejam: busca e contato com profissionais por meio do Linkedin ${ }^{\circledR}$ e anúncios em sites de vagas de emprego. Através desses meios, os currículos dos candidatos são armazenados pela recrutadora dentro do banco do sistema informático de gestão de RH. Portanto, a operação de recrutamento se desenrola por meio da relação sociotécnica entre, de um lado, dispositivos de cálculo como os canais de recrutamento, banco de currículos e currículos, e, de outro, a recrutadora. Essa relação sociotécnica é que torna possível à firma calcular a oferta disponível no mercado de trabalho, considerando os parâmetros que definem a sua demanda. Em outros termos, essa relação sociotécnica executa a operação para calcular a disponibilidade no mercado de trabalho de ofertantes com o perfil de competências valorizadas pela empresa e consideradas necessárias para o bom desempenho de um cargo. Cabe reforçar que, os pré-requisitos de competências técnicas, e até algumas comportamentais, são mormente definidos através da relação entre a recrutadora e o gestor da área técnica.

\footnotetext{
${ }^{98}$ Cabe lembrar que, quando do momento da pesquisa de campo, a EC3 não contava com um programa de indicações em funcionamento. As indicações ocorriam por iniciativa espontânea dos funcionários da empresa e por avisos de vagas abertas, divulgados pela equipe de $\mathrm{RH}$ via e-mail.
} 
O cálculo da oferta disponível no mercado de trabalho é realizado quando são selecionados currículos e, em seguida, os candidatos donos dos currículos são chamados para os procedimentos que conformam a operação de cálculo de seleção. Essa consiste em hierarquizar os possíveis cenários de realização da demanda de trabalho da EC3, que estão representados na oferta disponível no mercado de trabalho sob a forma de currículos selecionados no recrutamento. $\mathrm{Na}$ seleção, os seguintes agentes travam relações sociotécnicas: a recrutadora, um gestor de área técnica, teste lógico, exercícios técnicos, redação, técnica de entrevista e roteiro de entrevistas.

O teste lógico e a redação são aplicados e avaliados pela recrutadora. Eles são utilizados como dispositivos de cálculo para avaliar competências que ficam na fronteira entre o comportamental e o técnico - respectivamente, a capacidade de raciocínio e de aprendizado do candidato e sua habilidade de expressão escrita em português. Nota-se que o primeiro é um dispositivo que calcula algo que está relacionado ao valor que a EC3 atribui a profissionais capazes de produzirem "novas ideias", inovação num sentido amplo. O segundo se liga à questão da necessidade da empresa ter profissionais com habilidade de relação com o cliente; assim, saber se expressar corretamente e de maneira clara através da escrita, é uma forma de verificar e calcular essa habilidade no candidato. Ambos os dispositivos de cálculo são utilizados como critérios de eliminação e de seleção dos candidatos.

Os exercícios técnicos são para verificar, na prática, o grau de proficiência do candidato em competências específicas. Assim, por exemplo, um candidato para uma vaga de desenvolvedor irá fazer um exercício de desenvolvimento de código numa linguagem de programação que a EC3 utiliza nos seus projetos. Os exercícios são elaborados pelos gestores de áreas técnicas.

Os candidatos ainda passam por uma entrevista com o RH e outra com o gestor da área técnica. $\mathrm{Na}$ entrevista com a recrutadora são calculadas as competências comportamentais, mais do que as técnicas. Com base numa leitura prévia do currículo do candidato, na técnica de entrevista por competência e no roteiro de entrevistas, a recrutadora, em relação sociotécnica com esses dispositivos, faz perguntas de experiências passadas do candidato que expressam tanto o uso de competências comportamentais como algumas competências técnicas básicas (nível de experiência profissional, formação acadêmica, pretensão salarial e remuneração recebida no último emprego). $\mathrm{O}$ roteiro de entrevista traz perguntas abertas que servem para calcular as competências comportamentais, isto é, o saber trabalhar em equipe, importar-se e 
colaborar com soluções para processos da empresa além daqueles da sua área de trabalho, ter iniciativa e buscar exercer papel de liderança, manter o foco e buscar o melhor resultado na sua atividade profissional, interesse genuíno em desenvolver novas ideias e no aprendizado contínuo. Também a recrutadora leva em consideração atributos de perfil comportamental que estão ligados às preferências transmitidas pelo gestor de área, por exemplo, se a pessoa é introspectiva ou não. Cabe destacar que, essa entrevista pode ser feita por telefone, assim como, parte dela, é feita em inglês para justamente avaliar o grau de competência do candidato nesse idioma. Por fim, uma vez que o candidato apresenta os requisitos de competências técnicas básicas para o cargo da vaga em aberto e as competências comportamentais valorizadas, a recrutadora decide encaminhá-lo para a entrevista com o gestor de área.

$\mathrm{Na}$ entrevista com o coordenador de área técnica, além do cálculo de perfil comportamental mencionado acima, ele verifica, sobretudo, as competência técnicas através da relação sociotécnica com o currículo do candidato e o roteiro de entrevista utilizado pela recrutadora. Esse último faz com que o recrutador calcule as competências técnicas dos candidatos através de relatos das experiências profissionais. Ao fim do roteiro de entrevista, o gestor de área técnica deve marcar se o candidato foi ou não aprovado, explicando o porquê. Portanto, a operação de seleção é realizada para calcular as competências comportamentais e técnicas dos candidatos e, desse modo, classificá-los e hierarquizá-los de acordo com quão eles satisfazem o perfil elaborado, quando do planejamento da demanda.

Por fim, munidos de suas avaliações, RH e gestores técnicos decidem em conjunto a contratação. No caso da EC3 foi relatado que a palavra final a respeito de quem, entre os candidatos selecionados para uma vaga, será contratado, é de responsabilidade do coordenador de área técnica. Nesse sentido, cabe ao time de RH apenas verificar se a pretensão salarial declarada pelo candidato é compatível com o valor pago na EC3 para os funcionários com o mesmo nível de senioridade que o gestor atribui ao candidato.

\subsection{Estudo de Caso 4: o cálculo de valor adensado da nova economia}

A tabela abaixo esquematicamente apresenta a alocação dos agentes humanos e dos dispositivos de cálculo, que entram em relação sociotécnica em cada operação da capacidade de cálculo de valor da demanda por força-de-trabalho da EC4. 
Tabela 34 - Rede Sociotécnica e Operações de Cálculo de Valor da EC4.

\begin{tabular}{|c|c|c|c|c|c|}
\hline & & $\begin{array}{l}\text { Planejamento } \\
\text { da Demanda }\end{array}$ & Recrutamento & Seleção & Contrato \\
\hline \multirow{8}{*}{$\begin{array}{l}\text { Agentes } \\
\text { Humanos }\end{array}$} & $\begin{array}{l}\text { Direção Executiva e } \\
\text { Comercial }\end{array}$ & $\sqrt{ }$ & & & \\
\hline & Gestores de Áreas Técnicas & $\sqrt{ }$ & & $\sqrt{ }$ & $\sqrt{ }$ \\
\hline & Coornador de RH & $\sqrt{ }$ & & $\sqrt{ }$ & $\sqrt{ }$ \\
\hline & Recrutadores & & $\sqrt{ }$ & $\sqrt{ }$ & $\sqrt{ }$ \\
\hline & Diretor de Escritório & $\sqrt{ }$ & & $\sqrt{ }$ & $\sqrt{ }$ \\
\hline & $\begin{array}{l}\text { Coordenadora de } \\
\text { Recrutamento }\end{array}$ & $\sqrt{ }$ & $\sqrt{ }$ & $\sqrt{ }$ & $\sqrt{ }$ \\
\hline & Organizadora de Seleção & & & $\sqrt{ }$ & $\sqrt{ }$ \\
\hline & Funcionários Técnicos & & & $\sqrt{ }$ & $\sqrt{ }$ \\
\hline \multirow{22}{*}{$\begin{array}{l}\text { Dispositivos de } \\
\text { Cálculo }\end{array}$} & Programa de Benefícios & $\sqrt{ }$ & & & $\sqrt{ }$ \\
\hline & Plano de Cargos e Carreiras & $\sqrt{ }$ & & & $\sqrt{ }$ \\
\hline & Plano de Cargos e Salários & $\sqrt{ }$ & & & $\sqrt{ }$ \\
\hline & $\begin{array}{l}\text { Sistema Informático de } \\
\text { Gestão de RH }\end{array}$ & $\sqrt{ }$ & $\sqrt{ }$ & $\sqrt{ }$ & $\sqrt{ }$ \\
\hline & Pesquisa Radar Tecnológico & $\sqrt{ }$ & & & \\
\hline & $\begin{array}{l}\text { Reunião de Decisão de } \\
\text { Contratação }\end{array}$ & & & & $\sqrt{ }$ \\
\hline & Teste de Exercício Técnico & & & $\sqrt{ }$ & \\
\hline & Testes Lógicos & & & $\sqrt{ }$ & \\
\hline & $\begin{array}{l}\text { Entrevista } \\
\text { Técnica/Profissional }\end{array}$ & & & $\sqrt{ }$ & \\
\hline & Entrevista Comportamental & & & $\sqrt{ }$ & \\
\hline & Entrevista de Valores & & & $\sqrt{ }$ & \\
\hline & Cultura da Empresa & $\sqrt{ }$ & & $\sqrt{ }$ & $\sqrt{ }$ \\
\hline & $\begin{array}{l}\text { Programas de } \\
\text { Recomendação }\end{array}$ & & $\sqrt{ }$ & & \\
\hline & Site da Empresa & & $\sqrt{ }$ & & \\
\hline & Formulários de Assessment & & & $\sqrt{ }$ & $\sqrt{ }$ \\
\hline & Currículos & & $\sqrt{ }$ & $\sqrt{ }$ & \\
\hline & Banco de Currículos & & $\sqrt{ }$ & & \\
\hline & Sites de Redes Profissionais & & $\sqrt{ }$ & & \\
\hline & Sites de Redes Sociais & & $\sqrt{ }$ & & \\
\hline & $\begin{array}{l}\text { Eventos em Comunidades } \\
\text { de TI }\end{array}$ & & $\sqrt{ }$ & $\sqrt{ }$ & \\
\hline & Universidades & & $\sqrt{ }$ & & \\
\hline & Sites de Vagas de Emprego & & $\sqrt{ }$ & & \\
\hline
\end{tabular}

Fonte: Dados de Pesquisa de Campo.

O cálculo da demanda da EC4 envolve quatro tipos de valores econômicos: o de uso, o de investimento, o simbólico e o físico. Também identificamos a presença de um valor economicamente relevante denominado de "justiça social". A seguir serão descritas analiticamente as relações sociotécnicas que executam o planejamento da demanda, escudam-se nesses cinco valores.

A EC4 é uma empresa de desenvolvimento de softwares por encomenda para gestão de empresas e organizações. Essa atividade pode ser combinada com a de consultoria na área de TI. A EC4 se especializou em clientes com projetos de alta complexidade e de fronteira tecnológica, tendo seu processo de trabalho estruturado 
pelos chamados "métodos ágeis" e também por projetos "Open Source". Esses elementos se manifestam em um ambiente e numa gestão do trabalho marcadas pela informalidade, reduzidos níveis hierárquicos, trabalho por projeto, com forte colaboração com o cliente e realizado em equipes.

A EC4 possui um forte senso de cultura da empresa, que se encontra claramente definido entre seus funcionários e materiais de divulgação da empresa. Conforme exposto no capítulo anterior, na EC4, a cultura foi elaborada pelo fundador da empresa, principalmente no que se refere ao seu conteúdo moral de justiça social. Nesse sentido, os produtos produzidos pela empresa - os softwares de gestão - passam a ser concebidos como ferramentas capazes de produzir mudanças na realidade social, ajudando comunidades e organizações. Tudo isso se encontra amalgamado em "três pilares" que definem a cultura da EC4 - gestão sustentável e eficiente de negócios, inovação e excelência em TI e compromisso com a justiça social. Portanto, esse forte senso de cultura, materializado no ambiente de trabalho, passando pela gestão tecnológica e mercadológica, até o compromisso com o valor moral de justiça social, orienta o planejamento da demanda em termos da elaboração de um perfil de profissional, baseado em um conjunto de competências comportamentais e técnicas. Essas competências são demandadas e calculadas no mercado de trabalho por terem para EC4 um valor moral, de uso, simbólico e físico. Mas quais são essas competências que estão expressas no planejamento da demanda da empresa no mercado de trabalho?

Em primeiro lugar, identificou-se algo considerado como uma competência que é um perfil de profissional genuinamente preocupado com questões de justiça social, ou seja, com sensibilidade para com, por exemplo, problemas ligados à discriminação de gênero ou raça, ou, então, à desigualdade e à pobreza. Esse valor moral se torna justamente um valor economicamente relevante porque ele é calculado no planejamento da demanda da EC4; ou seja, ele é visto e calculado como uma competência comportamental que o candidato precisa possuir para ser contratado pela EC4. Em outras palavras, a preocupação e o engajamento em questões de justiça social são calculadas como uma competência demandada pela EC4, quando essa comparece no mercado de trabalho.

Ao mesmo tempo, essa competência é valorizada pela EC4 por ter um valor simbólico. O planejamento da demanda por força-de-trabalho da empresa também tem que simbolizar essa identidade da firma como "socialmente justa" e isso é obtido através da contratação de pessoas identificadas com a causa da empresa de transformar 
a sociedade através do software; também, tal como evidenciado no capítulo 7, esse valor moral é calculado na elaboração e cumprimento de metas sobre contratar profissionais de grupos considerados pela empresa como "socialmente excluídos e discriminados", por exemplo, negros, homossexuais e mulheres. O planejamento da demanda por essa competência é feito pela relação sociotécnica entre os diferentes agentes humanos dentro da EC4 e o seu dispositivo "cultura da empresa".

O planejamento da demanda também abrange competências comportamentais que têm valor de uso para EC4. A adoção de metodologias ágeis de desenvolvimento de softwares e o envolvimento com projetos de "código aberto" 99 estão relacionados a um ambiente e a um modelo de gestão do trabalho, que são marcados pela informalidade, flexibilidade, uso intensivo de conhecimento, poucas hierarquias, alto nível de contato e colaboração com pessoas externas à empresa. O profissional para se adaptar e bem desempenhar suas atividades dentro das condições desse modelo de gestão de trabalho, ele precisa possuir as seguintes competências comportamentais: saber trabalhar em grupo; capacidade de adaptação e interesse em aprender a lidar com novas ferramentas tecnológicas (que podem mudar de projeto para projeto); orientação para servir ao cliente; visão e preocupação com o negócio da empresa como um todo; capacidade de iniciativa própria; ser responsável pelos seus erros. Basicamente, o planejamento da demanda por essas competências é formulado a partir do conhecimento tácito que os funcionários da EC4 vão elaborando ao trabalhar dentro da empresa, pois, como será analisado adiante, serão esses mesmos funcionários os encarregados de avaliar/calcular essas competências nos candidatos que eles entrevistam.

Muitas das competências comportamentais acima mencionadas são, também, valorizadas pela empresa em função do seu valor econômico físico. O planejamento da demanda em termos de competências comportamentais com valor físico é feito pelos agentes humanos da EC4 em relação sociotécnica com o "segundo pilar" da cultura da empresa, ou seja, a questão da inovação. Ter e contratar profissionais com competências comportamentais que os fazem ser capazes de operar em um ambiente de trabalho organizado segundo os princípios das metodologias ágeis ${ }^{100}$ e com interesse no contínuo aprendizado de novas tecnologias é considerado estratégico para o objetivo da EC4 ser uma empresa inovadora e de excelência tecnológica. O planejamento da demanda por

${ }^{99} \mathrm{O}$ mesmo que open source.

100 Retomando, esses princípios são a redução de hierarquias e processos, trabalho em grupo e em colaboração com clientes e parceiros externos à empresa, flexibilidade e informalidade nas relações de trabalho. 
uma força-de-trabalho com essas competências comportamentais é feito tendo em consideração um valor físico, pois com a sua contratação se pretende produzir um efeito concreto, inovação e excelência tecnológica. Ao mesmo tempo, especialmente o planejamento da demanda por profissionais com a competência comportamental de interesse e capacidade de contínuo aprendizado tecnológico, é também baseado no valor de uso. Sendo a EC4 uma empresa de desenvolvimento de software por encomenda, ela necessita o uso de profissionais com capacidade de lidar e aprender diferentes tipos de ferramentas e conhecimentos da área de TI, tornando possível, deste modo, lidar com as variações exigidas por cada projeto de cada cliente.

Constata-se que, a EC4 planeja a sua demanda por força-de-trabalho visando duas modalidades de competências comportamentais. A primeira, denominada nesta tese de competência comportamental de caráter, que consiste na preocupação e engajamento com questões de responsabilidade social, relacionada, portanto, com o valor moral economicamente relevante de "justiça social" e do valor econômico simbólico. A segunda modalidade são as que foram aqui denominadas de competências comportamentais de natureza profissional, que são aquelas relacionadas tanto ao ambiente e ao modelo de gestão do trabalho, como às exigências do segmento de negócio de consultoria e de desenvolvimento de software por encomenda. Essa segunda modalidade de competências comportamentais, portanto, é valorizada pelo seu valor de uso e físico. O planejamento da demanda da EC4 nos termos desse par de modalidades de competências é realizado através de relações sociotécnicas entre diferentes agentes humanos internos à EC4 (fundador da empresa, diretores executivos, coordenadores e técnicos de RH, gestores e funcionários de áreas técnicas) e os seus dispositivos de cálculo como a "cultura da empresa" e as "metodologias ágeis".

Já o planejamento da demanda em termos de perfis de competências técnicas valorizadas e, por conseguinte, buscadas e calculadas quando do comparecimento da EC4 no mercado de trabalho, esse é elaborado através de relações sociotécnicas entre, de um lado, diretores comerciais e executivos, diretor de unidade, diretor de $\mathrm{RH}$ e coordenadora de recrutamento e, de outro, dispositivos como "plano de carreiras", "plano de cargos e salários" e "pesquisa Radar Técnico e Tecnológico". Os perfis de competências técnicas são basicamente formados por conhecimentos e níveis de proficiência em linguagens de programação, metodologias de teste de software, conhecimentos de análise de negócios, etc. Esses perfis, então, variam de acordo com as áreas profissionais constantes no "plano de carreiras" da EC4 (desenvolvimento, análise 
de teste, análise de negócio, gerência de projetos e gerência de interação) e conforme os cargos definidos em termos de senioridade - "consultant", "senior consultant", "lead consultant" e "principal consultant". Cabe destacar que, esses níveis de senioridade estão presentes em cada uma das modalidades de carreira da EC4 e que a definição desses níveis é feita por uma mistura de tempo de experiência profissional e de nível e abrangência de conhecimentos de TI. Desse modo, cada nível/cargo e cada área possui um perfil de competências técnicas que a EC4 demanda entre os profissionais de TI no mercado de trabalho.

Através da relação com a Pesquisa "Radar" é que são captadas tendências tecnológicas na área das tecnologias da informação que, por sua vez, aprimoram e atualizam as definições de perfis de competências técnicas para os diferentes tipos de carreiras e senioridades. Assim sendo, as competências técnicas têm um valor de uso no planejamento da demanda da empresa, pois elas materializam os pré-requisitos técnicos para que um profissional exerça uma das atividades/cargos necessárias ao desenvolvimento de softwares por encomenda e de serviços de consultoria de TI.

Até este momento foi tratado o planejamento da demanda sobre perfis de competências técnicas e comportamentais que a EC4 calculará na oferta disponível de profissionais no mercado de trabalho. Todavia, há ainda o conjunto de relações sociotécnica que estabelecem o planejamento da demanda em termos de decisões sobre quantidades de trabalhadores que serão contratados, distribuídas em quais cargos e o quanto será pago por essas contratações em termos de salários mais benefícios. Nesse sentido, cabe começar retomando o fato mencionado nos capítulos anteriores, de que a EC4 opera através de uma demanda constante de contratações, isto é, o RH da EC4 não trabalha com um sistema (tal como visto nos casos anteriores) de "abertura de vagas para cargos específicos dentro da empresa”. O que ocorre é que as contratações contínuas devem ser distribuídas entre os diferentes níveis de senioridade e as diferentes áreas de carreiras da empresa, formando uma distribuição em pirâmide na qual a base é o nível mais júnior de profissionais e o topo os mais seniores. Portanto, novamente o dispositivo "planos de cargos e salários" e o "plano de carreira" entram em relação sociotécnica com os agentes humanos - neste caso, recrutadoras, coordenadora de recrutamento e diretor de $\mathrm{RH}$ - para planejar a demanda em termo da distribuição de perfis de competências profissionais a serem contratadas. Também neste aspecto, a relação desses agentes humanos com a pesquisa "Radar Técnico e Tecnológico" é 
relevante, pois direciona a constante demanda para competências técnicas específicas, por exemplo, desenvolvedores proficientes em linguagem Java.

Assim sendo, essa parte do planejamento da demanda se escuda no valor de uso de perfis de competências técnicas para o bom andamento das operações da EC4. Todavia, a empresa também planeja sua demanda com base em metas de critérios nãotécnicos: privilegiar a contratação de profissionais mulheres, negros e/ou homossexuais. Neste caso, o planejamento é realizado calculando o valor moral e o simbólico.

Com relação ao planejamento da demanda em termos de quantidade de contratações e salários a serem pagos, esses são calculados em razão do valor econômico de investimento. Tal como as outras empresas estudadas, a EC4 planeja o número de contratações em função das necessidades para se atender a demanda de clientes. A diferença da EC4, neste aspecto, é que por ela ser uma consultoria/desenvolvedora de software por encomenda, cada cliente é um projeto, ou seja, um tipo de demanda; por isso, o retorno esperado no planejamento da demanda do número de contratações não é medido em termos de aumento de produtividade necessária para atender ou conquistar novos clientes; mas, sim, em termos de profissionais capazes de trabalhar, aprender e se adaptar a um maior número de tecnologias e técnicas, deste modo fazendo a empresa ganhar na sua capacidade de se adaptar às necessidades dos projetos de cada cliente. Por conseguinte, o planejamento da demanda em termos de salários também entra nessa lógica das contratações como valor de investimento, pois a empresa decide quanto irá pagar de acordo com o nível de proficiência e tipos de competências técnicas que o candidato possui. O salário é, então, o custo de investimento que a empresa precisa assumir para adquirir profissionais capazes de lidar com a variedade de competências técnicas necessárias às particularidades tecnológicas dos projetos sob medida para cada cliente da EC4.

$\mathrm{Na}$ EC4, o planejamento da demanda por força-de-trabalho é executado por relações sociotécnicas entre, de um lado, agentes humanos como os diretores executivos e comerciais, diretor de escritório, diretor de $\mathrm{RH}$, coordenadora de recrutamento, gestores e funcionários de áreas técnicas e as recrutadoras; e, de outro lado, participam dessas relações sociotécnicas, os seus dispositivos de cálculo como a cultura da empresa, plano de cargos e salários, plano de carreiras e a pesquisa "Radar Técnico e Tecnológico". O planejamento expressa quatro valores econômicos e um valor moral em diferentes tipos de decisões. A partir desse planejamento, a EC4 estabelece perfis de competências técnicas e comportamentais que ela irá calcular a disponibilidade no 
mercado de trabalho. Sendo assim, cabe analisar quais as relações sociotécnicas possibilitam as operações de cálculo da EC4, quando comparece ao mercado de trabalho.

As informações e decisões produzidas no processo de planejamento da demanda são materializadas em termos de metas de contratações: número de contratações, perfis de competências técnicas, atributos demográficos de profissionais ${ }^{101}$, senioridade e salários. Essas metas são elaboradas através das relações sociotécnicas formadas por diretores executivos e comerciais, diretor de escritório, diretor de RH e coordenadora de recrutamento, como parte do planejamento comercial da empresa (demanda de trabalho como demanda derivada). Uma vez que essas metas são estabelecidas para o ano, a sua realização é feita através do sistema de "demanda permanente" e elas são verificadas e reajustadas através de reuniões periódicas entre recrutadoras, coordenadora de recrutamento e diretores do RH e do escritório. É importante destacar que as operações de cálculo são feitas dentro desse sistema de demanda permanente que, por sua vez, implica em recrutamento ativo, em processos de seleção abertos para cada candidato (não por vagas) e em decisões de contratação para cada candidato.

Tal como na EC2 e na EC3, todo o processo que vai do recrutamento, passando pelos procedimentos de seleção, até o momento da decisão de contratação é organizado e articulado por um sistema informático de gestão de RH. A única diferença no caso da EC4 é que esse sistema não opera com base naquela lógica de comunicação de "vagas abertas". Logo, o que o sistema informático da EC4 organiza é o armazenamento de currículos e informações de candidatos (banco), avaliações que um candidato recebe nas diferentes etapas de seleção e a comunicação entre as diversas pessoas (por volta de 10) que participam do processo de seleção e de decisão de contratação do candidato.

A EC4 privilegia canais de recrutamento ativo justamente em função do sistema de demanda constante e orientado por metas. Todavia, as recrutadoras dispõem de dois canais de recrutamento passivo, a saber, o site da EC4 e uma das formas pela qual o programa de recomendações funciona. No primeiro se tem um espaço onde os profissionais interessados em trabalhar na EC4 podem se candidatarem a um cargo conforme sua lotação entre os escritórios ao redor do mundo da empresa. Via o sistema, a candidatura é avisada para as recrutadoras responsáveis pelo escritório, que, então, acessam as informações preenchidas pelo candidato e o seu currículo. No segundo, a

101 Consiste nas metas de contratações de pessoas de grupos considerados excluídos e 
EC4 tem um programa que oferece bônus financeiro ao funcionário que indicar um candidato com a condição do indicado ser contratado e passar pelo período de experiência (90 dias). Recebendo as indicações, as recrutadoras contatam o candidato indicado para coletar seu currículo e outras informações para cadastro no sistema informático.

O principal meio de recrutamento ativo utilizado pela EC4 são os eventos. Através da pesquisa na Internet, as recrutadoras localizam o que chamam de “comunidades de TI" e organizam eventos presenciais com os membros dessas comunidades. Conforme analisado nos capítulos anteriores, os eventos ocorrem nas mais diversas regiões do território brasileiro e até mesmo em localidades da América do Sul. Neles, as recrutadoras podem não somente coletar currículos de pessoas interessadas em trabalhar na EC4 como, também, elas organizam todo o processo de seleção de candidatos durante um final de semana, os chamados "boot camps". Os eventos são organizados com base no perfil de competência técnica, senioridade profissional e/ou perfil demográfico; por exemplo, foram mencionados eventos apenas para mulheres.

Além desse canal, as recrutadoras travam relações sociotécnicas com um agente não-humano para executar a operação de recrutamento ativo, qual seja: o Linkedin ${ }^{\circledR}$. As recrutadoras utilizam esse site de rede profissional para ativamente procurar profissionais que se encaixem com os perfis técnicos demandados pela $\mathrm{EC} 4^{102}$.

Conforme tratado no capítulo 6, o programa de recomendações é utilizado como canal de recrutamento ativo através de dinâmicas nas quais os funcionários do escritório são chamados pelas recrutadoras para trazerem indicações. As universidades se mostraram uma fonte de recrutamento, porém restrita a um programa de contratações de recém-formados, denominado de "Universidade EC4".

Enfim, através desses canais de recrutamento ativos e passivos, as recrutadoras travam relações sociotécnicas com diferentes tipos de agentes para calcular os cenários possíveis para realização da sua demanda por força-de-trabalho. Em outros termos, na operação de recrutamento as recrutadoras verificam a oferta disponível no mercado de trabalho, calculando as possibilidades de encontrarem profissionais que correspondam às metas que guiam o sistema de demanda contínua da EC4.

\footnotetext{
${ }^{102}$ Dentro dessa mesma lógica, também foi relatado o uso do site de rede social Facebook ${ }^{\circledR}$, porém com menor regularidade.
} 
Uma vez acessada essa oferta disponível, se são identificados dentro dela profissionais que interessem à EC4 contratar, ou seja, que tenham competências técnicas valorizadas pela EC4, esses são chamados para o processo de seleção. Desse modo, a operação de seleção é organizada em torno de um candidato, não um grupo de candidatos potenciais para uma vaga.

$\mathrm{Na}$ EC4, a operação de seleção está dividida em dois grandes grupos de procedimentos: as entrevistas e os testes/exercícios. Com exceção da pré-entrevista, normalmente realizada por telefone, com a recrutadora e a "entrevista gerencial" realizada pelo diretor de escritório, as outras três são realizadas por duplas de entrevistadores selecionadas pelas recrutadoras. A entrevista por telefone avalia questões básicas como nível de inglês do candidato, experiência profissional e formação acadêmica. Uma vez que a recrutadora julga, através da análise de currículo e dessa conversa por telefone, que o candidato apresenta potencialmente o perfil de competências para trabalhar na EC4, ela envia um exercício de código de programação, ou de análise de teste, para o candidato fazer em casa. Esse exercício é avaliado por um dos profissionais da área técnica da EC4, havendo avaliação positiva, o candidato é convidado para fazer os outros tipos de entrevistas e testes.

Conforme analisado nos capítulos anteriores, não há uma técnica de entrevista aplicada na EC4, os entrevistadores, frequentemente funcionários de diferentes níveis e áreas da empresa, aprendem a fazer entrevistas na prática, observando o seu par que já tem maior experiência nesse sentido. Os tipos de entrevistas se dividem pela natureza das competências que são avaliadas nelas: 1) "entrevista cultural ou de valores", que busca identificar se o candidato compartilha ou não das preocupações sociais da empresa e se tem entusiasmo para com o mundo da tecnologia. Trata-se, portanto, de procedimento da operação de seleção que calcula as competências comportamentais de caráter; 2) entrevista técnica na qual o candidato responde perguntas que verificam o seu nível de conhecimento em certas questões tecnológicas e técnicas, além da sua atitude de trabalho, por exemplo, se tem experiência e como trabalha em grupo, tem uma postura aberta para o aprendizado de novas linguagens de programação, possui integridade e assumi responsabilidade por erros cometidos, trabalha orientado para satisfação do cliente e sabe se comunicar com esse último. É um procedimento que calcula as competências técnicas e principalmente as competências comportamentais de natureza profissional; 3) entrevista técnica de codificação ou de teste, na qual o candidato trabalha junto com a dupla de entrevistadores, que, ao seu turno, avaliam não 
somente a sua competência nessa atividade, mas também se ele sabe ou não trabalhar dentro do modelo de pareamento e em grupo da EC4. Trata-se de uma operação de seleção para calcular competências técnicas e comportamentais de natureza profissional; 4) entrevista gerencial que verifica o perfil profissional do candidato em relação aos níveis de senioridade e os tipos de carreiras constantes na empresa.

Após cada uma dessas entrevistas, com exceção da de quarto tipo, os entrevistadores preenchem uma avaliação ou "assessment" no sistema informático de gestão de RH. Nesses dispositivos, os entrevistadores explicam o porquê da sua decisão de "aprovar", "aprovar sem certeza" ou "não aprovar" o candidato, baseados nos critérios que guiam cada tipo de entrevista. Além das entrevistas, os candidatos são submetidos a dois tipos de testes lógicos, usados pela recrutadora como critérios de eliminação.

Após esses procedimentos que configuram a operação de seleção, inicia-se a operação de contratação, que é dividida em três momentos: 1) em posse de todos os assessment de entrevista do candidato, seu currículo, testes e avaliações de exercícios que ele passou, a recrutadora se prepara e marca uma data para o momento seguinte, que envolve todos aqueles que entrevistaram o candidato; 2) a realização da reunião de "decisão de contratação" começa pelo ritual de cada um dos entrevistadores manifestaram se querem ou não que a empresa contrate o candidato. Se todos manifestarem que sim, a reunião se dá por encerrada. Todavia, foi relatado que o mais comum é haver discordâncias. Então, a recrutadora pede para aqueles que avaliaram negativamente o candidato, expliquem suas razões para o grupo. As razões são discutidas até que se forme um consenso sobre contratar ou não o candidato, ou mesmo se decidir pela realização de uma nova entrevista e avaliação do candidato por outras pessoas; 3) se a contratação é aprovada, a recrutadora se reúne com o diretor de escritório para discutir as questões de salário e de nível de senioridade que o candidato pode ser considerado. Essa reunião é feita com base na avaliação que o diretor chegou, quando da entrevista gerencial com o candidato.

Constata-se que a EC4 exercita de maneira bem distinta as três operações de cálculo que têm lugar no mercado de trabalho. Isso ocorre - e esse ponto será aprofundado nas conclusões - porque a firma trabalha com um sistema de demanda constante e, também, porque a sua demanda se baseia em modalidades de competências de natureza heterogêneas que, por sua vez, expressam uma maior diversidade de valores que motivam e direcionam a sua demanda de trabalho. Justamente por isso, a EC4 
realiza as operações de cálculo e o planejamento da demanda a partir de uma rede sociotécnica marcada pelo alto grau de interação (adensamento) entre um considerável número de agentes humanos e de dispositivos de cálculo. 


\section{CONCLUSÕES}

Esta tese teve como ponto de partido a reflexão em torno das limitações dos modelos teóricos da economia ortodoxa no que diz respeito à capacidade de cálculo de valor dos agentes econômicos nos mercados. A principal limitação destacada foi que essa perspectiva não possui um modelo de explicação sobre as condições de possibilidade da capacidade de cálculo, pois para essa corrente do pensamento econômico, as preferências são consideradas exógenas, isto é, estáveis e automaticamente formadas. Com isso, essa perspectiva não trata daquilo que constituiu o interesse analítico desta tese: como os agentes definem e calculam o valor daquilo que demandam nos mercados. Especificamente, empreendeu-se esse esforço analítico para o caso de firmas de tecnologia da informação, quando demandam no mercado de trabalho.

Entretanto, especialmente no capítulo primeiro, procurou-se demonstrar que mesmo tendo em vista suas limitações, a perspectiva econômica ortodoxa possui elementos de análise que são incontornáveis e heuristicamente valiosos para compreender o cálculo de valor das firmas no mercado de trabalho. Um desses elementos é o fato da demanda de trabalho das empresas ser calculada como uma demanda derivada, isto é, as firmas demandam e compram o insumo trabalho visando a ganhos de produtividade para atender aos níveis de demanda dos seus clientes no mercado de produtos e, assim, auferir lucros.

Contatou-se que esse é realmente um ponto relevante para uma perspectiva sociológica considerar ao compreender a realização do cálculo econômico de valor. Esse entendimento foi formado quando a análise dos quatro estudos de casos revelou a presença do valor econômico de investimento no cálculo da demanda por força-detrabalho. Conforme exposto nos capítulos sete e oito, essa modalidade de valor estava sempre relacionada com o planejamento que as firmas faziam para atender a demanda dos seus clientes. Portanto, o cálculo da demanda de trabalho das firmas, especialmente na forma de decisões sobre salários e quantidades de trabalhadores e profissionais para serem contratados, era feito tendo em vista esse valor, no sentido de que a realização da demanda de trabalho é condição para firma ser capaz de atender as demandas no seu mercado de produtos.

Todavia, ao contrário do que prevê a perspectiva econômica ortodoxa, a demanda de trabalho, como demanda derivada, não é calculada tomando o trabalho 
como um insumo homogeneamente ofertado. Dito de outro modo, para calcular a demanda de trabalho em termos de valor de investimento - revelando a importância de considerar essa como uma demanda derivada - as firmas precisam calcular outro valor econômico, que, por seu turno, revela que o cálculo da demanda não toma o trabalho como um insumo homogeneamente ofertado e, portanto, não basta definir apenas as relações entre quantidade e preço. Nesse sentido, nos quatro casos examinados, a demanda por força-de-trabalho era estabelecida também pelo cálculo do valor econômico de uso. Esse último, em todos os casos analisados, estava materializado em perfis de competências técnicas e comportamentais, que basicamente estabelecem modalidades qualitativas de oferta de força-de-trabalho; ou melhor, de tipos de trabalhos como insumo que as firmas deverão demandar no mercado de trabalho, para, então, tornarem-se capazes de atender as demandas nos seus mercados de produtos.

Portanto, o cálculo do valor de uso na demanda de trabalho das firmas revela que esses agentes econômicos consideram esse insumo de maneira não homogênea, ou seja, ao calcular em termos de valor de investimento, elas consideram os diferentes valores de uso em termos de perfis de competências técnicas e comportamentais, exatamente para determinarem qual tipo de trabalho elas devem contratar/comprar para poderem realizar o retorno esperado e calculado através do valor de investimento, sendo esse compreendido como capacidade para atender à demanda dos seus clientes.

Os resultados obtidos na análise dos quatro estudos de caso, ainda evidenciaram outro elemento relevante advindo da teoria econômica e que, por isso, a perspectiva sociológica sobre o cálculo de valor, não pode se furtar de incorporar ao seu modelo analítico, a saber, que a determinação dos valores dos bens transacionados nos mercados não está assentada em algum atributo objetivo desses bens; pelo contrário, a determinação dos valores é fruto de um processo subjetivo a partir da atividade reflexiva (cálculo) do agente econômico, exercitada na relação com esses bens no contexto de mercado.

Isso foi especialmente exposto no capítulo oito, quando demonstrado que essa atividade reflexiva, que é o cálculo de valor, comporta dois momentos: o planejamento da demanda e as operações de cálculo que a firma executa quando comparece no mercado de trabalho. O primeiro é revelador nesse sentido, porque é nele que a firma estabelece quais atributos no trabalho como mercadoria, ela valoriza. Ao planejar a sua demanda, a firma calcula quais tipos de valores tem, para ela, certas competências técnicas e comportamentais, que os trabalhadores ofertam no mercado de trabalho. Por 
exemplo, nos quatros casos estudados, as competências de natureza técnica experiência profissional, o nível e tipo de formação educacional, grau de proficiência em inglês, conhecimento em linguagens de programação, etc. - apresentavam um valor de uso para empresas. Esses valores de uso eram por elas definidos em termos de requisitos para o (bom) desempenho das atividades ligadas a um cargo. Trata-se, então, de uma atividade reflexiva na qual a empresa, ao seu relacionar com o bem demandado, isto é, a força-de-trabalho, antecipa quais qualidades que podem estar disponíveis nesses bens para calcular qual é o valor que eles possuem para ela.

Neste ponto, a perspectiva da ciência econômica é também incompleta. Essa atividade reflexiva, que é o cálculo do valor, não é realizada de maneira automática e isolada pela firma, seja no momento do planejamento, seja no momento das operações de cálculo desenvolvidas por ela quando comparece ao mercado de trabalho. Os capítulos dedicados à análise dos dados empíricos trazem as evidências sobre como o cálculo de valor é executado dentro das condições de possibilidade engendradas pelas relações sociotécnicas. Ao mesmo tempo, essas relações definem a firma como agente econômico dotado de capacidade de cálculo no mercado de trabalho.

Portanto, as primeiras conclusões alcançadas por esta tese subsidiam o entendimento de que a abordagem sociológica do cálculo de valor traz à tona dois elementos não abordados pela teoria econômica ortodoxa: 1) o cálculo da demanda de trabalho não se limita em considerar apenas uma modalidade de valor econômico, calculada apenas com base no seu preço. Para formar e calcular a sua demanda no mercado de trabalho, as firmas estudadas consideram diferentes modalidades de valor, inclusive, como no caso da EC4, uma modalidade de natureza extraeconômica, mas que se torna economicamente relevante; 2) a teoria econômica tem razão ao apontar que o valor de um bem não está determinado por alguma propriedade objetiva do próprio bem, mas que o valor é estabelecido por atividade reflexiva e subjetiva, que, no contexto dos mercados, assume a forma de cálculo. Porém, a perspectiva sociológica desenvolvida nesta pesquisa mostra que essa atividade de cálculo somente é possível a partir de condições de possibilidade extraeconômicas, que se revelam nas relações sociotécnicas que as firmas dispõem e mobilizam para calcular a sua demanda no mercado de trabalho.

Além dessa reflexão de ordem teórica, Esta tese constitui um esforço analiticamente delimitado de refletir acerca da capacidade de cálculo de valor das firmas 
no mercado de trabalho tendo em conta a sua relação com aspectos que caracterizam a chamada nova economia.

A noção de nova economia se liga a todo um conjunto de transformações que vem ocorrendo recentemente nas economias capitalistas. Grosso modo, boa parte da literatura em ciências sociais que vem examinando esses processos de transformações advoga a ideia de que houve uma mudança econômica tão profunda que estamos presenciando a formação de um novo modelo de desenvolvimento, produção e de funcionamento dos mercados em contraste ao modelo econômico anterior do capitalismo industrial. Assim, diversos nomes têm sido dados para essa nova economia, por exemplo, sociedade pós-industrial (BELL, 1973), capitalismo informacional (CASTELLS, 2007), economia do conhecimento (POWELL; SNELLMAN, 2004), pósfordismo (HARVEY, 1996) e sociedade da informação (MASUDA, 1982).

Como não podia ser diferente, o surgimento da nova economia também veio acompanhado de transformações nos modelos de organização e gestão das empresas. Essas transformações são respostas às determinações do novo contexto econômico como também são cursos de ações, que, por sua vez, moldam os rumos dessas transformações macroscópicas ligadas à nova economia. Assim sendo, compreende-se que a presença das seguintes seis características organizacionais pode servir para identificar o quanto uma firma se aproxima da nova economia: 1) se na etapa econômica anterior o paradigma de organização era a indústria voltada para o consumo de massa, na nova economia são atividades de serviços do segmento de tecnologias da informação que se tornam paradigmáticas; 2) a dinâmica competitiva e as estratégias comerciais das firmas se voltam para o aprimoramento de suas capacidades e o envolvimento sistemático em processos de inovação; 3) as relações de emprego e a gestão do trabalho se tornam mais flexíveis e com ambientes mais informais; 4) adoção de formas de organização marcadas pelo trabalho em grupo e pela polivalência; 5) maior valorização e nível de exigência de qualificações técnicas e comportamentais; 6) em contraste com o modelo de consumo de massa, há uma relação mais personalizada entre produtores e clientes gerando a customização de produtos e serviços.

Foi em razão desses aspectos organizacionais do contexto econômico contemporâneo que nesta tese se elegeu por compreender o cálculo econômico de valor realizado por firmas de tecnologia da informação quando estas comparecem no mercado de trabalho. 
Com base nas perspectivas teóricas de Michel Callon (CALLON, 1998, 2004, 2007; CALLON; MUNIESA, 2005; CALLON; MÉADEL; RABEHARISOA, 2002) e de Patrick Aspers e Jens Beckert (ASPERS, 2011; BECKERT, 2009; ASPERS; BECKERT, 2011), compreendeu-se que os agentes organizam suas preferências tanto com base em valores econômicos de diferentes modalidades, como em valores nãoeconômicos, mas que são economicamente relevantes. Ademais, o cálculo econômico é formado por três operações - classificar, julgar e planejar - que são exercidas pelo agente na sua relação com as propriedades e qualidades de um bem em um determinado mercado. Os agentes econômicos executam essas operações de cálculo subjetivamente, porém as condições de possibilidade dessa capacidade são socialmente construídas por redes sociotécnicas.

Portanto, a tese examinou a capacidade de cálculo de firmas de TI no mercado de trabalho a partir das seguintes questões:

1) Quais os valores econômicos e economicamente relevantes dão conteúdo e sentido à demanda da firma, assim como um objeto para o exercício da sua capacidade de cálculo?

2) Quais procedimentos essas firmas adotam para classificar e julgar a oferta de trabalho e planejar a realização de sua demanda diante dessa oferta?

3) Quais são os agentes humanos e não-humanos das redes sociotécnicas das firmas, que constituem as condições de possibilidade para o seu exercício do cálculo econômico de valor?

Com base nesse esforço analítico, o presente estudo compreendeu a relação entre nova economia e o cálculo de valor das firmas de TI no mercado de trabalho através da defesa da seguinte tese: uma maior aproximação das empresas em relação às mencionadas características organizacionais da nova economia implicam em mudanças no conjunto de valores que direcionam a demanda da firma no mercado de trabalho e, também, na composição da rede sociotécnica que estrutura a capacidade da firma em calcular esses valores nas ofertas de força-de-trabalho. Sobre a primeira parte dessa tese, acerca da mudança nos valores, constatou-se que essa transformação ocorre de maneira quantitativa e qualitativa. Quantitativamente, uma vez que a nova economia envolve novas formas de organização e gestão do trabalho, por conseguinte configura-se um perfil diferente de trabalhador que é valorizado pelas empresas; a tese defende que, quanto mais uma firma se aproximar das características peculiares à nova economia, 
mais o cálculo da sua demanda no mercado de trabalho envolverá maior diversidade de valores econômicos e economicamente relevantes. Sobre a mudança qualitativa dos valores, a tese sustenta que exista uma tendência das firmas em valorizarem perfis de profissionais através de valores cujos conteúdos são de ordem simbólica e intangível, remetendo a lógica da produção de conhecimento e inovação, em contraste com os valores mais tradicionais relacionados a aspectos tangíveis como a produtividade. No que diz respeito à segunda parte da tese que estamos defendendo, as mudanças nas modalidades e conteúdos dos valores, implicam em transformações nas redes sociotécnicas das empresas no sentido de que, quanto mais próximas ao modelo organizacional da nova economia, mais as interações na rede se adensam e aumenta-se a diversidade de agentes humanos e de dispositivos de cálculo.

Desse modo, a tese exposta acima foi formulada com base no teste de três hipóteses de pesquisa sobre o cálculo de valor das firmas no mercado de trabalho, no contexto da nova economia: 1) as empresas cujo modelo de organização, de gestão do trabalho e de negócios que se aproximem mais aos seis aspectos peculiares à nova economia referidos acima, apresentariam redes sociotécnicas mais diversificadas em termos de relações e de agentes humanos e não-humanos para executarem seu cálculo de valor no mercado de trabalho; 2) este grau de correspondência entre as firmas e as características peculiares à nova economia, também faria com que o cálculo de suas demandas no mercado de trabalho envolvessem maior diversidade de valores econômicos e economicamente relevantes; 3) como decorrência lógica das duas primeiras hipóteses, quanto maior o número de valores que envolvem o cálculo da demanda de uma firma no mercado de trabalho, maior será a diversidade de relações sociotécnicas e de agentes humanos e não-humanos envolvidos nas operações de cálculo da firma.

Através das evidências trazidas no capítulo cinco, contata-se que a EC1 é a empresa estudada que apresentou características organizacionais mais distantes daquelas consideradas como típicas da nova economia. Começando pelo fato de ser uma firma situada no setor industrial, mas que apresenta algo que a aproxima da nova economia, a prestação de serviços de produção e manufatura para outras empresas. Apesar de ter a inovação como uma de suas estratégias para competir no mercado de produtos, essa é encarada e organizada através de uma perspectiva mais tradicional, ou seja, como uma atividade limitada ao grupo de profissionais que compõem o departamento de P\&D da empresa. Se, por um lado, ela trava relação com os clientes para a elaboração de seus 
produtos, o processo produtivo da EC1 não pode ser definido como voltado para customização ou menos ainda por projetos por encomenda. A relação com os clientes ocorre mais no sentido de verificar a adoção de certos padrões tecnológicos, que, por sua vez, vão subsidiar o desenvolvimento de equipamentos que se inserem nesses padrões. Por fim, o modelo de gestão e o ambiente de trabalho da EC1 são tradicionais e pouco flexíveis. Cabe destacar que a maior parte de sua demanda de trabalho é por profissionais com formação entre ensino médio e nível técnico, isto é, poucos são os profissionais demandados com curso superior.

No extremo mais próximo à nova economia, constatou-se a EC4. Esta empresa não somente atua no segmento de serviços de desenvolvimento de softwares para outras empresas, como, também, ela desenvolve ferramentas e metodologias que serão usadas por outras empresas e organizações para o desenvolvimento de softwares (serviço de consultoria). É a firma que tem a relação mais próxima de interação e colaboração com seus clientes, pois ela desenvolve softwares por encomenda, isto é, de acordo com a demanda e necessidades de cada cliente. Ademais, por trabalhar em projetos de "código aberto", a EC4 estabelece relação de colaboração com profissionais e organizações externas, as chamadas “comunidades de TI". Essa estratégia de colaboração ainda se relaciona com uma baseada na busca por inovação em um sentido amplo, inclusive ligada ao objetivo de cunho moral de "mudar o mundo através do software". Também foi o caso que apresentou o modelo e ambiente de trabalho mais informal, em equipe e por projetos e, ainda, com poucas hierarquias e, por conseguinte, mais flexível. A EC4 somente demanda profissionais com curso superior completo.

No "meio" em termos de proximidade com a nova economia, classificou-se a EC2 e a EC3. Elas possuem as seguintes características em comum: atuam no segmento de prestação de serviços de desenvolvimento de softwares para outras empresas; seus produtos de softwares são customizáveis; têm a inovação como estratégia de competição no mercado e como objetivo disseminado entre praticamente todos os seus funcionários; porém, ao contrário da EC4, a inovação é um objetivo adotado por razões exclusivamente econômicas; e somente demandam profissionais com formação de nível superior. Entretanto, a EC2 se aproxima mais da nova economia no que concerne a um ambiente e modelo de gestão do trabalho mais informal e flexível; enquanto que, a EC3, apresenta características mais próximas ao mundo corporativo tradicional, isto é, possui um escritório dividido em estações de trabalho individuais (denominadas de "baias") e 
um modelo de gestão do trabalho com maior rigidez em termos de rotinas e horários de expediente.

Uma vez dessa forma classificadas as empresas estudadas, concluiu-se em considerar como confirmada a primeira hipótese. Conforme evidenciado nos capítulos seis e oito, a EC4, como empresa organizada dentro dos aspectos mais típicos da nova economia, apresenta um alto grau de interação entre seus agentes humanos e os dispositivos de cálculo no momento do planejamento da demanda e nas operações de cálculo (recrutamento, seleção e contratação) no mercado de trabalho. O aspecto mais ilustrativo desse ponto é o fato de a operação de contratação envolver um processo decisório por unanimidade entre todas as pessoas da empresa que entrevistaram um candidato; em contraste, na EC2 e na EC3, a decisão de contratação é formada através de comunicação de decisão entre gestor de área técnica e o setor de recursos humanos; já a EC1, nesse sentido, o RH por vezes não era envolvido na seleção e contratação de um trabalhador.

Ademais, o adensamento das interações entre agentes humanos e dispositivos de cálculo, na EC4, é incrementado pelo sistema de demanda constante no mercado de trabalho. Esse, conforme exposto, exigia a organização de processos de seleção por candidato e não por vagas, requerendo comunicação regular entre recrutadoras e diretor de RH e de escritório, para direcionar essa constante demanda às necessidades de momento da empresa. Nas demais empresas, seguia-se um modelo de demanda por autorização de abertura de vagas, que se estruturava em etapas segmentadas de interação entre os agentes humanos e não-humanos dos níveis de direção executiva e comercial, RH e gestores de áreas técnicas.

Por fim, a tabela abaixo traz esquematicamente os dados que confirmam a primeira hipótese. 
Tabela 35 - Agentes humanos e dispositivos de cálculo nas redes sociotécnicas das empresas estudadas.

\begin{tabular}{|c|c|c|c|c|c|}
\hline & & EC1 & EC2 & EC3 & EC4 \\
\hline \multirow{10}{*}{ Agentes Humanos } & Direção Executiva e Comercial & $\sqrt{ }$ & $\sqrt{ }$ & $\sqrt{ }$ & $\sqrt{ }$ \\
\hline & Gestores de Áreas Técnicas & $\sqrt{ }$ & $\sqrt{ }$ & $\sqrt{ }$ & $\sqrt{ }$ \\
\hline & Coornadores de $\mathrm{RH}$ & $\sqrt{ }$ & $\sqrt{ }$ & $\sqrt{ }$ & $\sqrt{ }$ \\
\hline & Recrutadores & & $\sqrt{ }$ & $\sqrt{ }$ & $\sqrt{ }$ \\
\hline & Diretor de Escritório & & $\sqrt{ }$ & & $\sqrt{ }$ \\
\hline & Conselho de Acionistas & & $\sqrt{ }$ & & \\
\hline & Coordenadora de Recrutamento & & & & $\sqrt{ }$ \\
\hline & Organizadora de Seleção & & & & $\sqrt{ }$ \\
\hline & Técnica de Departamento de Pessoal & $\sqrt{ }$ & & & \\
\hline & Funcionários Técnicos & & $\sqrt{ }$ & & $\sqrt{ }$ \\
\hline \multirow{27}{*}{ Dispositivos de Cálculo } & Tabela de Salários & $\sqrt{ }$ & & & \\
\hline & Programa de Benefícios & $\sqrt{ }$ & $\sqrt{ }$ & $\sqrt{ }$ & $\sqrt{ }$ \\
\hline & Plano de Cargos e Carreiras & & $\sqrt{ }$ & & $\sqrt{ }$ \\
\hline & Plano de Cargos e Salários & & $\sqrt{ }$ & & $\sqrt{ }$ \\
\hline & Sistema Informático de Gestão de RH & & $\sqrt{ }$ & $\sqrt{ }$ & $\sqrt{ }$ \\
\hline & Pesquisa de Salários & & $\sqrt{ }$ & $\sqrt{ }$ & \\
\hline & Pesquisa Radar Tecnológico & & & & $\sqrt{ }$ \\
\hline & Reunião de Decisão de Contratação & & & & $\sqrt{ }$ \\
\hline & Teste de Exercício Técnico & & $\sqrt{ }$ & $\sqrt{ }$ & $\sqrt{ }$ \\
\hline & Testes Lógicos & & $\sqrt{ }$ & $\sqrt{ }$ & $\sqrt{ }$ \\
\hline & Testes Psicológicos de Perfil Profissional & & $\sqrt{ }$ & & \\
\hline & Teste de Redação em Português & & & $\sqrt{ }$ & \\
\hline & Entrevista Técnica/Profissional & $\sqrt{ }$ & $\sqrt{ }$ & $\sqrt{ }$ & $\sqrt{ }$ \\
\hline & Entrevista Comportamental & $\sqrt{ }$ & $\sqrt{ }$ & $\sqrt{ }$ & $\sqrt{ }$ \\
\hline & Entrevista de Valores & & & & $\sqrt{ }$ \\
\hline & Cultura da Empresa & & $\sqrt{ }$ & $\sqrt{ }$ & $\sqrt{ }$ \\
\hline & Programas de Recomendação & & $\sqrt{ }$ & & $\sqrt{ }$ \\
\hline & Site da Empresa & $\sqrt{ }$ & $\sqrt{ }$ & $\sqrt{ }$ & $\sqrt{ }$ \\
\hline & Formulários de Assessment & & $\sqrt{ }$ & $\sqrt{ }$ & $\sqrt{ }$ \\
\hline & Currículos & $\sqrt{ }$ & $\sqrt{ }$ & $\sqrt{ }$ & $\sqrt{ }$ \\
\hline & Banco de Currículos & $\sqrt{ }$ & $\sqrt{ }$ & $\sqrt{ }$ & $\sqrt{ }$ \\
\hline & Sites de Redes Profissionais & & $\sqrt{ }$ & $\sqrt{ }$ & $\sqrt{ }$ \\
\hline & Sites de Redes Sociais & & $\sqrt{ }$ & $\sqrt{ }$ & $\sqrt{ }$ \\
\hline & Eventos em Comunidades de TI & & & & $\sqrt{ }$ \\
\hline & Universidades & $\sqrt{ }$ & $\sqrt{ }$ & $\sqrt{ }$ & $\sqrt{ }$ \\
\hline & Técnica de Entrevista & & $\sqrt{ }$ & $\sqrt{ }$ & \\
\hline & Sites de Vagas de Emprego & $\sqrt{ }$ & $\sqrt{ }$ & $\sqrt{ }$ & $\sqrt{ }$ \\
\hline Total & & 13 & 28 & 22 & 30 \\
\hline
\end{tabular}

Fonte: Dados de Pesquisa de Campo.

Portanto, a tabela acima mostra, conforme a empresa se aproxima das características da nova economia, mais agentes humanos e dispositivos de cálculo são inseridos na rede sociotécnica que exercita o cálculo de valor da demanda de trabalho das empresas; assim, a primeira hipótese é considerada como confirmada.

Conforme também se aproximam os casos em termos de suas características em relação à nova economia, os valores calculados na realização das suas demandas no mercado de trabalho, eles não somente diversificam-se, como, também, apontam para 
uma mudança qualitativa. Nesse sentido, vejamos primeiro a questão da diversidade de valores, que subsidia a confirmação da segunda hipótese, tomando caso por caso, analisando a relação entre modalidades de valores econômicos e economicamente relevantes e as relações sociotécnicas e/ou dispositivos de cálculo que as materializam.

- EC1: 1) inovação e valor de uso; 2) rotatividade/absenteísmo e valor de investimento; 3) planejamento de atendimento das demandas dos clientes e valor de investimento; 4) salário relacionado tanto com o valor de investimento como o valor relacional; 5) sistema de benefícios e valor relacional; 6) perfil de competências técnicas e comportamentais e o valor de uso.

- EC2: 1) cultura da empresa e valor de uso e valor simbólico; 2) inovação e valor físico; 3) rotatividade não se materializou em valores calculados pela firma no mercado de trabalho; 4) perfil de competências técnicas e valor de uso; 5) perfil comportamental tanto valor de uso como físico; 6) salários materializando o cálculo do valor de investimento e do relacional; 7) programa de benefícios e valor de investimento; 8) planejamento para o atendimento à demanda materializando o cálculo do valor de investimento.

- EC3: 1) cultura da empresa expressando tanto o valor de uso como o valor simbólico; 2) inovação materializando o valor físico; 3) perfil comportamental expressando valor de uso e o valor físico; 4) perfil de competências técnicas e valor de uso; 5) salários e o sistema de benefícios materializando o valor relacional; 6) planejamento para o atendimento à demanda expressando o valor de investimento.

- EC4: 1) valor moral materializado na cultura da empresa e no perfil de competências comportamentais; 2) valor de uso sendo calculado a partir da cultura da empresa e dos perfis de competências tanto técnicas como comportamentais; 3) valor simbólico e a cultura da empresa; 4) valor físico na inovação e no perfil comportamental; 5) valor de investimento calculado com base nas questões que envolvem salários, programa de benefícios e o planejamento para o atendimento da demanda.

Em suma, enquanto que, a EC1 como a empresa que mais se distancia da nova economia, apresenta apenas três modalidade de valor econômico sendo calculadas na 
sua demanda de trabalho, as demais empresas apresentam cinco modalidades de valores - confirmando a segunda hipótese. Nesse sentido, cabe destacar que, na EC4 (identificada como a empresa que mais se organiza em torno das características típicas de nova economia) constatou-se uma modalidade de valor extraeconômico, o valor moral de "justiça social". Relacionando a lista acima com a tabela anterior, conclui-se, por conseguinte, a confirmação da terceira hipótese.

Por fim, analisando o conjunto de dados que subsidiam a confirmação das três hipóteses aventadas, compreende-se que o cálculo de valor da demanda por força-detrabalho, que é realizado quando as empresas comparecem no mercado de trabalho, talvez esteja sofrendo uma mudança de lógica no que respeita aos valores do trabalho na nova economia. Nesse sentido, os resultados desta pesquisa de tese apontam para a tendência das empresas de nova economia valorizarem o trabalho menos em termos tangíveis de produtividade (EC1) e mais numa articulação de valores econômicos de natureza simbólica ou intangível, que remetem à produção de conhecimento e inovação (EC2, EC3 e EC4); ou seja, as combinações de valores que estruturam o planejamento da demanda de trabalho e as operações de cálculo das empresas, não somente se tornam mais diversificadas, como, também, privilegiam mais valores econômicos ou mesmo economicamente relevantes cujos conteúdos que assumem são de natureza simbólica e relacionados ao valor estratégico - típico da nova economia - de capacidade de inovação. Assim, não só o cálculo de valor se modifica na nova economia - adensando suas relações sociotécnicas e incluindo maior número de agentes humanos e dispositivos de cálculo - como, também, os próprios valores que são calculados passam a sofrerem mutações para corresponderem às exigências de sistemático envolvimento com a inovação e alta interação com os clientes.

Examinando essas diferenças nos valores das firmas estudadas, é possível, então, concluir que há uma mudança tanto quantitativa, como qualitativa nos valores das empresas. A importância da confirmação desta tese reside no fato de que ela aponta para uma perspectiva que toma a demanda de trabalho das firmas não como um dado trivial e automático, isto é, não se trata simplesmente da aquisição de um insumo homogeneamente ofertado cujo interesse da empresa é contratá-lo ao menor preço possível. A empresa precisa justamente determinar quais atributos e qualidades desse insumo ela valoriza para, então, justamente poder dar sentido aos preços. Assim se compreende que os estudos sociológicos sobre o funcionamento do mercado de trabalho 
podem se beneficiar com essa visão mais complexa da formação e mudança da demanda das firmas por força-de-trabalho.

Apesar dessas diferenças nos valores, na composição das redes sociotécnicas e na execução das operações de cálculo realizadas pelas quatro firmas estudadas, o exame em conjunto dos resultados da análise dos dados empíricos desta tese, ainda subsidia a identificação de uma estrutura comum de funcionamento das operações que compõem a capacidade de cálculo de valor que as firmas exercem no mercado de trabalho. Senão vejamos.

Constatou-se que a capacidade de cálculo é exercida em dois momentos: no planejamento da demanda e nas operações de cálculo que a firma executa quando comparece no mercado de trabalho. Essa distinção é um achado desta pesquisa, pois a definição de Callon (1998; 2004) de cálculo econômico não distingue esses dois momentos, talvez por não tomar o mercado de trabalho como referência. Assim sendo, fica em aberto a questão se essa divisão do cálculo econômico é algo que precisa ser considerado nos diferentes mercados ou se ela corresponde ao caráter particular do trabalho como mercadoria.

É no planejamento da demanda que a firma define o que ela valoriza em um trabalhador para contratá-lo. Assim sendo, ela precisa definir questões como, por exemplo, quantos trabalhadores, qual preço deverá (ou poderá pagar) e que tipos de trabalhadores e profissionais ela irá precisar vis-à-vis os requisitos do seu processo produtivo e o nível e a qualidade da demanda de clientes que pretende atender. Contratar certa quantidade de força-de-trabalho a um determinado preço esperando um retorno é justamente a definição de valor econômico de investimento. Por outro lado, planejar que tipos de trabalhadores e profissionais a firma precisa para executar as atividades que compõem o seu processo produtivo é justamente definir um valor de uso. Conforme exposto, esses dois valores econômicos estão presentes no planejamento da demanda de todas as empresas estudadas nesta tese, exatamente porque eles se referem a condições sine qua non para firma estabelecer o objeto da sua demanda. Todavia, esses dois valores econômicos, especialmente nos casos das empresas que mais se aproximam da nova economia, não são suficientes para as firmas planejarem suas demandas no mercado de trabalho.

Uma vez que os valores econômicos e economicamente relevantes são os "materiais" por meio dos quais a firma constrói o planejamento da sua demanda, cabe a pergunta: o quê será calculado quando ela comparecer no mercado de trabalho? E como 
será calculado? Os valores operacionalizam perfis de trabalhador valorizados pela firma em termos de competências técnicas e comportamentais. Esses perfis são demandados pela firma no mercado de trabalho através das operações que conformam a capacidade de cálculo econômico - recrutamento (classificar), seleção (julgar) e contratação (planejar).

Nas relações sociotécnicas que estruturam as condições de possibilidade para a operação de recrutamento, a firma verifica a disponibilidade no mercado de trabalho dos perfis valorizados de profissionais, segundo as diferentes modalidades de valores. $\mathrm{Na}$ seleção, a empresa, também através de um conjunto de relações sociotécnicas, julga as ofertas disponíveis no mercado de trabalho em função dos perfis valorizados que constituem a sua demanda. Por último, ela planeja e decide pela contratação de um ou mais dos ofertantes identificados e selecionados no mercado de trabalho.

Retomando e ao encontro da nossa tese, a análise dos dados evidenciou que as firmas mais próximas a modelos organizacionais da nova economia apresentam maior variedade de agentes humanos e de dispositivos de cálculos, assim como maior adensamento das relações sociotécnicas entre esses agentes para executarem as operações de cálculo descritas acima. Assim sendo, conforme exposto na tabela anterior, o total de agentes humanos e dispositivos de cálculo na EC1 é de 13, na EC2 foram identificados 28, 22 na EC3 e 30 na EC4. A EC4, além do maior número, também apresentou um modelo mais adensado, ou seja, com uma maior intensidade de interações entre todos os agentes envolvidos nas relações sociotécnicas que executam as operações de cálculo econômico de valor. Emblemático desse aspecto é o fato da EC4 adotar um modelo de demanda contínua no mercado de trabalho e que cada contratação de um candidato deve ocorrer por decisão unânime em reunião com todos os envolvidos no processo de seleção do candidato (no mínimo 10 pessoas).

Ao mesmo tempo, as mudanças nas redes sociotécnicas e nos valores não podem ser somente atribuídas exclusivamente à aproximação dos modelos organizacionais das empresas em relação à nova economia; a análise dos dados aponta que também influem aspectos organizacionais particulares de cada empresa, por exemplo, na EC1 e na EC3 identificou-se que o status ainda em formação dos seus setores de $\mathrm{RH}$, limitava a inserção de dispositivos de cálculo como programas de recomendação, cultura da empresa e planos de cargos e salários. Nesse sentido, os casos da EC2 e da EC4 apontam para a influência do fato da empresa ser uma multinacional ou não, pois esses dois casos apresentaram modelos bem estruturados de procedimentos de recrutamento, 
seleção e contrato de novos trabalhadores. Talvez porque essas duas empresas são multinacionais, isso imponha à direção corporativa maiores exigências em padronizar as suas práticas de recursos humanos.

Por fim, travando um dialogo entre a perspectiva de Michel Callon (CALLON, 1998, 2004, 2007; CALLON; MUNIESA, 2005; CALLON; MÉADEL; RABEHARISOA, 2002) e a tese que se está defendendo, cabe destacar o papel relevante que as tecnologias de informação assumem como dispositivos de cálculo. Se as redes se adensam como resposta a uma maior variedade de valores a serem calculados, ao seu turno, esse processo exige da firma maior poder em coletar e processar informações; as tecnologias de informação justamente atuam sobre essa capacidade de coletar e processar informações. Nesse sentido, os estudos de caso revelaram que os sistemas informáticos de gestão de RH são vitais para o bom desempenho dessa capacidade, isto é, esses dispositivos de cálculo se revelaram fundamentais em coordenar as relações sociotécnicas entre agentes humanos e nãohumanos na execução das operações de cálculo de valor da firma no mercado de trabalho. Assim sendo, esta tese contribui para chamar a atenção e abrir uma linha de pesquisa ainda pouco explorada pela análise sociológica dos mercados de trabalho, a saber, o papel da agência não-humana no funcionamento e mudanças nesses mercados. Nesta pesquisa foi identificada uma série desses dispositivos de cálculo, por exemplo, os sistemas informáticos de $\mathrm{RH}$, os sites de vagas de emprego e de redes sociais e profissionais, bancos de currículos, planos de cargos, salários e carreiras, entre outros. Encerra-se, então, por cogitar que a tese que defendida aqui, proporciona por inferir se estamos presenciando a tendência da ampliação do número e influência desses e outros agentes não-humanos no mercado de trabalho, em razão dos processos de mudanças nos valores do trabalho na nova economia. Deixa-se em aberto para futuros estudos explorar as implicações dessa possibilidade. 


\section{REFERÊNCIAS BIBLIOGRÁFICAS}

ABRAMOVAY, R. Entre Deus e o Diabo: mercados e interação humana nas ciências sociais. Revista Tempo Social, v. 16, n. 2, p. 35-84, 2004.

ADAMS, T. L.; DEMAITER, E. I. Skill, education and credentials in the new economy: the case of information technology workers. Work, Employment \& Society, v. 22, n. 2, p. 351-362, 2008.

AKERLOF, G. A.; KRANTON, R. E. Economics and Identity. The Quarterly Journal of Economics, v.115, n. 3, p. 715-753, 2000.

ALVES, D. A. de. Engajamento Subjetivo no Teletrabalho. In: GUIMARÃES, S. M. K. (Org.). Trabalho, Emprego e Relações Laborais em Setores Intensivos em Conhecimento: Brasil, México e Canadá. Porto Alegre: Editora da UFRGS, 2009. p. 75-101.

AOYAMA, Y.; CASTELLS, M. An empirical assessment of the informational society: Employment and occupational structures of G-7 countries, 1920-2000. International Labour Review, v. 141, n. 1-2, p. 123-159, 2002.

ARBIX, G. Innovation and the Development Agenda. Economic Sociology, The European Electronic Newsletter, v. 11, n. 2, p. 16-23, 2010. Disponível em: $<$ http://econsoc.mpifg.de/archive/econ_soc_11-2.pdf >. Acesso em: 3 Mar. 2010.

ASPERS, P. Markets. Cambridge: Polity Press, 2011.

ASPERS, P.; BECKERT, J. Value in Markets. In: BECKERT, J.; ASPERS, P. (Ed.). The Worth of Goods: Valuation and Pricing in the Economy. New York: Oxford University Press, 2011. p. 3-38.

AUTOR, D. H. Wiring the Labor Market. The Journal of Economic Perspectives, v. 15 , n. 1, p. 25-40, 2001.

BARDIN, L. Análise de Conteúdo. Lisboa: Edições 70, 1979.

. L'analyse de contenu et de la forme des communications. In : MOSCOVICI, S. ; GASKELL, G. (Org.). Les méthodes des sciences humaines. Paris : PUF, 2003. p. 243-270.

BARON, J.; HANNAN, M. T. The Impact of Economics on Contemporary Sociology. Journal of Economic Literature, v. 32, n. 3, p. 1111-1146, 1994.

BARR, T. With Friends like These: Endogenous Labor Market Segregation with Homogeneous, Nonprejudiced Agents. American Journal of Economics and Sociology, v. 68, n. 3, 2009.

BAUER, M. W. Análise de Conteúdo Clássica: uma revisão. In: BAUER, M. W.; GASKELL, G. (Org.). Pesquisa Qualitativa com Texto, Imagem e Som: um manual 
prático. Petrópolis: Vozes, 2002. p. 189-217.

BEAMISH, T. D.; BIGGART, N. W. Economic Worlds of Work: Uniting Economic Sociology with the Sociology of Work. In: KORZYNSKI, M.; HUDSON, R.; EDWARDS, P. (Ed.). Social Theory and Work. Oxford: Oxford University Press, 2006. p. 233-71.

BECKERT, J. What is Sociological about Economic Sociology? Uncertainty and the Embeddedness of Economic Action. Theory and Society, v. 25, p. 803-840, 1996.

. The social order of markets. Theory \& Society, v. 38, p. 245-269, 2009.

BELL, D. O Advento da Sociedade Pós-Industrial. São Paulo: Cultirx, 1973.

BEUNZA, D.; STARK, D. Tools of the Trade: the socio-technology of arbitrage in a Wall Street trading room. Industrial and Corporate Change, v. 13, n. 2, 369-400, 2004.

BIAN, Y. Bringing Strong Ties Back in: indirect ties, network bridges, and job searches in China. American Sociological Review, v. 63, n. 3, p. 366-85, 1997.

BICEV, J. T. Os Trabalhadores Subcontratados da Região Metropolitana de São Paulo: precariedade ou estabilização? 2010. 74 f. Dissertação (Mestrado) - Programa de Pós-Graduação de Sociologia, Faculdade de Filosofia, Letras e Ciências Humanas, Universidade de São Paulo, São Paulo, 2010.

BIGGART, N. W. (Ed.). Readings in Economic Sociology. Oxford: Blackwell Publishers Ltd, 2002.

BÖHM-BAWERK, E. von. A Teoria da Exploração do Socialismo Comunismo. 2 ed. São Paulo: Instituto Ludwig von Mises Brasil, 2010.

BORJAS, G. J. Labor Economics. New York: McGraw-Hill Irwin, 2010.

BOYER, G. R.; SMITH, R. S. The Development of the Neoclassical Tradition in Labor Economics. Industrial and Labor Relations Review, v. 54, n. 2, p. 199-223, 2001.

BUDROS, A. The Mean and Lean Firm and Downsizing: Causes of Involuntary and Voluntary Strategies. Sociological Forum, v. 17, n. 2, p. 307-342, 2002.

BURT, R. S. Structural Holes and Good Ideas. American Journal of Sociology, v. 110, n. 2, p. 349-399, 2004.

CALLON, M. Introduction: the embeddedness of economic markets in economics. In: (Ed.). The Laws of the Markets. Oxford: Blackwell Publishers, 1998a. p. 1-57. An essay on framing and overflowing: economic externalities revisited by sociology. In: (Ed.). The Laws of the Markets. Oxford: Blackwell Publishers, 1998b. p. $244-269$. 
Actor-network theory - the market test. In: LAW, J.; HASSARD, J. (Ed.). Actor-Network Theory and After. Oxford: Blackwell, 2004. p. 181-95.

An Essay on the Growing Contribution of Economic Markets to the Proliferation of the Social. Theory, Culture \& Society, v. 24, n. Jul./Ago., p. 139-163, 2007.

- Entrevista com Michel Callon: Dos estudos de laboratório aos estudos coletivos heterogêneos, passando pelos gerenciamentos econômicos. Sociologias, v. 10, n. 19, p. 302-321, 2008.

CALLON, M.; MÉADEL, C.; RABEHARISOA, V. The economy of qualities. Economy and Society, v. 31, n. 2, p. 194-217, 2002.

CALLON, M.; MUNIESA, F. Economic Markets as Calculative Collective Devices. Organization Studies, v. 26, n. 8, p. 1229-1250, 2005.

CALVÓ-ARMENGOL, A. Social Networks and Labour Market Outcomes. Els Opuscles del CREI, n. 17, p. 1-41, 2006.

CARNOY, M.; CASTELLS, M.; BENNER, C. Labour markets and employment practices in the age of flexibility: A case study of Silicon Valley. International Labour Review, v. 136, n. 1, p. 27-48, 1997.

CASTELLS, M. Materials for an exploratory theory of the network society. British Journal of Sociology, v. 51, n. 1, p. 5-24, 2000. $\overline{1 .}$

A Sociedade em Rede. 10ª Ed. São Paulo: Editora Paz e Terra, 2007. Volume

CHAPPLE, K. Networks to Nerdistan: The role of labor market intermediaries in the entry-level IT labor market. International Journal of Urban and Regional Research, v. 30, n. 3, p. 548-563, 2006.

COCCO, G.; GALVÃO, A. P.; SILVA, G. (Org.). Capitalismo Cognitivo: trabalho, redes e inovação. Rio de Janeiro: DP\&A, 2003.

COCHOY, F. Another discipline for the market economy: marketing as a performative knowledge and know-how for capitalism. In: CALLON, M. (Org.). The Laws of the Markets. Oxford: Blackwell Publishers, 1998. p. 194-221.

COSTA, M. da S. Sistemas de Relações de Trabalho no Brasil: alguns traços históricos e sua precarização atual. Revista Brasileira de Ciências Sociais, v. 20, n. 59, p. 111$131,2005$.

DAVIS, G. F.; DIEKMANN, K. A.; TINSLEY, C. H. The Decline and Fall of the Conglomerate Firm in the 1980s: The Deinstitutionalization of an Organizational Form. In: DOBBIN, F. (Ed.). The New Economic Sociology: A Reader. Princeton: Princeton University Press, 2004. p. 188-224. 
DAVIS, J. B. The turn in economics: neoclassical dominance to mainstream pluralism? Journal of Institutional Economics, v. 2, n. 1, p. 1-20, 2006.

DIMAGgiO, P. J.; POWELL, W. W. The Iron Cage Revisited: Institutional Isomorphism and Collective Rationality in Organizational Fields. In: DOBBIN, F. (Ed.). The New Economic Sociology: A Reader. Princeton: Princeton University Press, 2004. p. 111-134.

DOGANOVA, L.; EYQUEM-RENAULT, M. What do business models do? Innovation devices in technology entrepreneurship. Research Policy, v. 38, n. 10, p. 1559-1570, 2009.

DRUCK, G.; FRANCO, T. (Org.). A Perda da Razão Social do Trabalho: terceirização e precarização. São Paulo: Boitempo, 2007.

EISCHEN, K. Information Technology: History, Practice and Implication for Development. Center for Global, International \& Regional Studies. Santa Cruz: UC Santa Cruz, 2000. Disponível em: <htttp://escholarship.org/uc/item/951709tx>. Acesso em: 20 Out. 2011.

FEHR, E.; HOFF, K. Introduction: Tastes, Castes and Culture: The Influence of Society on Preferences. The Economic Journal, v. 121, n. 556, p. F396-F412, 2011.

FERNANDEZ, R. M.; CASTILLA, E. J.; MOORE, P. Social Capital at Work: Networks and employment at a Phone Center. American Journal of Sociology, v. 105, n. 5, p. 1288-1356, 2000.

FERNANDEZ, R. M.; SOSA, M. L. Gendering the Job: networks and recruitment at a Call Center. American Journal of Sociology, v. 111, n. 3, p. 859-904, 2005.

FERRARY, M.; GRANOVETTER, M. The role of venture capital firms in Silicon Valley's complex innovation network. Economy and Society, v. 38, n. 2, p. 326-359, 2009.

FLIGSTEIN, N. The Architecture of Markets: An Economic Sociology of TwentyFirst-Century Capitalist Society. Princeton: Princeton University Press, 2001.

FLIGSTEIN, N.; BRANTLEY, P. Bank Control, Owner Control, or Organizational Dynamics: Who Controls the Large Modern Corporation. American Journal of Sociology, v. 98, n. 2, p. 280-307, 1992.

FLigsteIn, N.; DAUTER, L. The Sociology of Markets. Annual Review of Sociology, v. 33, p. 105-28, 2007.

FOURCADE, M. Theories of Markets and Theories of Society. American Behavioral Scientist, v. 50, n. 8, p. 1015-1034, 2007.

Price and Prejudice: On Economics and the Enchantment (and Disenchantment) of Nature. In: BECKERT, J.; ASPERS, P. (Ed.). The Worth of Goods: Valuation and Pricing in the Economy. New York: Oxford University Press, 2011. p. 41- 
62.

FRANZEN, A.; HANGARTNER, D. Social Networks and Labour Market Outcomes: the non-monetary benefits of social capital. European Sociological Review, v. 22, n. 4, p. 353-68, 2006.

GAO, B. Efficiency, culture, and politics: the transformation of Japanese management in 1946 - 1966. In: CALLON, M. (Ed.). The Laws of the Markets. Oxford: Blackwell Publishers, 1998. p. 86-115.

GERRING, J. Case Study Research: principles and practices. New York: Cambridge University Press, 2007.

GIDDENS, A. As Consequências da Modernidade. São Paulo: Editora da UNESP, 1991.

GOODE, W. J.; HATT, P. K. Métodos em Pesquisa Social. $3^{\text {a }}$ edição. São Paulo: Companhia Editora Nacional, 1969.

GOUREVITCH, P. The Value of Ethics: Monitoring Normative Compliance in Ethical Consumption Markets. In: BECKERT, J.; ASPERS, P. (Ed.). The Worth of Goods: Valuation and Pricing in the Economy. New York: Oxford University Press, 2011. p. 86105.

GRANOVETTER, M. The Strength of Weak Ties. American Journal of Sociology, v. 78, n. 6, p. 1360-1380, 1973.

. The Strength of Weak Ties: A Network Theory Revisited. Sociological Theory, v. 1, p. 201-233, 1983.

Economic Action and Social Structure: The Problem of Embeddedness. American Journal of Sociology, v. 91, n. 3, p. 481-510, 1985.

. The Sociological and Economic Approaches to Labor Market Analysis: A Social Structural View. In: FARKAS, G.; ENGLAND, P. (Ed.). Industries, Firms and Jobs: Sociological and Economic Approaches. Nova York: Plenum Press, 1988. p. 187216.

The Old and the New Economic Sociology: A History and an Agenda. In: FRIEDLAN, R.; ROBERTSON, A. F. (Ed.). Beyond the Marketplace: Rethinking Economy and Society. New York: Walter de Gruyter, 1990. p. 89-112.

Afterword 1994: Reconsiderations and a New Agenda. In: Getting a Job: a study of contacts and careers. $2^{a}$ Ed. Chicago: Chicago University Press, 1994. p. 139-182.

The Impact of Social Structure on Economic Outcomes. Journal of Economic Perspectives, v. 19, n. 1, p. 33-50, 2005.

GRANOVETTER, M.; MCGUIRE, P. The making of an industry: electricity in the 
United States. In: CALLON, M. (Ed.). The Laws of the Markets. Oxford: Blackwell Publishers, 1998. p. 147-173.

GUILLÉN, M. F. The Limits of Convergence: Globalization and organizational change in Argentina, South Korea, and Spain. Princeton: Princeton University Press, 2001 .

GUIMARÃES, N. A. Caminhos Cruzados: Estratégias de empresas e trajetórias de trabalhadores. São Paulo: Editora 34, 2004.

À Procura de Trabalho: Instituições do Mercado e Redes. Belo Horizonte: Argvmentvm, 2009a.

Desemprego, uma construção social: São Paulo, Paris e Tóquio. Belo Horizonte: Argvmentvm, 2009b.

GUIMARÃES, S. M. K. Apresentação: Trabalho, emprego e relações laborais em setores intensivos em conhecimento. In:

(Org.). Trabalho, Emprego e Relações Laborais em Setores Intensivos em Conhecimento: Brasil, México e Canadá. Porto Alegre: Editora da UFRGS, 2009. p. 7-20.

HANCOCK, D. R.; ALGOZZINE, B. Doing Case Study Research: a practical guide for beginning researchers. New York: Teachers College Press, 2006.

HARDIE, I.; MACKENZIE, D. Assembling an economic actor: the agencement of a Hedge Fund. The Sociological Review, v. 55, n. 1, p. 57-80, 2007.

HARVEY, D. A Condição Pós-Moderna: uma pesquisa sobre as origens da mudança cultural. 6a Ed. São Paulo: Loyola, 1996.

HUALDE, A.; MICHELI, J. Mercados de Trabalho nos Setor de Tecnologias da Informação e Comunicação no México. In: GUIMARÃES, S. M. K. (Org.). Trabalho, Emprego e Relações Laborais em Setores Intensivos em Conhecimento: Brasil, México e Canadá. Porto Alegre: Editora da UFRGS, 2009. p. 103-125.

INSTITUTO BRASILEIRO DE GEOGRAFIA E ESTATÍSTICA. O Setor de Tecnologia da Informação e Comunicação no Brasil, 2003-2006. Estudos \& Pesquisas, N. 11, 2009. Disponível em: <http://www.ibge.gov.br>. Acesso em: 2 Dez. 2010.

IOANNIDES, Y. M.; LOURY, L. D. Job Information Networks, Neighborhood Effects, and Inequality. Journal of Economic Literature, v. 42, p. 1056-1093, 2004.

JACKSON, M. O. Literature Review: The study of social networks in economics. In: RAUCH, J. E. (Ed.). The Missing Links: Formation and decay of economic networks. New York: Russell Sage Foundation, 2007. p. 19-43.

An Overview of Social Networks and Economic Applications. In: BENHABIB, J.; BISIN, A.; JACKSON, M. O. (Ed.). Handbook of Social Economics. Oxford: Elsevier, 2010. V. 1A. p. 511-585. 
JAMESON, F. Pós-Modernidade e Sociedade de Consumo. Revista Novos Estudos CEBRAP, n. 12, p. 16-26, 1985.

JEVONS, W. S. A Teoria da Economia Política. $4^{\text {a }}$ Edição. São Paulo: Nova Cultural, 1996.

KALLEBERG, A. L. O Crescimento do Trabalho Precário: Um desafio global. Revista Brasileira de Ciências Sociais, v. 24, n. 69, p. 21-30, 2009.

KARPIK, L. Valuing the Unique: The Economics of Singularities. Princeton: Princeton University Press, 2010.

KATZ, H. C. (Ed.). Telecommunications: Restructuring work and employment relations worldwide. Ithaca: Cornell University Press, 1997.

KOVÁCS, I. As Metamorfoses do Emprego: Ilusões e problemas da sociedade da informação. Oeiras: Celta, 2002.

KUMAR, K. Da Sociedade Pós-Industrial à Pós-Moderna: Novas teorias sobre o mundo contemporâneo. Rio de Janeiro: Jorge Zahar, 1997.

LALLEMENT, M. Raison ou Trahison? Éléments de réflexion sur les usages de la comparasion en sociologie. In : LALLEMENT, M.; SPURK, J. (Org.). Stratégies de la Comparaison Internationale. Paris : CNRS Editions, 2003. p.107-120.

LARANGEIRA, S. M. G. A Reestruturação das Telecomunicações e os Sindicatos. Revista Brasileira de Ciências Sociais, v. 18, n. 52, p. 81-106, 2003.

LATOUR, B. On Recalling ANT. The Sociological Review, v. 46, p. 15-25, 1999.

Reassembling the Social: An Introduction to Actor-Network-Theory. New York: Oxford University Press, 2005.

LAW, J. After ANT: complexity, naming and topology. The Sociological Review, v. 46, p. 1-14, 1999.

LAZEAR, E. P. Economic Imperialism. The Quarterly Journal of Economics, v. 115, n. 1, p. 99-146, 2000a.

. The Future of Personnel Economics. The Economic Journal, v. 110, November, p. F611-F639, 2000 b.

LAZEAR, E. P.; SHAW, K. L. Personnel Economics: The Economist's View of Human Resources. Journal of Economic Perspectives, v. 21, n. 4, p. 91-114, 2007.

LIN, N.; ENSEL, W.; VAUGHN, J. Social Resources and Strength of Ties: Structural factors in occupational status attainment. American Sociological Review, v. 46, n. 4, p. 393-405, 1981.

MARCHAL, E. ; RIEUCAU, G. Le recrutement. Paris: La Découverte, 2010. 
MARSDEN, P. V. Selection Methods in US Establishments. Acta Sociologica, v. 37, p. 287-301, 1994.

MARX, K. O Capital: Crítica da Economia Política. 24a edição. Rio de Janeiro: Civilização Brasileira, 2006. Livro 1. Volume 1.

MASUDA, Y. A Sociedade da Informação como Sociedade Pós-Industrial. Rio de Janeiro: Ed. Rio, 1982.

MCDONALD, S.; LIN, N.; AO, D. Networks Opportunity: gender, race, and job leads. Social Problems, v. 56, n. 3, p. 385-402, 2009.

MENGER, C. Principles of Economics. Auburn: Ludwig von Mises Institute, 2007.

MILLER, P. The margins of accounting. In: CALLON, M. (Ed.). The Laws of the Markets. Oxford: Blackwell Publishers, 1998. p. 174-193.

MIZRUCHI, M. S. What do interlocks do? An analysis, critique, and assessment of research on interlocking directorates. Annual Review of Sociology, v. 22, p. 271-298, 1996.

Análise de Redes Sociais: avanços recentes e controvérsias atuais. In: MARTES, A. C. B. (Org.). Redes e Sociologia Econômica. São Carlos: EdUFSCar, 2009. p. 131-59.

MONTGOMERY, J. D. Job search and network composition: Implications of the strength-of-weak-ties hypothesis. American Sociological Review, v. 57, n.5, p. 586-96, 1992.

MUNIESA, F.; MILLO, Y.; CALLON, M. An introduction to market devices. The Sociological Review, v. 55, Special Issue 2, p. 1-12, 2007.

NAKAMURA, A. O. et. al. Jobs Online. In: AUTOR, D. H. (Ed.). Studies in Labor Market Intermediation. Chicago: Chicago University Press, 2009. p. 27-65.

NORONHA, E. G. "Informal”, Ilegal, Injusto: percepções do mercado de trabalho no Brasil. Revista Brasileira de Ciências Sociais, v. 18, n. 53, p. 111-129, 2003.

OBSERVATÓRIO SOFTEX. Software e Serviços de TI: a indústria brasileira em perspectiva. Campinas: SOFTEX, 2009.

Software e Serviços de TI: a indústria brasileira em perspectiva. Campinas: SOFTEX, 2012.

PEREIRA, L. H. Análise de conteúdo: um approach do social. Cadernos de Sociologia, v. 9, p. 87-114, 1998.

PEREIRA, R. M.; OLIVEIRA, S. R. de. Taylorismo e fordismo: A racionalidade técnica na organização. In: PICCININI, V. C.; ALMEIDA, M. L. de; OLIVEIRA, S. R. de 
(Org.). Sociologia e Administração: Relações sociais nas organizações. Rio de Janeiro: Elsevier, 2011. p. 239-256.

PETERSEN, T.; SAPORTA, I.; SEIDEL, M. L. Offering a Job: Meritocracy and Social Networks. American Journal of Sociology, v.106, n. 3, p.763-816, 2000.

PODOLNY, J. M. Networks as the Pipes and Prisms of the Market. American Journal of Sociology, v. 107, n. 1, p. 33-60, 2001.

PODOLNY, J. M.; BARON, J. Resources and Relationships: Social Networks and Mobility in the Workplace. American Sociological Review, v. 62, p. 673-693, 1997.

PODOLNY, J. M.; RAUCH, J. E. Introduction: On the formation and decay of interdisciplinary boundaries. In: RAUCH, J. E. (Ed.). The Missing Links: Formation and decay of economic networks. New York: Russell Sage Foundation, 2007. p. 1-15.

POUPART, J. A entrevista de tipo qualitativo: considerações epistemológicas, teóricas e metodológicas. In: POUPART, J. et. al. (Org.). A Pesquisa Qualitativa: enfoques epistemológicos e metodológicos. Petrópolis: Vozes, 2008. p. 215-253.

POWELL, W. W. Learning from Collaboration: Knowledge and Networks in the Biotechnology and Pharmaceutical Industries. In: BIGGART, N. W. (Ed.). Readings in Economic Sociology. Oxford: Blackwell Publishers Ltd, 2002. p. 262-273.

POWELL, W. W.; SNELlMAN, K. The Knowledge Economy. Annual Review of Sociology, v. 30, p. 199-220, 2004.

RAMALHO, J. R.; SANTANA. M. A. Flexibilidade à francesa: trabalhadores na Peugeot Citröen brasileira. Tempo Social, v. 18, n. 1, p. 115-132, 2006.

RICARDO, D. On the Principles of Political Economy and Taxation. Indianapolis: Liberty Fund, 2004. Disponível em: <files.libertyfund.org/files/113/0687.01_LF.pdf>. Acesso em: 15 Out. 2012.

RICHARDS, L. Using NVivo in Qualitative Research. London: SAGE Publications, 1999.

ROESE, M. A metodologia do estudo de caso. Cadernos de Sociologia, v. 9, p. 189200, 1998.

ROSENFIELD, C. L.; ALVES, D. A. de. Autonomia e Trabalho Informacional: O Teletrabalho. DADOS, v. 54, n. 1, p. 207-233, 2011.

SALAIS, R. L'analyse économique des conventions du travail. Revue économique, v. 40, n. 2, p. 199-240, 1989.

SALDANHA, R. da C. Sociedade da Informação e Mercado de Trabalho: uma abordagem empírica sob a ótica das atividades econômica. 2006. 222 f. Dissertação (Mestrado) - Escola Nacional de Ciências Estatísticas, Instituto Brasileiro de Geografia e Estatística, Rio de Janeiro, 2006. 
SAXENIAN, A. Regional Advantage: Culture and competition in Silicon Valley and Route 128. $9^{\text {a }}$ edição. Cambridge: Harvard University Press, 2000.

SCHNEIDER, S.; SCHMITT, C. J. O uso do método comparativo nas Ciências Sociais. Cadernos de Sociologia, v. 9, p.49-86, 1998.

SEIDEL, M. L.; POLZER, J. T.; STEWART, K. J. Friends in High Places: The effects of social networks on discrimination in salary negotiations. Administrative Science Quarterly, v. 45, n. 1, p. 1-24, 2000.

SILVA, L. F. S. C. da. A Heterogeneidade como Pressuposto. In: GUIMARÃES, S. M. K. (Org.). Trabalho, Emprego e Relações Laborais em Setores Intensivos em Conhecimento: Brasil, México e Canadá. Porto Alegre: Editora da UFRGS, 2009. p. 127-144.

SIMON, H. A. Rationality as Process and as Product of Thought. The American Economic Review, v. 68, n. 2, p. 1-16, 1978.

SMELSER, N. J.; SWEDBERG, R. Introducing Economic Sociology. In: (Ed.). The Handbook of Economic Sociology. $2^{\mathrm{a}}$ Ed. Princeton: Princeton University Press, 2005. p. 3-25.

SMITH, A. An Inquiry into the Nature and Causes of the Wealth of Nations. Edwin Cannan (Ed). Londres: Methuen \& Co., 1904. Disponível em: $<$ www.econlib.org/library/Smith/smWN.html>. Acesso em: 5 Out. 2012.

STARK, D. The Sense of Dissonance: Accounts of Worth in Economic Life. Princeton: Princeton University Press, 2009.

STEINER, P. A Sociologia Econômica. São Paulo: Atlas, 2006.

STEVENSON, B. The Internet and Job Search. In: AUTOR, D. H. (Ed.). Studies in Labor Market Intermediation. Chicago: Chicago University Press, 2009. p. 67-86.

SWEDBERG, R. Markets in Society. In: SMELSER, N. J.; SWEDBERG, R. (Ed.). The Handbook of Economic Sociology. 2a Ed. Princeton: Princeton University Press, 2005. p. 233-253.

SWEDBERG, R. Major Traditions of Economic Sociology. Annual Review of Sociology, v. 17, p. 251-276, 1991.

TASSIER, T. Labor Market Implications of Weak Ties. Southern Economic Journal, v. 72, n. 3, p. 704-19, 2006.

TSOUKAS, H. The Firm as a Distributed Knowledge System: A Constructionist Approach. Strategic Management Journal, v. 17, Winter Special Issue, p. 11-25, 1996.

UZZI, B. The Sources and Consequences of Embeddedness for the Economic Performance of Organizations: The Network Effect. American Sociological Review, v. 
61, n. 4, p. 674-698, 1996.

VARIAN, H. R. Microeconomia: conceitos básicos. Rio de Janeiro: Elsevier, 2006.

VIEIRA, P. P. F. A Experiência da Procura de Trabalho: um estudo de caso. 2009. 211 f. Dissertação (Mestrado) - Programa de Pós-Graduação de Sociologia, Faculdade de Filosofia, Letras e Ciências Humanas, Universidade de São Paulo, São Paulo, 2009.

WAJCMAN, J. New connections: social studies of science and technology and studies of work. Work, employment and society. v. 20, n. 4, p. 773-786, 2006.

WALRAS, L. Elements of Pure Economics or the Theory of Social Wealth. Londres: Allen, 1953.

WEBER, R. P. Basic Content Analysis. 2 Ed. Newbury Park: SAGE, 1990.

WEGENER, B. Job Mobility and Social Ties: Social resources, prior jobs, and status attainment. American Sociological Review, v. 56, p. 60-71, 1991.

WHITE, H. C. Where Do Markets Come From? American Journal of Sociology, v. 87, n. 3, p. 517-547, 1981.

WHITLEY, R. The Social Construction of Organizations and Markets: The Comparative Analysis of Business Recipes. In: DOBBIN, F. (Ed.). The New Economic Sociology: A Reader. Princeton: Princeton University Press, 2004. p. 162-187.

WILLIAMSON, O. E. The New Institutional Economics: Taking stock, looking ahead. Journal of Economic Literature, v. 38, p. 595-613, 2000.

WINSHIP, C.; ROSEN, S. Introduction: Sociological and Economic Approaches to the Analysis of Social Structure. American Journal of Sociology, v. 94, p. S1-S16, 1988.

WOODSIDE, A. G. Case Study Research: Theory, Methods and Practice. Bingley: Emerald, 2010.

YAKUBOVICH, V. Weak Ties, Information, and Influence: how workers find jobs in a local Russian labor market. American Sociological Review, v. 70, p. 408-21, 2005.

ZELIZER, V. A. Human Values and the Market: The Case of Life Insurance and Death in $19^{\text {th }}$-Century America. American Journal of Sociology, v. 84, n. 3, p. 591-610, 1978.

Beyond the Polemics on the Market: Establishing a Theoretical and Empirical Agenda. Sociological Forum, v. 3, n. 4, p. 614-634, 1988.

Pricing the Priceless Child: The Changing Social Value of Children. Princeton: Princeton University Press, 1994. 
ANEXO 


\section{ROTEIRO DE ENTREVISTAS DE ENTRADA}

1) ENTREVISTADO
a. Formação?
b. Como chegou à empresa?
c. Descreva sua função na empresa?

2) EMPRESA

a. Qual é a estrutura do RH?

b. Quais são os produtos e serviços desenvolvidos na empresa?

c. Competidores e principais mercados?

d. Quantos funcionários a empresa possui?

e. Nesse sentido, como você define a cultura da empresa e gestão de recursos humanos?

f. Seus principais valores?

g. Cargos e funções envolvidas diretamente na atividade fim da empresa?

3) DEMANDA

a. Quais são atualmente os principais tipos de profissionais procurados pela empresa? Para quais cargos?

b. Eu imagino que há um perfil de profissional procurado e valorizado pela empresa. Qual é esse perfil?

c. Por que esse perfil?

d. Como isso se manifesta em termos de qualidades pessoais?

e. E em competências técnicas?

f. Há diferenças, nesse aspecto, entre os cargos e funções?

g. Houve mudanças na concepção da empresa sobre esse perfil?

h. Como é conhecido por você esse perfil?

i. Há e como ocorre a comunicação de vocês com os outros departamentos da empresa? Quais departamentos?

j. Quais são os principais desafios na gestão e contratação desse perfil de profissional?

k. Há vagas em aberto na empresa?

1. Por quais pessoas passa a decisão de abrir vagas de trabalho? 
m. Quem define questões como: modalidade de contrato, salário, benefícios...?

n. Há preocupação sobre a questão da rotatividade?

4) RECRUTAMENTO

a. Uma vez que há essa decisão do interesse de contratar novos profissionais, como funciona o processo de "buscar", recrutar candidatos à vaga de emprego?

b. Quem são as pessoas responsáveis? Como funciona o trabalho dessas pessoas?

c. Há programa de recomendação? Como funciona?

d. Através de que meios são recrutados?

e. Há relacionamento, com essa finalidade, com Universidades, escolas técnicas ou semelhantes? Como funciona e com quem é essa relação?

f. Há relacionamento, com essa finalidade, com agência de emprego, headhunters, etc? Como funciona e com quem é essa relação?

\section{5) SELEÇÃO}

a. Como funciona a seleção de candidatos à vaga de emprego?

b. Quem são as pessoas responsáveis por fazer essa seleção?

c. Como elas fazem essa seleção?

d. Quais informações elas procuram levantar sobre o candidato? 